FHWA/IN/JTRP-2000/10

Final Report

DEVELOPMENT AND EVALUATION OF CEMENT-BASED PATCHING MATERIALS FOR REPAIR OF CORROSION-DAMAGED

REINFORCED CONCRETE SLABS

Rongtang Liu

Jan Olek

May 2001 
Final Report

FHWA/IN/JTRP-2000/10

\title{
Development and Evaluation of Cement-based Patching Materials for Repair of Corrosion-Damaged Reinforced Concrete Slabs
}

\author{
Rongtang Liu \\ Graduate Research Assistant \\ and \\ Jan Olek \\ Professor in Civil Engineering \\ Construction Materials Engineering \\ School of Civil Engineering \\ Purdue University
}

Joint Transportation Research Program

Project Number: C36-37HH

File Number: 5-8-34

SPR-2141

Prepared in Cooperation with the

Indiana Department of Transportation and the

U. S. Department of Transportation

Federal Highway Administration

The contents of this report reflect the views of the authors, who are responsible for the facts and the accuracy of the data presented herein. The contents do not necessarily reflect the official views and policies pf the Indiana Department of Transportation or Federal Highway Administration at the time of publication. The report does not constitute a standard, specification, or regulation.

Purdue University

West Lafayette, IN 47907

May 2001 
TECHNICAL REPORT STANDARD TITLE PAGE

\begin{tabular}{|c|c|c|}
\hline $\begin{array}{l}\text { 1. Report No. } \\
\text { FHWA/IN/JTRP-2000/10 }\end{array}$ & 2. Government Accession No. & 3. Recipient's Catalog No. \\
\hline \multirow{2}{*}{\multicolumn{2}{|c|}{$\begin{array}{l}\text { 4. Title and Subtitle } \\
\text { Development and Evaluation of Cement-Based Materials for Repair of Corrosion- } \\
\text { Damaged Reinforced Concrete Slabs }\end{array}$}} & $\begin{array}{l}\text { 5. } \quad \text { Report Date } \\
\text { May } 2001\end{array}$ \\
\hline & & 6. Performing Organization Code \\
\hline \multicolumn{2}{|l|}{$\begin{array}{l}\text { 7. Author(s) } \\
\text { Rongtang Liu and Jan Olek }\end{array}$} & $\begin{array}{l}\text { 8. Performing Organization Report No. } \\
\text { FHWA/IN/JTRP-2000/10 }\end{array}$ \\
\hline \multirow{2}{*}{\multicolumn{2}{|c|}{$\begin{array}{l}\text { 9. Performing Organization Name and Address } \\
\text { Joint Transportation Research Program } \\
\text { 1284 Civil Engineering Building } \\
\text { Purdue University } \\
\text { West Lafayette, Indiana } 47907-1284\end{array}$}} & 10. Work Unit No. \\
\hline & & $\begin{array}{l}\text { 11. Contract or Grant No. } \\
\text { SPR-2141 }\end{array}$ \\
\hline \multirow{2}{*}{\multicolumn{2}{|c|}{$\begin{array}{l}\text { 12. Sponsoring Agency Name and Address } \\
\text { Indiana Department of Transportation } \\
\text { State Office Building } \\
100 \text { North Senate Avenue } \\
\text { Indianapolis. IN } 46204\end{array}$}} & $\begin{array}{c}\text { 13. Type of Report and Period Covered } \\
\text { Final Report }\end{array}$ \\
\hline & & 14. Sponsoring Agency Code \\
\hline \multicolumn{3}{|l|}{ 15. Supplementary Notes } \\
\hline
\end{tabular}

\section{Abstract}

In this study, the results of an extensive laboratory investigation conducted to evaluate the properties of concrete mixes used as patching materials to repair reinforced concrete slabs damaged by corrosion are reported.

Seven special concrete mixes containing various combinations of chemical or mineral admixtures were developed and used as a patching material to improve the durability of the repaired slabs. Physical and mechanical properties of these mixes, such as compressive strength, static modulus of elasticity, dynamic modulus of elasticity, and shrinkage were evaluated. Durability-related parameters investigated included resistance of concrete to penetration of chloride ions and freeze-thaw resistance. The results generated during this research indicated that chemical and mineral admixtures improved physical, mechanical, and durability properties of repair concrete.

In addition, the ability of various repair mixes to reduce the progress of corrosion was monitored using half-cell potential, polarization resistance, and electrochemical impedance spectroscopy techniques. Half-cell potential measurements provided information about the possibility of corrosion taking place on the steel surface. Polarization resistance measurements were used to determine the corrosion current density, and provided a quantitative estimation of the corrosion rate. Electrochemical impedance spectroscopy technique was used to monitor the corrosion rate, the change in resistivity of concrete, and change in polarization resistance.

The results obtained from 21 reinforced concrete slabs exposed to cycles of wetting and drying indicated that both organic corrosion inhibitor and calcium nitrite (anodic corrosion inhibitor) delayed the initiation of active corrosion on the steel surface. Silica fume concrete, fly ash concrete, latex modified concrete, and concrete with shrinkage reducing admixture had low permeability and high resistivity. These properties improved the durability of repaired slabs either by delaying the initiation of active corrosion or by reducing the corrosion rate.

\section{Key Words}

Corrosion, rehabilitation, concrete, durability, reinforcing steel, bridge deck, chloride ion, corrosion rate, polarization resistance, electrochemical impedance spectroscopy.
18. Distribution Statement

No restrictions. This document is available to the public through the National Technical Information Service, Springfield, VA 22161

\begin{tabular}{|c|c|c|c|}
\hline $\begin{array}{c}\text { 19. Security Classif. (of this report) } \\
\text { Unclassified }\end{array}$ & $\begin{array}{c}\text { 20. Security Classif. (of this page) } \\
\text { Unclassified }\end{array}$ & 274 & 22. Price \\
\hline
\end{tabular}




\section{TECHNICAL Summary}

Technology Transfer and Project Implementation Information

INDOT Research

May 2001

TRB Subject Code: 32-4 Concrete Durability

Publication No.: FHWA/IN/JTRP-2000/10, SPR-2141

Final Report

\section{Development and Evaluation of Cement-Based Patching Materials for Repair of Corrosion-Damaged Reinforced Concrete Slabs}

\section{Introduction}

Damage of bridge decks due to corrosion of reinforcing steel resulting from the application of deicing salts is often extensive and typically requires expensive repairs.

A common method of bridge decks repair involves removal of the contaminated and delaminated concrete, sandblasting of the steel surface and, in most extreme cases, replacement of damaged steel bars. Finally, the area from which the concrete has been removed is filled (patched) with new concrete or mortar. In order to reduce the penetration rate of chloride ions and to prevent further corrosion damage to the steel, the new concrete is usually design to be of high quality and therefore of low permeability.

Application of high quality, less permeable patch right next to the existing concrete which is already saturated with chloride may, in some cases, lead to the development of chloride concentration gradients that will actually accelerate the corrosion of rebars in the areas just outside of the patches. In fact, based on the survey performed by the Research Division of the Indiana Department of Transportation some of the repaired bridges showed signs of extensive corrosion after about only seven years of service.

\section{Findings}

The results of physical and mechanical testing performed on the repair mixes indicate that both organic corrosion inhibitor and shrinkage reducing admixture can increase compressive strength, static and dynamic modulus of elasticity, and impermeability. As expected, when cured in air the repair concretes developed higher shrinkage. The addition of shrinkage-reducing admixture reduced drying shrinkage.

The polarization resistance of slabs repaired with silica fume concrete decreased with the increase in exposure time. After about 6 months of exposure to
The objective of this study was to develop portland cement-based mixes that can be used to repair corrosion-damaged bridge decks, and to evaluate their effectiveness in reducing the rate of corrosion after repair. In the course of the study, 21 reinforced concrete slabs were constructed using typical INDOT Class $\mathrm{C}$ concrete and exposed to drying-and-wetting cycles (using salt solution) to accelerate the process of reinforcement corrosion. After the rebars started corroding the concrete was removed from the central portion of the slabs, the reinforcement was cleaned, and the slabs were repaired with one of the 7 different mixes that were used as patching materials in the course of this study. For each of these slabs, electrochemical parameters related to corrosion were evaluated along with selected mechanical and durability properties of the repair materials. These properties included compressive strength, static modulus of elasticity, dynamic modulus of elasticity, length change, permeability, and freeze-thaw resistance. Electrochemical methods used to monitor the corrosion process

included, half-cell potential measurements, linear polarization resistance measurements, and electrochemical impedance spectroscopy.

wetting and drying cycles and to salt solution, the corrosion current density in slabs repaired with silica fume was higher than that of any of the other repaired slabs.

Slabs repaired with concrete that contained fly ash developed high electrical resistivity after prolonged period of curing (six months). The polarization resistance of the slabs repaired with this concrete was low, and the corrosion current density was high. Compared with the control concrete (INDOT 9-bag mix), fly ash concrete was not found 
to be highly effective repair material for corrosion damaged structures.

Concrete containing shrinkage reducing admixture had high electrical resistivity. The initial polarization resistance of slabs repaired with this concrete was at the same level as that of INDOT 9bag concrete (control concrete). Relatively high polarization resistance and low corrosion current density were maintained during the exposure time. Based on the results from this research, this concrete mix appears to be an effective repair material.

Slabs repaired with latex modified concrete had relatively low polarization resistance and high corrosion current density. This indicates that latex

\section{Implementation}

The results obtained from testing of seven patching materials indicate that chemicals and mineral admixtures can improve their corrosionprotective abilities. This improvement is the result of an increase in the compressive strength, reduction in shrinkage, decrease in permeability and an increase in freezing and thawing resistance.

The corrosion process of reinforcing steel can be monitored by the half-cell potential method, supplemented by polarization resistance measurements and electrochemical impedance spectroscopy measurements. Concrete with calcium nitrite and organic corrosion inhibitor can delay the initiation of active corrosion on the steel surface. Impedance spectroscopy can provide information about the interface between steel and concrete matrix. modified concrete was not an effective material for repair of corrosion-damaged structures. It should be stressed, however, that based on the results from chloride ponding test, air cured latex modified concrete significantly reduced penetration of chloride ions.

Based on the corrosion current density measurements, calcium nitrate provided better corrosion protection than organic corrosion inhibitor.

The results of this research indicate that INDOT 9-bag concrete appears to be an effective material for repair of corrosion damaged concrete bridge decks.

The selection of the repair system for a given bridge deck should be carefully evaluated taking into account local exposure conditions, frequency of salt application, and the experience of the contractor with "non-standard" materials and mixtures. The details of the procedure for installation of the repair system should be discussed and agreed upon during the pre-construction conferences. Since the standard INDOT 9-bag concrete mix appears to be quite effective (as compared to other mixtures evaluated in this study) in reducing the corrosion rate of rebars in the repaired structures, special emphasis should be placed on proper installation and curing of this repair system to maximize its effectiveness.

\section{Contact}

For more information:

\section{Prof. Jan Olek}

Principal Investigator

School of Civil Engineering

Purdue University

West Lafayette, IN 47907

Phone: (765) 494-5015

Fax: (765) 496-1364

\author{
Indiana Department of Transportation \\ Division of Research \\ 1205 Montgomery Street \\ P.O. Box 2279 \\ West Lafayette, IN 47906 \\ Phone: (765) 463-1521 \\ Fax: (765) 497-1665 \\ Purdue University \\ Joint Transportation Research Project \\ School of Civil Engineering \\ West Lafayette, IN 47907-1284 \\ Phone: (765) 494-9310 \\ Fax: (765) 496-1105
}


TABLE OF CONTENTS

Page

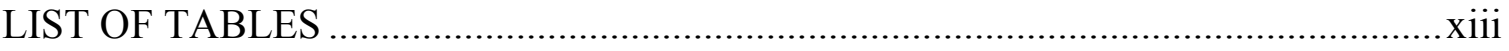

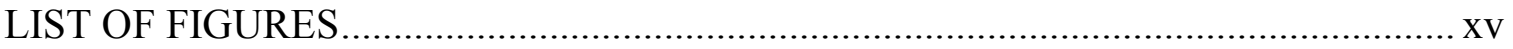

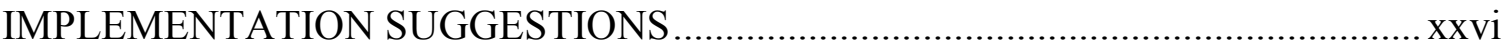

CHAPTER 1 INTRODUCTION.......................................................................

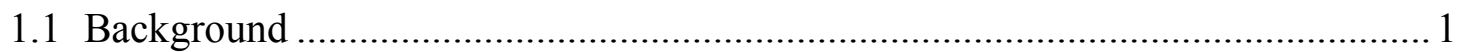

1.2 Objectives and scope ................................................................................. 3

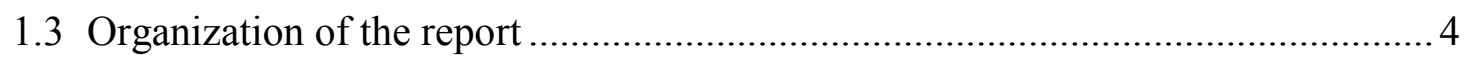

CHAPTER 2 FUNDAMENTALS OF CORROSION ............................................... 5

2.1 Electrochemical Nature of Corrosion.......................................................... 6

2.1 .1 Electrochemical Reactions of Corrosion ...................................................

2.1 .2 Thermodynamics and Electrode Potential.................................................

2.1 .3 Concentration Effects on Electrode Potential ........................................... 9

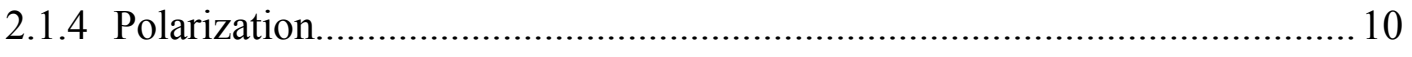

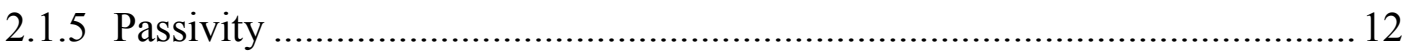

2.1.6 Corrosion of Steel............................................................................ 12

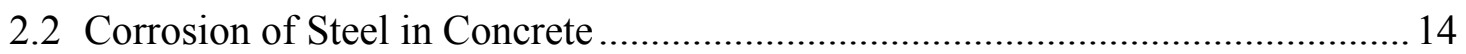

2.2 .1 Passivity of Steel in Concrete .............................................................. 15

2.2 .2 Effects of Carbonation and Chloride Ions................................................. 15

2.3 Principles of Corrosion Process Monitoring ................................................... 16 
$2.3 .1 \quad$ Half-Cell Potential............................................................................. 16

2.3.1.1 Standard Hydrogen Electrode …........................................................ 17

2.3.1.2 Secondary Reference Electrodes ........................................................ 17

2.3.1.3 Corrosion Potential.......................................................................... 18

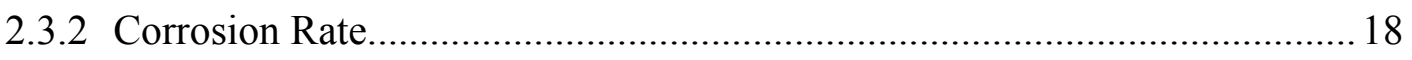

2.3 .3 Corrosion Current Density .................................................................... 19

2.4 Experimental Testing for Corrosion Process ……….........................................2 21

2.4 .1 Corrosion Potential Measurement...............................................................21

2.4 .2 Polarization Resistance Method ...........................................................22

2.4 .3 Electrochemical Impedance Spectroscopy.............................................24

2.4.3.1 Impedance Spectroscopy Basics ......................................................... 25

2.4.3.2 Equivalent Circuit ..........................................................................29

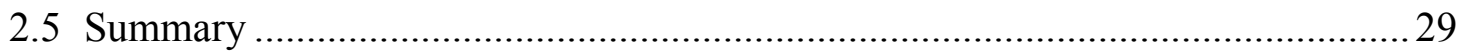

CHAPTER 3 CORROSION OF STEEL IN CONCRETE - LITERATURE REVIEW.46

3.1 Concrete Cover and Concrete-Steel Interface ................................................ 46

3.1.1 Microstructure of Cement Paste and Concrete...........................................47

3.1.1.1 Hydration of Portland Cement ............................................................4

3.1.1.2 Voids in Hydrated Cement Paste ....................................................... 48

3.1.2 Interfacial Transition Zone ..................................................................... 49

3.1.2.1 Microstructure of the Interfacial Transition Zone..................................49

3.1.2.2 Formation of Interfacial Transition Zone............................................50

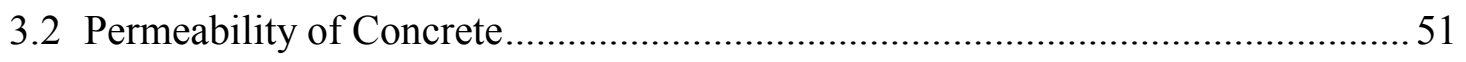

3.2.1 Diffusion of Chloride Ions into Concrete................................................... 51

3.2.1.1 Diffusion Equation .................................................................... 51

3.2.1.2 Diffusion of Chloride Ions in Concrete ..................................................5 52

3.3 Passivation of Steel in Concrete ................................................................. 54

3.3.1 Evans' Oxide Film Theory ........................................................................5 
3.3.2 Adsorption Theory ........................................................................... 55

3.4 Initiation of Corrosion on Reinforcing Steel........................................... 55

3.5 Measurements of Corrosion Rate ......................................................... 57

3.5.1 Polarization Resistance Measurement....................................................57

3.5.2 Electrochemical Impedance Measurement................................................59

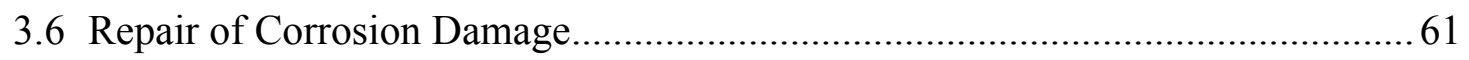

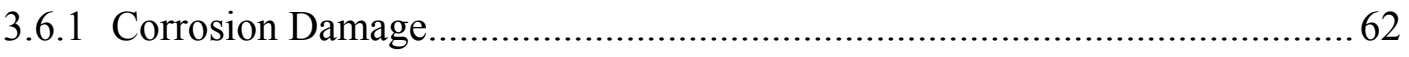

3.6.2 Repair and Rehabilitation Techniques .............................................. 63

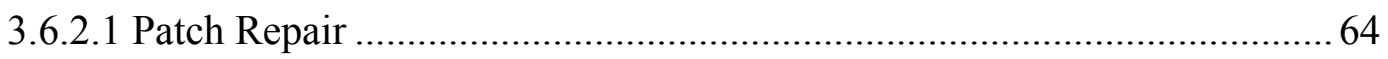

3.6.2.2 Use of Corrosion Inhibitors ......................................................... 65

3.6.2.3 Use of External Coatings........................................................ 66

3.6.2.4 Electrochemical Treatment ........................................................ 67

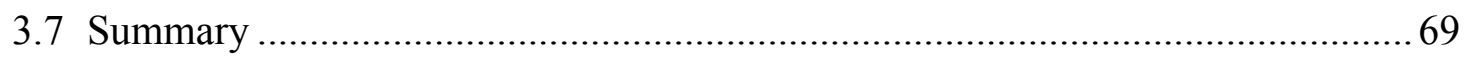

CHAPTER 4 EXPERIMENTAL PROCEDURES ........................................... 78

4.1 Specimens Preparation ............................................................................ 78

4.1 .1 Materials ................................................................................................ 79

4.1.1.1 Portland Cement..................................................................... 79

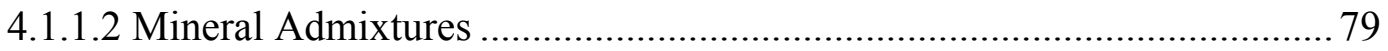

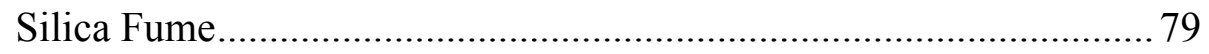

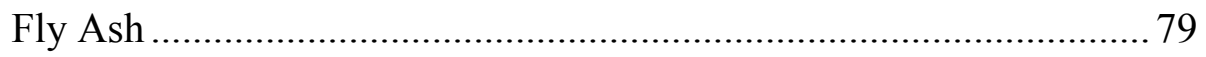

4.1.1.3 Aggregates................................................................................... 80

4.1.1.4 Chemical Admixtures........................................................................ 81

Water Reducing Agent (Superplasticizer) .................................... 81

Air Entraining Agent ............................................................. 81

Shrinkage Reducing Admixture …................................................... 81

4.1.1.5 Corrosion Inhibitors .................................................................... 81

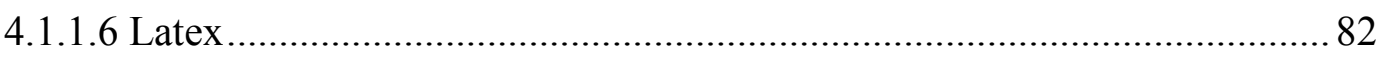

4.1 .2 Concrete Mixes ................................................................................. 83

4.1 .3 Preparation of the Reinforcing Steel ....................................................... 84 
4.1 .4 Fabrication and Curing of Concrete Specimens....................................... 85

4.1.4.1 Fabrication and Curing of Non-Reinforced Concrete Specimens.............85

4.1.4.2 Fabrication and Curing of Reinforced Concrete Specimens ..................... 86

4.1 .5 Ponding of Reinforced Slabs .................................................................... 87

4.2 Testing Procedures .............................................................................. 88

4.2.1 Testing of Mechanical and Physical Properties ..........................................8

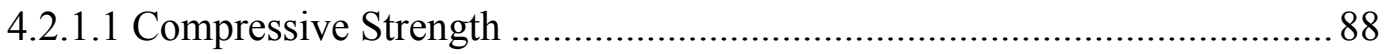

4.2.1.2 Static Modulus of Elasticity .............................................................. 89

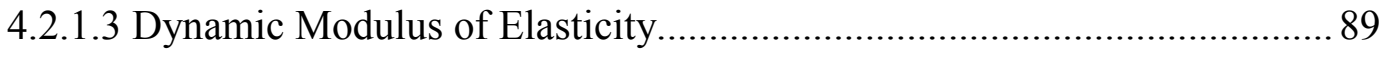

4.2.1.4 Freezing and Thawing Resistance ........................................................ 90

4.2.1.5 Rapid Chloride Ion Penetration (Electrical Conductance) ....................... 90

4.2.1.6 Length Change Measurements ...........................................................91

4.2.1.7 Chloride Profile ............................................................................ 92

4.2 .2 Electrochemical Measurements............................................................... 93

4.2.2.1 Half-Cell Potential Measurement........................................................ 93

4.2.2.2 Polarization Resistance Measurement.................................................... 94

4.2.2.3 Electrochemical Impedance Spectroscopy.............................................94

4.3 Repair of Reinforced Concrete Slabs ................................................................ 95

CHAPTER 5 MECHANICAL AND PHYSICAL PROPERTIES OF REPAIR CONCRETE - TEST RESULTS ......................................................... 121

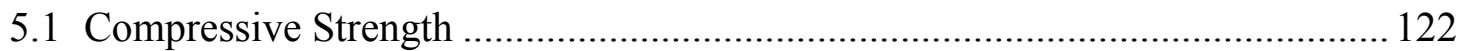

5.2 Static Modulus of Elasticity ......................................................................... 123

5.3 Dynamic Modulus of Elasticity and Dynamic Shear Modulus of Repair

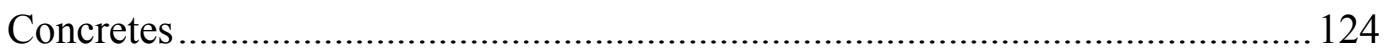

5.3 .1 Dynamic Modulus of Elasticity for Samples Cured in Moist Room .......... 124

5.3.2 Dynamic Modulus of Elasticity and Dynamic Shear Modulus for Samples

Cured in Air .................................................................................................... 126

5.4 Drying Shrinkage of Repair Concretes .......................................................... 127 
5.5 Freezing and Thawing Resistance......................................................... 129

5.6 Rapid Chloride Ion Penetration Results ..................................................... 129

5.6 .1 Effect of Curing Conditions ................................................................ 129

5.6 .2 Effect of Water to Cement Ratio........................................................... 130

5.6 .3 Effect of Mineral Admixtures .................................................................. 131

5.7 Chloride Content Results .................................................................. 131

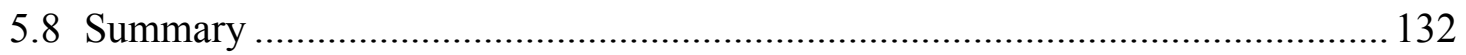

CHAPTER 6 CORROSION OF REINFORCING STEEL IN CONCRETE USING ELECTROCHEMICAL METHODS - TEST RESULTS ....................... 146

6.1 Half-cell Potential Measurement..................................................................... 147

6.1 .1 Half-Cell Potential Measurements before Repair ...................................... 147

6.1 .2 Half-Cell Potential Measurement after Repair........................................... 149

6.1 .3 Discussion of Half-Cell Potential Results.............................................. 150

6.1.3.1 Original Slabs (Before Repair) .............................................................. 150

6.1.3.2 Slabs After Repair .......................................................................... 151

6.2 Linear Polarization Resistance Measurement ................................................. 152

6.2 .1 Results from Polarization Resistance (PR) Method................................. 152

6.2.1.1 Original Slabs (Before Repair) ........................................................ 152

6.2.1.2 Slabs After Repair .............................................................................. 153

6.2 .2 Discussion on the Results of Polarization Resistance Measurement ........... 155

6.3 Monitoring Corrosion Process by Using Electrochemical Impedance

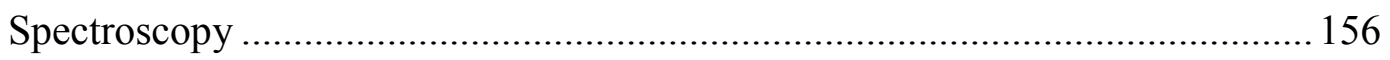

6.3 .1 Results from EIS Method................................................................... 157

6.3.1.1 Impedance Behavior of the Reinforced Concrete Slabs.......................... 157

6.3.1.2 Characterization of the Concrete Matrix.............................................. 158

6.3.1.3 Characterization of the Corrosion Process ............................................... 159 
6.3 .2 Discussion on the Results of EIS .......................................................162

6.4 Summary ........................................................................................... 163

CHAPTER 7 SUMMARY AND CONCLUSIONS …............................................201

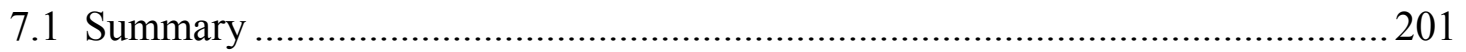

7.1.1 Physical and Mechanical Properties of Patching Materials ........................201

7.1 .2 Monitoring Corrosion Process by Electrochemical Techniques .................204

7.1.2.1 Half-Cell Potential Measurement.................................................204

7.1.2.2 Polarization Resistance Measurement....................................................205

7.1.2.3 Electrochemical Impedance Spectroscopy..............................................22

7.2 Conclusions .....................................................................................................208

CHAPTER 8 RECOMMENDATIONS FOR FUTURE RESEARCH .......................212

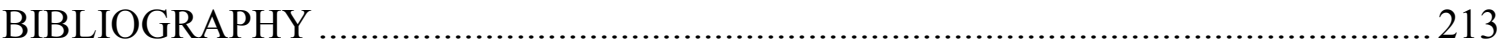

APPENDIX A - RESULTS FROM COMPRESSIVE STRENGTH TEST ..................216

APPENDIX B - RAW DATA FOR DYNAMIC MODULUS OF ELASTICITY .........218

APPENDIX C - LENGTH CHANGE OF CONCRETE SAMPLES ...........................233

APPENDIX D - HALF-CELL POTENTIALS OF THE REINFORCED SLABS ........244 


\section{LIST OF TABLES}

Table

2.1 Standard half-cell potentials (reduction potentials) ............................................. 31

2.2 Common secondary reference electrodes and their standard potential values............ 32

2.3 Common electrical elements, the n-values and their impedance functions ................ 32

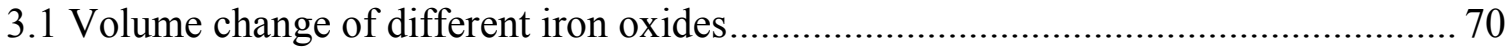

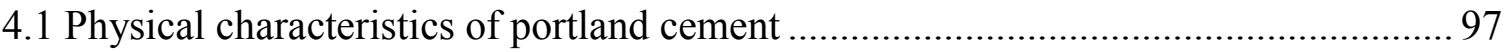

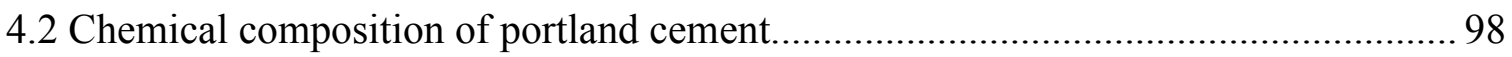

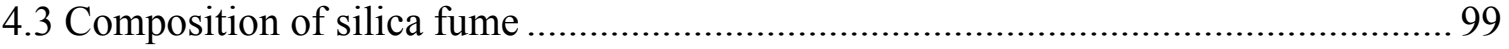

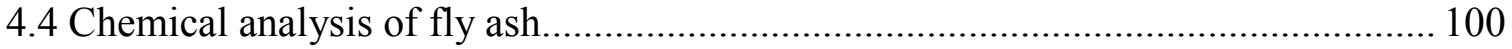

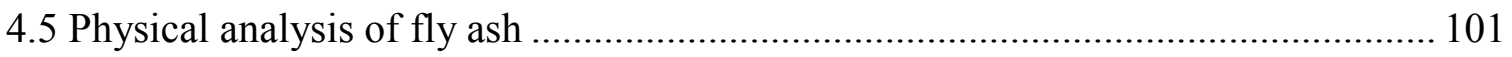

4.6 Mix composition and properties of the INDOT Class C concrete .......................... 102

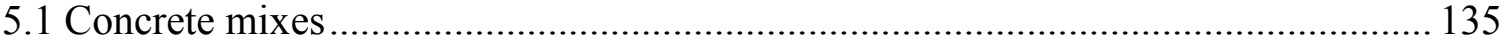

5.2 Code system used for repair concrete mixes.................................................. 136

5.3 Rapid chloride penetration values for samples cured in the moist room ................. 137

5.4 Rapid chloride penetration values for the samples cured in air ............................. 137

A Results from compressive strength test ............................................................. 217

B.1 Specimens made from silica fume concrete, cured in moist room ........................ 219

B.2 Specimens made from concrete with calcium nitrite, cured in moist room ............ 220

B.3 Specimens made from concrete with organic corrosion inhibitor,

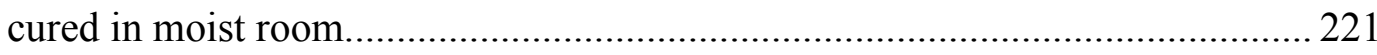

B.4 Specimens made from fly ash concrete, cured in moist room .............................. 222

B.5 Specimens made from INDOT 9-bag concrete, cured in moist room ..................... 223

B.6 Specimens made from concrete with shrinkage reducing admixture, cured

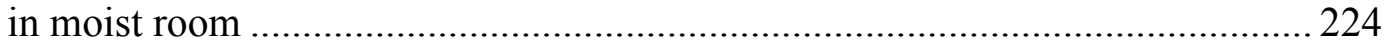

B.7 Specimens made from latex modified concrete, cured in moist room ................... 225 
B.8 Specimens made from silica fume concrete, cured in air ................................... 226

B.9 Specimens made from concrete with calcium nitrite, cured in air ........................ 227

B.10 Specimens made from concrete with organic corrosion inhibitor,

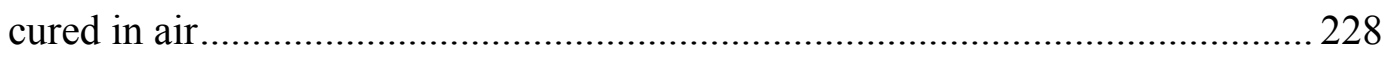

B.11 Specimens made from fly ash concrete, cured in air ......................................... 229

B.12 Specimens made from concrete with shrinkage reducing admixture,

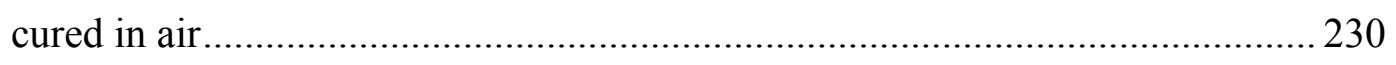

B.13 Specimens 1 and 2 made from latex modified concrete, cured in air................. 231

B.14 Specimens 3 and 4 made from latex modified concrete, cured in air.................. 232

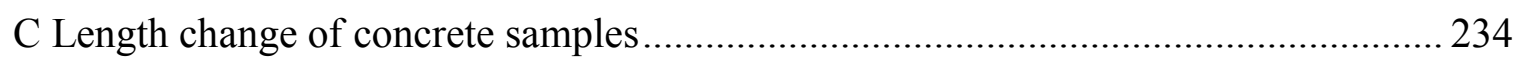




\section{LIST OF FIGURES}

Figure

2.1 An electrochemical cell with corresponding cell reactions.....

2.2 Changes in the corrosion rate of the anode with the change in the value of anodic polarization

2.3 Corrosion current density and corrosion activity of a metal as a function of electrode potential

2.4 Schematic representation of the microstructure of an alloy metal, showing different phases ( $a$ and $b$ ) and grain boundaries

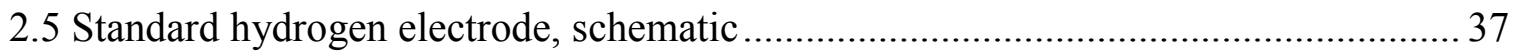

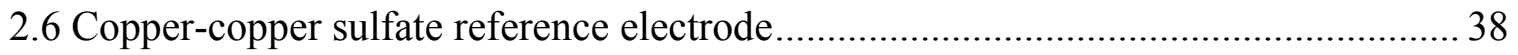

2.7 Polarization of anodic and cathodic half-cell reactions for $\mathrm{Zn}$ in acid

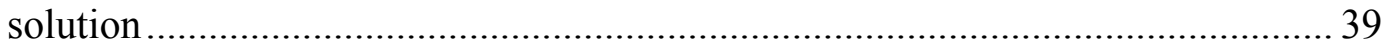

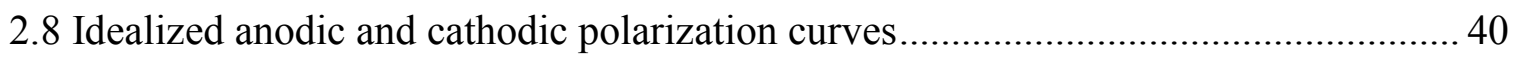

2.9 Experimental polarization curves graphically plotted on linear coordinates ............. 41

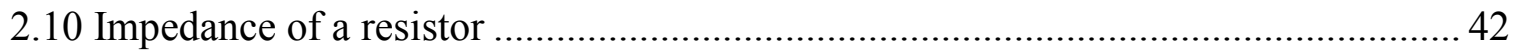

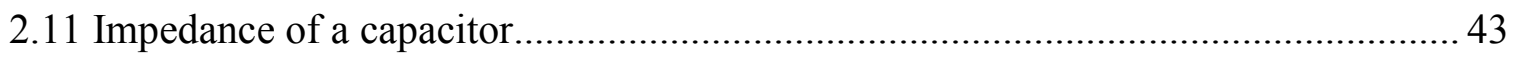

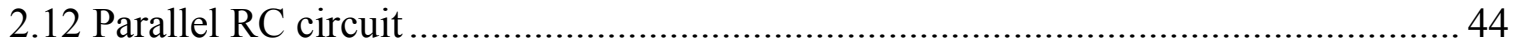

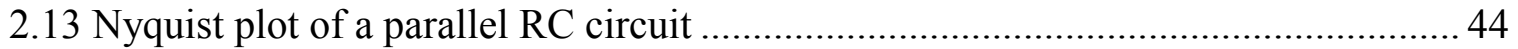

2.14 Schematic illustration of the depression of the impedance arc ............................ 45

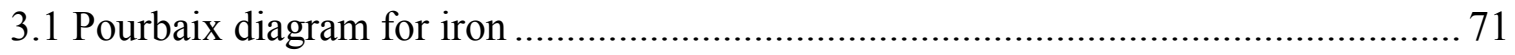

3.2 Schematic description of polarization resistance testing ...................................... 72

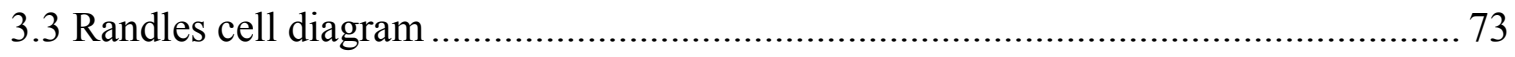

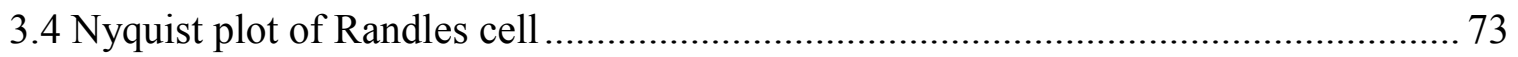

3.5 The equivalent circuit consists of three parallel combinations of a resistor and a CPE (a); Corresponding impedance plot on the complex plane (b) 
Figure

3.6 Schematic description of the corrosion process taking place at the tip of a pit or crack in a stressed metal leading to its embrittlement. Stress corrosion cracking (a), and Hydrogen embrittlement (b) .............................................. 75

3.7 Effect of anodic inhibitor on the potential-corrosion rate, schematic ....................... 76

3.8 Effect of cathodic inhibitor on the potential-corrosion rate, schematic ..................... 77

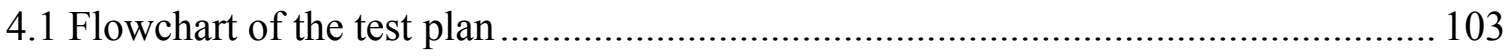

4.2 X-ray diffraction pattern of the silica fume (Q: quartz; H: hematite) ...................... 104

4.3 X-ray diffraction pattern of the fly ash (Q: quartz; M: mullite; H: hematite) ........... 104

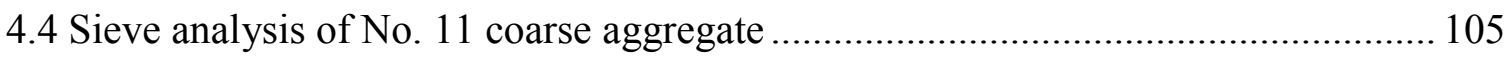

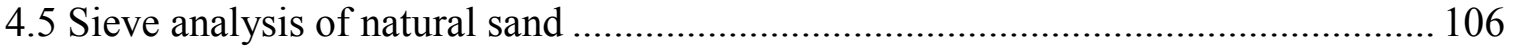

4.6 Schematic illustration of the corrosion protection system and the electrical wire connection for a reinforcing steel bar........................................................ 107

4.7 Configuration of a wooden mold used for fabricating reinforced concrete

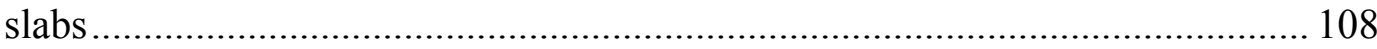

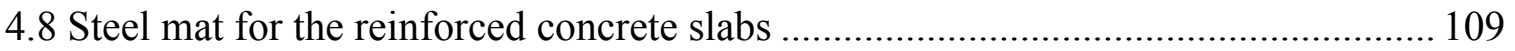

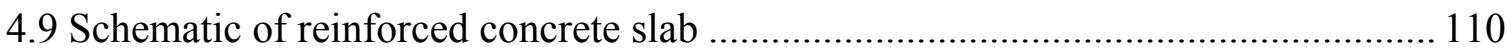

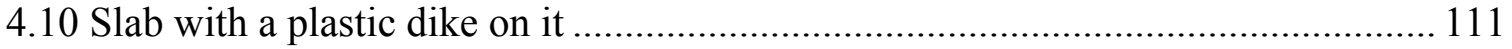

4.11 Slabs are ponded with salt water during wetting cycles.................................... 112

4.12 Slab is heated by halogen lamps during drying cycles....................................... 113

4.13 Setup for collection of powdered concrete sample for chloride profile

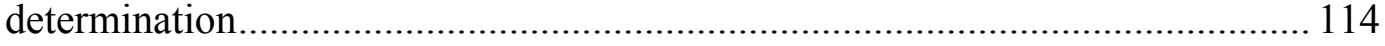

4.14 Setup for half-cell potential measurement ................................................... 115

4.15 Locations of half-cell potential measurements (Numbers indicate

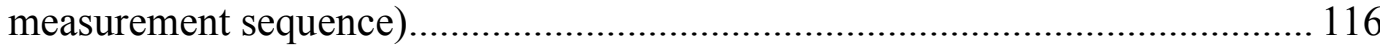

4.16 Schematic of electrical connections used for polarization resistance and

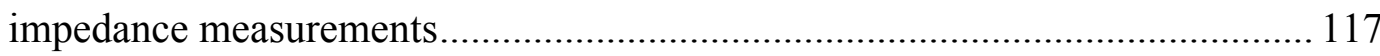

4.17 Equivalent circuit used for analysis of EIS data ........................................... 118

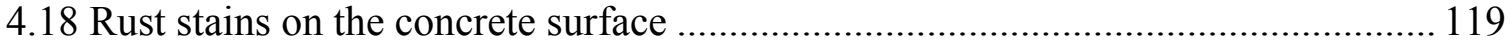

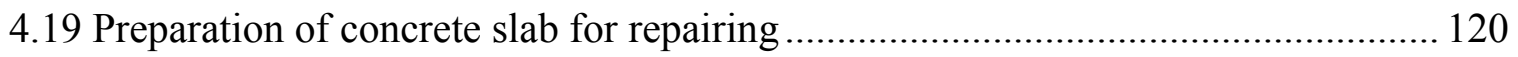

5.1 Compressive strength development of concrete mixes ....................................... 138

5.2 Static modulus of elasticity of concrete mixes.................................................... 139 
5.3 The dynamic modulus of elasticity calculated from fundamental transverse resonant frequency for concrete specimens cured in the moist room

5.4 The dynamic modulus of elasticity calculated from fundamental longitudinal resonant frequency for concrete specimens cured in the moist room ....

5.5 The dynamic shear modulus calculated from fundamental torsional resonant frequency for concrete specimens cured in the moist room.

5.6 The dynamic modulus of elasticity calculated from fundamental transverse resonant frequency for concrete specimens cured in air....

5.7 The dynamic modulus of elasticity calculated from fundamental longitudinal resonant frequency for concrete specimens cured in air ....

5.8 The dynamic shear modulus calculated from fundamental torsional resonant frequency for concrete specimens cured in air....

5.9 Shrinkage of specimens cured in the moist room

5.10 Shrinkage of specimens cured in air

5.11 Relative Dynamic modulus of elasticity of specimens subjected to rapid freezing and thawing cycles

5.12 Chloride content of concrete powder sample from INDOT Class C concrete. Concrete specimens were exposed to $5 \%$ sodium chloride solution and wetting-drying cycles

5.13 Chloride content results from different concrete mixes. Powder samples were taken after the concrete specimens were ponded with $10 \%$ sodium chloride solution for six months

6.1 Distribution of half-cell potentials for the middle (corrugated) part of the slabs (before repair).

6.2 Distribution of half-cell potentials for the outer (outside the corrugated zone) parts of the slabs (before repair).

6.3 (a) Polarization resistance (from PR) for the slabs before repair 165

6.3 (b) Corrosion current density (from PR) for the slabs before repair.....

6.4 (a) Polarization resistance (from PR) for the concrete slabs repaired by the silica fume concrete. 166

6.4 (b) Corrosion current density (from PR) for the slabs repaired by the silica fume concrete

6.5 (a) Polarization resistance (from PR) for the concrete slabs repaired by the calcium nitrite concrete. 
6.5 (b) Corrosion current density (from PR) for the slabs repaired by the concrete with calcium nitrite

6.6 (a) Polarization resistance (from PR) for the concrete slabs repaired by concrete with the organic corrosion inhibitor 168

6.6 (b) Corrosion current density (from PR) for the slabs repaired by concrete with organic corrosion inhibitor.

6.7 (a) Polarization resistance (from PR) for the concrete slabs repaired by the fly ash concrete.

6.7 (b) Corrosion current density (from PR) for the slabs repaired by the fly ash concrete

6.8 (a) Polarization resistance (from PR) for the concrete slabs repaired by the INDOT 9-bag cement concrete

6.8 (b) Corrosion current density (from PR) for the slabs repaired with the INDOT 9-bag cement concrete

6.9 (a) Polarization resistance (from PR) for the concrete slabs repaired by the concrete with the shrinkage reducing admixture.

6.9 (b) Corrosion current density (from PR) for the slabs repaired by concrete with shrinkage reducing admixture

6.10 (a) Polarization resistance (from PR) for the concrete slabs repaired by the latex modified concrete

6.10 (b) Corrosion current density (from PR) for the slabs repaired with latex modified concrete

6.11 (a) Nyquist plot of slab 2A at different exposing time

6.11 (b) Nyquist plot of slab 2B at different exposing time

6.11 (c) Nyquist plot of slab 2C at different exposing time

6.12 (a) Nyquist plot of slab 3A at different exposing time 174

6.12 (b) Nyquist plot of slab 3B at different exposing time 175

6.12 (c) Nyquist plot of slab 3C at different exposing time 175

6.13 (a) Nyquist plot of slab 4A at different exposing time 176

6.13 (b) Nyquist plot of slab 4B at different exposing time 176

6.13 (c) Nyquist plot of slab 4C at different exposing time 177

6.14 (a) Nyquist plot of slab 5A at different exposing time 
6.14 (b) Nyquist plot of slab 5B at different exposing time 178

6.14 (c) Nyquist plot of slab 5C at different exposing time 178

6.15 (a) Nyquist plot of slab 6A at different exposing time 179

6.15 (b) Nyquist plot of slab 6B at different exposing time 179

6.16 (a) Nyquist plot of slab 7A at different exposing time 180

6.16 (b) Nyquist plot of slab 7B at different exposing time 180

6.16 (c) Nyquist plot of slab 7C at different exposing time 181

6.17 (a) Nyquist plot of slab 8A at different exposing time 181

6.17 (b) Nyquist plot of slab 8B at different exposing time 182

6.17 (c) Nyquist plot of slab 8C at different exposing time 182

6.18 Concrete resistivity values for slabs being repaired with silica fume concrete

6.19 Concrete resistivity values for slabs being repaired by concrete with calcium nitrite.

6.20 Concrete resistivity values for slabs being repaired by concrete with organic corrosion inhibitor

6.21 Concrete resistivity values for slabs being repaired with fly ash concrete

6.22 Concrete resistivity values for slabs being repaired with INDOT 9-bag cement concrete

6.23 Concrete resistivity values for slabs being repaired by concrete with shrinkage reducing admixture

6.24 Concrete resistivity values for slabs being repaired with latex modified concrete

6.25 (a) Polarization resistance from EIS for slabs being repaired with silica fume concrete

6.25 (b) Corrosion current density from EIS for the slabs repaired by silica fume concrete

6.26 (a) Polarization resistance from EIS for slabs being repaired by the concrete with calcium nitrite

6.26 (b) Corrosion current density from EIS for the slabs repaired by the concrete with calcium nitrite. 
Figure

6.27 (a) Polarization resistance from EIS for slabs being repaired by the concrete with the organic corrosion inhibitor....

6.27 (b) Corrosion current density from EIS for the slabs repaired by the concrete with the organic corrosion inhibitor....

6.28 (a) Polarization resistance from EIS for slabs being repaired by the fly ash concrete

6.28 (b) Corrosion current density from EIS for the slabs repaired by the fly ash concrete

6.29 (a) Polarization resistance from EIS for slabs being repaired by INDOT 9-bag cement concrete

6.29 (b) Corrosion current density from EIS for slabs being repaired by INDOT 9-bag cement concrete

6.30 (a) Polarization resistance from EIS for slabs being repaired by concrete with shrinkage reducing admixture

6.30 (b) Corrosion current density from EIS for the slabs repaired with concrete containing shrinkage reducing admixture.

6.31 (a) Polarization resistance from EIS for slabs being repaired with latex modified concrete

6.31 (b) Corrosion current density from EIS for the slabs repaired by the latex modified concrete

6.32 The values of the constant phase element (CPE) for the slabs repaired by the silica fume concrete.

6.33 The values of the constant phase element (CPE) for the slabs repaired by the concrete with the calcium nitrite

6.34 The values of the constant phase element (CPE) for the slabs repaired by the concrete with the organic corrosion inhibitor.

6.35 The values of the constant phase element (CPE) for the slabs repaired by the fly ash concrete.

6.36 The values of the constant phase element (CPE) for the slabs repaired by the INDOT 9-bag cement concrete

6.37 The values of the constant phase element (CPE) for the slabs repaired by the concrete with the shrinkage reducing admixture.

6.38 The values of the constant phase element (CPE) for the slabs repaired by the latex modified concrete 
Figure

6.39 Alpha $(\alpha)$ values of the constant phase element (CPE) for the slabs repaired by the silica fume concrete.

6.40 Alpha $(\alpha)$ values of the constant phase element (CPE) for the slabs repaired by the concrete with the calcium nitrite

6.41 Alpha $(\alpha)$ values of the constant phase element (CPE) for the slabs repaired by the concrete with the organic corrosion inhibitor.

6.42 Alpha $(\alpha)$ values of the constant phase element (CPE) for the slabs repaired by the fly ash concrete.

6.43 Alpha ( $\alpha$ ) values of the constant phase element (CPE) for the slabs repaired by the INDOT 9-bag cement concrete

6.44 Alpha $(\alpha)$ values of the constant phase element (CPE) for the slabs repaired by the concrete with the shrinkage reducing admixture

6.45 Alpha $(\alpha)$ values of the constant phase element (CPE) for the slabs repaired by the latex modified concrete

C.1 Half-cell potentials of slab 2A before repair. Potential values are versus copper-copper sulfate electrode

C. 2 Half-cell potentials of slab 2A one week after repair with silica fume concrete.

Potential values are versus copper-copper sulfate electrode.

C.3 Half-cell potentials of slab 2A eight weeks after repair with silica fume concrete. Potential values are versus copper-copper sulfate electrode

C. 4 Half-cell potentials of slab $2 \mathrm{~B}$ before repair. Potential values are versus copper-copper sulfate electrode

C. 5 Half-cell potentials of slab 2B one week after repair with silica fume concrete. Potential values are versus copper-copper sulfate electrode

C.6 Half-cell potentials of slab 2B eight weeks after repair with silica fume concrete. Potential values are versus copper-copper sulfate electrode

C.7 Half-cell potentials of slab $2 \mathrm{C}$ before repair with silica fume concrete. Potential values are versus copper-copper sulfate electrode.

C.8 Half-cell potentials of slab $2 \mathrm{C}$ one week after repair with silica fume concrete. Potential values are versus copper-copper sulfate electrode.

C.9 Half-cell potentials of slab $2 \mathrm{C}$ eight weeks after repair with silica fume concrete. Potential values are versus copper-copper sulfate electrode

C.10 Half-cell potentials of slab 3A before repair with concrete containing calcium nitrite. Potential values are versus copper-copper sulfate electrode 
C.11 Half-cell potentials of slab 3A first week after repair with concrete containing calcium nitrite. Potential values are versus copper-copper sulfate electrode...... 250

C.12 Half-cell potentials of slab 3A eight weeks after repair with concrete containing calcium nitrite. Potential values are versus copper-copper sulfate electrode...... 250

C.13 Half-cell potentials of slab 3B before repair with concrete containing calcium nitrite. Potential values are versus copper-copper sulfate electrode...... 251

C.14 Half-cell potentials of slab 3B first week after repair with concrete containing calcium nitrite. Potential values are versus copper-copper sulfate electrode...... 251

C. 15 Half-cell potentials of slab 3B eight weeks after repair with concrete containing calcium nitrite. Potential values are versus copper-copper sulfate electrode...... 252

C.16 Half-cell potentials of slab 3C before repair with concrete containing calcium nitrite. Potential values are versus copper-copper sulfate electrode...... 252

C.17 Half-cell potentials of slab 3C first week after repair with concrete containing calcium nitrite. Potential values are versus copper-copper sulfate electrode...... 253

C. 18 Half-cell potentials of slab 3C eight weeks after repair with concrete containing calcium nitrite. Potential values are versus copper-copper sulfate electrode...... 253

C.19 Half-cell potentials of slab 4A before repair with the concrete containing organic corrosion inhibitor. Potential values are versus copper-copper sulfate electrode

C.20 Half-cell potentials of slab 4A first week after repair with the concrete containing organic corrosion inhibitor. Potential values are versus copper-copper sulfate electrode

C.21 Half-cell potentials of slab 4A eight weeks after repair with the concrete containing organic corrosion inhibitor. Potential values are versus copper-copper sulfate electrode

C.22 Half-cell potentials of slab 4B before repair with the concrete containing organic corrosion inhibitor. Potential values are versus copper-copper sulfate electrode.

C.23 Half-cell potentials of slab 4B first week after repair with the concrete containing organic corrosion inhibitor. Potential values are versus copper-copper sulfate electrode 256

C.24 Half-cell potentials of slab 4B eight weeks after repair with the concrete containing organic corrosion inhibitor. Potential values are versus copper-copper sulfate electrode 
C. 25 Half-cell potentials of slab 4C before repair with the concrete containing organic corrosion inhibitor. Potential values are versus copper-copper sulfate electrode.

C.26 Half-cell potentials of slab 4C first week after repair with the concrete containing organic corrosion inhibitor. Potential values are versus copper-copper sulfate electrode

C.27 Half-cell potentials of slab 4C eight weeks after repair with the concrete containing organic corrosion inhibitor. Potential values are versus copper-copper sulfate electrode

C.28 Half-cell potentials of slab 5A before repair with the fly ash concrete. Potential values are versus copper-copper sulfate electrode.

C.29 Half-cell potentials of slab 5A first week after repair with the fly ash concrete. Potential values are versus copper-copper sulfate electrode

C.30 Half-cell potentials of slab 5A eight weeks after repair with the fly ash concrete. Potential values are versus copper-copper sulfate electrode

C.31 Half-cell potentials of slab 5B before repair with the fly ash concrete. Potential values are versus copper-copper sulfate electrode

C.32 Half-cell potentials of slab 5B first week after repair with the fly ash concrete. Potential values are versus copper-copper sulfate electrode

C.33 Half-cell potentials of slab 5B eight weeks after repair with the fly ash concrete. Potential values are versus copper-copper sulfate electrode

C.34 Half-cell potentials of slab 5C before repair with the fly ash concrete. Potential values are versus copper-copper sulfate electrode.

C.35 Half-cell potentials of slab 5C first week after repair with the fly ash concrete. Potential values are versus copper-copper sulfate electrode

C.36 Half-cell potentials of slab 5C eight weeks after repair with the fly ash concrete. Potential values are versus copper-copper sulfate electrode

C.37 Half-cell potentials of slab 6A before repair with the INDOT 9-bag concrete. Potential values are versus copper-copper sulfate electrode

C.38 Half-cell potentials of slab 6A first week after repair with the INDOT 9-bag concrete. Potential values are versus copper-copper sulfate electrode ..... 263

C.39 Half-cell potentials of slab 6A eight weeks after repair with the INDOT 9-bag concrete. Potential values are versus copper-copper sulfate electrode ..... 264

C.40 Half-cell potentials of slab 6C before repair with the INDOT 9-bag concrete. Potential values are versus copper-copper sulfate electrode 
C.41 Half-cell potentials of slab 6C first week after repair with the INDOT 9-bag concrete. Potential values are versus copper-copper sulfate electrode

C.42 Half-cell potentials of slab 6C eight weeks after repair with the INDOT 9-bag concrete. Potential values are versus copper-copper sulfate electrode ..... 265

C.43 Half-cell potentials of slab 7A before repair with the concrete containing the shrinkage reducing admixture. Potential values are versus copper-copper sulfate electrode.

C.44 Half-cell potentials of slab 7A first week after repair with the concrete containing the shrinkage reducing admixture. Potential values are versus copper-copper sulfate electrode

C.45 Half-cell potentials of slab 7A eight weeks after repair with the concrete containing the shrinkage reducing admixture. Potential values are versus copper-copper sulfate electrode

C.46 Half-cell potentials of slab 7B before repair with the concrete containing the shrinkage reducing admixture. Potential values are versus copper-copper sulfate electrode.

C.47 Half-cell potentials of slab 7B first week after repair with the concrete containing the shrinkage reducing admixture. Potential values are versus copper-copper sulfate electrode

C.48 Half-cell potentials of slab 7B eight weeks after repair with the concrete containing the shrinkage reducing admixture. Potential values are versus copper-copper sulfate electrode

C.49 Half-cell potentials of slab 7C before repair with the concrete containing the shrinkage reducing admixture. Potential values are versus copper-copper sulfate electrode.

C.50 Half-cell potentials of slab 7C first week after repair with the concrete containing the shrinkage reducing admixture. Potential values are versus copper-copper sulfate electrode

C.51 Half-cell potentials of slab 7C eight weeks after repair with the concrete containing the shrinkage reducing admixture. Potential values are versus copper-copper sulfate electrode

C.52 Half-cell potentials of slab 8A before repair with the latex modified concrete. Potential values are versus copper-copper sulfate electrode

C.53 Half-cell potentials of slab 8A first week after repair with the latex modified concrete. Potential values are versus copper-copper sulfate electrode 
Figure

C.54 Half-cell potentials of slab 8A eight weeks after repair with the latex modified concrete. Potential values are versus copper-copper sulfate electrode

C.55 Half-cell potentials of slab 8B before repair with the latex modified concrete. Potential values are versus copper-copper sulfate electrode

C.56 Half-cell potentials of slab 8B first week after repair with the latex modified concrete. Potential values are versus copper-copper sulfate electrode

C.57 Half-cell potentials of slab 8B eight weeks after repair with the latex modified concrete. Potential values are versus copper-copper sulfate electrode

C.58 Half-cell potentials of slab 8C before repair with the latex modified concrete. Potential values are versus copper-copper sulfate electrode

C.59 Half-cell potentials of slab 8C first week after repair with the latex modified concrete. Potential values are versus copper-copper sulfate electrode

C.60 Half-cell potentials of slab 8C eight weeks after repair with the latex modified concrete. Potential values are versus copper-copper sulfate electrode 


\section{IMPLEMENTATION SUGGESTIONS}

This research was focused on the evaluation of the effectiveness of various portland cement-based mixes as a repair material for the corrosion damaged reinforced concrete bridge decks. In order to complete this task, two major types of experiments were

performed. These two types included: (a) testing of the physical and mechanical properties of the patching materials, and (b) monitoring the corrosion process of the repaired concrete specimens. Physical and mechanical tests performed on patching materials included compressive strength and static modulus of elasticity, dynamic modulus of elasticity, length change of hardened concrete, freeze-thaw resistance, electrical conductance, and chloride ions penetration. Corrosion process in reinforced concrete slabs was monitored using three techniques: half-cell potential measurement, linear polarization resistance method, and electrochemical impedance spectroscopy methods.

In general, the selection of the repair material will be driven by its mechanical properties, durability, and ability to effectively reduce the rate of corrosion. While both durability and mechanical properties of repair mixes developed during this research study have been found satisfactory, their ability to provide an effective corrosion protection after repair varies. Some mixes, including the control 9-bag INDOT mix and mixes containing shrinkage-reducing admixtures were found to be highly effective repair materials. On the other hand, repair mixes containing silica fume and fly ash were found to be less effective. Calcium nitrate provided better corrosion protection than organic corrosion inhibitor.

Considering the above findings both advantages and disadvantages of the proposed repair system should be carefully evaluated before proposing a repair material. In certain 
cases, combination of repair systems studied in this research may offer the best solution. For example, combining a shrinkage-reducing admixture and silica fume may yield highly impermeable system that may be beneficial in cases where both freeze/thaw and corrosion damage occur simultaneously and the chloride content of the existing concrete is small. Similarly, a combining corrosion inhibitor and a shrinkage-reducing admixture may also yield an effective repair material. Before they can be implemented any of the above example combinations would have to be further evaluated, as they were not studied in the course of this research. 


\section{CHAPTER 1 INTRODUCTION}

\section{$1.1 \quad$ Background}

People used to believe that reinforced concrete is durable and maintenance free. However, while reinforced concrete performs very well in some environments, it may develop problems in others. In particular, if concrete is exposed to moisture (especially in the presence of chloride ions) the corrosion of reinforcing steel may lead to damage of the structural elements. In the United States, the application of de-icing salts on the road during winters often leads to extensive damages of both bridge decks and structural elements of parking garages. Intensive use of de-icing salts on highways started in the late 1950s. About ten years later, damage of bridge deck due to corrosion of reinforcing steel became a problem, and rehabilitation was carried out from then on.

A common method of bridge decks rehabilitation involves removal of the contaminated and delaminated concrete, sandblasting the surface of reinforcing steel and, in some cases, replacing the reinforcing steel bars. Finally, the area from which the concrete has been removed is patched (filled) with new concrete or mortar. In order to reduce the penetration rate of chloride ions and to prevent further corrosion damage to the reinforcing steel, the new concrete is usually less permeable than the substrate concrete. Indiana Department of Transportation uses 9-bag cement concrete to repair (patch) corrosion-damaged bridge decks. It is estimated that the patching itself will 
increase the service life of the bridge decks by an average of 6 years. To further reduce the risk of corrosion in the bridge deck, concrete overlay is placed on top of the patched area. In most cases, the overlay is constructed at the same time as the patch and the same material is used for both installations. The combination of patching-overlay system is expected to add a 20-year service life to the bridge deck.

However, in some bridges that were monitored by the Indiana Department of Transportation Research Division and Design Division, the newly patched area underneath the overlay was damaged due to corrosion of reinforcing steel after about only seven years of service. At the same time, the steel bars outside the patched areas did not show signs of any additional corrosion damage

Initially, it was believed that the problem might have been related to development of cracks in the patched areas which, in turn, might have led to an increased rate of ingress of water and chloride ions. These cracks were believed to have formed as a result of vibration of flexible bridges during construction, as one lane was usually opened to traffic. However, the same problem was also encountered on rigid bridges, indicating that factors other than cracks may have caused the acceleration of corrosion.

For the cement-based repair materials, low water to cement ratio is desirable. Besides low water-cement ratio, chemical and mineral admixtures are also added into the patching mix in order to achieve highly impermeable concrete. At the same time, concrete may develop an excessive plastic and/or drying shrinkage strains. Excessive shrinkage will cause concrete to crack and will, in turn, expose steel bars to corrosive environment. 


\subsection{Objectives and scope}

The objective of this study was to develop portland cement-based mixes that can be used to repair corrosion-damaged bridge decks, and to evaluate their effectiveness in reducing the rate of corrosion after repair. In the course of the study, twenty-one reinforced concrete slabs were repaired with seven different concrete mixes. For each of these slabs, electrochemical parameters related to corrosion were evaluated along with selected mechanical and durability properties of the repair materials.

The original reinforced concrete slabs were made using INDOT Class C concrete, and exposed to drying-and-wetting cycles (in the presence of salt solution) to accelerate the process of corrosion. Seven different concrete mixes were developed to repair the deteriorated slabs. Mechanical, physical, and durability properties of these patching mixes were evaluated. These properties included compressive strength, static modulus of elasticity, dynamic modulus of elasticity, length change, permeability, and freeze-thaw resistance.

Electrochemical methods used to monitor the corrosion process included half-cell potential measurements, linear polarization resistance measurements, and electrochemical impedance spectroscopy.

The main purpose of this study was to monitor the corrosion behavior of reinforcing steel bars in concrete slabs repaired with different patching materials, to evaluate the properties of these patching materials and ultimately, to suggest a proper patching materials for bridge deck repairs. 


\subsection{Organization of the report}

Chapter 1 of the report presents the background information, objectives, and scope of the research. In chapter 2, the fundamentals of corrosion are briefly explained. Chapter 3 contains literature review related to the corrosion of reinforced concrete. It covers basic cement and concrete chemistry, the influence of concrete cover on corrosion, passivity and pitting corrosion of steel in concrete, techniques for monitoring corrosion, and repair and rehabilitation techniques. The experimental procedures used in this study are presented in Chapter 4. Chapter 5 provides the results and analysis of the mechanical and physical test results of concrete specimens and Chapter 6 provides the results of electrochemical measurements. Chapter 7 contains the summary and conclusion while Chapter 8 includes recommendations for future studies. 


\section{CHAPTER 2 FUNDAMENTALS OF CORROSION}

Corrosion of steel in concrete has become a considerable durability problem in the past three decades. The cost of corrosion damages is significant. For example in 1992, the yearly cost of bridge decks repairs in the United States was estimated to be between \$50 to \$200 millions [Menzies, 1992]. In 1994, the USA Today reported that the total cost for repairing all of the damaged bridges in this country was \$78 billions [USA Today, 1994].

Corrosion is a common distress mechanism associated with materials exposed to elements. The understanding of basic principles of corrosion is necessary for its prevention and control. Recent research activities in the area of corrosion have been focused on two separate but correlated issues: the mechanism of corrosion and the control of corrosion.

This chapter starts with the description of basic principles of corrosion. Then the half-cell potential testing method is discussed, followed by the theory of linear polarization resistance test. Finally the use of electrochemical impedance method in corrosion studies is addressed. 


\subsection{Electrochemical Nature of Corrosion}

It is well known that pure metals, such as, iron and aluminum, exist in nature in the oxide forms. Iron is produced from iron ore through a process of iron oxide reduction. A lot of energy is involved in this process, and as a result the iron has higher energy level than the iron oxide. Since the most stable form of the material is always associated with the lowest energy level, the energy acquired by iron during its production is ready to be released and provides the driving force for corroding iron into an iron oxide form (corrosion process).

\subsubsection{Electrochemical Reactions of Corrosion}

Corrosion is defined as the spontaneous degradation of a reactive material by an aggressive environment and involves charge transfer or exchange of electrons between metals and their environment [Jones, 1996]. Two simultaneous reactions take place during corrosion process. One of these reactions is called anodic reaction and the other one is called cathodic reaction. Because the pertaining chemical reaction is a chargetransfer process, corrosion is intrinsically an electrochemical phenomenon. Corrosion processes and reactions are commonly studied with the help of an electrochemical cell.

An electrochemical cell consists of two electrodes, or metal conductors, in contact with an electrolyte, which is the ionic conductor (it may be a solution, a liquid, or a solid) [Atkins, 1998]. Corrosion reaction can be viewed as a process similar to that which occur in a galvanic cell. Such cell produces electricity as a result of the spontaneous reaction occurring inside it. 
The two electrodes are, depending on the nature of the reactions taking place on them, defined as anode and cathode. Oxidation takes place on anode, and it produces electrons, which move away from the substance. Reduction takes place on cathode, and electrons are consumed by it. A redox reaction is referred to a reaction that involves transfer of electrons from anode to cathode. The electron transfer is always accompanied by other events, such as ion transfer and consumption of oxygen.

A simple electrochemical cell is shown in Figure 2.1 [Eisenberg and Crothers, 1979]. A zinc rod in contact with zinc sulfate solution is connected to a copper rod immersed in copper sulfate solution. A salt bridge, in this case, a concentrated solution of $\mathrm{KCl}$ in an agar gel, connects the two solutions. The chemical reactions occurring on the zinc rod and the copper rod are as shown below:

$$
\begin{gathered}
\mathrm{Zn} \rightarrow \mathrm{Zn}^{2}+2 e^{-} \\
\mathrm{Cu}^{2+}+2 e-\rightarrow \mathrm{Cu}
\end{gathered}
$$

The zinc rod releases electrons and the corresponding reaction is an oxidation since the zinc valence increases from 0 to +2 . The copper rod consumes electrons and the corresponding reaction is a reduction in which the copper ion valence decreases from +2 to 0 . The zinc rod is thus acting as the anode and the copper rod is acting as the cathode.

The complete redox reaction involves ion transfer and of electron exchange. Ion transfer is accomplished through salt bridge and the charges of the two solutions are always balanced. Electrons migrate from anode (zinc bar) through the wire to the cathode (copper bar). 
Any redox reaction may be expressed as the difference of two half-reactions. Thus, the previous reaction can be written as:

$$
\square \mathrm{Zn}+\mathrm{Cu}^{2+} \rightarrow \mathrm{Zn}^{2+}+\mathrm{Cu}
$$

\subsubsection{Thermodynamics and Electrode Potential}

Corrosion is an electrochemical phenomenon because it involves electron or charge transfer. Thermodynamics explains the energy change in the process of corrosion. This energy change not only supplies the driving force of corrosion reaction but also controls the direction of the reaction.

An electrochemical cell can do electrical work when the reaction drives electrons through an external circuit. The amount of electrons transferred and the potential of the cell determine the work that the cell can accomplish. Assuming the process occurs at constant pressure and temperature, the relation between the Gibbs free-energy change, $\Delta G$, of the reaction and the zero-current potential, $E$ (equilibrium potential), can be expressed as:

$$
\square-n F E=\Delta G
$$

where $n$ is the number of moles of electrons transferred. $E$ is the electrochemical potential at equilibrium $\left(E=E_{\text {reduction }}-E_{\text {oxidation }}\right)$, and $F$ is the Faraday constant, 96500 coulombs per equivalent. The negative sign (-) in the equation is used for purposes of conforming to convention: for a spontaneous reaction, the free energy change is negative and the potential is positive. 
In order to evaluate the potential, $E$, one must know the relative potentials of both anode and cathode in the electrochemical cell with respect to some arbitrary reference electrode. This reference electrode in reality makes only a half of the complete electrochemical cell (the other half being the system under the actual corrosion) and is often referred to as a reference half-cell. The most common reference electrode (halfcell) used is so-called standard hydrogen electrode, which by convention, has been assigned zero potential. This electrode consists of platinum $(\mathrm{Pt})$ metal in contact with both hydrogen gas and sulfuric acid solution of unit activity. The pressure of hydrogen gas is one atmosphere. Hydrogen electrode can be used to measure the potential difference between the reference and any other half-cells. Some common half-cell potentials with respect to standard hydrogen electrode (SHE) are listed in Table 2.1

\subsubsection{Concentration Effects on Electrode Potential}

The standard half-cell electrode potentials are measured at standard thermodynamic conditions. This means that the chemical activities of all reactants and products are equal to one unit, and the pressure of gas phase is one atmosphere [Goodisman, 1987]. Obviously, most naturally occurring corrosion cells do not match this condition. Electrode potential in corrosion cell is influenced by the concentrations of both reactants and products.

A common corrosion half-cell reaction in acid solution can be written as:

$$
x \mathrm{~A}+y \mathrm{H}^{+}+n e^{-}=z \mathrm{~B}+w \mathrm{H}_{2} \mathrm{O}
$$


Taking $\Delta G^{0}$ as the Gibbs free energy change at standard state and $\Delta G$ as the Gibbs free energy change at nonstandard state, the difference between $\Delta G$ and $\Delta G^{0}$ can be expressed as:

$$
\square \Delta G-\Delta G^{0}=R T \ln \left[(\mathrm{B})^{z} /(\mathrm{A})^{x}\left(\mathrm{H}^{+}\right)^{y}\right]
$$

Since $\Delta G=-n F E$ and $\Delta G^{0}=-n F E^{0}$, the equation can be re-written as:

$$
\square n F\left(E^{0}-E\right)=R T \ln \left[(\mathrm{B})^{z} /(\mathrm{A})^{x}\left(\mathrm{H}^{+}\right)^{y}\right]
$$

It follows that as the activities of $\mathrm{A}$ and $\mathrm{H}^{+}$increase, the half-cell electrode potential, $E$, will be more positive.

In solutions, the activity is approximately defined as the concentration. This simplification is adequate as long as the concentration is not extremely high or extremely low. For common corrosion reactions, concentration is generally used as a substitute for activity.

\subsubsection{Polarization}

In an electrochemical reaction cell, the anode releases electrons while the cathode consumes electrons. The anodic and cathodic reactions are in balance if the production and the consumption of electrons proceed at the same rate.

This does not always happen in nature. If the reaction rate at the anode is slower than the reaction rate at the cathode, a deficiency of electrons occurs at the surface of anode because electrons are consumed at the cathode at a faster rate than the anode can supply them. This deficiency of electrons produces a positive potential change at the anode (anodic overpotential, $e_{a}$ ). This potential change is called anodic polarization. 
When the positive potential change at the anode increases, the tendency for anodic dissolution also increases. On account of this, anodic polarization represents the driving force for corrosion reaction at the anode.

On the other hand, if the amount of electrons supplied by anode is greater than the amount that can be consumed at cathode, extra electrons will accumulate at the surface of cathode waiting for reaction. Since the electrons are negatively charged, the potential of cathode will become more negative. This potential change is called cathodic polarization (cathodic overpotential, $e_{c}$ ).

Polarization can be calculated from the following expressions:

$$
\begin{aligned}
& e_{a}=E_{a}-E_{\text {corr }} \\
& e_{c}=E_{c}-E_{c o r r}
\end{aligned}
$$

where $E_{a}$ is the surface potential produced by deficiency of electrons at anode, $E_{c}$ is the surface potential produced by extra electrons accumulated at cathode, and $E_{\text {corr }}$ is the steady state potential (potential generated by corrosion reactions when anodic reaction and cathodic reaction are in equilibrium).

Polarization is a very important concept in corrosion, since the ability to artificially polarize either the anode or the cathode gives one the control over the rate of corrosion reaction. For example, by supplying electrons to the anode from external source of current, the rate of anodic reaction will be greatly reduced and the corrosion process will effectively stop. This is the basic idea for cathodic protection. This method is widely used for corrosion protection of pipelines, offshore oil drilling structures and high temperature containers [Jones, 1996]. The relationship between anodic polarization and corrosion rate is schematically illustrated in Figure 2.2. It could be seen that the 
negative anodic potential produces negative polarization $\left(e_{a}^{-}\right)$which, in turn, leads to reduction in corrosion rate.

\subsubsection{Passivity}

Experiments show that the corrosion rate is extremely low when the potential of the metal is above a critical potential, $E_{p}$, as shown in Figure 2.3. This phenomenon is called passivity, and the potential, $E_{p}$, is called passive potential. Passivity is the result of formation of an oxide film on the surface of the metal. Usually, corrosion rate of metals at passive state is $10^{3}$ to $10^{6}$ times below the corrosion rate in active state.

The thin oxide film formed on the surface of metal provides protective layer that prevents direct contact of the bulk metal with the environment. Usually, the passive film is composed of a hydrated oxide of the metal. For example, steel generally has an oxide film consisting of either ferrous $\left(\mathrm{Fe}^{2+}\right)$ or ferric $\left(\mathrm{Fe}^{3+}\right)$ oxide. This film acts as a barrier separating metal and corrosive environment. However, it can easily be broken either by mechanical force or chemical attack. The breakdown of the passive film can results in localized form of corrosion, such as pitting.

\subsubsection{Corrosion of Steel}

The force that drives the corrosion process is the difference in electrical potentials between the anode and the cathode. This difference in electrical potentials can be generated by various mechanisms. One of them develops when two dissimilar metals, for example zinc and copper, are in contact with each other. Potentials between metals are determined by taking the absolute differences between their standard electrode potentials. 
There is a potential of 1.10 volt between copper and zinc electrodes. That difference in potential can also exist on one piece of metal due to the differences in chemical compositions between various sites on the surface of the metal, or due to the fact that various parts of the same metal object are exposed to different environments.

Steel is an iron-carbon alloy that usually contains certain amount of alloying elements. The carbon content is normally less than about $0.25 \%$. Microstructure of steel is heterogeneous, consisting of $\alpha$-iron crystal usually referred to as ferrite, and an iron carbon compound $\left(\mathrm{Fe}_{3} \mathrm{C}\right)$ called cementite. The heterogeneous microstructure of steel is illustrated schematically in Figure 2.4. The ferrite is more reactive than the cementite, and the former will become an anode in the corrosion cell [Bentur, Diamond, and Berke, 1998].

The difference in electrical potential can also exit at the crystal grain boundaries even if the chemical composition is homogeneous. The atoms at or near the grain boundaries are more active and their electrons are at higher energy level than the electrons in the atoms, within the bulk of the grain. As a result, these electrons can be easily removed from the atoms and the boundary region becomes an anode while the bulk of the grain becomes a cathode.

Corrosion will not occur if there is no electrolyte connecting anode and a cathode. When iron is exposed to atmosphere (that provides oxygen and electrolyte), corrosion will happen spontaneously. The anodic reaction for iron corrosion is:

$$
\mathrm{Fe}_{(\mathrm{s})}=\mathrm{Fe}^{2+}+2 e^{-}
$$

The released electrons will migrate to the cathode and, in the presence of oxygen and water, will be consumed during following reaction: 


$$
\mathrm{H}_{2} \mathrm{O}_{(\mathrm{aq})}+1 / 2 \mathrm{O}_{2(\mathrm{~g})}+2 e^{-}=2 \mathrm{OH}_{(\mathrm{aq})}^{-}
$$

Ferrous ion $\left(\mathrm{Fe}^{2+}\right)$ and hydroxide ion $\left(\mathrm{OH}^{-}\right)$will react and produce ferrous hydroxide:

$$
\mathrm{Fe}^{2+}+2 \mathrm{OH}^{-}=\mathrm{Fe}(\mathrm{OH})_{2}
$$

Ferrous hydroxide is not stable and will be oxidized by oxygen to become ferric hydroxide:

$$
2 \mathrm{Fe}(\mathrm{OH})_{2}+1 / 2 \mathrm{O}_{2}+\mathrm{H}_{2} \mathrm{O}=2 \mathrm{Fe}(\mathrm{OH})_{3}
$$

This compound may loss water in atmosphere and become ferric oxide, which has a reddish brown color and is commonly called rust.

\subsection{Corrosion of Steel in Concrete}

Corrosion process of steel in concrete is different from corrosion of steel in atmosphere, since the concrete cover surrounding the steel significantly changes the chemical environment [Bentur, Diamond, and Berke, 1998]. The concrete cover with high alkalinity of pore solution and good impermeability provides not only a chemical barrier but also a physical barrier protecting the steel. Corrosion of steel may begin if the chemical barrier ceases to be effective and the passive film becomes unstable. Once corrosion begins, its rate will depend on several factors. The most important of these factors are: (a) the availability of oxygen at the cathode and (b) the presence of water solutions in the concrete pores adjacent to the steel. 


\subsubsection{Passivity of Steel in Concrete}

Pore solution of normal concrete has a $\mathrm{pH}$ value of above 12.5 [Neville, A. M., 1997]. In this strong basic environment, a protective oxide film (passive layer composed of the mixture of ferric and ferrous oxide) is formed on the surface of steel. Both ferrous and ferric oxides are chemically stable because of high alkalinity of the concrete.

However, ferric oxide is more stable than ferrous oxide and with time the latter will be converted to the ferric oxide, which is referred to as $\gamma$-FeOOH. The development of the oxide film can be represented by the following reactions:

$$
\begin{gathered}
\mathrm{Fe} \rightarrow \mathrm{Fe}^{2+}+2 e^{-} \\
\mathrm{Fe}^{2+}+2 \mathrm{OH}^{-} \rightarrow \mathrm{Fe}(\mathrm{OH})_{2} \\
\mathrm{Fe}(\mathrm{OH})_{2}+\mathrm{O}_{2} \rightarrow \gamma-\mathrm{FeOOH}+\mathrm{H}_{2} \mathrm{O}
\end{gathered}
$$

\subsubsection{Effects of Carbonation and Chloride Ions}

The formation and stability of the passive oxide file on the surface of the steel is dependent on the $\mathrm{pH}$ level of the solutions in the concrete. However, the passive film can be broken in practice under two conditions: (a) reduction of the $\mathrm{pH}$ level due to concrete carbonation, and (b) penetration of chloride ions into the concrete to the steel level. Neither ferrous nor ferric oxide are stable when the $\mathrm{OH}^{-}$ion concentration is low $(\mathrm{pH}$ less than 11.5), and corrosion takes place on the steel surface. Also, when the chloride ions are present in the concrete pore solution and reach a certain concentration $(1 \%$ by weight of the cement content), ferrous oxide is unstable and reacts with chloride ions to form a soluble complex according to the following reaction: 


$$
\mathrm{Fe}(\mathrm{OH})_{2}+\mathrm{Cl}^{-} \rightarrow[\mathrm{FeCl}]_{\mathrm{x}}
$$

This causes localized corrosion that is referred to as pitting corrosion.

\subsection{Principles of Corrosion Process Monitoring}

The process of corrosion reaction can be studied by monitoring its chemical thermodynamics and kinetic. Whether a chemical reaction progresses or not is a function of the thermodynamic properties of this reaction. Since corrosion is thermodynamically possible under most environmental conditions, majority of the corrosion studies focuses on the kinetics of the process. By measuring the corrosion rate, one can conveniently monitor the kinetics of corrosion. Chemists have established a framework for the study of corrosion based on electrochemistry [Stern, 1957, 1958, 1959; Fontana, 1986; Jones, 1996; and MacDonald, 1987]. Some basic parameters that can be monitored in order to evaluate the corrosion process include corrosion potential, corrosion rate, and corrosion current density. More detailed description of these parameters is presented below.

\subsubsection{Half-Cell Potential}

The driving force for corrosion process is the energy change of the corrosion reaction. Every corrosion cell contains an anode and a cathode, and the overall corrosion reaction can be separated into two half-cell reactions: the anodic reaction and the cathodic reaction. Each half-cell reaction is associated with its own free energy change and the corresponding potential. This potential is usually called half-cell potential. 


\subsubsection{Standard Hydrogen Electrode}

By connecting the anode and cathode through a sensitive voltmeter, we can read a potential value, which is actually the potential difference between the anode and cathode and it represents the potential of the whole cell.

Standard hydrogen electrode (SHE) is often chosen as a standard reference electrode, and its potential is arbitrarily defined as zero. By connecting this electrode to any other half-cell electrode and measuring the potential difference between the two electrodes, the potential of the unknown half-cell electrode can be determined.

One version of the standard hydrogen electrode is shown in Figure 2.5. A piece of platinum foil is suspended in sulfuric acid solution, and the solution is purged with pure hydrogen gas. The standard state requires that the activity of $\mathrm{H}^{+}$in the sulfuric acid is one unit and the pressure of hydrogen is one atmosphere.

\subsubsection{Secondary Reference Electrodes}

Standard hydrogen electrode is not the only reference electrode used in practice. Actually, this electrode is difficult to use in some situations, such as field-testing. Standard hydrogen electrode is usually called the primary reference electrode, and its main usage is in establishing of a scale for electrode potential measurement. All other reference electrodes are therefore called secondary reference electrodes. Some commonly used secondary reference electrodes and their corresponding half-cell electrode potentials are listed in Table 2.2. The values of their potentials are based on the scale of standard hydrogen electrode. 
Copper-copper sulfate electrode is most commonly used for the study of steel corrosion in reinforced concrete. A schematic of copper-copper sulfate electrode is shown in Figure 2.6. When compared to the standard hydrogen electrode, copper-copper sulfate electrode has relatively simple structure. The main part of this electrode is a copper rod that is immersed in saturated copper sulfate solution. In order to keep the solution saturated, the copper sulfate solution is usually supersaturated, so that there are always some copper sulfate crystals in the solution. The electrode potential is $+0.318 \mathrm{~V}$ versus standard hydrogen electrode.

\subsubsection{Corrosion Potential}

Corrosion potential represents the potential at which the anode and the cathode processes are in equilibrium. As shown in Figure 2.7, anode and cathode have the same corrosion rate (current density) at corrosion potential, $\mathrm{E}_{\text {corr. }}$ By measuring the voltage difference between a reference electrode and the metal to be tested (zinc in this case) one can assess the corrosion potential.

\subsubsection{Corrosion Rate}

Corrosion process involves production and consumption of electrons. The higher the rate of corrosion reaction, the higher the rate at which electrons are released from the anode and consumed at the cathode. Thus, measurement of the rate of electron movement can be used to evaluate the corrosion rate. 
Electron flow is represented by current, $I$, which is typically reported in units of amperes. One ampere is equal to one coulomb of charge $\left(6.2 \times 10^{18}\right.$ electrons $)$ passing through the surface in one second. The relationship between current, $I$, and mass reacted, $m$, in a corrosion reaction is given by Faraday's Law:

Eqn. 2.18

where $a$ is the atomic weight, $t$ is the time in which the measurement is carried out, $F$ is Faraday constant (96500 coulombs per equivalent), and $\mathrm{n}$ is the number of electrons lost (valence change).

Dividing the previous equation by time, $t$, and the surface area of the electrode, $A$, one gets the corrosion rate, $r$, as:

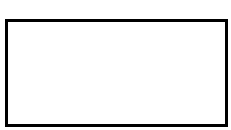

Eqn. 2.19

where $i$ is the current density, I/A.

When the reaction on the electrode is in equilibrium, the forward rate is equal to the reverse rate. The current density at equilibrium is referred to as exchange current density and is indicated by symbol $i_{0}$.

\subsubsection{Corrosion Current Density}

When a metal such as steel is corroding, both the anodic and the cathodic half-cell reactions occur simultaneously on the surface of the metal, and each of these reactions has its own half-cell electrode potential and exchange current density. However, the two half-cell electrode potentials cannot coexist separately on an electrically conductive 
surface. Each must polarize or change its value to a common value, which is called corrosion potential, $E_{\text {corr }}$. The corrosion potential is often referred to as a mixed potential since it is a combination (or mixture) of the half-cell potentials for both anodic and cathodic reactions. The current densities at both the anode and the cathode are identical and equal to the corrosion rate, $i_{c o r r}$, which is:

$$
I_{c o r r}=i_{a}=i_{c}
$$

Corrosion rate could be determined from equation 2.19 once the corrosion current density is known. Usually, the corrosion current density is calculated based on a measured value of polarization resistance as described in section 2.4.2

The relationship between corrosion current density and overvoltage of an electrode can be described by Tafel equation. Overvoltage, usually abbreviated as $\eta$, is a measure of the polarization with respect to the equilibrium potential of an electrode. That is, the equilibrium potential of an electrode is considered as a reference, and the overpotential is stated in terms of volts or millivolts with respect to the reference. Thus, overvoltage, $\eta$, can be expressed as:

$$
\eta=E-E^{0}
$$

where $\mathrm{E}^{0}$ is the equilibrium potential of the electrode. The relation between overvoltage, $\eta$, and the current density, $i$, for idealized anode and cathode, is known as Tafel relationship and can be expressed as follows:

$$
\begin{aligned}
& \eta_{a}=\beta_{a} \log \left(i_{a} / i_{0}\right) \\
& \eta_{c}=\beta_{c} \log \left(i_{c} / i_{0}\right)
\end{aligned}
$$


where $i_{a}$ is the anodic current density, $i_{c}$ is the cathodic current density, $\beta_{a}$ and $\beta_{c}$ are Tafel constants (slopes of idealized anode and cathode polarization curves, respectively, as shown in Figure 2.8 for anode and cathode, respectively. The absolute values of the $\beta$ Tafel constants usually range from 0.03 to $0.2 \mathrm{~V}$.

\subsection{Experimental Testing for Corrosion Process}

The experimental techniques most commonly used for corrosion measurements are described in this section. These techniques include half-cell potential measurement, polarization resistance method, and electrochemical impedance spectroscopy (EIS) method. Half-cell potential measurement can be used to get information about the thermodynamics of the corrosion process. For an electrochemical cell, half-cell potential value is commonly used to determine the probability of corrosion taking place. However, this method cannot provide information about the corrosion rate. Polarization resistance method and electrochemical impedance spectroscopy measurements are commonly used to measure the corrosion rate. These two techniques are discussed in sections 2.4.2 and 2.4 .3 .

\subsubsection{Corrosion Potential Measurement}

When a corrosion cell is in equilibrium, the anodic potential is equal to the cathodic potential, and this common potential is called the corrosion potential. Using the half-cell potential measurement, one can measure the corrosion potential of a corrosion cell. In order to perform the measurement, a reference electrode is connected to the negative pole of a voltmeter. An anode (for common corrosion cell, anode is metal and is 
electrically conductive) of the corrosion cell under testing is connected to the positive pole of the voltmeter. The potential difference between the reference electrode and the anode is measured. A voltmeter with high built-in resistance is used to measure the voltage difference. High resistance is required for the voltmeter because it can decrease the current to a very low level, so that measured potential is close to the true value. If the resistance is not high enough, the current in the circuit may be so high that the corroding metal can be polarized. For example, if we use a voltmeter with 10,000 ohms resistance to measure a cell potential of $1 \mathrm{~V}$, the current would be $100 \mu \mathrm{A}$, which will polarize not only the corrosion electrode but also the reference electrode [Jones, 1996]. In

electrochemical potential measurements, voltmeters with resistance of $10^{14} \mathrm{ohms}$ are used in order to eliminate the excessive level of current. A voltmeter with at least $10^{6} \mathrm{ohms}$ build-in resistance is required for corrosion potential measurement of reinforcing steel in concrete.

\subsubsection{Polarization Resistance Method}

Polarization resistance method involves the application of a small external dc current (or potential) to polarize the electrodes in a corrosion cell. This method is based on the fact that for a corrosion cell, there is a linear relationship between the overpotential and the corrosion current density when the overpotential is very small (a few millivolts).

When a corrosion cell is in equilibrium, anode and cathode are at the same potential---corrosion potential. At this potential, the anodic and cathodic current densities are equal in magnitude. The application of an external current source will move 
the potential away from the corrosion potential. This is known as polarization. If the polarization is within several $\mathrm{mV}$ of corrosion potential, the potential change (overpotential) is almost always proportional to the current applied as shown in Figure $2.9\left[\right.$ Stern, 1957, 1958, 1959; Simmons, 1955]. Polarization resistance, $\mathrm{R}_{\mathrm{p}}$, is defined as the ratio of the overpotential to the current in the linear region.

Two methods are commonly used to measure the polarization resistance, one is called galvanostatic method, and the other one is called potentiostatic method.

For galvanostatic method, a constant current is applied to a corrosion cell, and the corresponding overpotential is measured. For potentiostatic method, a constant overvoltge is exerted on a corrosion cell and the corresponding current is measured. The polarization resistance technique allows for determination of polarization resistance $R_{p}$ which, in turn, can be used to calculate the corrosion current density. The relationship between polarization resistance and corrosion current density can be developed as follows.

Considering the polarization curves in Figure 2.8 the applied cathodic current density, $i_{\text {app, c }}$, can be expressed as below:

$$
i_{a p p, c}=i_{c}-i_{a}
$$

The applied anodic current, $i_{a p p, a}$, is given by:

$$
i_{a p p, a}=i_{a}-i_{c}
$$

Using Tafel relationships, polarization at both the anode and the cathode can be written as:

$$
\begin{aligned}
& e_{c}=\beta_{c} \log \left(i_{c} / i_{c o r r}\right) \\
& e_{a}=\beta_{a} \log \left(i_{a} / i_{c o r r}\right)
\end{aligned}
$$


where $e_{c}$ is the cathodic overpotential, $e_{a}$ is the anodic overpotential, and $\beta_{a}$ and $\beta_{c}$ are Tafel coefficients for anode and cathode, respectively.

By combining equations 2.24-2.27 into one, we have:

$$
i_{a p p, c}=i_{c o r r}\left(10^{-e_{c} / \beta_{c}}-10^{e_{a} / \beta_{a}}\right)
$$

Since $i_{a p p, c}$ and the overpotential, $e$, have a linear relationship as $e$ approaches zero, the polarization resistance, $R_{p}$, is determined by the equation:

$$
R_{p}=\left[\frac{d e}{d i_{a p p}}\right]_{e \rightarrow 0}=\left[\frac{\Delta e}{\Delta i_{a p p}}\right]_{e \rightarrow 0}=\frac{\beta_{a} \beta_{c}}{2.3 i_{c o r r}\left(\beta_{a}+\beta_{c}\right)}=\frac{B}{i_{c o r r}}
$$

where, the constant $B=\frac{\beta_{a} \beta_{c}}{2.3\left(\beta_{a}+\beta_{c}\right)}$.

Hence, by measuring the polarization resistance of a corrosion cell, one can calculate the corrosion current density, assuming that the coefficients $\beta_{a}$ and $\beta_{c}$ are known.

\subsubsection{Electrochemical Impedance Spectroscopy}

Electrochemical impedance spectroscopy (EIS) method is a popular tool often used to study the corrosion [MacDonald, 1987]. In this method, an alternating potential with varying frequencies is applied to the corrosion cell, and the resulting alternating current is measured. The impedance (or alternating voltage divided by the alternating current) is plotted as a function of frequency, and from this plot the value of polarization 
resistance, $R_{p}$, can be calculated. EIS has been used to study the mechanism of corrosion process, or to measure the polarization resistance.

\subsubsection{Impedance Spectroscopy Basics}

Ohm's Law defines resistance, $R$, in terms of the ratio between voltage, $V$, and current, $I$, as expressed below:

$$
R=V / I
$$

This equation is limited to only one circuit element - ideal resistor. It is assumed that a resistor has the following properties:

- It follows Ohm's Law at all current and voltage levels.

- Its resistance value is independent of frequency.

- AC current and voltage signals through the resistor are in phase with each other. System that only includes an ideal resistor cannot accurately portrait the behavior of real world electrical systems. Such system typically can only be represented by including other elements, such as capacitor, and inductor. To describe the behavior of such systems, we use the term impedance, which is a more general circuit parameter. Impedance, like resistance, is a measure of the ability of a circuit to resist the flow of electrical current, but it is not limited by the assumptions listed above.

When an alternating current is applied to a circuit, the relation between the timevarying voltage, $V(t)$, and the time-varying current $I(t)$, is given by:

$$
Z(\omega)=V(t) / I(t)
$$

where $Z(\omega)$ is defined as the impedance. 
The ac voltage and ac current can be represented as shown below:

$$
\begin{gathered}
V(t)=V_{m} \sin (\omega t) \\
I(t)=I_{m} \sin (\omega t+\phi)
\end{gathered}
$$

where, $V_{m}$ and $I_{m}$ are the maximum voltage and maximum current, respectively; $\omega$ is the frequency; and $\phi$ is the phase angle between $V_{m}$ and $I_{m}$. The impedance can be calculated as:

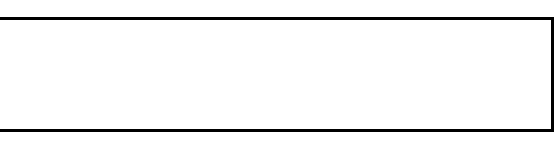

Eqn. 2.34

where, $\square$ is the modulus of the impedance, and $j$ is defined as $\square$.

Impedance may be expressed as a complex value consisting of both real and imaginary components. The real part of the impedance is usually indicated by $Z_{r}$, and the imaginary part is indicated by $Z_{i}$. The modulus of the impedance can be expressed as: $|Z|=\sqrt{Z_{r}{ }^{2}+Z_{i}^{2}}$. Like any complex vector, impedance has not only a magnitude but also a phase angle. When impedance is plotted in a complex coordinate system, the real part, $Z_{r}$, is plotted on the real axis, and the imaginary part, $Z_{i}$, is plotted on the imaginary axis.

When an ac current is passing through a resistor, the measured impedance has a phase angle of zero. In other words, the voltage and the current are in the same phase. For such a system, the impedance is simply equal to resistance, as shown below:

$$
Z(\text { resistor })=\square=R
$$

where $R$ is the resistance. Figure 2.10 shows a complex coordinate plane plot of impedance for a resistor. Since the impedance of a resistor has only the real part, a single point on the real axis would represent it. 
When an ac current with a frequency of $\omega$ is applied to a capacitor, its impedance can be expressed as shown below:

$$
Z(\text { capacitor })=-j / \omega C
$$

where $C$ is the capacitance and its unit is Farad, named after the famous British scientist Faraday. Figure 2.11 shows a complex coordinate plane plot of impedance for a capacitor. The impedance of a capacitor has only the imaginary part and is represented by a series of points (corresponding to various frequencies) on the imaginary axis.

For an inductor, its impedance can be calculated as:

$$
Z(\text { inductor })=j \omega L
$$

where $L$ is the inductance of the material. Inductors are not commonly used in corrosion studies.

The impedance of a parallel $R C$ circuit (a circuit composed of a resistor in parallel with a capacitor, as shown in Figure 2.12 can be calculated as:

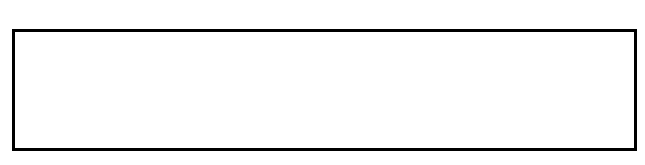

An impedance spectrum plot (also known as Nyquist plot) of a $R C$ circuit is shown in Figure 2.13. The frequency increases along the semi-circle from right to the left. The impedance of a capacitor is very small if the frequency is very high. Under such conditions, the capacitor is short-circuited and the current freely passes through it. On the impedance spectrum plot, this situation is represented by the left most point on the semi-circle. On the other hand, when the frequency is approaching zero (such as for direct current), the capacitor can not transfer current and, as a result, current can only 
flow through the resistor. Under these conditions, the impedance of the $R C$ system is equal to the resistance of the resistor. This corresponds to the very right point on the semi-circle.

At the middle point of the semi circle, the absolute values of real part and the imaginary part are equal. From equation 2.38, we can get the following equation:

$$
\omega=\omega_{\max }=1 / R C
$$

This is a very useful equation, since by knowing the diameter of the arc, $R$, and the frequency at the top of the arc, $\omega_{\max }$, the capacitance $C$ of the circuit can be calculated.

When impedance spectroscopy is applied to the study of corrosion, the impedance spectrum is different from that of ideal circuit. Usually, the impedance spectrum looks like the one shown in Figure 2.14 [MacDonald, 1987]. The semi-circle is depressed by the angle $\alpha$. The reason for this deviation is that typically the tested system does not exhibit the behavior of a circuit that is composed of ideal resistor and capacitor. In order to simulate this phenomenon, a new electrical element - constant phase element (CPE) is introduced. A CPE has an impedance value of

$$
Z(C P E)=A(j \omega)^{-n}
$$

where $A$ is a constant with the unit of $\Omega^{-1} \mathrm{~s}^{\mathrm{n}}, n$ is related to the degree of depression of the semi-circle, and its value is between -1 and 1 . The depression angle, $\alpha$, can be expressed as:

$$
\alpha=n \cdot \pi / 2
$$


Eqn. 2.40 with proper $n$ values, as listed in Table 2.3. can also express the impedance of basic electrical elements (resistor, capacitor and inductor). For $n=0.5$, the CPE is called Warburg impedance, which is associated the diffusion process.

\subsubsection{Equivalent Circuit}

Electrical properties, such as resistance, capacitance, and other parameters of the system under investigation can be obtained from the analysis of the impedance spectrum. Equivalent circuit method is usually employed for analyzing experimental impedance spectrum.

An equivalent circuit is so constructed that each element in the circuit represents a certain physical or electrochemical process in the real system. The most commonly used elements are resistor and capacitor.

\subsection{Summary}

The concrete cover surrounding the reinforcing bars forms a physical barrier that separates the steel bars from corrosive environment. The high alkali pore solution produces and maintains the passive film on the surface of steel bars. Chloride ions from de-icing salts penetrate and diffuse into concrete and, once they reach the steel level, damage the passive film. Usually, corrosion initiated by chloride ions is localized pitting corrosion.

Corrosion is an electrochemical process involving charge transfer. The fundamental properties of corrosion reaction can be studied by means of thermodynamics 
and kinetics. Electrode potential is associated with the free energy change of the reaction on the electrode, and by measuring the half-cell potentials of the corrosion cell we can usually detect the possibility of corrosion taking place. Polarization resistance is a dc method widely used for the corrosion rate measurement. Electrochemical impedance spectroscopy is an ac method for corrosion study. It can measure several electrical properties, including the polarization resistance of the corrosion cell. 
Table 2.1 Standard half-cell potentials (reduction potentials) [Atkins, 1998]

\begin{tabular}{llc}
\hline \multicolumn{1}{c}{ Reaction } & $\begin{array}{c}\text { Standard Potential } \\
\text { (volts vs. SHE) }\end{array}$ \\
\hline Noble & $\mathrm{Au}^{3+}+3 \mathrm{e}^{-}=\mathrm{Au}$ & +1.498 \\
& $\mathrm{O}_{2}+4 \mathrm{H}^{+}+4 \mathrm{e}^{-}=2 \mathrm{H}_{2} \mathrm{O}(\mathrm{pH}=0)$ & +1.229 \\
$\mathrm{Pt}^{2+}+3 \mathrm{e}^{-}=\mathrm{Pt}$ & +1.118 \\
$\mathrm{O}_{2}+2 \mathrm{H}_{2} \mathrm{O}+4 \mathrm{e}^{-}=4 \mathrm{OH}^{-}(\mathrm{pH}=7)$ & +0.820 \\
$\mathrm{Ag}^{+}+\mathrm{e}^{-}=\mathrm{Ag}$ & +0.799 \\
$\mathrm{Fe}^{3+}+\mathrm{e}^{-}=\mathrm{Fe}^{2+}$ & +0.771 \\
$\mathrm{O}_{2}+2 \mathrm{H}_{2} \mathrm{O}+4 \mathrm{e}^{-}=4 \mathrm{OH}^{-}(\mathrm{pH}=14)$ & +0.401 \\
$\mathrm{Cu}^{2+}+2 \mathrm{e}^{-}=\mathrm{Cu}$ & +0.342 \\
$2 \mathrm{H}^{2+}+2 \mathrm{e}^{-}=\mathrm{H}_{2}$ & 0.000 \\
$2 \mathrm{H}_{2} \mathrm{O}+2 \mathrm{e}^{-}=\mathrm{H}_{2}+2 \mathrm{OH}^{-}(\mathrm{pH}=7)$ & -0.413 \\
$\mathrm{Fe}^{2+}+2 \mathrm{e}^{-}=\mathrm{Fe}$ & -0.447 \\
$\mathrm{Zn}^{2+}+2 \mathrm{e}^{-}=\mathrm{Zn}$ & -0.762 \\
$2 \mathrm{H}_{2} \mathrm{O}+2 \mathrm{e}^{-}=\mathrm{H}_{2}+2 \mathrm{OH}^{-}(\mathrm{pH}=14)$ & -0.828 \\
$\mathrm{Al}^{3+}+3 \mathrm{e}^{-}=\mathrm{Al}$ & -1.662 \\
$\mathrm{Mg}^{2+}+2 \mathrm{e}^{-}=\mathrm{Mg}$ & -2.372 \\
$\mathrm{Na}^{+}+\mathrm{e}^{-}=\mathrm{Na}$ & -2.710 \\
$\mathrm{~K}^{+}+\mathrm{e}^{-}=\mathrm{K}$ & -2.931 \\
\hline
\end{tabular}


Table 2.2 Common secondary reference electrodes and their standard potential values [Jones, 1996].

\begin{tabular}{ccc}
\hline Name & Half-Cell Reaction & $\begin{array}{c}\text { Potential, V } \\
\text { vs. SHE }\end{array}$ \\
\hline Mercury-Mercurous & $\mathrm{HgSO}_{4}+2 \mathrm{e}^{-}=\mathrm{Hg}+\mathrm{SO}_{4}{ }^{2-}$ & +0.615 \\
Sulfate & $\mathrm{CuSO}_{4}+2 \mathrm{e}^{-}=\mathrm{Cu}+\mathrm{SO}_{4}{ }^{2-}$ & +0.318 \\
Copper-Copper Sulfate & $\mathrm{Hg}_{2} \mathrm{Cl}_{2}+2 \mathrm{e}^{-}=2 \mathrm{Hg}+2 \mathrm{Cl}^{-}$ & +0.241 \\
Saturated Calomel & $\mathrm{AgCl}^{-} \mathrm{e}^{-}=\mathrm{Ag}+\mathrm{Cl}^{-}$ & +0.222 \\
Silver-Silver Chloride & & 0.000 \\
Standard Hydrogen & $2 \mathrm{H}^{+}+2 \mathrm{e}^{-}=\mathrm{H}_{2}$ & \\
\hline (SHE) & &
\end{tabular}

Table 2.3 Common electrical elements, the n-values and their impedance functions [Ford, 1998].

\begin{tabular}{ccc}
\hline Electrical Element & n-value & $\mathrm{Z}(\mathrm{CPE})$ \\
\hline Resistor & 0 & $\mathrm{Z}(\mathrm{R})=\mathrm{R}$ \\
Capacitor & 1 & $\mathrm{Z}(\mathrm{C})=-\mathrm{j} \omega \mathrm{C}^{-1}$ \\
Inductor & -1 & $\mathrm{Z}(\mathrm{L})=\mathrm{j} \omega \mathrm{L}$ \\
Warburg & 0.5 & $\mathrm{Z}(\mathrm{W})=\mathrm{A}(\mathrm{j} \omega)^{-0.5}$ \\
Constant Phase Element & -1 to +1 & $\mathrm{Z}(\mathrm{CPE})=\mathrm{A}(\mathrm{j} \omega)^{-\mathrm{n}}$ \\
$(\mathrm{CPE})$ & & \\
\hline
\end{tabular}




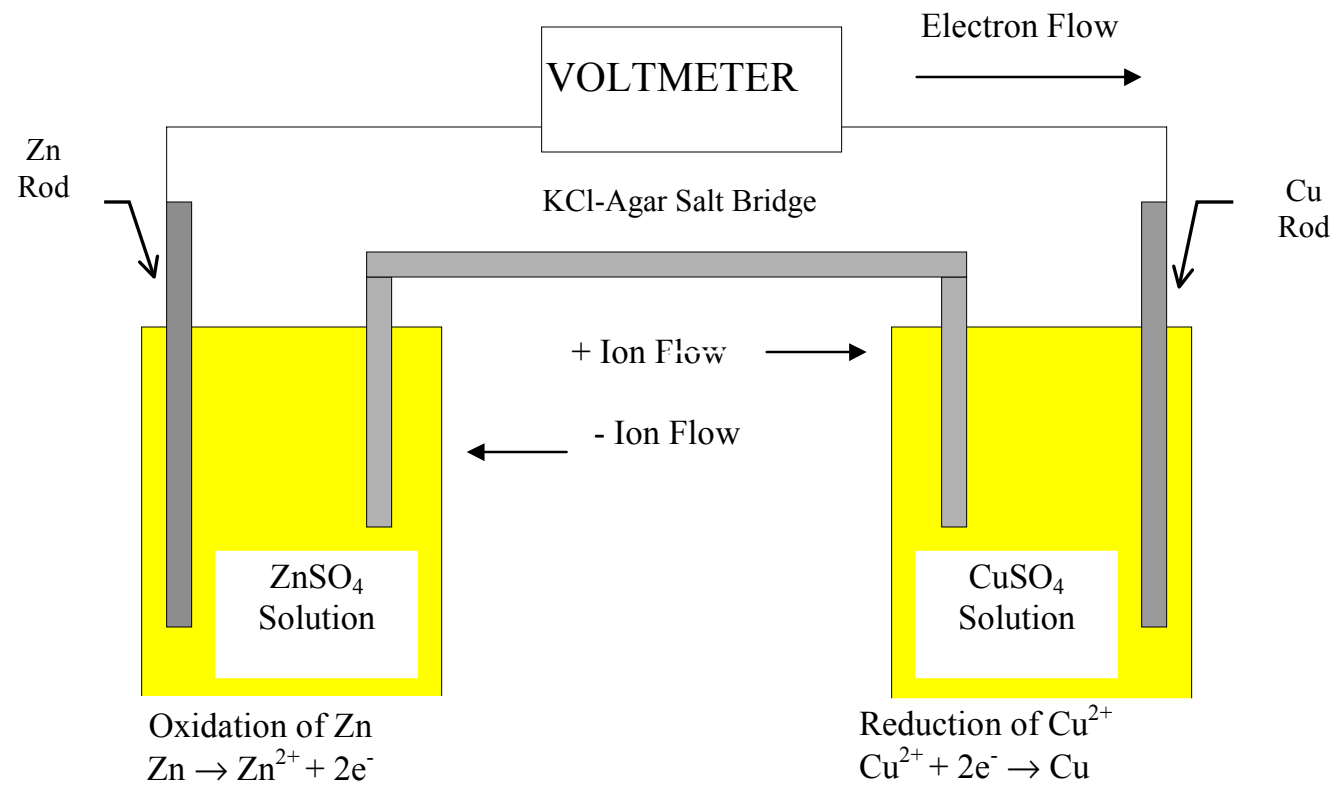

Figure 2.1 An electrochemical cell with corresponding cell reactions [Eisenberg and Crothers, 1979]. 


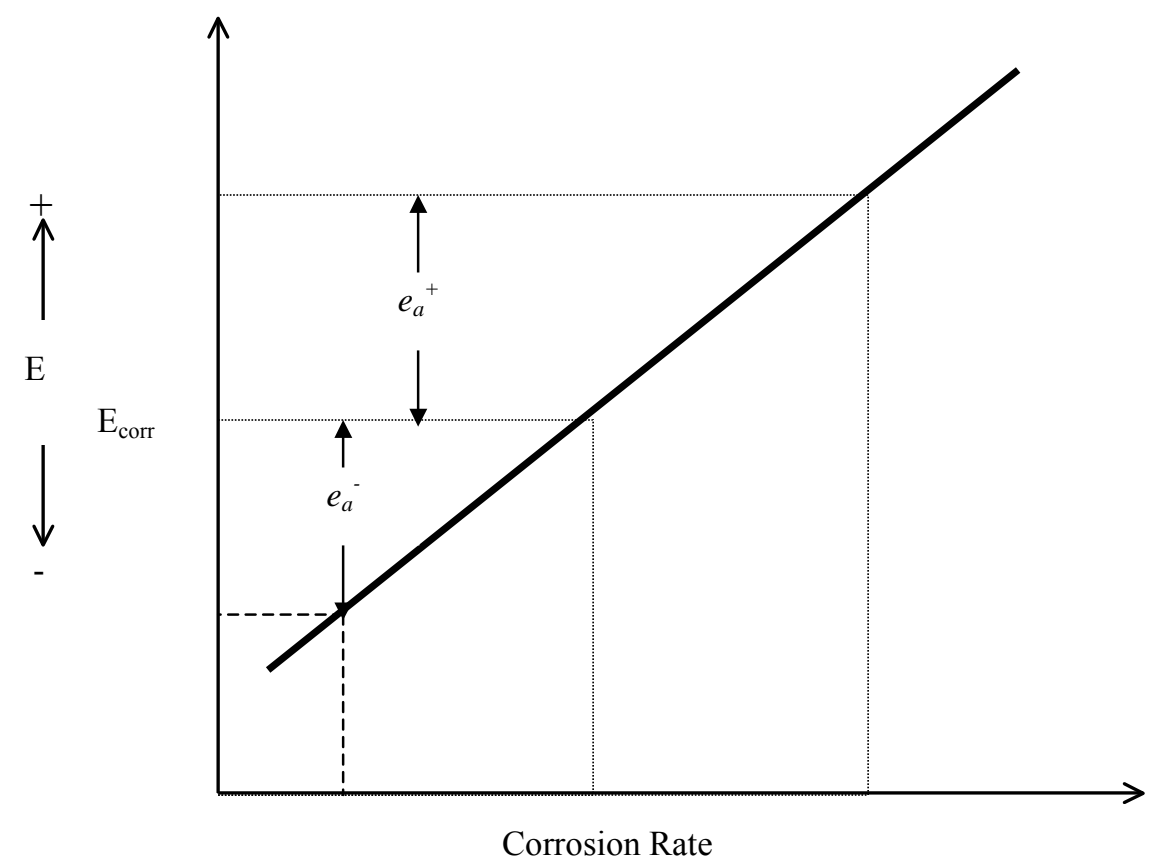

Figure 2.2 Changes in the corrosion rate of the anode with the change in the value of anodic polarization. 


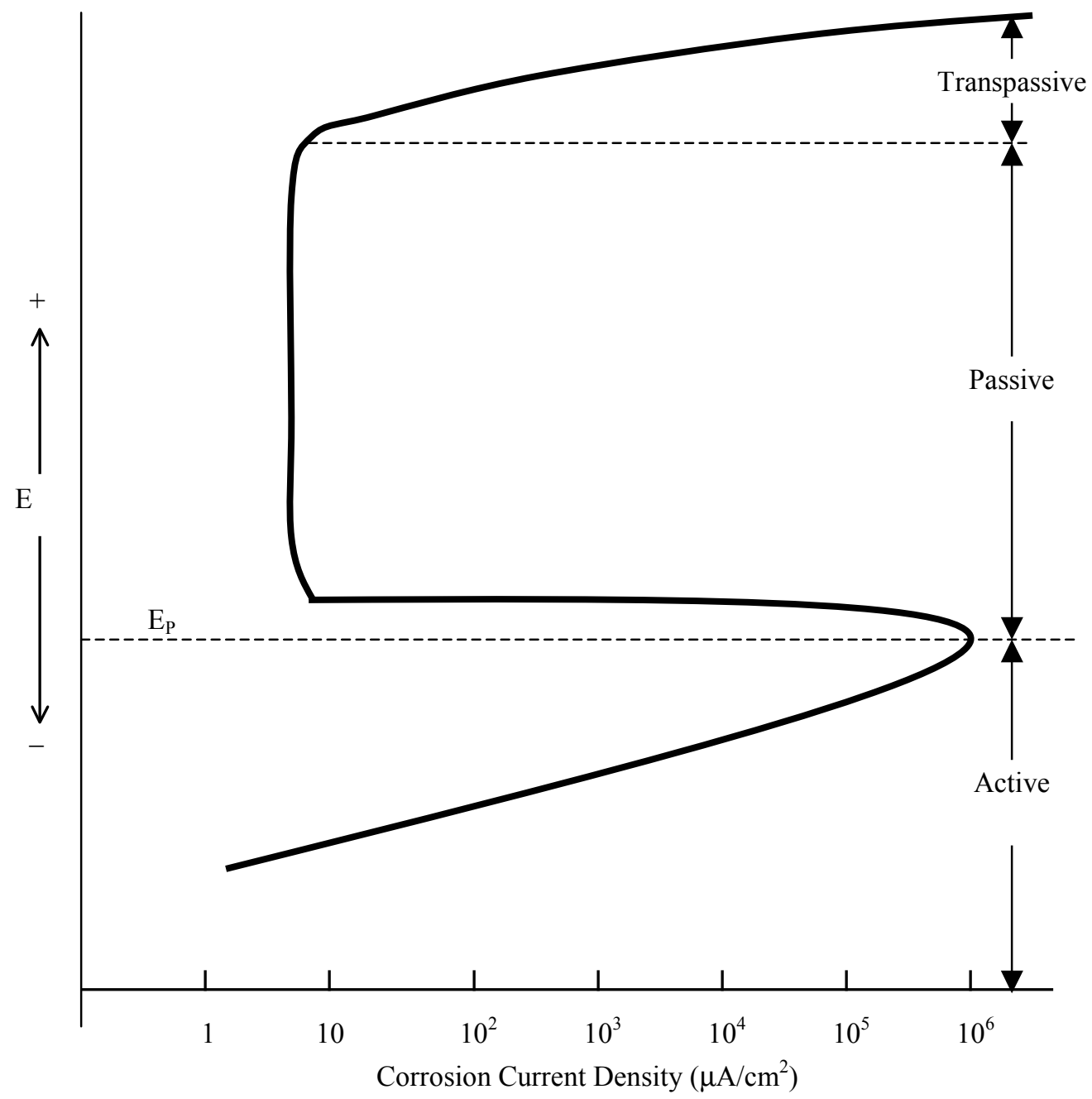

Figure 2.3 Corrosion current density and corrosion activity of a metal as a function of electrode potential. 


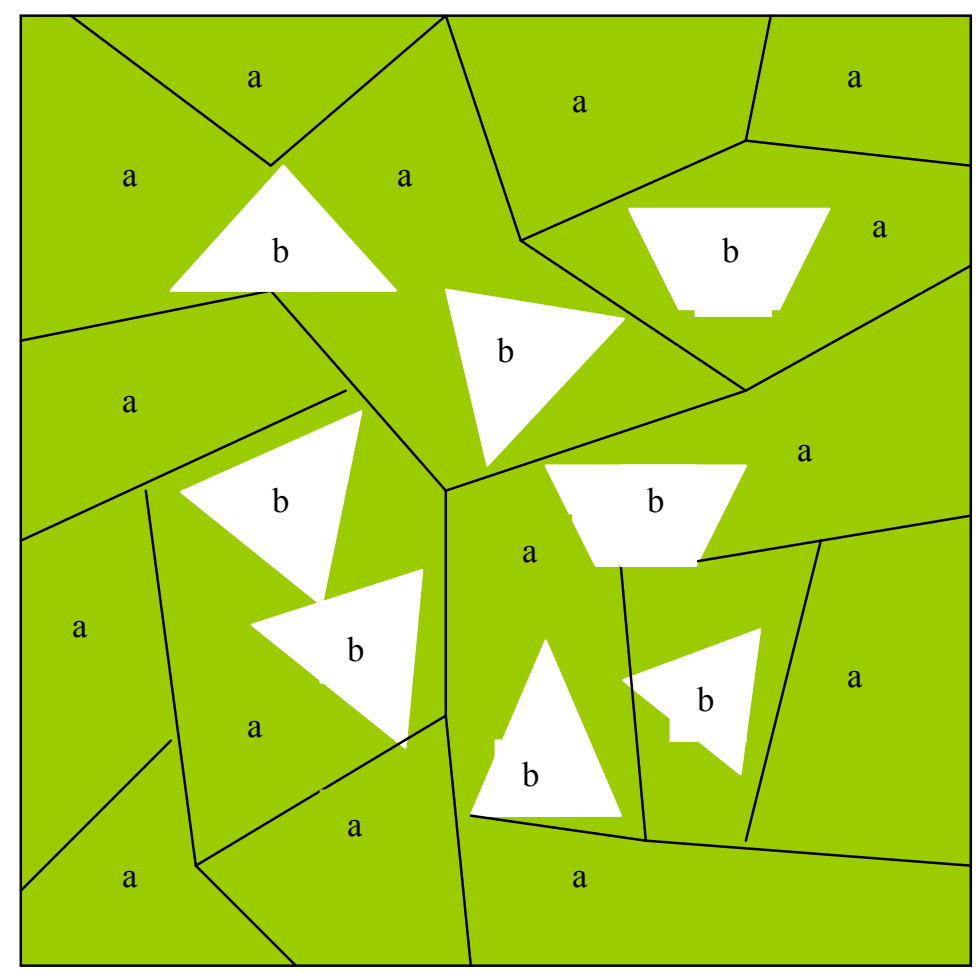

Figure 2.4 Schematic representation of the microstructure of an alloy metal, showing different phases ( $a$ and $b$ ) and grain boundaries. 


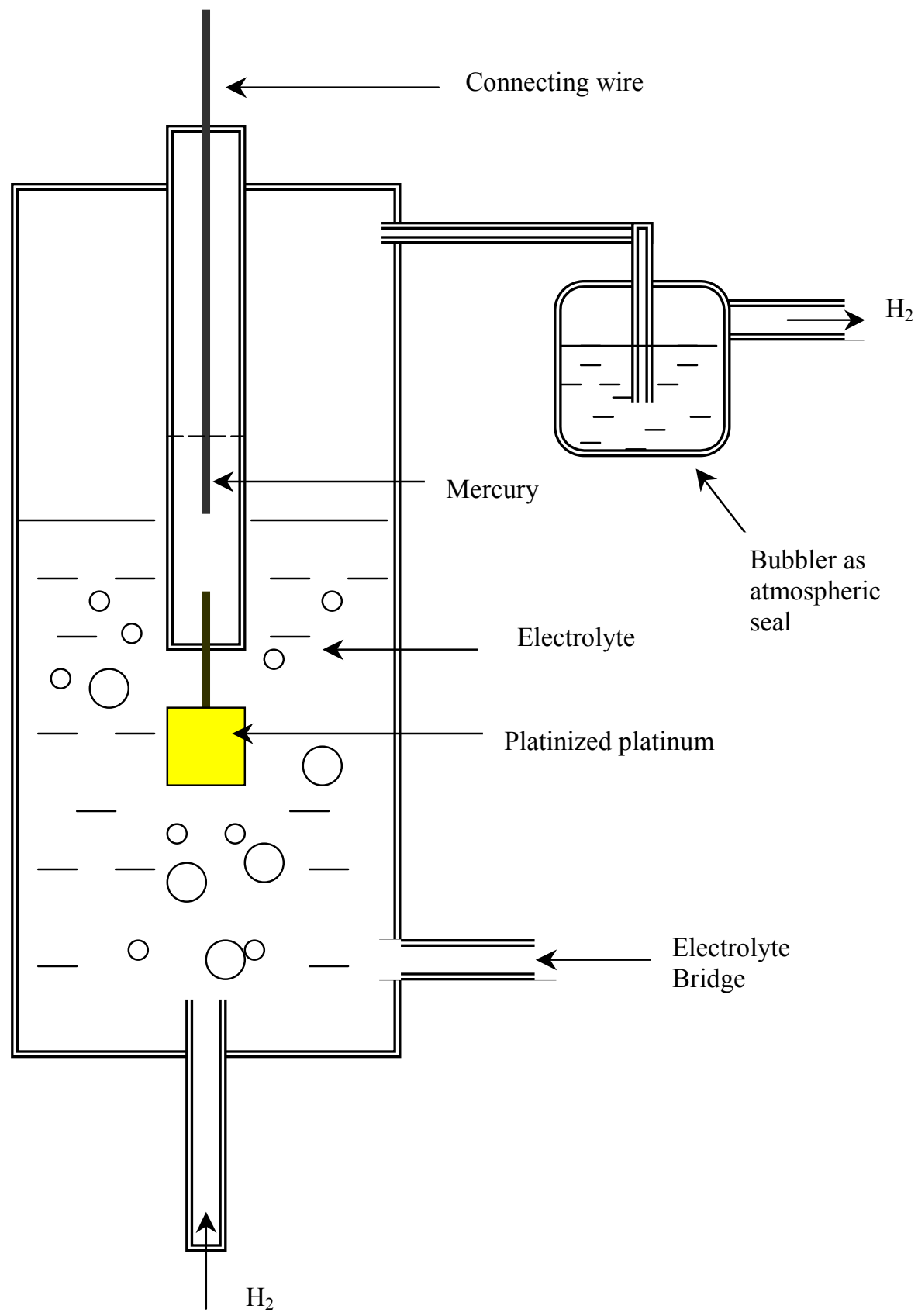

Figure 2.5 Standard hydrogen electrode, schematic [Jones, 1996]. 


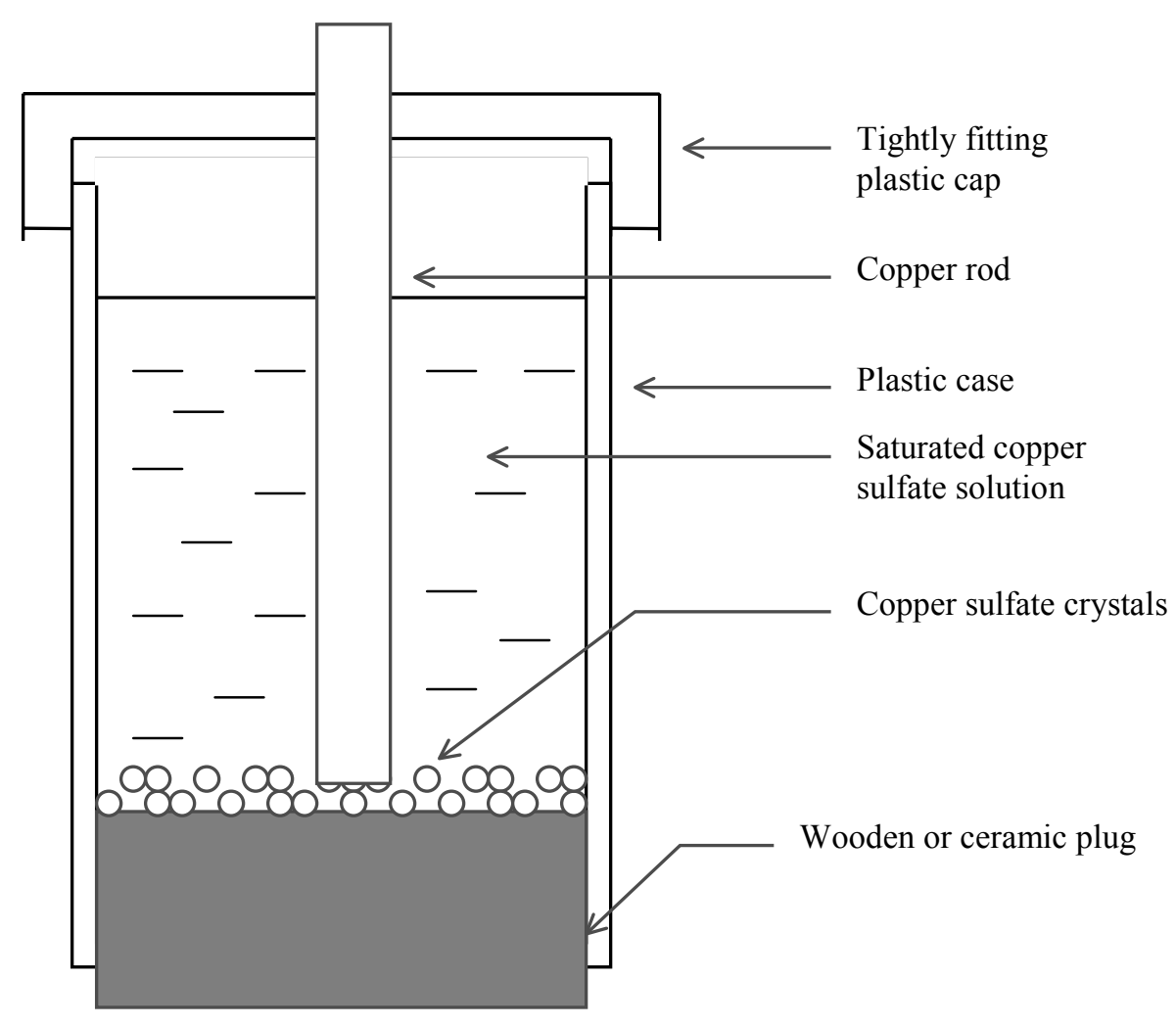

Figure 2.6 Copper-copper sulfate reference electrode [Jones, 1996]. 


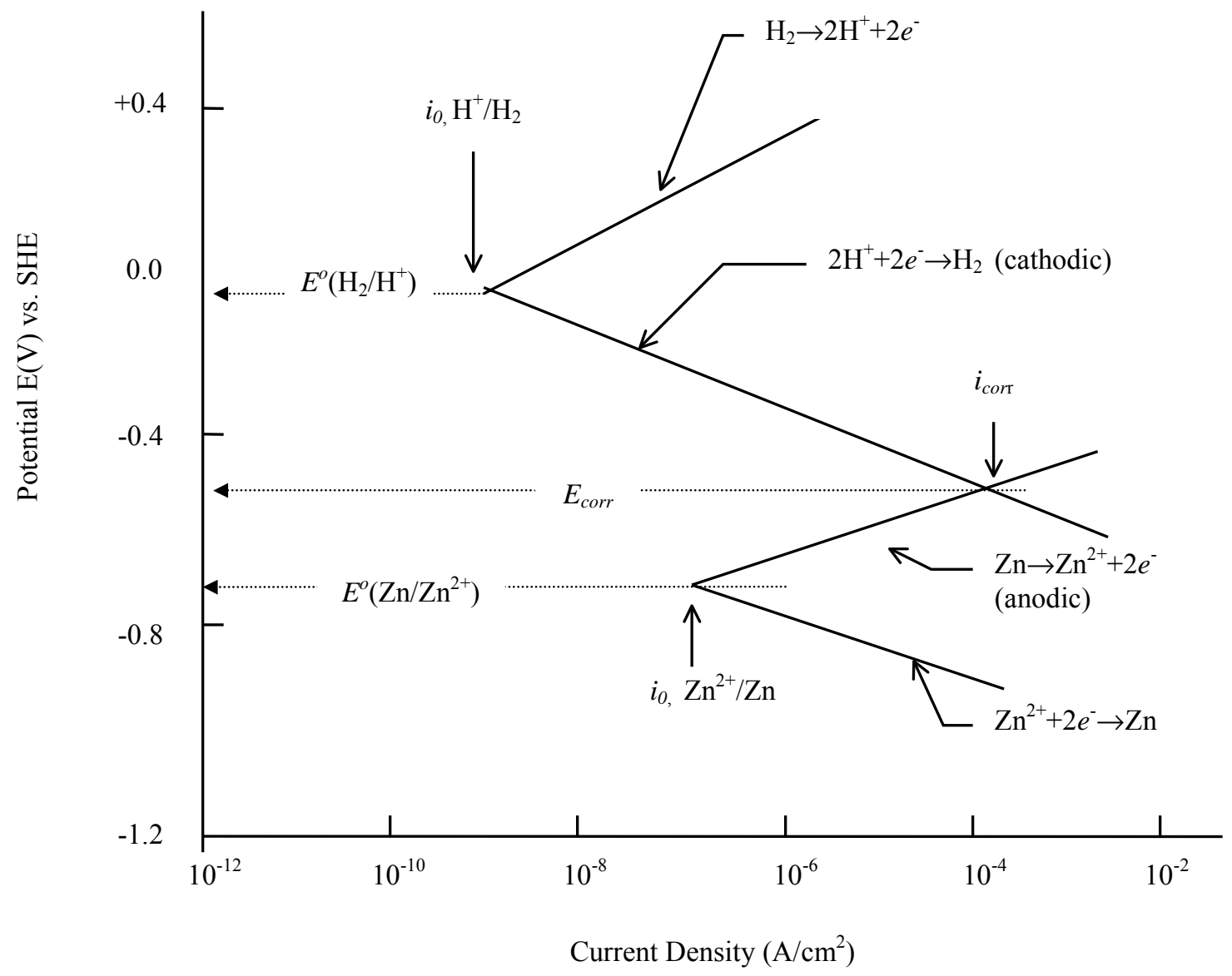

Figure 2.7 Polarization of anodic and cathodic half-cell reactions for $\mathrm{Zn}$ in acid solution to give a mixed potential, $E_{c o r r}$, and a corrosion rate (current density), $i_{c o r r}$ [Jones, 1996]. 


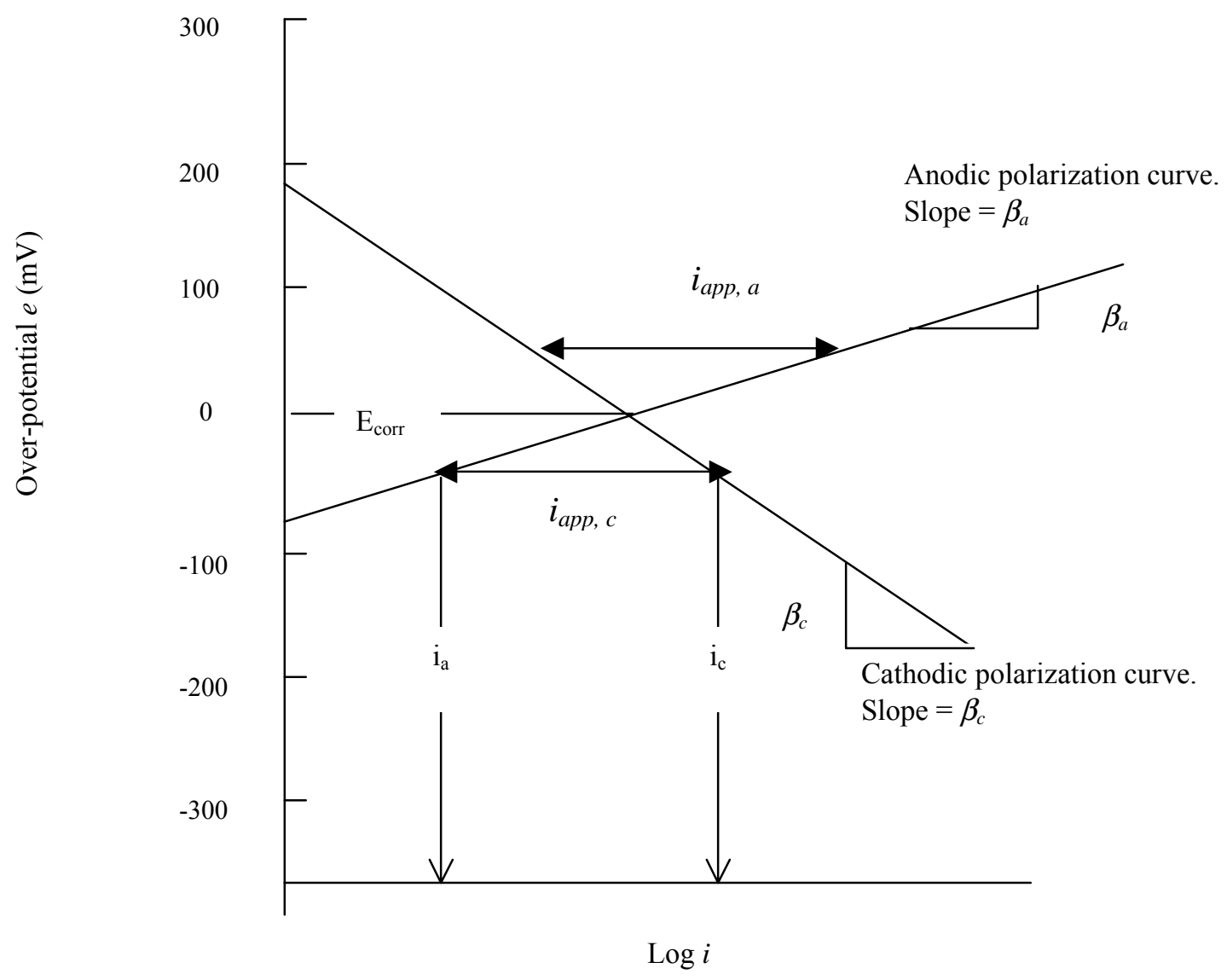

Figure 2.8 Idealized anodic and cathodic polarization curves. 


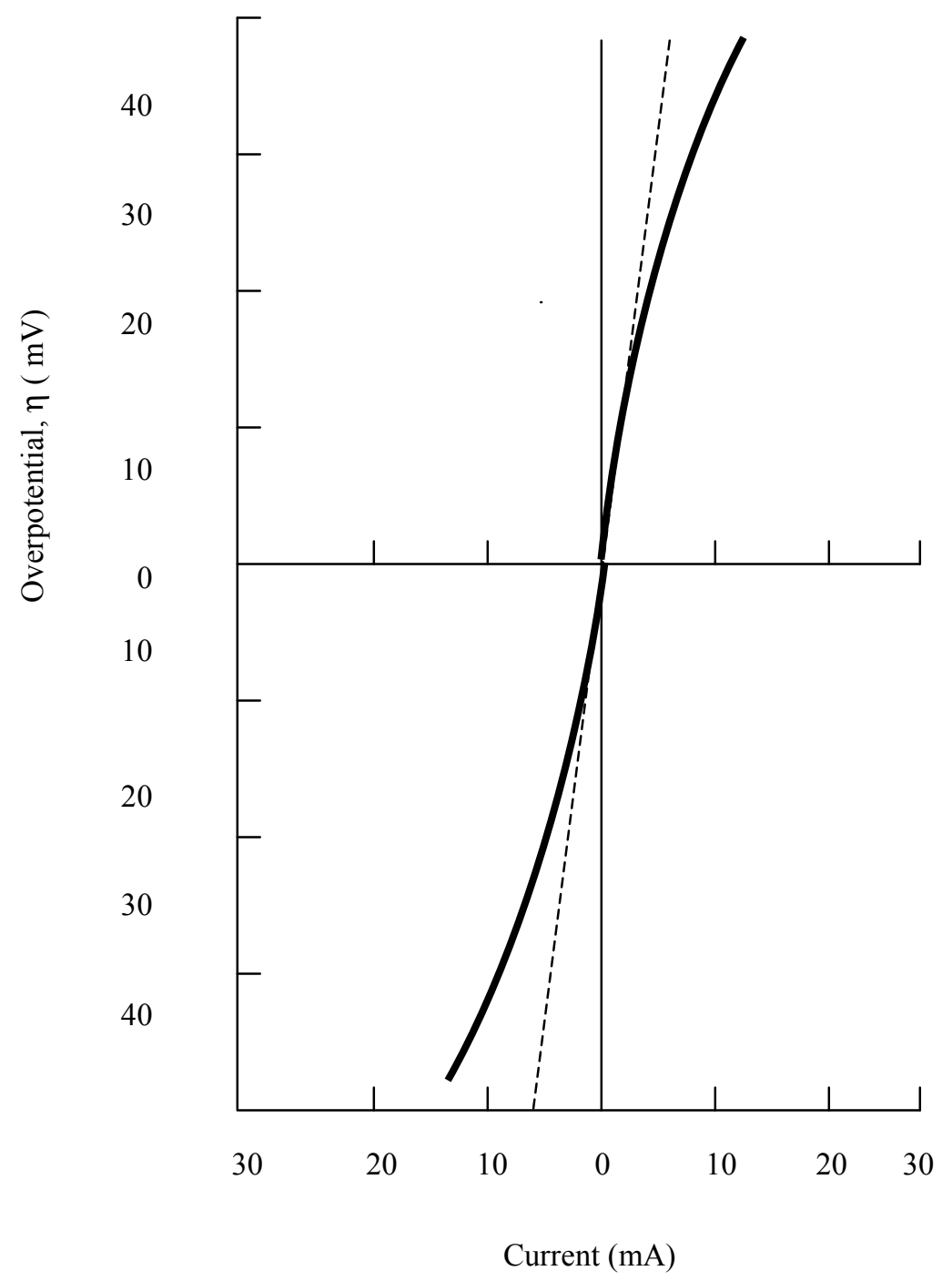

Figure 2.9 Experimental polarization curves graphically plotted on linear coordinates. 


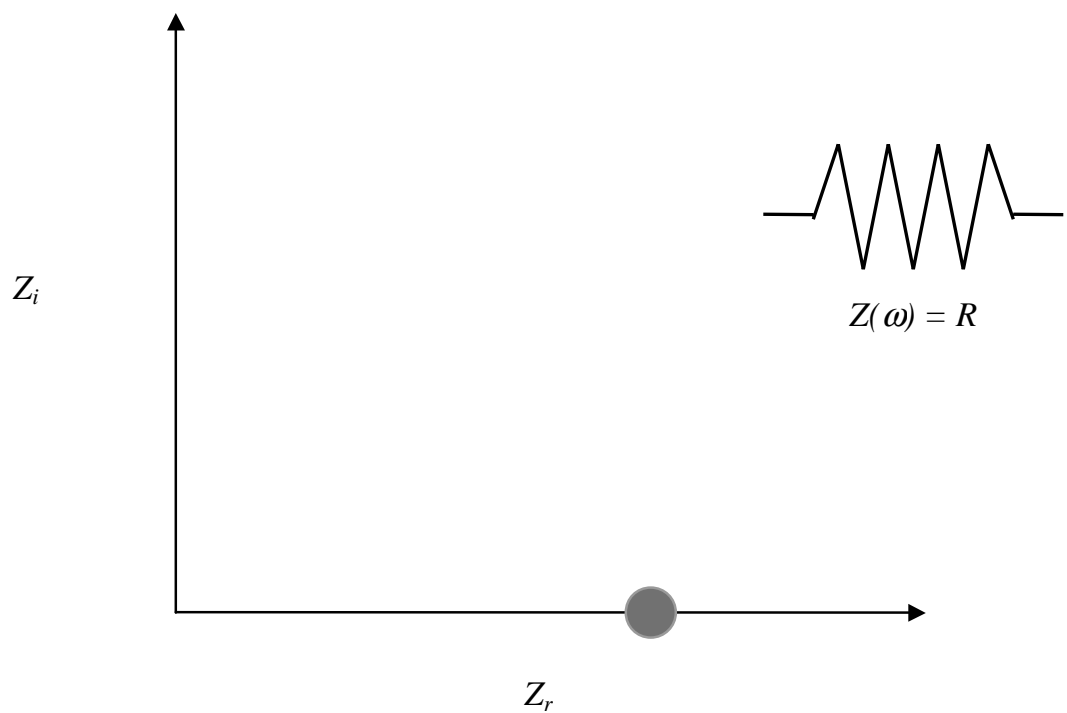

Figure 2.10 Impedance of a resistor. 


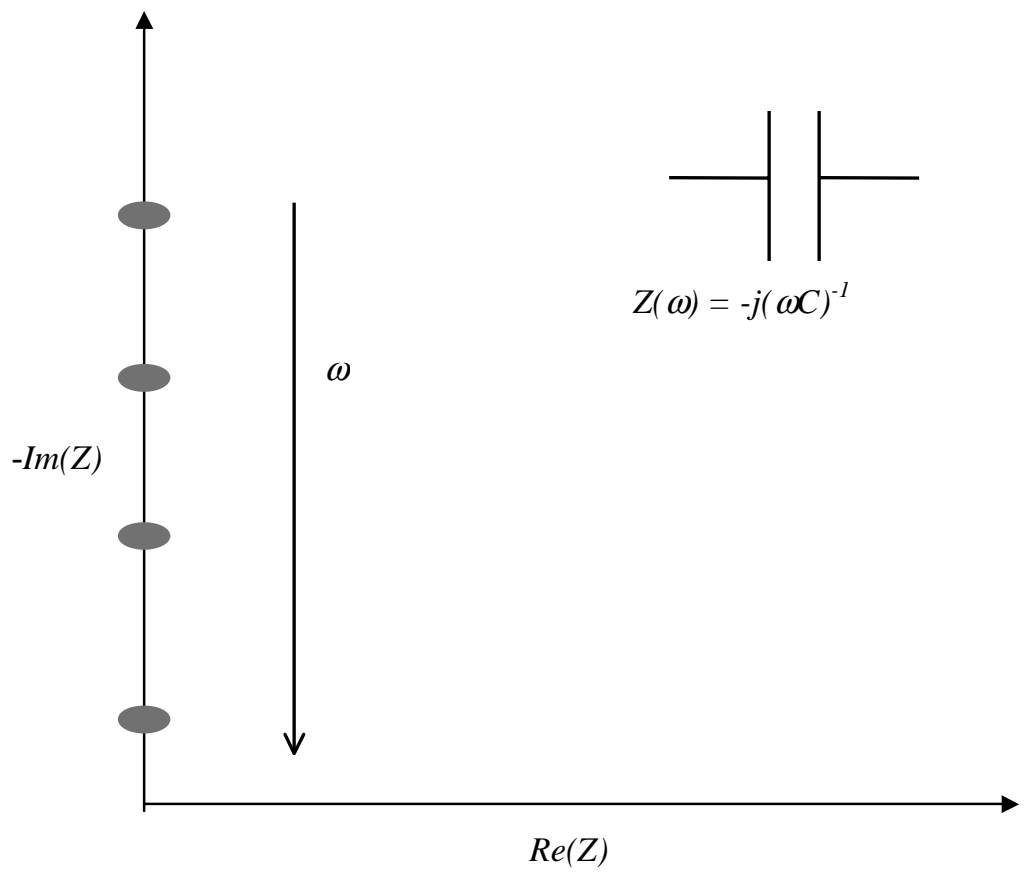

Figure 2.11 Impedance of a capacitor. 


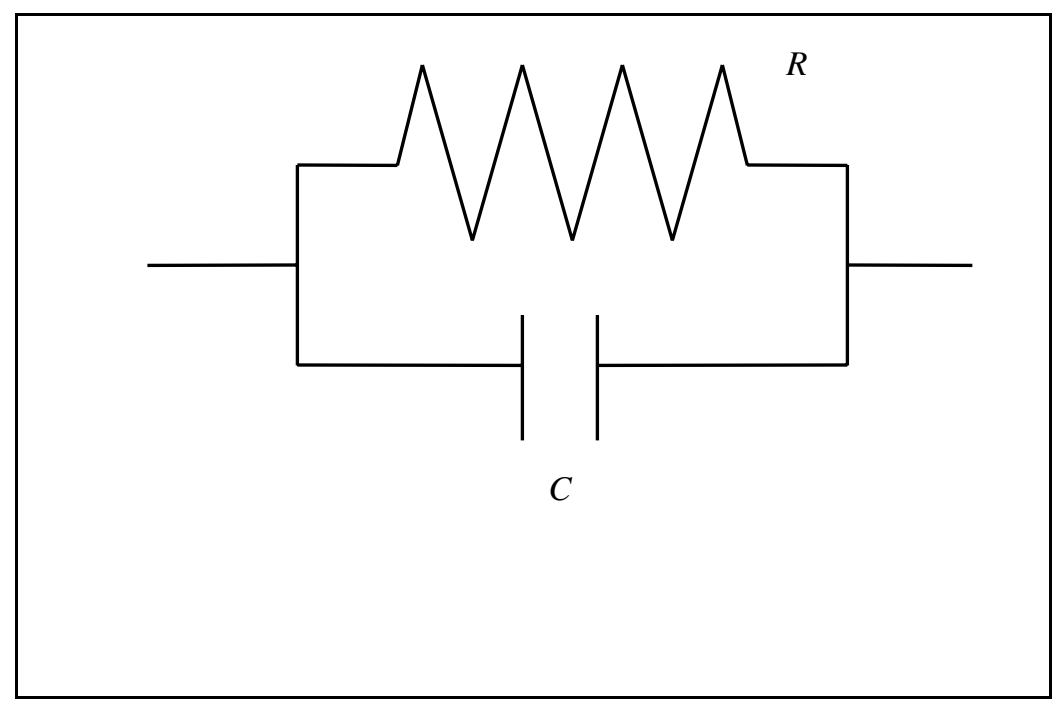

Figure 2.12 Parallel RC circuit

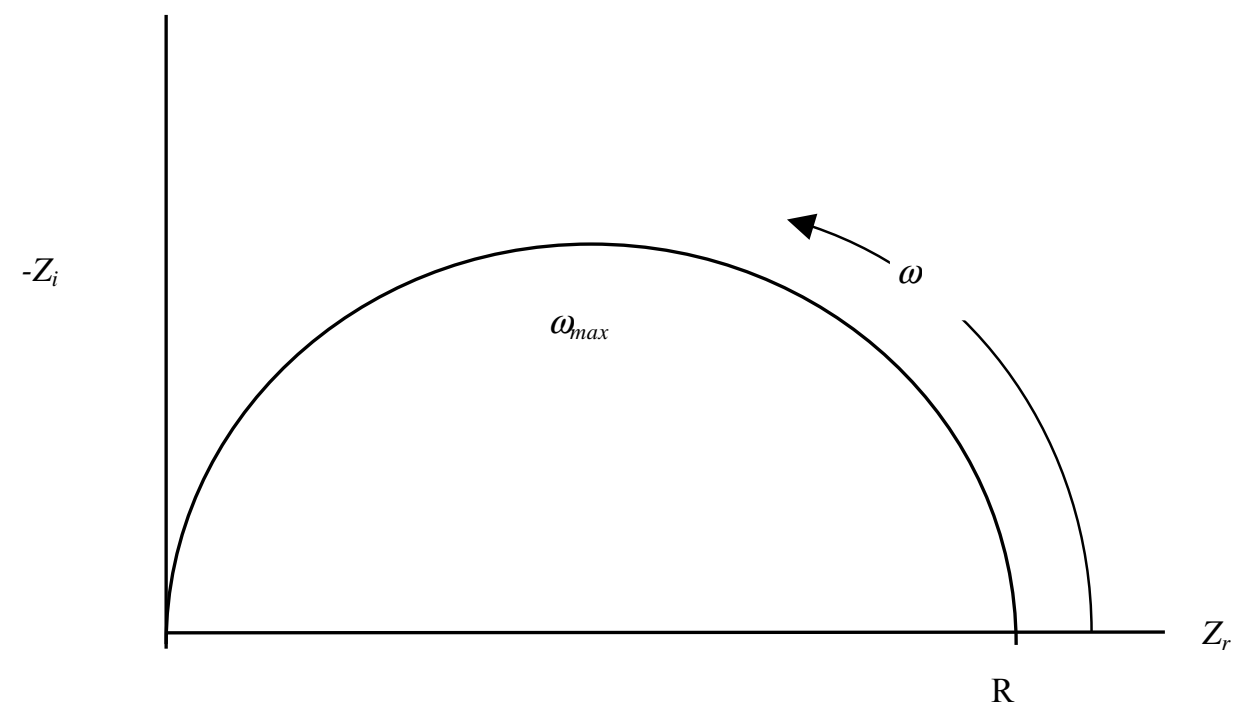

Figure 2.13 Nyquist plot of a parallel RC circuit. 


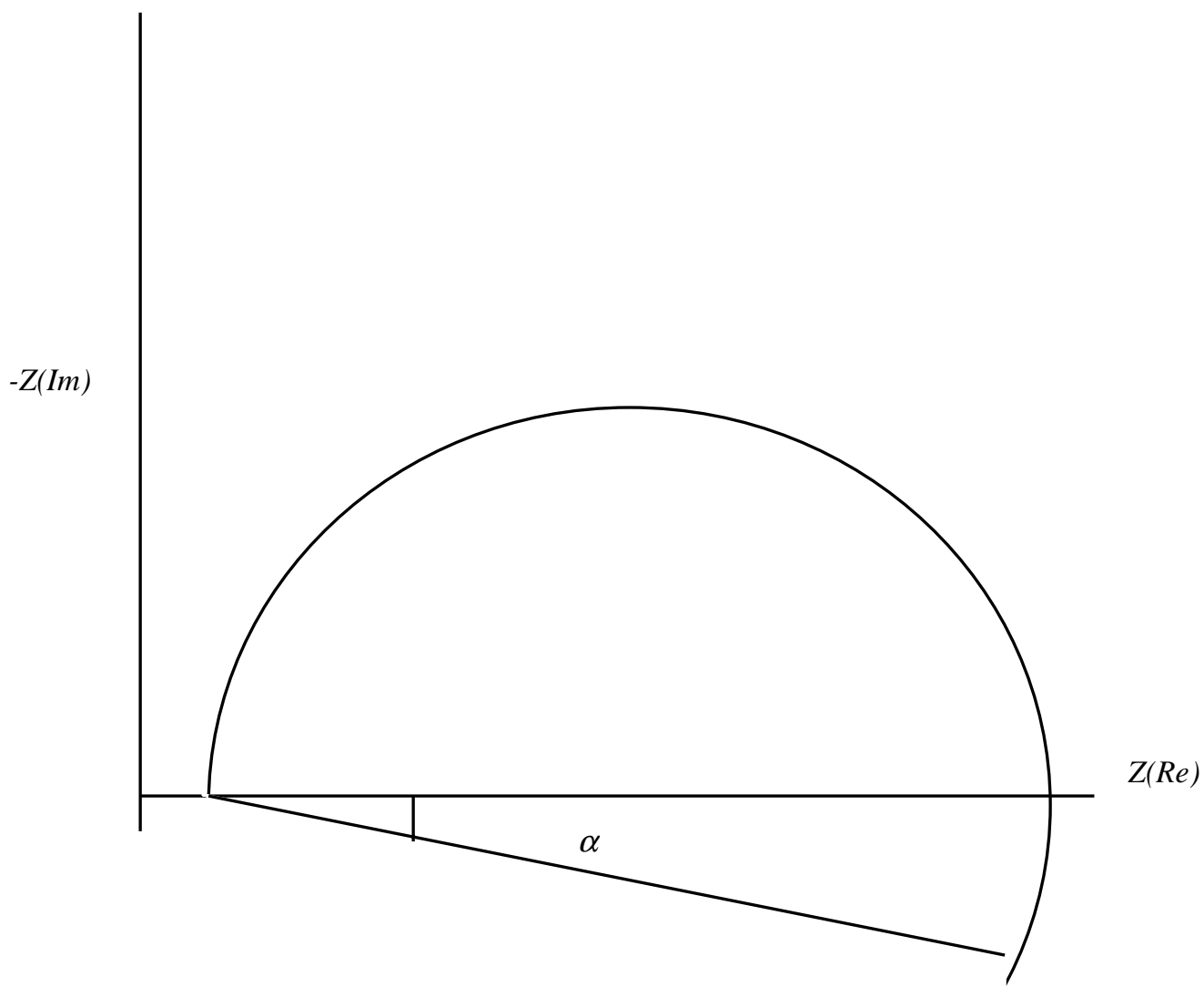

Figure 2.14 Schematic illustration of the depression of the impedance arc. 


\section{CHAPTER 3 CORROSION OF STEEL IN CONCRETE — LITERATURE REVIEW}

The corrosion process of reinforcing steel in concrete is different from the corrosion process of steel exposed to the atmosphere. The concrete surrounding the reinforcing steel provides a special (highly alkaline) chemical environment that generally protects the steel. However, several factors can cause corrosion of the reinforcing steel. The most commonly encountered cause for reinforcing corrosion is associated with chloride ions that penetrate into concrete. The chloride ions attack the passive film on the steel surface and initiate corrosion. In this chapter, information about factors influencing the quality of concrete cover, penetration of chloride ions, corrosion measurements, and rehabilitation of corrosion damaged concrete structures is presented.

\subsection{Concrete Cover and Concrete-Steel Interface}

Reinforced concrete is a combination of concrete and reinforcing steel. The concrete surrounding the steel forms a physical barrier that protects the steel bars from corrosive environments. In addition, concrete pore solution chemically interacts with the surface of reinforcing steel and that interaction leads to the formation of passive film on the steel surface. The concrete pore solution has a high $\mathrm{pH}$ value (usually higher than 12.5). The passive film is stable in the high $\mathrm{pH}$ environment. 


\subsubsection{Microstructure of Cement Paste and Concrete}

Concrete is made from cement, aggregates, and water (mineral and chemical admixtures may also be added). The formation of concrete microstructure is directly associated with the hydration of the cement. Hardened concrete consists of many different solid components along with pores of various sizes and shapes. Solutions that are formed during the hydration of the cement exist in the small pores.

Examination of polished concrete surface reveals a heterogeneous structure with two phases: aggregates and hydrated cement paste, distinguishable with a naked eye. The cement paste binds the aggregates together. With a modern electron microscope, one more phase - the transition zone between the particles of coarse aggregate and the hydrated cement paste - can also be identified.

\subsubsection{Hydration of Portland Cement}

The mineral components of cement are mainly tricalcium silicate $\left(\mathrm{C}_{3} \mathrm{~S}\right)$, dicalcium silicate $\left(\mathrm{C}_{2} \mathrm{~S}\right)$, tricalcium aluminate $\left(\mathrm{C}_{3} \mathrm{~A}\right)$, and tetracalcium ferroaluminate $\left(\mathrm{C}_{4} \mathrm{AF}\right)$. The hydration products of cement paste are calcium silicate hydrate (C-S-H), calcium hydroxide $(\mathrm{CH})$, and calcium sulfoaluminate. Unhydrated cement particles may also exist in the paste.

Calcium silicate hydrate (C-S-H) is the main component of hardened cement paste, occupying 50 to $60 \%$ of the total volume. The C-S-H has an amorphous structure. Several models have been proposed to aid in understanding of the C-S-H structure. Powers [1958] and Brunauer [1962] established one of these models. In this model, the 
C-S-H has a layered structure and a high specific surface area. The average size of the pores in the C-S-H (or the distance between layers) is about 18 angstroms $\left(18 \times 10^{-10} \mathrm{~m}\right)$. The strength of the C-S-H is mainly from van der Waals forces. In another model, proposed by Feldman and Sereda [1970], the C-S-H structure was described as collection of randomly arranged layers with varying interlayer spaces and sizes. The interlayer space proposed for this model was in the range of 5 to 25 angstroms ( 5 to $\left.25 \times 10^{-10} \mathrm{~m}\right)$.

Another important component of the hardened cement paste is calcium hydroxide, occupying about 20 to $25 \%$ of the total volume. Calcium hydroxide crystals are large hexagonal prisms or plates. The specific surface area of calcium hydroxide crystals is lower than that of the C-S-H.

Calcium sulfoaluminate is a minor component in the hardened cement paste. At

early stage of cement hydration, trisulfate hydrate $(\square)$, commonly called ettringite, is formed due to high ratio of sulfate/alumina in the solution. Ettringite crystals are needle-shaped prisms. In ordinary portland cement paste, the trisulfate hydrate eventually converts to monosulfate hydrate $\left(C_{4} A \bar{S}_{3} H_{18}\right)$. Monosulfate hydrate is a hexagonal plate crystal.

\subsubsection{Voids in Hydrated Cement Paste}

In addition to solid components, hydrated cement paste also contains voids. Based on their location, size and origin, voids can be divided into several types. 
The smallest voids are the interlayer spaces in the C-S-H, occupying $28 \%$ of the total volume. Water in the interlayer space, or pore solution, can be held by hydrogen bonding.

Capillary voids are the spaces between the hydration products of cement particles. The size of capillary voids depends mainly on the water-cement ratio and the degree of hydration. In low water-cement ratio systems and well-hydrated cement paste, the capillary voids are in the range of 10 to $50 \mathrm{~nm}\left(10\right.$ to $\left.50 \times 10^{-9} \mathrm{~m}\right)$.

Air voids can be entrapped in the fresh cement paste during the mixing operation. Air-entraining agent can also be used to purposely entrain air voids in the cement paste. Typically, entrained air voids have a size of 50 to 200 micrometers (50 to $200 \times 10^{-6} \mathrm{~m}$ ).

\subsubsection{Interfacial Transition Zone}

\subsubsection{Microstructure of the Interfacial Transition Zone}

Farren [1956] first introduced the concept of interfacial transition zone when he studied the microstructure of reinforced concrete under an optical microscope. He found the hydration products of the cement paste close to the reinforcing steel to be looser than those in the bulk paste. The thickness of this transition region was about 50 micrometers. Other researchers have also studied the interfacial transition zone. Al-Khalaf and Page [1979] observed that there was a higher concentration of calcium hydroxide in the interfacial transition zone than in the surrounding paste. They described this phenomenon as a "discontinuous polycrystalline layer" with a "variable thickness". Taylor [1990] also found high content of calcium hydroxide in the interfacial transition 
zone. They described the transition region as a smooth layer, consisting of both $\mathrm{CH}$ and porous C-S-H.

Hadley [1972] and Barnes and Dolch [1978] used scanning electron microscopes

and X-ray spectrometers to study the interfacial transition zone between cement paste and glass slides. They found the transition zone to be divided into three layers. The first layer was a thin film of calcium hydroxide, approximately 1 micrometer in thickness. The c-axis of the $\mathrm{CH}$ crystal was perpendicular to the surface of the glass. This thin film was covered by the second layer, which consisted of elongated calcium silicate hydrate particles. The third layer was composed of large calcium hydroxide crystals (10 to 30 micrometers in thickness) with the c-axis parallel to the glass surface. The interface was porous and less dense than the bulk of the cement paste.

\subsubsection{Formation of Interfacial Transition Zone}

The formation of the interfacial transition zone is associated with the hydration process of cement particles. At the beginning of hydration, a water film on the surface of aggregates keeps the cement particles away from the surface of the aggregates. In the vicinity of the aggregates, the packing of cement particles is looser than in the bulk of the cement paste. This phenomenon is referred to as wall effect [Maso, 1980; Escadeillas and Maso, 1991]. Therefore, the water-cement ratio decreases as the distance from the surface of the aggregate increases. 


\subsection{Permeability of Concrete}

From a microstructural point of view, concrete is a porous material. Water, chloride ions, and oxygen can pass through the pores in the concrete. The availability of water, chloride ions and oxygen at the level of reinforcement may lead to the initiation and propagation of corrosion on the surface of the steel.

\subsubsection{Diffusion of Chloride Ions into Concrete}

Chloride ions diffuse into concrete through the aqueous solution in the concrete pores [Bentur, Diamond, and Berke, 1998]. The "driving force" for this diffusion is the difference in ionic concentrations between the external environment and the concrete pore solution. Since the concentration of chloride ions in the external environment is higher than the concentration within the pore solution of concrete, the chloride ions will diffuse into the concrete.

\subsubsection{Diffusion Equation}

Diffusion is commonly expressed by Fick's Second Law [Eisenberg and Crothers, 1979]:

$$
\left(\frac{\partial C}{\partial t}\right)_{x}=D\left(\frac{\partial^{2} C}{\partial x^{2}}\right)
$$

where $C$ is the concentration of the diffusing substance at a distance $x$ from the surface at a time $t$, and $D$ is the effective diffusion coefficient in units of $\mathrm{m}^{2} / \mathrm{s}$. 
Assuming that the chloride concentration at the surface of the concrete is constant and independent of time, $t$, the concentration of chloride ions, $C$, at a distance $x$ from the concrete surface is given by the following equation:

$$
C_{(x, t)}=C_{0}\left[1-\operatorname{erf}\left(\frac{x}{2 \sqrt{D t}}\right)\right.
$$

where $C_{0}$ is the concentration of chloride ions at the surface of the concrete, and erf is the error function.

\subsubsection{Diffusion of Chloride Ions in Concrete}

Chloride ions diffuse through the pores in the cement paste and also through the interfacial transition zone. Hence, the microstructure of the concrete affects the diffusion of chloride ions. If the concrete is very dense, most of the pores will not be connected and the diffusion path will be tortuous. As a result, it will be difficult for the chloride ions to diffuse into the concrete and the diffusion coefficient of the concrete will be low [Tuuti, 1982; Page, Short, and El-Tarra, 1981].

Mineral admixtures, such as silica fume, fly ash, and slag, react with calcium hydroxide that is a byproduct of hydration of cement. These reactions can cause changes in the microstructure of the concrete and in the composition of the pore solution.

For example, when silica fume reacts with calcium hydroxide to form C-S-H, this reaction is typically accompanied by a minor reduction in the $\mathrm{pH}$ of the concrete, and reduction in the threshold chloride concentration needed for breaking the passive film on the surface of the steel [Fidjestol, 1987]. 
Normally, the pore solution of concrete has a $\mathrm{pH}$ value of 13 to 14 . With the addition of silica fume, the $\mathrm{pH}$ level is reduced as a result of pozzolanic reactions. The concentration of both $\mathrm{K}^{+}$and $\mathrm{OH}^{-}$in the pore solution decreases as the replacement level of silica fume is increased. Gjorv [1995] found that by replacing up to $20 \%$ of cement by silica fume the $\mathrm{pH}$ did not drop below a level of a saturated calcium hydroxide solution that is approximately 12.5. According to Diamond [1983], it appears the removal of alkalis from the pore solution, with consequent reduction in the $\mathrm{pH}$, is less effective if the water-cement ratio is low.

However, the effect of $\mathrm{pH}$ reduction is small compared with the substantial reduction in the effective chloride diffusion coefficient (due to densification of microstructure) resulting from the addition of silica fume.

Gjorv [1995] reported that the effective chloride diffusion coefficient of concrete could be reduced markedly by replacing 5 to $15 \%$ of the cement with silica fume. For example, by replacing $8 \%$ of cement with silica fume the effective diffusion coefficient was reduced from $1.5 \times 10^{-11} \mathrm{~cm}^{2} / \mathrm{sec}$ to $1.1 \times 10^{-12} \mathrm{~cm}^{2} / \mathrm{sec}$.

In the literature, only limited information about the effect of silica fume on oxygen availability in concrete is reported [Bentur et al., 1998]. The effective oxygen diffusion coefficient of concrete, normally in the range of $1 \times 10^{-9}$ to $1 \times 10^{-7} \mathrm{~m}^{2} / \mathrm{s}$, is larger than that of chloride ions. The specific value depends on the pore structure, the extent of the pore saturation, and the temperature. General experience indicates that the availability of oxygen is not a controlling factor for corrosion, except for submerged concrete. 


\subsection{Passivation of Steel in Concrete}

As discussed in Section 3.1. cement paste provides a high alkaline environment. When the steel is surrounded by cement paste, a passive film is formed on the steel surface due to the high $\mathrm{pH}$ of the cement paste. A simplified potential-pH diagram (Pourbaix diagram) of iron is presented in Figure 3.1. Normally, the pore solution of concrete has a $\mathrm{pH}$ value of 13 to 14 . Thus, steel embedded in concrete is in a passive state. As a physical barrier to corrosion reactions, the passive film reduces the corrosion rate to a negligible level. However, the structure of this thin, fragile film is difficult to define. Two theories of passive film formation are briefly discussed in the following sections.

\subsubsection{Evans' Oxide Film Theory}

Evans [1922, 1927, and 1958] proposed an oxide film theory based on the experimental analysis of a thin oxide film using an electron diffraction technique. He removed the oxide film from a metal surface, and by using electron diffraction technique he found this oxide film to have a composition approximating that of $\gamma-\mathrm{Fe}_{2} \mathrm{O}_{3}$. However, Uhlig, the originator of the adsorption theory (discussed in Section 3.3.2, did not agree with Evans. Uhlig suggested that when the film was removed from the metal surface, the metal beneath the film would simultaneously dissolve. On the other hand, Kruger [1963] provided evidence supporting the oxide film theory based on an elaborate experimental work. He cleaned iron specimens in vacuum environment to obtain an oxide free surface. Then the iron specimens were exposed to a passivating atmosphere. At the same time, 
ellipsometric and potential measurements were done. The results of these experiments indicated that a passive film formed on the iron surface in the following three steps:

1. Within 30 second, a thin film of $\mathrm{Fe}_{3} \mathrm{O}_{4}$ formed

2. After 30 seconds, the film began to dissolve

3. A thin film of $\gamma-\mathrm{Fe}_{2} \mathrm{O}_{3}$ formed.

Since the iron specimens were never exposed to air, no oxygen was absorbed by the iron surface.

\subsubsection{Adsorption Theory}

Uhlig [1946] put forward an adsorption theory for the passivation of metals. Based on his theory, passivation was the result of selective adsorption occurring on the metal surface. Oxygen was adsorbed on the surface of the metal to replace space previously occupied by moisture. Metal oxide was subsequently formed due to the decomposition of the adsorbed layer, and a layer of oxygen molecules was found covering the adsorbed layer. The adsorbed film would then decompose to form a layer of $\mathrm{Fe}_{2} \mathrm{O}_{3}$.

\subsection{Initiation of Corrosion on Reinforcing Steel}

Failure of the passive film initiates corrosion of reinforcing steel. Chloride ions are a common cause of the breakdown of the protective passive film that is otherwise stable in concrete in the absence of chloride ions. Chloride ions in reinforced concrete can originate from several sources. For example, calcium chloride is often added to 
concrete as an accelerating agent, de-icing salt is used in winter on highways for traffic safety purposes, coastal structures are exposed to salt spray, and sea sand and other natural aggregates may bring chloride into concrete.

The threshold concentration of chloride ions in concrete, sufficient for initiating corrosion, has been studied by several researchers [Hansson, 1984; Page and Treadaway, 1982; Bird et al., 1988; and Wheat and Eliezer, 1987]. The threshold concentration of chloride ions is influenced by several characteristics of concrete such as the $\mathrm{pH}$ value of the pore solution, the concentration ratio between hydroxide ions and chloride ions, and the chemical composition of the pore solution. The threshold concentration of chloride ions commonly accepted as sufficient to initiate corrosion of reinforcing steel is $0.4 \%$ by weight of cement.

Chloride ions act as a catalyst in the corrosion reaction since the corrosion reaction does not consume any chloride ions. The chloride ions also reduce the resistivity of the concrete. Corrosion current increases as the resistivity decreases, and, as a result, the corrosion rate increases.

Chloride ion can cause localized corrosion on the steel surface. In the presence of chloride ions, ferrous oxide $(\mathrm{FeO})$ is less stable than ferric oxide $\left(\mathrm{Fe}_{2} \mathrm{O}_{3}\right)$, and the chloride ions attack the ferrous oxide as described in Section 2.2.2. Localized corrosion is commonly referred to as pitting corrosion. When pitting corrosion occurs, the anodic area is limited to the pit area, while the remainder of the steel acts as a cathode. As a result, the area ratio between cathode and anode, $A_{d} / A_{a}$, is high. Since the anodic current and cathodic current must be equal to balance the charge transfer, pitting corrosion tends to have a high anodic current density. 


\subsection{Measurements of Corrosion Rate}

Direct current electrical technique (linear polarization resistance measurement) and alternating current electrical method (electrochemical impedance spectroscopy) were used in this study to evaluate the rate of corrosion of reinforcing steel in concrete. The basic principles of these methods were discussed in Section 2.3. Some special aspects of measuring the corrosion rate of reinforcing steel are presented in the following sections.

\subsubsection{Polarization Resistance Measurement}

Polarization resistance method is based on theory established by Stern and Geary [1957]. They found that when an electrode was polarized with an external dc source, the electrode potential changed to a new level. If the potential change was very small (within several $\mathrm{mV}$ ), the potential change was proportional to the applied current, as described in Section 2.4.2 Polarization resistance was defined as the ratio of the potential change and the applied current. By measuring the potential change of the electrode and the corresponding current applied on the electrode, the polarization resistance can be calculated.

There are two methods for polarization resistance measurements. One is called galvanostatic (or constant current) method and the other one is called potentiostatic (or constant potential) method. The galvanostatic method involves the application of a small constant current to the electrode. As a result, a small potential change is generated on the electrode. The advantage of the galvanostatic method is that once the external current is 
removed from the electrode, the polarization effect decays quickly and the electrode returns to its corrosion potential. Potentiostatic method involves application of constant overpotential to steel (working electrode) and measurement of resulting current between steel and the counter electrode. Figure 3.2 shows the electrical circuit for polarization resistance measurement. In order to produce a constant potential change on the electrode, the corrosion potential of the electrode must be stable during the measurement. Any changes in the corrosion potential would affect the measurement. If the corrosion potential has significant fluctuation, the measured data are unreliable.

When galvanostatic and potentiostatic methods are used to measure the polarization resistance of the reinforced concrete, the measured resistance $R_{\text {measured }}$ is the total resistance, equal to:

$$
R_{\text {measured }}=R_{p}+R_{c}
$$

where $R_{c}$ is the resistance of the concrete, or the ohmic resistance of the electrolyte, and $R_{p}$ is the polarization resistance. For corrosion in aqueous environments the resistance of the electrolyte is much smaller than the polarization resistance so the measured resistance is approximately equal to the polarization resistance. However, when the resistance of the electrolyte is not small when compared with the polarization resistance, this approximation may cause significant error. For reinforced concrete, the resistance of the concrete is so great that it should not be neglected. Therefore, the measured resistance must be corrected in order to have an accurate polarization resistance measurement. The resistance of concrete can either be measured directly, or be cancelled by the use of a current interruption technique [Bentur, Diamond, and Berke, 1998]. The concrete 
resistance can be reduced by either placing the reference electrode close to the working electrode, or by keeping the concrete surface saturated [Ford, 1998].

\subsubsection{Electrochemical Impedance Measurement}

Electrochemical impedance spectroscopy (EIS) has been used to study the corrosion of reinforcing steel and the electrical properties of cementitious materials [Gu, 1997; Ford, 1998; and Crentsil, 1992]. The advantage of the impedance technique is that it allows for modeling the behavior of steel in concrete using equivalent circuit. The typical equivalent circuit used in connection with EIS technique usually accounts not only for the behavior of corroding steel, but also represents the electrical properties of the concrete, and the interface between the steel and the concrete [MacDonald, 1987].

A modified Randles circuit, such as the one presented in Figure 3.3 is a simple electrical analog model used to simulate the corrosion of steel in concrete. It includes the concrete resistance, $R_{c}$, polarization resistance, $R_{p}$, and the double layer capacitance, $C_{d l}$. When an ac current is applied to this circuit over a wide range of frequencies, the corresponding impedance of this circuit, Z, will appear as a semi-circle on a Nyquist plot, as shown in Figure 3.4. Impedance $\mathrm{Z}$ consists of a real component, $Z_{r}$, and an imaginary component, $Z_{i}$. The highest frequency intercept represents the resistance of the concrete, $\mathrm{R}_{\mathrm{c}}$, while the lowest frequency intercept represents the combined resistance of the concrete and the polarization resistance, $R_{c}+R_{p}$. Hence, the diameter of the semi-circle is the polarization resistance, $R_{p}$. 
Some additional equivalent circuits were proposed by other researchers [John, Searson, and Dawson, 1988; Newton and Sykes, 1988; Feliu, et al., 1985; Keddam et al., 1994; MacDonald, McKubre and Urquidi-MacDonald, 1988] for the study of the corrosion process of reinforcing steel, and some valuable progress has been accomplished by using these models to explore the mechanism of corrosion in concrete. In these equivalent circuits, the interface between steel and concrete was modeled with a capacitor parallel to a resistor. Sagues, Kranc, and Moreno [1995] argued that the electrical characteristics of the steel-concrete interface should be modeled with a constant phase element (CPE), because the behavior of the steel-concrete interface was different from a capacitor, but could be simulated by a constant phase element, as discussed in Section 2.4 .3 .

Gu and his co-workers [1997] studied the effect of corrosion inhibitors by using the electrochemical impedance spectroscopy method. The concrete specimens contained 0 to $4 \%$ chloride ions and $5 \%$ of corrosion inhibitors (either sodium nitrite or dinitrobenzoic acid, percentages were based on mass of cement). The specimens were moist-cured for seven days before they were placed in a $3.4 \% \mathrm{NaCl}$ solution. When the study was carried out, the specimens were five years old. The equivalent circuit used in their study is shown in Figure 3.5 (a). It consisted of three parallel combinations of resistors and CPEs. The frequency of the applied ac voltage ranged from $0.5 \mathrm{mHz}$ to 75 $\mathrm{kHz}$. There were two partial arcs and one entire arc in the impedance diagram, as shown in Figure 3.5 (b). A tail of an arc in the high frequency range (10 kHz and higher) was associated with the bulk concrete. A depressed arc, with a frequency range of $1 \mathrm{~Hz}$ to 10 $\mathrm{kHz}$ was attributed to the steel-concrete interface, or the transition zone [Ford, 1998; 
Crentsil et al., 1992]. The low frequency $\operatorname{arc}(0.5 \mathrm{mHz}$ to $1 \mathrm{~Hz})$ was due to the steel surface corrosion process. A complete arc of low frequency was hard to obtain because of time and equipment limitation. It was found from these measurements that:

1. The concrete resistance, $\mathrm{R}_{\mathrm{c}}$, decreased with an increase of chloride content in the concrete. The specimens containing sodium nitrite had higher resistance values, while the specimens containing dinitrobenzoic acid had lower resistance values compared to the control specimens.

2. The interface layer resistance, $R_{i}$, did not decrease with the increase of chloride content in the concrete. It was not clear what controlled the interfacial layer resistance. The capacitance also did not change much among different specimens.

3. The polarization resistance, $R_{p}$, decreased with the increase in the amount of chloride. The $\mathrm{R}_{\mathrm{p}}$ values in the specimens followed the sequence: calcium nitrite $>$ dinitrobenzoic acid $>$ control. On the other hand, the double-layer capacitance, $\mathrm{C}_{\mathrm{dl}}$, increased with the chloride content but the trend was not very clear.

\subsection{Repair of Corrosion Damage}

Repair or rehabilitation of structure may be necessary when corrosion of steel has caused extensive damage. The repair methods and materials selected depend not only on the extent of corrosion of the reinforcing steel, but also on the environmental conditions to which the structures are exposed. Several steps are involved in the repair and rehabilitation process. First, the mechanism and extent of the corrosion damage should be evaluated; then the methods for repair and rehabilitation are designed; and at last, the structure may be repaired using certain techniques to increase its service life. 


\subsubsection{Corrosion Damage}

The corrosion damage to steel in reinforced concrete structure is usually not recognized until stains are present and concrete cover has cracked or popped out. Repairing damaged structures in this stage is often more difficult and costly. For some important structures, rehabilitation should be carried out before visible damage has occurred in order to maintain functionality and safety to the travelling public. Therefore, the strategy of rehabilitation should be optimized with respect to safety and economic aspects.

Corrosion attacks the reinforcing steel directly by reducing the steel diameter and the cross-sectional area. The stress in the steel with reduced cross-sectional area will increase and structural failure may take place. The corrosion damage of prestressed or post-tensioned concrete structures is of greater concern than that of conventionally reinforced concrete structures, since stress corrosion cracking and hydrogen induced cracking may happen on the tendons.

Stress corrosion cracking occurs as the consequence of localized pitting corrosion. As a result, stress is highly concentrated at the tip of the pit and plastic deformation of the steel may occur. Stress corrosion cracking is illustrated in Figure 3.6 (a). Due to the stress concentration, the metal atoms in the tip area are more active than in the bulk of the metal, and the re-passivation process is prevented by progressive plastic deformation. Therefore, the combination of corrosion and stress concentration can damage the steel quickly. 
Hydrogen embrittlement tends to occur when the steel is in acidic environment and cathodic reaction takes place on the steel surface. Hydrogen atoms are produced from a cathodic reaction taking place on the steel surface. The small hydrogen atoms dissolve and diffuse into the steel, especially at the tip of a crack, as illustrated in Figure 3.6. This reduces the ductility of the steel and can make it brittle [Bentur, Diamond, and Berke, 1998].

The damage of the concrete cover is a secondary damage caused by the corrosion of steel in reinforced concrete. The term "secondary" does not mean it is less important or less severe. It means that the damage on concrete cover is caused by the corrosion of the steel. The corrosion products have much larger volume than the original steel, as shown in Table 3.1 [Monteiro et al., 1995]. The corrosion products, accumulating in the vicinity of the steel, will cause expansion. The tensile strength of concrete is low and therefore, concrete cracks due to the tensile stresses caused by the increasing volume of corrosion products. Once the concrete cover has cracked or popped out, the steel is directly exposed to the corrosive environment, and the rate of corrosion tends to increase.

\subsubsection{Repair and Rehabilitation Techniques}

The commonly used repair and rehabilitation techniques include patch repair, construction overlay, applications of corrosion inhibitors, coating, and electrochemical methods. These techniques, except for the overlay, are discussed in the following sections. 


\subsubsection{Patch Repair}

Patch repair involves removal of delaminated concrete, cleaning of reinforcement and filling of the delaminated area with new concrete or mortar. Damaged concrete can be removed by various means including hand-held pneumatic chisels or high-pressure water jets. In order to remove the corrosive products from the steel, the concrete surrounding the steel bars should be removed to a depth of at least $50 \mathrm{~mm}$ beyond the corroded portion. Also, a clearance of at least $20 \mathrm{~mm}$ underneath the bars is required [Bentur, Diamond, and Berke, 1998]. Caution should be exercised when heavy tools are used for concrete removal since they may damage the remaining concrete. If damage does occur, the fractured concrete should be removed with lighter tools.

Reinforcing steel is usually sandblasted and/or brushed in order to remove the corrosion products. If the diameter or the cross-sectional area of the bar has been significantly reduced, the bar should be replaced with a new one.

High quality, low permeability concrete or mortar should be used to fill the cavity. This is usually achieved by adding mineral and chemical admixtures to the concrete mix. Silica fume, high range water-reducing admixtures and polymers are the most commonly used materials. A potential problem with this method is that the repair materials may lead to active corrosion just beyond the repair area because the new and the old concretes may have significantly different properties, such as concentration of chloride ions, electrical conductivity, moisture, and permeability. These differences increase the driving force for a corrosion reaction and can therefore accelerate the corrosion rate of the steel near the repaired area or initiate corrosion at different location. 


\subsubsection{Use of Corrosion Inhibitors}

Corrosion inhibitors for concrete are chemical substances that reduce the corrosion rate or eliminate the corrosion process entirely without reducing the concentration of corrosive agents. Corrosion inhibitors can either influence the anodic or cathodic reactions, or both. Since the anodic and the cathodic reactions must balance each other, a reduction in either or both will result in a reduction in the corrosion rate.

Figure 3.7 shows the effect of anodic inhibitor on the corrosion potential and corrosion rate, while Figure 3.8 shows the effect of cathodic inhibitor on the corrosion potential and the corrosion rate.

The most commonly used anodic corrosion inhibitor is calcium nitrite, $\mathrm{Ca}\left(\mathrm{NO}_{2}\right)_{2}$. The mechanism by which calcium nitrite inhibits corrosion involves stabilization of the passive film of the steel that would otherwise be disrupted by the presence of chloride ions at the steel level. When calcium nitrites are present, the ferrous ions $\left(\mathrm{Fe}^{2+}\right)$ are further oxidized and produce more stable ferric oxide:

$$
\mathrm{Fe}^{2+}+\mathrm{OH}^{-}+\mathrm{NO}_{2}^{-} \rightarrow \mathrm{NO} \uparrow+\gamma-\mathrm{FeOOH}
$$

Calcium nitrite protects the passive film on the steel surface by competing for ferrous ions with the chloride ions. On the other hand, the chloride ions react with ferrous oxide to form a soluble complex (Eqn. 2.17). As a result, the relative concentrations of chloride and nitrite ions determine which reaction controls the process. The threshold level of chloride ions for initiation of corrosion is increased when nitrite ions are present.

Dinitrobenzoic acid is a typical organic corrosion inhibitor. It protects the steel from corrosion by forming a strong chemical bond with the steel through its carboxyl 
group $\left(\mathrm{RCOO}^{-}\right)$. It also makes the steel surface less active and facilitates the passivation of the steel [Rozenfeld, 1981].

\subsubsection{Use of External Coatings}

To reduce the risk of further corrosion of reinforcements, both concrete and reinforcing steel can be treated with externally applied sealers and coatings. The reinforcing steel can be coated with epoxy, cement-based mortar, or zinc. The surface of the steel bar needs to be well cleaned so that sufficient bond between the steel and the coating can be achieved. It is important to ensure that the coating material covers the entire surface of the steel. Otherwise, the non-coated steel will act as an anode and the coated steel as a cathode. Under such conditions, the ratio of the cathodic area to that of the anodic area will be high and, subsequently, the corrosion rate will be high.

Concrete coating is traditionally used on concrete structures exposed to aggressive chemical attack. Sealers and membranes applied to concrete surface can reduce or eliminate the access of moisture and aggressive chemicals to concrete. Three types of techniques are normally used for coating concrete [Bentur, Diamond, and Berke, 1998]. One of the techniques involves the application of a continuous film (the film is composed of a binder and fillers, such as pigments, plasticizers, catalysts, and fungicides) on the concrete surface with a thickness of 100 to $300 \mu \mathrm{m}$. The second technique is called pore lining. Silicone resin can be dissolved in organic liquid which after evaporation deposits a film of the resin on the pore surface. Alternatively, the resin can be formulated so that it reacts with the moisture in the pore to form the water-repellent lining. The third 
technique is to block the concrete pores. Some special materials, such as liquid silicate and siliconfluoride, can be used to penetrate into the pores and react with the concrete to block the pores.

\subsubsection{Electrochemical Treatment}

There are three electrochemical methods commonly used for rehabilitation of reinforced concrete structures: cathodic protection, electrochemical chloride removal, and electrochemical re-alkalization.

Cathodic protection is based on the principle that when the anodic potential is more negative, the corrosion current is small. This can be done by connecting the anode to an external source that has a more negative potential. For reinforced concrete structures, the steel bars are connected to the negative (-) pole of a battery or a rectifier, and the positive $(+)$ outlet is connected to an inert material which serves as an anode. As a result, the steel bars act as a cathode (electrons flow from the inert anode to the steel bars, and the current flows from steel bars to the inert anode). An alternative method of supplying an electron flow to the steel bar is by using a sacrificial anode. Usually, sacrificial anode is a piece of metal, which has a more active corrosion potential. In this system, the active metal is the anode, and the steel bars act as the cathode. The active metal dissolves as a result of the corrosion reaction, while the steel bars are protected. Magnesium, zinc, and aluminum are commonly used as sacrificial anodes.

Cathodic protection is a widely used method for corrosion protection. However, some special precautions must be taken when it is used in reinforced concrete structures. 
The reinforcement must be electrically continuous; otherwise some steel bars are not protected. Another potential problem is that the cathodic reaction produces hydroxide ions $\left(\mathrm{OH}^{-}\right)$, which may cause alkali-aggregate reaction if the aggregates are reactive. For a more detailed discussion, the reader is referred to the RILEM report [RILEM, 1994] or the manuscript of Brown and Tinnea [1991].

Electrochemical chloride removal process was designed to remove chloride ions from concrete. A mesh of steel or cellular material is placed on the surface of the concrete as a temporary anode, while the steel bar acts as a cathode. When dc voltage is applied to this system, the chloride ions move toward the anode in this de field. This method can have some adverse effects on reinforced concrete. The accumulation of cationic ions in the vicinity of the steel may cause alkali-aggregate reaction. The quality of bond between the steel and concrete may also be reduced. In addition, hydrogen can be produced by the cathodic reaction at the surface of the steel, causing hydrogen embrittlement.

Electrochemical re-alkalization is commonly used to control the rate of corrosion in reinforced concrete caused by carbonation. A steel mesh is usually used as a temporary anode on the concrete surface, while the reinforcement acts as cathode. A sodium carbonate solution is used as electrolyte and a dc voltage is applied to the system. The sodium ions and the cationic ions migrate toward the steel under the dc field, resulting in a high $\mathrm{pH}$ in the pore solution of concrete surrounding the steel. This method has the same adverse effects as the chloride removal technique. 


\subsection{Summary}

Concrete, being a high alkaline material, keeps the passive film on the steel surface stable. Chloride ions can penetrate into concrete and, once they reach the steel level, initiate the pitting corrosion. Chloride ions act as a catalyst in the active corrosion reaction, since they are not consumed by the reaction.

Corrosion damages both the steel and the concrete cover. Cracks and pop-outs in concrete provide direct access for aggressive agents to enter the concrete and potentially reach the level of the reinforcement. If that happens, corrosion rate becomes higher and a severe corrosion damage could be anticipated.

Polarization resistance measurement and electrochemical impedance spectroscopy are useful techniques for determining the rate of corrosion. Polarization resistance measurement is a dc method, while impedance spectroscopy is an ac method.

Concrete damaged by corrosion is often repaired by patching the affected area (after prior removal of delaminated concrete and cleaning the surface of the rebars) with good quality, low permeability concrete. Frequently, the patch material will contain supplementary cementitious materials such as fly ash or silica fume to reduce permeability. Typically, the patched areas are subsequently covered with overlay that is made of the same material as a patch. Preventive measures aimed at reducing the risk and severity of corrosion damage include coating of the reinforcing rebars with epoxy and application of sealers and membranes to the surface of the concrete. 
Table 3.1 Volume change of different iron oxides [Monteiro, P. J. M., Prezzi, M., Wang, K. J., and Ghio, V].

\begin{tabular}{ccc}
\hline Corrosion Products & $\mathrm{O}: \mathrm{Fe}$ (Molar Ratio) & Volume Increase \\
\hline $\mathrm{FeO}$ & $1: 1$ & 1.8 \\
$\mathrm{Fe}_{3} \mathrm{O}_{4}$ & $4: 3$ & 2.0 \\
$\mathrm{Fe}_{2} \mathrm{O}_{3}$ & $3: 2$ & 2.2 \\
$\mathrm{Fe}(\mathrm{OH})_{2}$ & $2: 1$ & 4.0 \\
$\mathrm{Fe}(\mathrm{OH})_{3}$ & $3: 1$ & 4.4 \\
$\mathrm{Fe}(\mathrm{OH})_{3} \cdot 3 \mathrm{H}_{2} \mathrm{O}$ & $6: 1$ & 6.6 \\
\hline
\end{tabular}




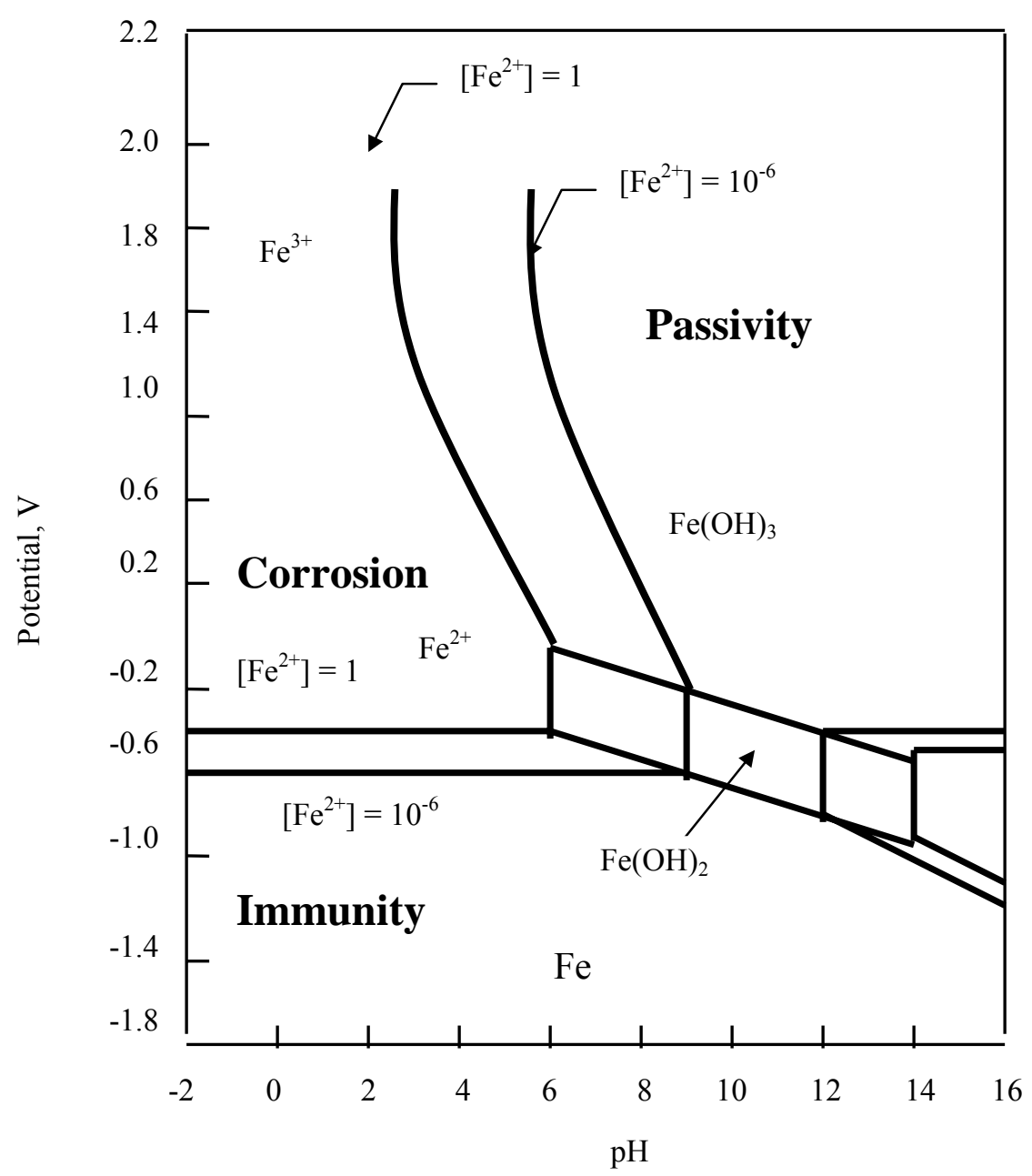

Figure 3.1 Pourbaix diagram for iron. Lines indicate the areas of thermodynamic stability of species[Jones, 1996; Ford, 1998]. 


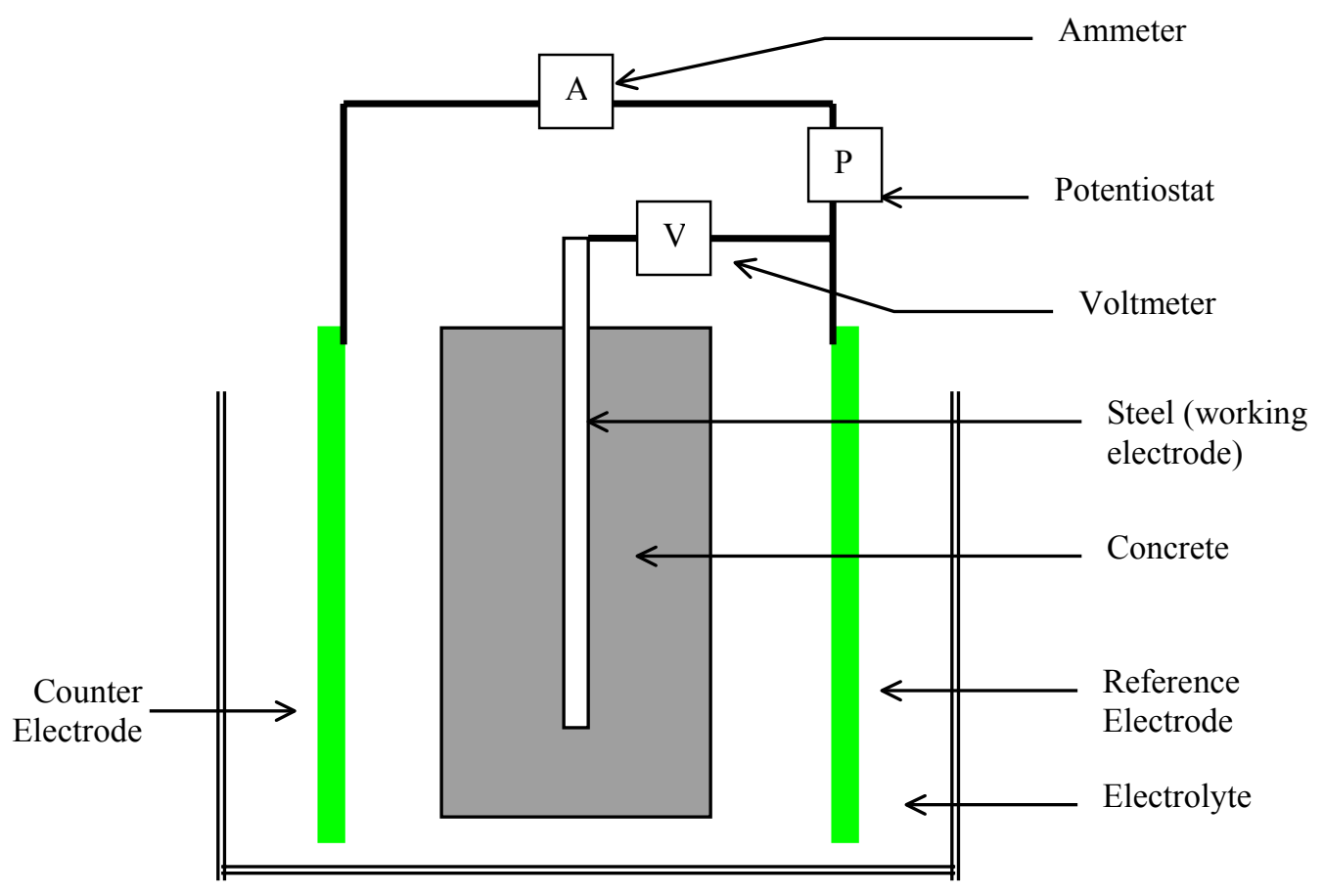

Figure 3.2 Schematic description of polarization testing [Bentur, Diamond, and Berke, 1998]. 


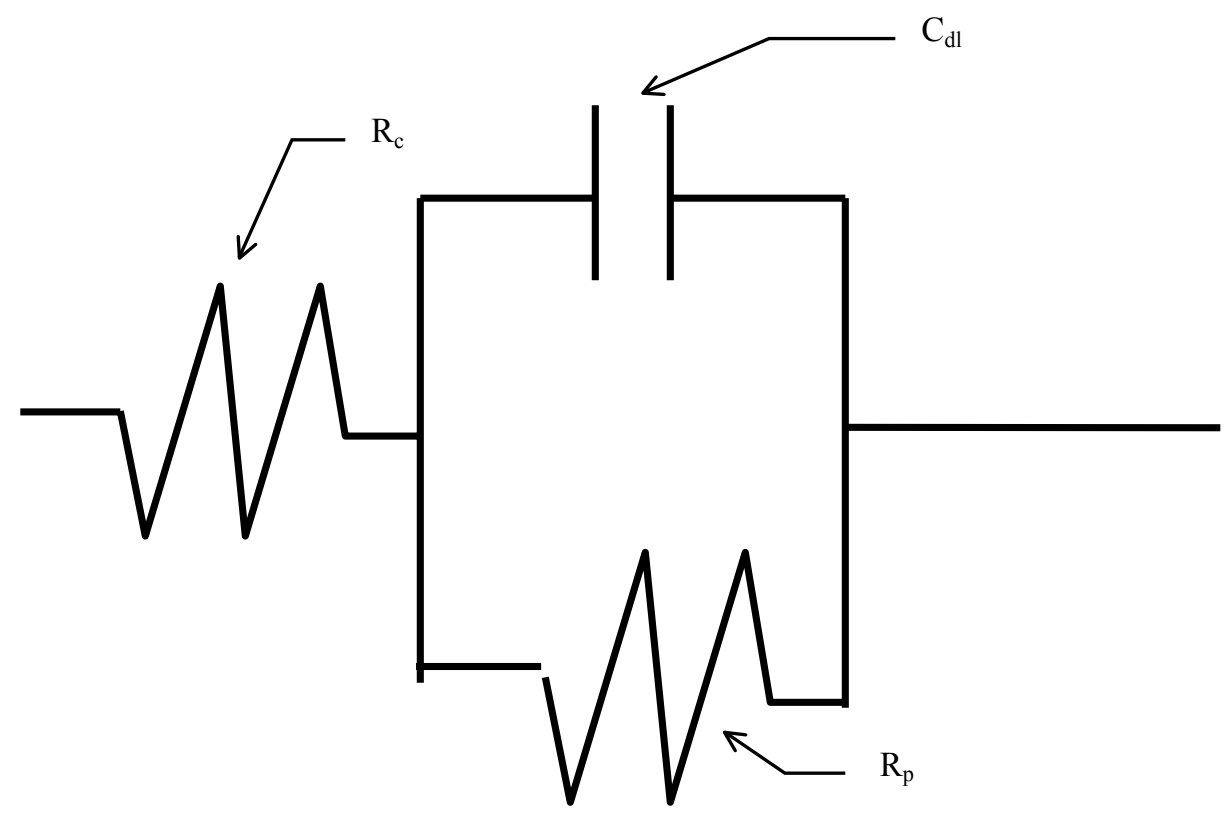

Figure 3.3 Randles cell diagram. $\mathrm{R}_{\mathrm{c}}$--- concrete resistance, $\mathrm{R}_{\mathrm{p}}$--- polarization resistance, and, $\mathrm{C}_{\mathrm{dl}} \mathrm{l}_{\mathrm{c}}^{--}$double layer capacitance.

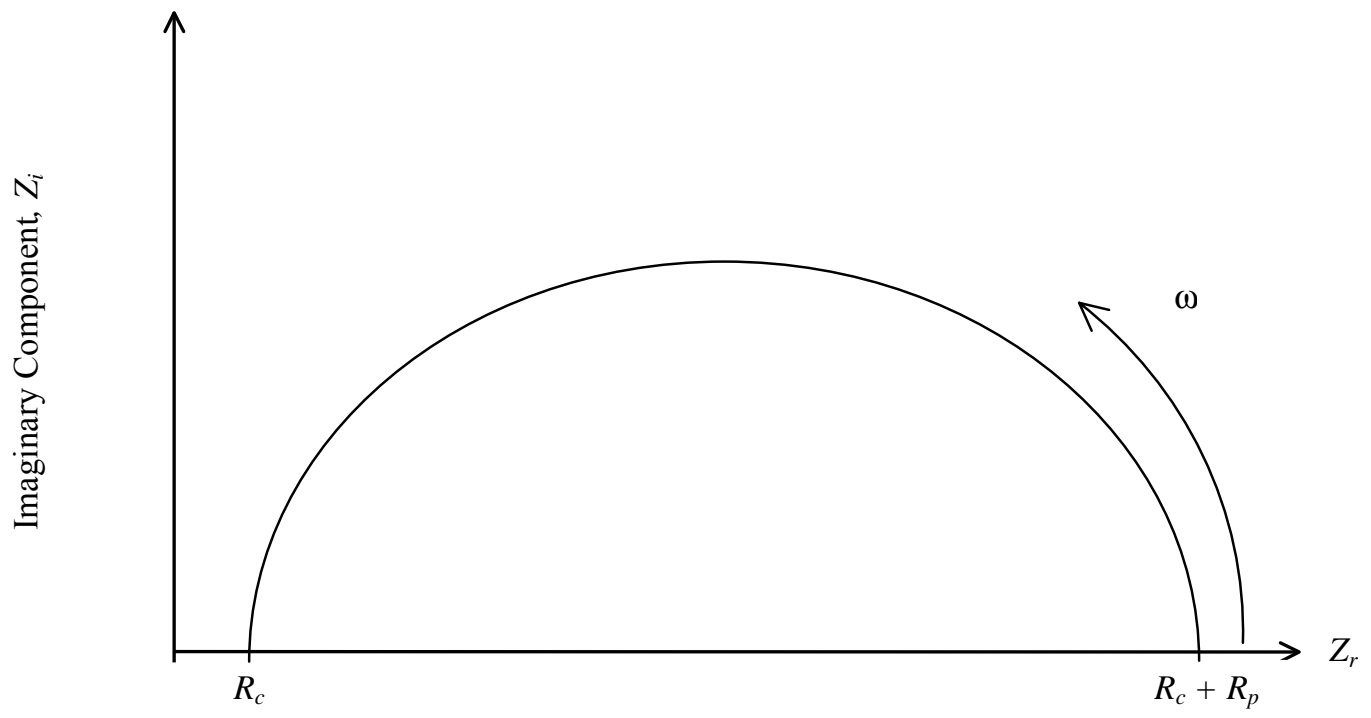

Real Component, $\mathrm{Z}_{\mathrm{r}}$

Figure 3.4 Nyquist plot of Randles cell [McDonalds, 1987]. 


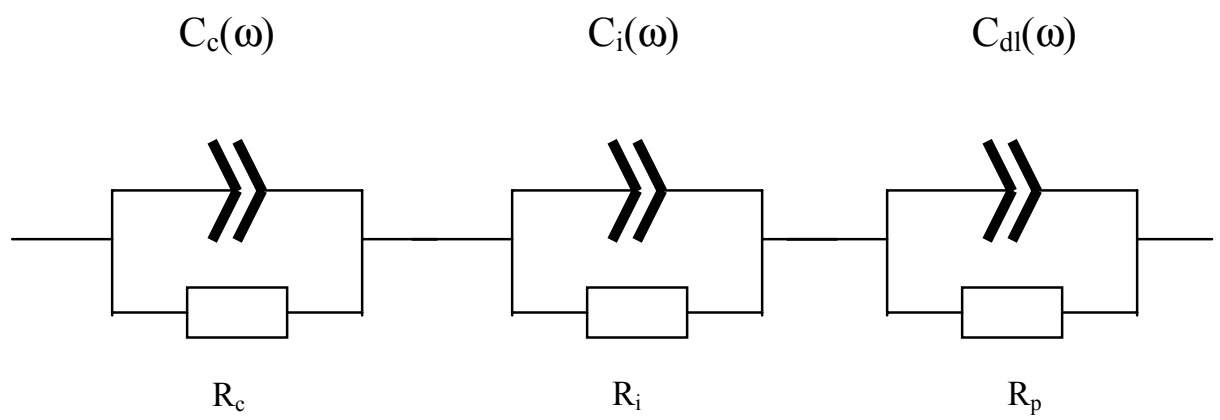

(a)

$\mathrm{R}_{\mathrm{c}}$ and $\mathrm{C}_{\mathrm{c}}(\omega)$--- Concrete resistance and matrix solid/liquid interface capacitance; $\mathrm{R}_{\mathrm{i}}$ and $\mathrm{C}_{\mathrm{i}}(\omega)$--- Steel/concrete interface film resistance and capacitance; $\mathrm{R}_{\mathrm{p}}$ and $\mathrm{C}_{\mathrm{dl}}(\omega)$--- Rebar polarization resistance and steel surface double layer capacitance.

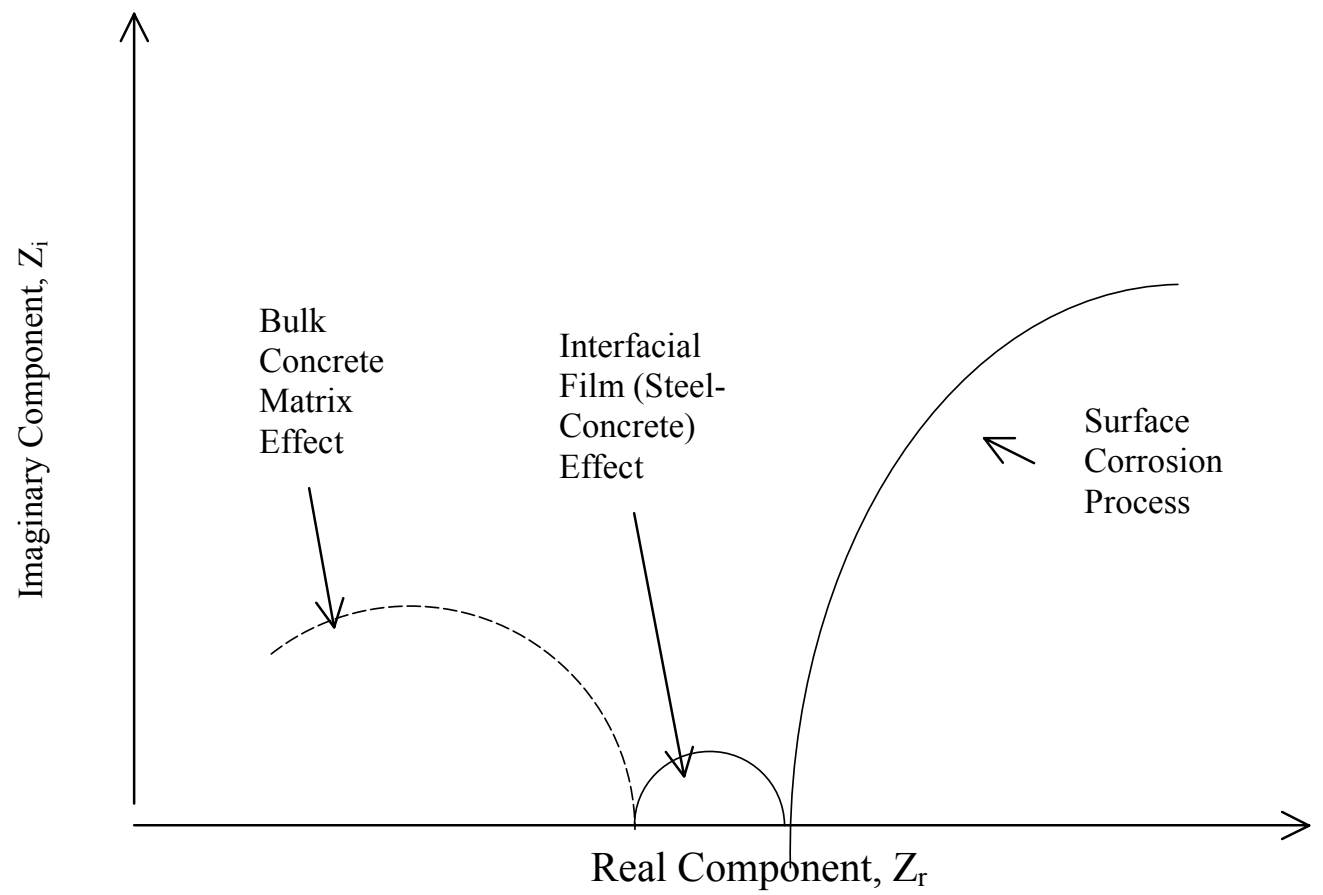

(b)

Figure 3.5 The equivalent circuit consists of three parallel combinations of a resistor and a CPE (a); Corresponding impedance plot on the complex plane (b); [Gu et al., 1997]. 
Metal Surface

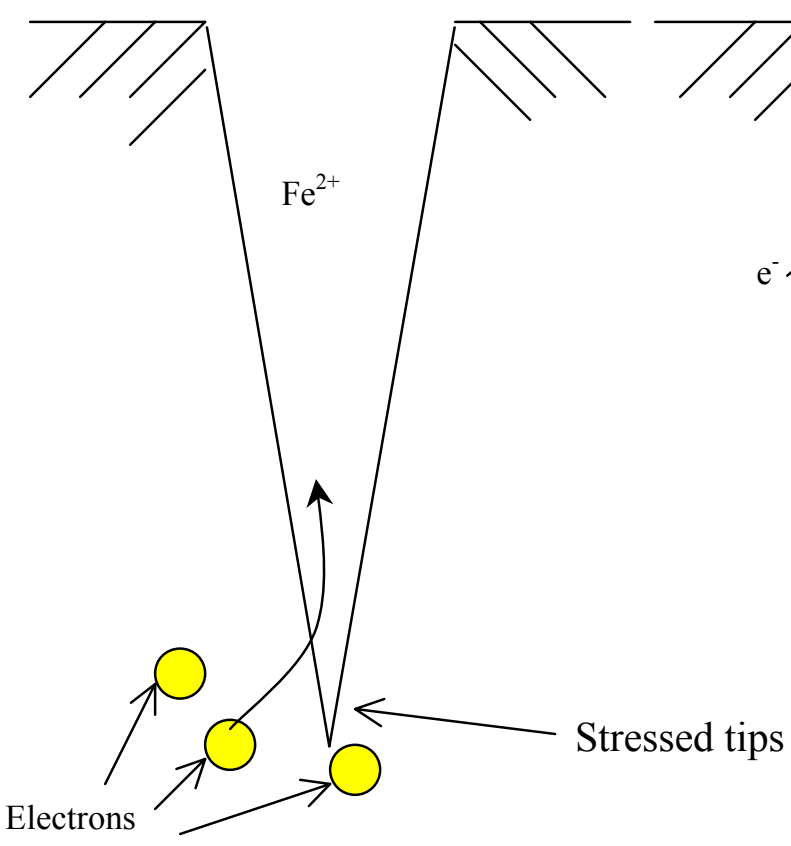

(a)
Metal Surface

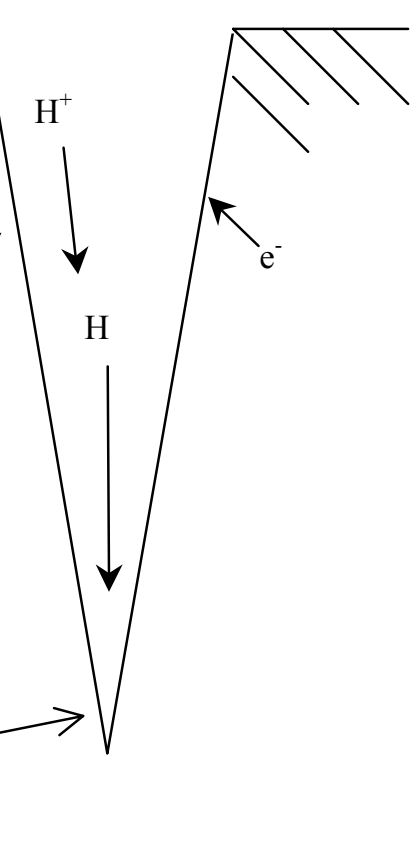

(b)

Figure 3.6 Schematic description of the corrosion process taking place at the tip of a pit or crack in a stressed metal leading to its embrittlement. Stress corrosion cracking (a), and Hydrogen embrittlement (b) [Bentur, Diamond, and Berke, 1998]. 


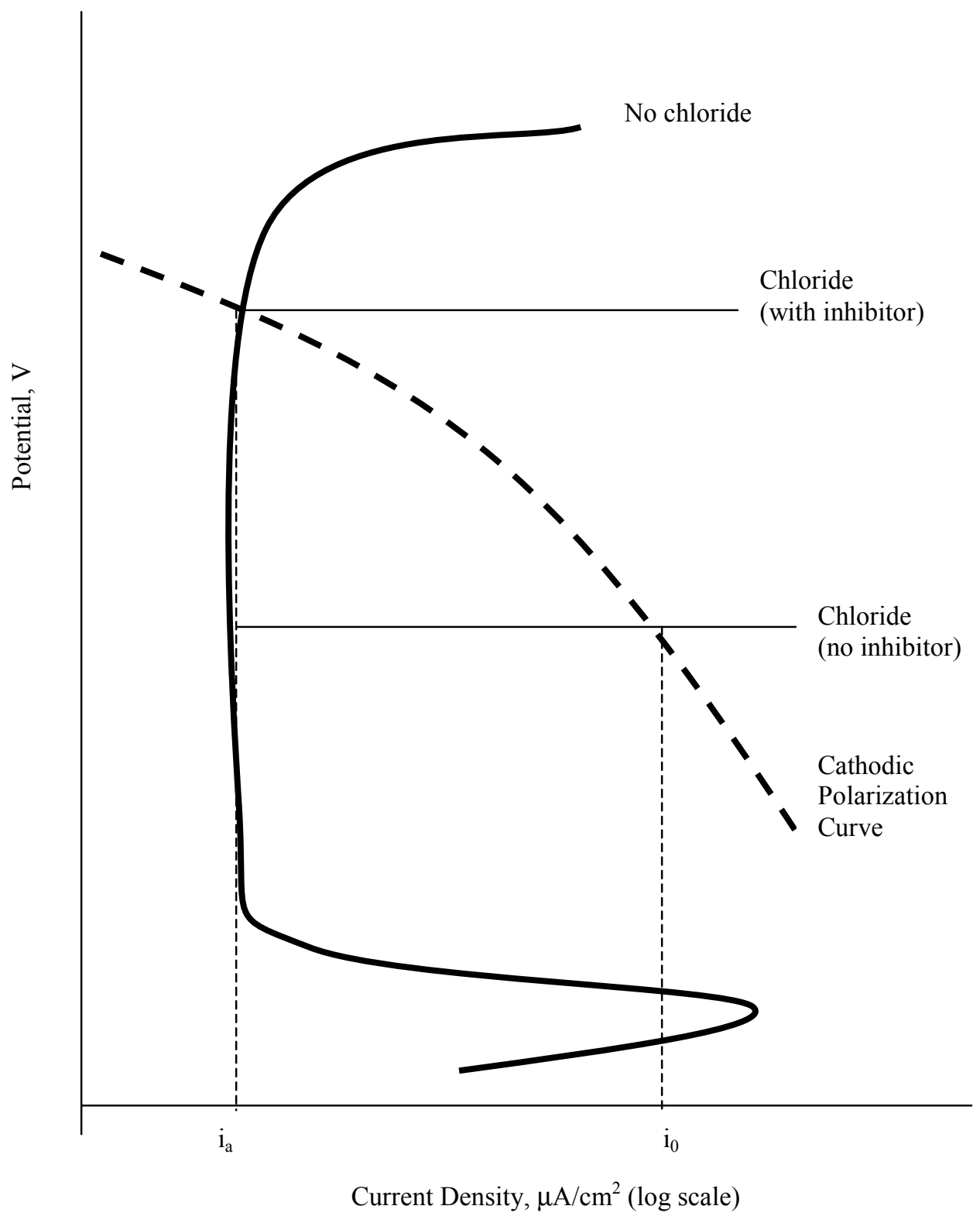

Figure 3.7 Effect of anodic inhibitor on the potential-corrosion rate, schematic [Bentur, Diamond, and Berke, 1998]. $\mathrm{i}_{0}$,--- Corrosion current density without anodic inhibitor; $\mathrm{i}_{\mathrm{a}}$--- Corrosion current density with anodic inhibitor. 


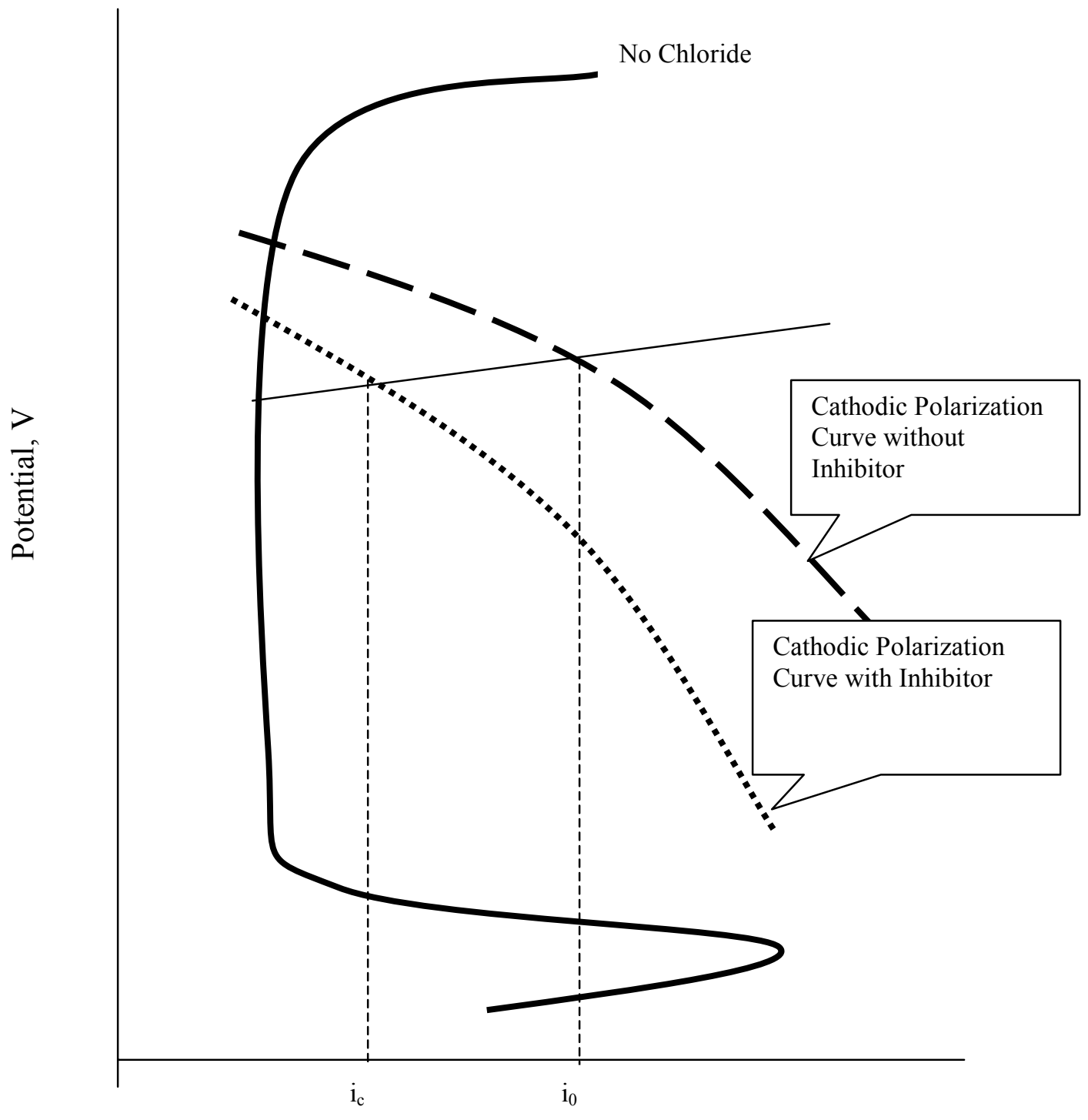

Current Density, $\mu \mathrm{A} / \mathrm{cm}^{2}$ (log scale)

Figure 3.8 Effect of cathodic inhibitor on the potential-corrosion rate, schematic [Bentur, Diamond, and Berke, 1998]. $\mathrm{i}_{0}---$ Corrosion current density without cathodic inhibitor; $\mathrm{i}_{\mathrm{c}}$---Corrosion current density with cathodic inhibitor. 


\section{CHAPTER 4 EXPERIMENTAL PROCEDURES}

This chapter summarizes the materials and techniques that were used in the course of this study. Since the main goals of this research study included evaluation of properties of several types of concrete with respect to their usefulness in repairing corrosion damage, the experimental program has been separated into two phases. The first phase was focused on testing the properties of various concrete mixes used for repair purposes, and the second phase emphasized the evaluation of the corrosion process of the reinforcing steel using electrochemical techniques.

\subsection{Specimens Preparation}

Both plain concrete specimens and reinforced concrete specimens were used during this research study. Reinforced concrete slabs were used for chloride penetration testing and electrochemical corrosion measurements. After the initial exposure period during which reinforcing bars were corroded the slabs were repaired with patching material and subsequent progress of corrosion was monitored. The test plan for all specimens is shown schematically in Figure 4.1. 


\subsubsection{Materials}

\subsubsection{Portland Cement}

Type I portland cement was used by the ready mix concrete supplier to make the INDOT Class $\mathrm{C}$ concrete, which was used for the fabrication of the original reinforced concrete slabs.

A commercially available ASTM Type I portland cement, manufactured by Lone Star Cement Plant in Greencastle, Indiana, was used in this project to make the repair concrete mixes. The chemical compositions and physical properties of this cement were provided by the manufacturer and are presented in Tables 4.1 and 4.2, respectively.

\subsubsection{2 $\underline{\text { Mineral Admixtures }}$}

\section{Silica Fume}

Silica fume was used as a mineral admixture in this study to make one of the repair concrete mixes. A commercial-grade silica fume (Force 10,000 D Densified Microsilica) was provided by W. R. Grace. Its chemical composition is listed in Table 4.3 and the X-ray diffraction pattern is shown in Figure 4.2. The broad hump visible in the $\mathrm{X}$-ray pattern indicates that the main component of this material is amorphous silica.

Fly Ash

Class C fly ash was used in this study and it was obtained from the American Fly Ash Company. The chemical analysis of this fly ash is presented in Table 4.4, and the physical analysis is shown in Table 4.5 The X-ray diffraction pattern of this fly ash is 
shown in Figure 4.3 The broad hump visible in the region from $15^{\circ} 2 \theta$ to $35^{\circ} 2 \theta$ is due to the amorphous glass phases of aluminosilicate and calcium aluminosilicate present in this fly ash. The fly ash also contains some crystalline phases, such as quartz $\left(\mathrm{SiO}_{2}\right)$ and hematite $\left(\mathrm{Fe}_{2} \mathrm{O}_{3}\right)$.

\subsubsection{3 $\underline{\text { Aggregates }}$}

According to INDOT Standard Specifications (1995), the coarse aggregate used for bridge deck should be Class A aggregate with a maximum particle size of 1 inch (No. 8 coarse aggregate). For repairs of bridge decks, No. 11 coarse aggregate with maximum particle size is $1 / 2$ inch should be used.

INDOT standard Class $\mathrm{C}$ concrete was used to make the original concrete specimens (reinforced slabs, cylinders, and beams). This concrete was supplied by a local ready mix concrete producer and contained Indiana No. 8 coarse aggregate. Concrete used to patched corrosion-damaged slabs was produced in the laboratory and the coarse aggregate used was No. 11 crushed limestone. No. 11 coarse aggregate was also used to make other specimens in the laboratory for testing the physical and mechanical properties of the concrete. The sieve analysis for No. 11 coarse aggregate is shown in Figure 4.4 It meets the INDOT specifications. No sieve analysis was provided by the ready mix concrete supplier for No. 8 coarse aggregate.

Natural sand was used as fine aggregate in all concrete mixes. The maximum particle size was $9.5 \mathrm{~mm}$ (3/8 in.). The sieve analysis for the fine aggregate is shown in Figure 4.5 


\subsubsection{Chemical Admixtures}

Water Reducing Agent (Superplasticizer)

Water reducing admixture, PS-1140 supplied by Master Builders, was used in the production of the patching concrete. The recommended dosage is 0.26 to $0.78 \mathrm{~L} / 100 \mathrm{~kg}$ cement (4 to $12 \mathrm{oz} / 100 \mathrm{lb}$ cement). The dosage used in this project was $0.75 \mathrm{~L} / 100 \mathrm{~kg}$ cement (11.5 oz/100 lb cement)

\section{Air Entraining Agent}

All concrete mixtures used for repairs were air-entrained. The air-entraining agent used was Master Builders' product called Micro-Air. The recommended dosage of this admixture is 8 to $98 \mathrm{ml}$ per $100 \mathrm{~kg}$ of cement, or $1 / 8$ to $1 \frac{1}{2} \mathrm{oz}$ per 100 pounds cement. The dosage used for this project is listed in Table 5.1.

\section{Shrinkage Reducing Admixture}

In order to reduce the shrinkage of the patching concrete, a shrinkage reducing admixture (ECLIPSE) provided by W.R. Grace was used in one of the mixes. This product is a liquid with a specific gravity of 0.93 . The addition rate used in this project was $2 \%$ by the weight of cement as recommended by the manufacturer.

\subsubsection{Corrosion Inhibitors}

Two types of corrosion inhibitors (organic and inorganic) were used in this research project to make some of the patching mixes. The inorganic inhibitor was calcium nitrite produced by W. R. Grace, Inc. (the DCI corrosion inhibitor), which is, 
classified by ASTM C494 as a Type C corrosion inhibitor. It is also known as an anodic corrosion inhibitor since it reacts with the steel to produce a protective barrier on the steel surface. This corrosion inhibitor was supplied in a liquid form and contained at least 30 $\%$ of calcium nitrite. The manufacturer recommended dosage rate was 10 to $30 \mathrm{~L} / \mathrm{m}^{3}(2.0$ to $\left.6.0 \mathrm{gal} / \mathrm{yd}^{3}\right)$ concrete. The dosage used for this project was $20 \mathrm{~L} / \mathrm{m}^{3}\left(4.0 \mathrm{gal} / \mathrm{yd}^{3}\right)$.

The organic corrosion inhibitor used in this project was called RHEOCRETE and was supplied by Master Builders. According to the manufacturer, this corrosion inhibitor is capable of providing two levels of corrosion protection for steel in concrete. The first level involves reduction of concrete permeability and, as a result, reduction of chloride ions and moisture penetration into the concrete. This reduction in permeability effectively delays the off-set of corrosion. The second level involves the reduction of corrosion rate after the initiation of corrosion. This is the effect of formation of a molecular barrier on the steel surface. The dosage used in this project was $5 \mathrm{~L} / \mathrm{m}^{3}(1$ $\left.\mathrm{gal} / \mathrm{yd}^{3}\right)$, as recommended by the manufacturer.

\subsubsection{6 $\underline{\text { Latex }}$}

Latex modified concrete has been successfully used for bridge deck overlays in the past. In this research project, latex modified concrete was used to repair some of the reinforced concrete slabs. The latex used was "Modifier A" produced by Dow Chemical Company. It was supplied in a form of an emulsion and the main solid compound was styrene butadiene. The solid content of this latex was $50 \%$. The dosage used in this project was $31 \mathrm{~L} / 100 \mathrm{~kg}$ cement (3.72 gal/100 lb cement). 


\subsubsection{Concrete Mixes}

INDOT Class $\mathrm{C}$ concrete was used to fabricate the original reinforced concrete slabs. The concrete was supplied by a local ready mix concrete supplier (IMI Materials Company in Lafayette, Indiana), and the unit weight, air content, and slump were tested just before the concrete was placed into the forms. The mix composition and properties of the fresh concrete are listed in Table 4.6.

Seven different types of concrete mixes were developed for use as candidate mixes to repair corrosion-damaged concrete slabs. All of the mix designs were based on the INDOT standard 9-bag mix that is traditionally used in repairing concrete bridge decks. Mineral and chemical admixtures as well as corrosion inhibitors were added to these concrete mixes. The seven mixes used in this study are listed below::

1. Standard INDOT 9-bag cement concrete mix for patching of bridge deck as per INDOT 1995 Standard Specifications.

2. Concrete with silica fume (10\% replacement by weight of cement, based on 9-bag mix).

3. Concrete with Class C fly ash (20\% replacement by weight of cement, based on 9-bag mix).

4. Standard INDOT 9-bag cement concrete mix for patching of bridge decks as per INDOT 1995 Standard Specifications, plus calcium nitrite corrosion inhibitor. 
5. Standard INDOT 9-bag cement concrete mix for patching of bridge deck as per INDOT 1995 Standard Specifications, plus RHEOCRETE corrosion inhibitor.

6. Standard INDOT 9-bag cement concrete mix for patching of bridge deck as per INDOT 1995 Standard Specifications, plus shrinkage reducing agent.

7. Latex modified concrete 31 liters of latex/100 kg cement (3.5 gal latex/94 lb. cement) as per INDOT 1995 Standard Specifications.

\subsubsection{Preparation of the Reinforcing Steel}

The No. 4 reinforcing steel bars with a nominal diameter of $12.5 \mathrm{~mm}(0.5 \mathrm{inch})$ were used as slab reinforcement. The reinforcing steel was delivered as bars of 6.7-m (20-ft) length and was cut into smaller pieces, $0.91 \mathrm{~m}$ (36 inches) long in the laboratory. Figure 4.6 shows the schematic of a corrosion protection system and electrical wiring connection installed at the end of the rebars. Before the rebars were placed in the forms a hole was drilled at each end of each bar (about 1 in. from the end), and the bars were polished using rotating wire brush. The end portion of the bars ( 5 in. from the end) that was to remain outside of the slab was coated with epoxy to avoid corrosion when the specimens were exposed to atmosphere. After the concrete was cast, thermal shrink-wrap plastic tube was installed to cover the ends of the bars that extended out of the concrete (this was done after the installation of stainless steel bolts and nuts).

Electrical wire was connected to washers, and the washers were fastened to the steel bar with bolts and nuts. In order to avoid corrosion, these connections were coated 
with epoxy. Banana plugs were used for connections between these wires and the testing equipment.

\subsubsection{Fabrication and Curing of Concrete Specimens}

\subsubsection{Fabrication and Curing of Non-Reinforced Concrete Specimens}

Four types of concrete specimens without reinforcing bars (both Class C concrete and patching concrete). These included:

1. Cylinders, $101.6 \times 203.2 \mathrm{~mm}(4 \times 8$ in. $)$

2. Prismatic beams, $76.2 \times 76.2 \times 381 \mathrm{~mm}(3 \times 3 \times 15$ in. $)$

3. Prismatic beams, $76.2 \times 76.2 \times 279.4 \mathrm{~mm}(3 \times 3 \times 11$ in. $)$

4. Slabs, $76.2 \times 254.3 \times 381 \mathrm{~mm}(3 \times 10 \times 15$ in. $)$

The cylinders were used for compressive strength testing and modulus of elasticity testing. The samples for rapid chloride ions penetration testing were also prepared from these cylinders by cutting them into 50.8-mm (2-in.) thick slices. The 76.2 x $76.2 \times 381 \mathrm{~mm}(3 \times 3 \times 15$ in.) beams were used for freeze-thaw resistance testing, and the $76.2 \times 76.2 \times 279.4 \mathrm{~mm}(3 \times 3 \times 11$ in.) beams were used for shrinkage and dynamic modulus testing. The $76.2 \times 254.3 \times 381 \mathrm{~mm}(3 \times 10 \times 15$ in.) slabs were ponded with salt solution for testing the diffusion of chloride ions.

For the non-reinforced concrete specimens, the fabrication and curing procedures used were as follows:

1. All of the ingredients were mixed in a $2-\mathrm{ft}^{3}$ capacity pan mixer in the laboratory and after the fresh properties of concrete were determined the mix 
was placed in wooden slab forms and finished. The slabs were covered with wet burlap and de-molded after 1 day of curing.

2. After removal from the molds, some specimens were cured in a fog room while others were cured in laboratory (relative humidity about $50 \%$ ) in order to determine the influence of curing conditions on properties.

\subsubsection{Fabrication and Curing of Reinforced Concrete Specimens}

The twenty four original reinforced concrete slabs $(762.0 \times 304.8 \times 254.0 \mathrm{~mm}$, or $30 \times 12$ x 10 in.) were cast from concrete delivered by IMI Materials Company in Lafayette, Indiana. This concrete was a Class C mix as per INDOT 1995 Specifications (cement: $658 \mathrm{~kg} / \mathrm{m}^{3}$, or $391 \mathrm{lb} / \mathrm{yd}^{3}$; maximum water/cement ratio: 0.443 ). The fresh concrete properties (determined just before placing concrete in the forms) included slump, air content, and unit weight. The detailed information on concrete mix composition and fresh concrete properties is given listed in Table 4.6. The configuration of forms used to cast concrete slabs is shown in Figure 4.7 A channel of $762 \times 101.6 \times$ $25.4 \mathrm{~mm}(30 \times 4 \times 1 \mathrm{in}$.) was formed on the top of each slab to reduce the thickness of concrete cover over the reinforcing bars in the middle portion of the slab and thus accelerate the corrosion process. The channel was formed by installing the wooden board at the top of the form and removing it after concrete hardened around it. The thickness of concrete cover in the middle portion of the slab (under the channel) was $12.7 \mathrm{~mm}(0.5$ in.). The thickness of concrete cover outside the channel was $38.1 \mathrm{~mm}$ (1.5 in.). 
Each slab was reinforced with top and bottom steel mats with a configuration shown in Figure 4.8 Each mat consisted of No. 4 rebars. The longitudinal bars and the transverse bars were tied together with steel wire. After casting and finishing, the slabs were covered with wet burlap and water-spray cured for 7 days. Cylinder specimens (101.6 $\times 203.2 \mathrm{~mm}$, or $4 \times 8$ in.) were also made at the same time and cured under the same condition. The slab specimens were de-molded after seven days of curing. The schematic representation of concrete slab after de-molding is shown in Figure 4.9.

\subsubsection{Ponding of Reinforced Slabs}

In order to accelerate the corrosion process of the steel in the reinforced slabs, the slabs were exposed to wetting and drying cycles by alternately ponding their surface with salt solution and heating it using halogen lamps. The salt solution was kept at the surface of the slabs in a 1-in. deep dike as schematically shown in Figure 4.10. Salt water (5\% sodium chloride solution) was pumped into the dike and kept on the top surface of the slabs for 4 days, as shown in Figure 4.11. In order to facilitate the drying of the top surface of the slabs, a special support structure was constructed, to which four halogen lamps, (each capable of delivering 500 watts), were attached (see Figure 4.12). The lamps were located 1.3 meters above the surface of the slabs. When turned on, the lamps raised the temperature of the surface of the slabs to $43^{\circ} \mathrm{C}\left(110^{\circ} \mathrm{F}\right)$. In summary, the sequence of wetting and drying cycles was as follows:

1. Salt water ( $5 \%$ sodium chloride solution) was pumped into the dike on the top of each slab to a height of about $25.4 \mathrm{~mm}$ (1 in.), as shown in Figure 4.11 
2. After 4 days of ponding, the salt water was removed from the dike using a commercial-grade vacuum cleaner.

3. The slabs were dried and heated by halogen lamps for 3 days, as shown in Figure 4.12

\subsection{Testing Procedures}

\subsubsection{Testing of Mechanical and Physical Properties}

Mechanical properties evaluated during this research project included compressive strength, static modulus of elasticity, and dynamic modulus of elasticity. Freeze-thaw resistance, electrical conductance (resistance to rapid chloride ion penetration), and shrinkage were the physical properties of the concrete that were tested as well. Whenever possible, the relevant ASTM and AASHTO standard test methods were followed.

\subsubsection{Compressive Strength}

Cylindrical concrete specimens $101.6 \mathrm{~mm}$ (4 inches) in diameter and $203.2 \mathrm{~mm}$ (8 inches) in length were used for compressive strength determination. These cylinders were removed from the molds at the age of one day and cured in moist room until tested. Three cylinders were tested at the ages of 7 days, 28 days, 56 days, and 6 months. The testing machine used for this test had a maximum load capacity of $1.11 \times 10^{6} \mathrm{~N}(250,000$ lb). The load was applied at a rate within the range of 0.14 to $0.34 \mathrm{MPa} / \mathrm{s}$ (20 to $50 \mathrm{psi} / \mathrm{s})$. The results are discussed in Section 5.1 . 


\subsubsection{Static Modulus of Elasticity}

The static modulus of elasticity of the concrete cylinders was measured following the ASTM C 469-94 procedure. The concrete specimens were tested at the age of 28 days, 56 days and 6 months. First, the ultimate compressive strength was measured for each batch of concrete, then the concrete cylinders used for modulus of elasticity measurements were loaded from 0 to $40 \%$ of the ultimate strength. The loading rate was $35 \pm 5 \mathrm{psi} / \mathrm{s}(26400 \mathrm{lb} / \mathrm{min}$.). A compressometer with a sensitivity of 0.0001 inches was used to measure the strain of the cylinders in longitudinal direction during loading. The results of the static modulus of elasticity test are discussed in Section 5.2.

\subsubsection{Dynamic Modulus of Elasticity}

The dynamic modulus of elasticity of the non-reinforced concrete specimens was measured on $3 \times 3 \times 11$ in. concrete prisms using the Grindo-Sonic MK4X Instrument. The testing was performed according to the ASTM E 1876 method. This equipment measured the frequencies of the wave generated by an elastic impact when the wave propagated in the specimens in the transverse, longitudinal, and torsional directions. The dynamic modulus of elasticity and the dynamic modulus of rigidity were calculated using the equations provided in the ASTM method. The actual frequency data collected for all samples are given in Appendix B, and the results are discussed in Section 5.3 . 


\subsubsection{Freezing and Thawing Resistance}

ASTM 666 - 92 provides two procedures for the determination of the resistance of concrete to rapidly repeated freezing-and-thawing cycles. In Procedure A, both freezing and thawing of the concrete samples occur in water. In Procedure B, freezing takes place in air and thawing takes place in water. Procedure A is generally considered to be more severe than Procedure B since specimens do not loose water during freezing step and are more likely to suffer damage.

In this project, the Procedure A was used to test the freeze-thaw resistance of the concrete specimens. The weight and fundamental transverse frequency were measured for each specimen after approximately every 30 cycles of freezing and thawing in water. The relative dynamic modulus of elasticity of the concrete samples were calculated based on the measured fundamental transverse frequency following ASTM C666 - 92. The results are discussed in Section 5.5

\subsubsection{Rapid Chloride Ion Penetration (Electrical Conductance)}

This test was performed following the ASTM C 1202-94 testing procedure using an instrument manufactured RLC Instrument Company. At each test age, three concrete slices with a nominal diameter of $95.3 \mathrm{~mm}(3.8 \mathrm{in}$.$) and a thickness of 50.8 \mathrm{~mm}(2 \mathrm{in.})$ were cut from concrete cylinders using a circular saw. After cutting, these slices were saturated (under vacuum) with water and secured within the test cells with silicone sealant. Sodium chloride (reagent grade) was dissolved in distilled water to make a $3 \%$ (by mass) solution, which was used in the test cell connected to the negative pole of the 
dc source. Sodium hydroxide (reagent grade) was also dissolved in distilled water to make $0.3 \mathrm{~N}$ solution that was used in the test cell connected to the positive pole of the dc source. The testing voltage applied was $60 \mathrm{~V} \mathrm{dc}$, and the current and coulombs were recorded automatically every 30 minutes for a period of six hours. The results of this test are discussed in Section 5.6.

\subsubsection{Length Change Measurements}

Length change measurements were performed following the ASTM C 157-89 standard method. A digital comparator with a sensitivity of $0.00254 \mathrm{~mm}$ (0.0001 in.) was used for measuring the length change of concrete beams of $279.4 \mathrm{~mm}$ (11 in.) in length. The length of a reference bar was measured first, followed by measurement of the length of the specimens. The initial length of the specimen was measured just after the specimen was de-molded (one day after casting). The length change at any age was calculated as follows:

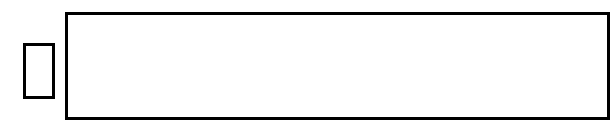

where:

$\Delta \mathrm{L}_{\mathrm{x}}=$ relative length change of specimen at any age, $\%$

$\mathrm{CRD}=$ difference between the comparator reading of the specimen and the reference bar at any age

$\mathrm{G}=$ the gage length $(254 \mathrm{~mm}$ or 10 inches $)$

The results of this test are discussed in Section 5.4 . 


\subsubsection{Chloride Profile}

This test was performed in order to determine the chloride content at various depths of a concrete specimen. Concrete powder samples were taken from both original reinforced concrete slabs and the additional slabs made from repair materials. Concrete powder samples were taken at five different depths. The first sample was taken at the depth of 0-15.0 $\mathrm{mm}$. The additional samples were collected at $15.0 \mathrm{~mm}$ increments. The reinforced concrete slabs were exposed to wetting-drying cycles while being exposed to a $5 \%$ sodium chloride solution. The repair slabs were ponded with $10 \%$ sodium chloride solution.

A handheld rotary hammer drill was used to drill holes into the concrete to obtain the powder concrete samples. Figure 4.13 schematically shows this equipment. A special hollow-drill bit was hooked up to a vacuum pump through a filter. As the drill penetrated the concrete, the resulting powder was collected in the filter. A depth indicator attached to the body of the drill to determine the depth of the hole from the surface of the specimen.

Concrete powder samples from the original reinforced concrete slabs were collected after $12,24,28,34$, and 40 weeks of ponding to determine the chloride content. For repair concrete mixes, the concrete powder samples were collected after 40 weeks of ponding only. The procedure involved removing concrete (by drilling) in $15.0 \mathrm{~mm}(0.59$ in.) increments and collecting the powder from the filter. The Materials and Testing Division of the Indiana Department of Transportation analyzed the powder samples following the AASHTO Standard Test T260 method. This method determines the total 
chloride ion content of the concrete powder sample. The results were shown in Section 5.7.

\subsubsection{Electrochemical Measurements}

Electrochemical measurements performed in the course of this study included the half-cell potential measurements, polarization resistance measurements, and electrochemical impedance spectroscopy (EIS) measurements. The details of instrumentation, individual test setups, and testing procedures are presented in the following sections.

\subsubsection{Half-Cell Potential Measurement}

Half-cell potentials were measured in the laboratory by following the procedure described in ASTM C 876-87. A copper-copper sulfate half-cell electrode was used as a reference electrode. A digital voltmeter with an input impedance of $10 \mathrm{M} \Omega$ and accuracy of $1 \mathrm{mV}(0.001 \mathrm{~V})$ was used to monitor the potential. The schematic of the set-up for the half-cell potential measurement is shown in Figure 4.14. The top mat of the reinforcement was connected to the positive pole $(+)$ of the voltmeter, while the reference electrode was connected to the negative pole (-).

The potential was measured at twenty different points on the surface of each slab as shown in Figure 4.15. These points were located along the longitudinal steel bars and were spaced at 127-mm (5-in.) intervals. Half-cell potentials were measured weekly at the end of a wetting phase (after the salt solution was removed), but before the start of a 
heating cycle. The results of the half-cell potential measurements are presented in Section 6.1

\subsubsection{Polarization Resistance Measurement}

Polarization resistance measurement as well as electrochemical impedance spectroscopy measurements were performed using a computer-based CMS 100 Electrochemical Impedance Spectroscopy System from Gamry Instruments Inc. (Willow Grove, Pennsylvania, USA). The schematic of electrical connections used for

polarization resistance measurement is shown in Figure 4.16 The electrical cable used to perform these measurements had five wires with different colors. The white wire was connected to the reference electrode, the blue wire was connected to the top steel mat, the red wire was connected to the bottom steel mat, and two black wires were connected together, but were not used.

Before starting the polarization resistance measurement, used to measure the corrosion potential. Once the corrosion potential was known, the initial polarization potential was set at $0.02 \mathrm{~V}$ below corrosion potential, and the final polarization potential was $0.02 \mathrm{~V}$ above the corrosion potential. The polarization potential was varied within this range at a rate of $0.5 \mathrm{mV} / \mathrm{s}$.

\subsubsection{Electrochemical Impedance Spectroscopy}

The Gamry CMS 100 Electrochemical Impedance Spectroscopy System was also used for impedance spectroscopy measurement. This computer-based system also 
included software for data analysis. The electrical impedance was measured using the same cable that was used for polarization resistance measurement (see Figure 4.16). The SR 810 Amplifier (made by Stanford Research Systems, Inc., Sunnyvale, California, USA) was used as a lock-in amplifier. The initial frequency of the potentiostat was set at $5,000 \mathrm{~Hz}$, and the final frequency was set to $2 \times 10^{-5} \mathrm{~Hz}$. The measurements were performed using $10 \mathrm{mV}$ ac voltage.

The equivalent circuit used in this project for EIS data analysis is shown in Figure

4.17 This equivalent circuit consisted of a resistor $\left(\mathrm{R}_{\mathrm{p}}\right)$ in parallel with a constant phase element (CPE). These two components were connected (in series) with a resistor $\left(\mathrm{R}_{\mathrm{c}}\right)$. In this equivalent circuit, the resistor $\mathrm{R}_{\mathrm{p}}$ represents the polarization resistance of the corrosion cell, CPE is introduced to account for the shape of the depressed complex plot, and $\mathrm{R}_{\mathrm{c}}$ represents the resistance of concrete matrix.

\section{3 $\underline{\text { Repair of Reinforced Concrete Slabs }}$}

All 24 reinforced concrete slabs were repaired after the steel in the concrete had corroded. According to ASTM C 876-87, when the half-cell potential is below $-350 \mathrm{mV}$ (as measured versus saturated copper-copper sulfate reference electrode), the probability of steel corrosion is above $90 \%$. At this stage, rust stains may be present on the surface of the concrete, as shown in Figure 4.18. In this project, the slabs were repaired when half-cell potential values were below $-450 \mathrm{mV}$ versus sulfate reference electrode potential (SCE).

The repair procedure used was as follows: 
1. A portion of concrete was removed from the middle of the slab (as shown in Figure 4.19 with a jackhammer, over the full depth.

2. The longitudinal reinforcing bars were removed and cleaned by sand blasting. The transverse reinforcing bars were also cleaned by sandblasting but were not removed from the slabs.

3. Slabs were placed in wooden molds and the longitudinal bars were reattached.

4. The vertical inside surfaces of the remaining portions of the slab were wetted with water.

5. Repair concrete was cast in the cavity between the remaining portions of the slabs. The thickness of the repair concrete was of the same thickness as of the existing concrete (full-depth repair).

6. Wet burlap was placed on the slabs after the concrete surface was finished.

7. Repaired slabs were cured by spraying burlap with water for 7 days ( 28 days for slabs repaired by fly ash concrete).

8. Slabs were de-molded.

9. Plastic dikes were placed on the surface of the slabs; the exposed ends of the reinforcing bars were re-connected with wires.

10. Slabs were exposed to repeated cycles of wetting and drying for six months. 
Table 4.1 Physical characteristics of portland cement.

\begin{tabular}{|l|l|}
\hline \multicolumn{1}{|c|}{ Property } & \multicolumn{1}{|c|}{ Data } \\
\hline Blaine Fineness (cm $\left.{ }^{2} / \mathrm{g}\right)$ & 3473 \\
\hline Fineness (\#325, \% passing) & 89.57 \\
\hline Soundness: Autoclave Expansion (\%) & 0.019 \\
\hline Time of Setting (Vicat) & 103 \\
Initial Setting (min.) & 194 \\
Final Setting (min.) & 113 \\
\hline $\begin{array}{l}\text { Time of Setting (Gilmore) } \\
\text { Initial Setting (min.) } \\
\text { Final Setting (min.) }\end{array}$ & 219 \\
\hline Compressive Strength MPa (psi) & $13.8(2003)$ \\
1-day & $22.6(3270)$ \\
3-day & $32.1(4658)$ \\
7-day & $42.5(6164)$ \\
28-day & \\
\hline
\end{tabular}


Table 4.2 Chemical composition of portland cement.

\begin{tabular}{|c|c|}
\hline Composition & Percentage \\
\hline $\mathrm{CaO}$ & 64.72 \\
\hline $\mathrm{SiO}_{2}$ & 20.93 \\
\hline $\mathrm{Al}_{2} \mathrm{O}_{3}$ & 5.24 \\
\hline $\mathrm{Fe}_{2} \mathrm{O}_{3}$ & 2.49 \\
\hline $\mathrm{MgO} \mathrm{O}$ & 2.22 \\
\hline $\mathrm{SO}_{3}$ & 2.34 \\
\hline $\mathrm{Na}_{2} \mathrm{O}$ & 0.08 \\
\hline $\mathrm{K}_{2} \mathrm{O}$ & 0.58 \\
\hline $\mathrm{TiO}_{2}$ & 0.36 \\
\hline $\mathrm{P}_{2} \mathrm{O}_{5}$ & 0.11 \\
\hline $\mathrm{Mn}_{2} \mathrm{O}_{3}$ & 0.04 \\
\hline $\mathrm{SrO}$ & 0.09 \\
\hline $\mathrm{Ignition} \mathrm{Loss}, \%$ & 1.04 \\
\hline $\mathrm{Free} \mathrm{CaO}_{3}$ & 0.34 \\
\hline $\mathrm{C}_{3} \mathrm{~S}^{*}$ & 58.93 \\
\hline $\mathrm{C}_{2} \mathrm{~S}^{*}$ & 15.55 \\
\hline $\mathrm{C}_{3} \mathrm{~A}$ & 9.68 \\
\hline $\mathrm{C}_{4} \mathrm{AF}$ & 7.58 \\
\hline $\mathrm{CaSO}_{4}$ & 3.98 \\
\hline Equivalent $\mathrm{Na}$ & 0.46 \\
\hline &
\end{tabular}

* Calculated using Bogue equations. 
Table 4.3 Composition of silica fume.

\begin{tabular}{|c|c|}
\hline Oxide & Percentage \\
\hline $\mathrm{CaO}$ & 0.19 \\
\hline $\mathrm{SiO}_{2}$ & 98.25 \\
\hline $\mathrm{Al}_{2} \mathrm{O}_{3}$ & 0.36 \\
\hline $\mathrm{Fe}_{2} \mathrm{O}_{3}$ & 0.21 \\
\hline $\mathrm{MgO}$ & 0.00 \\
\hline $\mathrm{SO}_{3}$ & 0.62 \\
\hline $\mathrm{Na}_{2} \mathrm{O}$ & 0.28 \\
\hline $\mathrm{K}_{2} \mathrm{O}$ & 0.14 \\
\hline $\mathrm{TiO}_{2}$ & 0.00 \\
\hline $\mathrm{P}_{2} \mathrm{O}_{5}$ & 0.00 \\
\hline $\mathrm{Mn}_{2} \mathrm{O}_{3}$ & 0.00 \\
\hline & \\
\hline
\end{tabular}


Table 4.4 Chemical analysis of fly ash.

\begin{tabular}{|c|c|}
\hline Items & Amount (\%) \\
\hline $\mathrm{SiO}_{2}$ & 35.00 \\
\hline $\mathrm{Al}_{2} \mathrm{O}_{3}$ & 19.30 \\
\hline $\mathrm{Fe}_{2} \mathrm{O}_{3}$ & 5.27 \\
\hline $\mathrm{CaO}$ & 59.57 \\
\hline $\mathrm{MgO}_{2}+\mathrm{Al}_{2} \mathrm{O}_{3}+\mathrm{Fe}_{2} \mathrm{O}_{3}$ & 25.80 \\
\hline $\mathrm{SO}_{3}$ & 5.40 \\
\hline Moisture Content & 2.06 \\
\hline Loss on Ignition & 0.05 \\
\hline Variation, \% points from average & 0.25 \\
\hline Total Alkalis & 0.01 \\
\hline $\mathrm{Na}_{2} \mathrm{O}$ & \\
\hline $\mathrm{K}_{2} \mathrm{O}$ & 1.77 \\
\hline Equivalent Na${ }_{2} \mathrm{O}$ & 0.36 \\
\hline Analysis Total & 2.01 \\
\hline Available Alkalis & 95.3 \\
\hline $\mathrm{Na}_{2} \mathrm{O}$ & \\
\hline $\mathrm{K}_{2} \mathrm{O}$ & 0.92 \\
\hline Equivalent Na & 0.13 \\
\hline
\end{tabular}


Table 4.5 Physical analysis of fly ash.

\begin{tabular}{|c|c|}
\hline Items & Amount (\%) \\
\hline Fineness, \#325 sieve residue & 16.7 \\
Variation, \% points from average & 0.2 \\
\hline Density, g/cm $\mathrm{cm}^{3}$ & 2.77 \\
Variation, \% points from average & 0.36 \\
\hline Strength activity index & \\
With Portland cement & 100.2 \\
At 7 days, \% of control & 101.1 \\
At 28 days, \% of control & 95.0 \\
\hline Water requirement, \% of control & 0.09 \\
\hline Soundness, autoclave expansion or & \\
contraction, \% & \\
\hline
\end{tabular}


Table 4.6 Mix composition and properties of INDOT Class C concrete

\begin{tabular}{cc}
\hline Gravel & $1097 \mathrm{~kg} / \mathrm{m}^{3}\left(1850 \mathrm{lb} / \mathrm{yd}^{3}\right)$ \\
Sand & $725 \mathrm{~kg} / \mathrm{m}^{3}\left(1222 \mathrm{lb} / \mathrm{yd}^{3}\right)$ \\
Cement & $390 \mathrm{~kg} / \mathrm{m}^{3}\left(658 \mathrm{lb} / \mathrm{yd}^{3}\right)$ \\
Water & $173 \mathrm{~kg} / \mathrm{m}^{3}\left(291 \mathrm{lb} / \mathrm{yd}^{3}\right)$ \\
w/c & 0.443 \\
Air Content & $3.5 \%$ \\
Unit Weight & $2420 \mathrm{~kg} / \mathrm{cm}^{3}\left(151 \mathrm{lb} / \mathrm{ft}^{3}\right)$ \\
Slump & $82.6 \mathrm{~mm}^{3}(3.25 \mathrm{in})$. \\
\hline
\end{tabular}




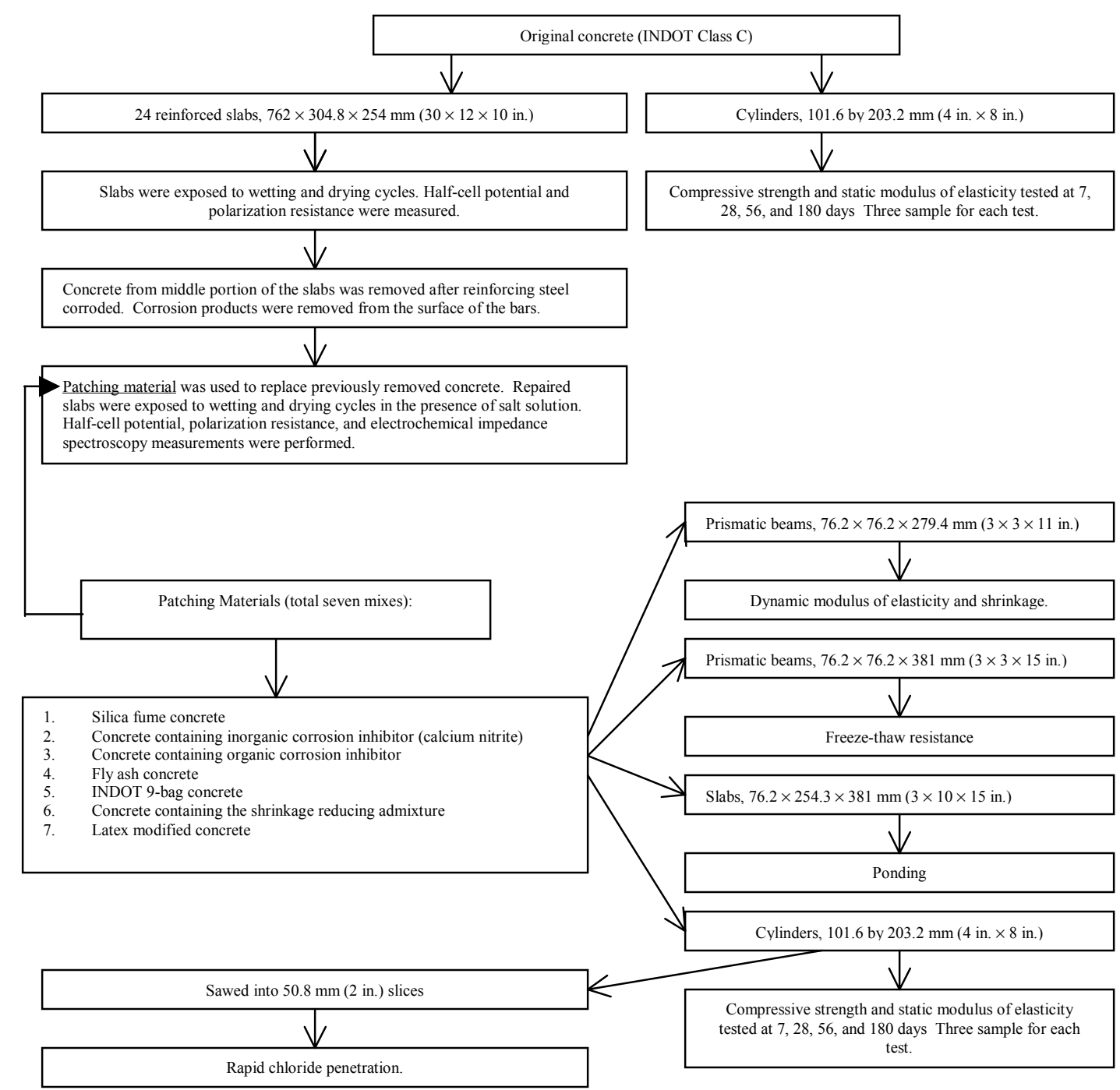

Figure 4.1 Flowchart of the test plan. 


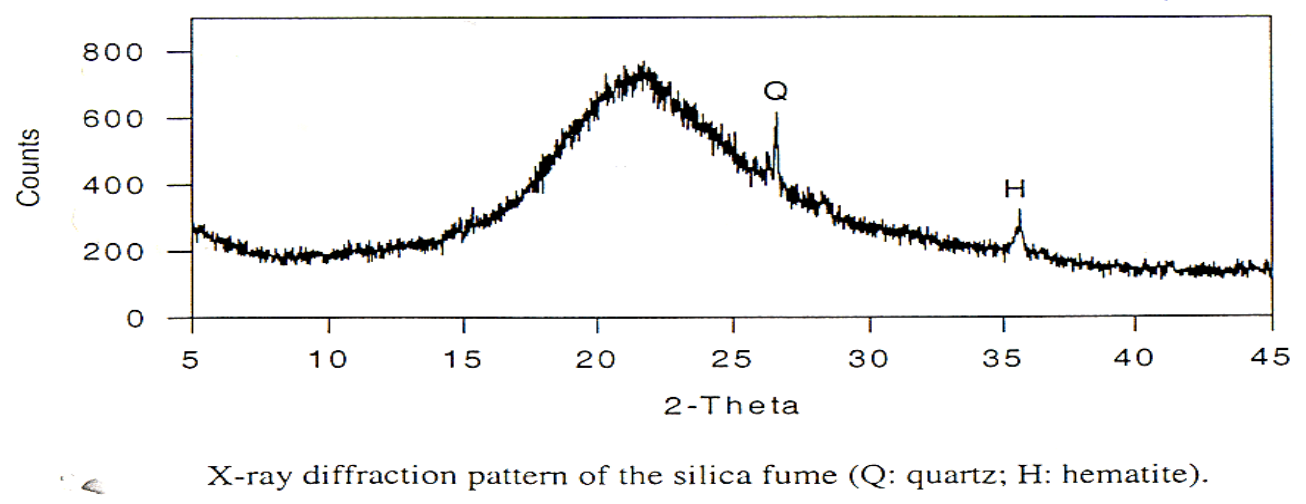

Figure 4.2 X-ray diffraction pattern of the silica fume (Q: quartz; H: hematite).

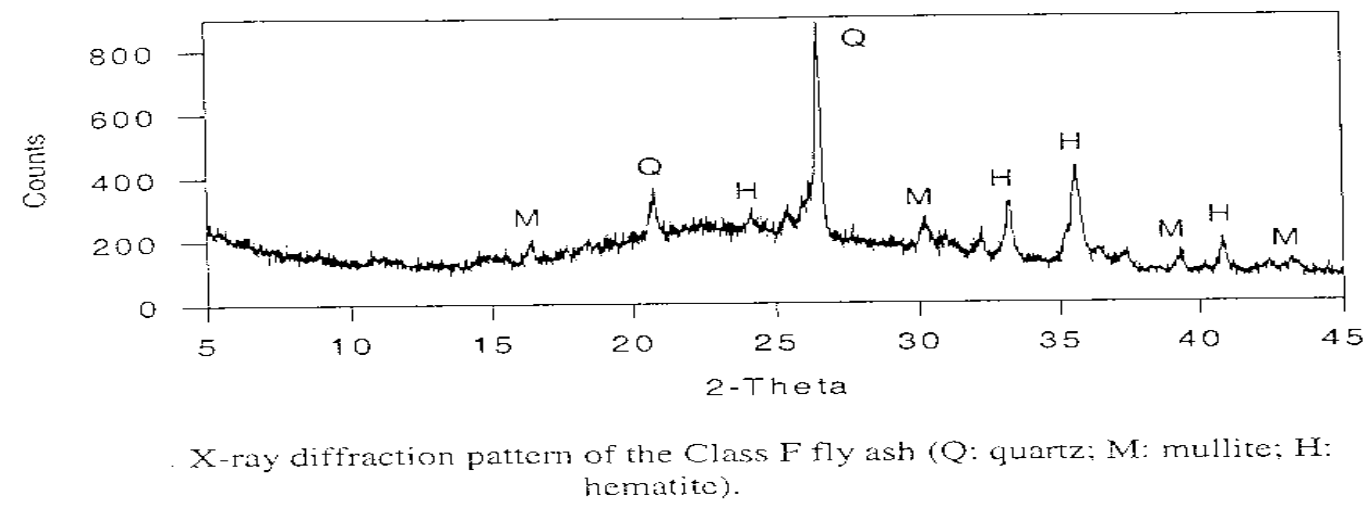

Figure 4.3 X-ray diffraction pattern of the fly ash (Q: quartz; M: mullite; H: hematite). 


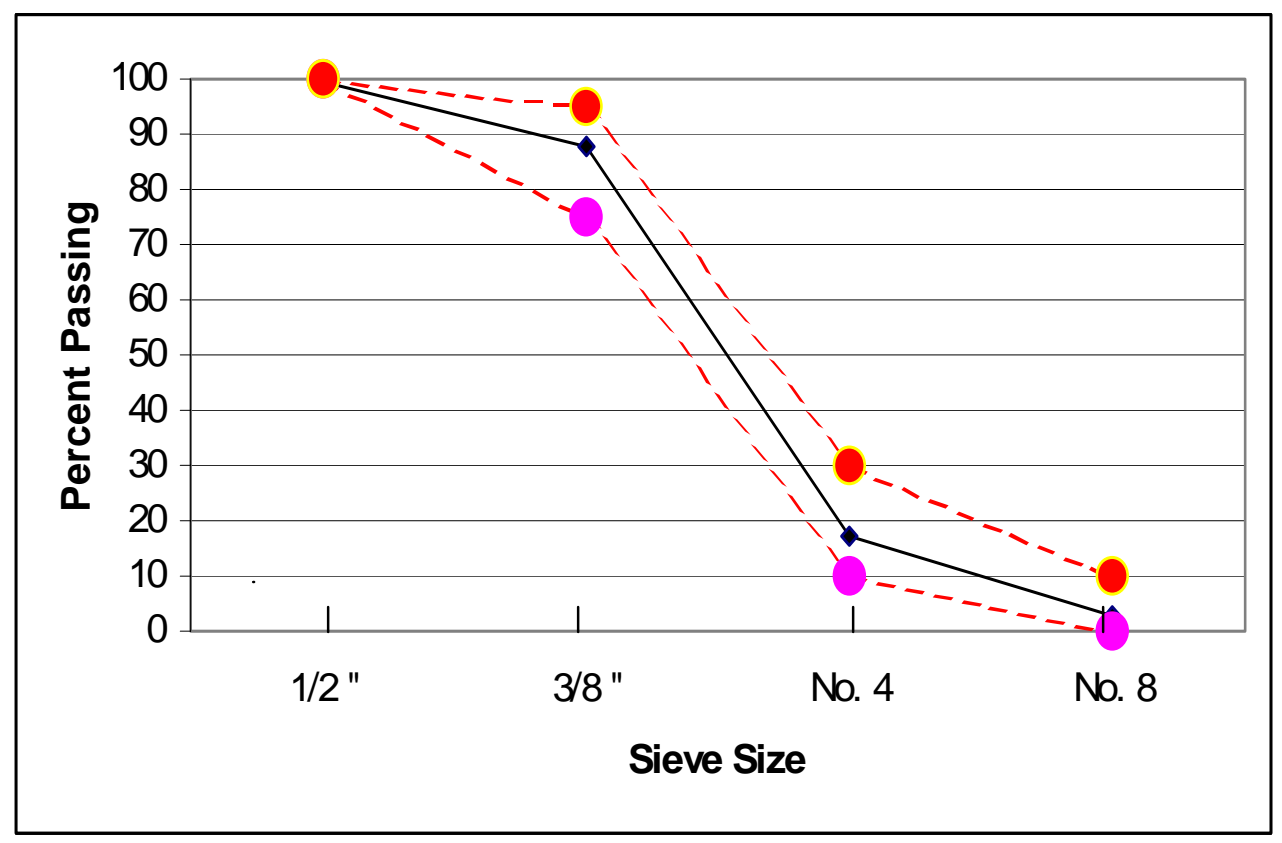

Figure 4.4 Sieve analysis of No. 11 coarse aggregate. 
INDOT Specification

Test Data

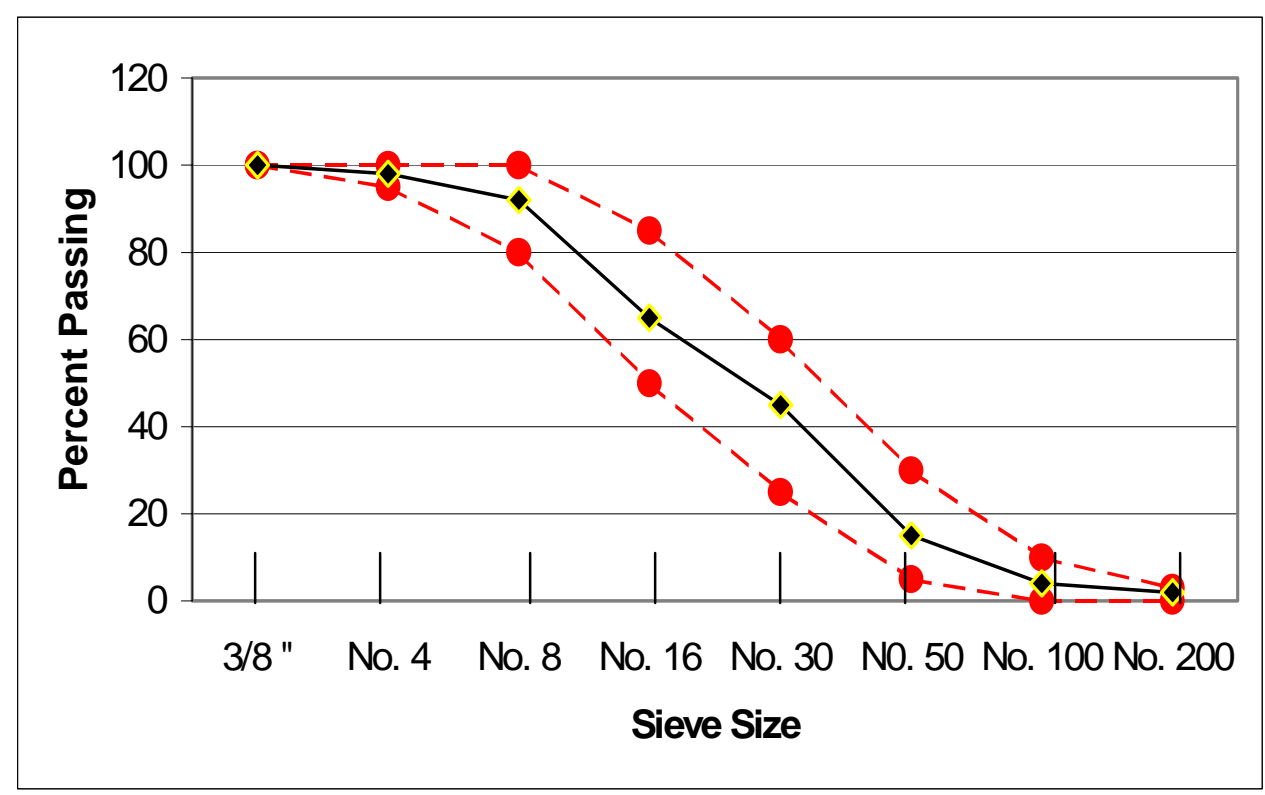

Figure 4.5 Sieve analysis of natural sand. 


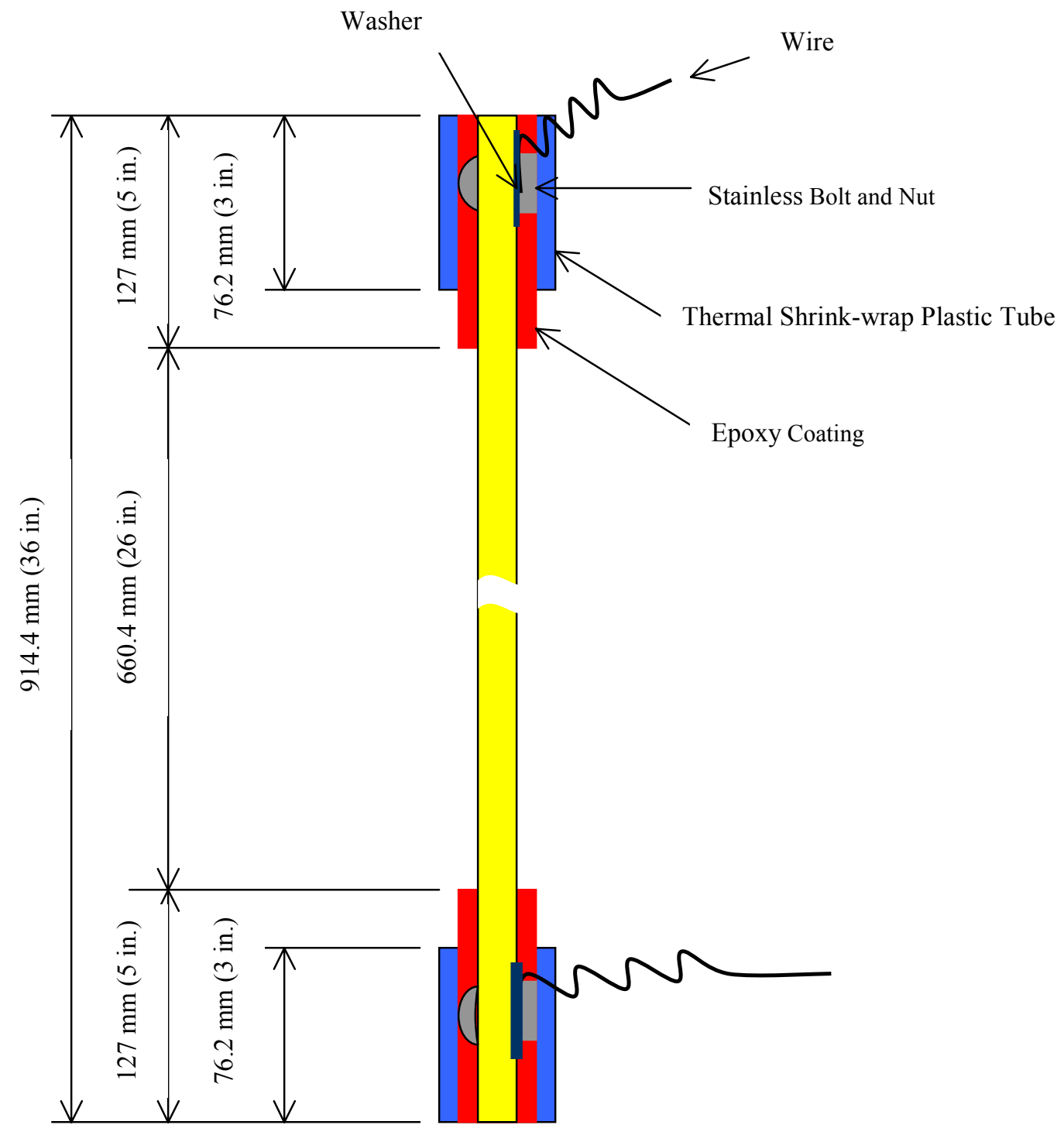

Figure 4.6 Schematic illustration of the corrosion protection system and the electrical wire at the ends of a reinforcing steel bar. 

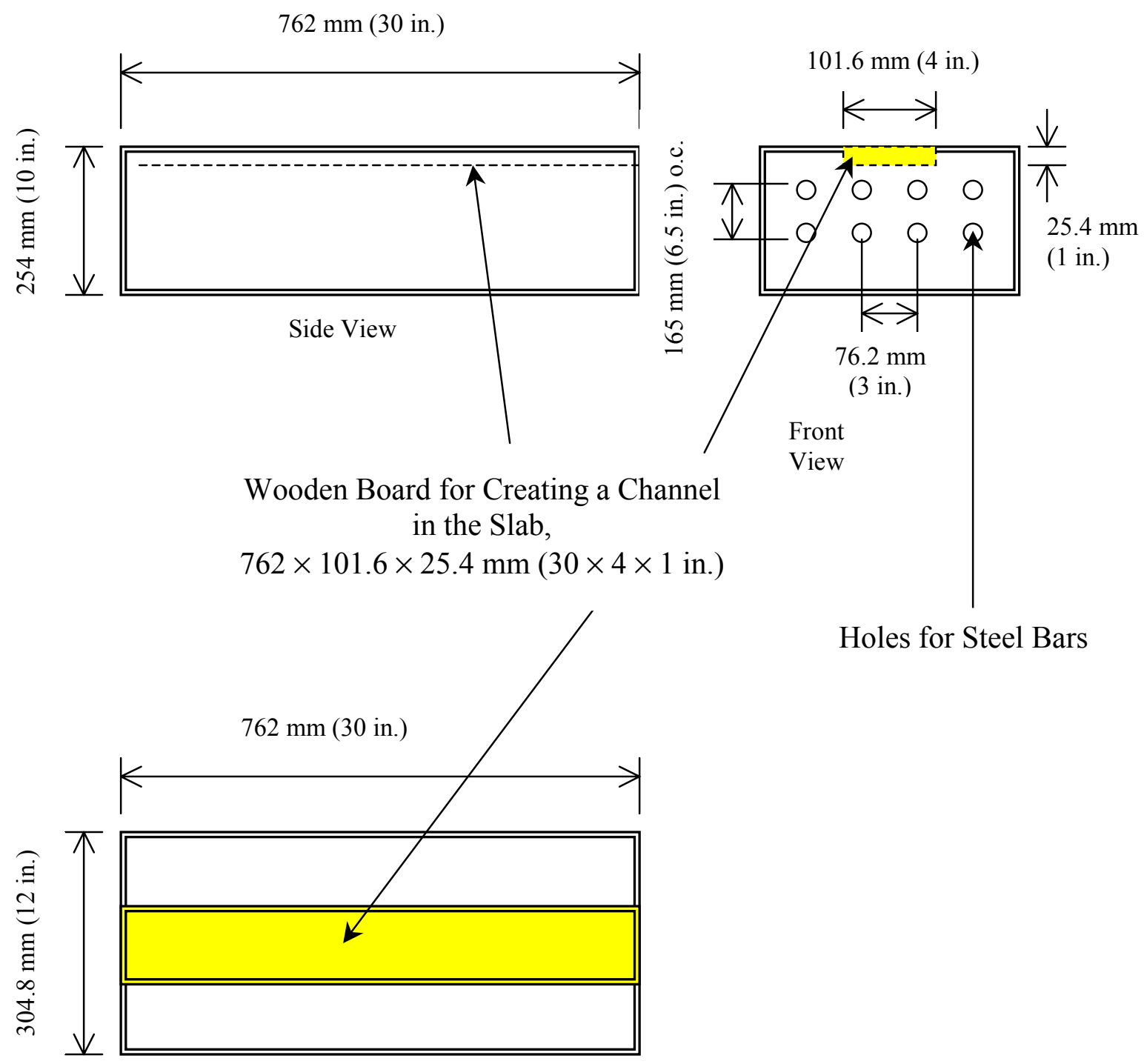

Holes for Steel Bars

Top View

Figure 4.7 Configuration of a wooden mold used for fabricating reinforced concrete slabs. 


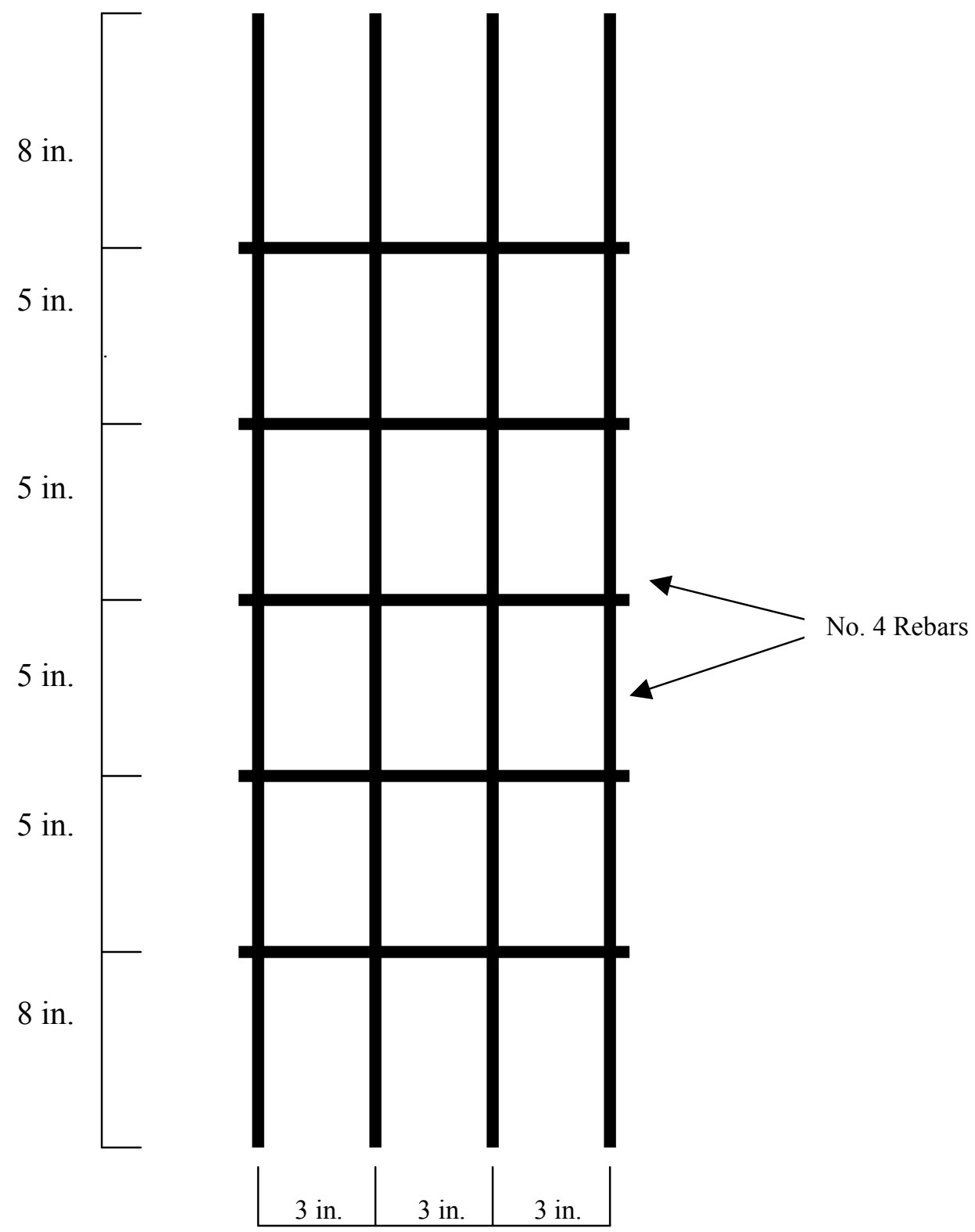

Figure 4.8 Steel mat for the reinforced concrete slabs. 


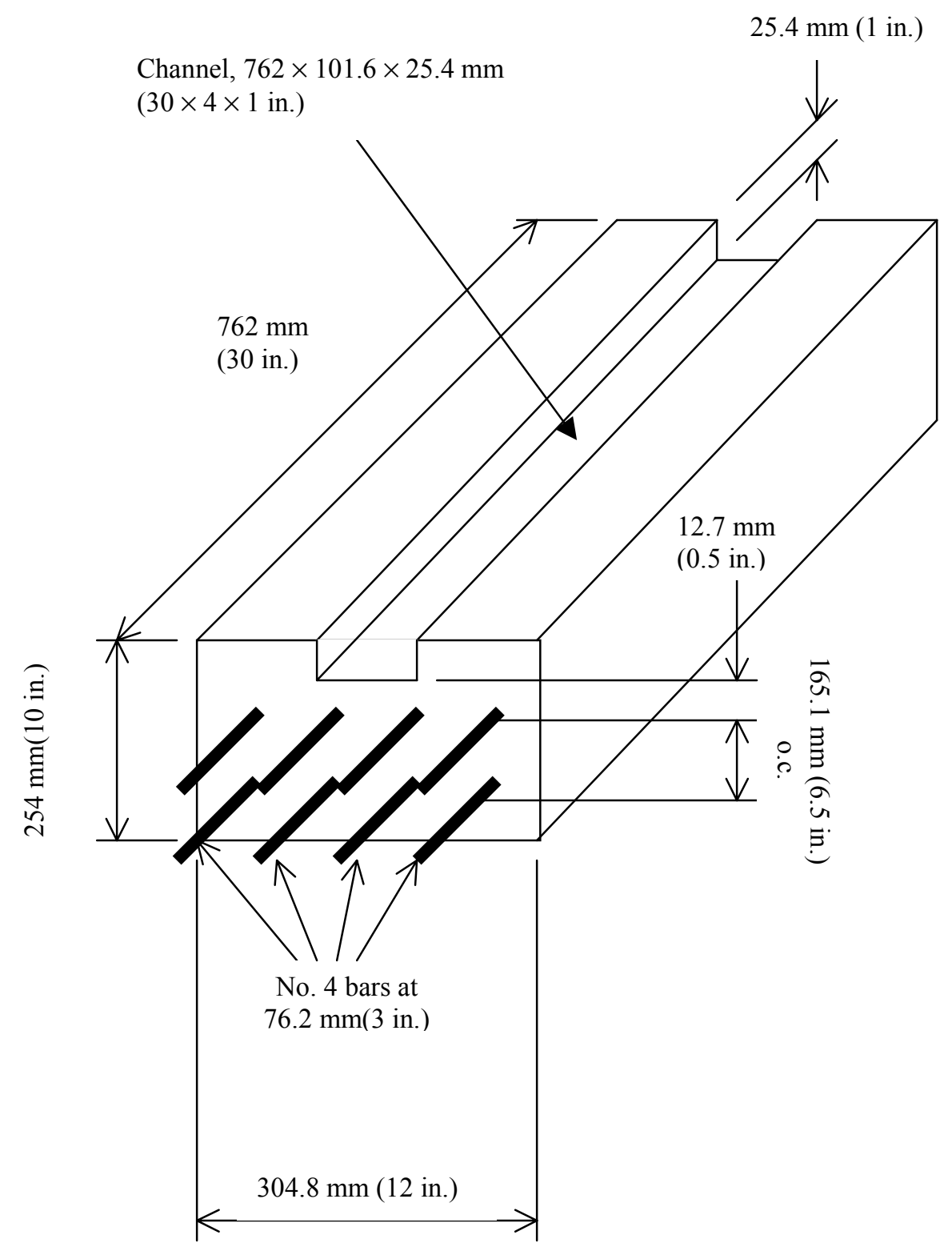

Figure 4.9 Schematic of reinforced concrete slab. 


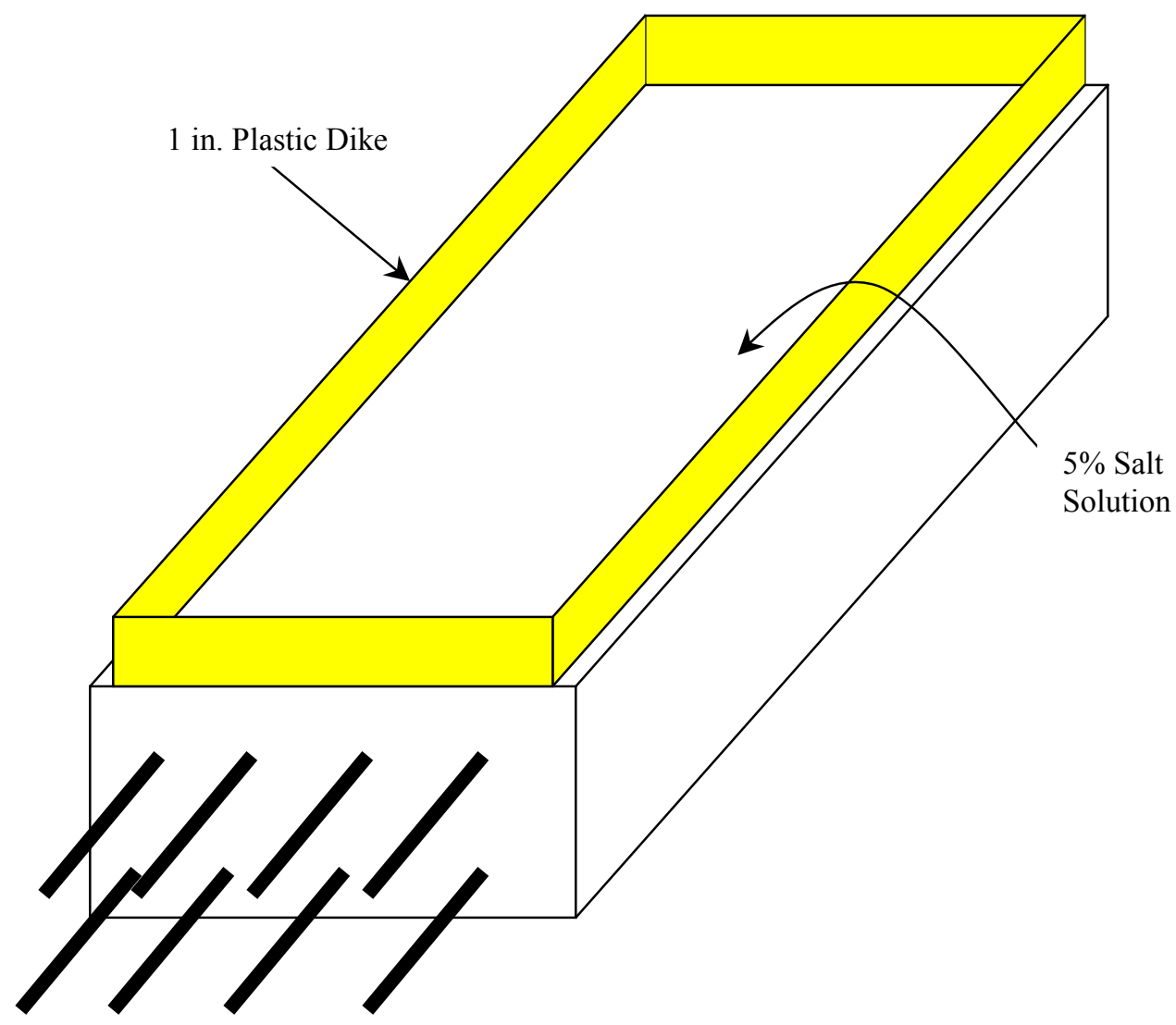

Figure 4.10 Slab with a plastic dike on it. 


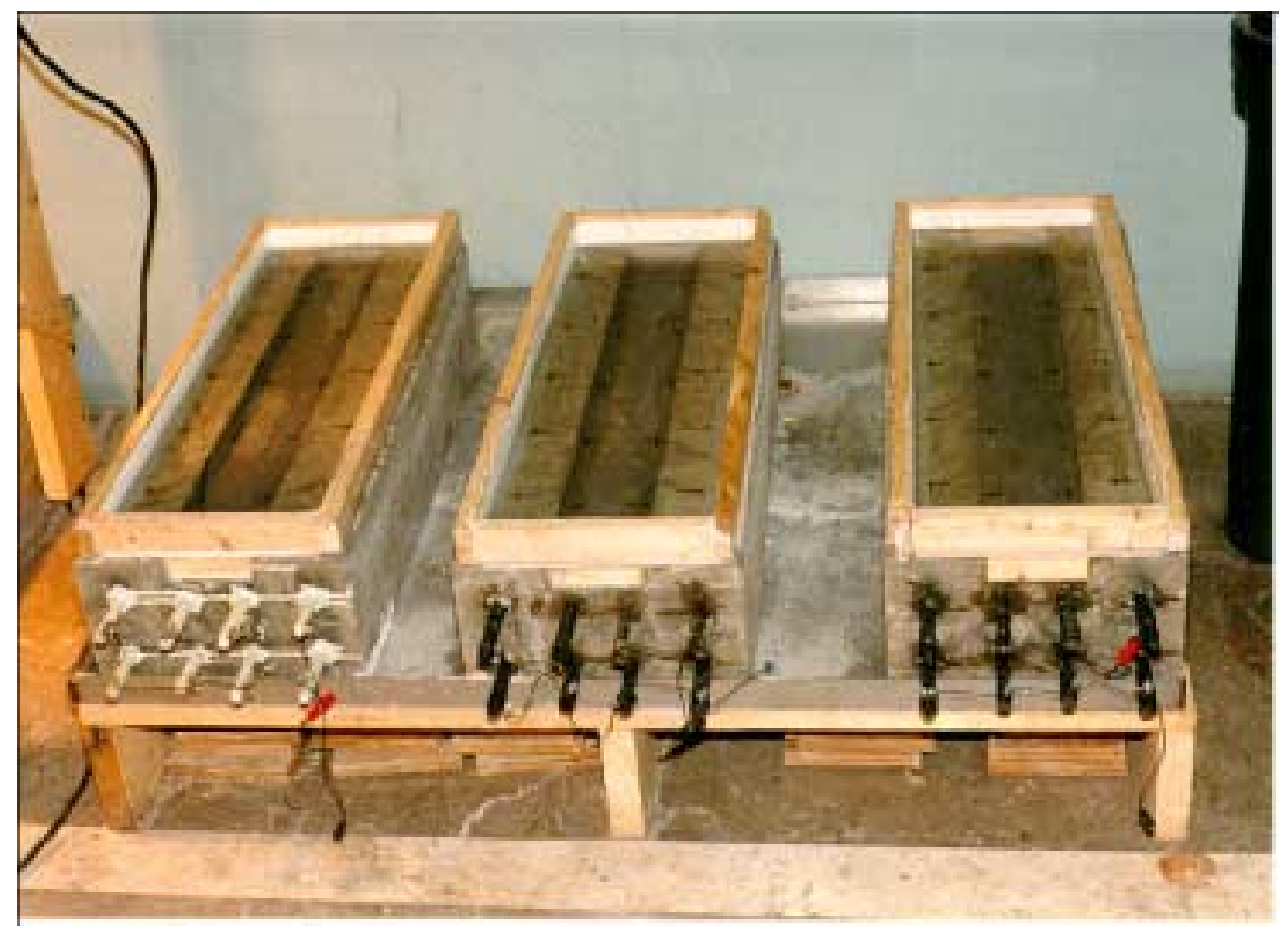

Figure 4.11 Slabs are ponded with salt water during wetting cycles. 


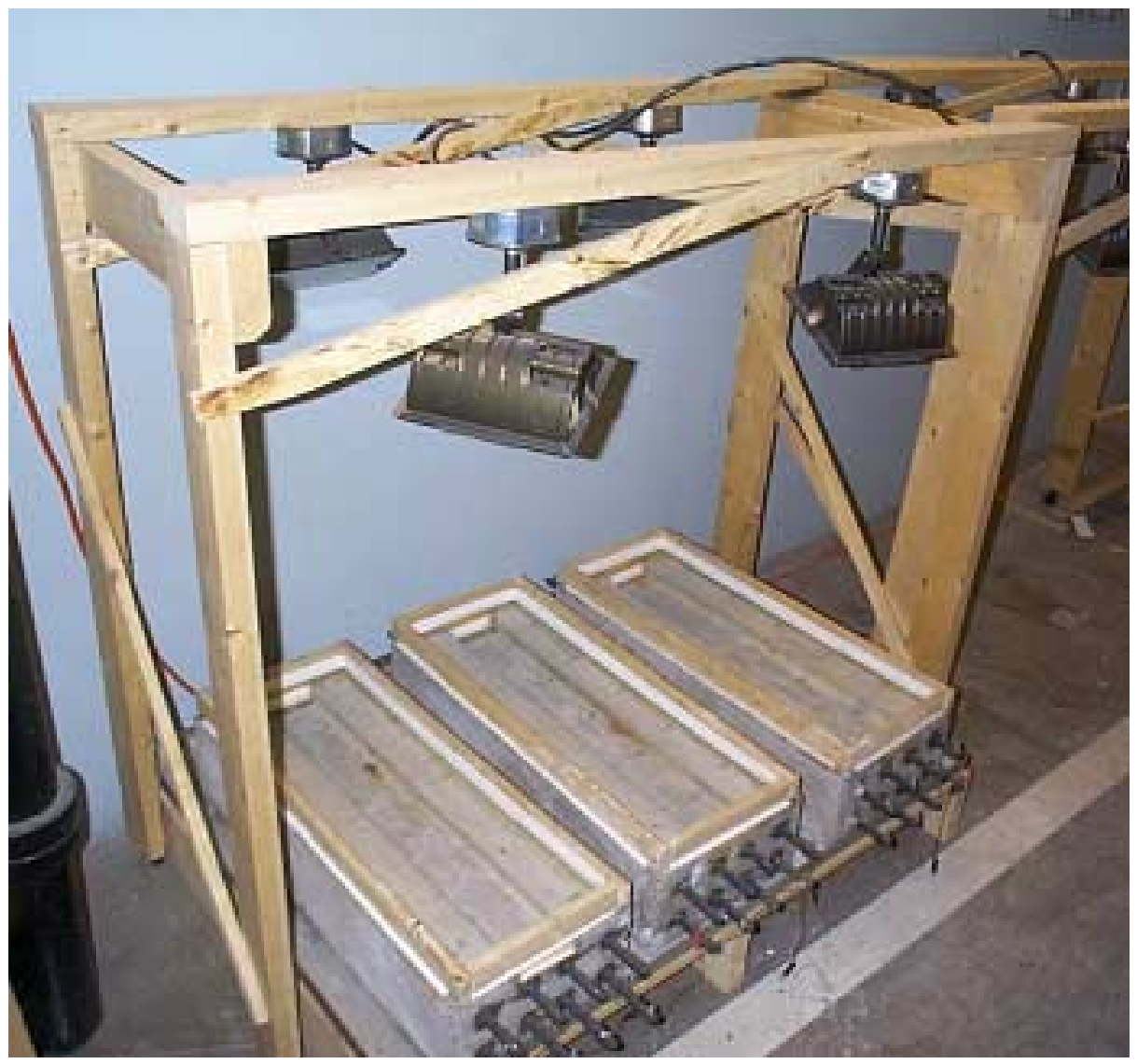

Figure 4.12 Slab is heated by halogen lamps during drying cycles. 


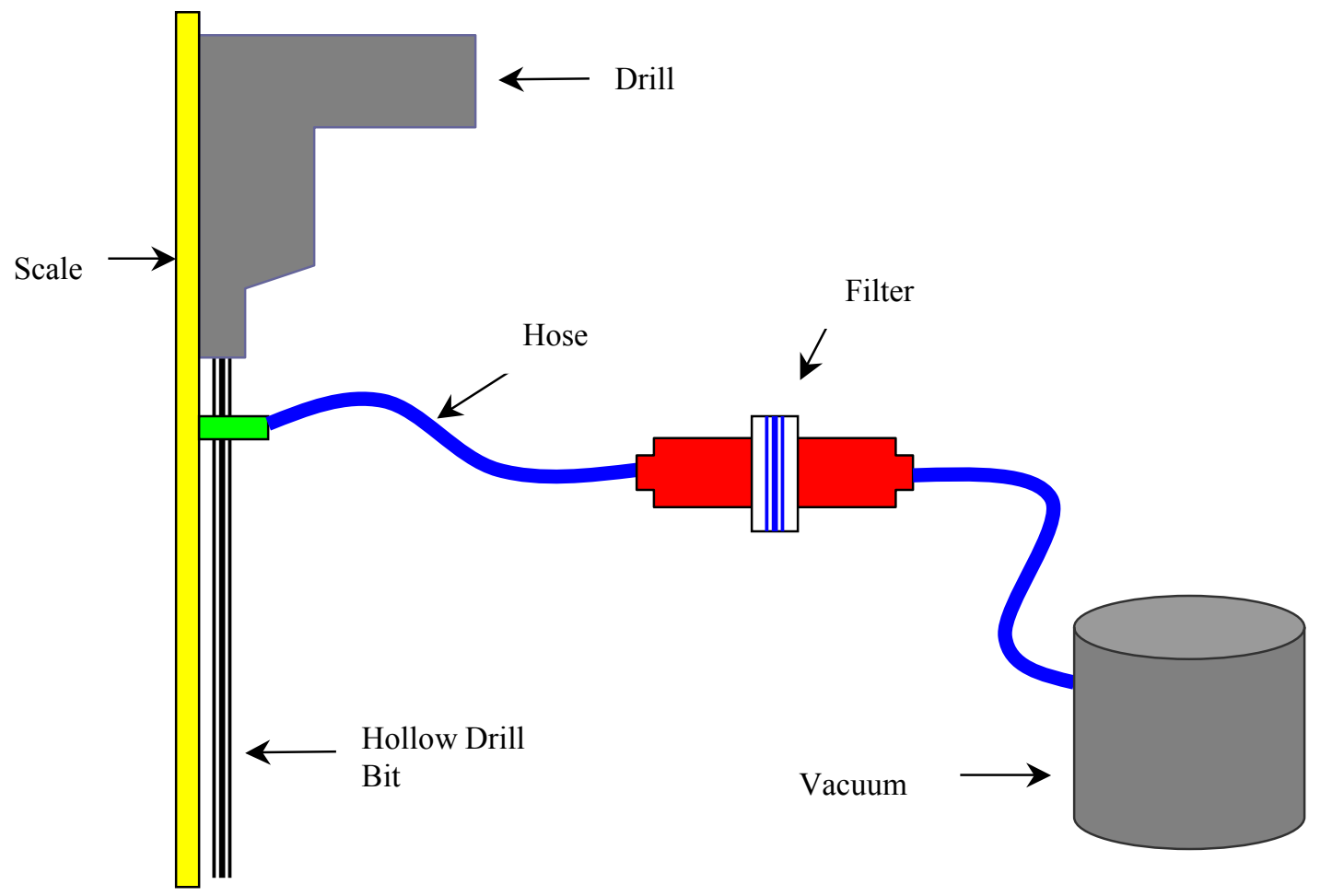

Figure 4.13 Setup for collection of powdered concrete sample for chloride profile determination. 


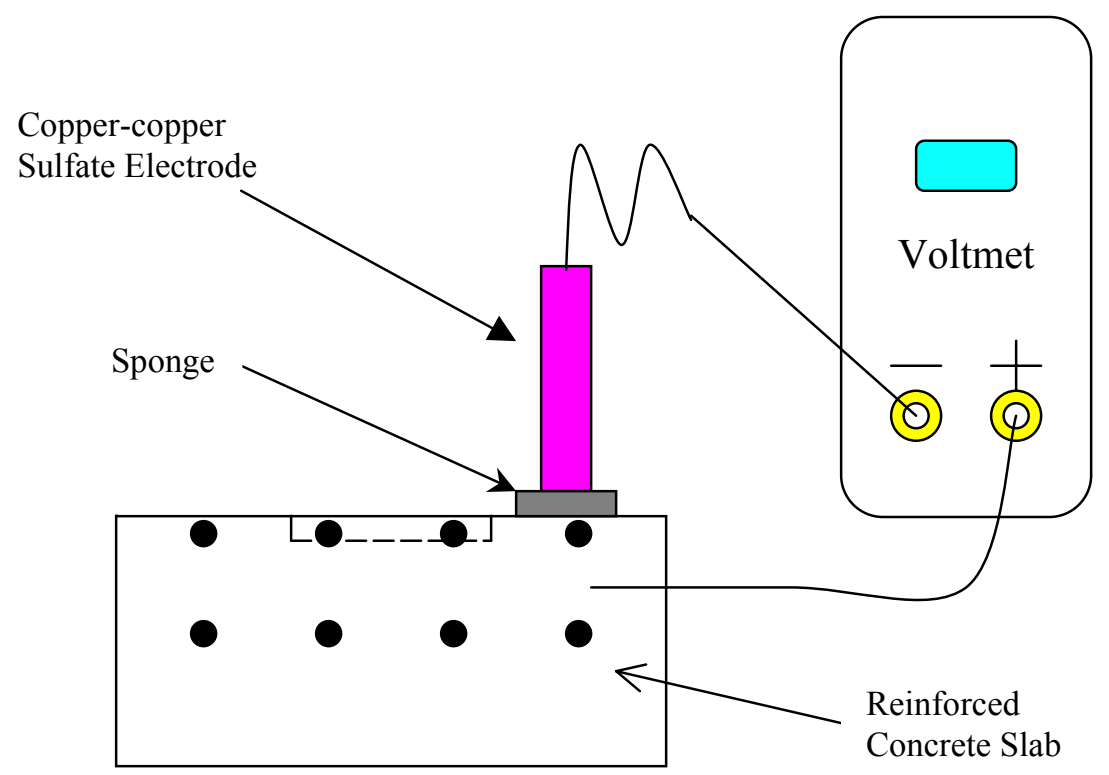

Figure 4.14 Setup for half-cell potential measurement. 


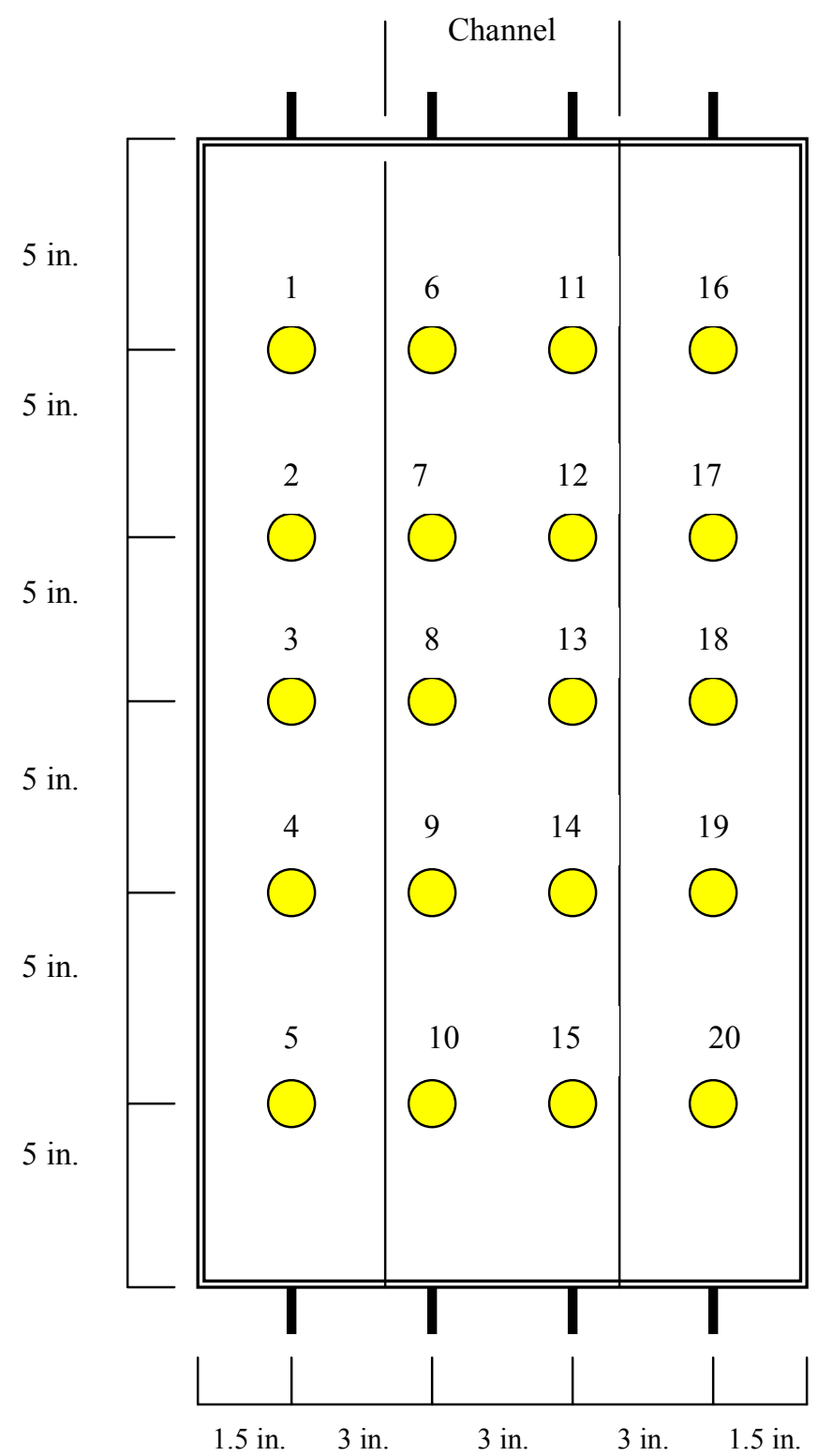

Figure 4.15 Locations of half-cell potential measurements (Numbers indicate measurement sequence). 


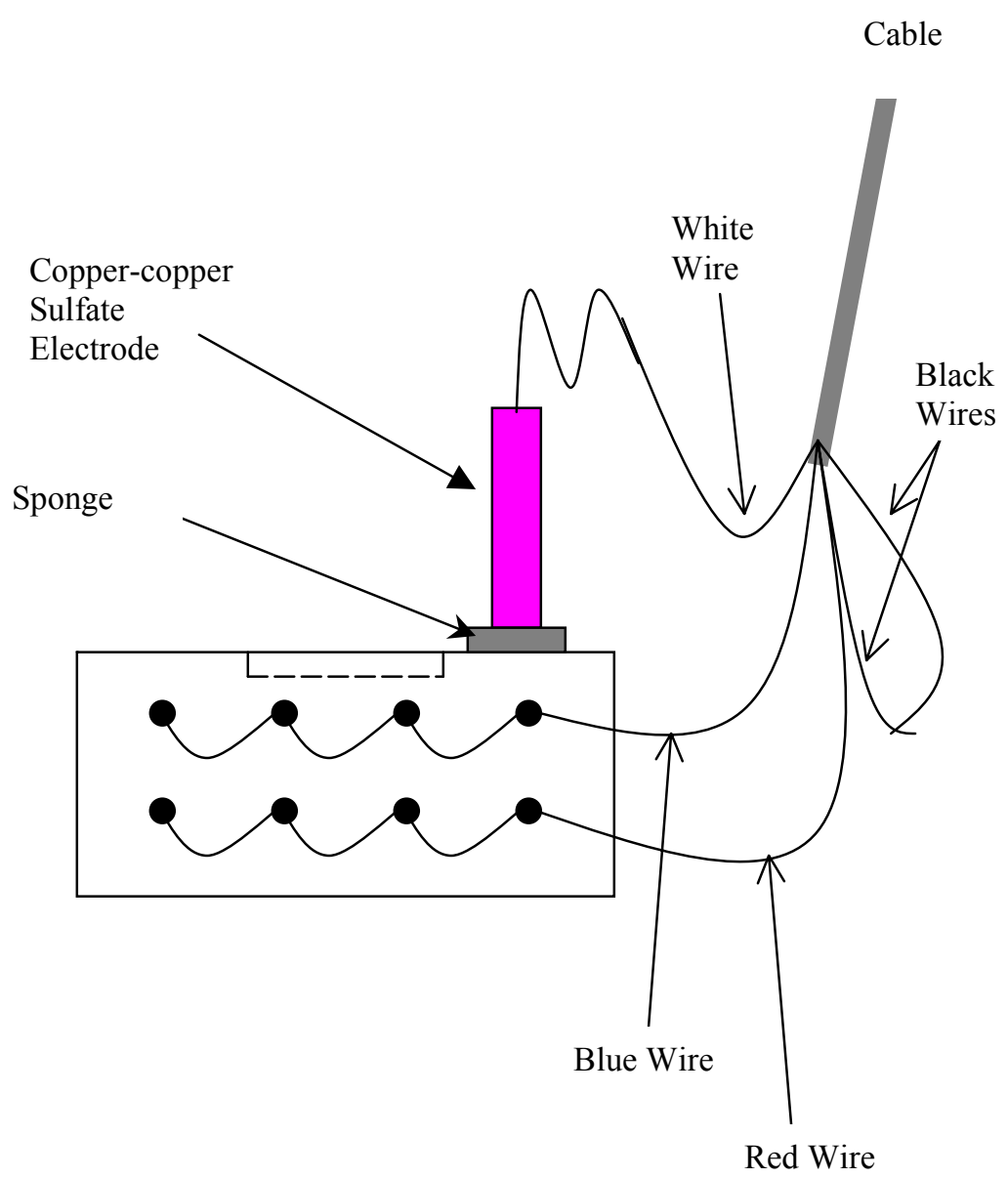

Figure 4.16 Schematic of electrical connections used for polarization resistance and impedance measurements 


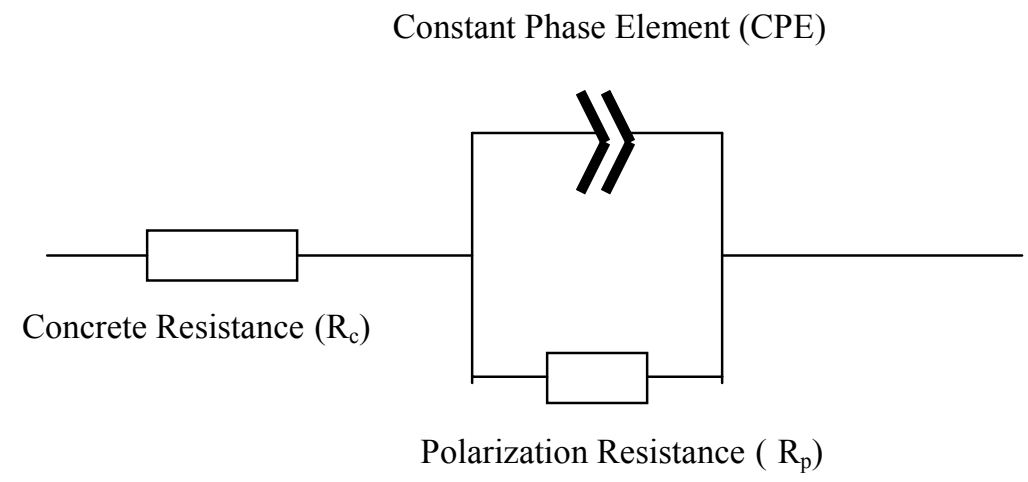

Figure 4.17 Equivalent circuit used for analysis of EIS data. 


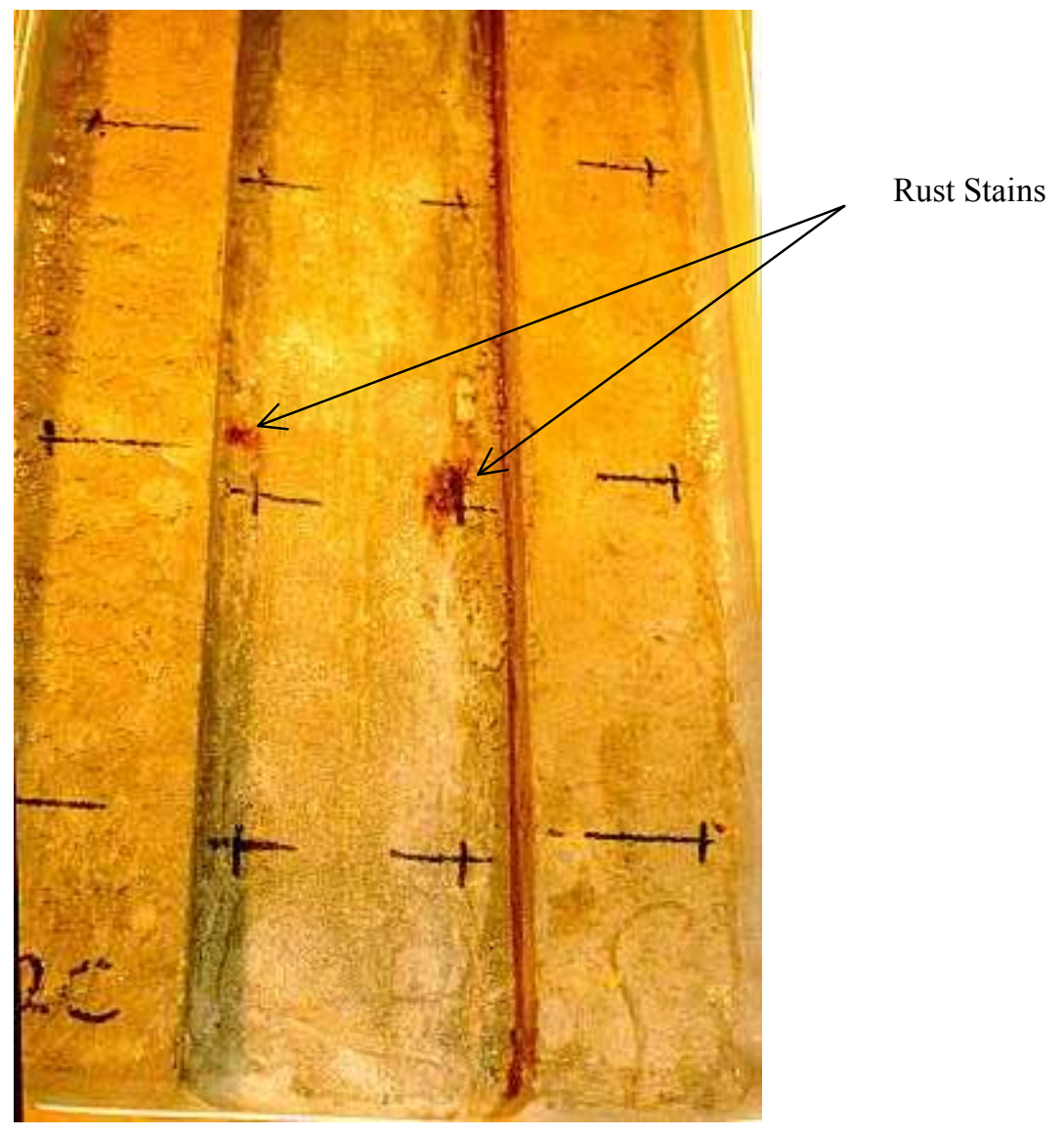

Figure 4.18 Rust stains on the concrete surface. 


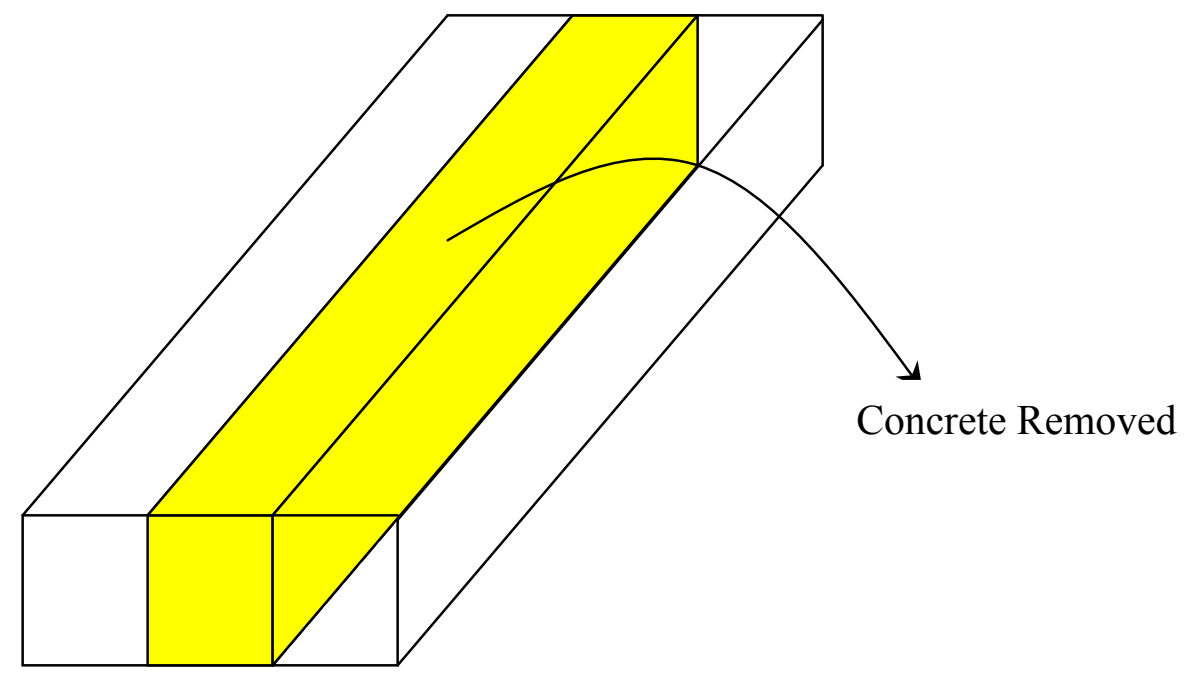

Figure 4.19 Preparation of concrete slab for repairs. 
CHAPTER 5 MECHANICAL AND PHYSICAL PROPERTIES OF REPAIR CONCRETE TEST RESULTS

Reinforced concrete $(\mathrm{RC})$ is a composite material that is composed of plain concrete matrix and steel bars embedded in the matrix. The overall performance of areinforced concrete member is controlled by both the concrete, which can develop a high compressive strength but is weak in tension, and the reinforcement that provides the needed tensile capacity.

For concrete, some mechanical properties commonly considered in designing of RC structures include compressive strength and modulus of elasticity. Durability is another important property for reinforced concrete structures, especially for bridge decks that are commonly exposed to natural environment and deicing salts. The ability of concrete to resist freezing and thawing and penetration of chloride ions is required for durable reinforced concrete structures. Concrete used for repair of corrosion damaged bridge decks must satisfy both mechanical and durability requirements. In order to achieve good bond between the old and the new concrete and to avoid shrinkage cracks, the shrinkage of the repair (patching) concrete must be small.

Mechanical properties of repair concrete tested in this project included compressive strength, static modulus of elasticity, and dynamic modulus of elasticity. Physical properties determined for the repair concrete included freeze-thaw durability, rapid chloride penetration resistance, ponding, and shrinkage. Eight different types of 
concrete were used in this project. One of the eight mixes was used for the construction of the original reinforced concrete slabs (see Section 4.1.4.2 and Table 4.6. The remaining seven mixes were specially developed for repair and patching of the corrosion damaged slabs (see Section 4.3. The mix proportions of the eight types of concrete are presented in Table 5.1 The mechanical and physical properties of these concrete mixes were tested in laboratory and the results are presented below. Each of the repair mixes was assigned a numerical code for identification purpose. This list of the repair concrete mixes and their corresponding code is given in Table 5.2.

\subsection{Compressive Strength}

Figure 5.1 illustrates the compressive strength development of both original and repair concrete mixes. Each of the values presented in Figure 5.1 is an average of three samples. The raw data for the compressive strength test are given in Appendix A. The compressive strengths of the specimens were measured at the age of 7,28 and 56 days. For some of the concrete mixes, the compressive strength at six months was also tested. For most of the concrete mixes, the compressive strength increased with the increase of curing time.

The compressive strength of repair concrete with shrinkage reducing admixture was $79.4 \mathrm{MPa}$ at 28 days. This was the highest 28 days compressive strength for the group of eight concrete mixes tested. In fact, a slight decrease was observed after 56 days of curing when the strength dropped to 74.1 MPa. The repair concrete with an organic corrosion inhibitor had a compressive strength of $75.3 \mathrm{MPa}$ at 28 days and 86.9 $\mathrm{MPa}$ at 180 days. Compressive strength of concrete with calcium nitrite was relatively 
low at 28 days (about $37.5 \mathrm{MPa}$ ), but increased to $75.4 \mathrm{MPa}$ at 180 days. The fly ash concrete also had relatively low compressive strength at 28 days (about $36.4 \mathrm{MPa}$ ), but its strength increased to $74.1 \mathrm{MPa}$ at 180 days. The silica fume concrete had a compressive strength of 58.3 MPa at 28 days, which was slightly lower than that of the standard INDOT 9-bag cement concrete, which achieved the compressive strength of $59.5 \mathrm{MPa}$ at the same age. This is mostly due to the fact that the silica fume concrete had an air content of $8.5 \%$, which was higher than that in the INDOT 9-bag cement concrete $(6 \%)$. The latex modified repair concrete had compressive strengths of $41.2 \mathrm{MPa}$ at 28 days and 47.9 $\mathrm{MPa}$ at 180 days. INDOT Class $\mathrm{C}$ concrete had a compressive strength of $46.8 \mathrm{MPa}$ at 28 days.

\subsection{Static Modulus of Elasticity}

The development of the static modulus of elasticity of the eight concrete mixes is illustrated in Figure 5.2 Concrete with shrinkage reducing admixture had the highest static modulus of elasticity (45.4 GPa at 28 days). The concrete with the organic corrosion inhibitor also had a high modulus of elasticity (45.0 GPa at 28 days). Latex modified concrete had relatively low modulus of elasticity (27.0 GPa at 28 days). Other concrete mixes had a modulus of elasticity in the range of 34.0 to $37.0 \mathrm{GPa}$ at the age of 28 days.

The increase in modulus of elasticity of the eight concrete mixes with the increase of curing time was not significant, except for concrete with fly ash. At 28 days, the modulus of elasticity of concrete with fly ash was $35.2 \mathrm{GPa}$ and increased to $48.8 \mathrm{GPa}$ at the age of 180 days. This increase in modulus of elasticity was due to the pozzolanic 
reaction between the fly ash and the calcium hydroxide produced during the hydration of the cement.

\subsection{Dynamic Modulus of Elasticity and Dynamic Shear Modulus of Repair Concretes}

Dynamic modulus of elasticity of each repair concrete was calculated twice using measured values of the fundamental transverse resonant frequency and the fundamental longitudinal resonant frequency. The dynamic shear modulus of each of the repair concrete was calculated using measured values of fundamental torsional resonant frequency. All the data used for determination of both dynamic modulus of elasticity and dynamic shear modulus are presented in Appendix B.

\subsubsection{Dynamic Modulus of Elasticity for Samples Cured in Moist Room}

The dynamic modulus of elasticity calculated using the fundamental transverse resonant frequency data is shown in Figure 5.3. It can be seen that the dynamic modulus of elasticity of all the specimens increased significantly during the first four weeks of storage in the moist room, but the rate of increase was reduced after the first 28 days. In general, the values of the dynamic modulus of elasticity calculated from the fundamental transverse resonant frequency data are similar to that of the dynamic modulus of elasticity calculated from the fundamental longitudinal resonant frequency data, as can be seen by comparing Figure 5.3 and Figure 5.4 The values of the dynamic modulus of elasticity of specimens made from concrete with organic corrosion inhibitor were the highest among the repair concrete mixes, averaging about $63.4 \mathrm{GPa}\left(9.2 \times 10^{6} \mathrm{psi}\right)$ at 28 
days. Concrete with shrinkage reducing admixture had a dynamic modulus of elasticity about $56.6 \mathrm{GPa}\left(8.2 \times 10^{6} \mathrm{psi}\right)$ at 28 days, which is the second highest value measured. The dynamic modulus of elasticity of specimens made from fly ash concrete, concrete with calcium nitrite, silica fume concrete, and INDOT 9-bag cement concrete were in the range of 36.6 to $43.4 \mathrm{GPa}\left(5.3\right.$ to $\left.6.3 \times 10^{6} \mathrm{psi}\right)$ at 28 days. The dynamic modulus of elasticity of specimens made from concrete with the organic corrosion inhibitor reached a value of $48.3 \mathrm{GPa}\left(7 \times 10^{6} \mathrm{psi}\right)$ at one day. This one-day value was higher than the laterage modulus developed by any other mix (except for concrete with shrinkage reducing admixture) at 28 days.

The pattern of the dynamic shear modulus (dynamic modulus of rigidity) of concrete specimens cured in the moist room is shown in Figure 5.5. This pattern is similar to the patterns observed for the dynamic modulus of elasticity calculated from the fundamental transverse resonant frequency and the longitudinal resonant frequency. The dynamic shear modulus of moist cured specimens increased significantly during the first 28 days, but increase was small beyond that age. The concrete with the organic corrosion inhibitor had the highest dynamic shear modulus, about $26.2 \mathrm{GPa}\left(3.8 \times 10^{6} \mathrm{psi}\right)$ at 28 days. The concrete with the shrinkage reducing admixture had the second highest value of modulus of about $22.8 \mathrm{GPa}\left(3.3 \times 10^{6} \mathrm{psi}\right)$ at 28 days. The dynamic shear modulus of specimens made from fly ash concrete, concrete with calcium nitrite, silica fume concrete, INDOT 9-bag cement concrete, and latex modified concrete were in the range of 15.2 to $18.6 \mathrm{GPa}\left(2.2\right.$ to $\left.2.7 \times 10^{6} \mathrm{psi}\right)$ at 28 days. The dynamic shear modulus of both the concrete with the organic corrosion inhibitor and the concrete with the shrinkage 
reducing admixture at early age (3 days) were as high as those of the other concrete mixes at the age of 28 days.

\subsubsection{Dynamic Modulus of Elasticity and Dynamic Shear Modulus for Samples Cured in Air}

Figure 5.6 shows the dynamic modulus of elasticity of concrete specimens cured in air. These values were calculated using the fundamental transverse resonant frequency data. All of the values increased significantly during the first week of storage, but subsequent increases were small. The concrete with organic corrosion inhibitor had the highest dynamic modulus of elasticity values, about $58.6 \mathrm{GPa}\left(8.5 \times 10^{6} \mathrm{psi}\right)$ at 28 days. The dynamic modulus of elasticity of specimens made from concrete with shrinkage reducing admixture was about $53.1 \mathrm{GPa}\left(7.7 \times 10^{6} \mathrm{psi}\right)$ at 28 days. The dynamic modulus of elasticity of the latex modified concrete was higher when the specimens were cured in air than when they were cured in the moist room. The value of dynamic modulus of elasticity for the air cured specimens was $49.7 \mathrm{GPa}\left(7.2 \times 10^{6} \mathrm{psi}\right)$ at 28 days, as compared to $32.8 \mathrm{GPa}\left(4.8 \times 10^{6} \mathrm{psi}\right)$ observed in the moist cured specimens. This indicates that latex modified concrete must be cured in air for a period of time before it is exposed to moisture. On the other hand, the values of dynamic modulus of elasticity for both silica fume concrete and the fly ash concrete were higher for moist room cured specimens.

The pattern of development of the dynamic modulus of elasticity of concrete specimens calculated from the fundamental longitudinal resonant frequency is similar to 
that calculated from the fundamental transverse resonant frequency. The development of the dynamic modulus of elasticity calculated from the fundamental longitudinal frequency for concrete samples cured in air is shown in Figure 5.7. The ranking of the seven concrete mixtures (from high to low) based on the dynamic modulus of elasticity, is as follows:

Concrete with organic corrosion inhibitor $>$ Concrete with shrinkage reducing admixture $>$ Latex modified concrete $>$ Concrete with calcium nitrite $>$ Silica fume concrete / Fly ash concrete / INDOT 9-bag cement concrete.

The dynamic shear modulus of concrete specimens cured in air is shown in Figure 5.8. Again, the highest value (about $24.8 \mathrm{GPa}\left(3.6 \times 10^{6} \mathrm{psi}\right)$ at 28 days) of shear modulus was observed in concrete containing organic corrosion inhibitor. Concretes with shrinkage reducing admixture and the latex modified concrete both developed the second highest values of dynamic shear modulus. These values ranged from 20.7 to $22.1 \mathrm{GPa}$ (3.0 to $3.2 \times 10^{6} \mathrm{psi}$ ) at 28 days. The concrete specimens with the calcium nitrite had a dynamic shear modulus of about $16.6 \mathrm{GPa}\left(2.4 \times 10^{6} \mathrm{psi}\right)$ at 28 days. The silica fume concrete, fly ash concrete, and INDOT 9-bag cement concrete reached the same level of dynamic shear modulus, or about $15.2 \mathrm{GPa}\left(2.2 \times 10^{6} \mathrm{psi}\right)$ at 28 days.

\subsection{Drying Shrinkage of Repair Concretes}

All raw data related to drying shrinkage of concrete used in this research are presented in Appendix C. The shrinkage of repair concrete specimens cured in the moist room is shown in Figure 5.9. In general, except for specimens made from the latex modified concrete, the specimens cured in moist room did not show significant shrinkage. 
As mentioned earlier, air curing rather than moist curing us recommended for latex modified concrete. The specimens made from silica fume concrete showed shrinkage of $0.005 \%$ at the age of 28 days, but remained stable thereafter. The specimens from the other mixes experienced small expansion, typically in the range of 0.003 to $0.008 \%$.

For specimens made from the concrete containing shrinkage reducing admixtures, some shrinkage was observed during the first two weeks of storage in moist room. However, expansion started after two weeks and at the end of the testing period the expansion had offset the previous shrinkage. At 28 days, the specimens showed about $0.003 \%$ of expansion. Specimens made from INDOT 9-bag cement concrete showed a similar pattern of length change.

Figure 5.10 shows the shrinkage values of the repair concrete specimens cured in air. All of the specimens experienced continuous shrinkage. Concrete with the shrinkage reducing admixture had the smallest shrinkage, about $0.020 \%$ at 28 days and $0.023 \%$ at 56 days. Specimens made from the latex modified concrete had the second lowest shrinkage, or $0.030 \%$ at 28 days and $0.035 \%$ at 48 days. Concrete with organic corrosion inhibitor had shrinkage of $0.034 \%$ at 28 days and about $0.040 \%$ at 56 days. Specimens made from the silica fume concrete, fly ash concrete, concrete with calcium nitrite, and INDOT 9-bag cement concrete had the same level of shrinkage at later ages, but at early ages, the silica fume concrete experienced larger shrinkage than the other concretes specimens. 


\subsection{Freezing and Thawing Resistance}

The values of relative dynamic modulus of elasticity of repair concrete specimens are shown in Figure 5.11 As indicated in the figure, the relative dynamic modulus of elasticity of all specimens decreased with the increase in the number of freeze-thaw cycles. After 300 freeze-thaw cycles, specimens made from the silica fume concrete, concrete with calcium nitrite, fly ash concrete, and INDOT 9-bag cement concrete still had a relative dynamic modulus of more than $95 \%$.

For specimens made from concrete with the shrinkage reducing admixture, the relative dynamic modulus of elasticity was about $90 \%$ after 300 freeze-thaw cycles. For concrete with organic corrosion inhibitor the relative dynamic modulus of elasticity was about $83 \%$ after 300 freeze-thaw cycles. This can be attributed to the fact that these mixes had a lower air content than the other mixes.

\subsection{Rapid Chloride Ion Penetration Results}

The experimental results of rapid chloride penetration testing are presented and discussed in this section. Some of the specimens were cured in the moist room, while others were air cured in the laboratory.

\subsubsection{Effect of Curing Conditions}

The results of the rapid chloride ion penetration tests for moist cured and air cured concrete specimens are presented in Tables 5.3 and 5.4, respectively. In general, specimens cured in the moist room had higher coulomb values than their companion 
specimens cured in air. Although specimens cured in the moist room are expected to have a denser microstructure, the electrical conductance of concrete (which is essentially what the rapid chloride permeability test measures) is also strongly dependent on the amount and chemistry of the pore solution. Both of these parameters are likely to be quite different for samples cured under wet and dry conditions, respectively, and may be responsible for the observed differences in coulomb values.

\subsubsection{Effect of Water to Cement Ratio}

Concrete with a low water to cement ratio has smaller porosity and lower permeability than concrete with a high water to cement ratio. When the water to cement ratio is low, the capillary pores in the cement paste are segmented and mostly filled by cement hydration products. Thus, the volume of the capillary pores is reduced as the water to cement ratio is decreased, and subsequently, the movement of ions within the concrete in inhibited.

The rapid chloride penetration testing showed that the coulomb value depends on the water to cement ratio, as shown in Table 5.3. For example, silica fume concrete, cured in moist room for 28 days and with a water to cement ratio of 0.32 had a value of 403 coulombs, while silica fume concrete with a water to cement ratio of 0.30 had a value of 313 coulombs. 


\subsubsection{Effect of Mineral Admixtures}

Based on the rapid chloride ion penetration test results, silica fume significantly reduces the value of coulombs passed through concrete. When $10 \%$ of the cement was replaced by silica fume, the total charge passed through concrete during six hours was 313 coulombs. The charge passed through concrete with the same water to cement ratio but without silica fume was 3488 coulombs. Both concretes were cured in the moist room for 28 days. For specimens cured in the moist room for 56 days, the charge passed through concrete with silica fume was 242 coulombs while the charge passed through concrete without silica fume was 2942 coulombs.

When silica fume was used in combination with the shrinkage reducing admixture, the reduction in charge passed through concrete specimens was even more significant than the one observed for concrete with silica fume alone (183 coulombs vs. 313 coulombs at 28 days). At the same age, the value of charge passed through concrete containing just shrinkage reducing admixture was 1750 coulombs.

Since the reaction of fly ash in concrete takes a long time, the measured coulomb value for concrete containing fly ash was higher in the early ages. For concrete cured in moist room for 28 days it was 2241 coulombs. This value was 2277 coulombs at 56 days, and at the age of 180 days it dropped to 592 coulombs.

\subsection{Chloride Content Results}

The results of chloride content analysis obtained from INDOT Class C concrete after 12, 24, 28, 34 and 40 weeks of exposure to wetting and drying cycles (as described in Section 4.1.5 are shown in Figure 5.12. After 12 weeks of exposure, the chloride 
content at the steel level in the repaired section of the slab (at the depth of $12.7 \mathrm{~mm}(0.5$ in.) below surface) was about $2.1 \mathrm{~kg} / \mathrm{m}^{3}$, or $0.54 \%$ by weight of cement. A reasonable threshold value needed for the initiation of corrosion is $0.4 \%$, or $1.56 \mathrm{~kg} / \mathrm{m}^{3}$ in this case. Using this value, the data in Figure 5.12 show that after 12 weeks of exposure, the chloride content was greater than the threshold level for initiation of corrosion for the repaired portion of the slab where the concrete cover was $12.7 \mathrm{~mm}(0.5 \mathrm{in}$.$) .$

The chloride concentration data for repair concrete mixes is provided in Figure 5.13. The concrete powder samples were collected from the repaired portion or concrete slabs that were continuously ponded with $10 \%$ sodium chloride solution for six months. This figure shows that the latex modified concrete had the lowest overall chloride content. For all other concrete specimens, the differences in chloride content at depths greater than one inch below the surface were negligible. However, within the first one inch of concrete cover, the difference in chloride content was quite significant.

\subsection{Summary}

Compared with the INDOT 9-bag concrete (control concrete), concrete with the shrinkage reducing agent had higher compressive strength. The organic corrosion inhibitor also increased the compressive strength of concrete. Concrete with calcium nitrite $(0.3 \%$ by mass of cement) had relatively low strength at early age but the 180 -day strength was higher than that of the control concrete. Silica fume concrete had compressive strength higher than the 9-bag mix (the content of silica fume was $10 \%$ by mass of the total binding material). As expected, the fly ash concrete had low early strength but the 180-day strength was higher than that of the control concrete. 
Concrete with the shrinkage reducing admixture had the highest static modulus of elasticity among the seven concrete mixes tested. Concrete with the organic corrosion inhibitor also had a high modulus of elasticity. Silica fume concrete had a higher modulus of elasticity than the control concrete. Fly ash concrete also developed high modulus of elasticity at the age of 180 days.

Dynamic modulus of elasticity increased with the increase in curing time for all repair concrete specimens tested and reached a relatively constant level after about 28 days of curing. The specimens cured in air had lower dynamic modulus of elasticity than those cured in the moist room. Compared with other concrete mixes, the concrete mixes with organic corrosion inhibitor and with the shrinkage reducing admixture had the highest dynamic moduli of elasticity.

As expected, concrete specimens cured in air developed higher shrinkage than those cured in the moist room. Addition of shrinkage reducing admixture reduced the drying shrinkage.

The freeze-thaw resistance of concrete was evaluated by determining the relative dynamic modulus of elasticity. After 300 freeze-thaw cycles, silica fume concrete had no significant change in its dynamic modulus of elasticity, indicating good durability. Concrete with calcium nitrite also had excellent freeze-thaw resistance. Fly ash concrete had a relative dynamic modulus of elasticity of $97 \%$ after 300 cycles of freeze-thaw cycles, which was similar to that of the control concrete. Concrete with the shrinkage reducing admixture had $90 \%$ relative dynamic modulus of elasticity after 300 cycles of freezing and thawing. Concrete with the organic corrosion inhibitor had fair performance 
with respect to freeze-thaw resistance, achieving the value of a relative dynamic modulus of elasticity of $85 \%$ after 300 freeze-thaw cycles.

Rapid chloride penetration test was used to evaluate the effects of curing conditions, water to cement ratio, and mineral admixtures on the conductivity of concrete. Concrete specimens cured in air had a lower coulomb value than those cured in the moist room. The silica fume concrete had a low coulombs value when compared with the control concrete. Fly ash concrete had high conductivity at early age, while at the age of 180 days, the conductivity was very low.

Results from ponding test showed that chloride content at the steel level in the repaired portion of the reinforced concrete slabs was above the threshold level for initiation of corrosion after the slabs were exposed to wetting and drying cycles for 6 weeks. Latex modified concrete had the lowest chloride content of all the repair concrete mixes. 
Table 5.1 Concrete Mixes

\begin{tabular}{|c|c|c|c|c|c|c|c|c|}
\hline & $\begin{array}{l}\text { INDOT } \\
\text { Class C } \\
\text { Concrete }\end{array}$ & $\begin{array}{l}\text { Silica Fume } \\
\text { Concrete } \\
\# 2\end{array}$ & $\begin{array}{c}\text { Concrete with } \\
\text { Calcium } \\
\text { Nitrite } \\
\text { \#3 }\end{array}$ & $\begin{array}{c}\text { Concrete with } \\
\text { Organic } \\
\text { Corrosion } \\
\text { Inhibitor } \\
\# 4\end{array}$ & $\begin{array}{c}\text { Fly Ash } \\
\text { Concrete } \\
\text { \# } 5\end{array}$ & $\begin{array}{c}\text { INDOT } \\
\text { 9-bag cement } \\
\text { concrete } \\
\text { \# } 6\end{array}$ & $\begin{array}{c}\text { Concrete with } \\
\text { Shrinkage } \\
\text { Reducing } \\
\text { Agent } \\
\text { \# } 7\end{array}$ & $\begin{array}{l}\text { Latex } \\
\text { Modified } \\
\text { Concrete } \\
\quad \# 8\end{array}$ \\
\hline $\begin{array}{l}\text { Coarse Aggregate, } \\
\mathrm{kg} / \mathrm{m}^{3}\left(\mathrm{lb} / \mathrm{yd}^{3}\right)\end{array}$ & $1097(1850)$ & $1023(1725)$ & $1023(1725)$ & $1023(1725)$ & $1023(1725)$ & $1023(1725)$ & $1023(1725)$ & $999(1685)$ \\
\hline Sand, $\mathrm{kg} / \mathrm{m}^{3}\left(\mathrm{lb} / \mathrm{yd}^{3}\right)$ & 725 (1222) & $682(1150)$ & $682(1150)$ & $682(1150)$ & $682(1150)$ & $682(1150)$ & $682(1150)$ & $666(1123)$ \\
\hline $\begin{array}{l}\text { Silica Fume, } \mathrm{kg} / \mathrm{m}^{3} \\
\left(\mathrm{lb} / \mathrm{yd}^{3}\right)\end{array}$ & 0 & $50(85)$ & 0 & 0 & 0 & 0 & 0 & 0 \\
\hline $\begin{array}{l}\text { Fly Ash, } \mathrm{kg} / \mathrm{m}^{3} \\
\left(\mathrm{lb} / \mathrm{yd}^{3}\right)\end{array}$ & 0 & 0 & 0 & 0 & $100(169)$ & 0 & 0 & 0 \\
\hline $\begin{array}{l}\text { Water, } \mathrm{kg} / \mathrm{m}^{3} \\
\left(\mathrm{lb} / \mathrm{yd}^{3}\right)\end{array}$ & $124(209)$ & $179(302)$ & $165(279)$ & $160(279)$ & $156(264)$ & $151(255)$ & $145(245)$ & $19(33)$ \\
\hline $\begin{array}{l}\text { Superplasticizer, } \\
\text { L/100 kg cement }\end{array}$ & N/A & 0.75 & 0.75 & 0.75 & 0.75 & 0.75 & 0.75 & 0.75 \\
\hline $\begin{array}{l}\text { Air Entraining } \\
\text { Agent, } \mathrm{ml} / 100 \mathrm{~kg} \\
\text { cement }\end{array}$ & N/A & 60 & 60 & 150 & 60 & 60 & 80 & 45 \\
\hline $\begin{array}{l}\text { Calcium Nitrite, } \\
\mathrm{L} / \mathrm{m}^{3}\end{array}$ & 0 & 0 & 20 & 0 & 0 & 0 & 0 & 0 \\
\hline $\begin{array}{l}\text { Organic Corrosion } \\
\text { Inhibitor, } \mathrm{L} / \mathrm{m}^{3} \text { (gal/ } \\
\mathrm{yd}^{3} \text { ) concrete }\end{array}$ & 0 & 0 & 0 & $5(1)$ & 0 & 0 & 0 & 0 \\
\hline $\begin{array}{l}\text { Shrinkage-reducing } \\
\text { Admixture, \% of } \\
\text { cement }\end{array}$ & 0 & 0 & 0 & 0 & 0 & 0 & 2 & 0 \\
\hline $\begin{array}{l}\text { Latex, L/100kg } \\
\text { cement }\end{array}$ & 0 & 0 & 0 & 0 & 0 & 0 & 0 & 31 \\
\hline $\begin{array}{l}\text { Unit Weight, } \mathrm{kg} / \mathrm{m}^{3} \\
\left(\mathrm{lb} / \mathrm{yd}^{3}\right)\end{array}$ & $2420(151)$ & $2386(4024)$ & 2371 (3999) & $2366(3990)$ & $2362(3983)$ & $2357(3976)$ & $2352(3966)$ & $2345(3954)$ \\
\hline Air Content, $\%$ & 3.5 & 8.5 & 6.3 & 5.5 & 7.5 & 7.2 & 5.6 & 6.7 \\
\hline
\end{tabular}


Table 5.2 Code system used for repair concrete mixes.

\begin{tabular}{|l|l|}
\hline Code & Concrete Mix \\
\hline No.2 & Silica fume concrete \\
\hline No.3 & $\begin{array}{l}\text { Concrete containing calcium nitrite } \\
\text { inhibitor }\end{array}$ \\
\hline No.4 & $\begin{array}{l}\text { Concrete containing organic corrosion } \\
\text { inhibitor }\end{array}$ \\
\hline No.5 & Fly ash concrete \\
\hline No.6 & INDOT 9-bag concrete \\
\hline No.7 & $\begin{array}{l}\text { Concrete containing the shrinkage reducing } \\
\text { admixture }\end{array}$ \\
\hline No.8 & Latex modified concrete \\
\hline
\end{tabular}


Table 5.3 Rapid chloride penetration values for samples cured in the moist room.

\begin{tabular}{|l|c|c|c|}
\hline \multirow{2}{*}{ Concrete } & \multicolumn{3}{c|}{ Coulomb Value } \\
\cline { 2 - 4 } & 28 -day & 56 -day & 180 -day \\
\hline Silica Fume Concrete & 313 & 242 & 205 \\
\hline No.2 $^{*}$ & 403 & 289 & 243 \\
\hline No.2 $^{+}$ & 247 & 235 & 197 \\
\hline Concrete with Calcium Nitrite & 1776 & 1814 & 1650 \\
\hline $\begin{array}{l}\text { Concrete with Organic Corrosion } \\
\text { Inhibitor }\end{array}$ & 2035 & 1937 & 1587 \\
\hline Fly Ash Concrete & 2241 & 2277 & 592 \\
\hline INDOT 9-bag cement concrete & 3488 & 2942 & 2314 \\
\hline $\begin{array}{l}\text { Concrete with Shrinkage Reducing } \\
\text { Admixture }\end{array}$ & 1750 & 1659 & 1620 \\
\hline No.7 & & 151 & 135 \\
\hline
\end{tabular}

Notes: No. ${ }^{*}$ Silica fume concrete with water to binder ratio of 0.32 .

No. $2^{+}$Silica fume concrete with a water to binder ratio of 0.30 .

No. ${ }^{*}$ Concrete with shrinkage reducing admixture, with $10 \%$ of silica fume by mass of total binder.

Table 5.4 Rapid chloride penetration values for the samples cured in air.

\begin{tabular}{|l|c|c|c|}
\hline \multirow{2}{*}{\multicolumn{1}{|c|}{ Concrete }} & \multicolumn{3}{c|}{ Coulomb Value } \\
\cline { 2 - 4 } & 28 -day & 56 -day & 180 -day \\
\hline Silica Fume Concrete & 253 & 125 & 115 \\
\hline Concrete with Calcium Nitrite & 1764 & 1491 & 1354 \\
\hline $\begin{array}{l}\text { Concrete with Organic Corrosion } \\
\text { Inhibitor }\end{array}$ & 1378 & 855 & 673 \\
\hline Fly Ash Concrete & 2243 & 1794 & 1360 \\
\hline INDOT 9 bag Concrete & 2060 & 1767 & 1581 \\
\hline $\begin{array}{l}\text { Concrete with Shrinkage } \\
\text { Reducing Admixture }\end{array}$ & 1033 & 675 & 574 \\
\hline Latex Modified Concrete & 550 & 382 & 223 \\
\hline
\end{tabular}




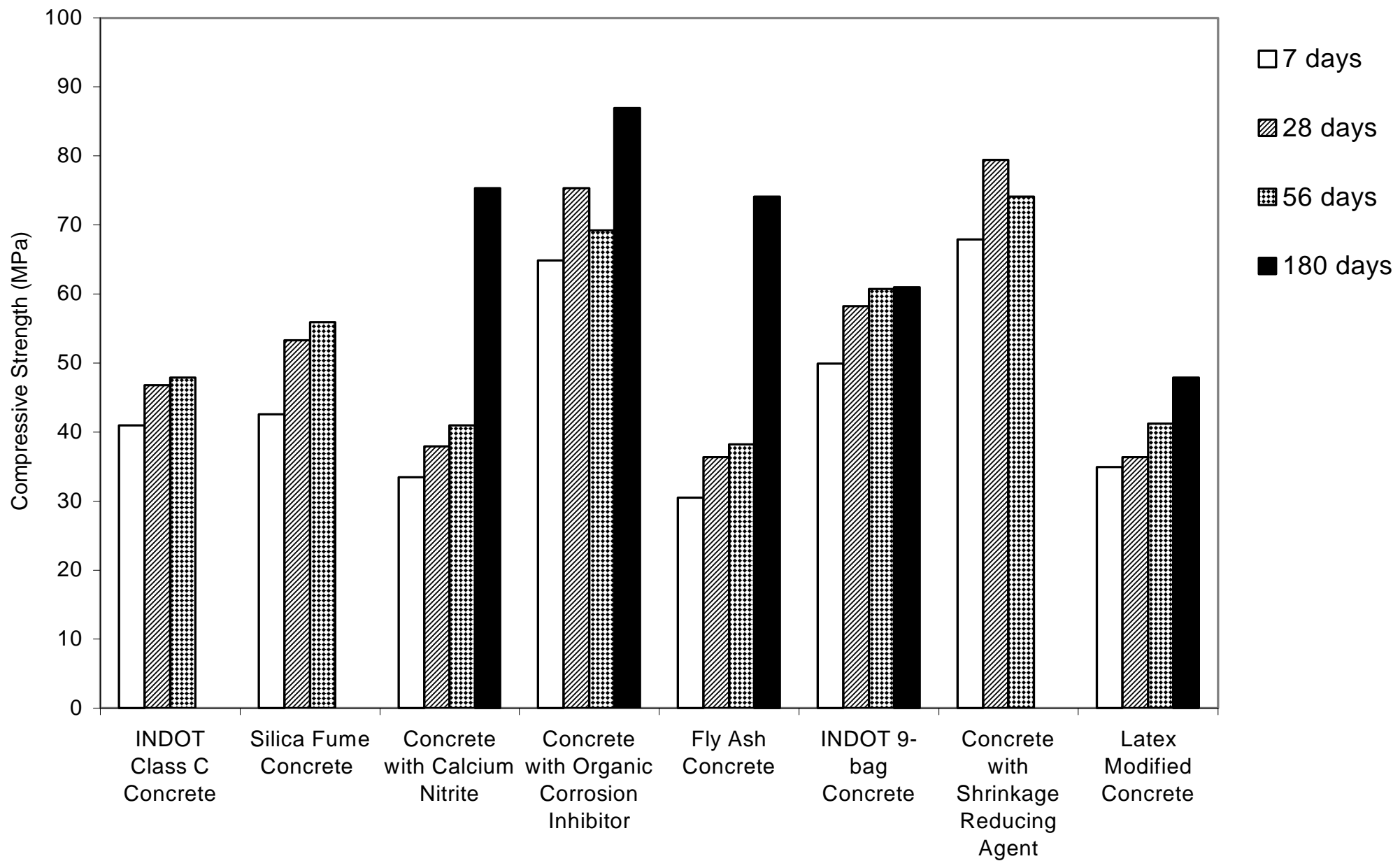

Figure 5.1 Compressive strength development of concrete mixes 


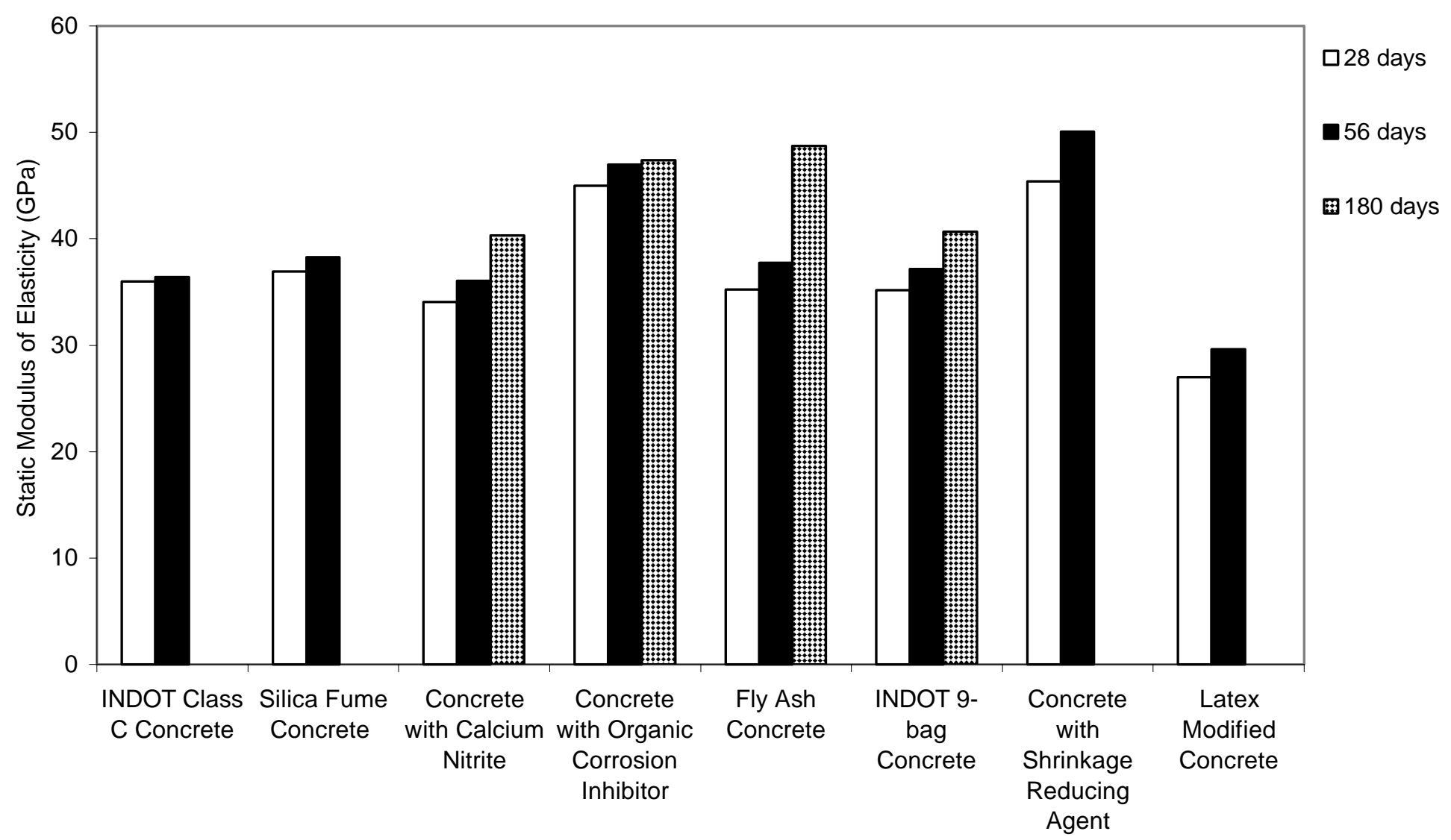

Figure 5.2 Static modulus of elasticity of concrete mixes. 


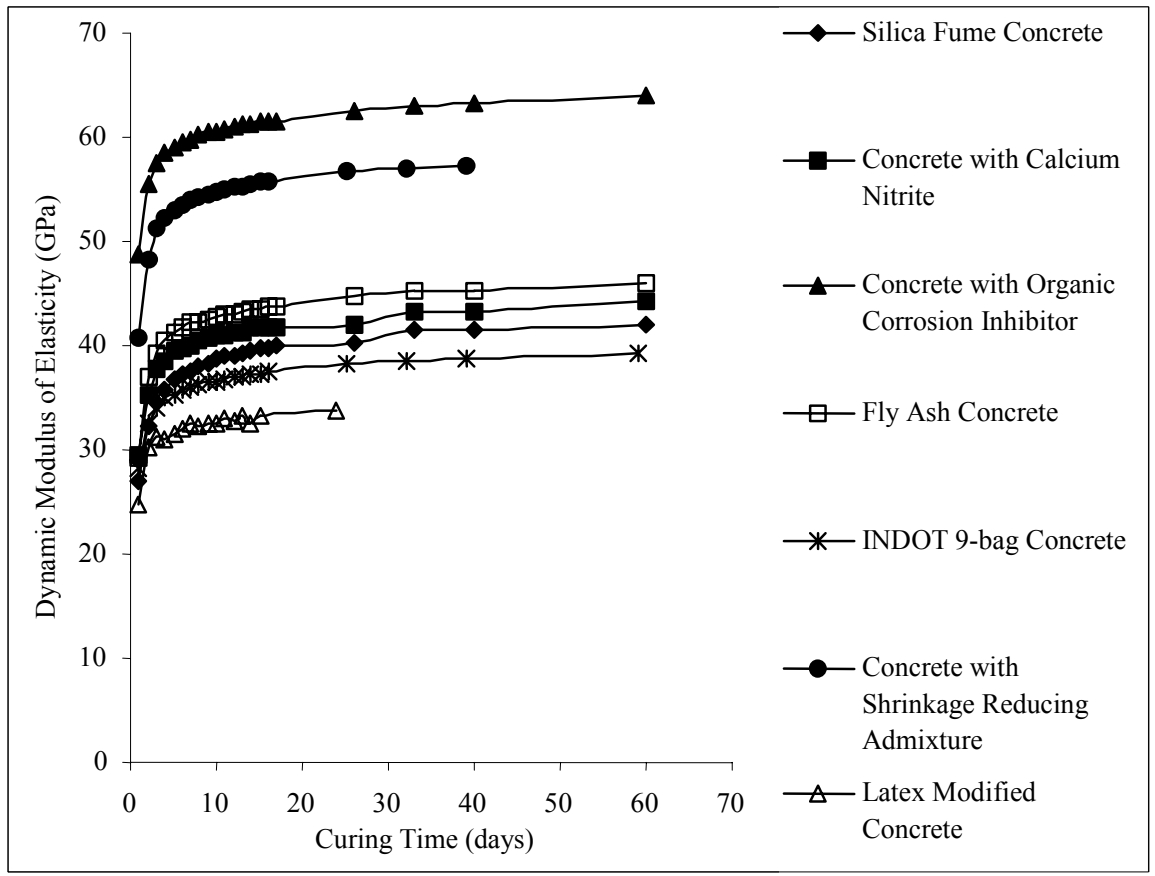

Figure 5.3 The dynamic modulus of elasticity calculated from fundamental transverse resonant frequency for concrete specimens cured in the moist room.

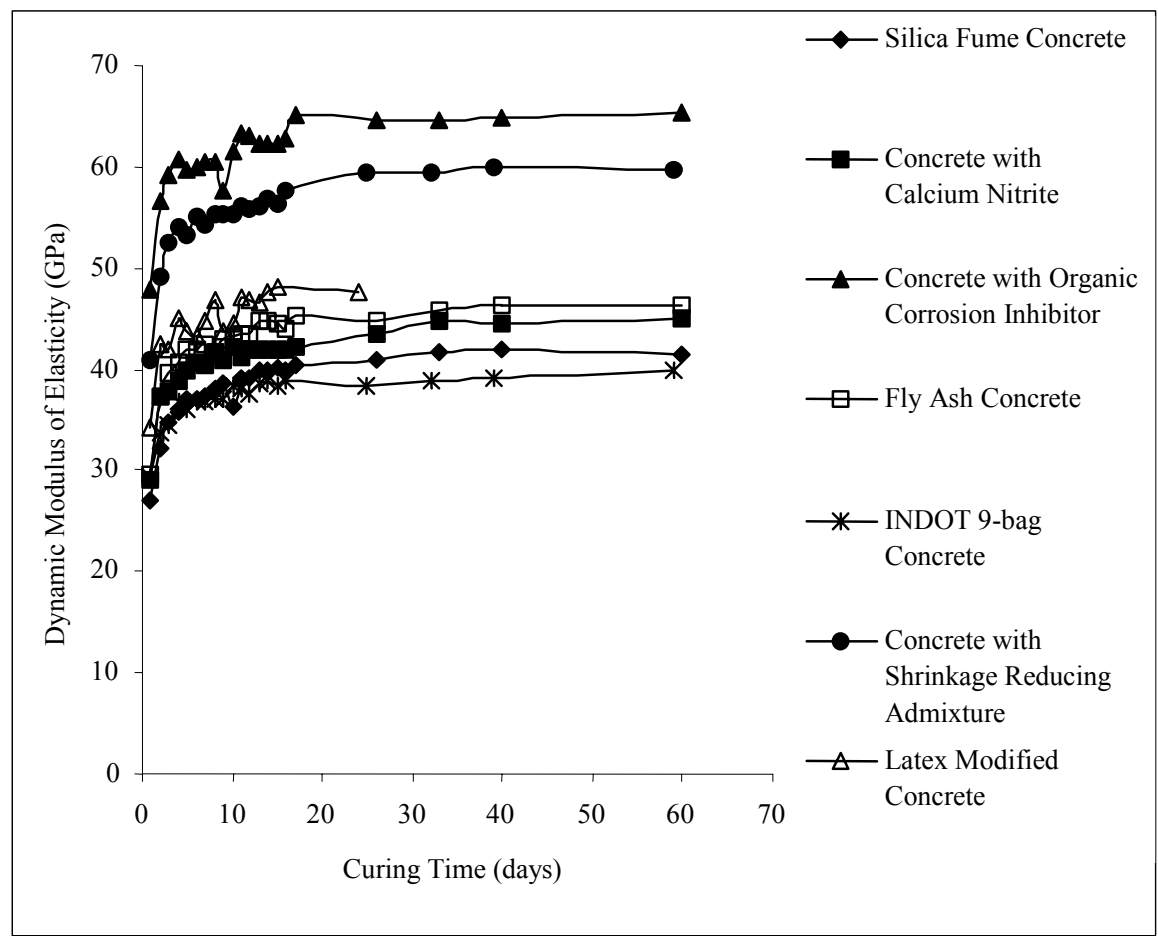

Figure 5.4 The dynamic modulus of elasticity calculated from fundamental longitudinal resonant frequency for concrete specimens cured in the moist room. 


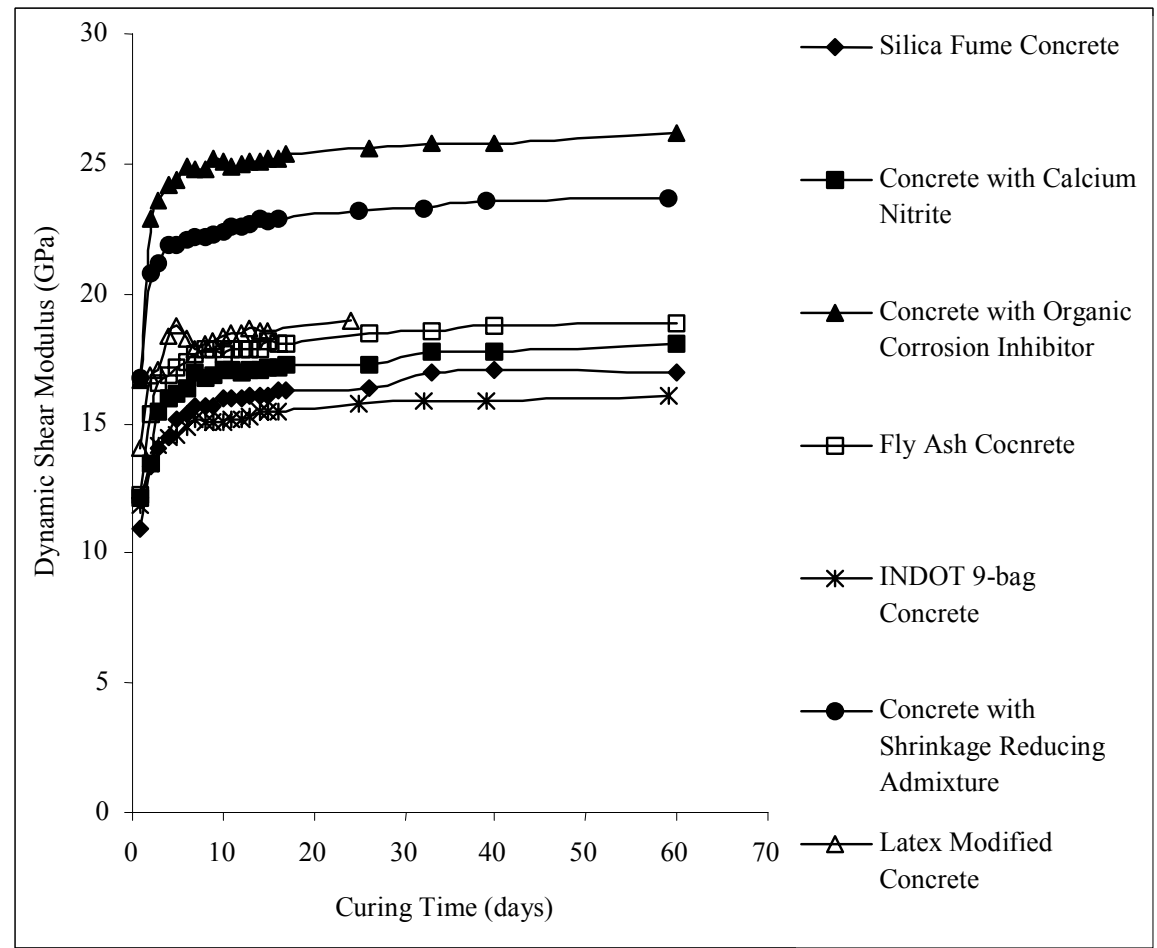

Figure 5.5 The dynamic shear modulus calculated from fundamental torsional resonant frequency for concrete specimens cured in the moist room.

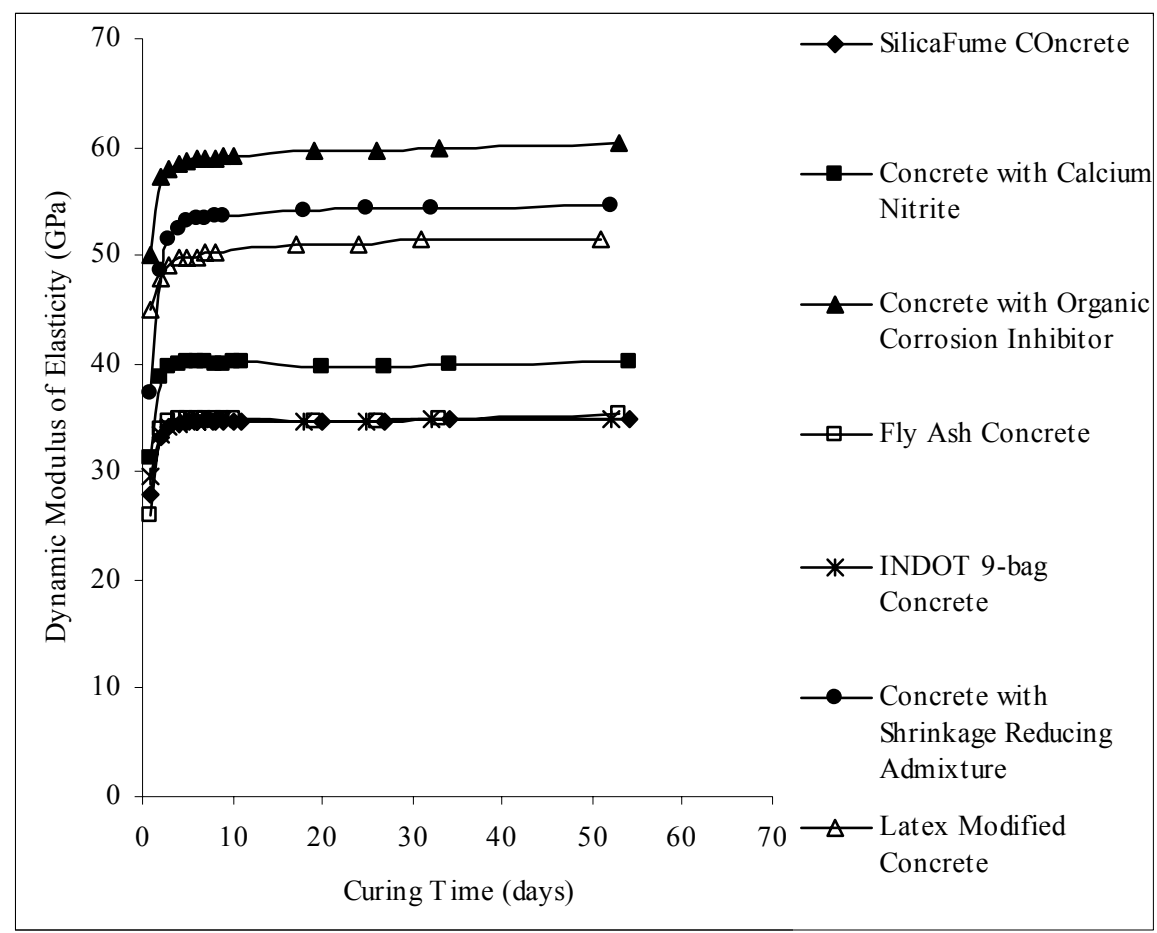

Figure 5.6 The dynamic modulus of elasticity calculated from fundamental transverse resonant frequency for concrete specimens cured in air. 


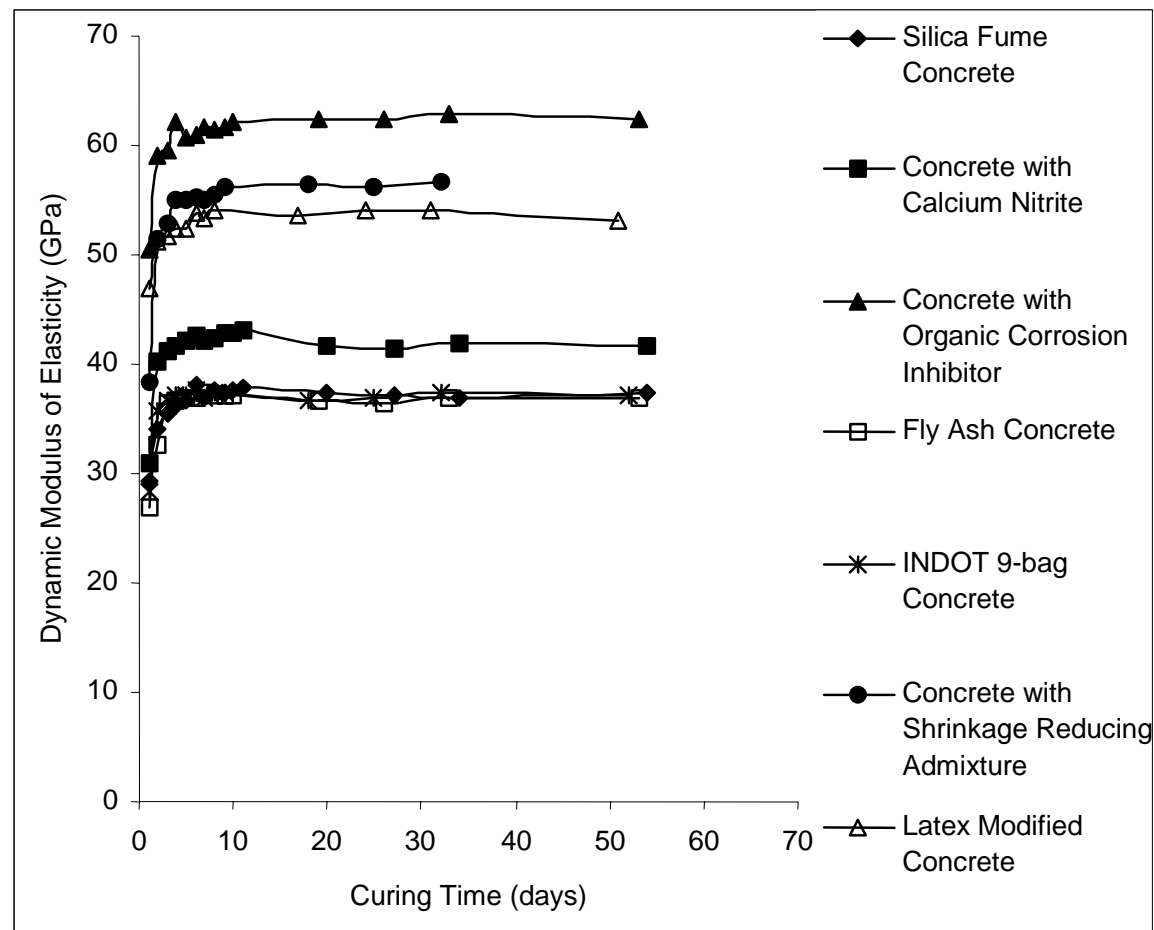

Figure 5.7 The dynamic modulus of elasticity calculated from fundamental longitudinal resonant frequency for concrete specimens cured in air.

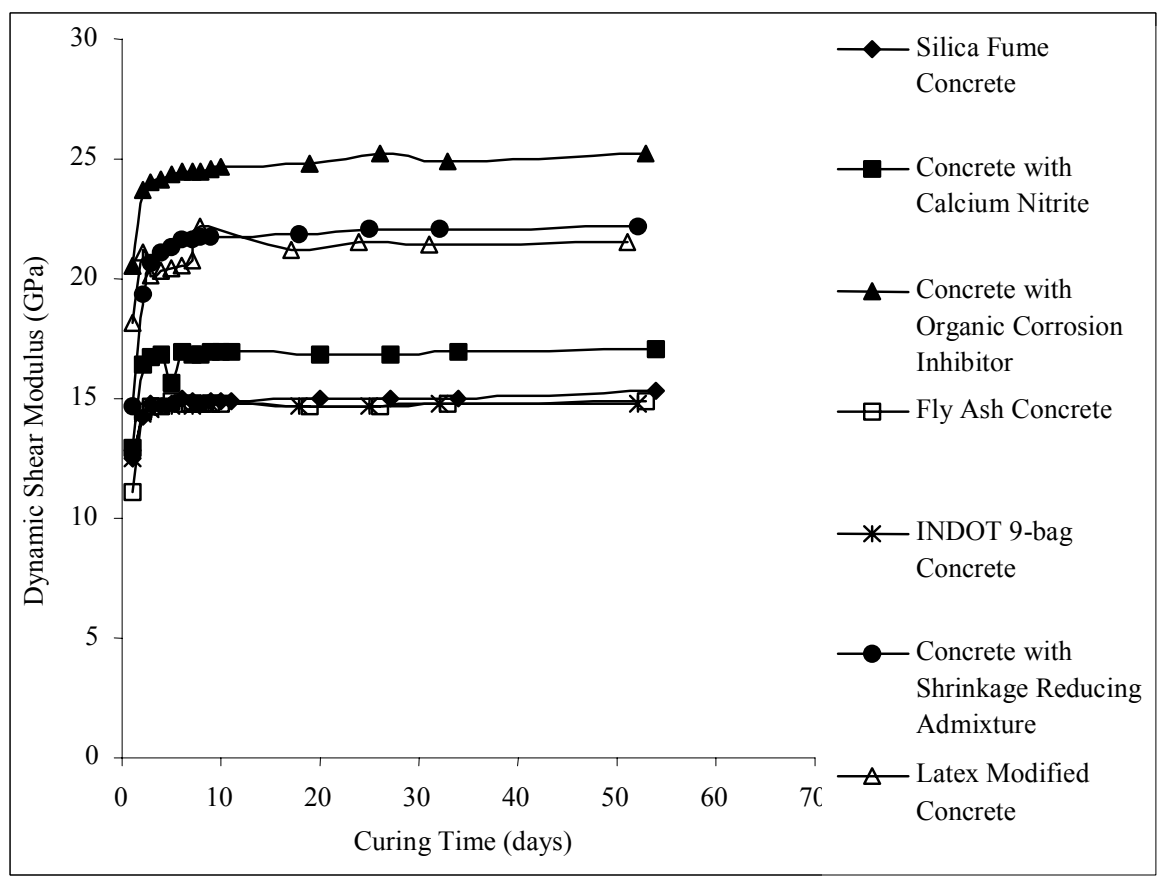

Figure 5.8 The dynamic shear modulus calculated from fundamental torsional resonant frequency for concrete specimens cured in air. 


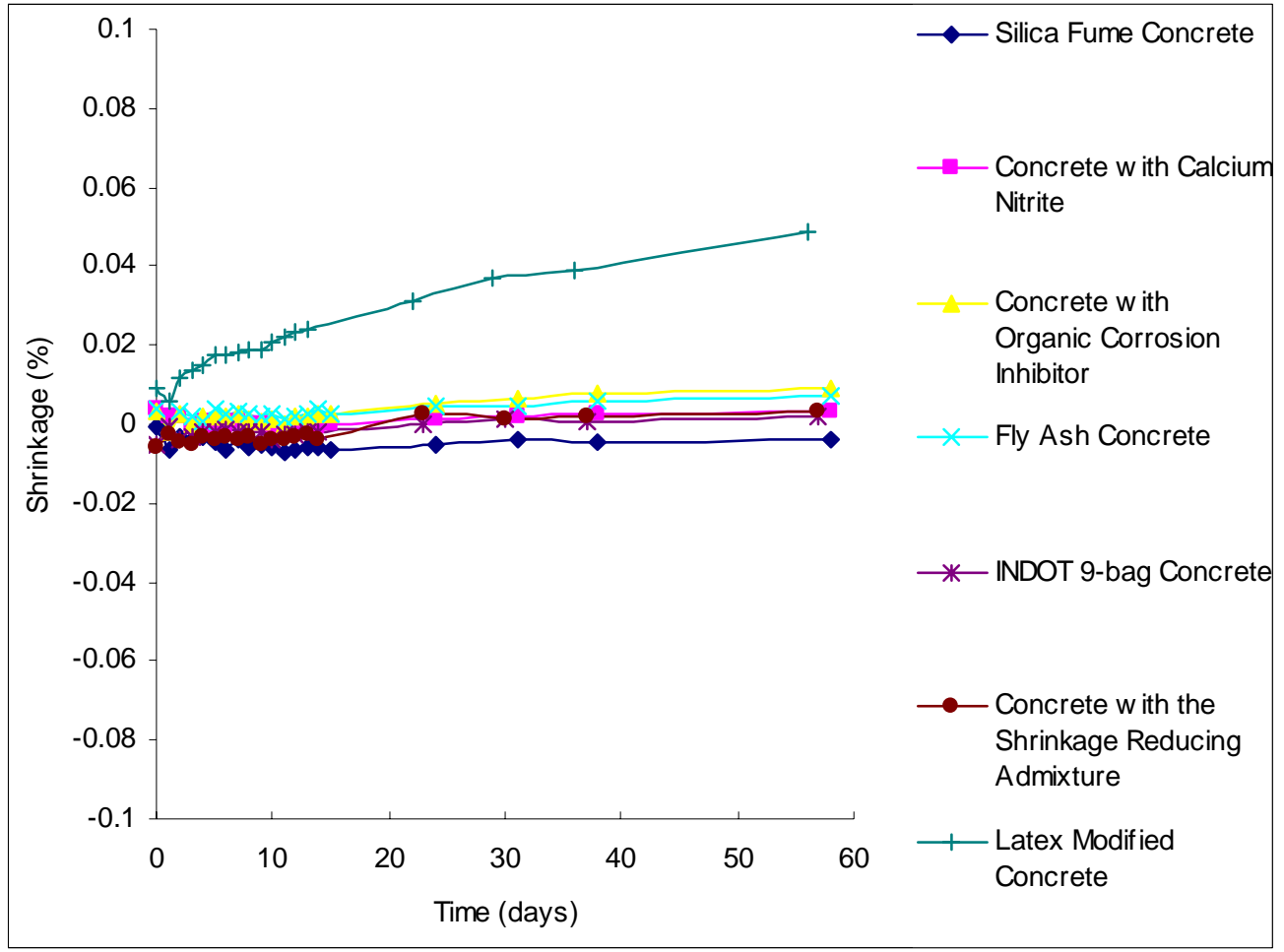

Figure 5.9 Shrinkage of specimens cured in the moist room.

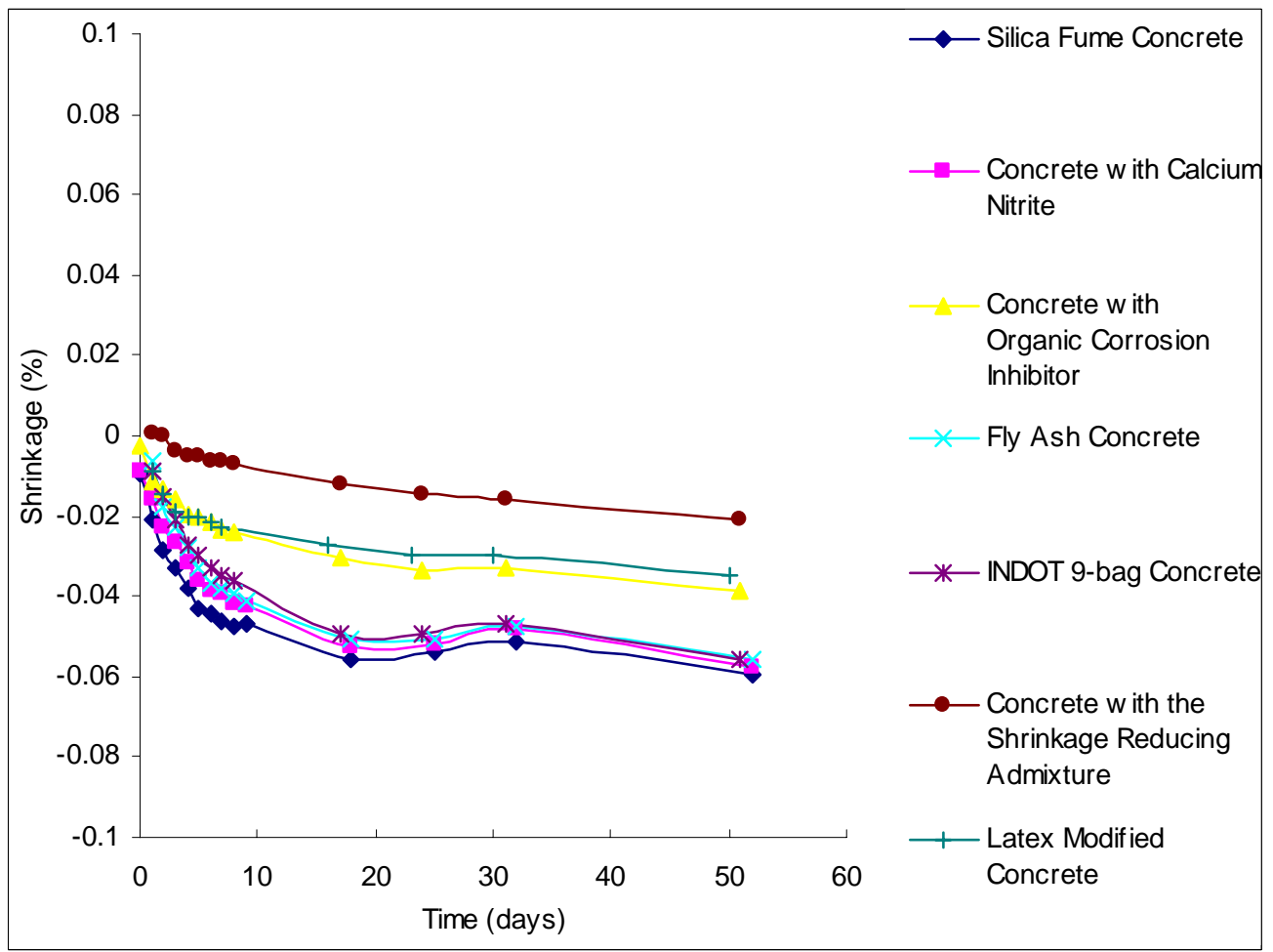

Figure 5.10 Shrinkage of specimens cured in air. 


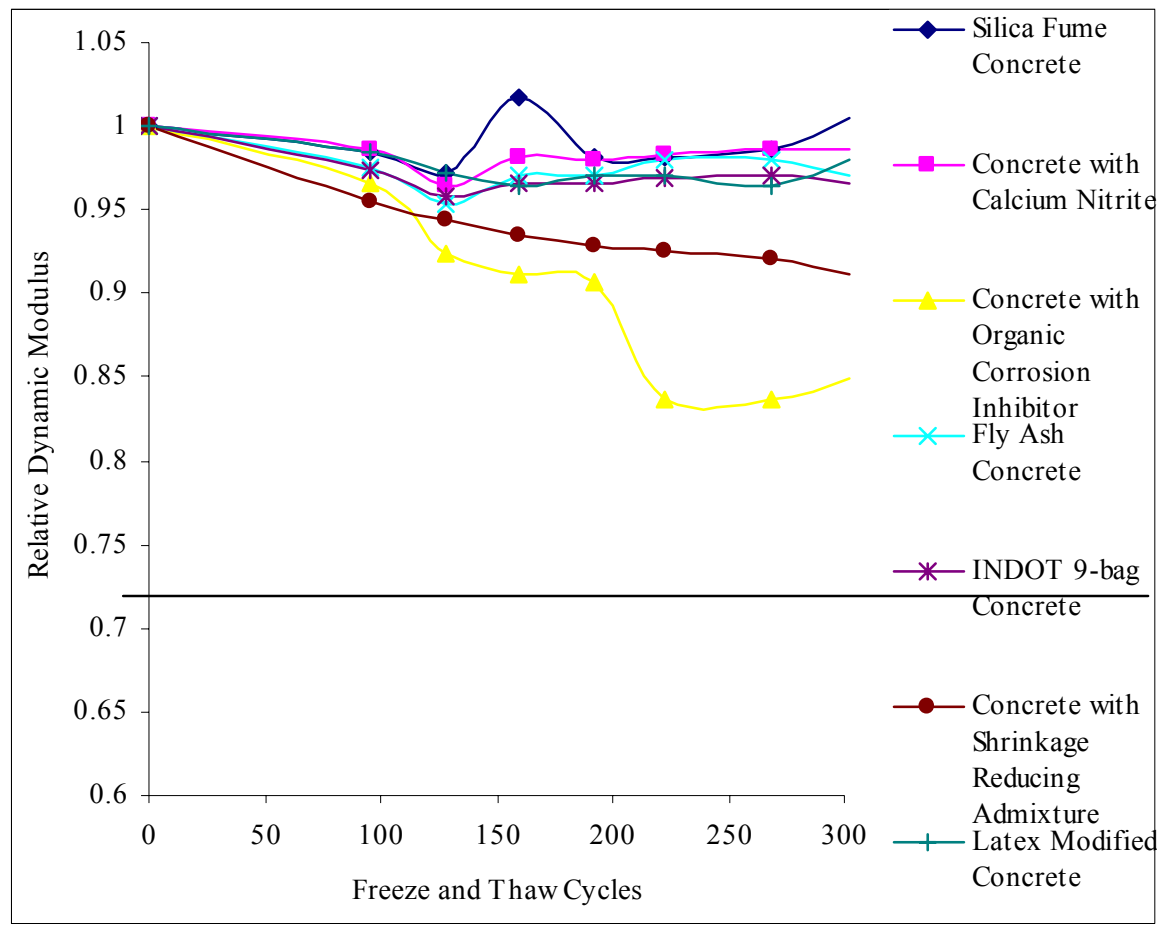

Figure 5.11 Relative Dynamic modulus of elasticity of specimens subjected to rapid freezing and thawing cycles.

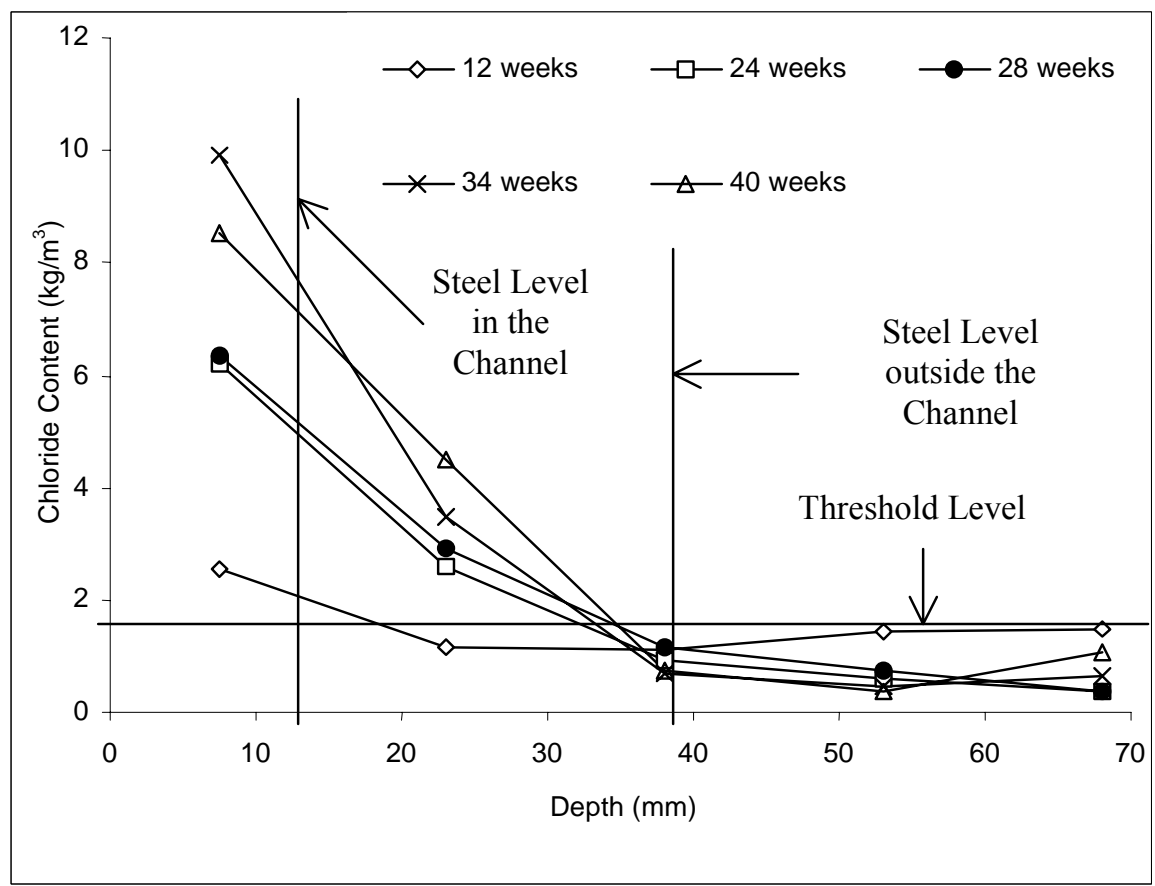

Figure 5.12 Chloride content of concrete powder sample from INDOT Class C concrete. Concrete specimens were exposed to $5 \%$ sodium chloride solution and wetting-drying cycles. 


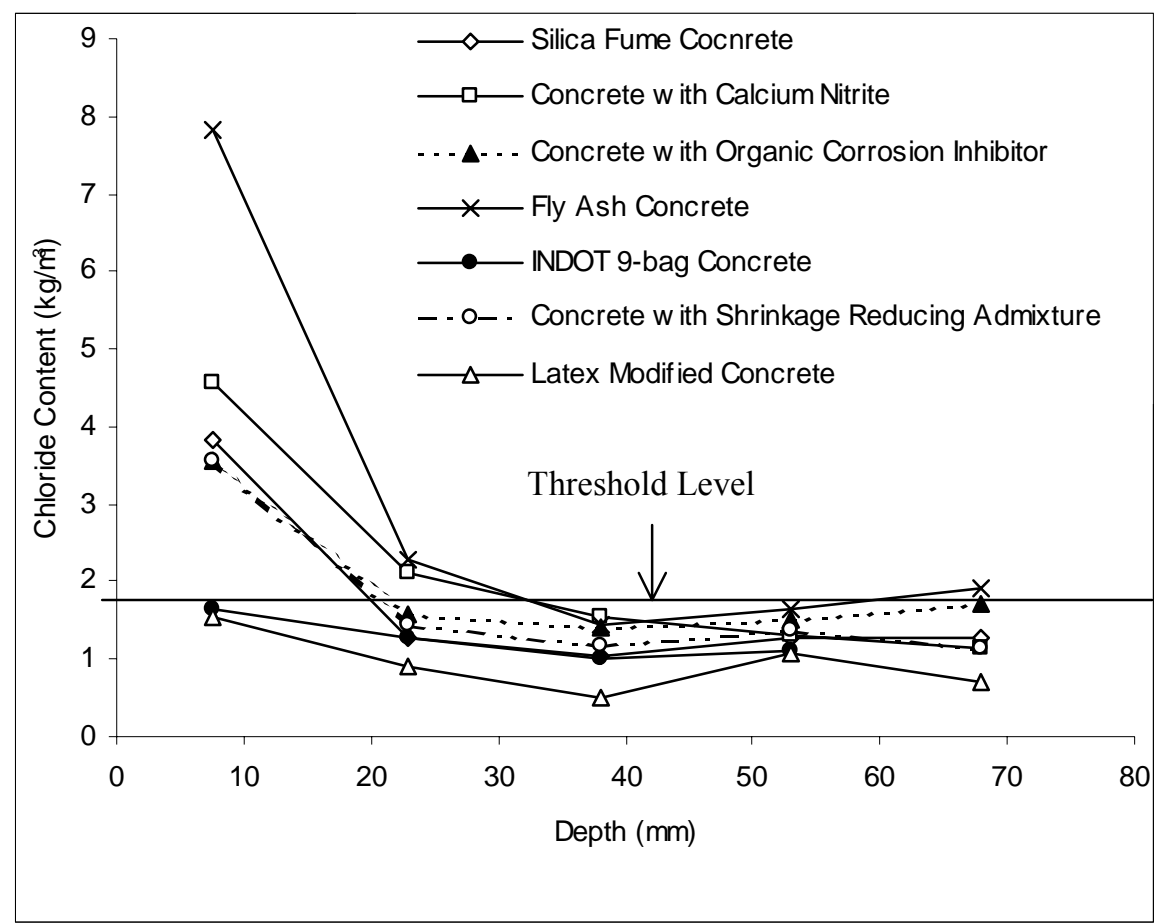

Figure 5.13 Chloride content results for different repair concrete mixes. Powder samples were taken after the concrete specimens were continuously ponded with $10 \%$ sodium chloride solution for six months. 
CHAPTER 6 MONITORING OF CORROSION OF REINFORCING STEEL IN CONCRETE USING ELECTROCHEMICAL METHODS — TEST RESULTS

In this project, three testing techniques were used to monitor the corrosion of reinforcing steel embedded in concrete. These techniques were half-cell potential, polarization resistance and electrochemical impedance spectroscopy. Half-cell potential is commonly being used to determine the probability of active corrosion of the reinforcing steel. Polarization resistance technique and electrochemical impedance spectroscopy are useful tools for quantitative evaluation of the kinetics of the corrosion process.

In the course of this project, the measurements of corrosion on the surface of the reinforcing steel were divided into two phases. The first phase started when the original reinforced concrete slabs (made from INDOT Class $\mathrm{C}$ concrete) were exposed to salt solution and ended just before the slabs were repaired with new concrete mixes. Halfcell potential measurement was the major test method performed on the specimens in this phase to monitor the corrosion process, but the other two techniques were also applied for comparative purposes. The second phase started after the slabs were repaired with new concrete and ended when the corrosion of reinforcing resulted in visible rust spots on the surface of the slabs). During this phase, half-cell potential measurements, polarization resistance measurements, and impedance spectroscopy measurements were performed on 
every repaired slab to monitor the corrosion process. In this chapter, the results of these measurements are presented and discussed.

\subsection{Half-Cell Potential Measurement}

\subsubsection{Half-Cell Potential Measurements Before Repair}

The half-cell potentials of the 24 reinforced concrete slabs were measured weekly. All slabs were made from the same concrete, cured under the same conditions, and exposed to the same drying and wetting cycles. As illustrated in Figure 4.9 the 25.4-mm deep (1-in.) corrugation was formed along the center part of each slab to reduce the concrete cover above the reinforcement to $12.7-\mathrm{mm}(0.5-\mathrm{in}$.$) and thus to accelerate the$ corrosion of the rebar. The thickness of concrete cover above the rebar in the portion of the slab not covered by the corrugation was $38.1 \mathrm{~mm}(1.5 \mathrm{in}$.$) .$

Changes in half-cell potential values were monitored as a function of the exposure time and number of wetting and drying cycles. During analysis the potentials were separated into three groups. Potentials more positive than $-200 \mathrm{mV}$ were in the first group (no-active corrosion), potentials between $-200 \mathrm{mV}$ to $-350 \mathrm{mV}$ were in the second group (uncertain), potentials more negative than $-350 \mathrm{mV}$ were in the third group (active corrosion). The percentage distribution of these three groups is shown in Figure 6.1 for points located in the middle (corrugated) section of the slab. These percentages were calculated by taking the number of points falling in one of the above three categories and dividing them by the total number of points (in this case 240) falling within the 
corrugated area. Figure 6.2 presents similar information for points located outside the corrugated zone.

These figures show that at the beginning, about $60 \%$ of the points in both the middle and the outer areas had potential values that were more positive than $-200 \mathrm{mV}$. However, the potentials measured at points located in the corrugate area became more negative during the first four weeks of exposure to wetting and drying cycles. After about four weeks, there were no points in the middle area with half-cell potential values that were more positive than $-200 \mathrm{mV}$.

For the corrugated area, the number of points with potential values between -200 and $-350 \mathrm{mV}$ decreased to less than $5 \%$ after 9 weeks of exposure, but increased to more than $40 \%$ in the following two weeks. After that, the fraction of these points continuously decreased to less than $20 \%$ after 14 weeks of exposure.

For points with a potential more negative than $-350 \mathrm{mV}$, the outer and corrugated areas showed different patterns. In the outer area, the fraction of these points increased to $55 \%$ after 5 weeks of exposure. However, at the end of the testing period, the fraction of points with a potential more negative than $-350 \mathrm{mV}$ increased to almost $100 \%$.

In the corrugated area, the fraction of the points with half-cell potential more negative than $-350 \mathrm{mV}$ was more than $90 \%$ after 6 weeks of exposure and about $100 \%$ after 9 weeks. However, after 9 weeks of exposure, there was a significant reduction in the number of points with a potential more negative than $-350 \mathrm{mV}$. The number of points with potential more negative than $-350 \mathrm{mV}$ increased continuously after the 10 th week and was more than $80 \%$ at the end of the testing. 
For points located outside the corrugated area, the percentage of points with a potential value more positive than $-200 \mathrm{mV}$ was about $0 \%$ after 4 weeks, as shown in Figure 6.2 It also can be observed from this figure that at the beginning of the test only $25 \%$ of the points had potential values between -200 to $-350 \mathrm{mV}$. After one week of exposure to wetting and drying cycles, more than $70 \%$ of the points were in the range of -200 to $-350 \mathrm{mV}$. After 11 weeks of exposure, there were only about $10 \%$ of the points were still in that range.

\subsubsection{Half-Cell Potential Measurement After Repair}

After exposure to wetting and drying cycles for 14 weeks, the reinforced concrete slabs were repaired with new concrete mixes. The slabs were divided into seven groups, each containing three slabs. Seven different concrete mixes were used to repair the slabs, as discussed in Section 4.3. Half-cell potential measurements were started after the slabs were cured for seven days. In order to compare the effects of different concrete mixes on the half-cell potential change in the repaired slabs, the half-cell potentials of each slab are presented. Due to large number of data, the measured values of half-cell potentials for repaired slabs are presented in Appendix D.

In general, the half-cell potentials of repaired slabs changed significantly compared with the half-cell potentials of the original slabs, especially in the corrugated area. Except for slabs repaired by latex modified concrete and fly ash concrete, the potentials in the repaired area of the slabs became more positive than those measured in the outer points. Reinforced concrete slabs repaired with concrete containing the anodic 
corrosion inhibitor (slabs 3A, 3B and 3C) had very significant change in the potentials of the points located within the corrugated area, with most of the points being more positive than $-200 \mathrm{mV}$. This indicated that the reinforcing steel was not undergoing corrosion. Slabs repaired with the silica fume concrete, INDOT 9-bag mix concrete, and concrete with the organic corrosion inhibitor showed similar patterns as those repaired with concrete containing anodic corrosion inhibitor, with respect to development of the halfcell potentials. Slabs repaired with the fly ash concrete and latex modified concrete did not show significant difference in half-cell potentials between the repaired and the remaining portions of the slab.

The potentials of the repaired portion of the slabs became more and more negative with the increase in exposure time. After eight weeks of exposure, the half-cell potentials of the repaired and the remaining portions of the slabs were about the same. At that time, most of the points in both areas had half-cell potential values that were more negative than $-350 \mathrm{mV}$.

\subsubsection{Discussion of Half-Cell Potential Results}

\subsubsection{Original Slabs (Before Repair)}

Corrosion occurred first on the reinforcing steel in the middle area of the slab, where the concrete cover was thinner than the cover in the outer area. As shown in Figure 6.1 after six weeks of exposure more than $90 \%$ of the middle points had a halfcell potential value of more negative than $-350 \mathrm{mV}$, indicating more than $90 \%$ 
probability of corrosion [ASTM C 876-91, Test Method for Half Cell Potentials of Uncoated Reinforcing Steel in Concrete]. For the outer portions of the slab, the half-cell potentials also become more negative with the exposure time, but the change was more gradual when compared with that of the middle portion. After six weeks of exposure, about $50 \%$ of the points of the outer portions had a half-cell potential value more negative than $-350 \mathrm{mV}$, as shown in Figure 6.2 . After 11 weeks of exposure, about $85 \%$ of the points in the outer portions had a half-cell potential value more negative than -350 $\mathrm{mV}$.

It could be observed that after initial increase, the percentage of points with active corrosion potentials dropped with the exposure time. This is most likely due to the fact that after active corrosion had continued for a while, the corrosion products had accumulated in the vicinity of the steel. These corrosion products may have blocked the access of chloride ions, water, and oxygen, to the steel surface. As a result, the corrosion reactions were obstructed and the corrosion rate decreased.

\subsubsection{Slabs After Repair}

Anodic corrosion inhibitor (calcium nitrite) stabilizes the passive film on the surface of the steel. The more stable the passive film, the more it can reduce the corrosion rate to a very low level. This is the reason for the significant decrease in the half-cell potentials in the repaired area of slabs repaired with concrete containing the calcium nitrite inhibitor. The results obtained for silica fume concrete, concrete with the organic corrosion inhibitor, concrete with shrinkage reducing agent, and INDOT 9-bag 
cement concrete indicate that the steel was able to form a stable passive film as a result of repair. This was due to the high alkalinity of the concrete pore solution. The potential decrease in fly ash concrete was less significant than that of the INDOT 9-bag mix. For the latex modified concrete, no significant re-passivation of the reinforcing steel was observed.

\subsection{Linear Polarization Resistance Measurement}

Linear polarization resistance technique was used in this project to measure the corrosion rate of steel embedded in concrete. The basis of this technique was discussed in Section 2.4.2. In this section, the measured polarization resistance and the corresponding corrosion rate are presented and discussed.

\subsubsection{Results from Polarization Resistance (PR) Method}

\subsubsection{Original Slabs (Before Repair)}

Before repair, the polarization resistance of the reinforced concrete slabs was measured periodically. The results of the measurements are presented in Figure 6.3 (a). The corresponding corrosion current density is shown in Figure 6.3 (b). It can be seen that the polarization resistance decreased and the corrosion current density increased as the exposure time increased. At the beginning, the corrosion current density was about $0.45 \mu \mathrm{A} / \mathrm{cm}^{2}$. After about six months, the corrosion current density was about 3.0 
$\mu \mathrm{A} / \mathrm{cm}^{2}$. The corrosion current density after six months indicated that the relative corrosion rate of the steel was high.

\subsubsection{2 $\underline{\text { Slabs After Repair }}$}

The results of the polarization resistance measurements of the reinforced concrete slabs after repair are shown in Figures 6.4 (a) to 6.10 (a). It can be seen from these figures that generally, the polarization resistance of the reinforced concrete slabs decreased with the increase of exposure time. However, the rates of decrease in the polarization resistance varied between slabs repaired with different concrete mixes. The slabs that were repaired with silica fume concrete, fly ash concrete, concrete with shrinkage reducing admixture, and latex modified concrete showed significant decrease in the polarization resistance. Only small changes in the polarization resistance were observed for concrete slabs repaired by concrete with calcium nitrite, concrete with the organic corrosion inhibitor, and the INDOT 9-bag cement concrete had small changes in the polarization resistance.

Slabs repaired with silica fume concrete had an initial polarization resistance of about 50,000 ohm- $\mathrm{cm}^{2}$, as shown in Figure 6.4 (a). But the polarization resistance decreased to less than $20,000 \mathrm{ohm}-\mathrm{cm}^{2}$ after about 180 days of exposure to salt solution. Compared with the polarization resistance of the slabs before they were repaired with the silica fume concrete, the slabs developed high (above 50,000 ohm- $\mathrm{cm}^{2}$ ) polarization resistance after the repair. 
Reinforced concrete slabs repaired by the concrete with the anodic corrosion inhibitor (calcium nitrite) had a relatively low polarization resistance, or about 18,000 ohm- $\mathrm{cm}^{2}$, as shown in Figure 6.5 (a). The polarization resistance of these slabs did not change significantly during the exposure time.

Slabs repaired with concrete containing organic corrosion inhibitor had a polarization resistance of $18,000 \mathrm{ohm}-\mathrm{cm}^{2}$, as shown in Figure 6.6 (a). This value did not change significantly during the first 180 days of exposure.

Concrete slabs repaired with the fly ash concrete had polarization resistance of about 30,000 ohm- $\mathrm{cm}^{2}$ after the repair, as shown in Figure 6.7 (a). After 180 days of exposure, the polarization resistance of these concretes was reduced to about 17,000 ohm-cm ${ }^{2}$.

Slabs repaired with the INDOT 9-bag cement concrete mix for repair had a polarization resistance of $31,000 \mathrm{ohm}-\mathrm{cm}^{2}$ just after repair, as shown in Figure 6.8 (a). After 180 days of exposure to wetting and drying, the polarization resistance of these concretes was about $30,000 \mathrm{ohm}-\mathrm{cm}^{2}$.

Three slabs were repaired with containing shrinkage reducing admixture. Polarization resistance of these slabs decreased with exposure time, as shown in Figure 6.9 (a), from about $40,000 \mathrm{ohm}-\mathrm{cm}^{2}$ (value measured right after repair) to $27,000 \mathrm{ohm}$ $\mathrm{cm}^{2}$ after about 180 days of exposure.

Slabs repaired with latex modified concrete had polarization resistance of 20,000 ohm- $\mathrm{cm}^{2}$ which decreased to about $10,000 \mathrm{ohm}-\mathrm{cm}^{2}$ after about 180 days of exposure, as shown in Figure 6.10 (a). Compared with the polarization resistance of the slabs before 
the repair, the slabs repaired with latex modified concrete did not attain high polarization resistance.

The corrosion current density of the slabs after repair was calculated based on the measured polarization resistance, and the results are presented in Figures 6.4 (b) to 6.10 (b). It can be seen from these figures that for slabs repaired with the silica fume concrete, fly ash concrete, concrete with shrinkage reducing admixture, and latex modified concrete, the corrosion current density increased with the increase in exposure time.

The corrosion current density of the slabs repaired with calcium nitrite concrete, organic corrosion inhibitor concrete, and INDOT 9-bag cement concrete did not change significantly during the exposure time. For this group of concretes, the current density was about 1.0 to $1.2 \mu \mathrm{A} / \mathrm{cm}^{2}$, which was lower than that measured before the slabs were repaired $\left(3.0 \mu \mathrm{A} / \mathrm{cm}^{2}\right)$.

\subsubsection{Discussion on the Results of Polarization Resistance Measurement}

Generally, the polarization resistance of reinforced concrete slabs was reduced with the exposure time. The slabs repaired with the silica fume concrete, fly ash concrete, and concrete with shrinkage reducing admixture had high polarization resistance when compared with the slabs before repair. Slabs repaired with calcium nitrite concrete did not show significant changes in both polarization resistance and corrosion current density. 
For slabs repaired with silica fume concrete and concrete with shrinkage reducing admixture, the observed high polarization resistance can be attributed to the low permeability of concrete. Calcium nitrite and organic corrosion inhibitors did not change the polarization resistance of the slabs significantly, but they maintained the corrosion current density at a stable level during the time of exposure.

Slabs repaired with latex modified concrete had relatively low polarization resistance. This can be attributed to the low alkalinity of latex modified concrete. For slabs repaired with fly ash concrete, the relatively low polarization resistance is due to the high permeability of this concrete at early age. For slabs repaired with INDOT 9-bag cement concrete, the polarization resistance was relatively constant. This is due to the high alkalinity of the concrete, which kept the reinforcement in a passive state.

\subsection{Monitoring Corrosion Process by Electrochemical Impedance Spectroscopy}

Electrochemical impedance spectroscopy (EIS) was used to evaluate the corrosion process of the reinforcing steel. Unlike the polarization resistance method, the electrochemical impedance spectroscopy is basically an AC method involving an impression of an alternating potential of small amplitude (but over a very wide frequency range) on the corroding electrode. The response of the corroding electrode is recorded and analyzed by the use of an equivalent circuit. In the following sections, the results of the impedance spectroscopy measurements are presented and discussed. 


\subsubsection{Results from EIS Method}

During the analysis, the information obtained from the impedance spectroscopy measurements were separated into two parts. The first part was focused on the performance of the concrete cover of the reinforced concrete slabs. The second part was focused on the behavior of the steel surface and the value of the corrosion rate.

\subsubsection{Impedance Spectra of the Reinforced Concrete Slabs}

The impedance spectra obtained from the reinforced concrete slabs after repair are shown in Figures 6.11 to 6.17 (slabs 2A, 2B, and 2C were repaired with silica fume concrete; slabs $3 \mathrm{~A}, 3 \mathrm{~B}$, and $3 \mathrm{C}$ were repaired with concrete with calcium nitrite inhibitor; slabs $4 \mathrm{~A}, 4 \mathrm{~B}$, and $4 \mathrm{C}$ were repaired with concrete containing the organic corrosion inhibitor; slabs $5 \mathrm{~A}, 5 \mathrm{~B}$, and $5 \mathrm{C}$ were repaired with fly ash concrete; slabs $6 \mathrm{~A}, 6 \mathrm{~B}$, and $6 \mathrm{C}$ were repaired with INDOT 9-bag cement concrete; slabs 7A, 7B, and 7C were repaired with concrete containing shrinkage reducing admixture; slabs $8 \mathrm{~A}, 8 \mathrm{~B}$, and $8 \mathrm{C}$ were repaired with latex modified concrete). The data are presented as Nyquist plots. Examinations of all the impedance spectra show some common characteristics. Partial arcs were observed in the Nyquist plots for all reinforced concrete specimens. A tail of an arc was in the high frequency range. The arc decreased with the increase in the exposure time.

Electrical parameters of the equivalent circuit were calculated based on the measured data. These parameters included the depression angle of the constant phase element, $\alpha$ (alpha), the constant phase element (CPE) characteristic value, $\mathrm{C}_{\mathrm{c}}$, the concrete resistance, $R_{c}$, and the polarization resistance, $R_{p}$. 


\subsubsection{Characterization of the Concrete Matrix}

The resistivity of concrete is presented with a unit of ohm-cm. The results showed that slabs repaired with different concrete mixes had different values and different characteristic trend patterns.

Slabs (2A, 2B, and 2C) repaired with the silica fume concrete had a resistivity of 4,400 ohm-cm just after the repair, as shown in Figure 6.18. The resistivity decreased to about 2,000 ohm-cm after the slabs were exposed to the wetting and drying cycles for a period of 180 days.

Concrete with the anodic corrosion inhibitor (calcium nitrite) was used to repair slabs of 3A, 3B, and 3C. These slabs, as expected, had a lower concrete resistance, as shown in Figure 6.19 since the addition of ions to this concrete decreased its resistivity. It can also be seen that the concrete resistivity did not decrease during the exposure time.

The resistivity values of slabs repaired with organic corrosion inhibitor concrete, shown in Figure 6.20, follow trends similar to those observed in concrete containing calcium nitrite.

Slabs repaired with fly ash concrete (Figure 6.21) had relatively high resistivity. This may be due to changes in the amount and composition of the pore solution. The resistivity remained essentially constant over the exposure time.

Slabs repaired by the INDOT 9-bag cement concrete mix had a resistivity of about 2,000 ohm-cm, as shown in Figure 6.22. The concrete resistivity did not decrease during the exposure time.

Shrinkage reducing admixture was expected to reduce the concrete resistivity because of the increase in ion concentration in the concrete pore solution. On the other 
hand, the addition of shrinkage reducing admixture reduces the cracks in the concrete. This effect may increase the resistivity of the concrete. As indicated by the resistivity values of the slabs repaired by using concrete with the shrinkage reducing admixture, shown in Figure 6.2 3 , the concrete resistivity increased as the slabs were exposed to wetting and drying cycles.

Figure 6.24 shows the resistivity values of the slabs repaired with the latex modified concrete. The resistivity of this concrete remained relatively constant (about 2,000 ohm-cm) during the exposure period.

\subsubsection{Characterization of the Corrosion Process}

Figures 6.25 (a) to 6.31 (a) show that the polarization resistance of concrete changes with exposure time. Corrosion current densities calculated from polarization resistance are presented in Figures 6.25 (b) to 6.31 (b). The values of the characteristic parameter of the constant phase element $(\mathrm{CPE}), \mathrm{C}_{\mathrm{c}}$, are shown in Figures 6.32 to 6.38 . The $\alpha$ values, which are constants used to represent the degree of perfection of the capacitor and extent to which the arc of the impedance is depressed, are presented in Figures 6.39 to 6.45 .

Polarization resistance decreased with the increase in exposure time. For the slabs repaired with silica fume concrete, shown in Figure 6.25 (a), and the slabs repaired with concrete containing calcium nitrite, shown in Figure 6.26 (a), the patterns of the polarization resistance during the exposure time are similar. At the beginning, the slabs repaired with silica fume concrete had a polarization resistance value of about 60,000 ohms- $\mathrm{cm}^{2}$. For the slabs repaired with the calcium nitrite concrete, the initial 
polarization resistance was about $52,000 \mathrm{ohms}-\mathrm{cm}^{2}$. In both cases, the polarization resistance decreased upon prolonged exposure, reaching values as low as 10,000 ohms$\mathrm{cm}^{2}$ and 25,000 ohm- $\mathrm{cm}^{2}$ for silica fume can calcium nitrite concrete, respectively, after about 180 days of exposure to wetting and drying cycles.

The polarization resistance values of the slabs repaired with concrete containing organic corrosion inhibitor decreased during the exposure time, as shown in Figure 6.27 (a). After the repair, the slabs had a polarization resistance of about 25,000 ohms-cm ${ }^{2}$. This value dropped to about $10,000 \mathrm{ohms}-\mathrm{cm}^{2}$ after 180 days of exposure.

Figure 6.28 (a) shows the polarization resistance of the slabs repaired with fly ash concrete. These slabs had low polarization resistance values. This is due to the relatively low alkalinity of the concrete pore solution of the fly ash concrete. After 180 days of exposure, the polarization resistance of the slabs repaired with INDOT 9-bag cement concrete was about $25,000 \mathrm{ohms}-\mathrm{cm}^{2}$, while the value for fly ash concrete was 10,000 ohms-cm ${ }^{2}$

Slabs repaired with concrete containing the shrinkage reducing admixture had an initial polarization resistance value of $55,000 \mathrm{ohms}-\mathrm{cm}^{2}$, as shown in Figure 6.30 (a). After 180 days of exposure, the polarization resistance was down about 33,000 ohms$\mathrm{cm}^{2}$

The polarization resistance values for the slabs repaired with latex modified concrete, as shown in Figure 6.31 (a), were lower than those of the other slabs. They decreased with the increase in exposure time.

The corrosion current density of the slabs (shown in Figures 6.25 (b) to 6.31 (b)) based on the electrochemical impedance spectroscopy indicated that the corrosion rate 
increased with the increase in exposure time. When comparing these figures with the companion figures obtained from the polarization resistance method, different patterns and values can be observed. For example, the corrosion current density of the slabs repaired with silica fume concrete had a value of $2.0 \mu \mathrm{A} / \mathrm{cm}^{2}$ based on the polarization resistance method. The value obtained from electrochemical impedance spectroscopy was about $5.0 \mu \mathrm{A} / \mathrm{cm}^{2}$.

For all the slabs, except for those repaired by silica fume concrete, the characteristic parameter for the CPE did not change significantly during the exposure time, as shown in Figures 6.32 to 6.38 . This indicated that the capacitance of the steel bar surface did not change significantly during the exposure time.

Figures 6.39 to 6.45 show the alpha $(\alpha)$ values of the slabs. Except for the slabs repaired with latex modified concrete, the alpha values decreased with the increase in exposure time. Insignificant corrosion is assumed when $\alpha>0.9$, and heavy corrosion when $\alpha<0.6$ [Gu P., et al., 1997]. Based on this rule, corrosion would be expected to occur in the slabs repaired with silica fume concrete, concrete with organic corrosion inhibitor, and fly ash concrete. The probability of corrosion was lower in the slabs repaired with concrete containing calcium nitrite, INDOT 9-bag cement concrete, and latex modified concrete. 


\subsubsection{Discussion on the Results of EIS}

For all slabs, except those repaired with silica fume concrete, the resistivity of the concrete did not change significantly during the exposure time. The values of the resistivity were below 3,500 ohm-cm after about 180 days of exposure.

Polarization resistance increased after the slabs were repaired with new concrete mixes. However, the polarization resistance decreased with the increase in exposure time. This indicated that the corrosion rate increased with the increase in exposure time. Since the concrete resistivity did not decrease (except for slabs repaired with silica fume concrete), the increase in corrosion rate is due to the availability of chloride ions, oxygen, and moisture.

After repair, the slabs repaired with silica fume concrete and fly ash concrete had high concrete resistivity. This is due to the densification of microstructure resulting from pozzolanic reaction and reduction of permeability.

Corrosion current density for slabs repaired with concrete containing calcium nitrite was low, about 0.5 to $1.2 \mu \mathrm{A} / \mathrm{cm}^{2}$. This indicates that, as an anodic corrosion inhibitor, calcium nitrite could maintain the steel surface in a passive state.

When compared with fly ash concrete and silica fume concrete, INDOT 9-bag cement concrete had low resistivity. But the slabs repaired with INDOT 9-bag cement concrete had low corrosion current density during the exposure time. This is due to the high alkalinity of the concrete pore solution, which can maintain the steel surface in passive state. The threshold concentration of chloride ions for initiation of corrosion is high if the alkalinity of the concrete pore solution is also high. 
Latex modified concrete has limited ability to keep the steel in passive state, as it does not significantly increase the alkalinity of the pore solution. Latex concrete is usually used to overly reinforced concrete decks. It can prevent water and other corrosive substances from penetrating into concrete.

\subsection{Summary}

Corrosion process of the reinforcing steel can be investigated by the electrochemical techniques. Half-cell potential measurements are based on the thermodynamic principles of the corrosion reaction. They can be used to qualitatively determine the probability of corrosion, but cannot indicate the rate of the corrosion reaction.

Polarization resistance and electrochemical impedance spectroscopy techniques can be used to quantitatively determine the kinetics of the corrosion reaction. The results from electrochemical impedance spectroscopy were similar to those determined by the polarization resistance method.

Based on corrosion current density, calcium nitrite provided better corrosion protection than organic corrosion inhibitor. Concrete without mineral admixtures maintained high polarization resistance, and kept the corrosion rate low during the exposure time.

For the repaired concrete slabs, the resistivity did not change significantly during the exposure time. The acceleration of corrosion rate could be attributed to the availability of chloride ions, oxygen, and moisture. 


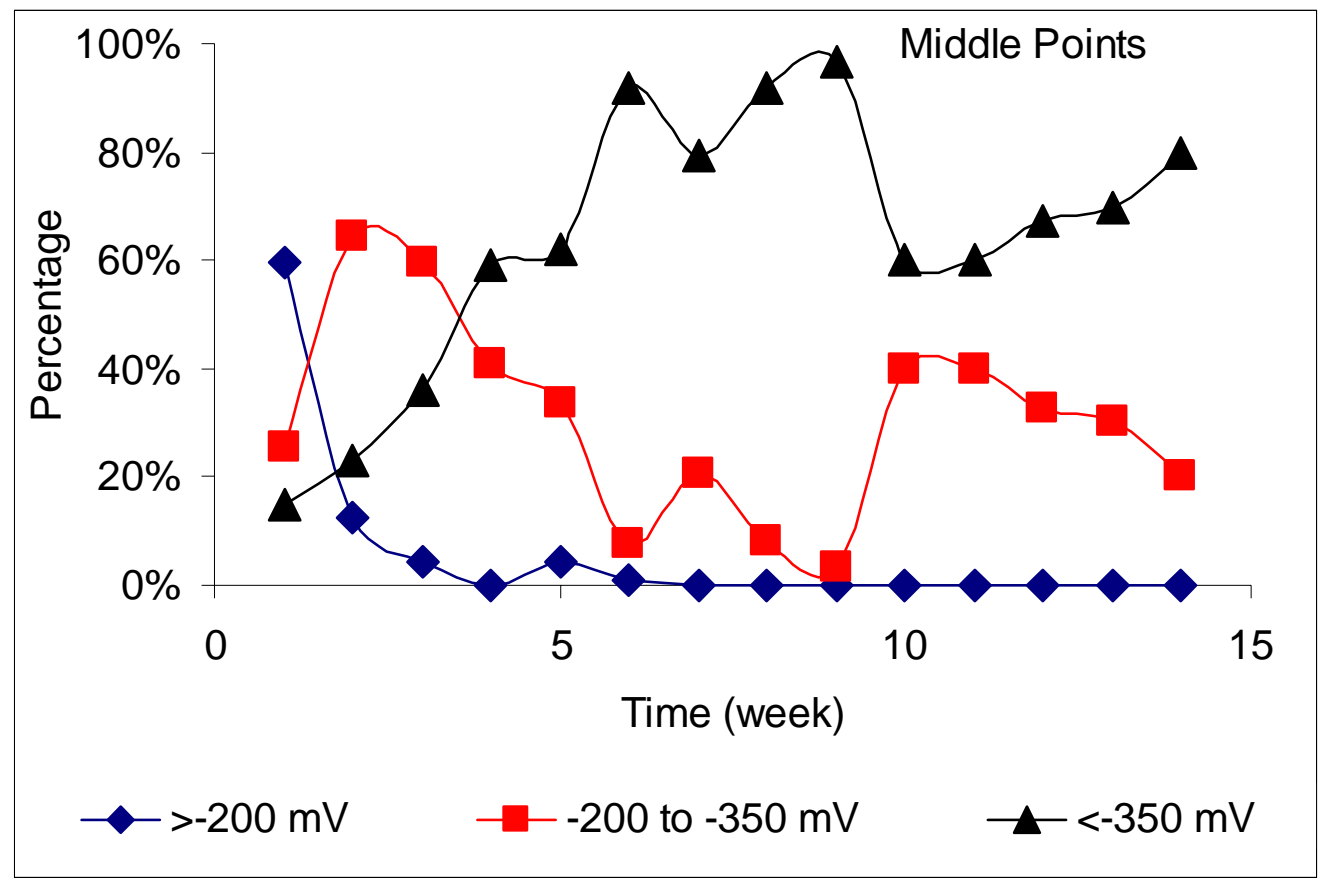

Figure 6.1 Distribution of half-cell potentials for the middle (corrugated) part of the slabs (before repair).

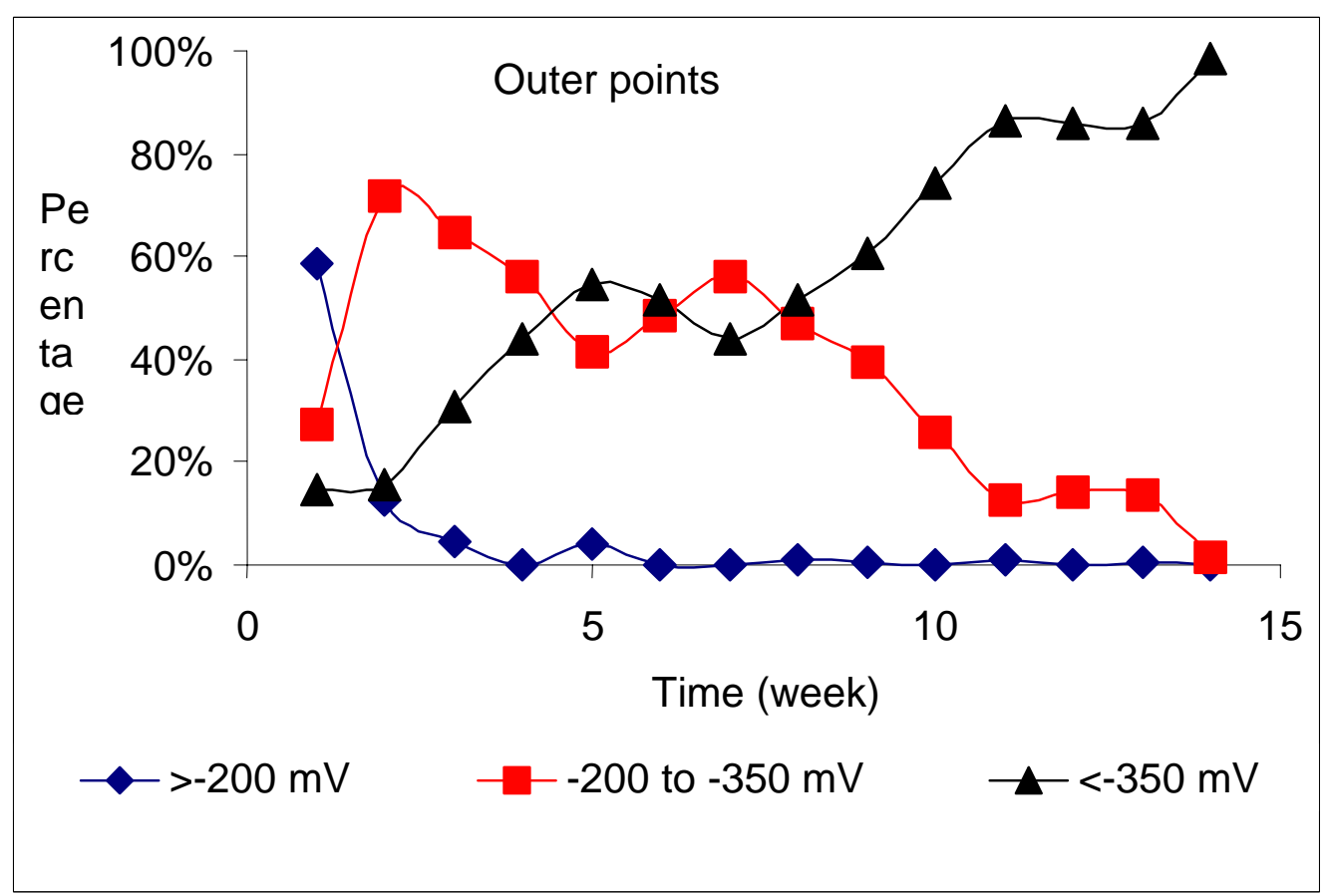

Figure 6.2 Distribution of half-cell potentials for the outer (outside the corrugated zone) parts of the slabs (before repair). 


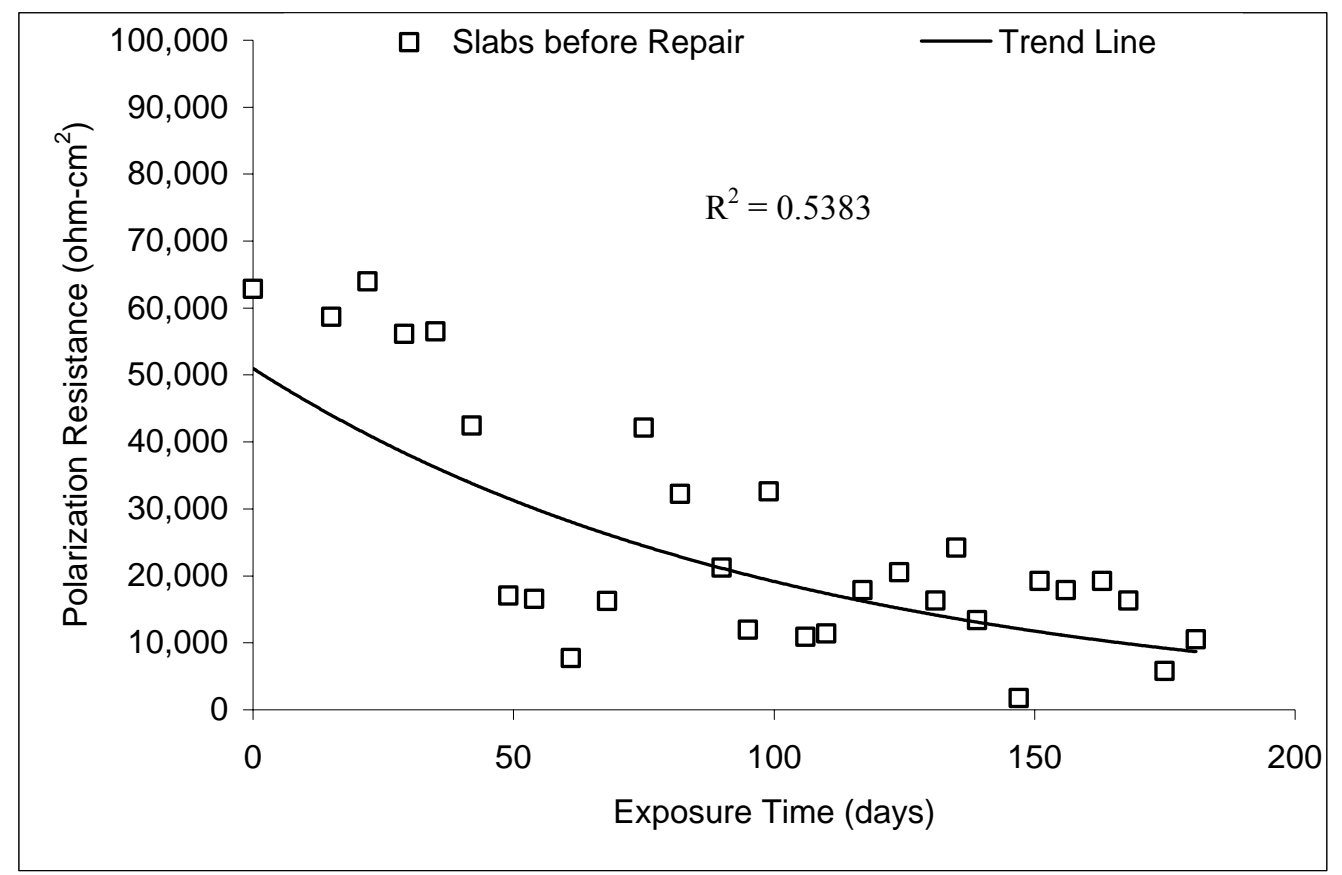

Figure 6.3 (a) Polarization resistance (from PR method) for the slabs before repair.

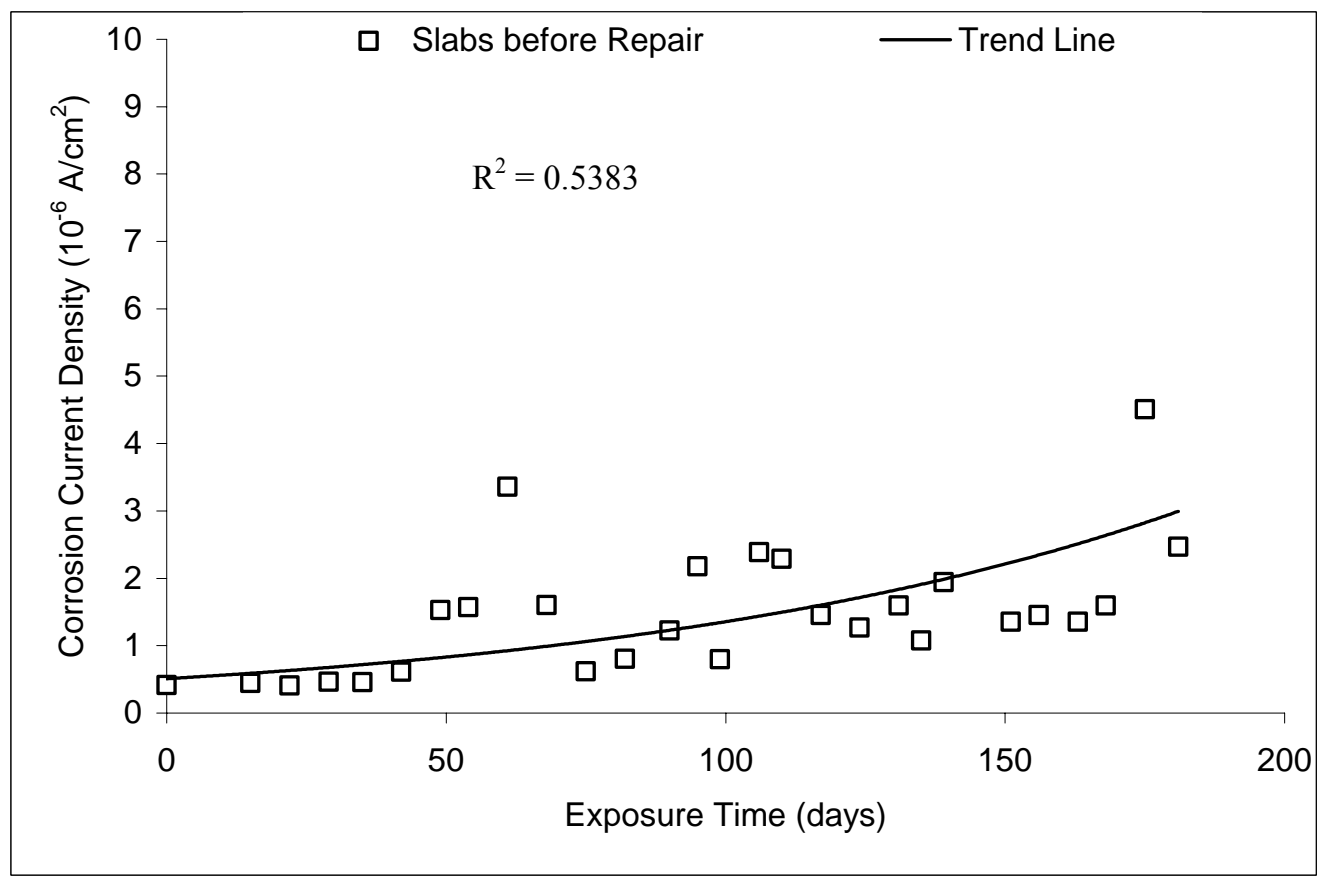

Figure 6.3 (b) Corrosion current density (from PR method) for the slabs before repair. 


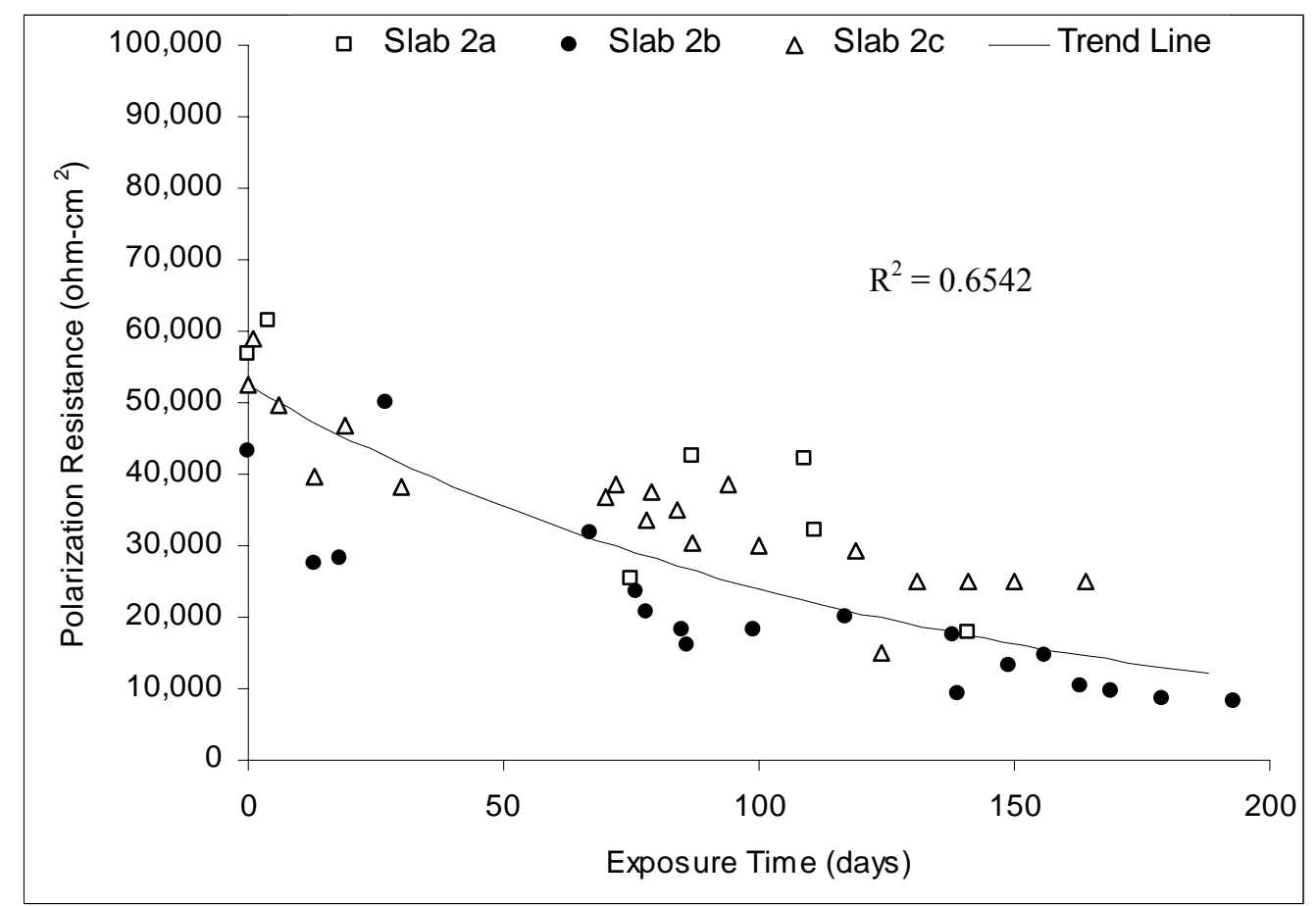

Figure 6.4 (a) Polarization resistance (from PR method) for the concrete slabs repaired by the silica fume concrete.

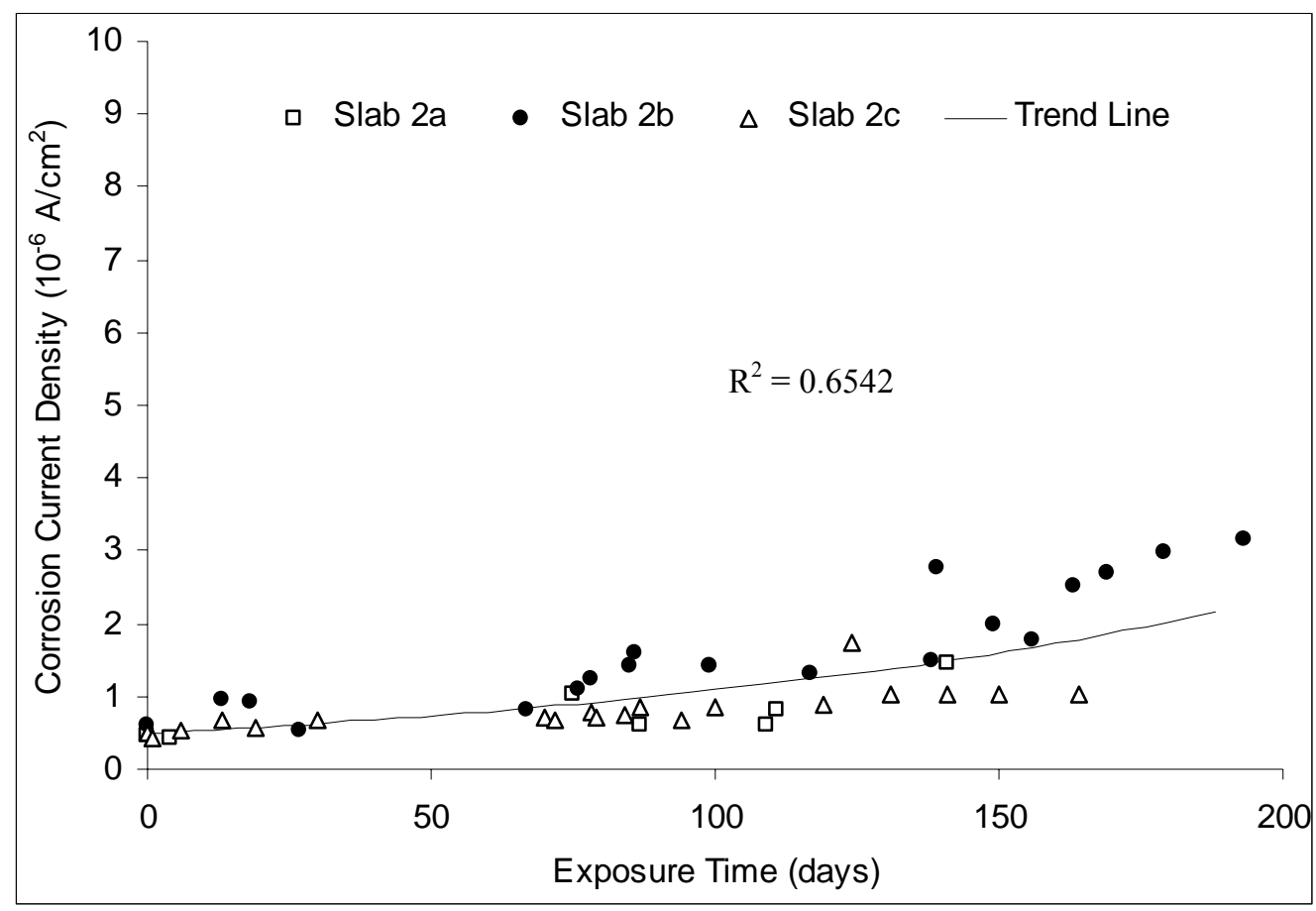

Figure 6.4 (b) Corrosion current density (from PR method) for the slabs repaired by the silica fume concrete. 


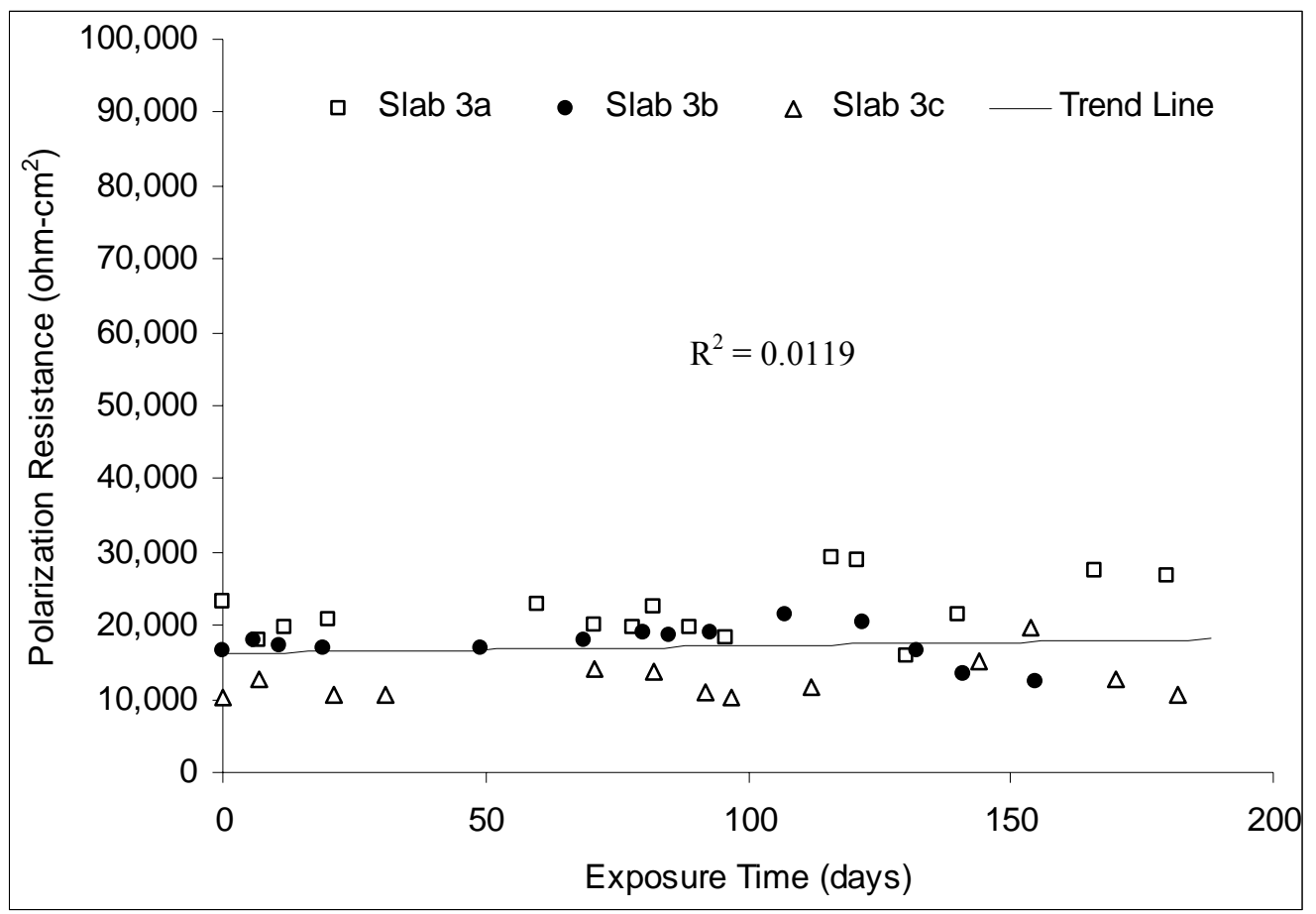

Figure 6.5 (a) Polarization resistance (from PR method) for the concrete slabs repaired by the calcium nitrite concrete.

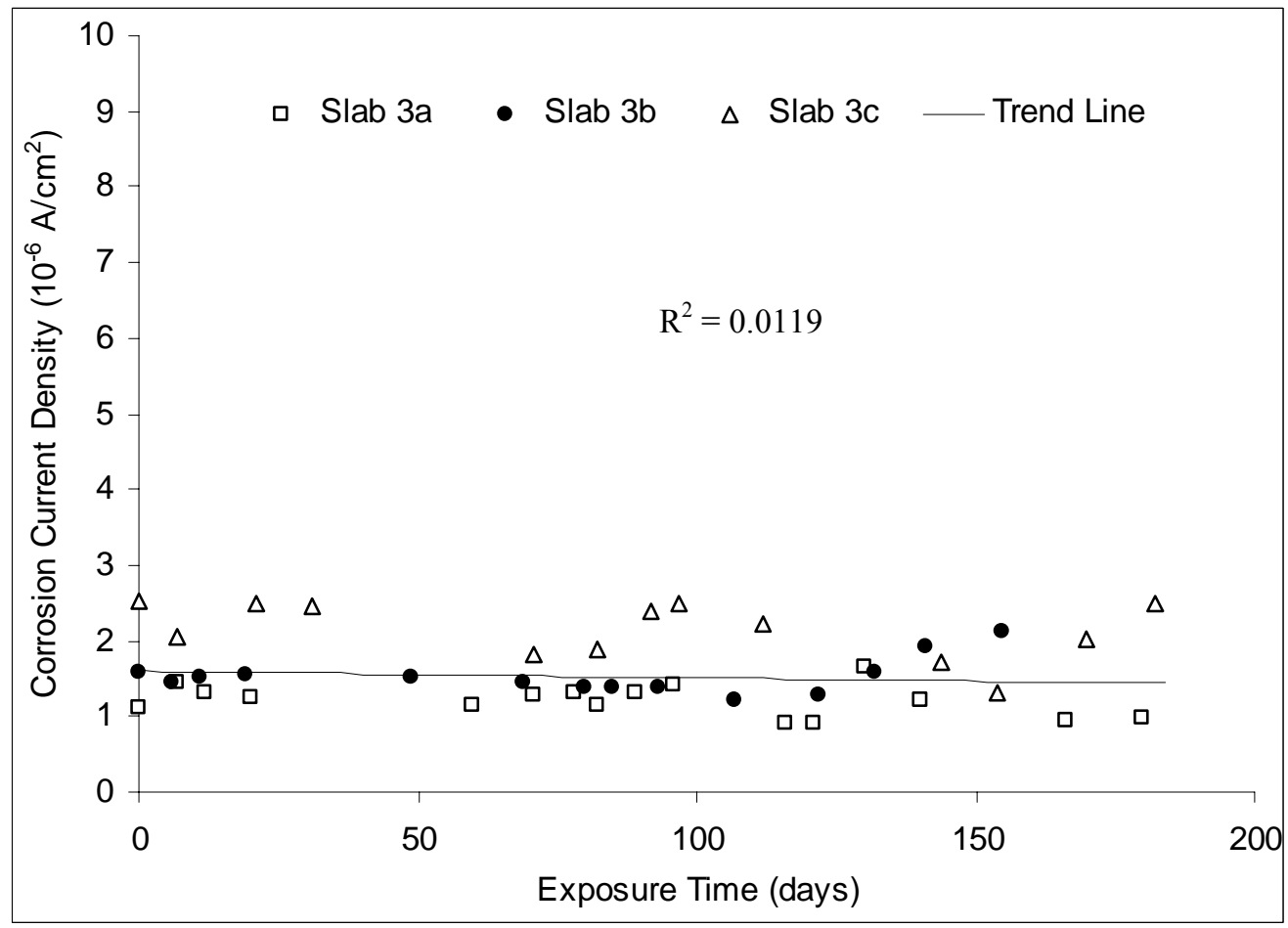

Figure 6.5 (b) Corrosion current density (from PR method) for the slabs repaired by the concrete with calcium nitrite. 


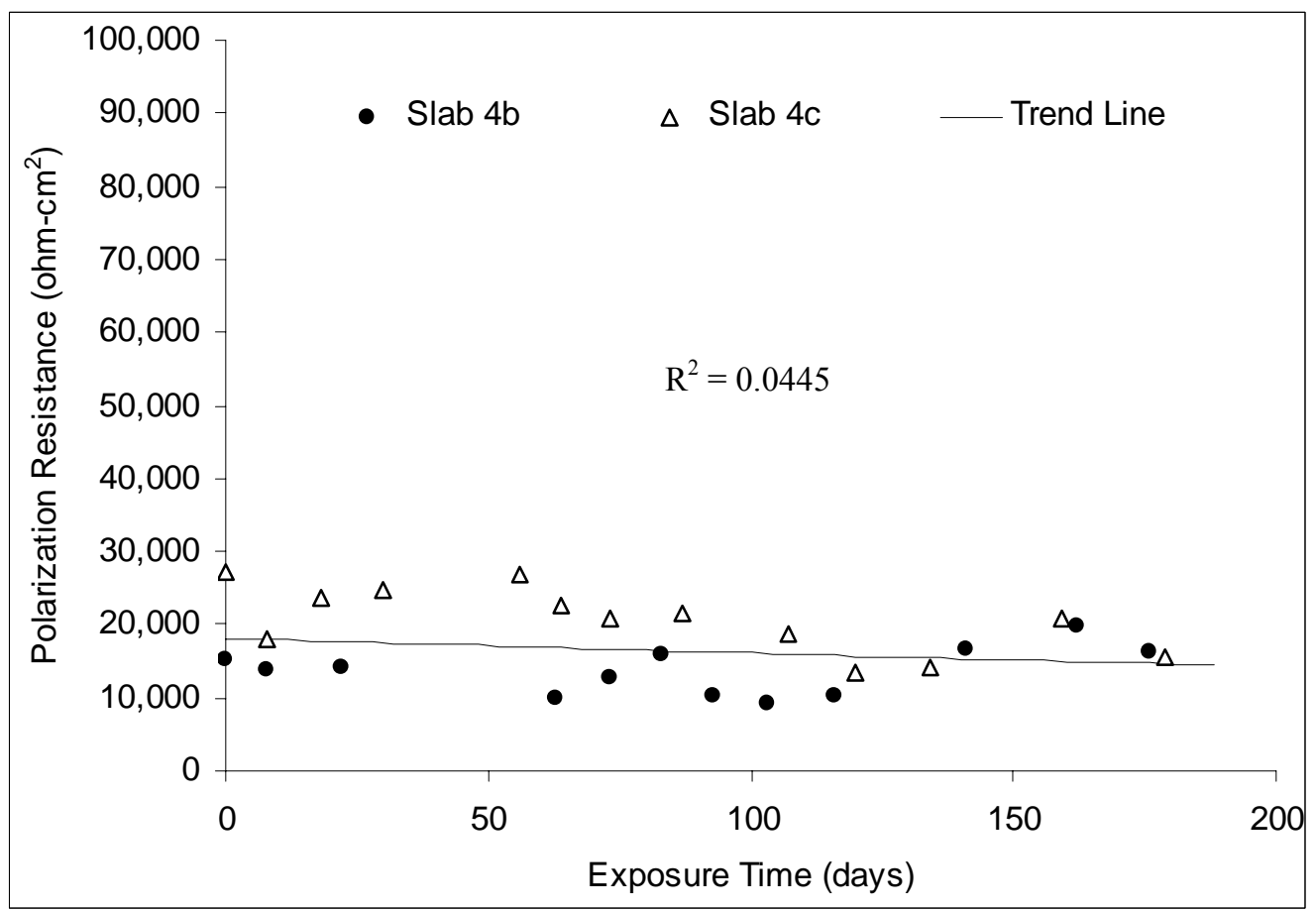

Figure 6.6 (a) Polarization resistance (from PR method) for the concrete slabs repaired by concrete with the organic corrosion inhibitor.

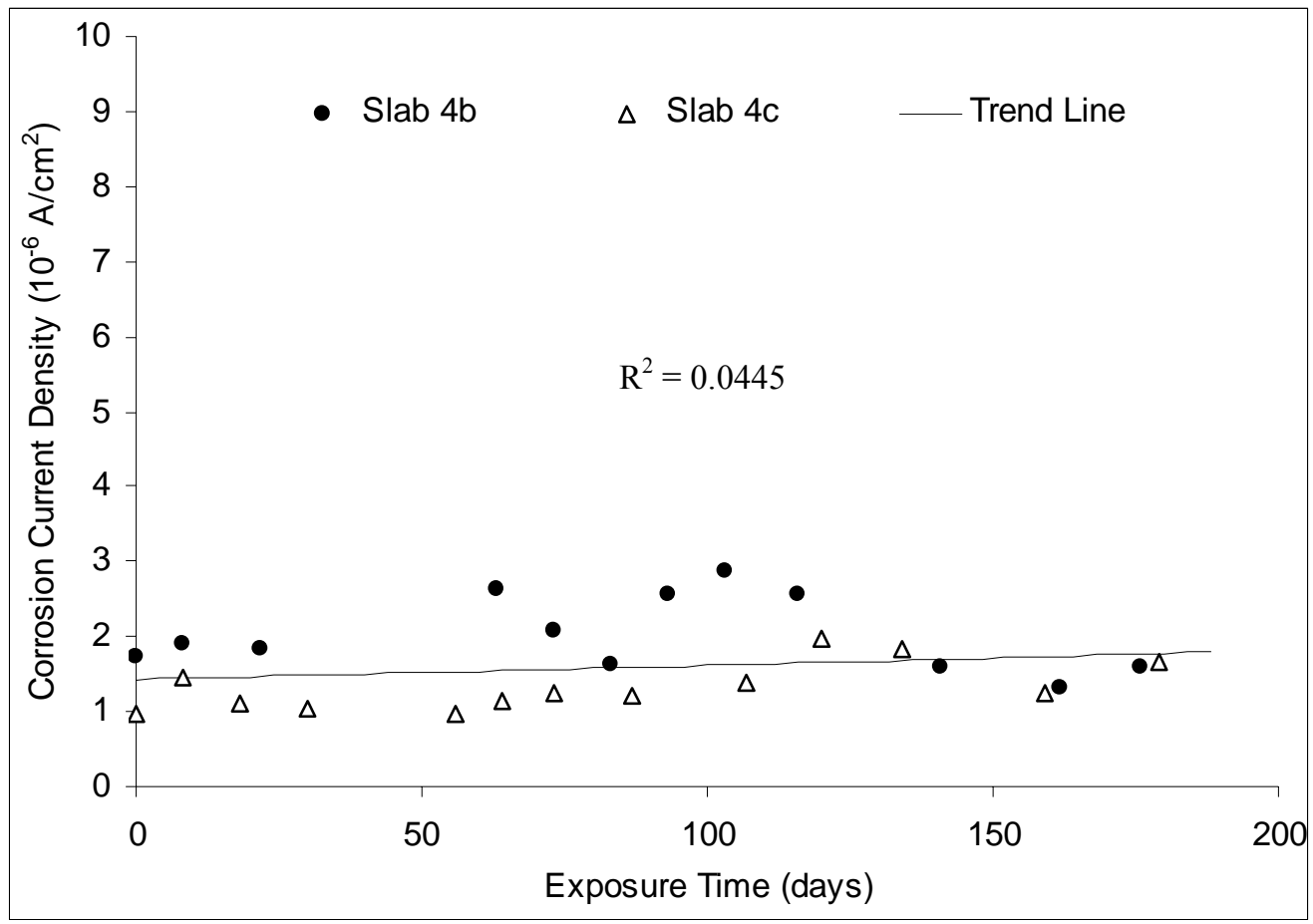

Figure 6.6 (b) Corrosion current density (from PR method) for the slabs repaired by concrete with organic corrosion inhibitor. 


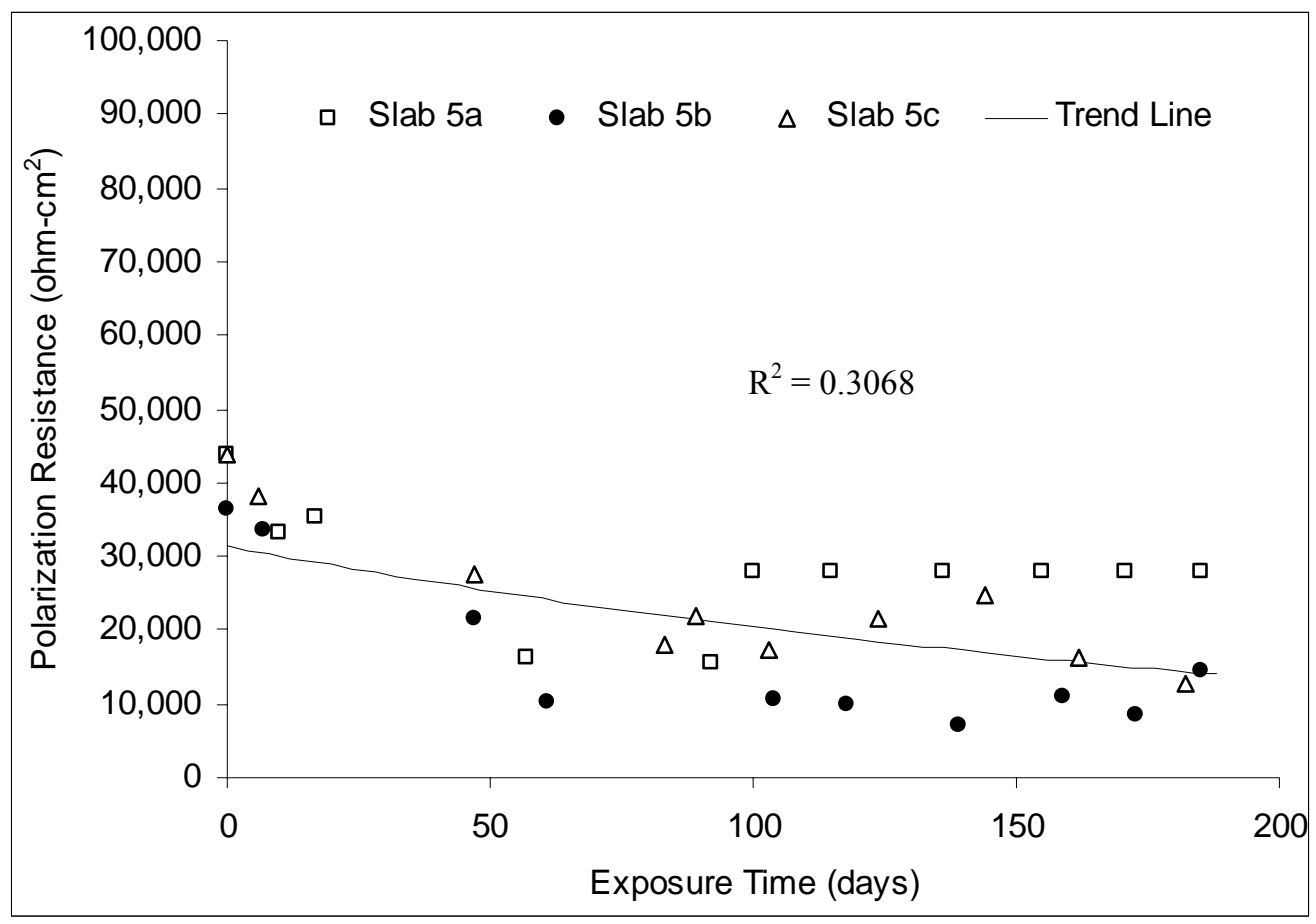

Figure 6.7 (a) Polarization resistance (from PR method) for the concrete slabs repaired by the fly ash concrete.

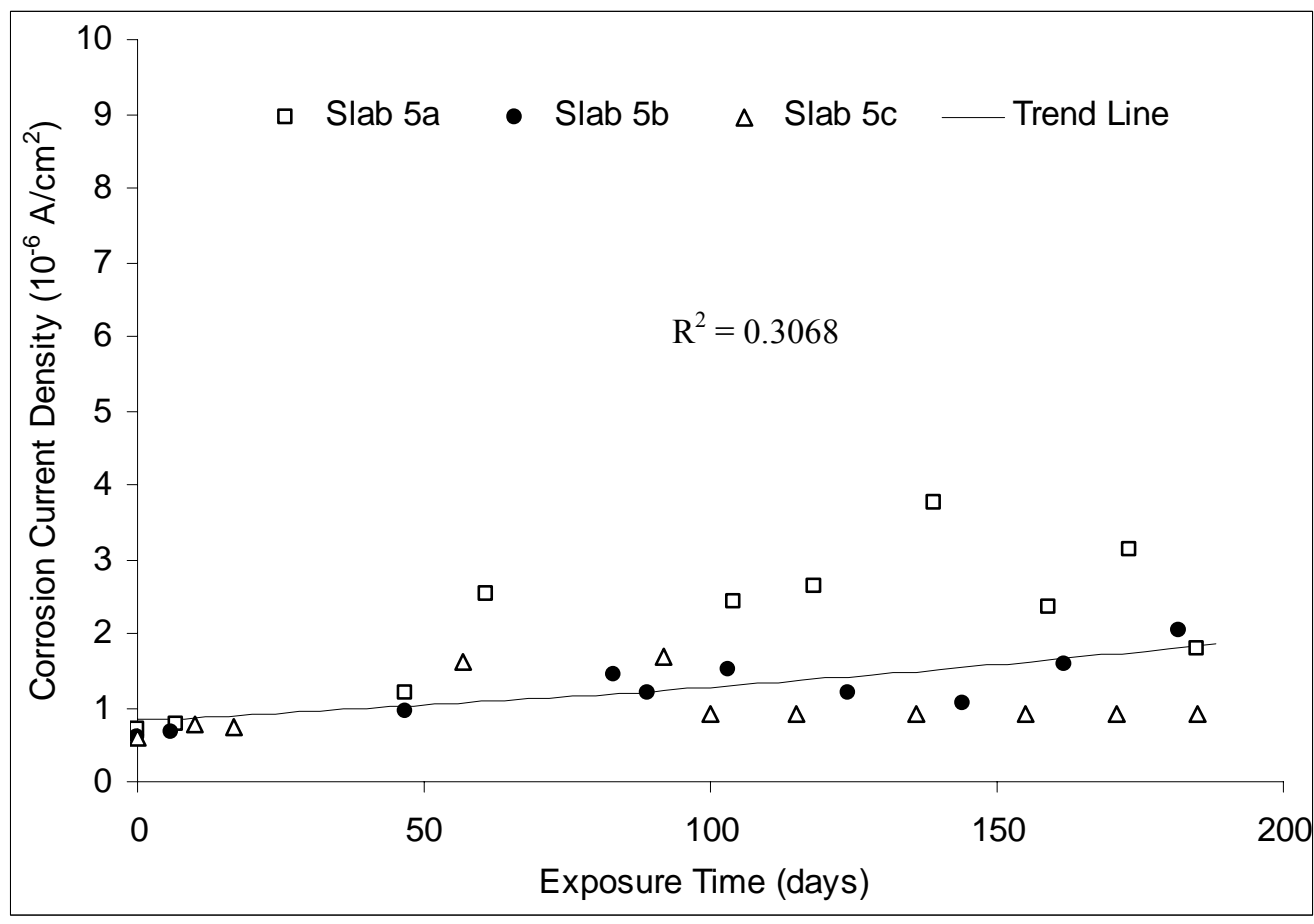

Figure 6.7 (b) Corrosion current density (from PR method) for the slabs repaired by the fly ash concrete. 


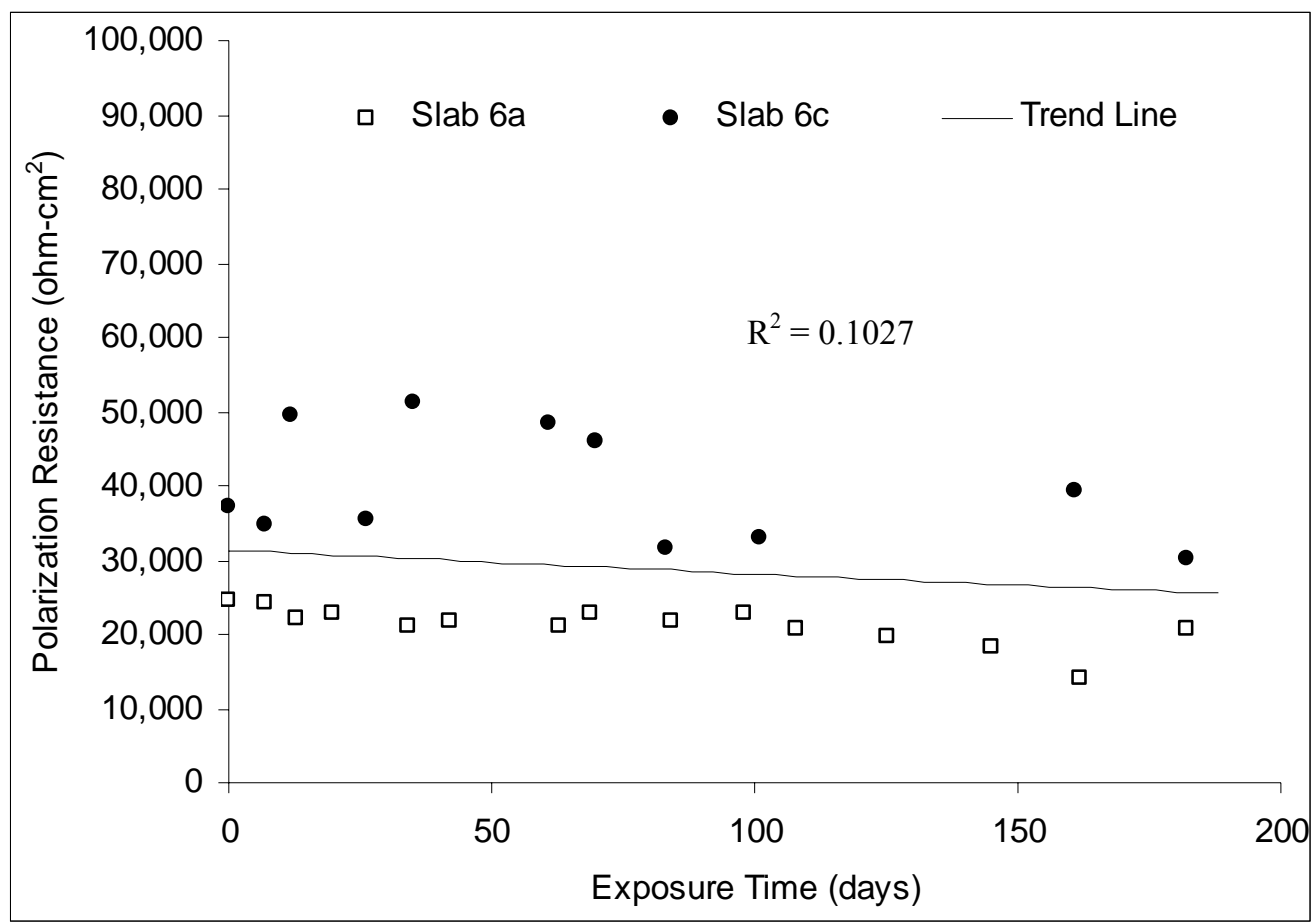

Figure 6.8 (a) Polarization resistance (from PR method) for the concrete slabs repaired by the INDOT 9-bag cement concrete.

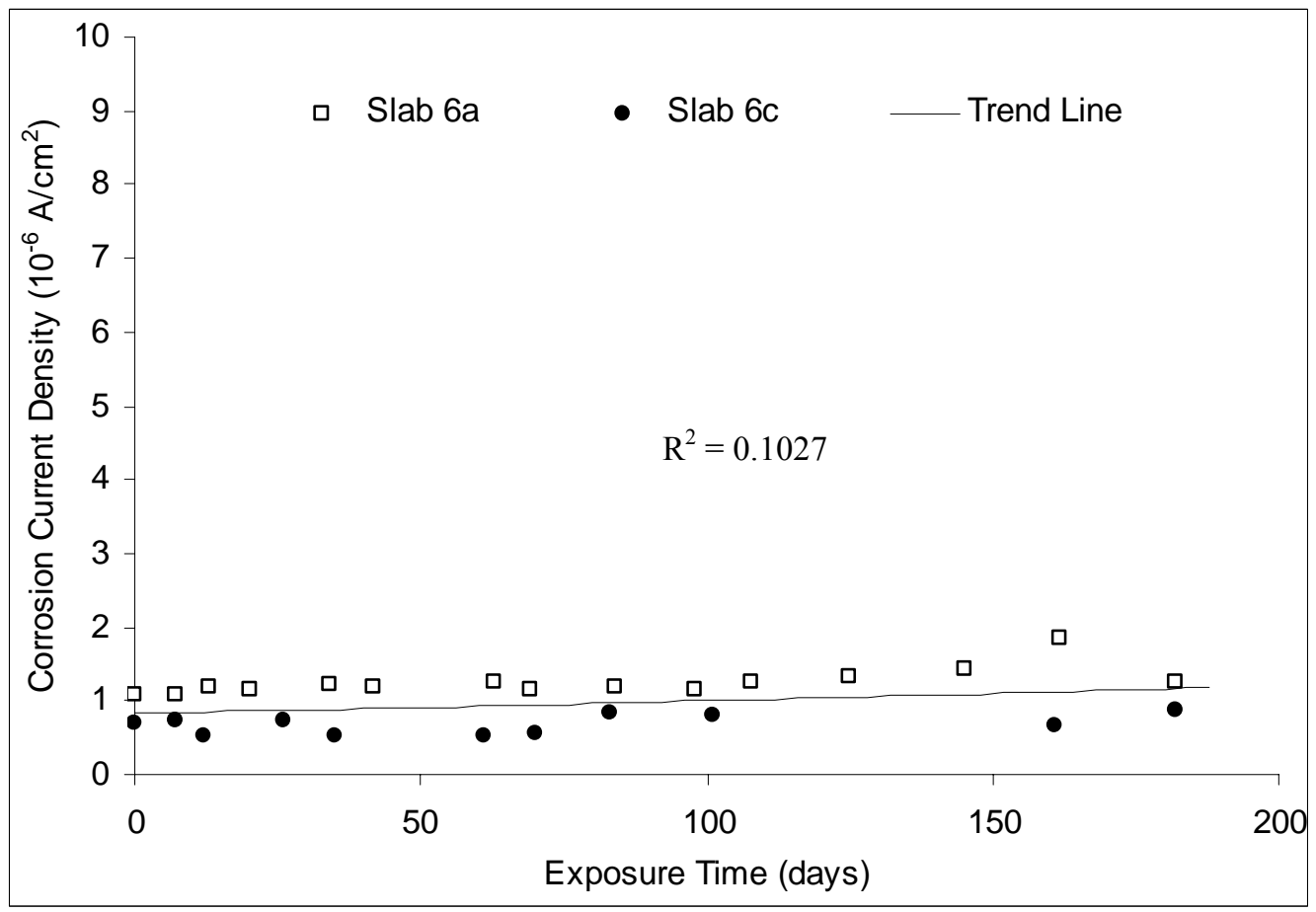

Figure 6.8 (b) Corrosion current density (from PR method) for the slabs repaired with INDOT 9-bag cement concrete. 


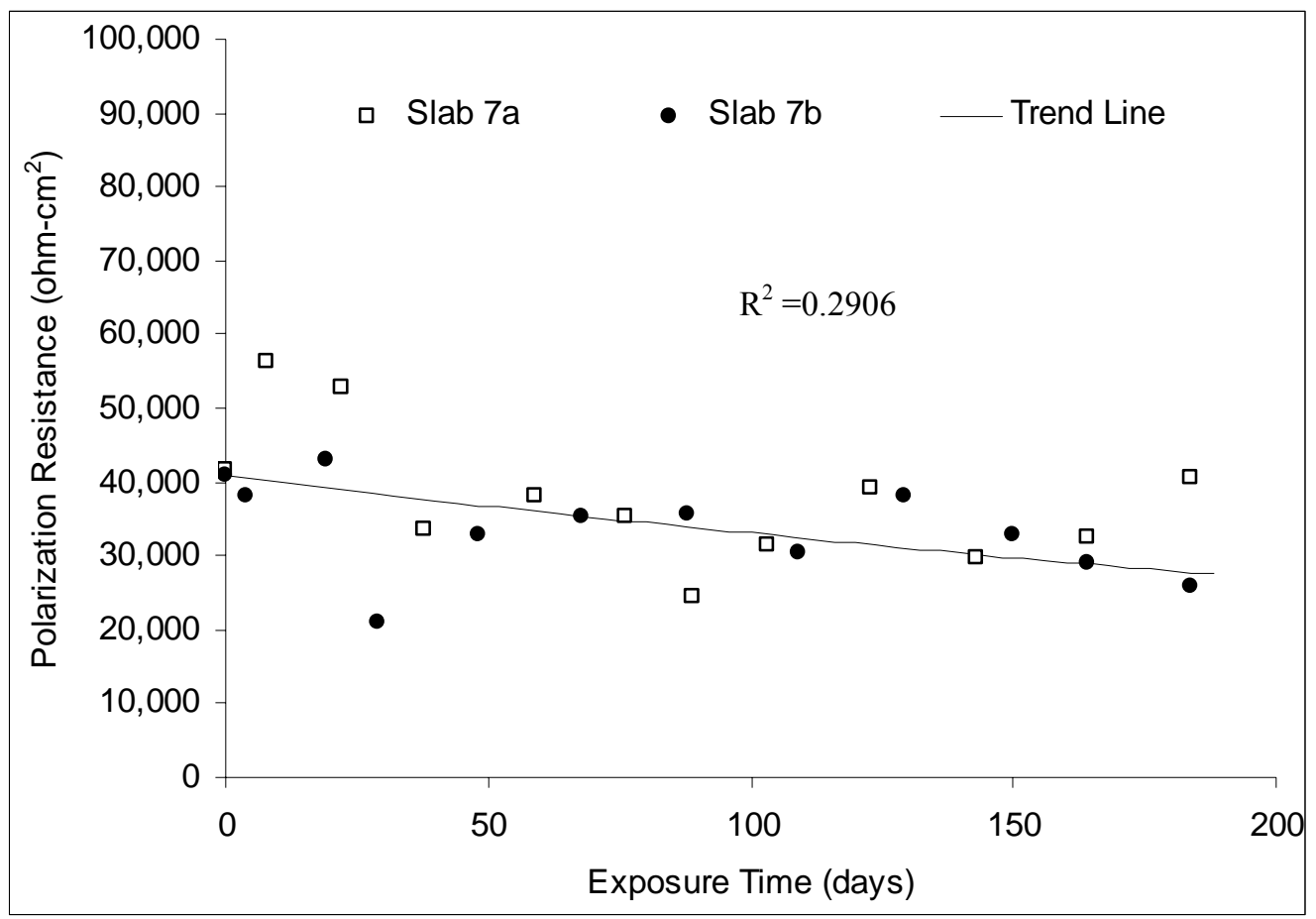

Figure 6.9 (a) Polarization resistance (from PR method) for the concrete slabs repaired by the concrete with the shrinkage reducing admixture.

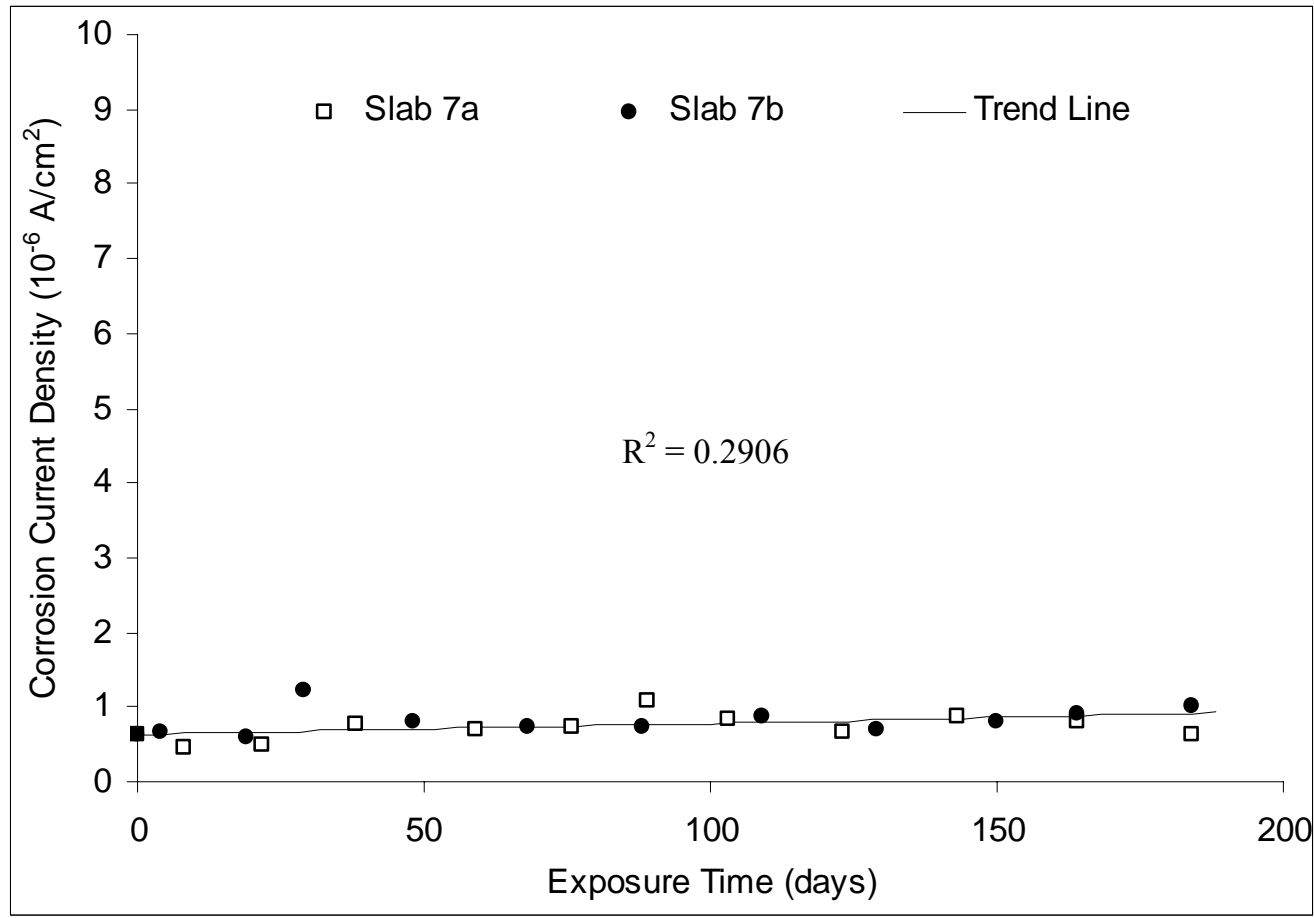

Figure 6.9 (b) Corrosion current density (from PR method) for the slabs repaired by concrete with shrinkage reducing admixture. 


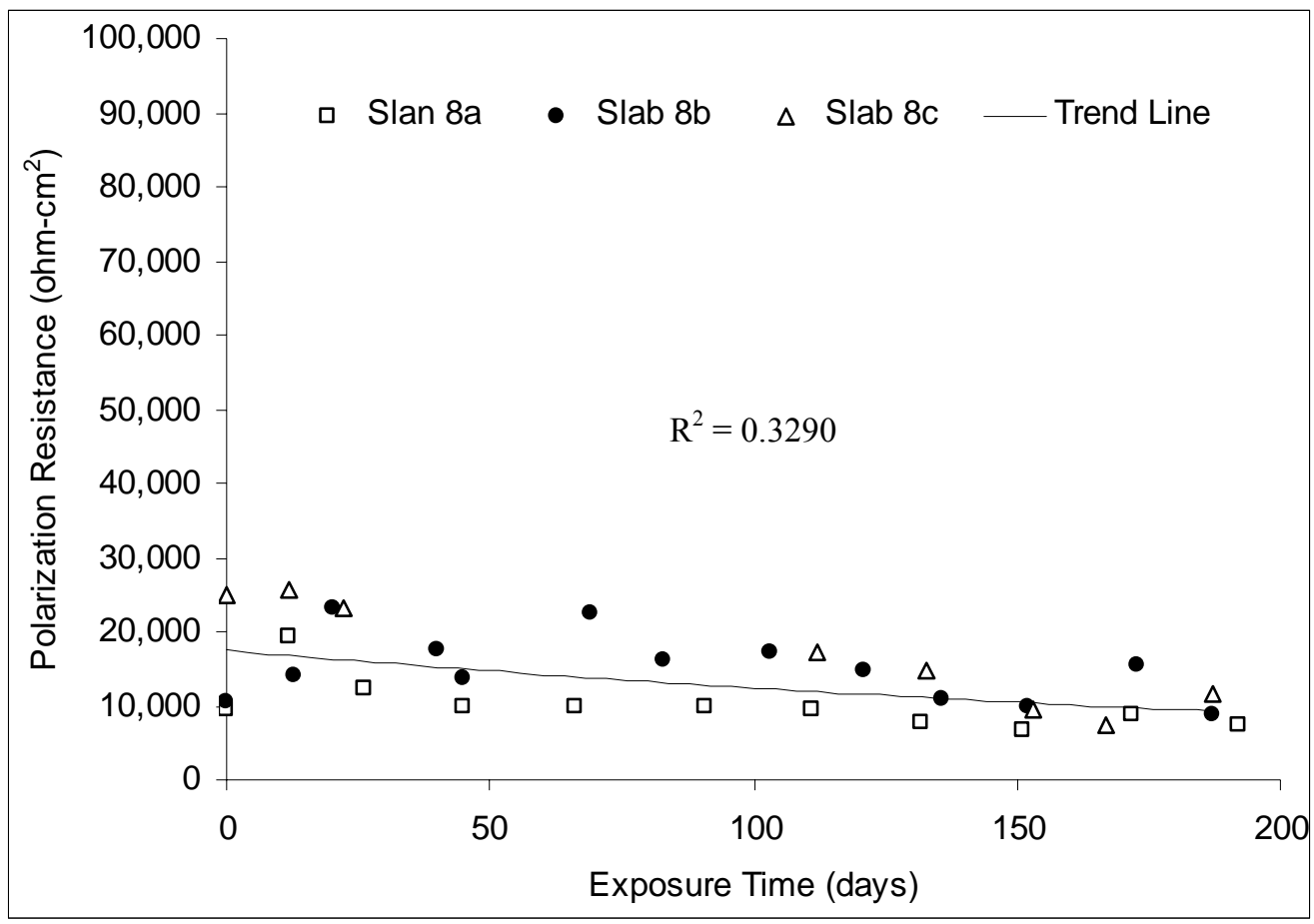

Figure 6.10 (a) Polarization resistance (from PR method) for the concrete slabs repaired by the latex modified concrete.

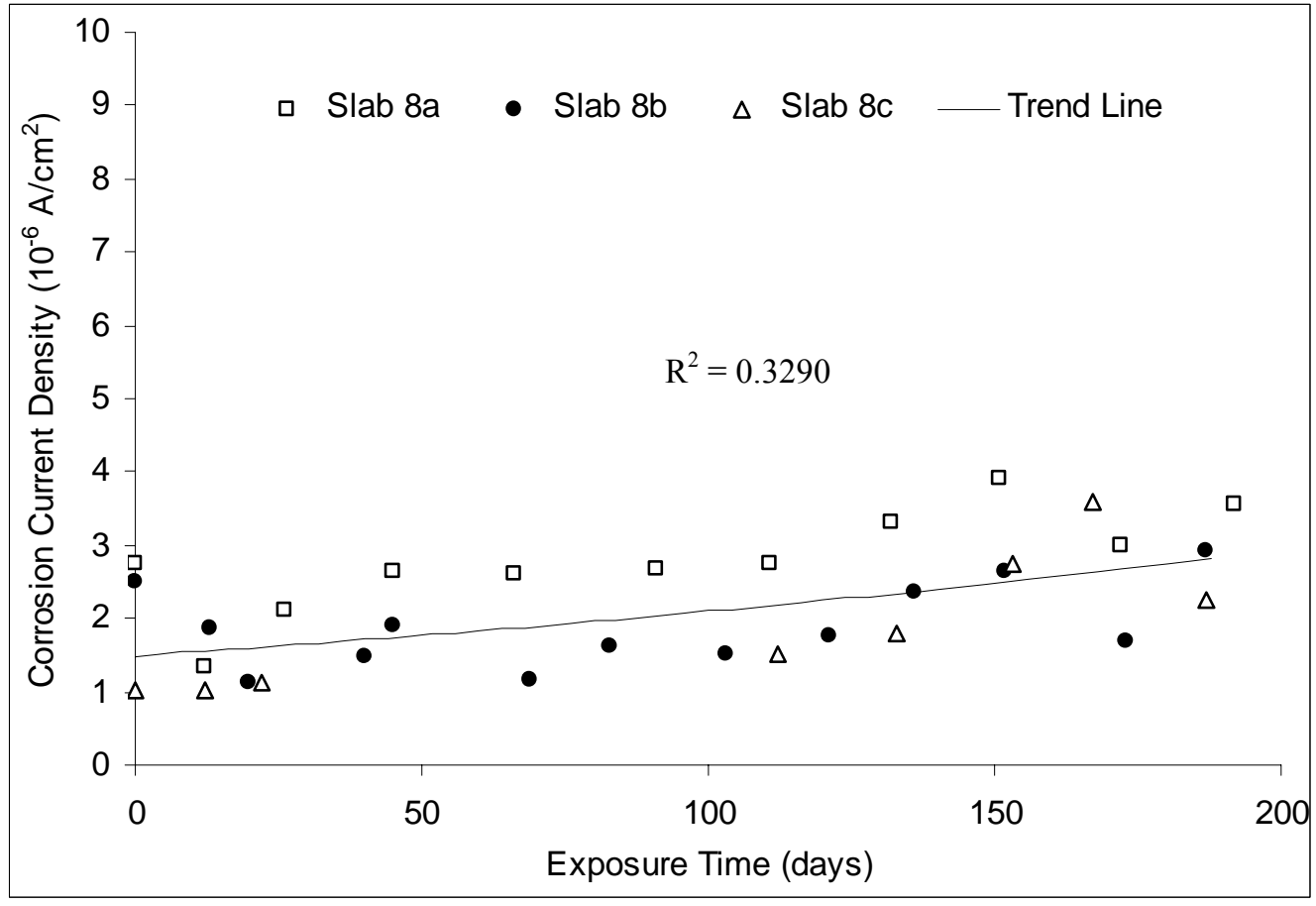

Figure 6.10 (b) Corrosion current density (from PR method) for the slabs repaired with latex modified concrete. 


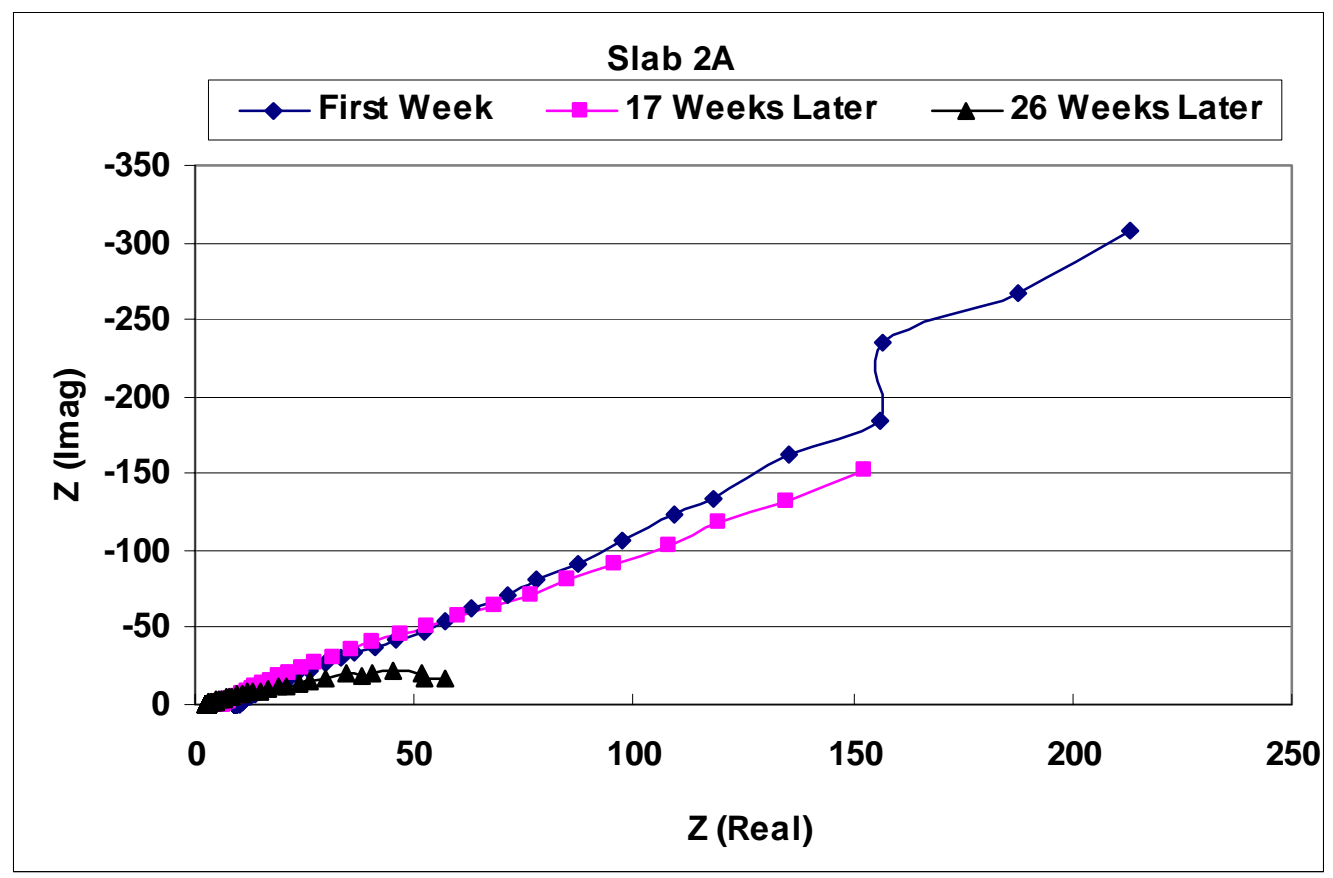

Figure 6.11 (a) Nyquist plot of slab 2A at different exposing time.

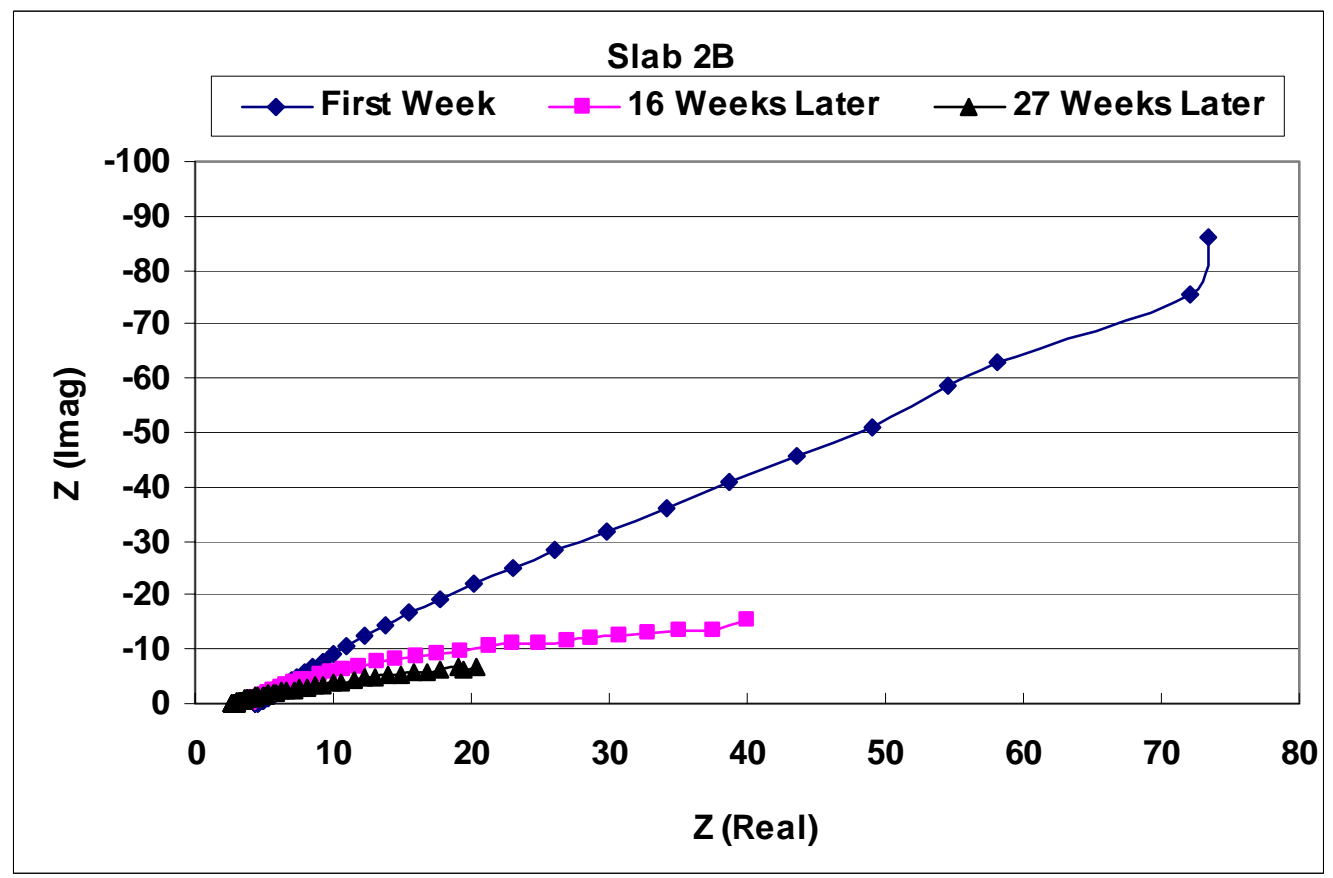

Figure 6.11 (b) Nyquist plot of slab 2B at different exposing time. 


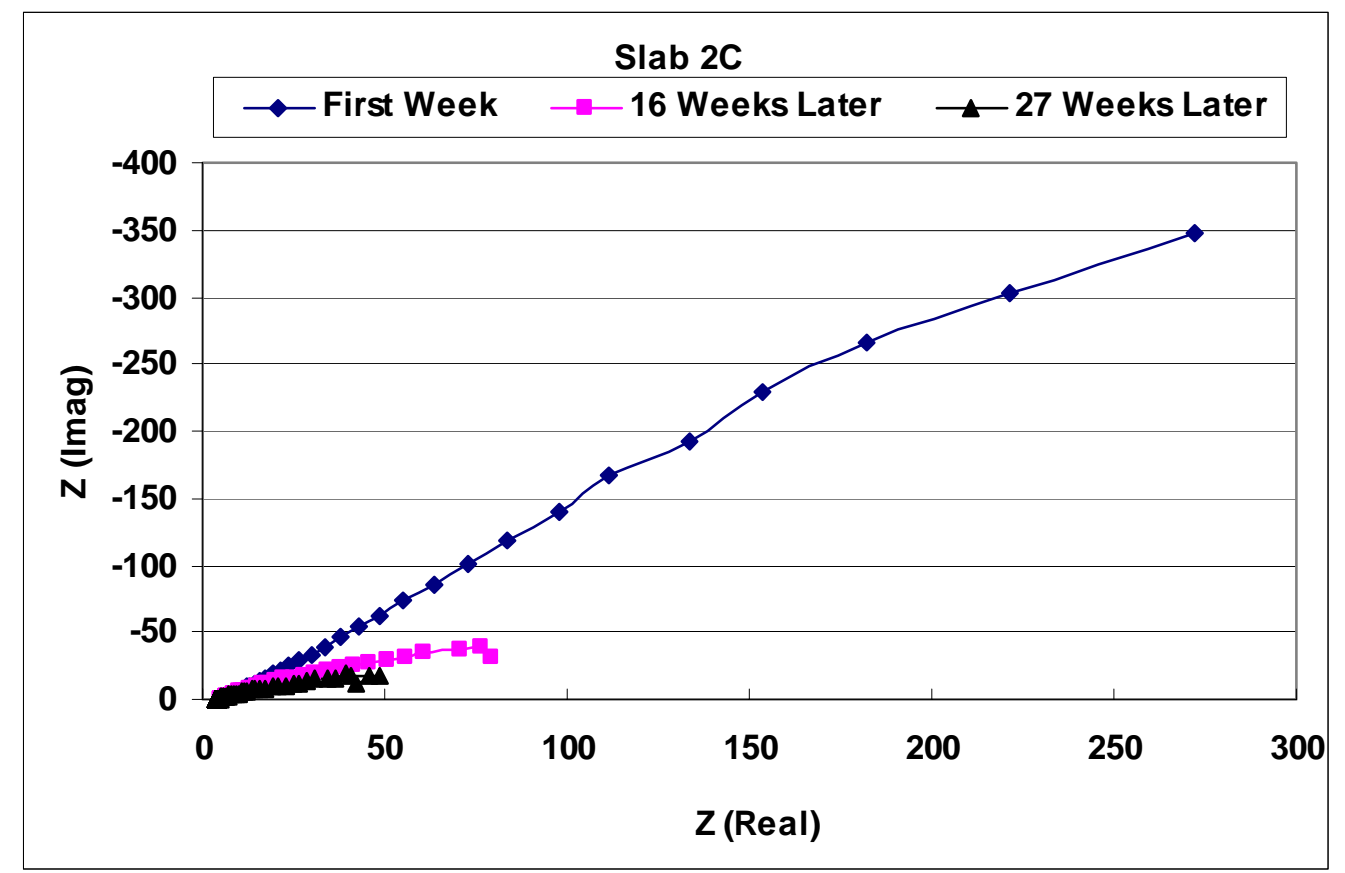

Figure 6.11 (c) Nyquist plot of slab 2C at different exposing time.

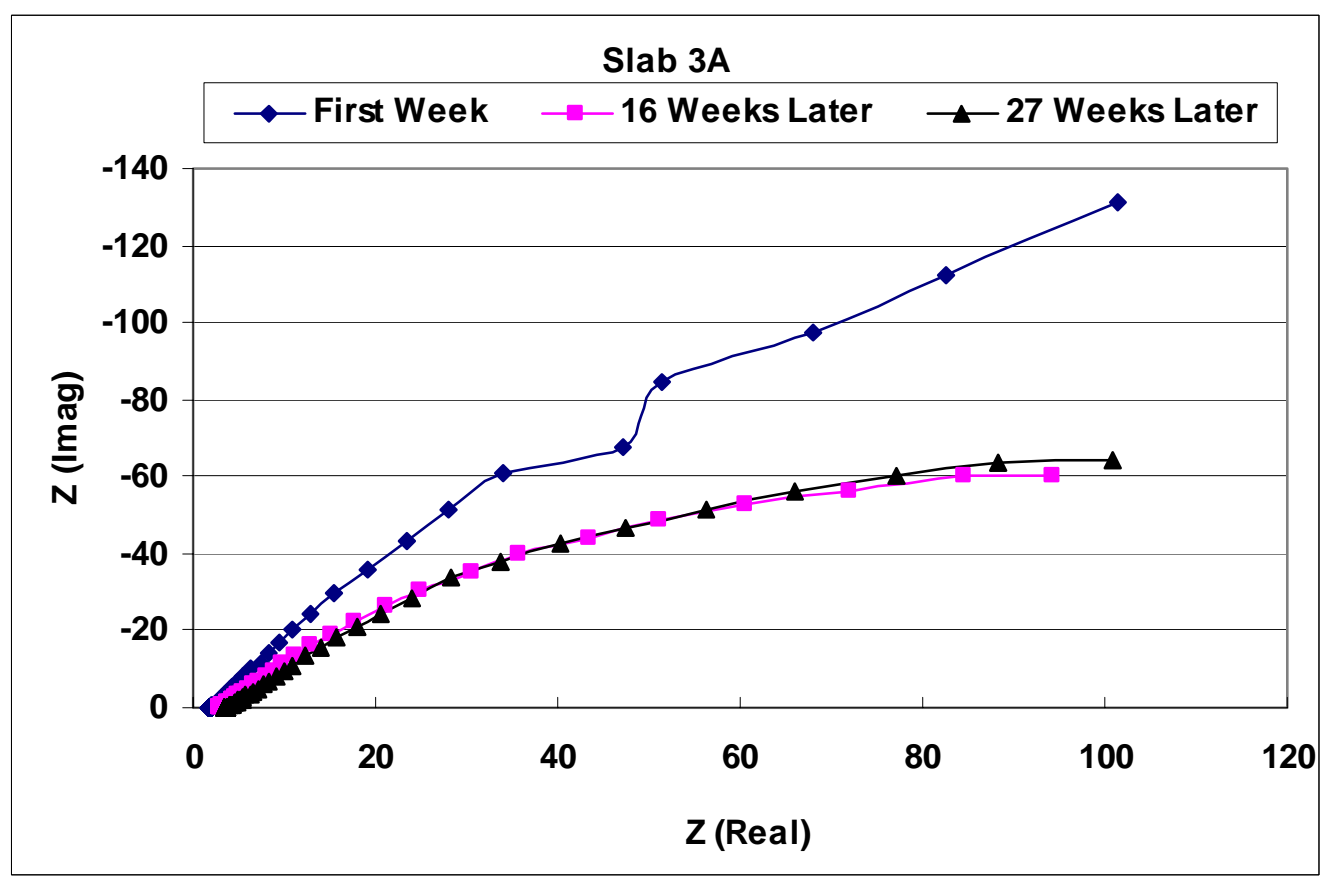

Figure 6.12 (a) Nyquist plot of slab 3A at different exposing time. 


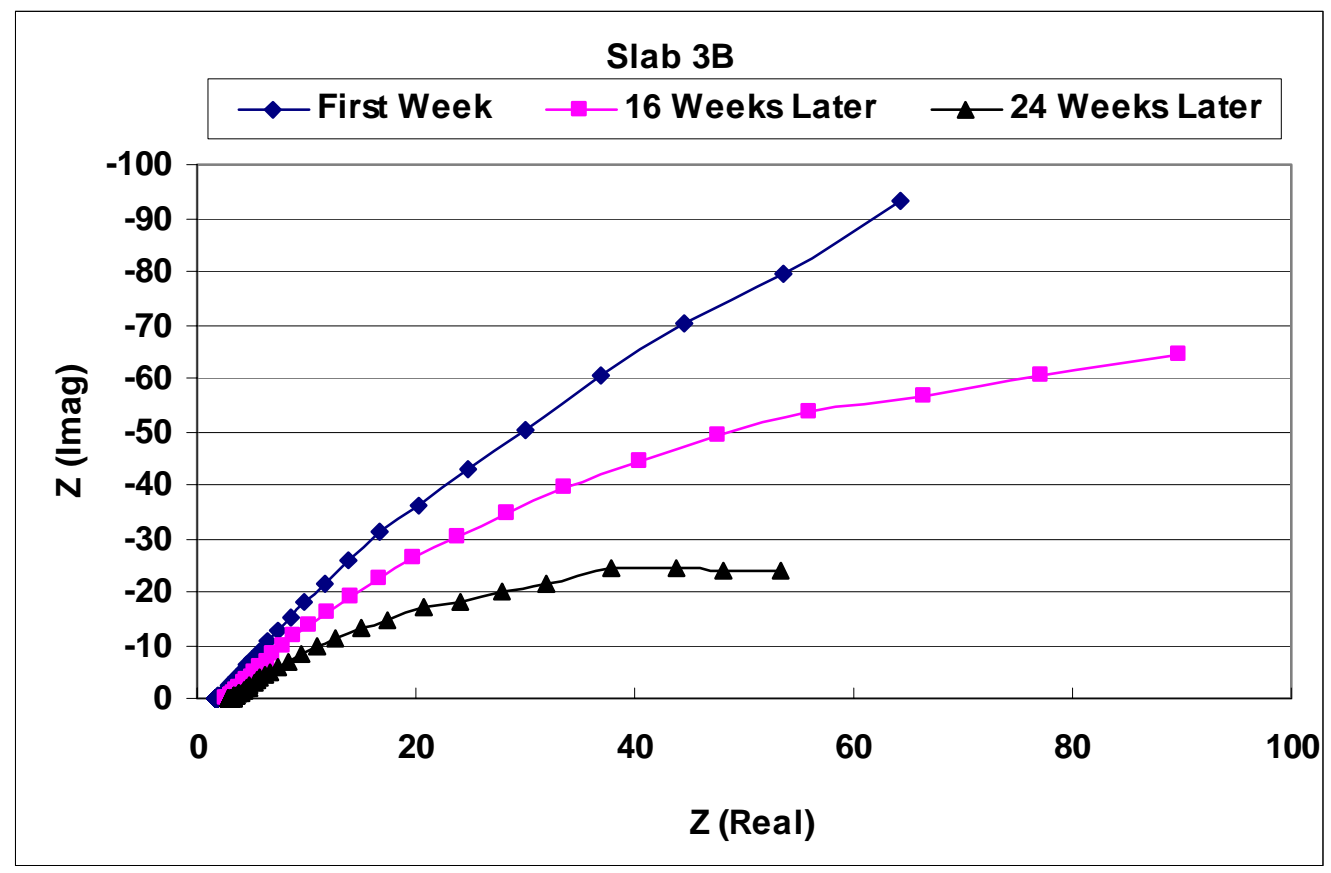

Figure 6.12 (b) Nyquist plot of slab 3B at different exposing time.

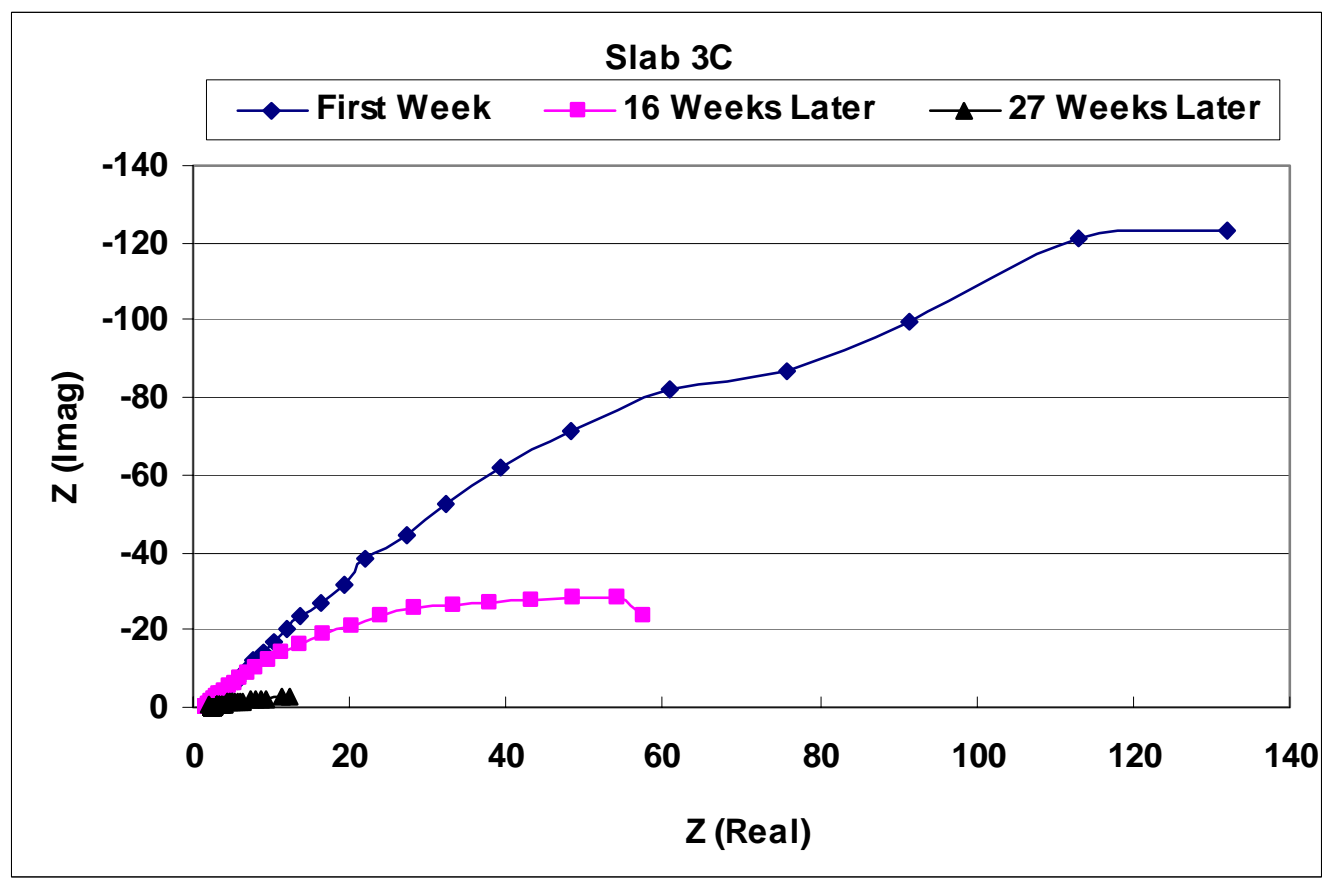

Figure 6.12 (c) Nyquist plot of slab 3C at different exposing time. 


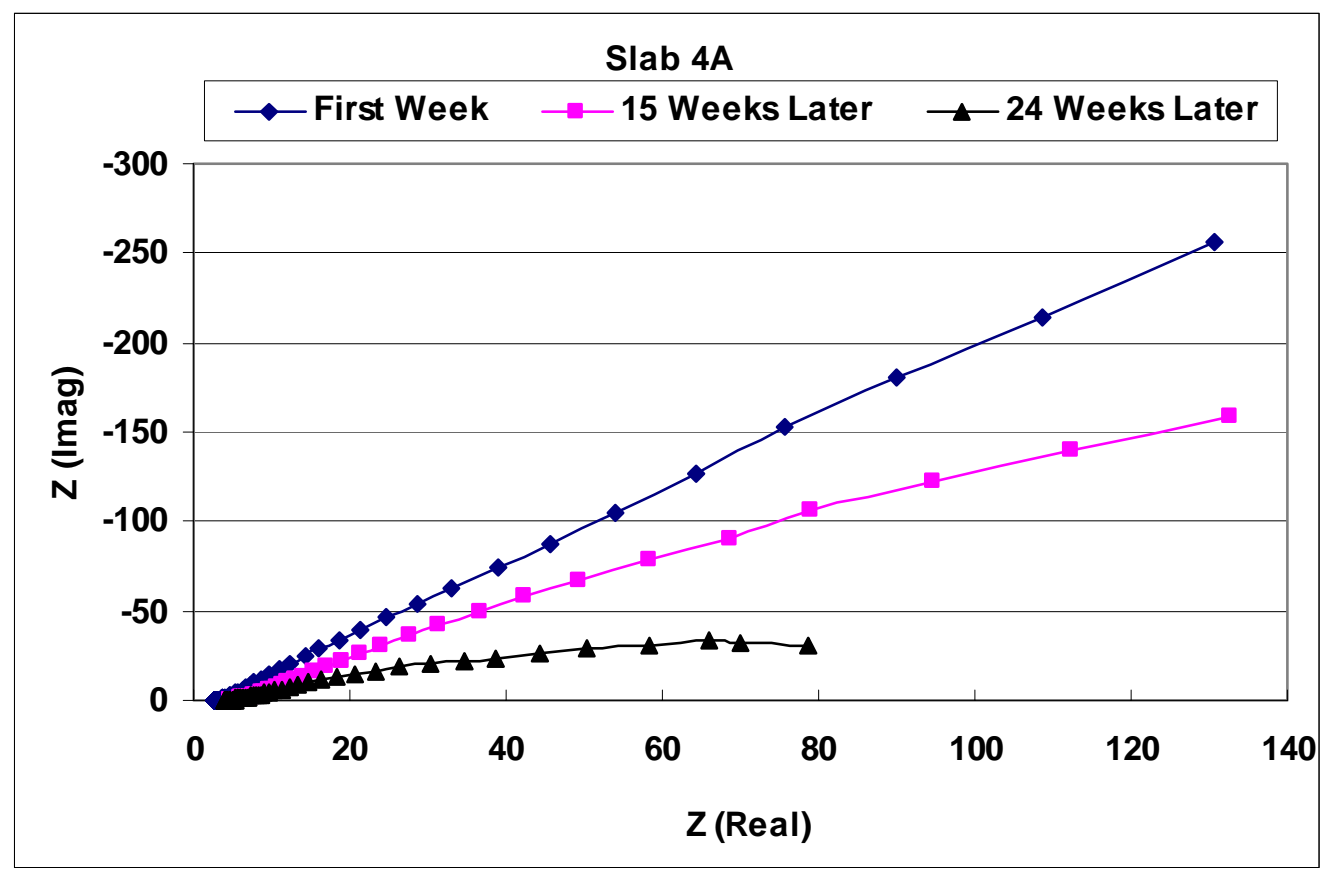

Figure 6.13 (a) Nyquist plot of slab 4A at different exposing time.

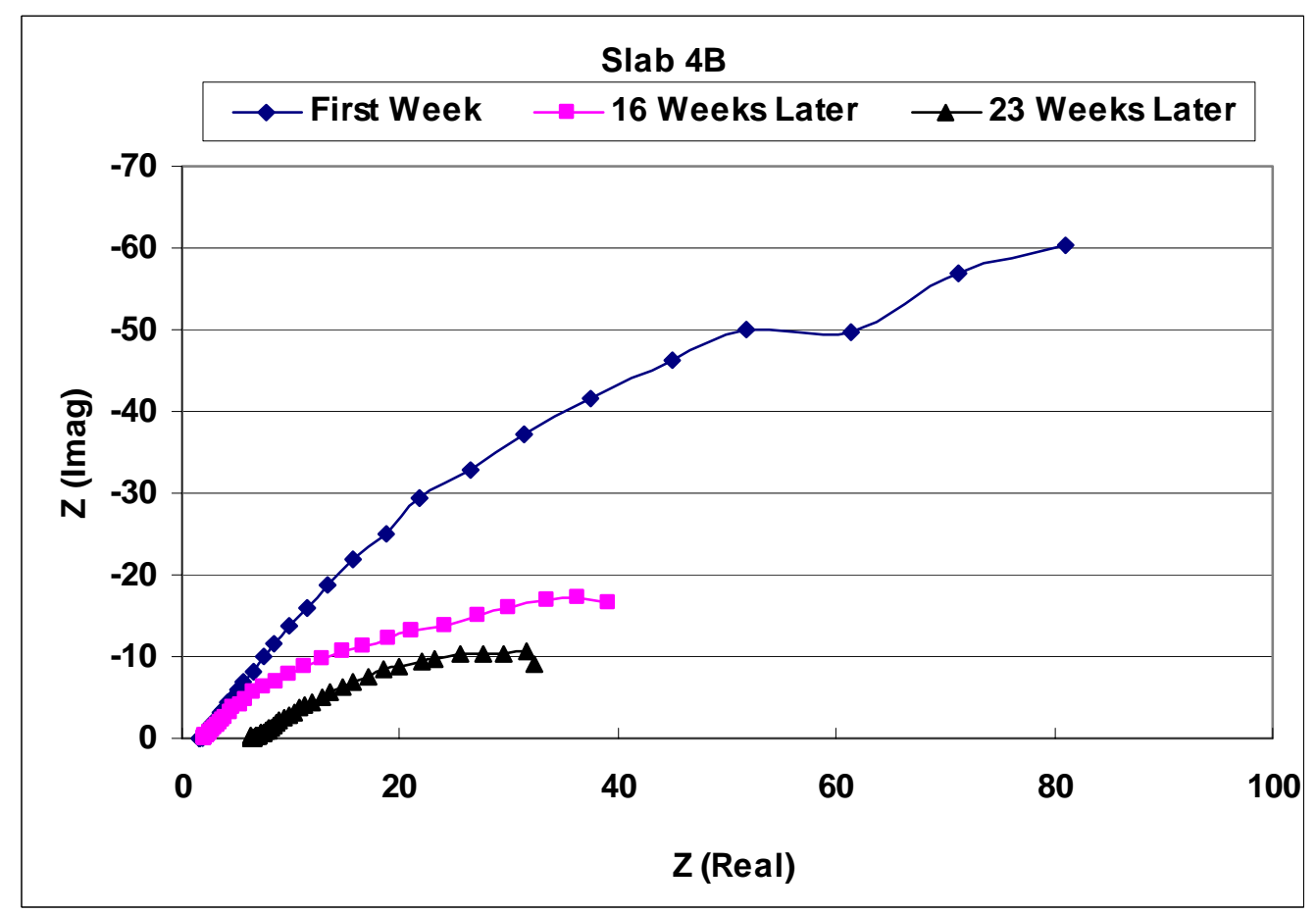

Figure 6.13 (b) Nyquist plot of slab 4B at different exposing time 


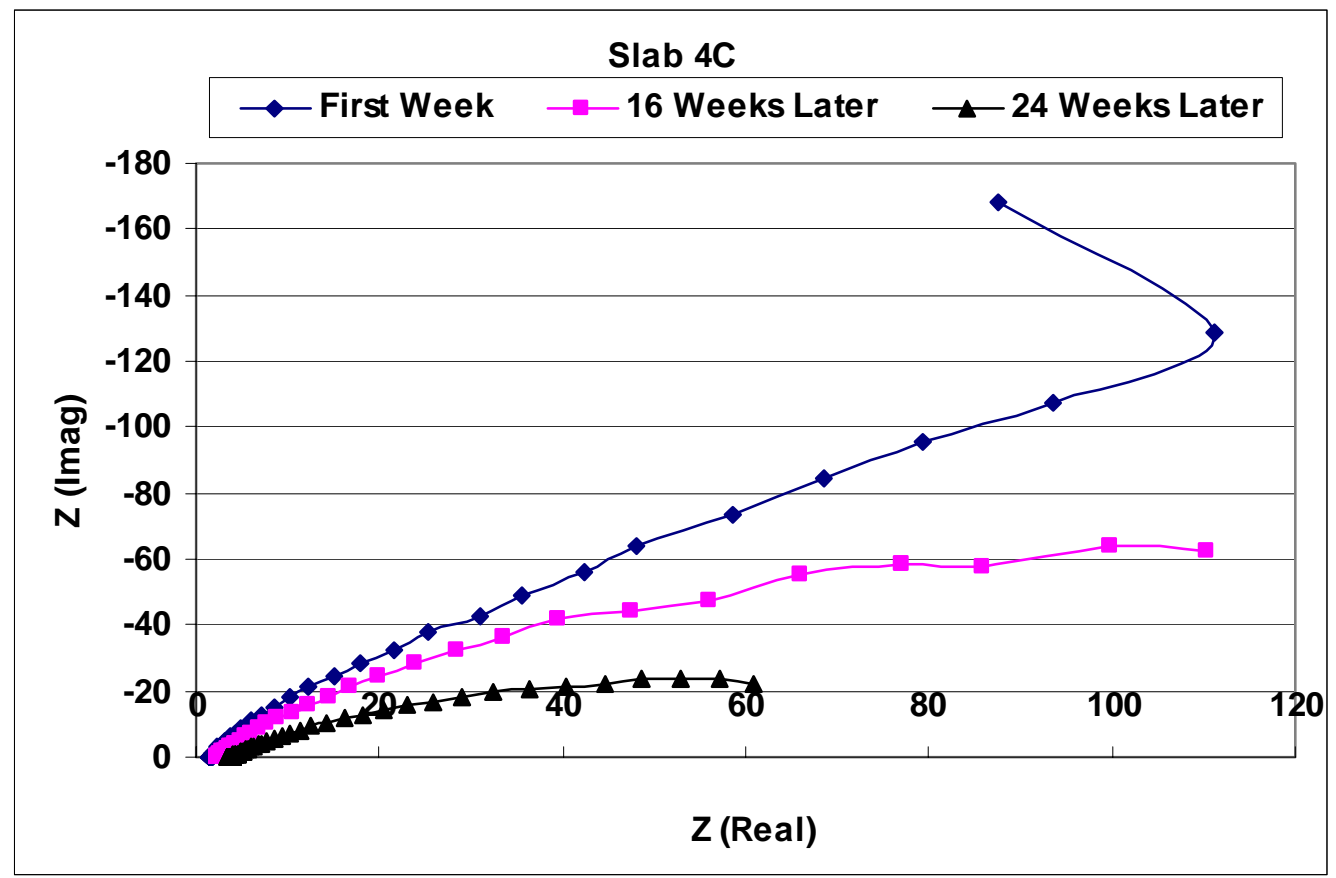

Figure 6.13 (c) Nyquist plot of slab 4C at different exposing time

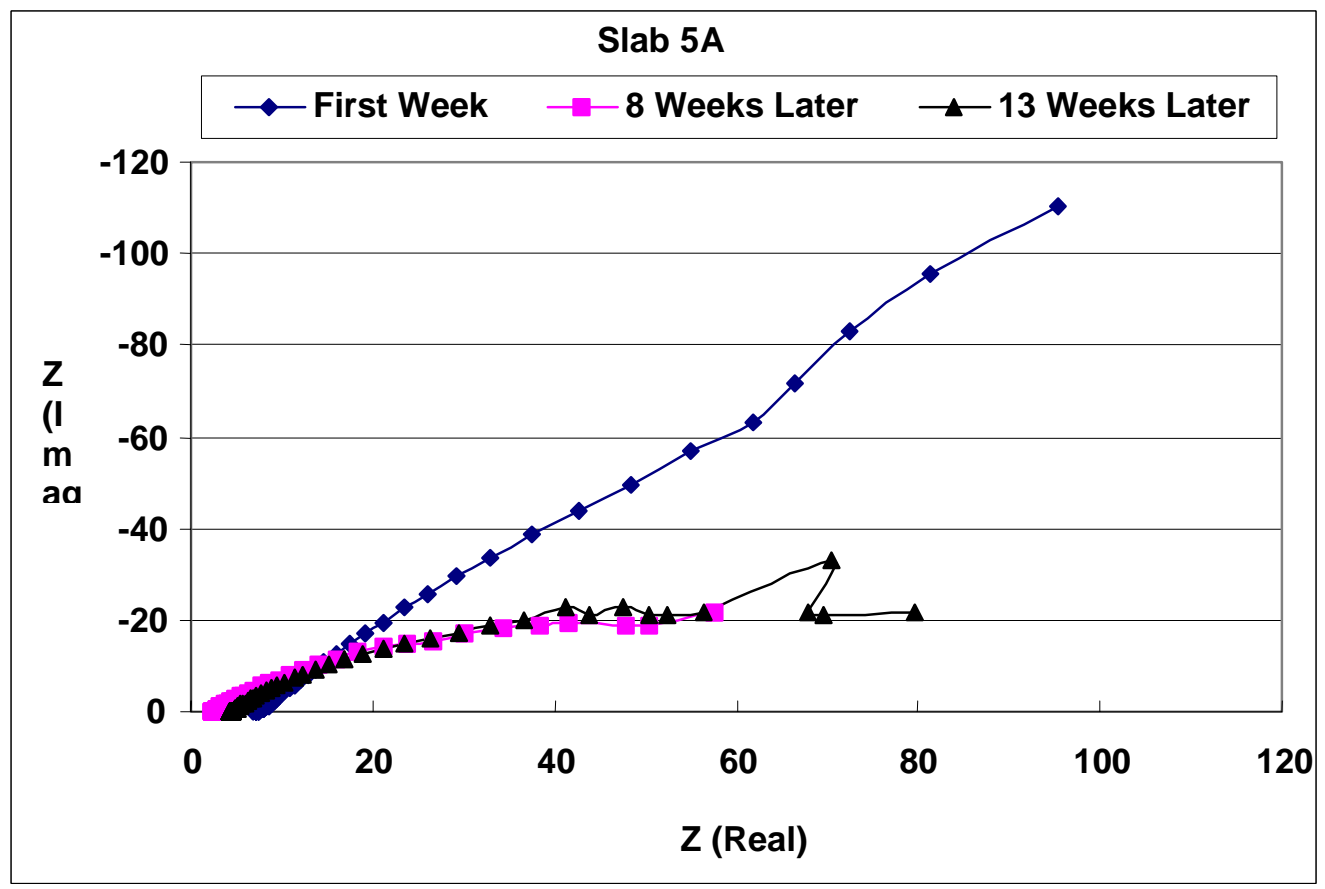

Figure 6.14 (a) Nyquist plot of slab 5A at different exposing time. 


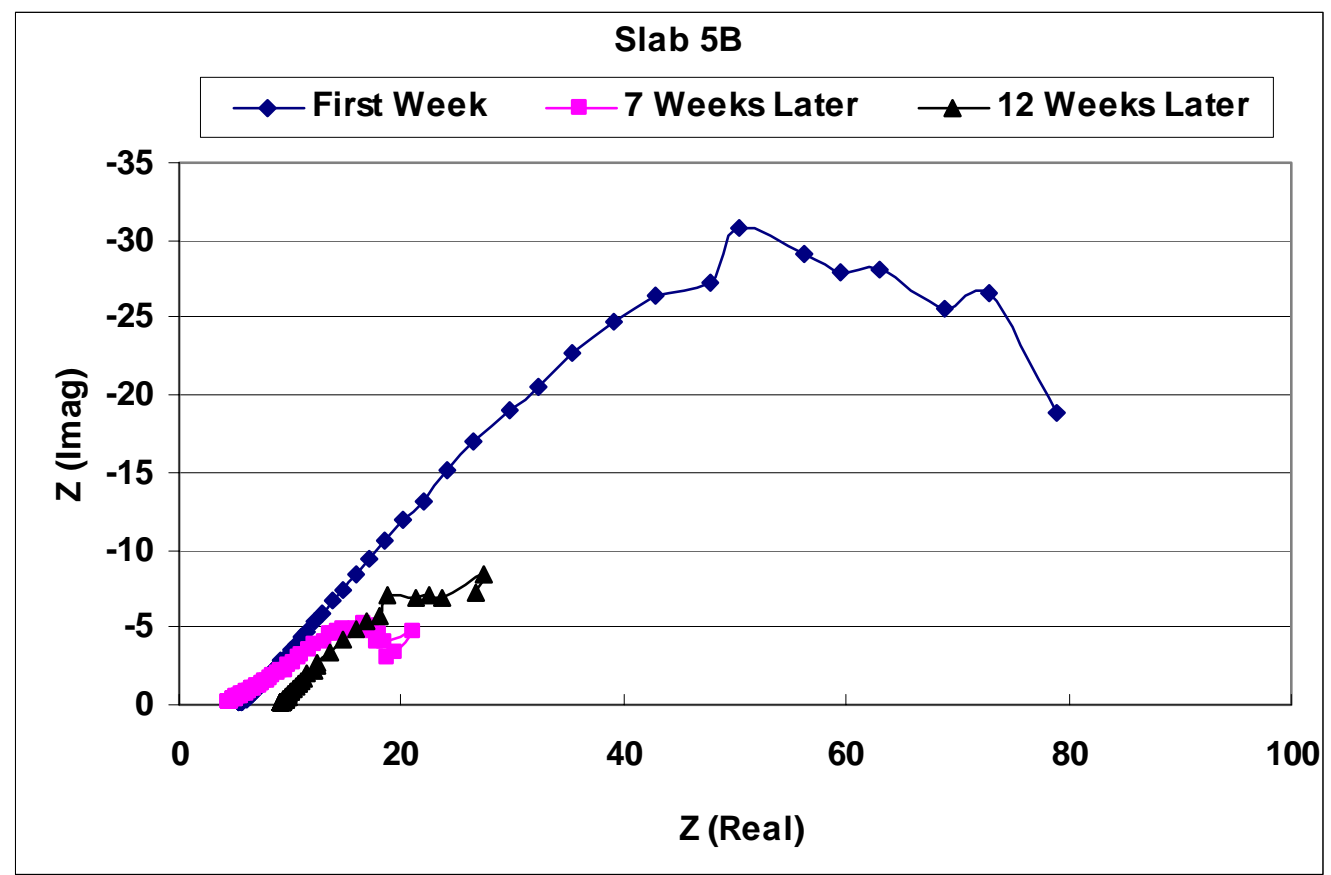

Figure 6.14 (b) Nyquist plot of slab 5B at different exposing time.

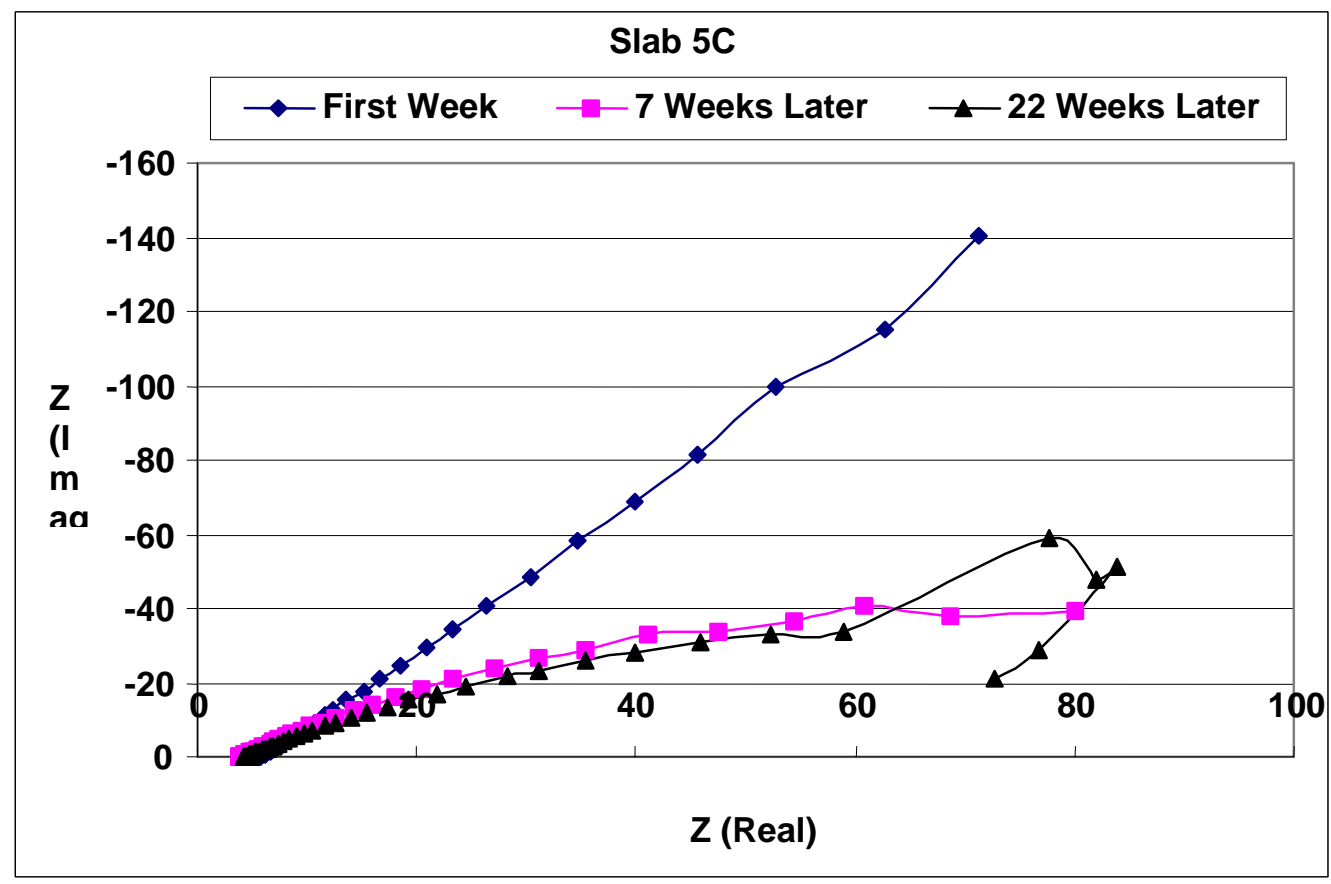

Figure 6.14 (c) Nyquist plot of slab 5C at different exposing time. 


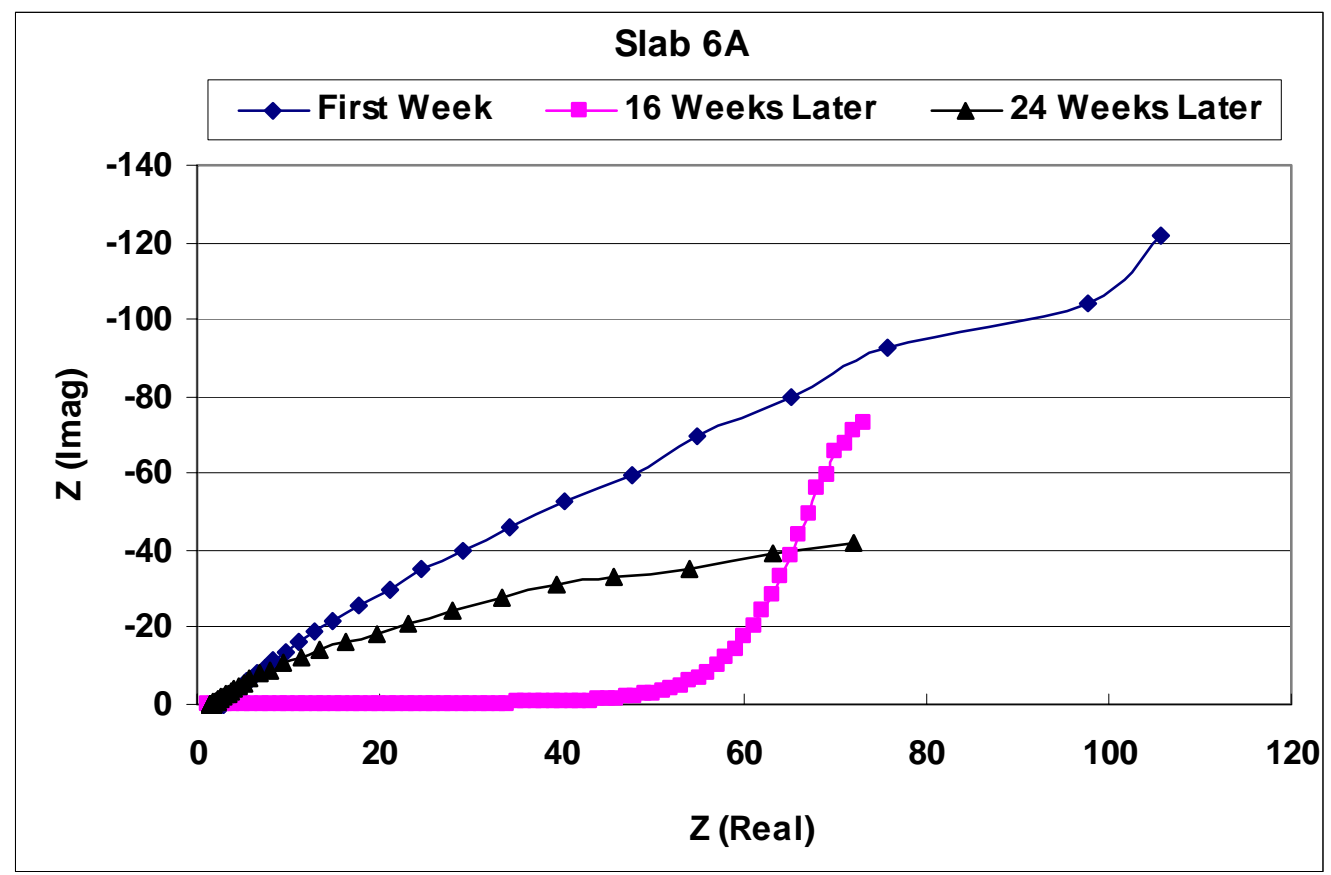

Figure 6.15 (a) Nyquist plot of slab 6A at different exposing time.

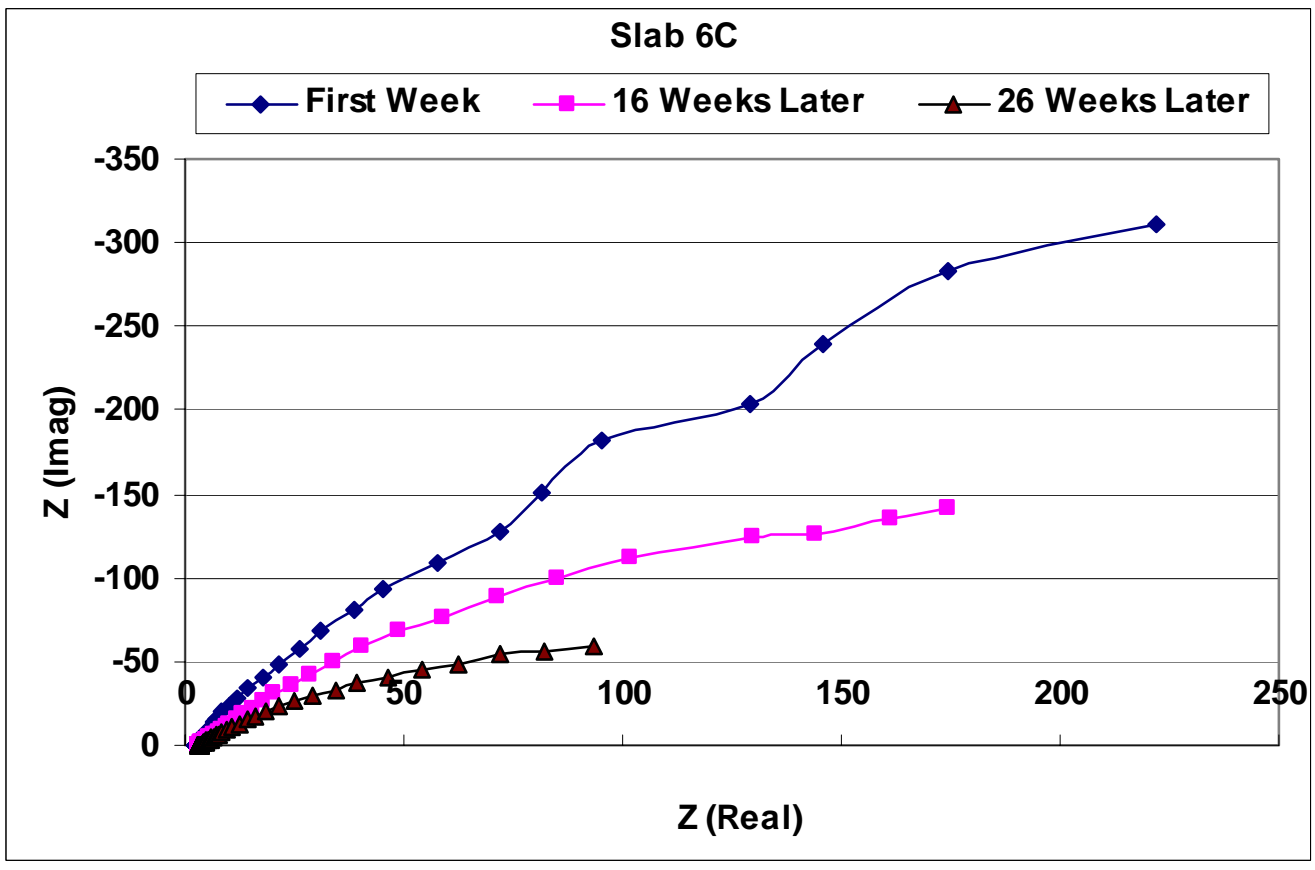

Figure 6.15 (c) Nyquist plot of slab 6C at different exposing time. 


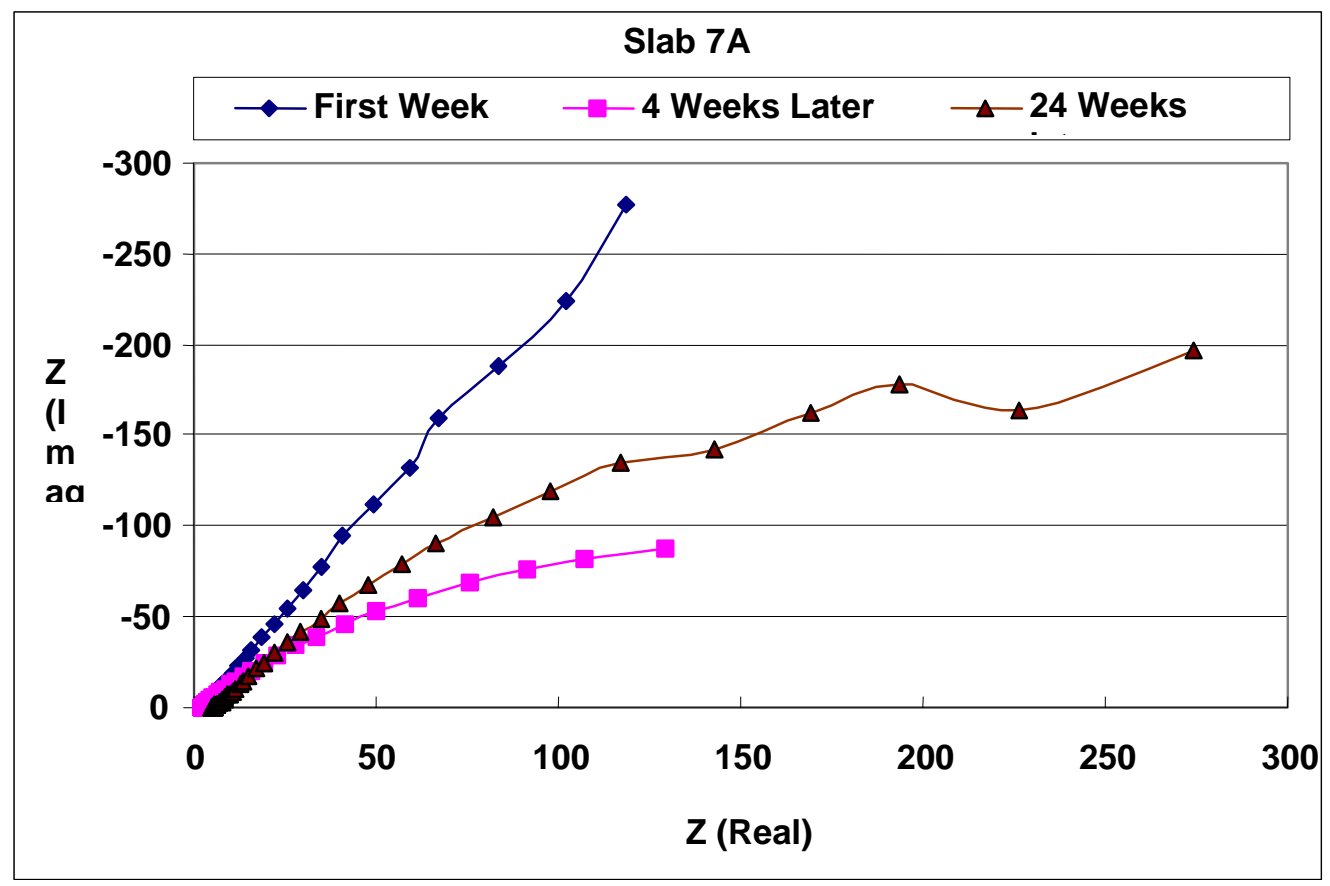

Figure 6.16 (a) Nyquist plot of slab 7A at different exposing time.

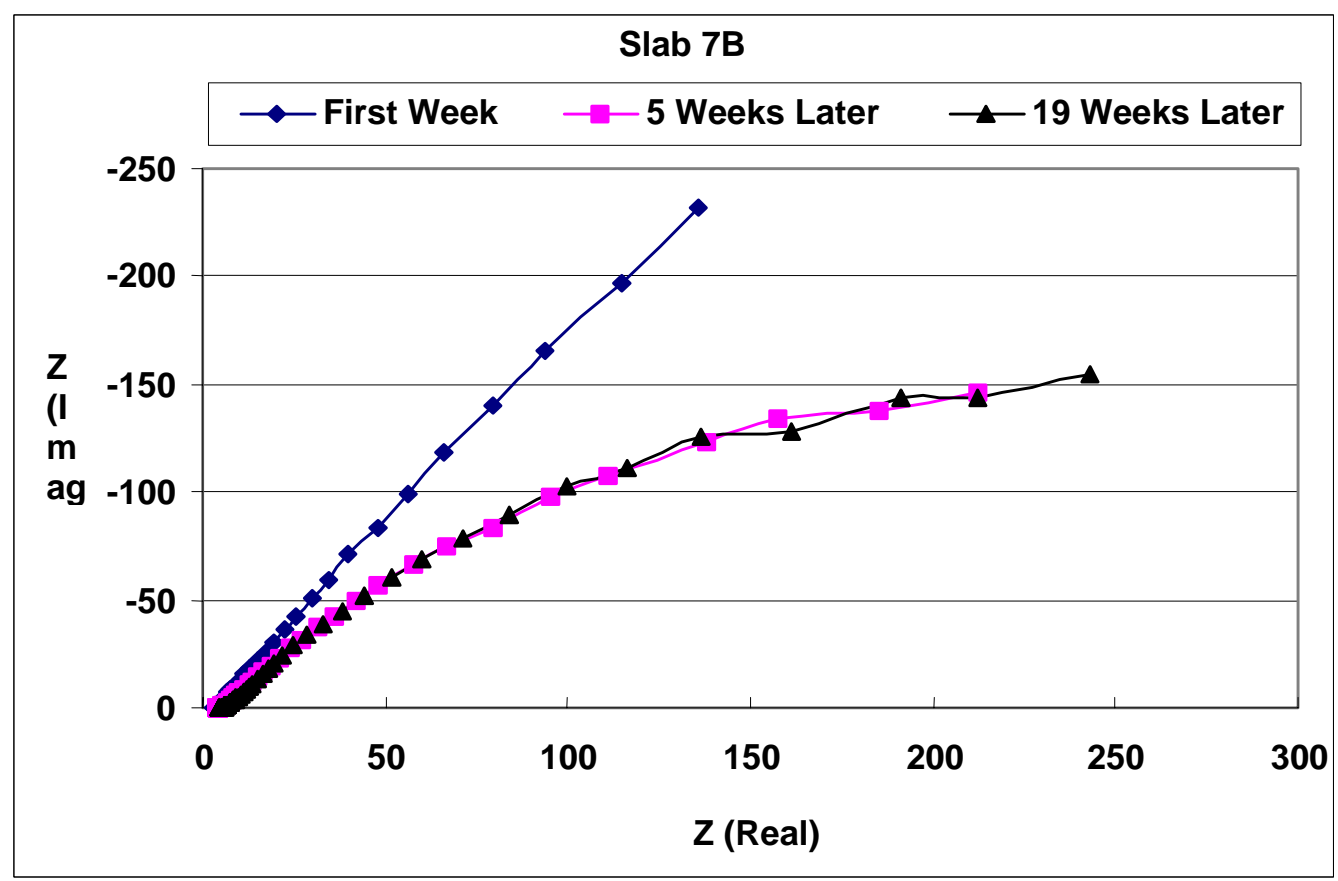

Figure 6.16 (b) Nyquist plot of slab 7B at different exposing time. 


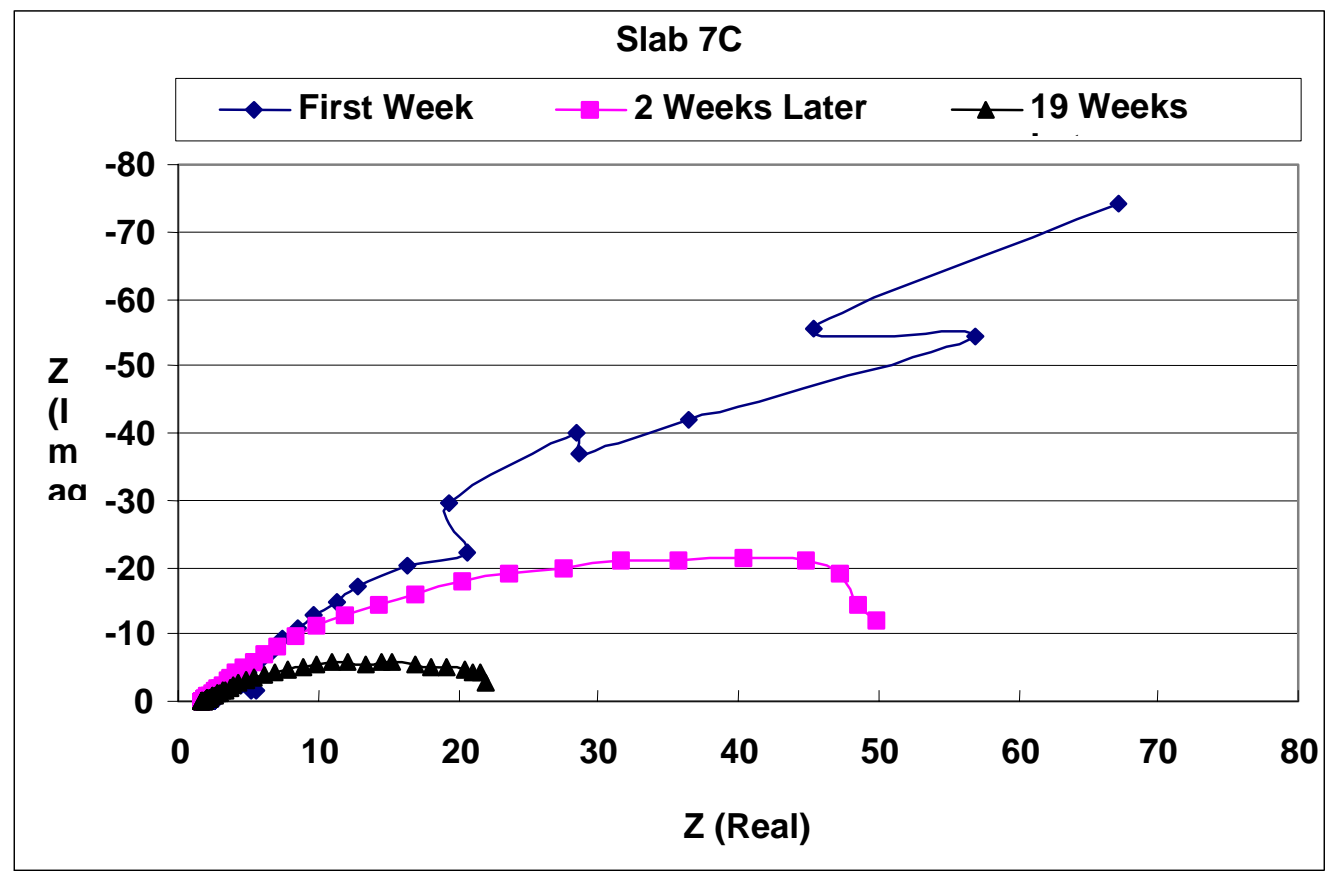

Figure 6.16 (c) Nyquist plot of slab 7C at different exposing time.

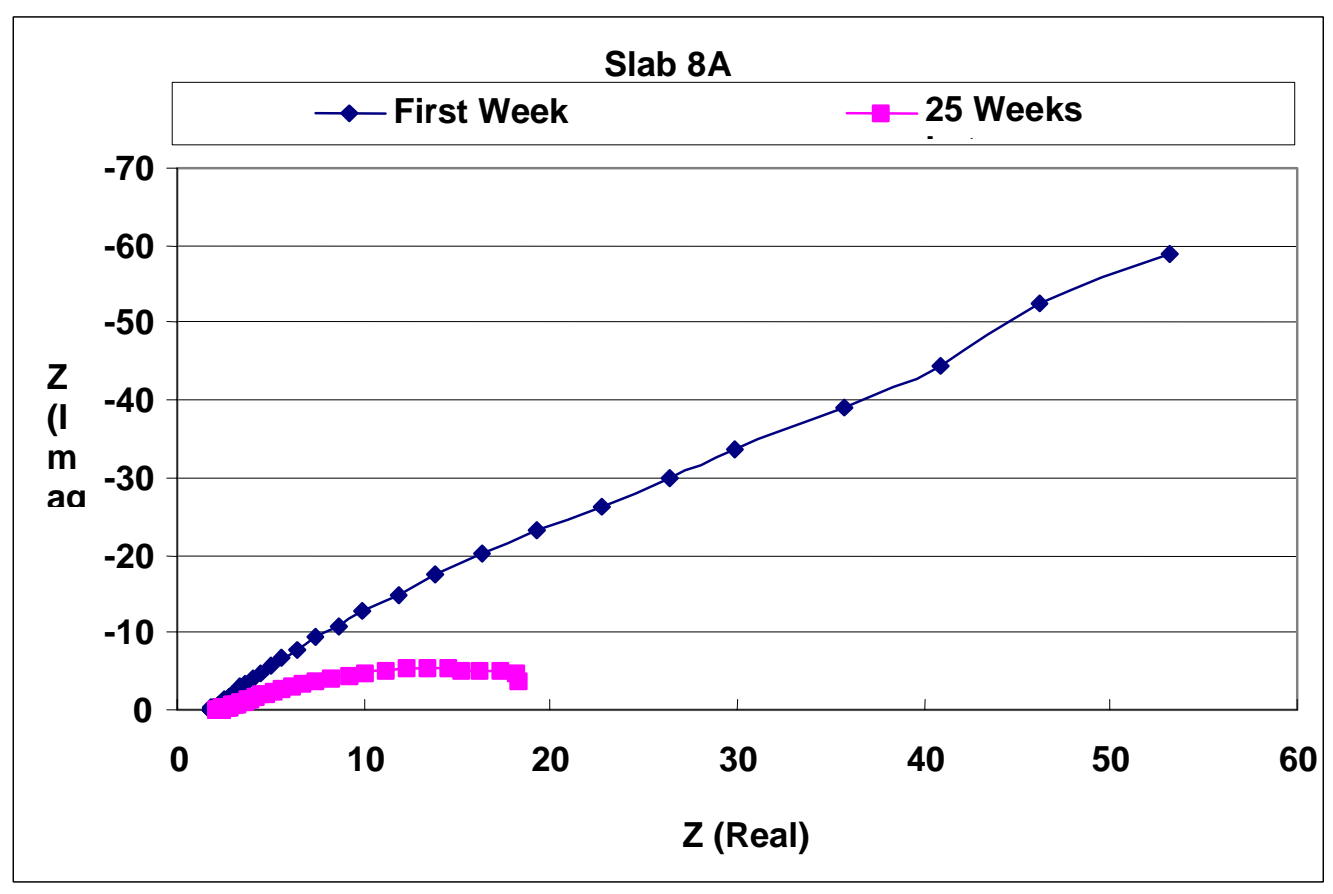

Figure 6.17 (a) Nyquist plot of slab 8A at different exposing time. 


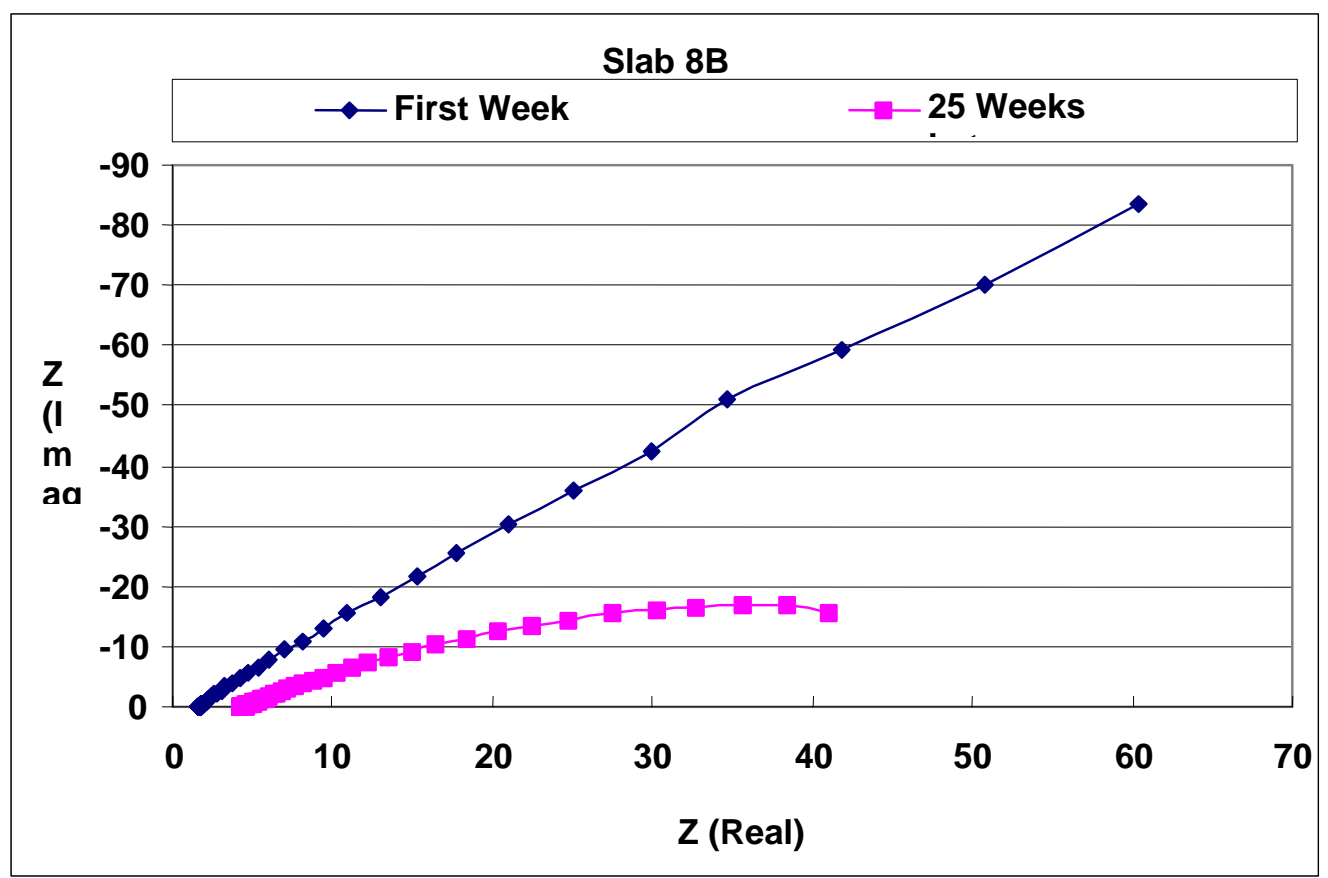

Figure 6.17 (b) Nyquist plot of slab 8B at different exposing time.

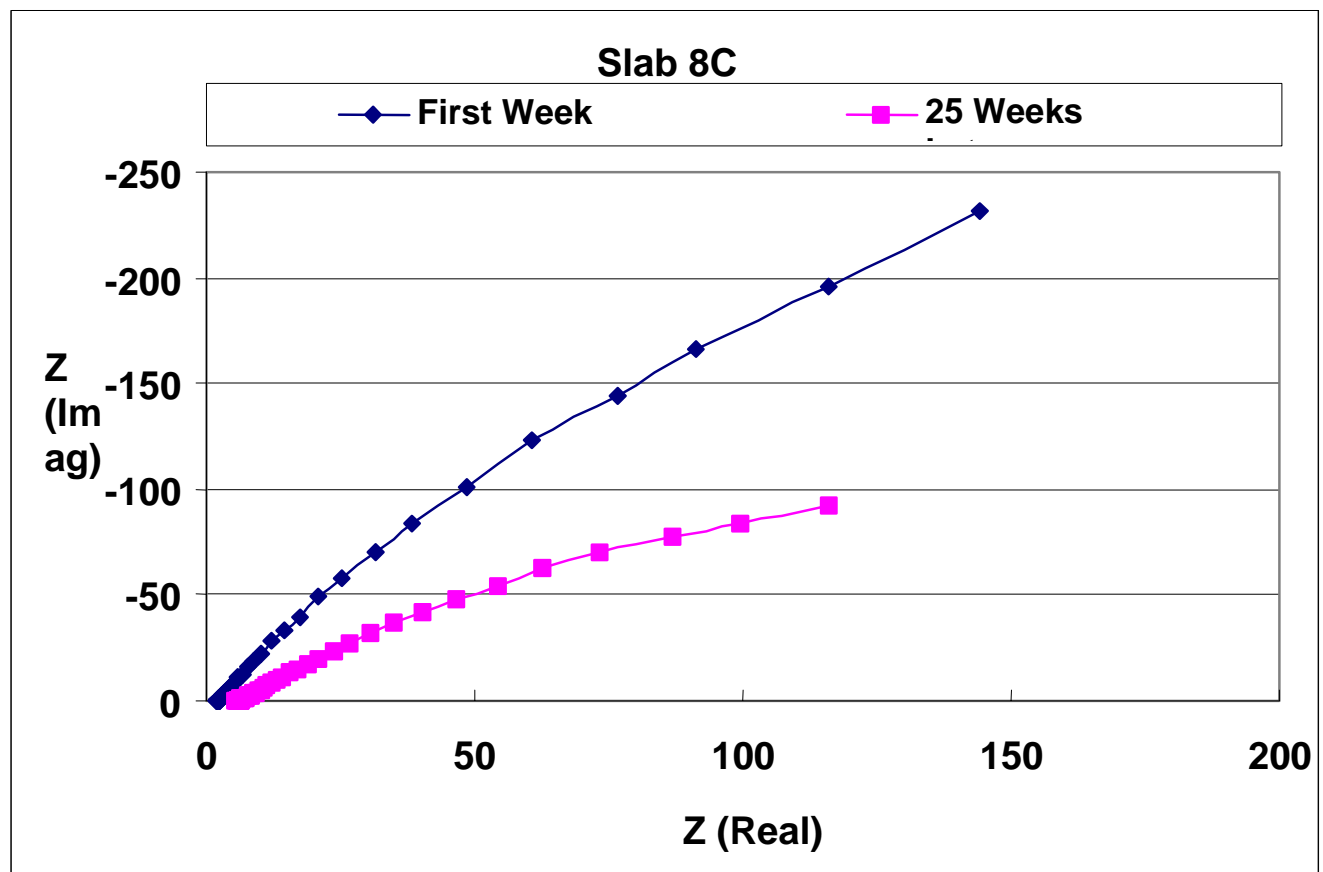

Figure 6.17 (c) Nyquist plot of slab 8C at different exposing time 


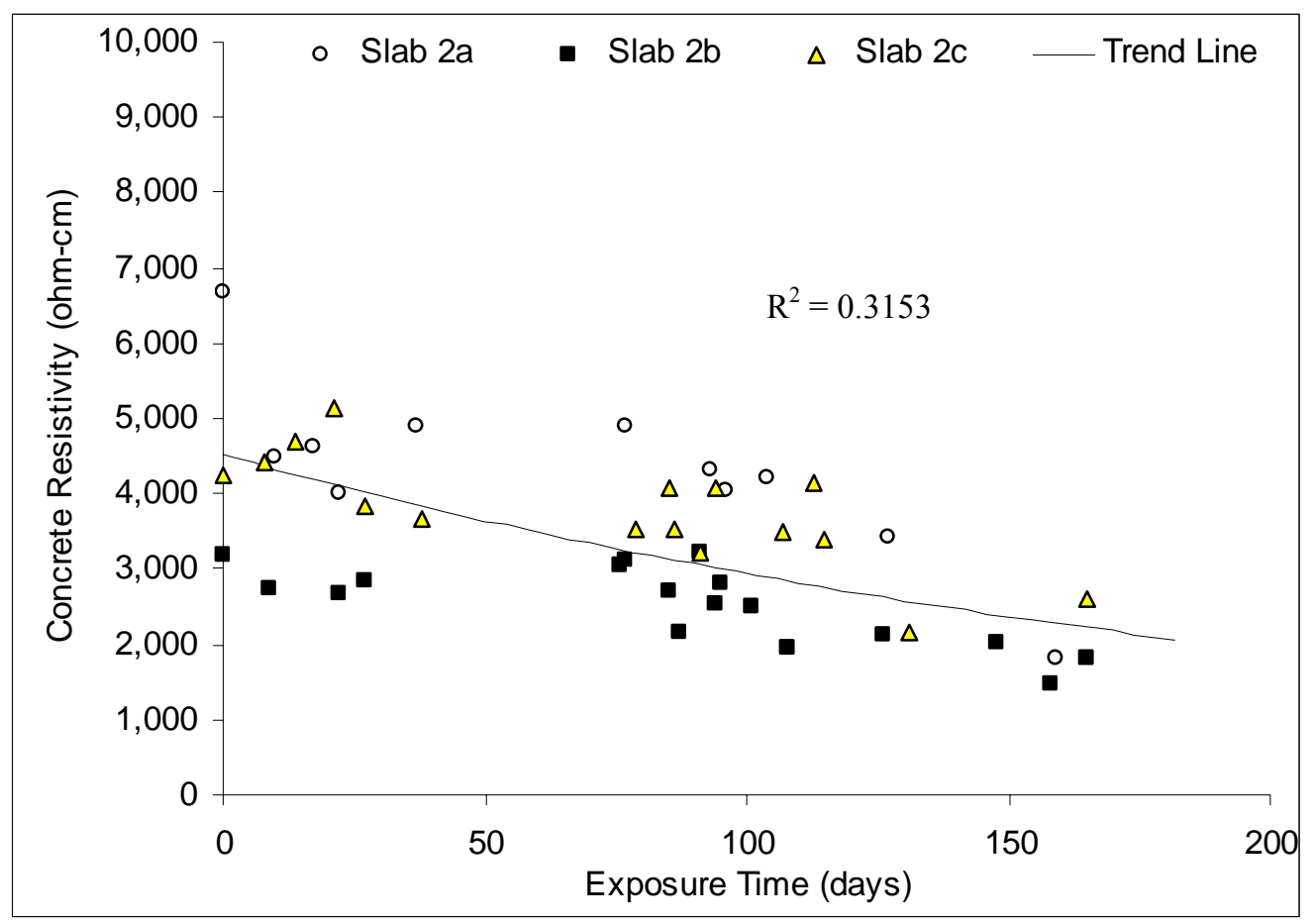

Figure 6.18 Concrete resistivity values for slabs repaired with silica fume concrete.

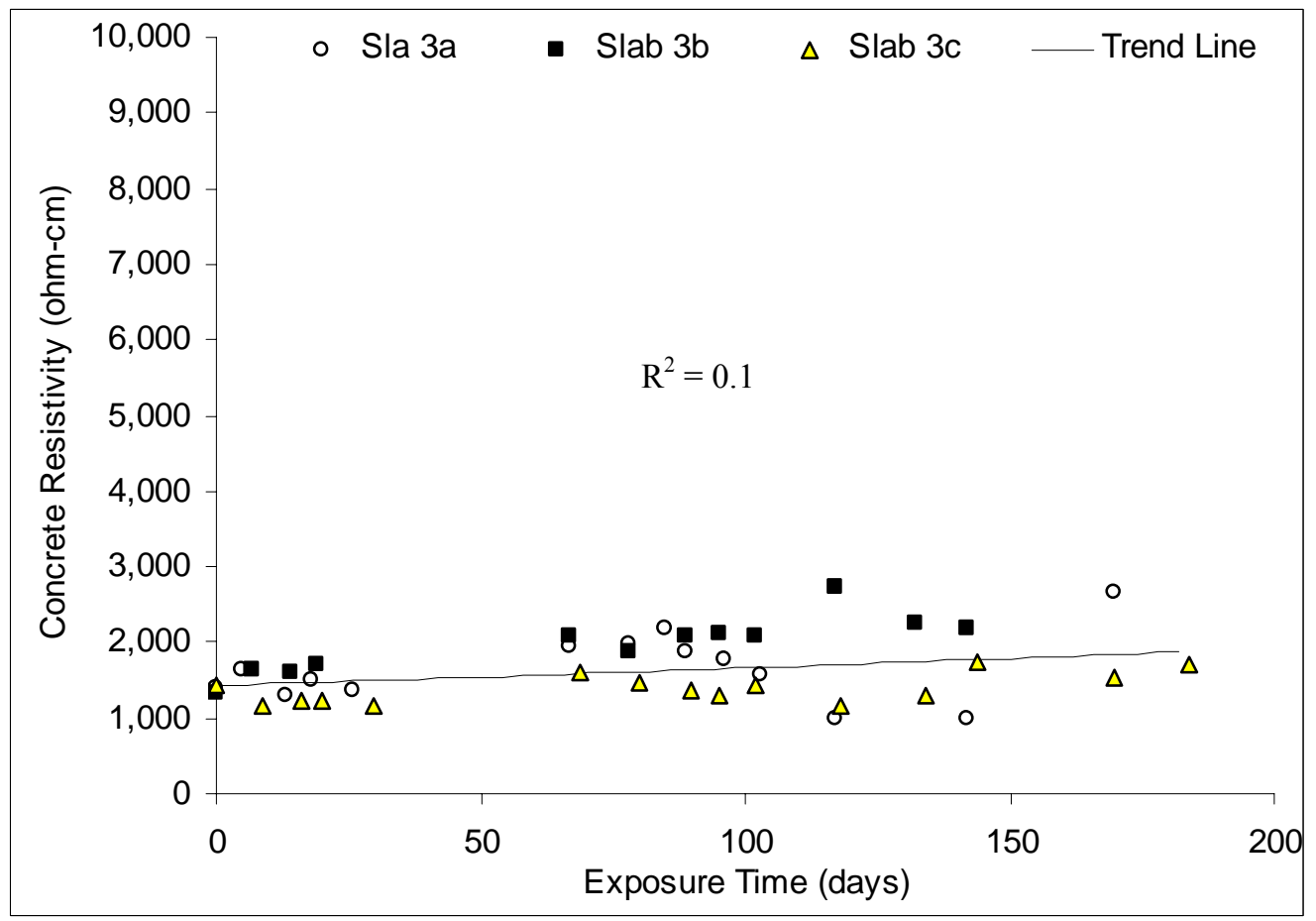

Figure 6.19 Concrete resistivity values for slabs repaired by concrete with calcium nitrite. 


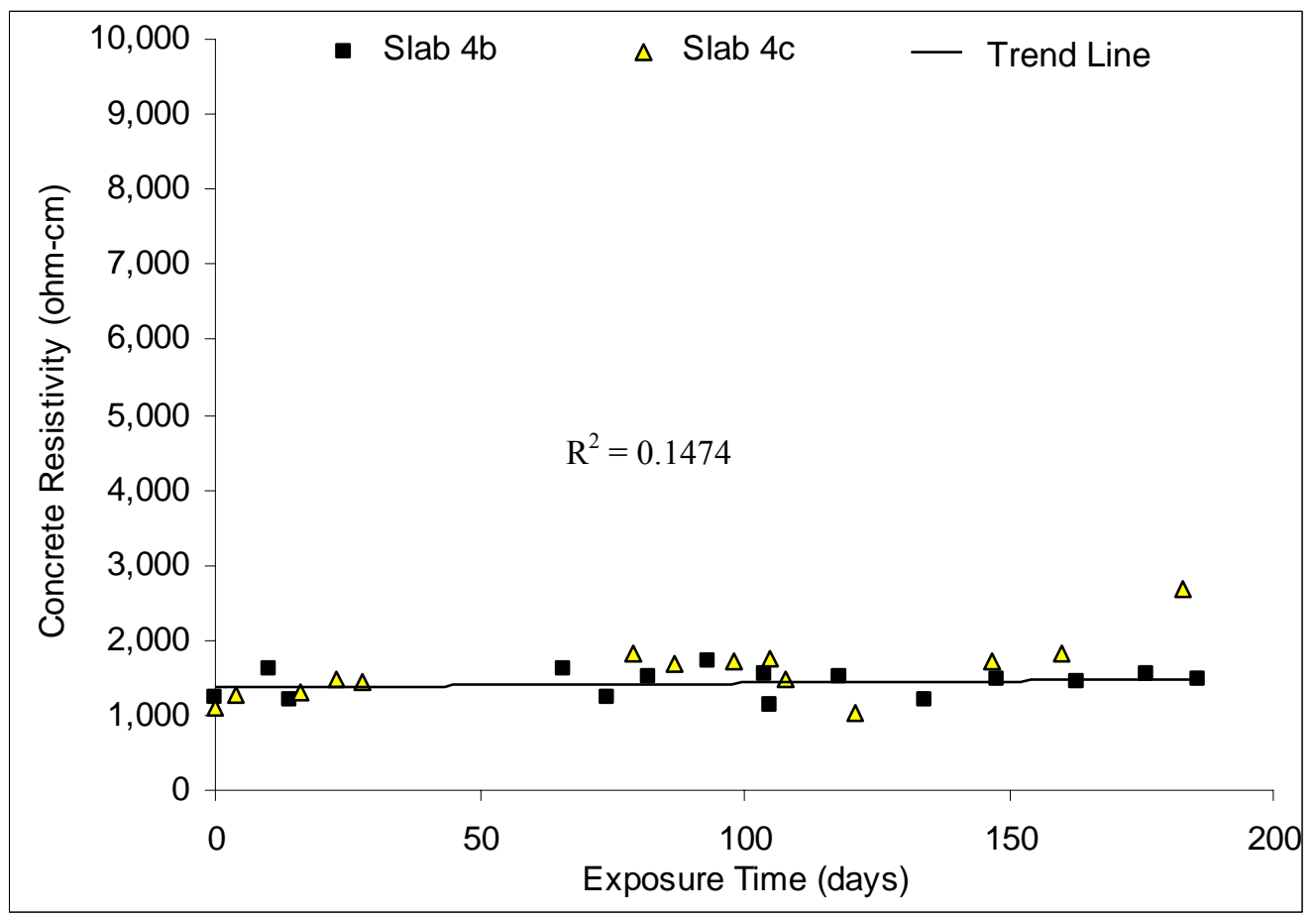

Figure 6.20 Concrete resistivity values for slabs repaired by concrete with organic corrosion inhibitor.

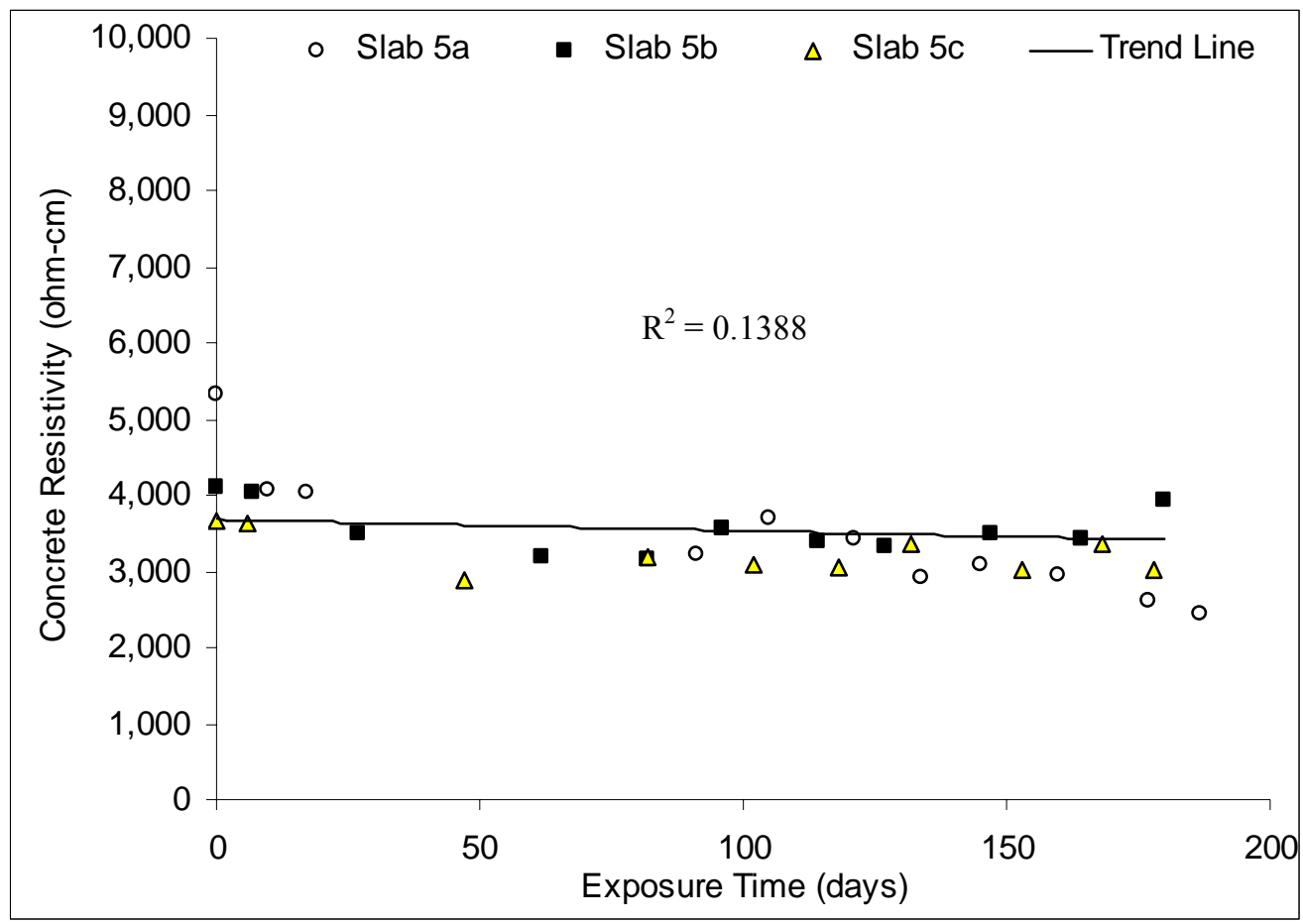

Figure 6.21 Concrete resistivity values for slabs repaired with fly ash concrete. 


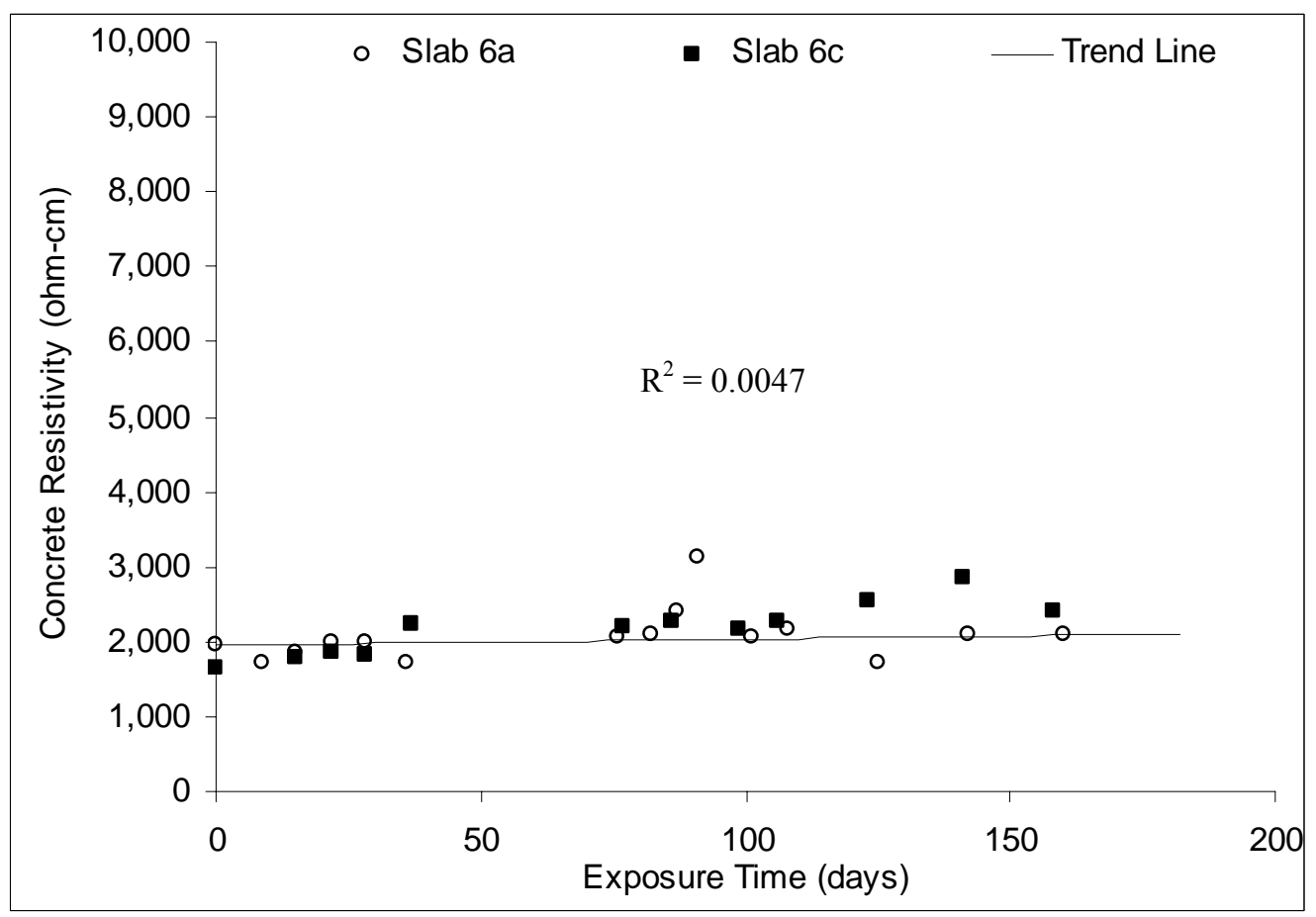

Figure 6.22 Concrete resistivity values for slabs repaired with INDOT 9-bag cement concrete.

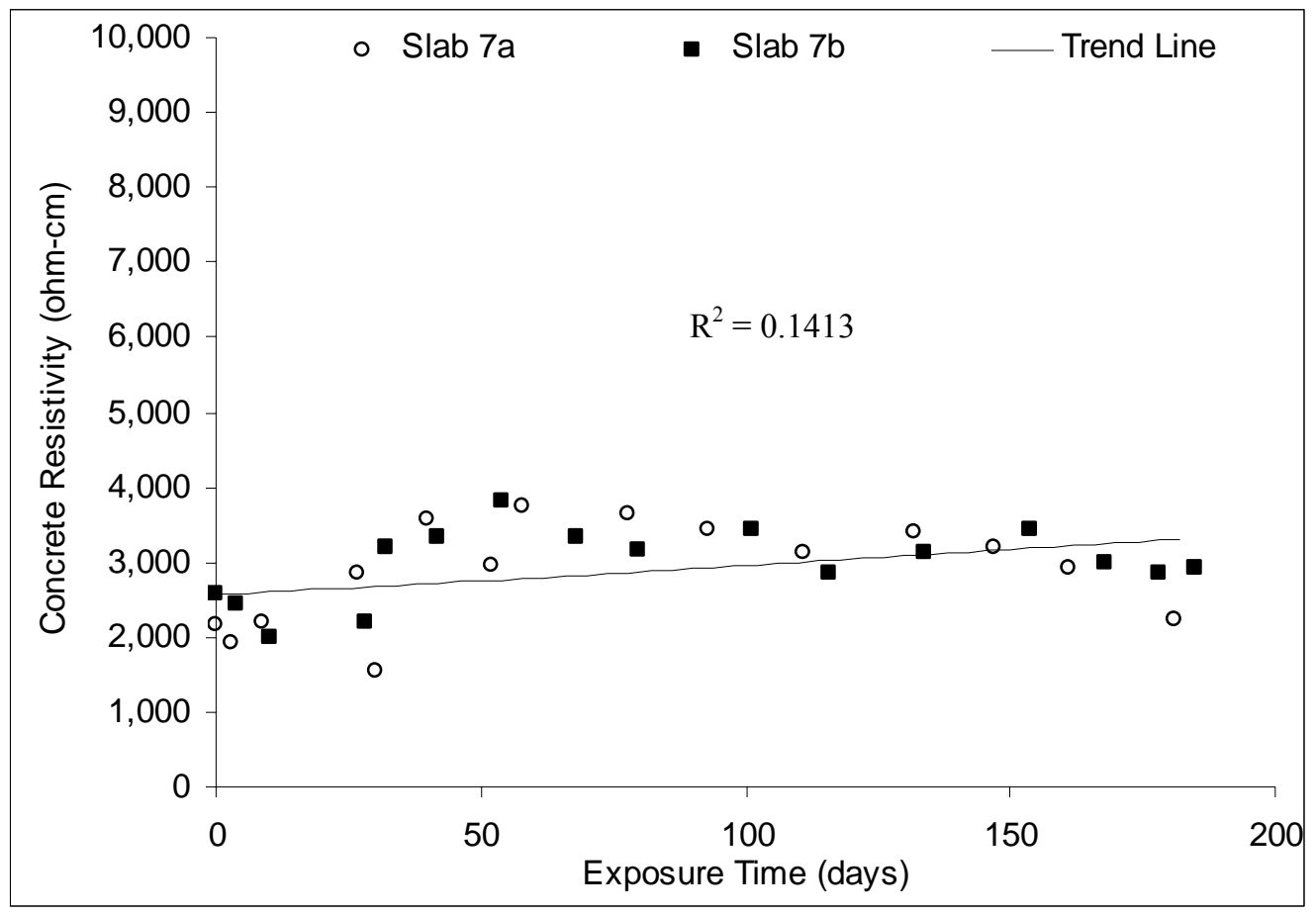

Figure 6.23 Concrete resistivity values for slabs repaired by concrete with shrinkage reducing admixture. 


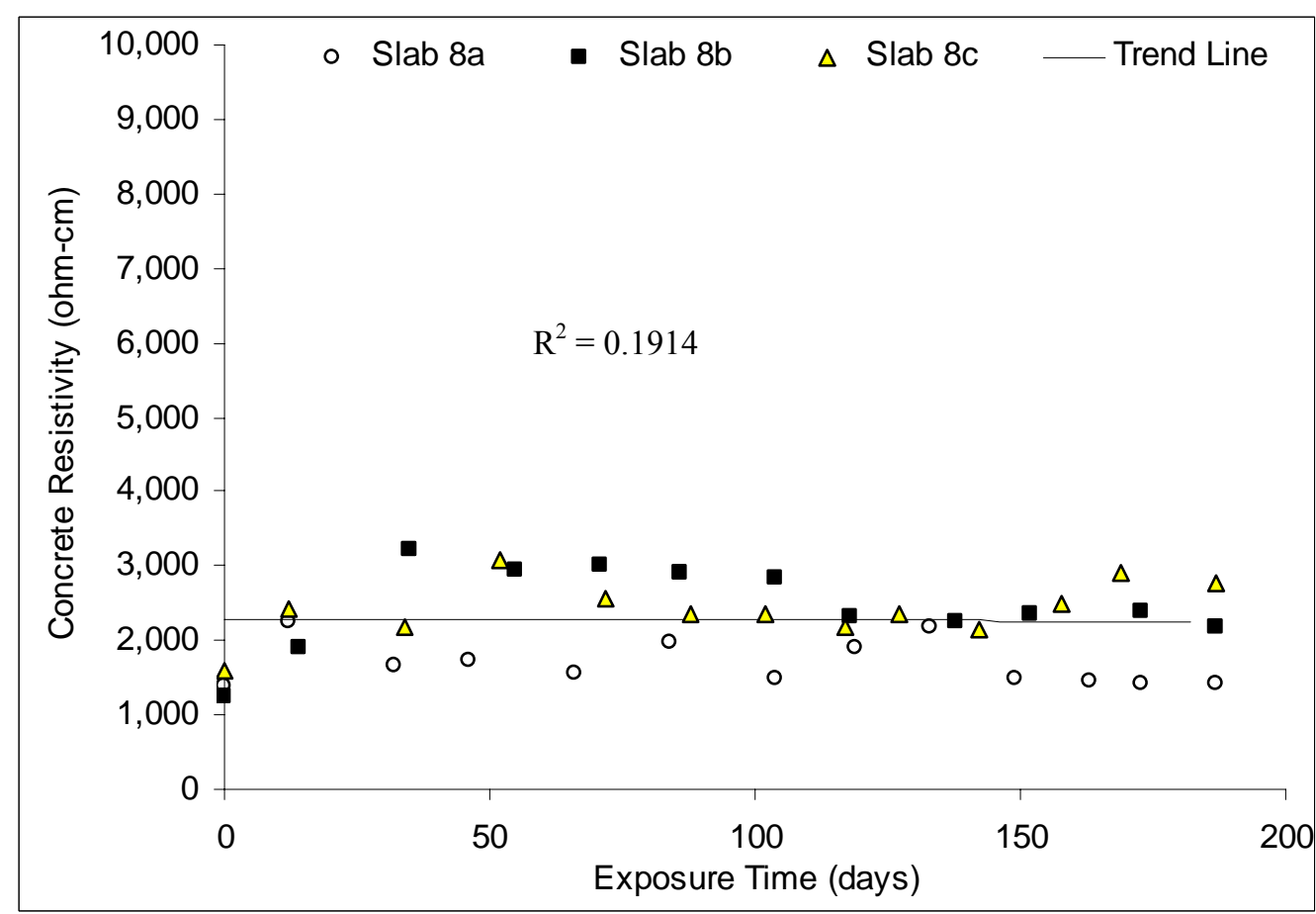

Figure 6.24 Concrete resistivity values for slabs repaired with latex modified concrete.

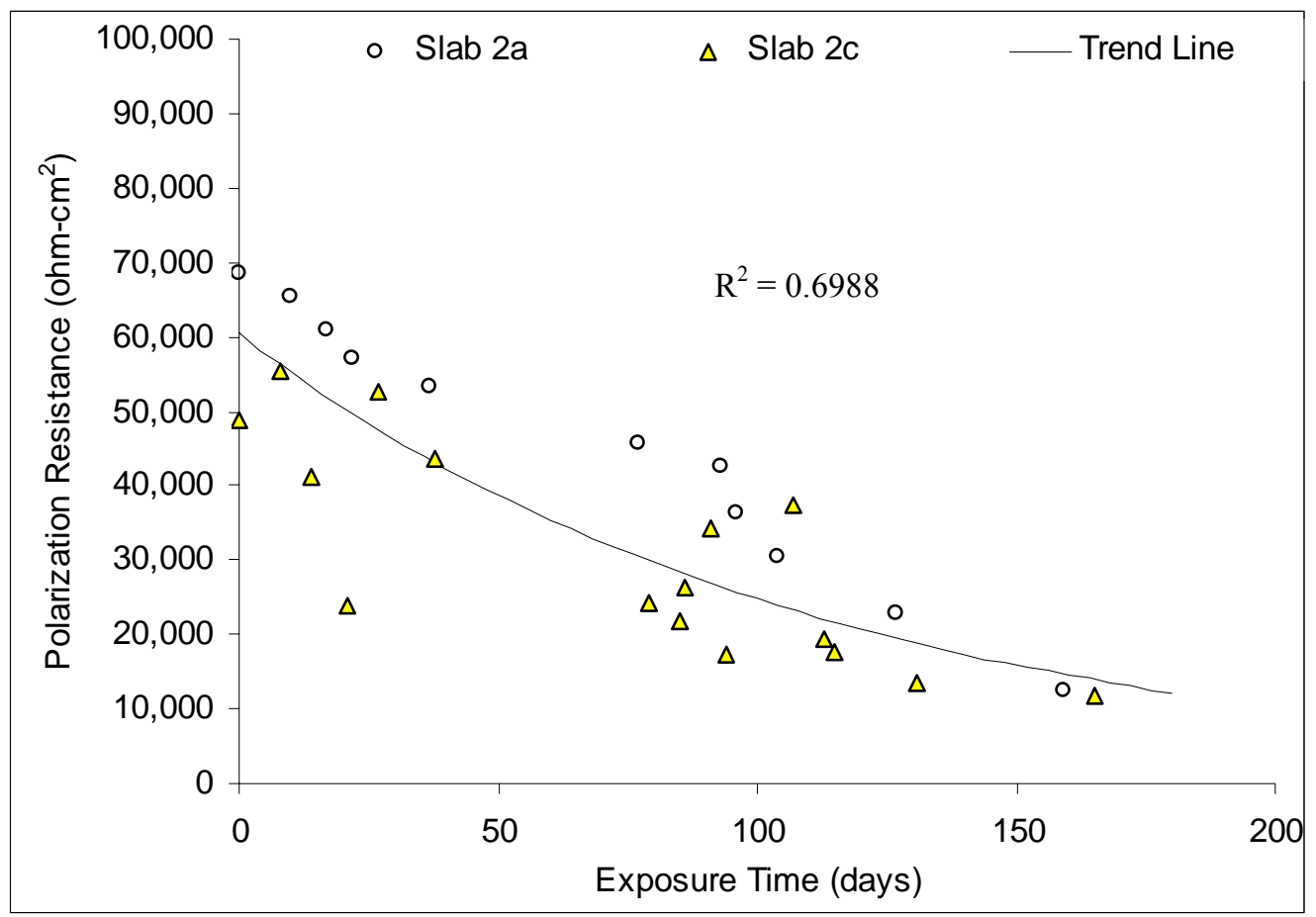

Figure 6.25 (a) Polarization resistance from EIS for slabs repaired with silica fume concrete. 


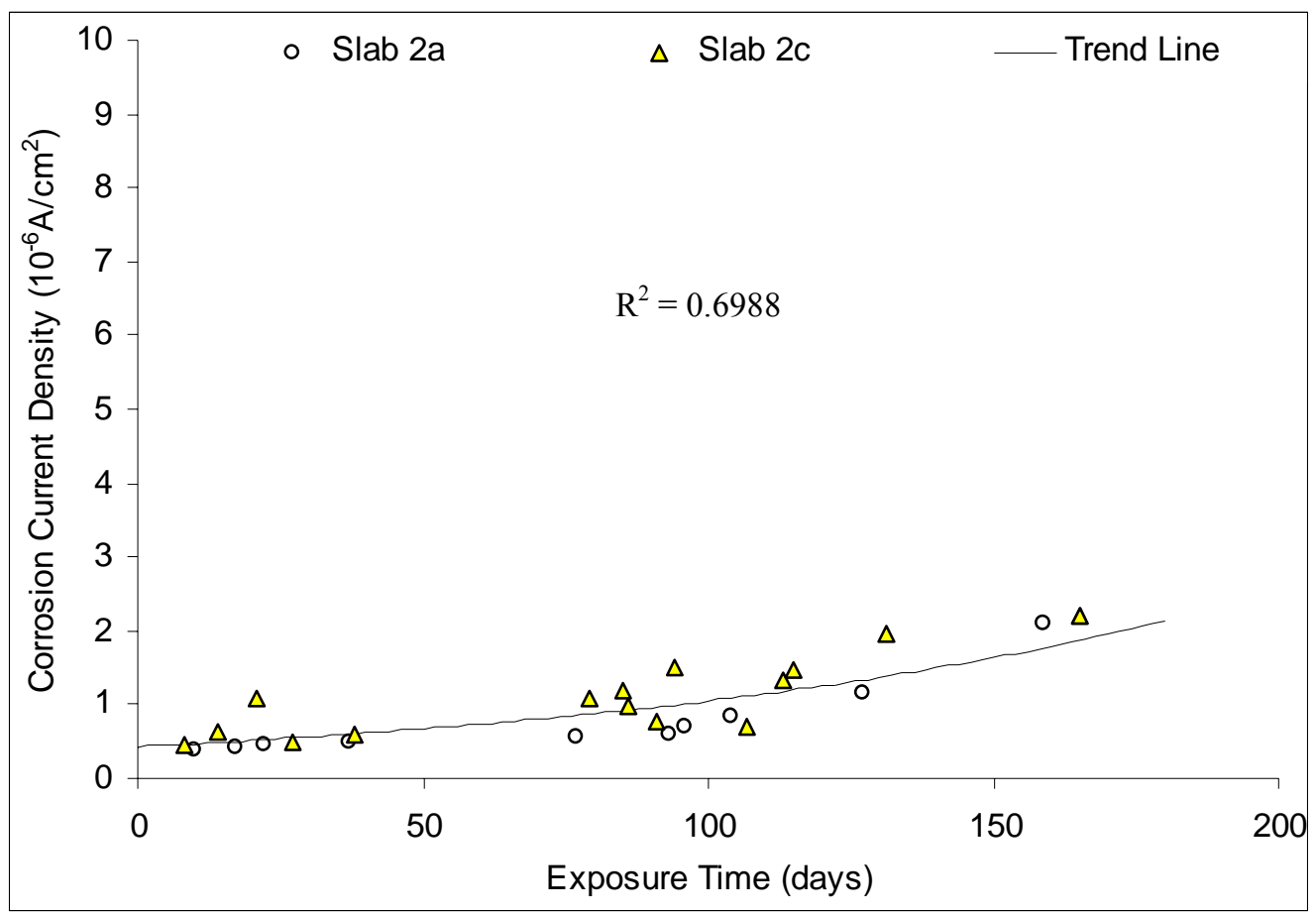

Figure 6.25 (b) Corrosion current density from EIS for the slabs repaired by silica fume concrete.

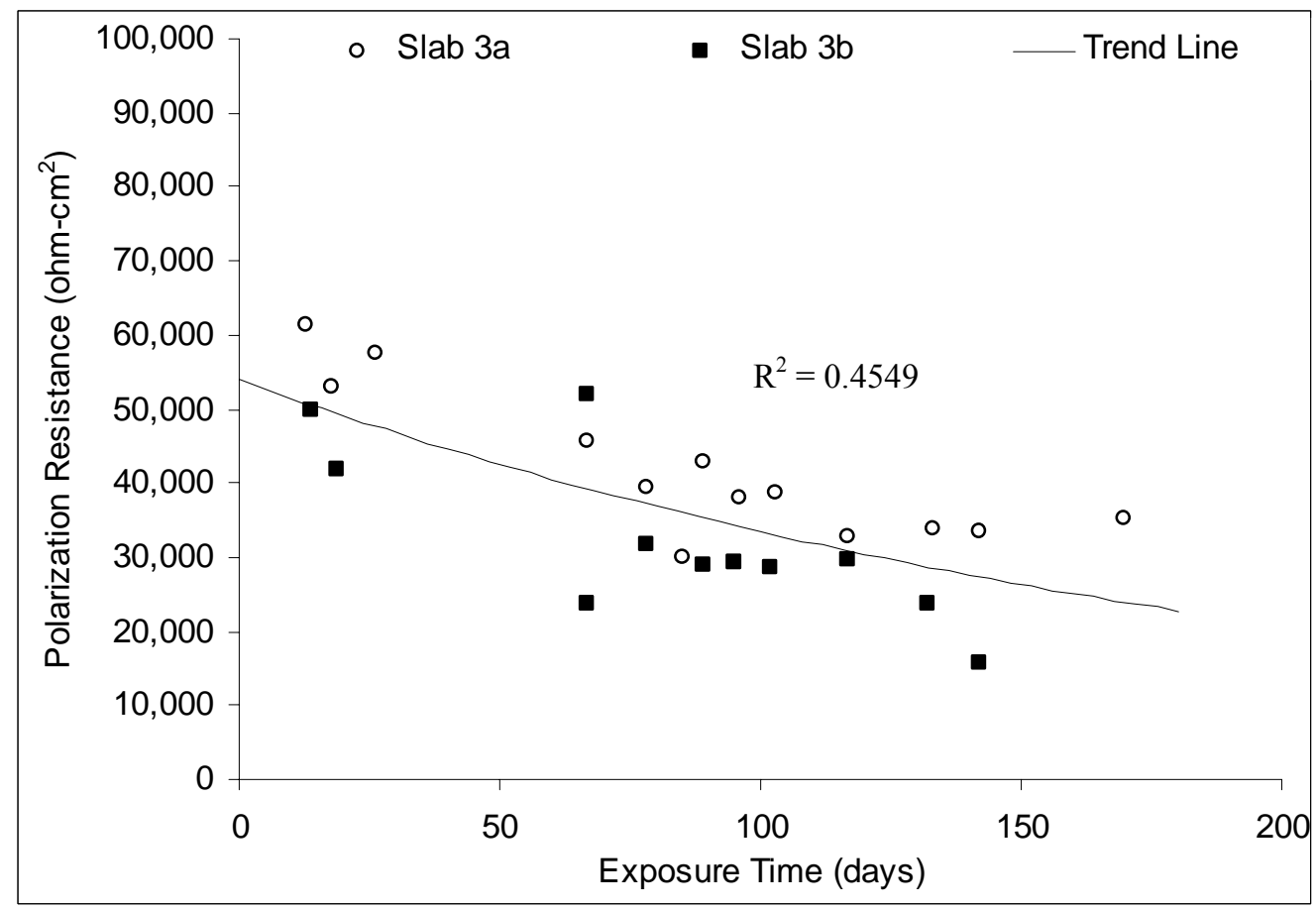

Figure 6.26 (a) Polarization resistance from EIS for slabs repaired by the concrete with calcium nitrite. 


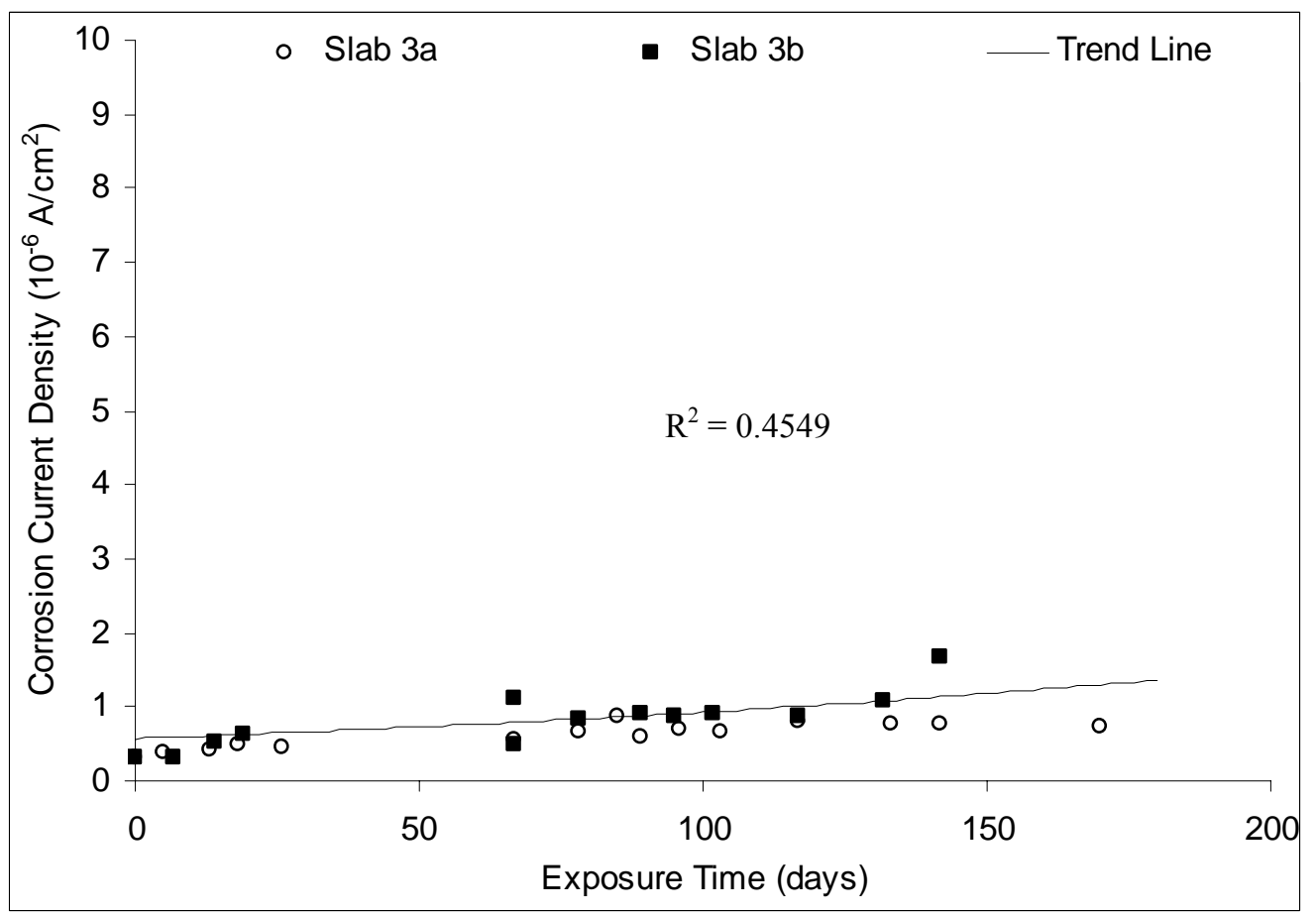

Figure 6.26 (b) Corrosion current density from EIS for the slabs repaired by the concrete with calcium nitrite.

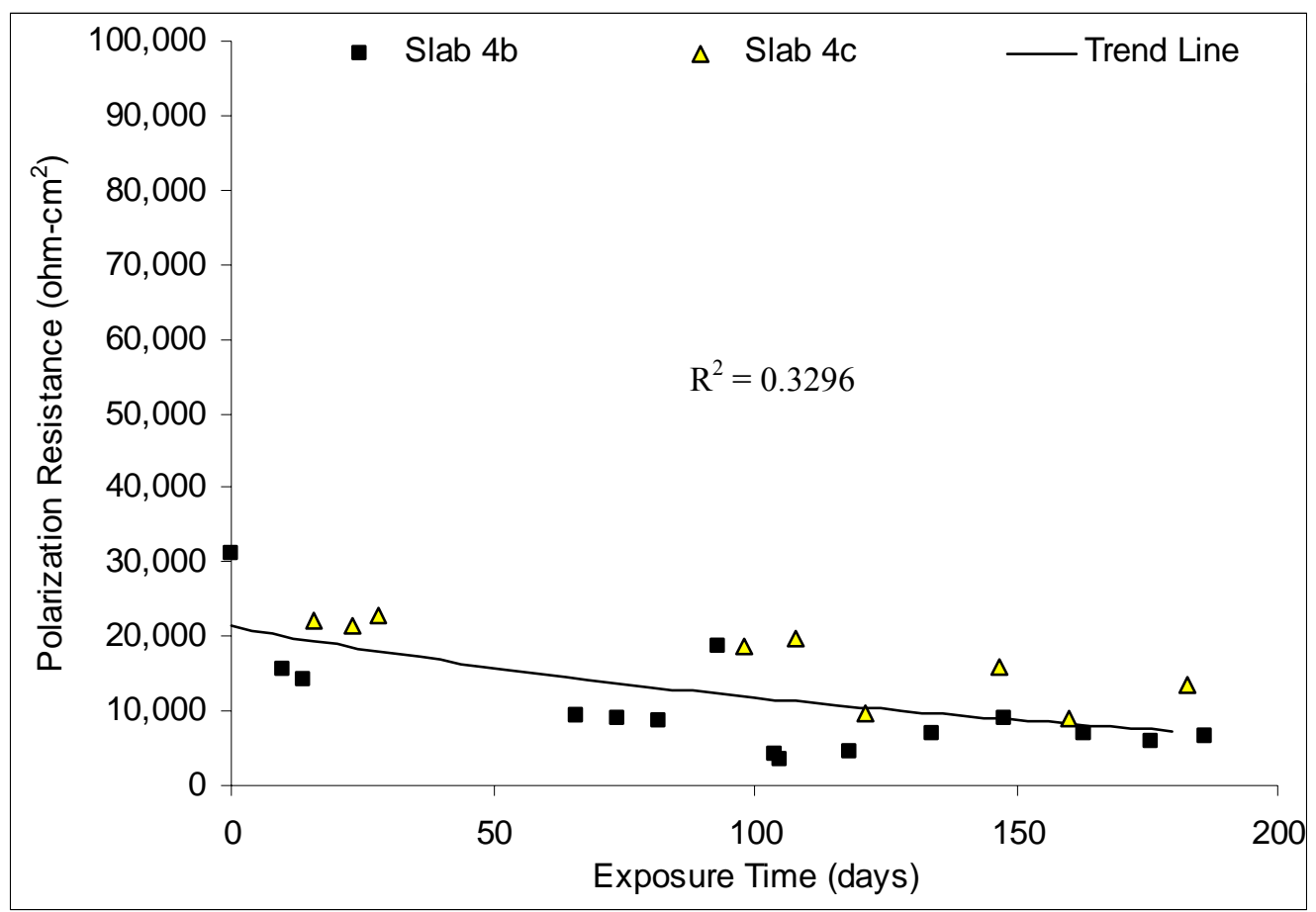

Figure 6.27 (a) Polarization resistance from EIS for slabs repaired by the concrete with the organic corrosion inhibitor. 


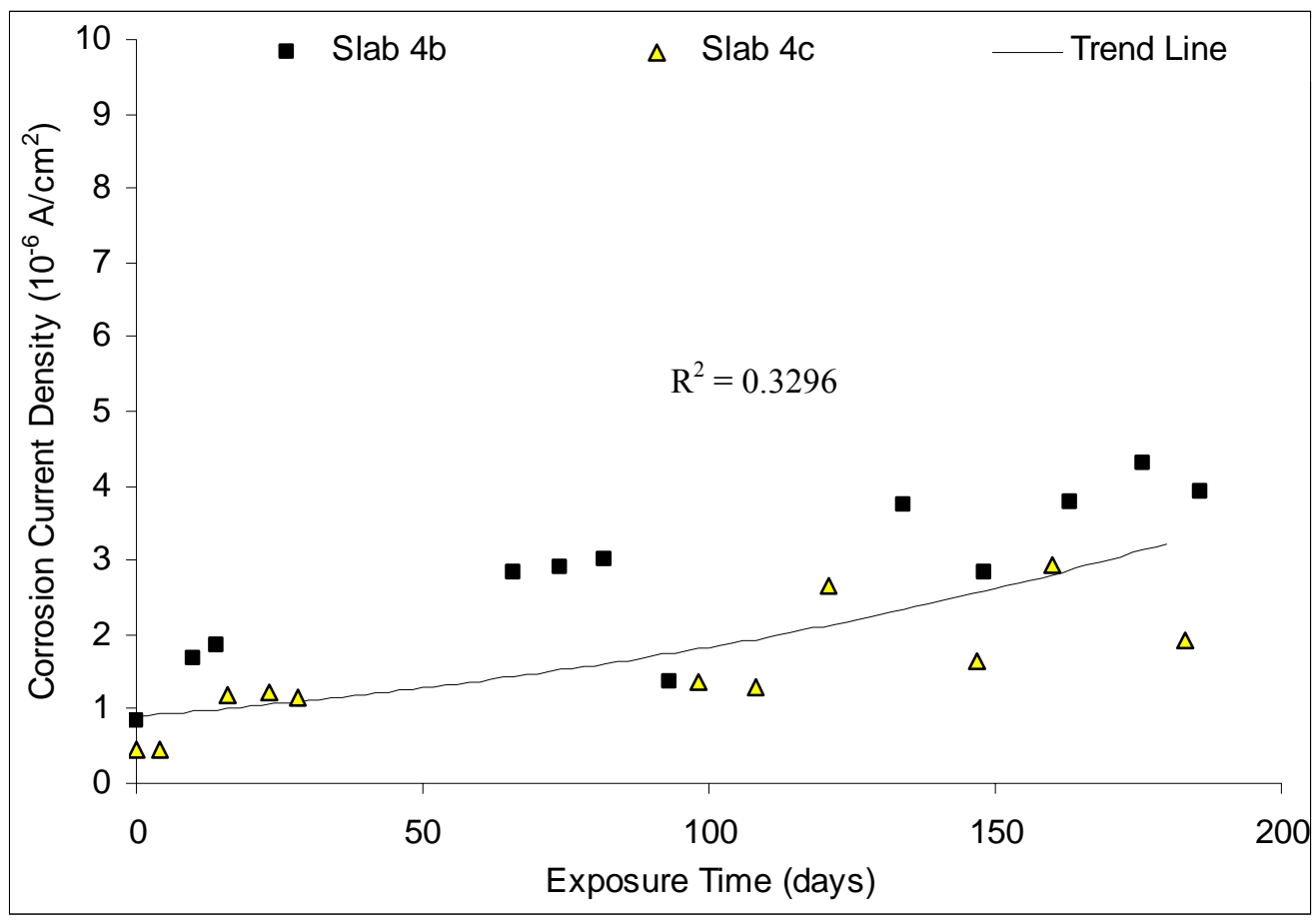

Figure 6.27 (b) Corrosion current density from EIS for the slabs repaired by the concrete with the organic corrosion inhibitor.

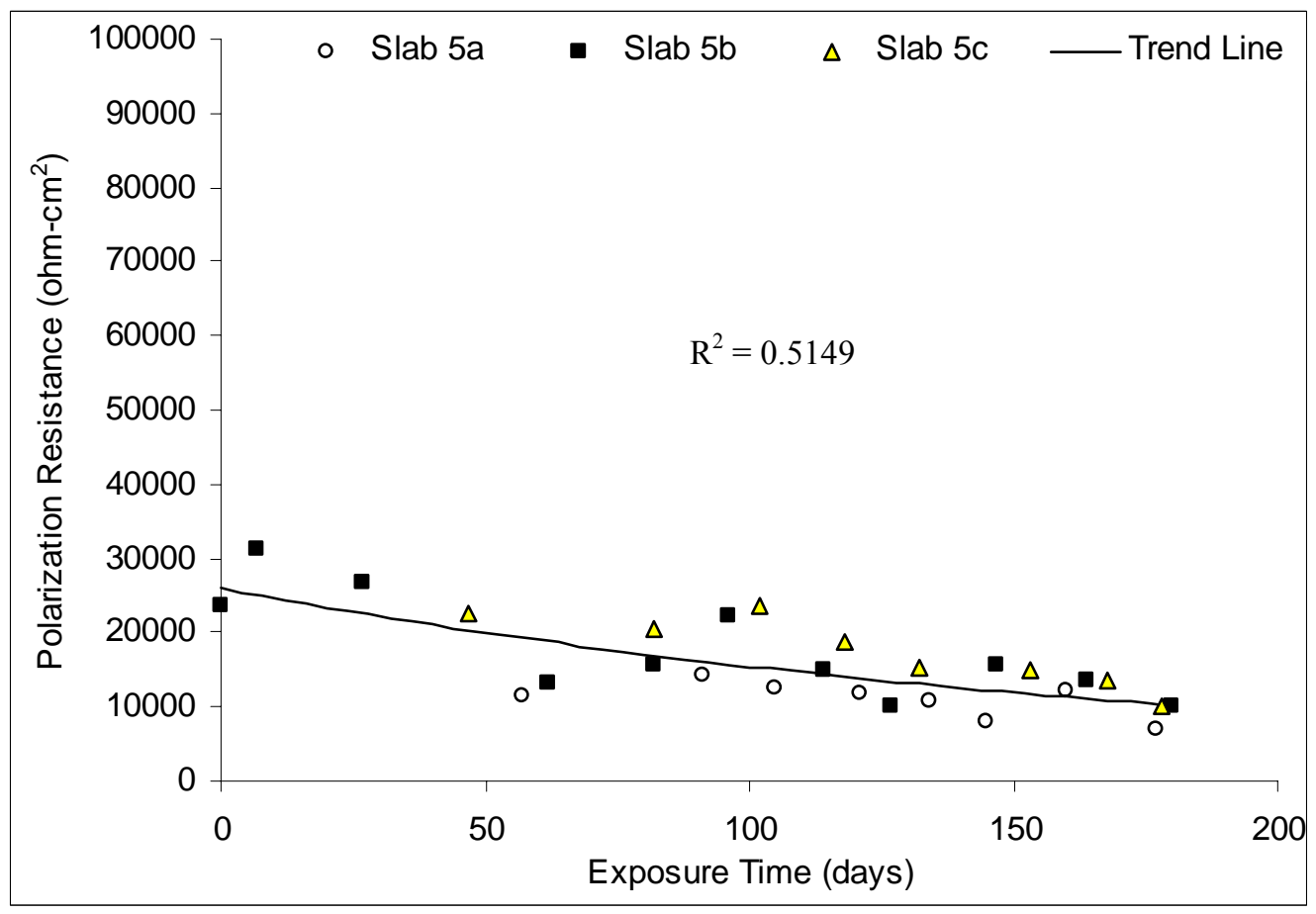

Figure 6.28 (a) Polarization resistance from EIS for slabs repaired by the fly ash concrete. 


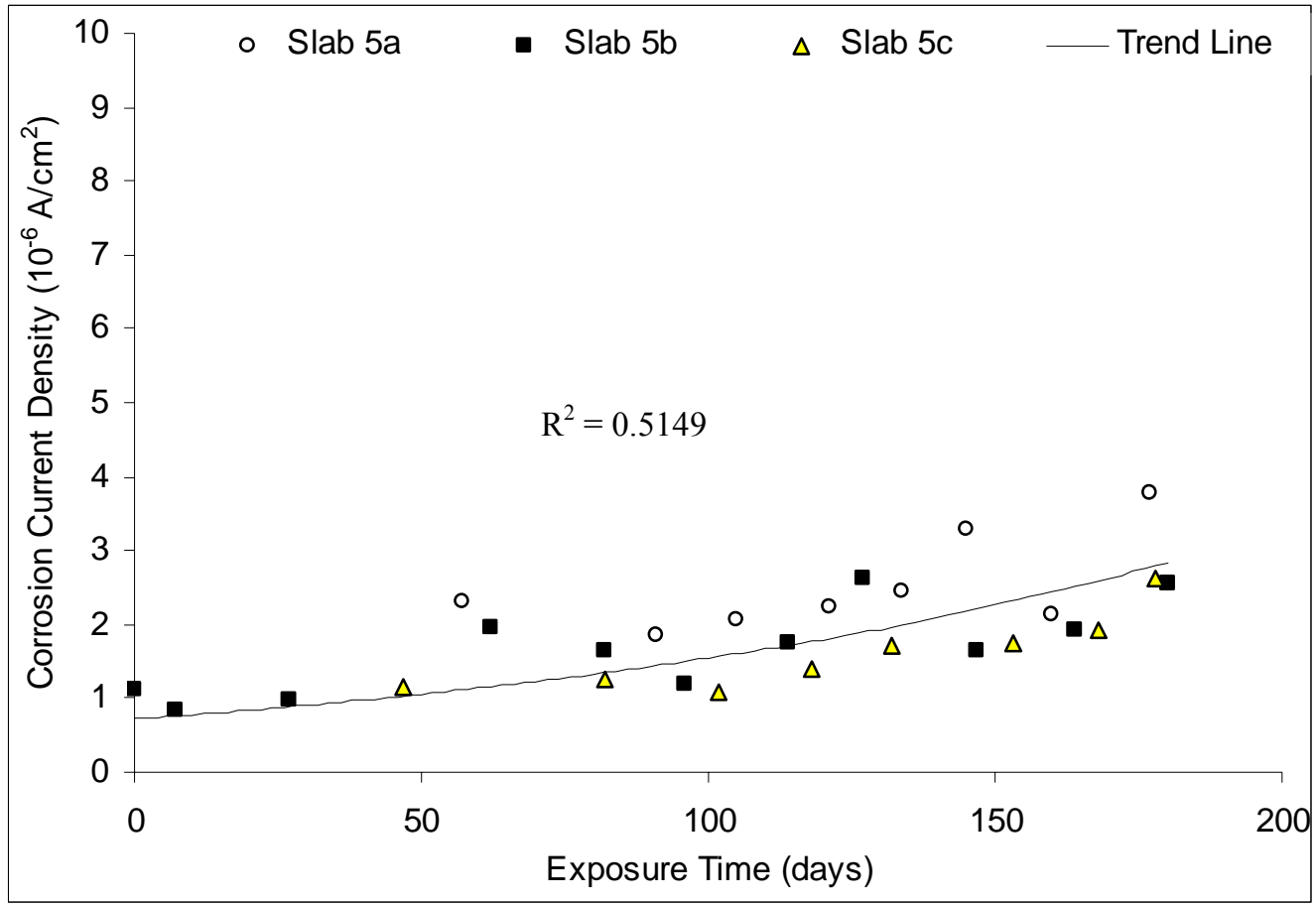

Figure 6.28 (b) Corrosion current density from EIS for the slabs repaired by the fly ash concrete.

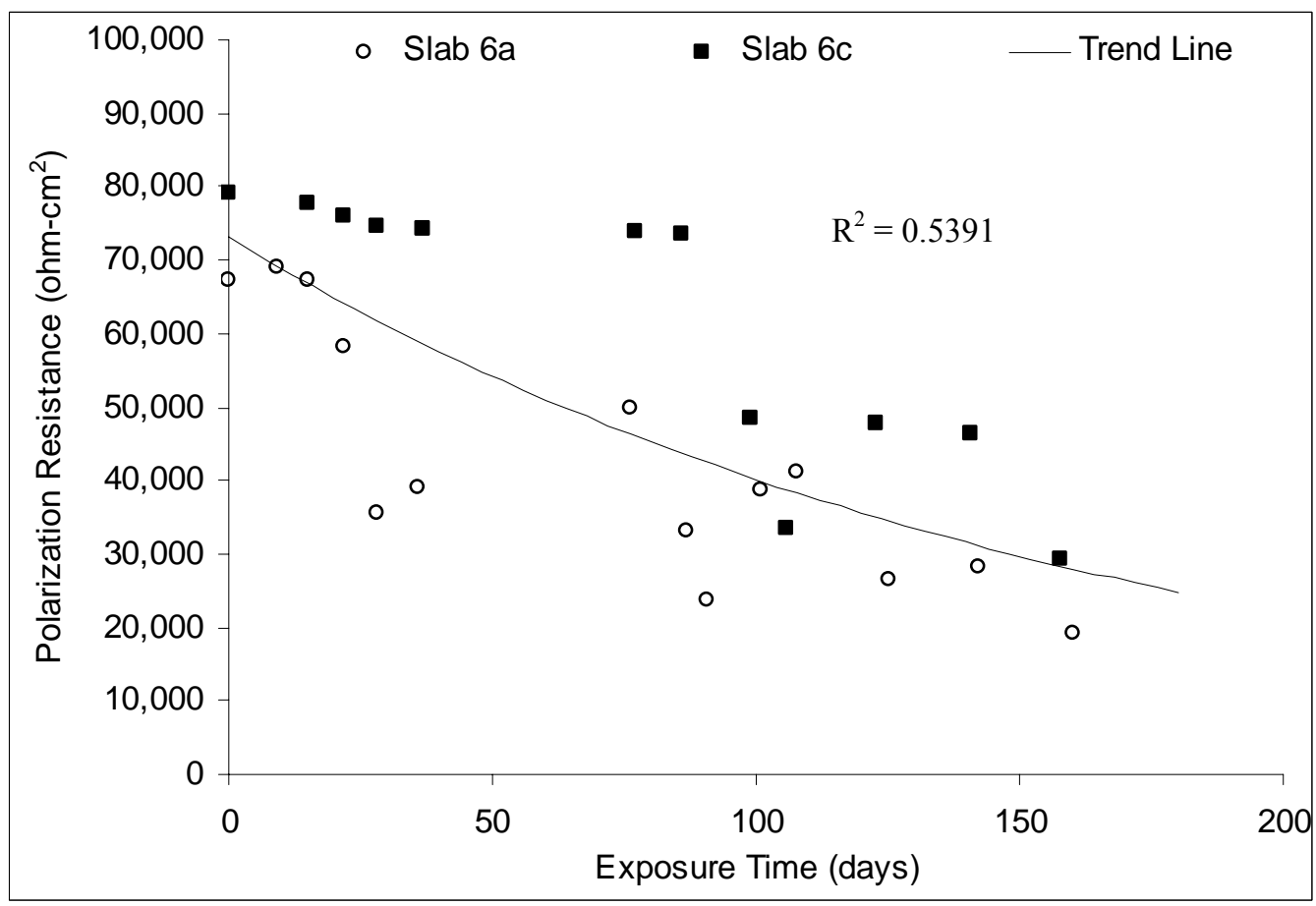

Figure 6.29 (a) Polarization resistance from EIS for slabs repaired by INDOT 9-bag cement concrete. 


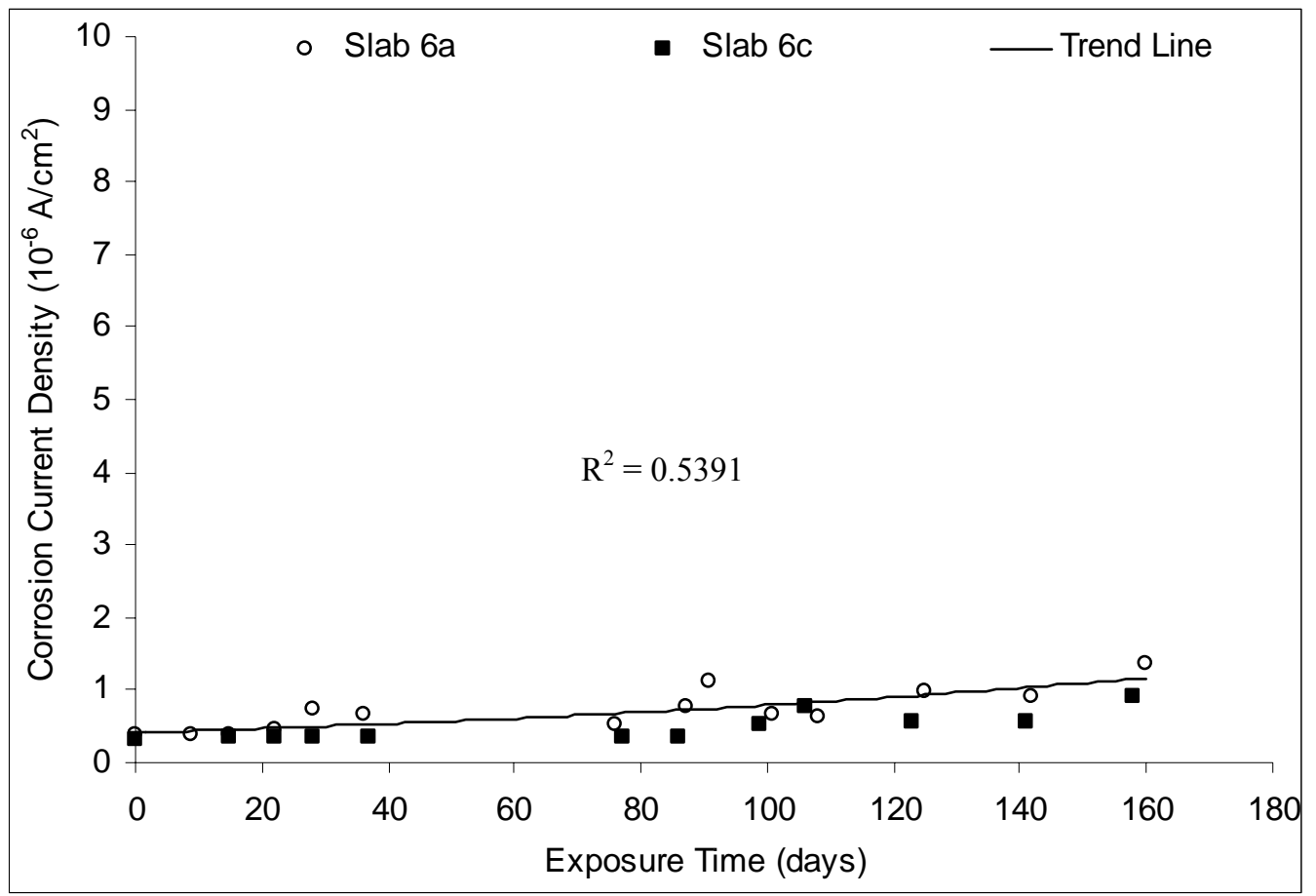

Figure 6.29 (b) Corrosion current density from EIS for slabs repaired by INDOT 9-bag cement concrete.

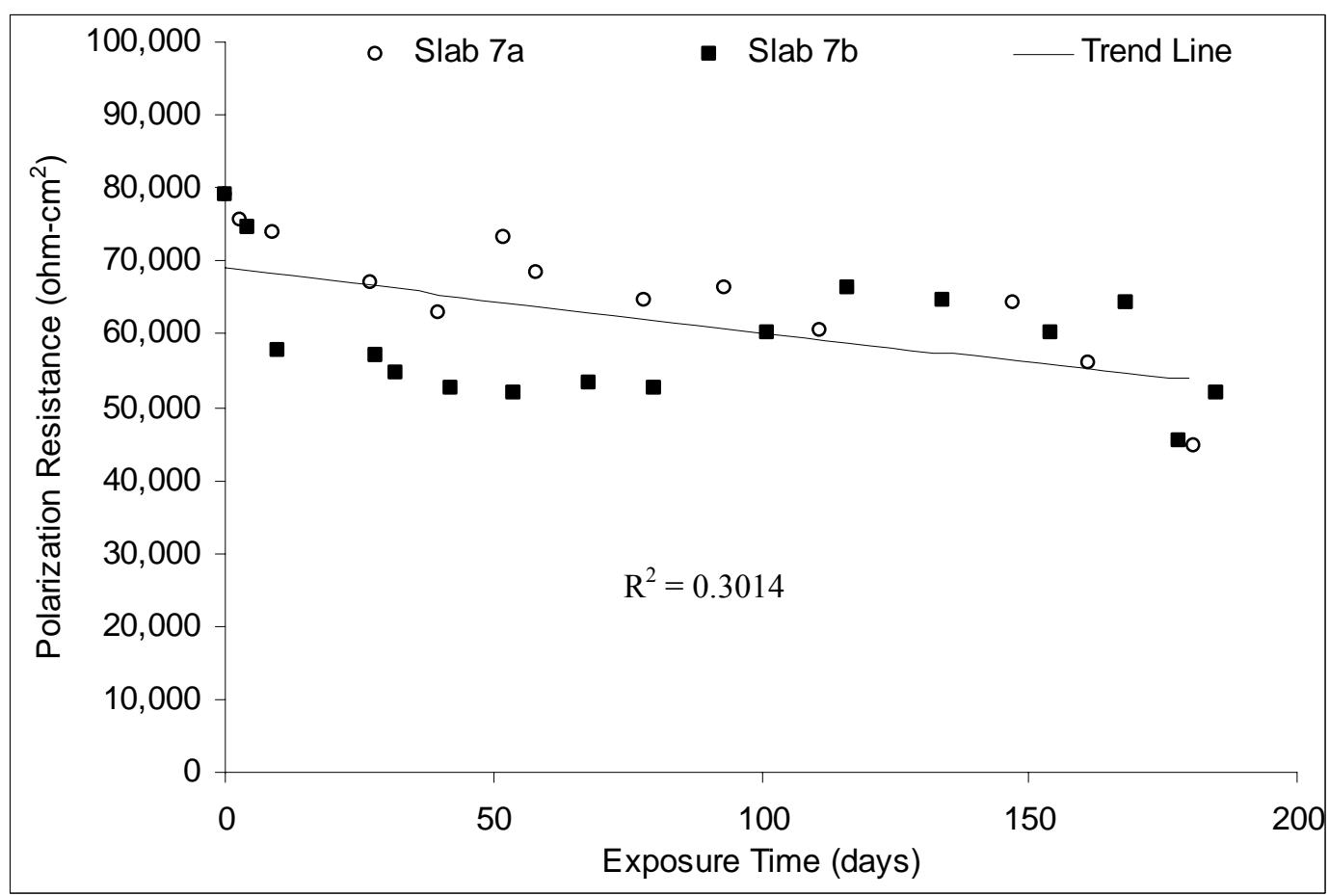

Figure 6.30 (a) Polarization resistance from EIS for slabs repaired by concrete with shrinkage reducing admixture. 


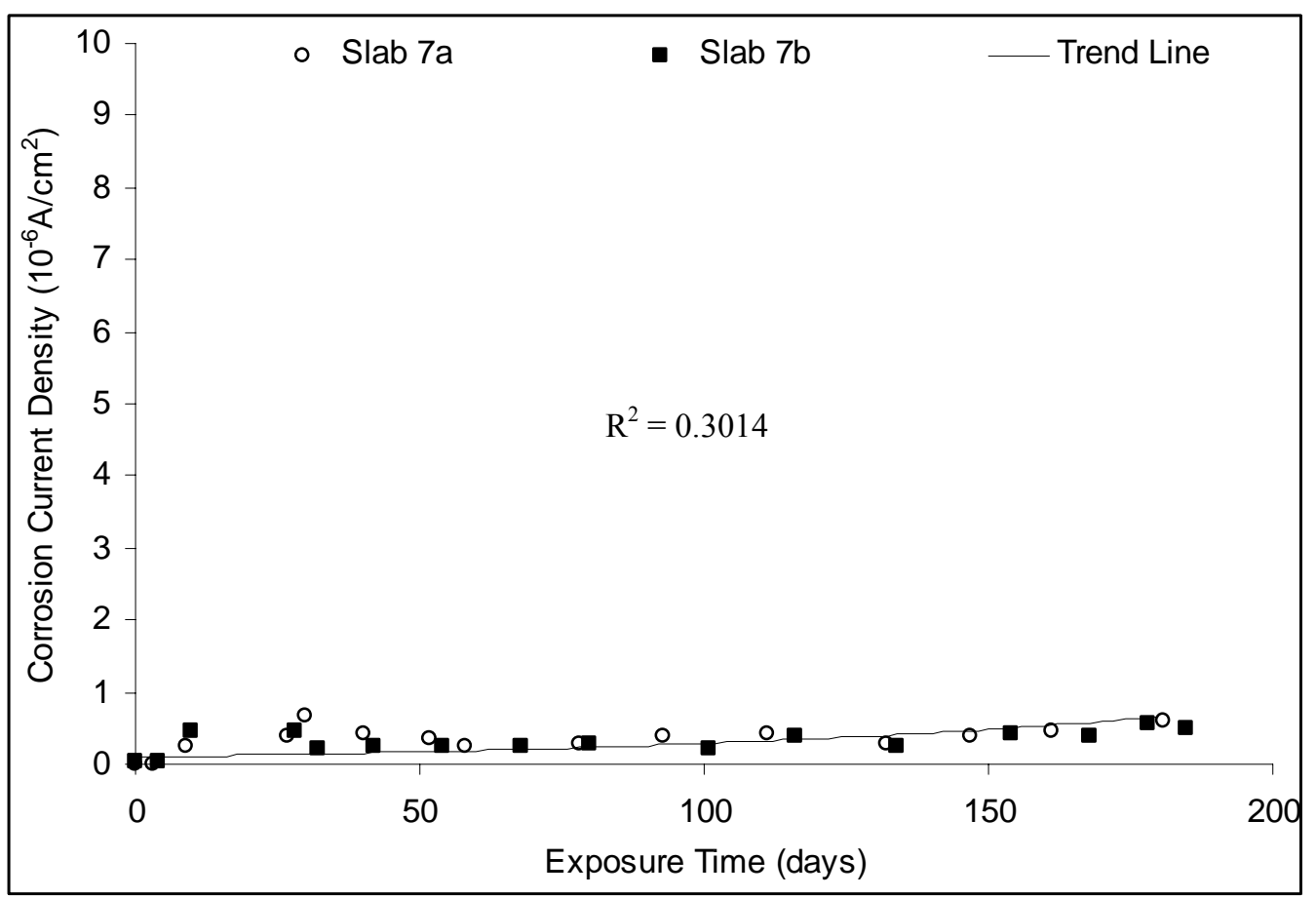

Figure 6.30 (b) Corrosion current density from EIS for the slabs repaired with concrete containing shrinkage reducing admixture.

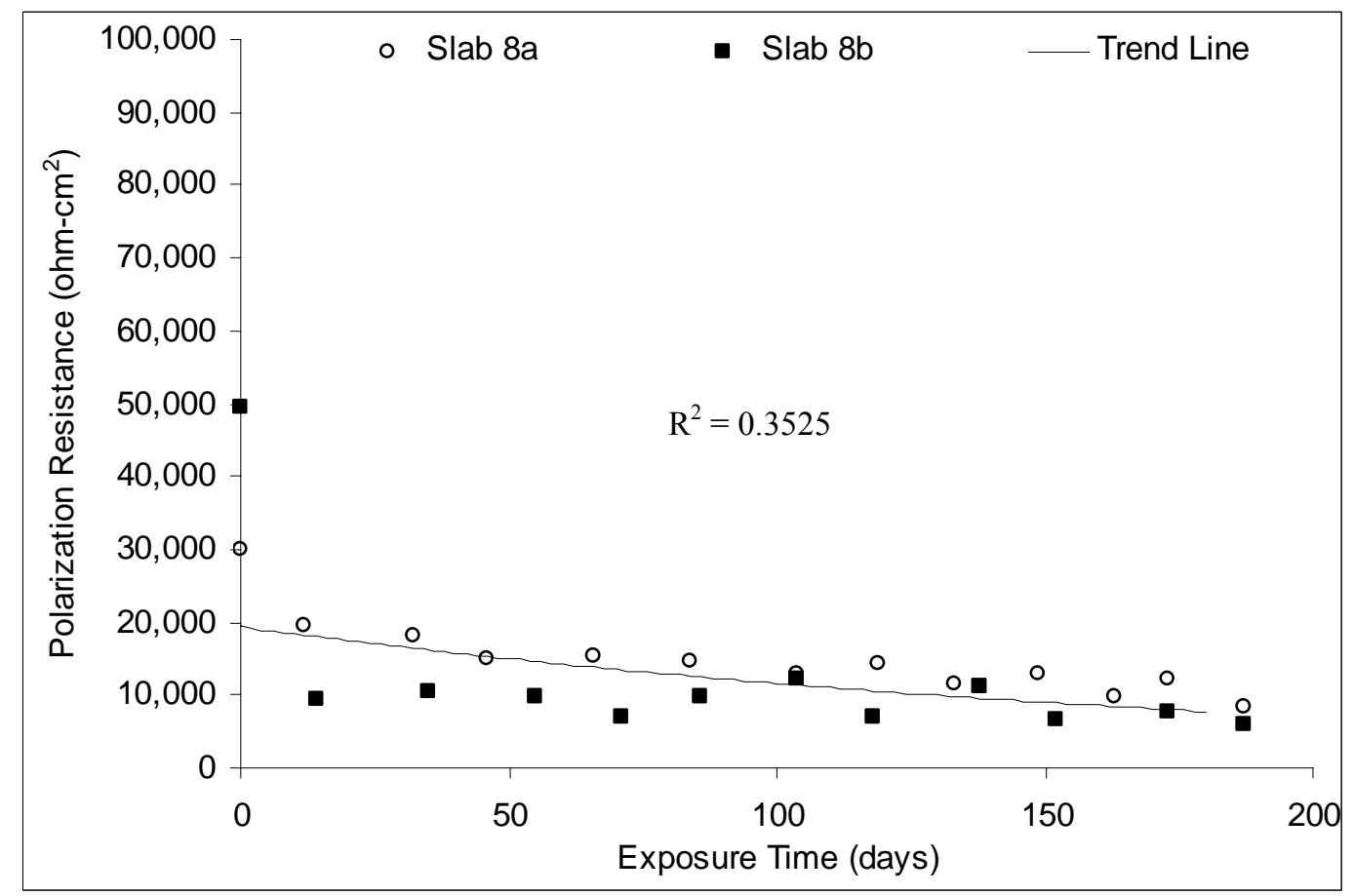

Figure 6.31 (a) Polarization resistance from EIS for slabs being repaired with latex modified concrete. 


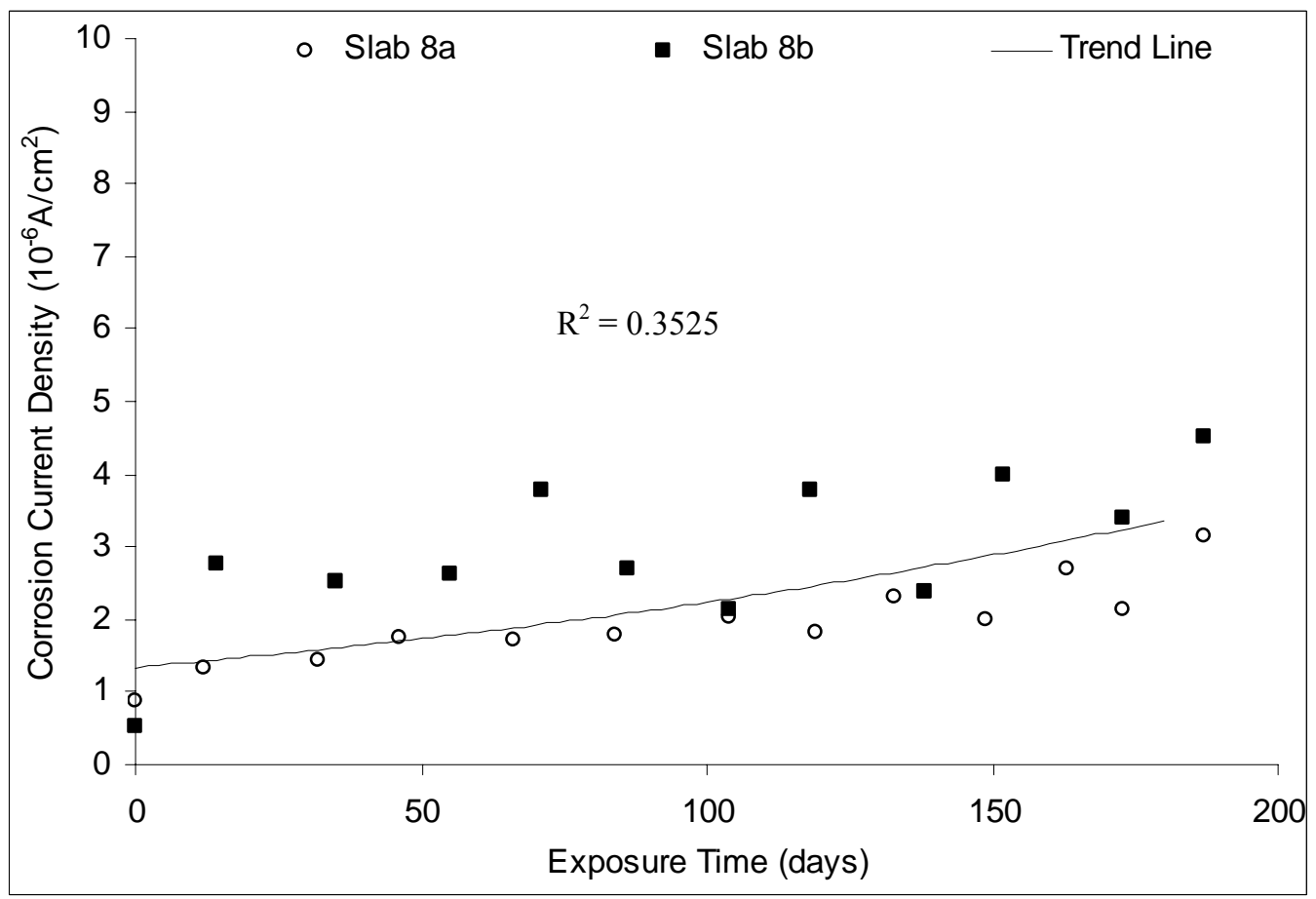

Figure 6.31 (b) Corrosion current density from EIS for the slabs repaired by the latex modified concrete.

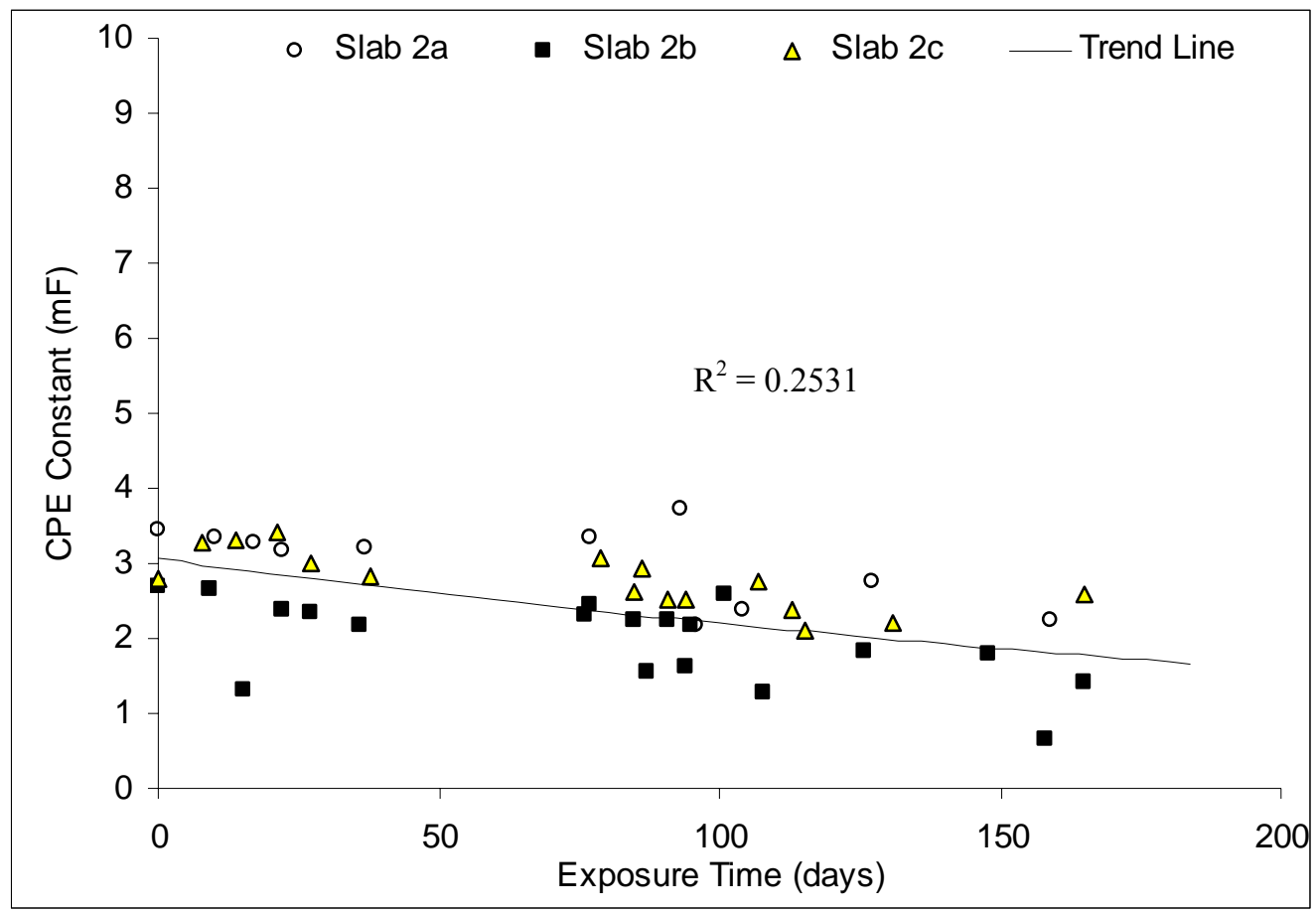

Figure 6.32 The values of the constant phase element (CPE) for the slabs repaired by the silica fume concrete. 


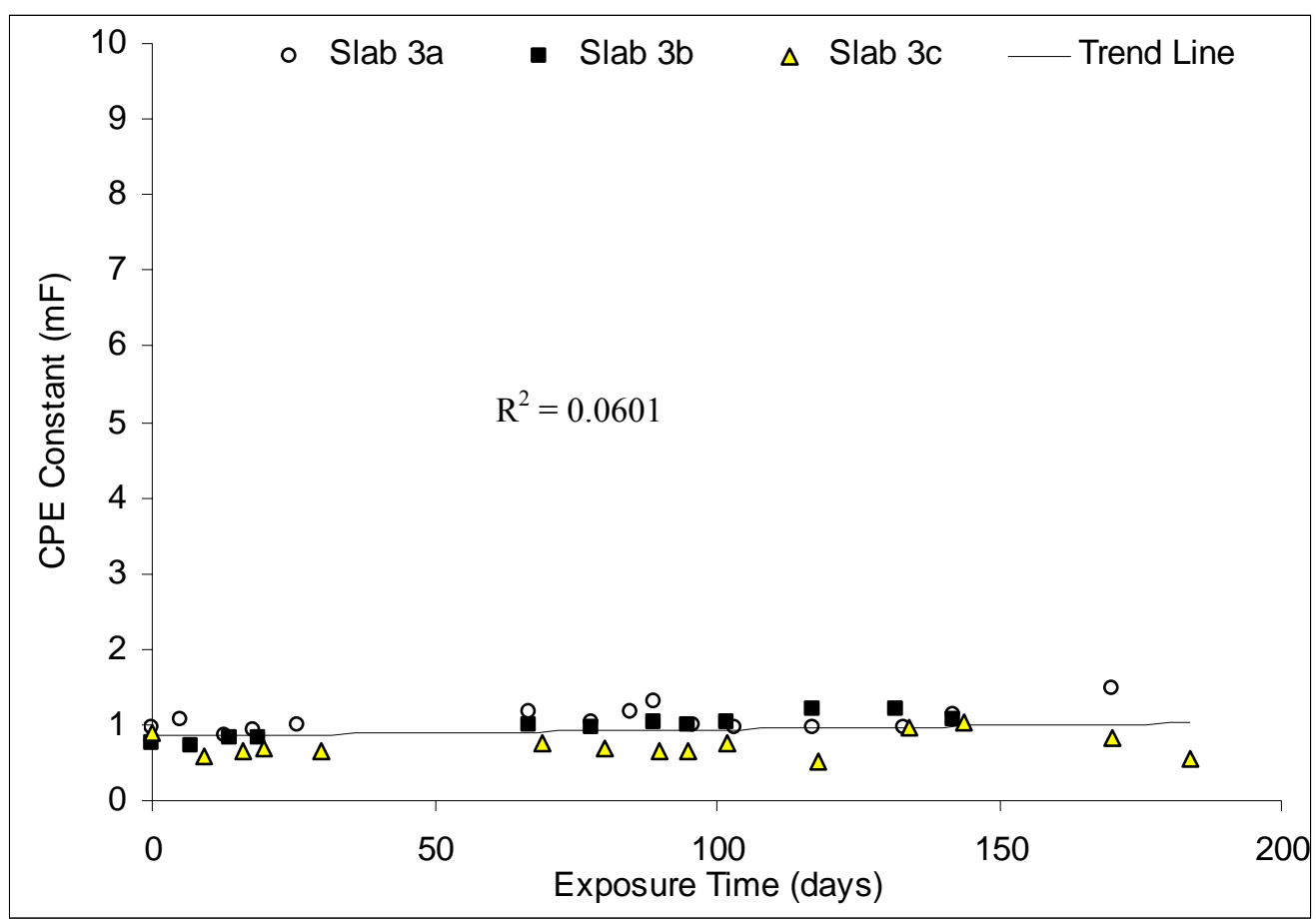

Figure 6.33 The values of the constant phase element (CPE) for the slabs repaired by the concrete with the calcium nitrite.

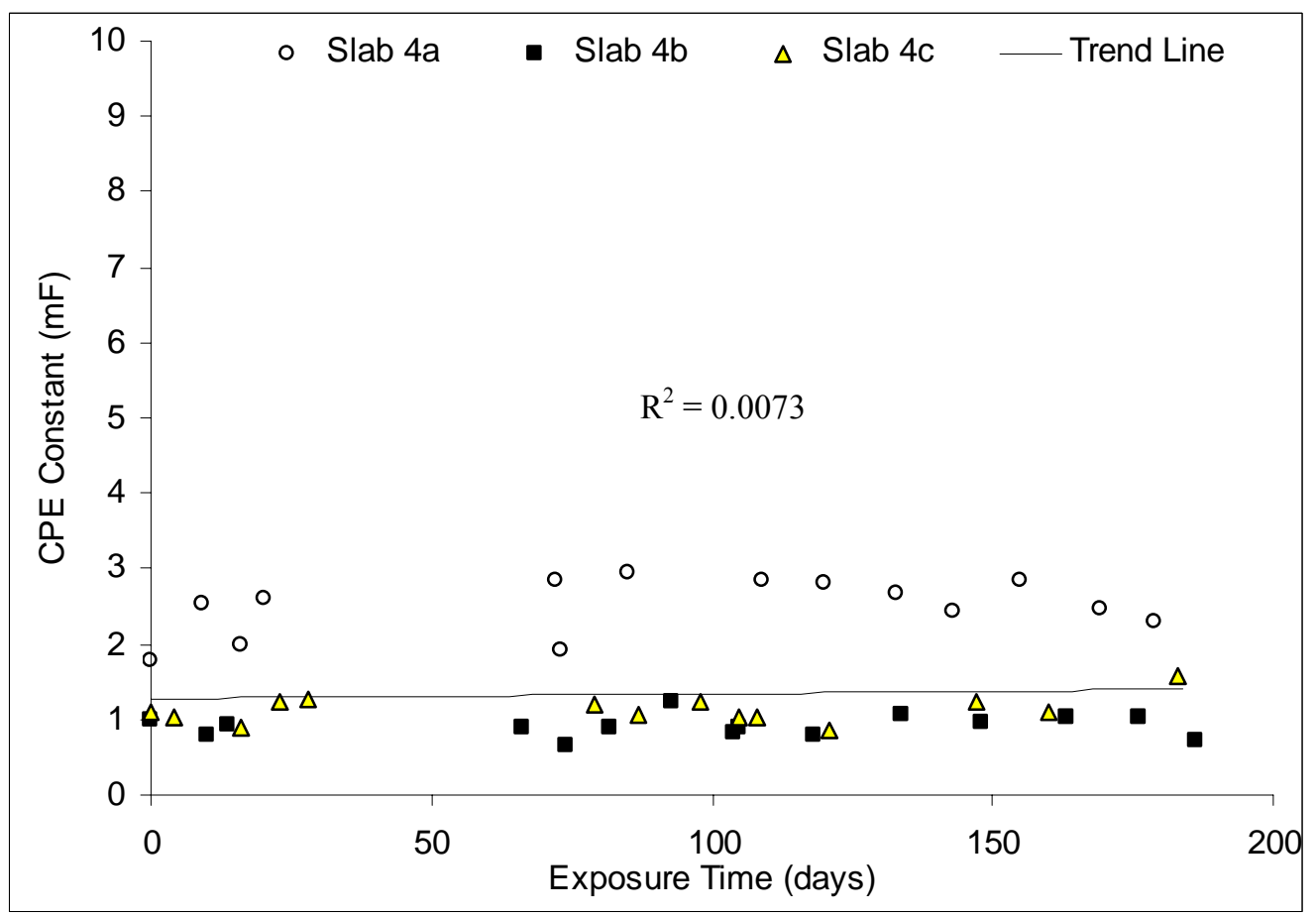

Figure 6.34 The values of the constant phase element (CPE) for the slabs repaired by the concrete with the organic corrosion inhibitor. 


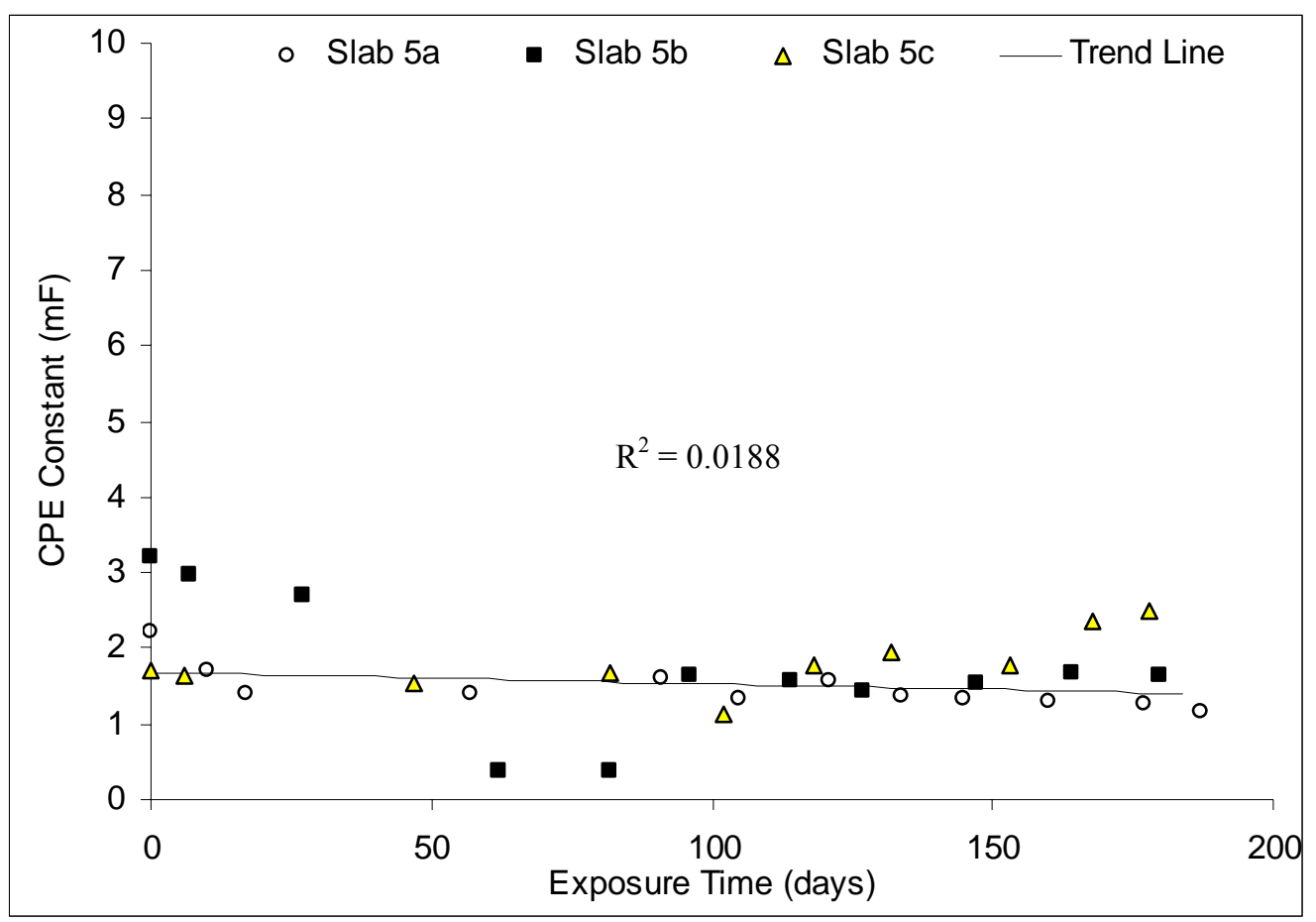

Figure 6.35 The values of the constant phase element (CPE) for the slabs repaired by the fly ash concrete.

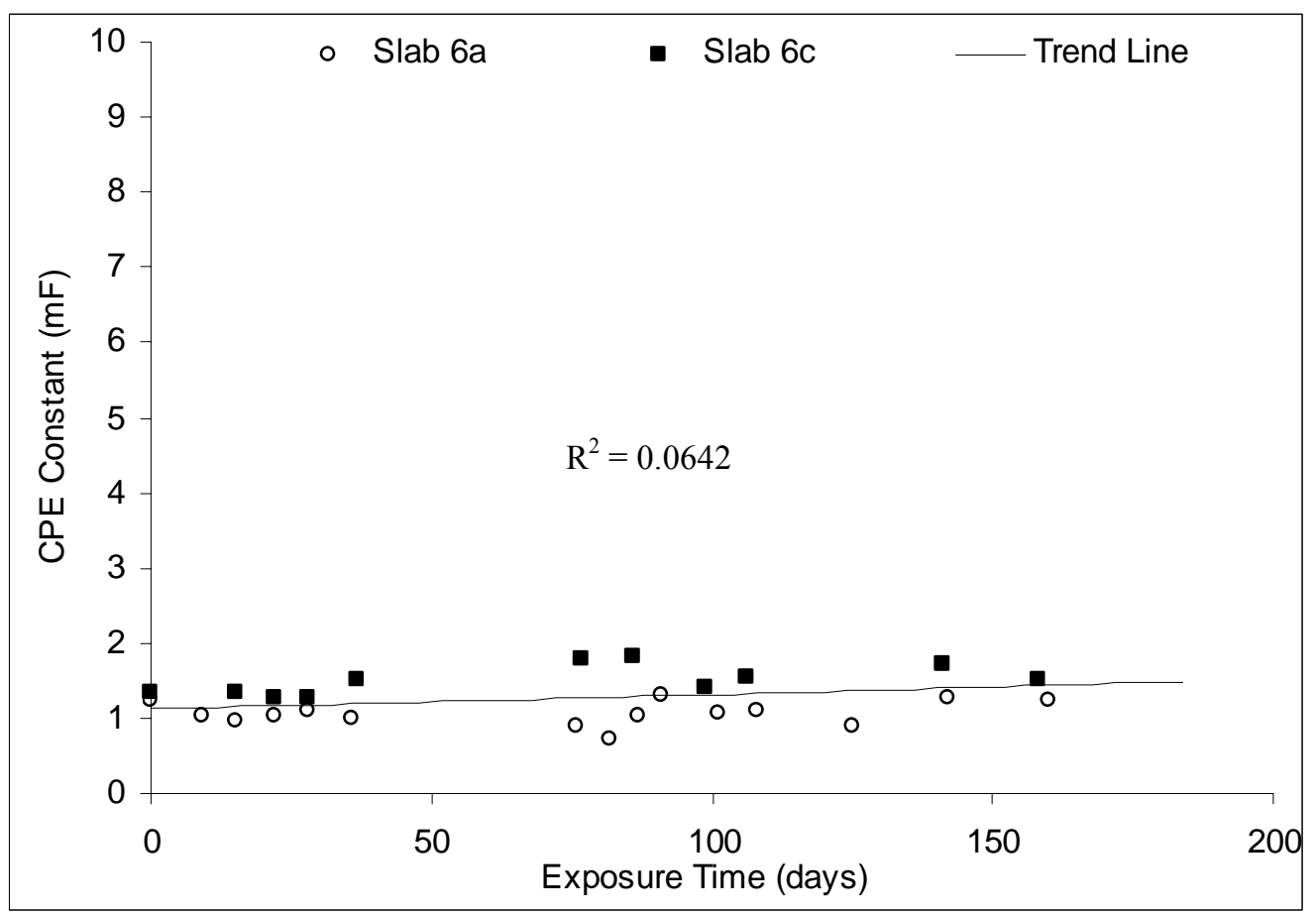

Figure 6.36 The values of the constant phase element (CPE) for the slabs repaired by the INDOT 9-bag cement concrete. 


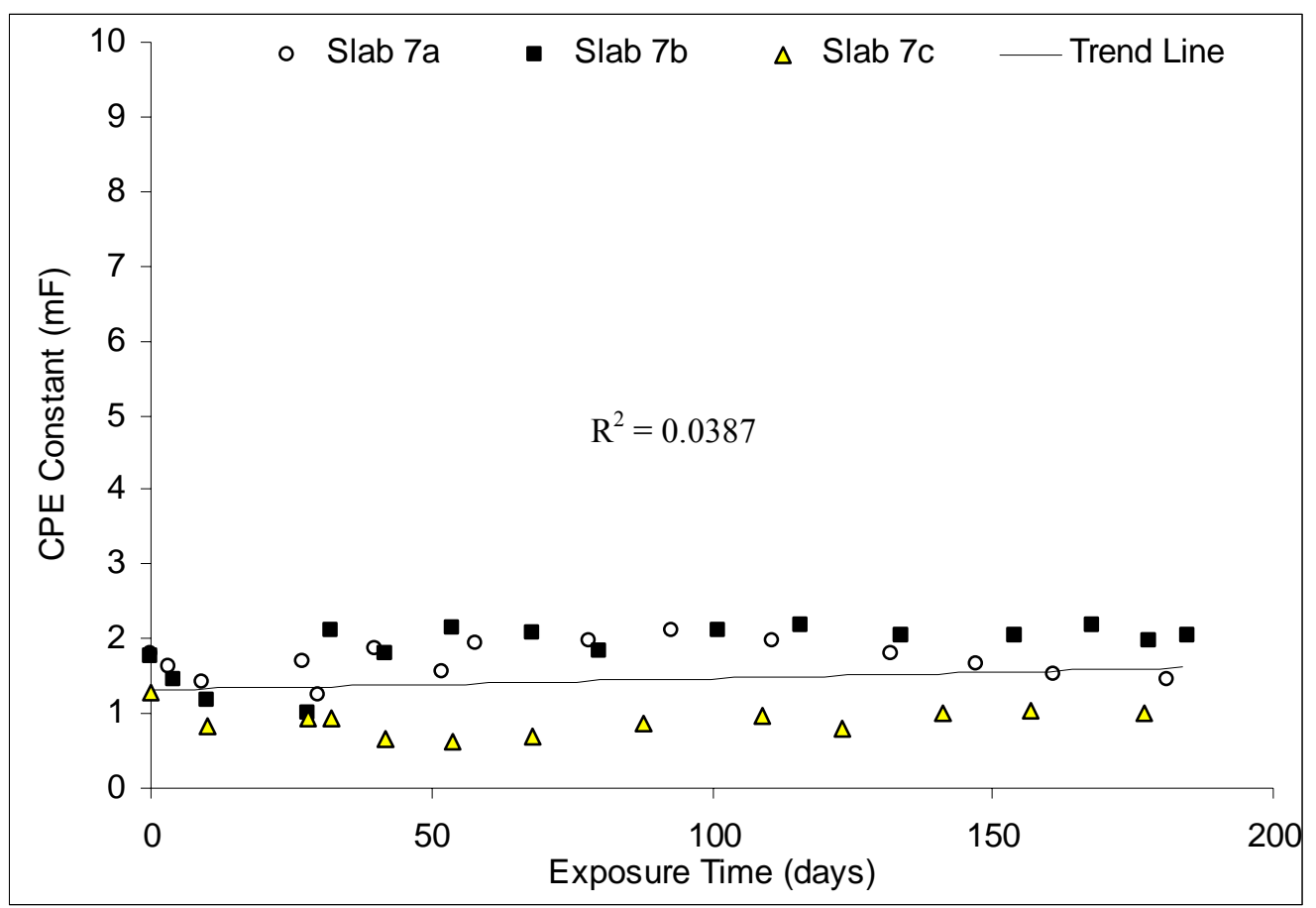

Figure 6.37 The values of the constant phase element (CPE) for the slabs repaired by the concrete with the shrinkage reducing admixture.

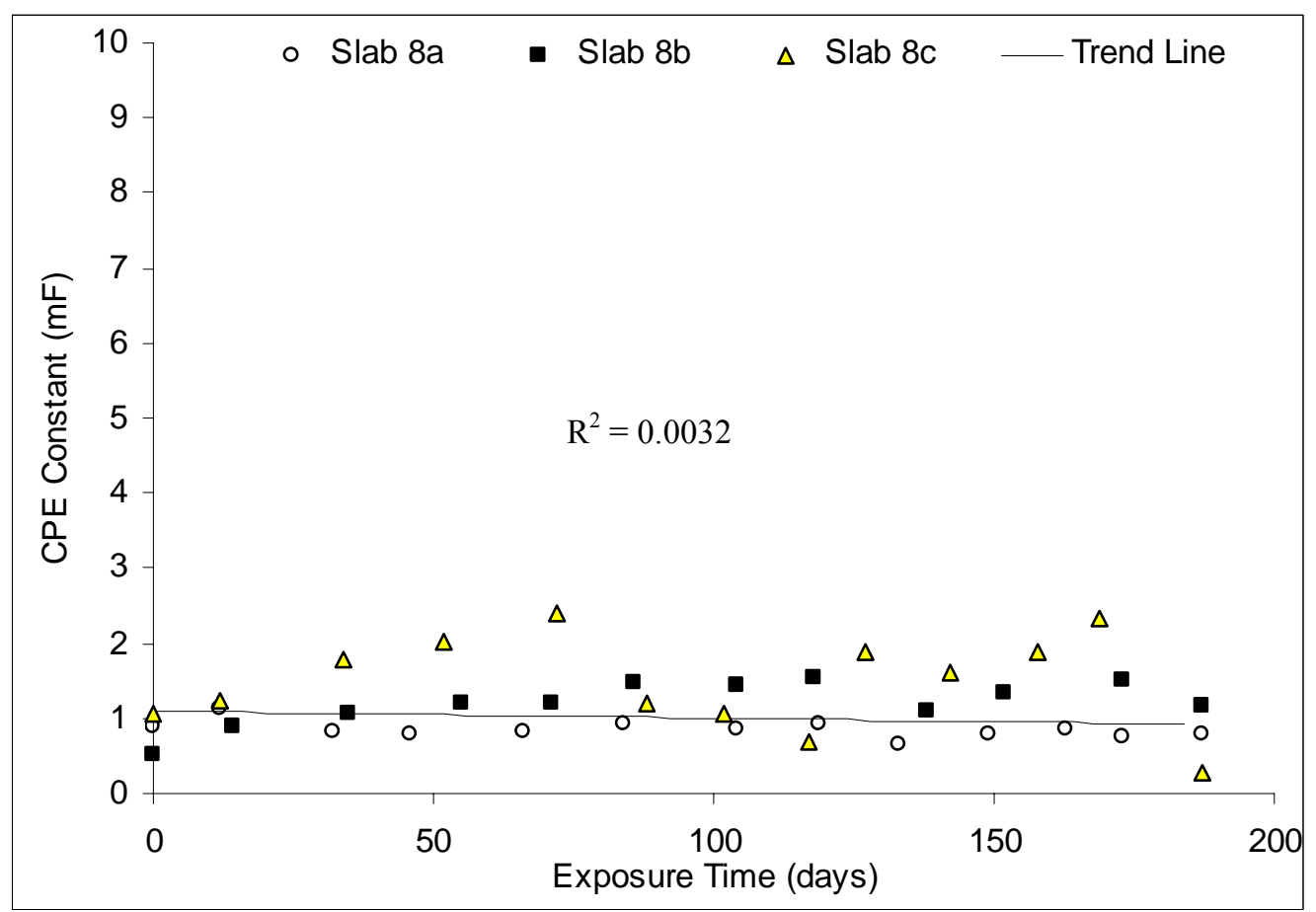

Figure 6.38 The values of the constant phase element (CPE) for the slabs repaired by the latex modified concrete. 


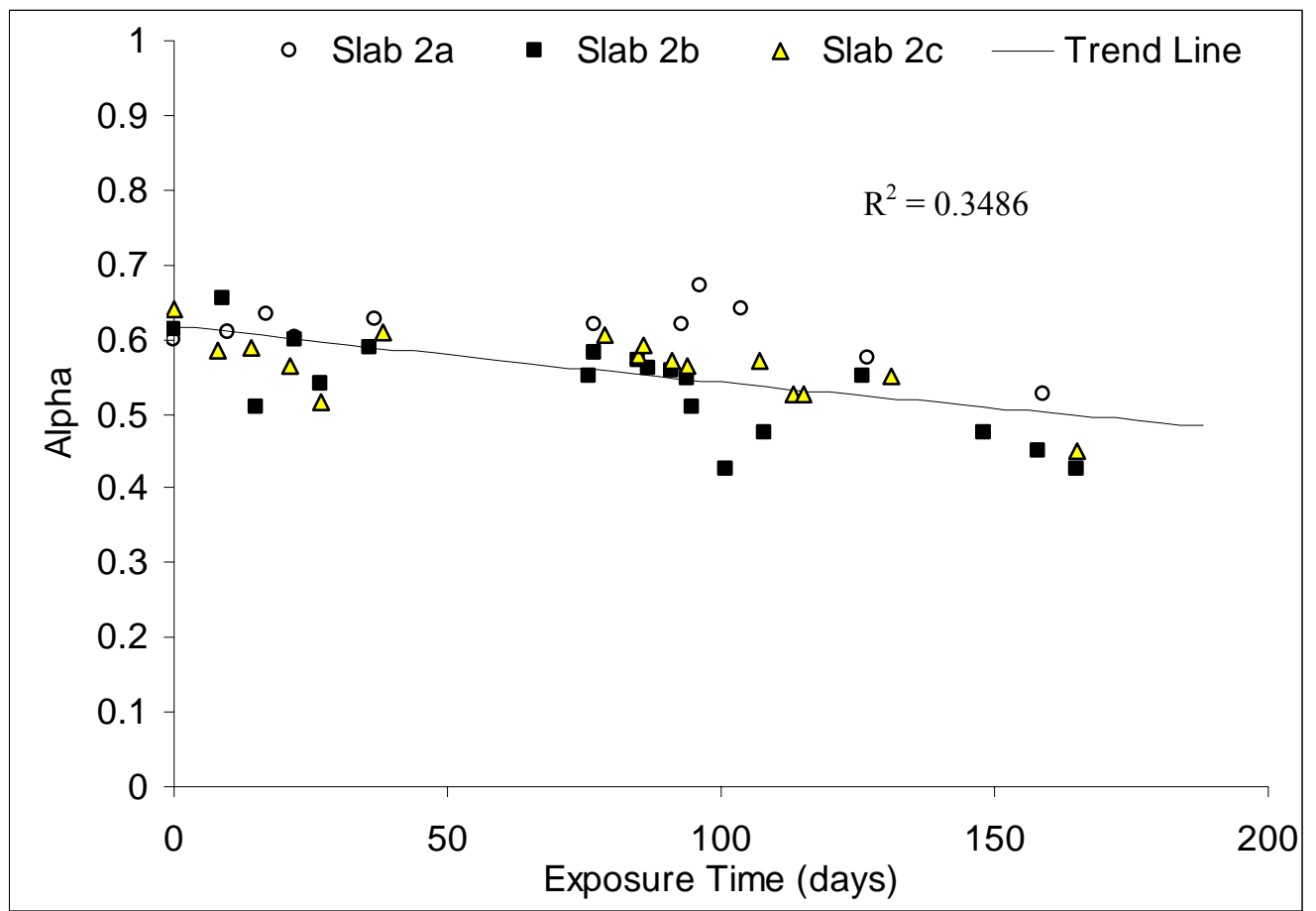

Figure 6.39 Alpha $(\alpha)$ values of the constant phase element (CPE) for the slabs repaired by the silica fume concrete.

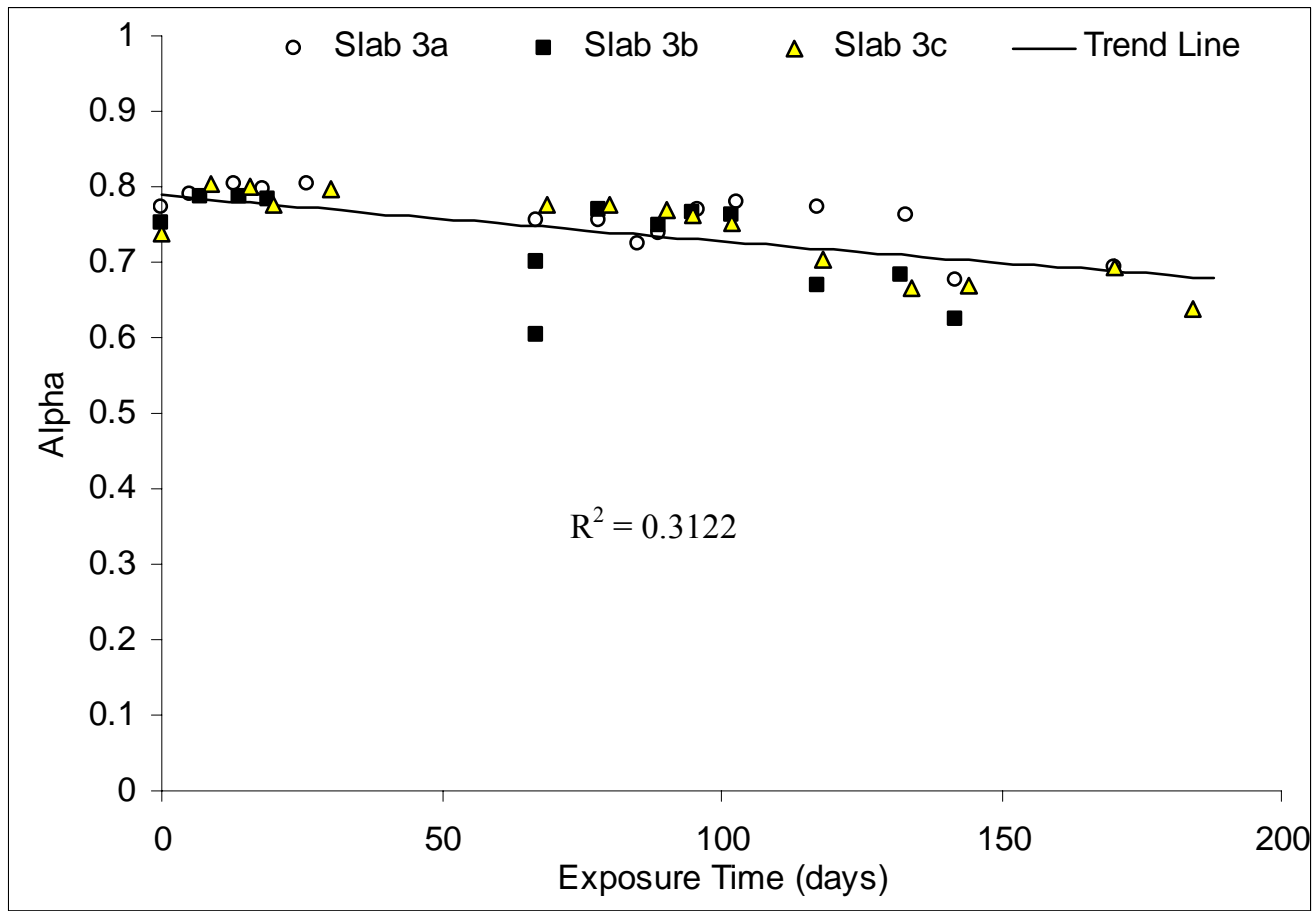

Figure 6.40 Alpha $(\alpha)$ values of the constant phase element (CPE) for the slabs repaired by the concrete with the calcium nitrite. 


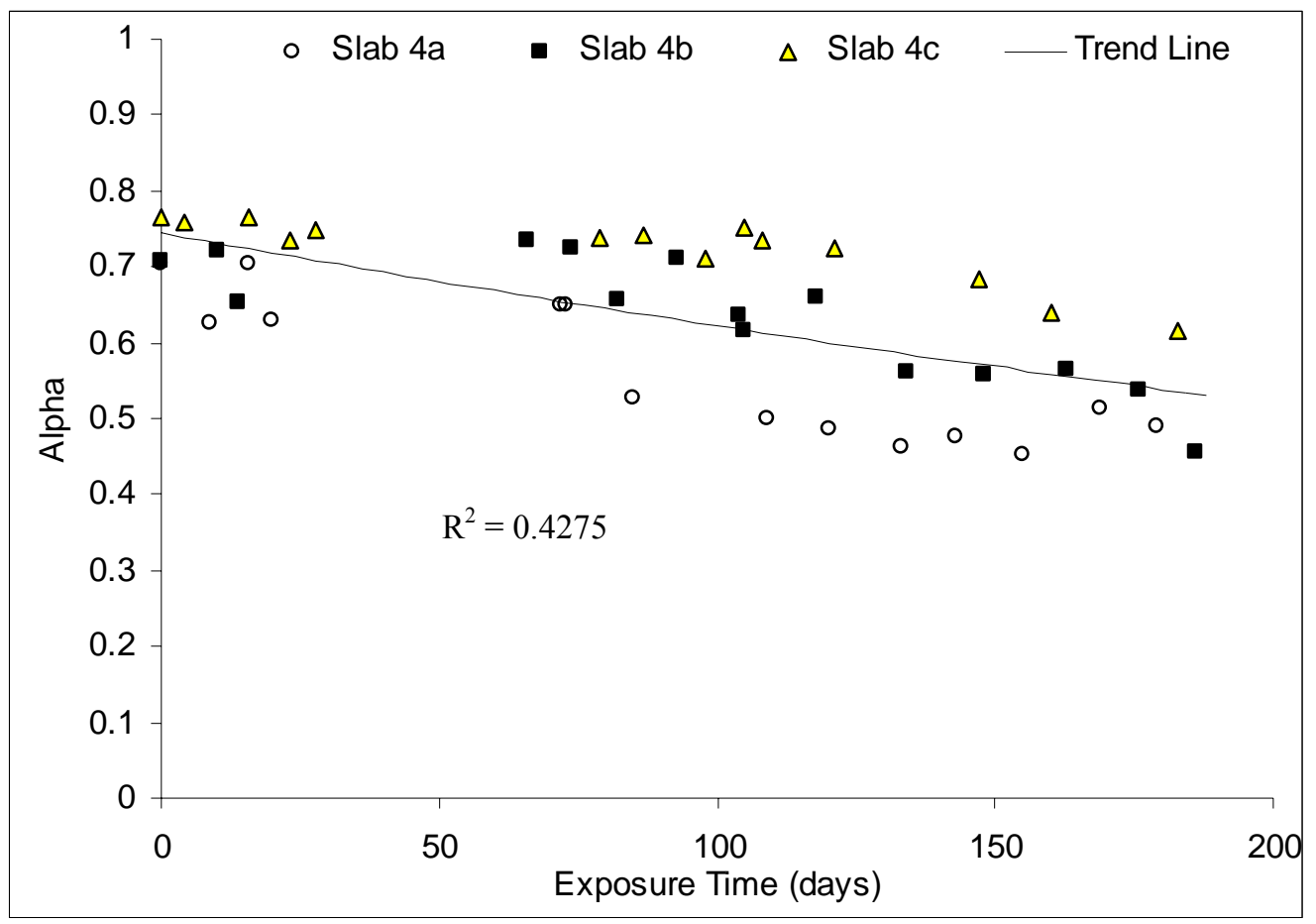

Figure 6.41 Alpha $(\alpha)$ values of the constant phase element (CPE) for the slabs repaired by the concrete with the organic corrosion inhibitor.

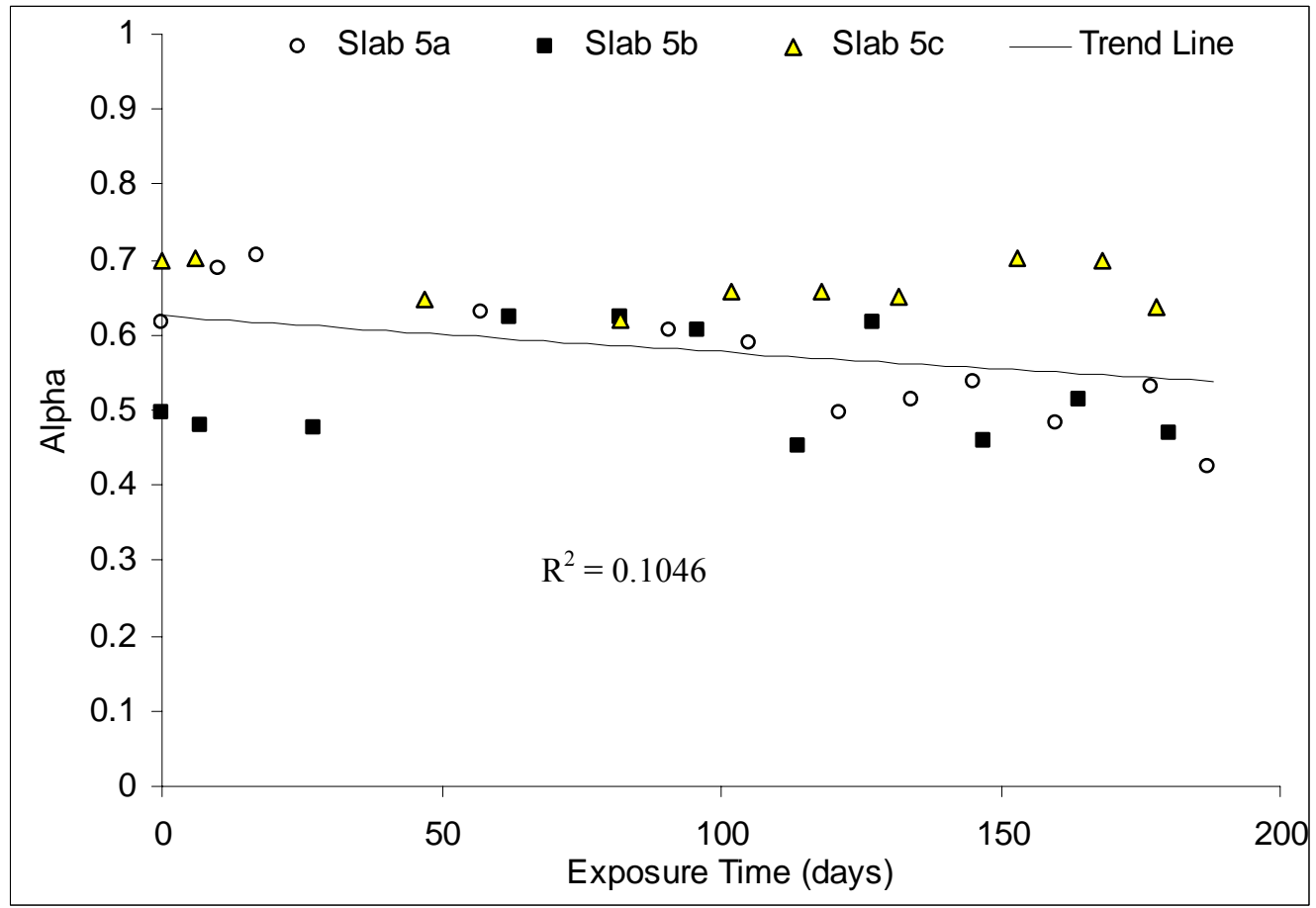

Figure 6.42 Alpha $(\alpha)$ values of the constant phase element (CPE) for the slabs repaired by the fly ash concrete. 


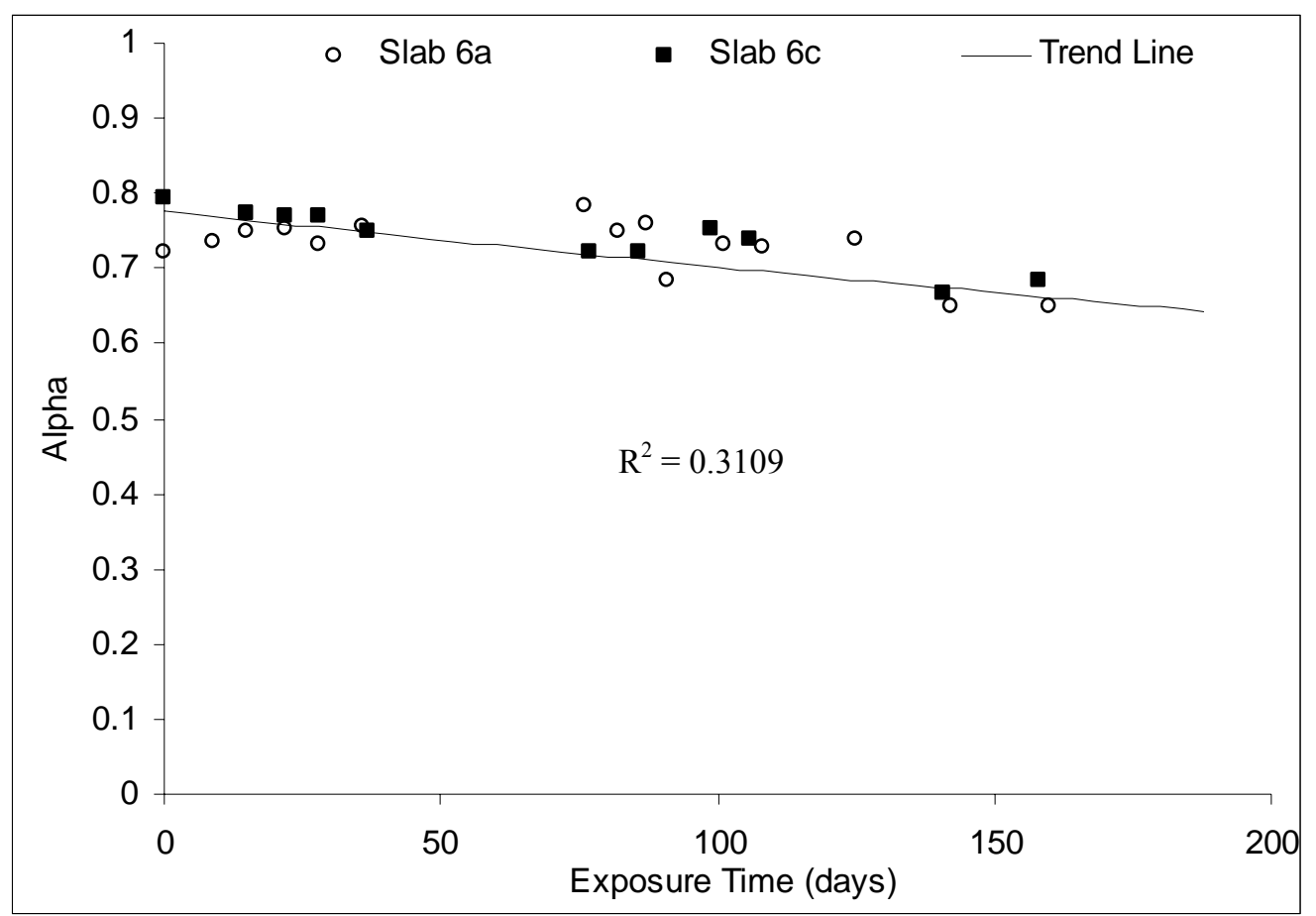

Figure 6.43 Alpha $(\alpha)$ values of the constant phase element (CPE) for the slabs repaired by the INDOT 9-bag cement concrete.

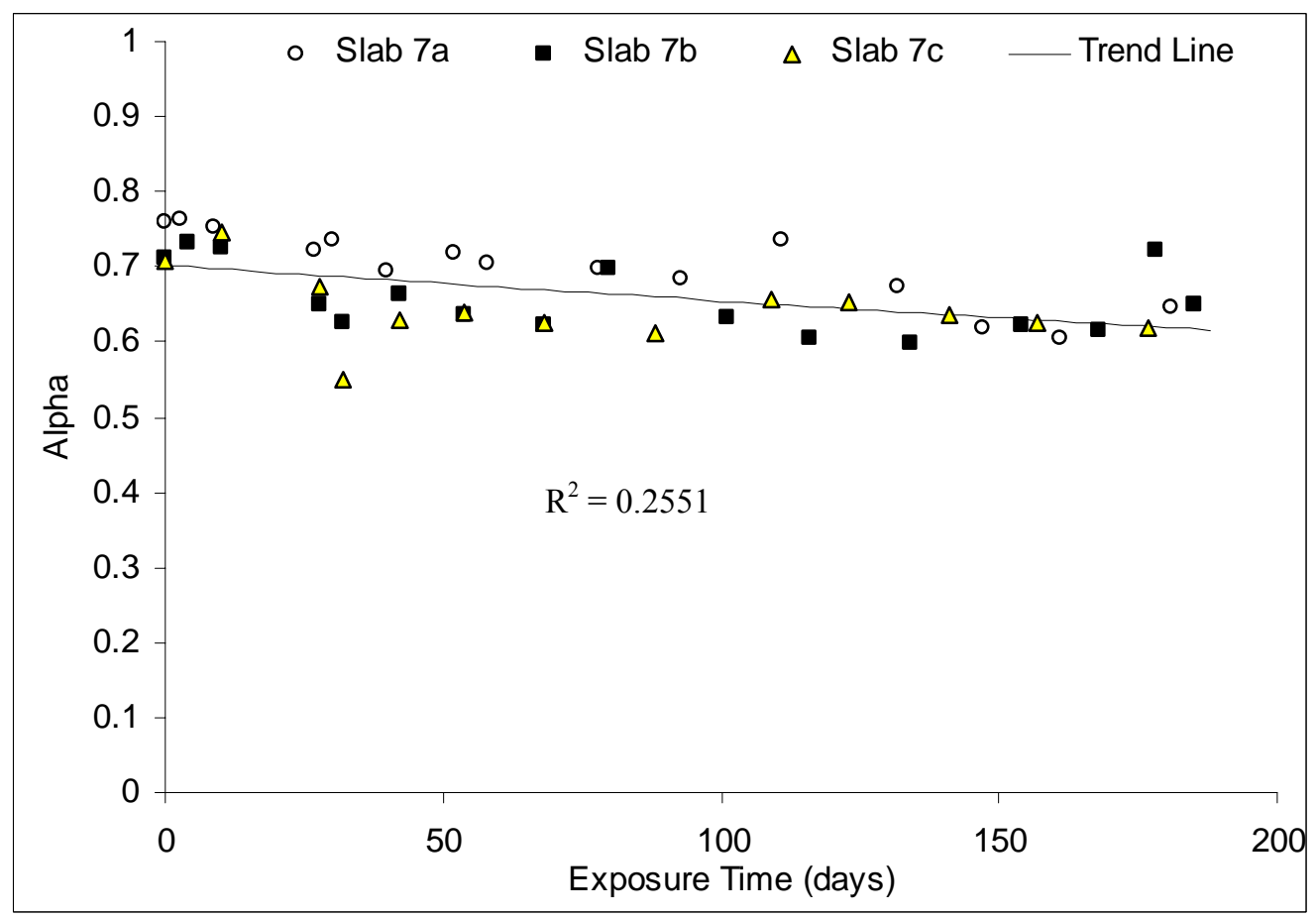

Figure 6.44 Alpha $(\alpha)$ values of the constant phase element (CPE) for the slabs repaired by the concrete with the shrinkage reducing admixture. 


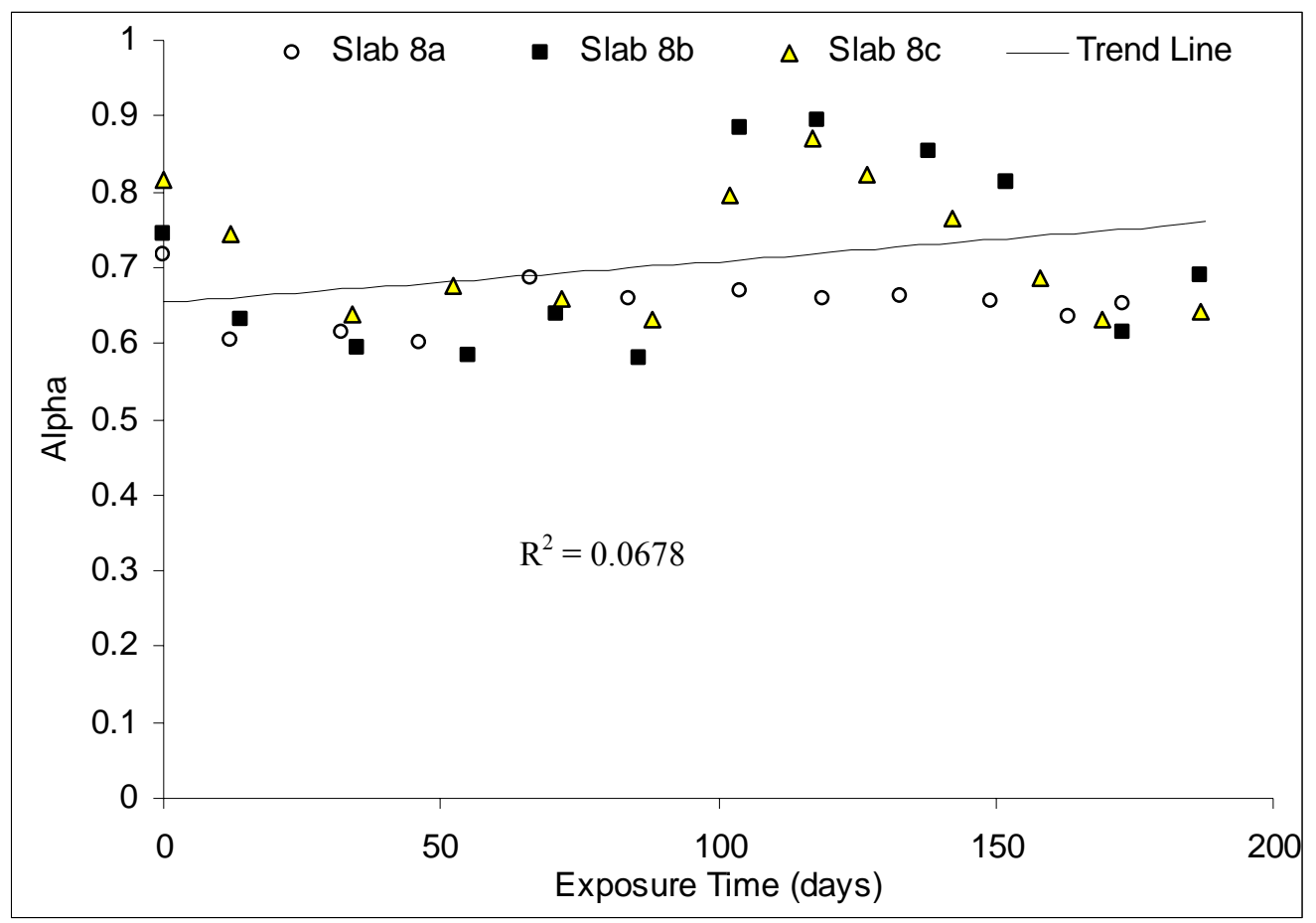

Figure 6.45 Alpha $(\alpha)$ values of the constant phase element (CPE) for the slabs repaired by the latex modified concrete. 


\section{CHAPTER 7 SUMMARY AND CONCLUSIONS}

\section{1 $\underline{\text { Summary }}$}

This research was focused on the evaluation of the effectiveness of various portland cement-based mixes for use as a repair material for the corrosion damaged reinforced concrete bridge decks. In order to complete this task, two major types of experiments were performed: (a) testing of the physical and mechanical properties of the patching materials, and (b) monitoring the corrosion process of the repaired concrete specimens. Physical and mechanical tests performed on patching materials included determination of compressive strength, static modulus of elasticity, dynamic modulus of elasticity, length change of hardened concrete, freeze-thaw resistance, electrical conductance, and chloride ions penetration. Corrosion process in reinforced concrete slabs was monitored using three techniques: half-cell potential, linear polarization resistance, and electrochemical impedance spectroscopy.

\subsubsection{Physical and Mechanical Properties of Patching Materials}

When compared to the INDOT 9-day mix (control) concrete, the repair concrete with the shrinkage reducing agent had higher compressive strength. The organic corrosion inhibitor was also shown to increase the compressive strength of concrete. The concrete with calcium nitrite ( $0.3 \%$ by mass of cement) had relatively low strength at early age, but its 180-day strength was higher than that of the control specimens. The 
silica fume concrete had higher compressive strength than the control concrete. As expected, the fly ash concrete had a low early strength, but the 180-day strength was higher than that of the control concrete.

Concrete with shrinkage reducing agent had the highest static modulus of elasticity among the seven concrete mixes tested. The concrete with organic corrosion inhibitor also had high modulus of elasticity. The silica fume concrete had higher modulus of elasticity than the control concrete. The fly ash concrete also developed high modulus of elasticity, but it required a longer curing time (about six months).

Dynamic modulus of elasticity of all repair concretes increased with the increase in curing time. The highest rate of increase in the dynamic modulus of elasticity was observed during the first four weeks after casting. Only very small changes were observed when concrete specimens were cured longer than four weeks. As expected, specimens cured in air developed lower dynamic modulus of elasticity than those cured in moist room. Compared with other concrete mixes, concrete mixes with organic corrosion inhibitor and shrinkage reducing admixture had high dynamic modulus of elasticity.

Concrete specimens cured in air experienced greater length change than those cured in moist room. Addition of the shrinkage reducing admixture reduced the shrinkage of the concrete specimens.

The freeze-thaw resistance of concrete specimens was evaluated based on the relative dynamic modulus of elasticity. After 300 freezing-thawing cycles, silica fume concrete did not show significant change in its dynamic modulus of elasticity. Concrete with calcium nitrite also had excellent freeze-thaw resistance. After 300 cycles the 
relative dynamic modulus of elasticity of fly ash concrete was about $97 \%$, which was similar to the control concrete. Concrete with shrinkage reducing admixture had a durability index of about $90 \%$ after 300 cycles of freezing and thawing. The freeze-thaw resistance of concrete with the addition of organic corrosion inhibitor was fair (relative dynamic modulus of elasticity was about $85 \%$ after 300 cycles of freezing and thawing). The freeze-thaw resistance of INDOT Class C concrete delivered from the ready-mix plant was poor (the relative dynamic modulus of elasticity dropped to less than $60 \%$ after less than 200 of freezing and thawing cycles). This can be most likely attributed to low content of entrained air (only $3.5 \%$, see Table 5.1).

Concrete specimens cured in air had lower coulomb values than those cured in moist room. This can be most likely attributed to the reduction in the amount of the pore solution which will, in turn, significantly reduce the conductivity of concrete. Concrete with the shrinkage reducing admixture also had low coulomb value. Silica fume concrete had relatively lower conductivity than the control concrete. Fly ash concrete had high conductivity at early age, but at the age of six months, the conductivity was significantly reduced. It is generally accepted that the conductivity value below 2000 coulombs indicates that concrete will be able to offer good protection against corrosion.

Chloride content of concrete exposed to salt solution was analyzed using powder samples obtained both from original reinforced concrete slabs and from the slabs prepared from repair concrete mixes. The original and reinforced concrete slabs were exposed to $50 \%$ sodium chloride solution. For INDOT Class $\mathrm{C}$ concrete, chloride content at the depth of $12.7 \mathrm{~mm}\left(0.5 \mathrm{in}\right.$.) was about $2.1 \mathrm{~kg} / \mathrm{m}^{3}$ after 12 weeks of exposure to salt solution. The chloride content at the depth of $38.1 \mathrm{~mm}$ (1.5 in.) was about 1.0 
$\mathrm{kg} / \mathrm{m}^{3}$ after 12 weeks of exposure, and it did not change much with the increase of exposure time.

The repair concrete slabs were ponded with $10 \%$ sodium chloride solution. Latex modified concrete had the lowest chloride content of all the repair concrete mixes.

\subsubsection{Monitoring Corrosion Process by Electrochemical Techniques}

\subsubsection{Half-Cell Potential Measurement}

The half-cell potentials measured on the reinforced slabs before repair indicated that corrosion took place on the steel bars located in the corrugated section of the slab, where the concrete cover was reduced to $12.7 \mathrm{~mm}$ ( $0.5 \mathrm{in})$, after the slabs were exposed to wetting and drying cycles for one week. The potential of steel bars in the section of the slab outside the corrugated section (where the concrete cover was $38.1 \mathrm{~mm}(1.5 \mathrm{in}$.)) was more positive, indicating that these rebars were not corroding to the same extend as rebars in the corrugated part of the slab.

With the increase in exposure time, the half-cell potentials of all rebars became more and more negative. After 14 weeks of exposure, the potential values of the rebars for both corrugated and remaining part of the slabs reached the same level. For most rebars, the half-cell potentials were more negative than $-350 \mathrm{mV}$ vs. copper-copper sulfate electrode, indicating active corrosion. Rust spots developed on the surface of some slabs after 14 weeks of exposure to wetting and drying cycles.

After 14 weeks of wetting and drying cycles, the middle (corrugated) portions of the reinforced concrete slabs were repaired with new concrete. The distribution of half- 
cell potential values changed significantly after the slabs were repaired. Except for slabs repaired with latex modified concrete and fly ash concrete, the potentials of the rebars located in the repaired area of the slabs became more positive than those of the rebars located in the outer portion of the slab. Reinforced concrete slabs repaired by concrete with anodic corrosion inhibitor showed one of the largest positive changes in the potentials of the rebars located in the repaired area, and most rebars were in the potential range that indicated low probability of corrosion. Slabs repaired by silica fume concrete, INDOT 9-bag mix concrete, and concrete with organic corrosion inhibitor showed similar behavior. Slabs repaired by fly ash concrete and latex modified concrete did not experience significant changes in the potentials of the rebars located in the repaired area.

For most of the repaired systems, the values of half-cell potential became more negative as the exposure time increased. The potentials of the middle rebars and the outer rebars were at the same level after 8 week of exposure. For most of the slabs, the potential values were also more negative than $-350 \mathrm{mV}$ vs. copper-copper sulfate electrode, which indicated that active corrosion took place on the steel surface.

\subsubsection{Polarization Resistance Measurement}

Polarization resistance measurements were performed on the reinforced concrete slabs before and after repair. Before the slabs were repaired with new concrete mixes, the polarization resistance continued to reduce with time of exposure. During the 14 weeks of exposure to wetting and drying cycles, the polarization resistance reduced from 
$50,000 \mathrm{ohm}-\mathrm{cm}^{2}$ to less than $10,000 \mathrm{ohm}-\mathrm{cm}^{2}$. At the same time, the corrosion current density increased from $0.5 \mu \mathrm{A} / \mathrm{cm}^{2}$ to $3.0 \mu \mathrm{A} / \mathrm{cm}^{2}$.

Immediately after the slabs were repaired with the new patching materials, the polarization resistance increased. At the same time, the corrosion current density also dropped to about $1.0 \mu \mathrm{A} / \mathrm{cm}^{2}$ for all the slabs.

When the repaired slabs were exposed to wetting and drying cycles again, the change in polarization resistance was strongly influenced by the type of repair material used.

The initial polarization resistance of the slabs repaired with silica fume concrete was about 50,000 ohm- $\mathrm{cm}^{2}$. The slabs repaired with fly ash concrete and INDOT 9-bag concrete had a polarization resistance of about $31,000 \mathrm{ohm}-\mathrm{cm}^{2}$, and the value of polarization resistance for slabs repaired by the concrete with the shrinkage reducing admixture was about $40,000 \mathrm{ohm}-\mathrm{cm}^{2}$. The initial polarization resistance for the slabs repaired with latex modified concrete was about $18,000 \mathrm{ohm}-\mathrm{cm}^{2}$. The slabs repaired with the other concrete mixes had polarization values less than $20,000 \mathrm{ohm}-\mathrm{cm}^{2}$. A polarization resistance of $50,000 \mathrm{ohm}-\mathrm{cm}^{2}$ is equivalent to the corrosion rate of about 6 $\mu \mathrm{m} /$ year. Corrosion rates higher than that indicate areas that may be in the initial stages of corrosion and which, if left untreated, will become problem areas in the next $5-10$ years (Bentur, et al, 1998).

Generally, corrosion current density increased as the exposure time increased. But the slabs repaired with concrete with the calcium nitrite inhibitor, concrete with the organic corrosion inhibitor, and the INDOT 9-bag cement concrete maintained constant 
corrosion current density during the exposure time. Slabs repaired with other concrete mixes experienced significant increase in corrosion current density.

\subsubsection{Electrochemical Impedance Spectroscopy}

Electrochemical impedance spectroscopy measurements were performed on the slabs. Based on the equivalent circuit established to simulate the corrosion process of the reinforced concrete slabs, the electrical parameters used to describe the corrosion process were calculated and analyzed from the impedance spectroscopy data.

Concrete resistivity was calculated based on the measured concrete resistance. Slabs repaired with silica fume concrete and fly ash concrete had high initial concrete resistivity. In general, the resistivity of these concretes decreased with the increase in exposure time. Slabs repaired with other concrete mixes did not show significant change in concrete resistivity.

The general patterns of polarization resistance calculated from the impedance spectroscopy were similar to that measured directly using the polarization resistance method. Generally, the initial polarization resistance after repair was higher than that before repair. Polarization resistance decreased with the increase in exposure time. In general, high and stable resistivity and high polarization resistance are indicators of reduced susceptibility to corrosion.

Slabs repaired with INDOT 9-bag cement had high polarization resistance, or above $73,000 \mathrm{ohm}-\mathrm{cm}^{2}$. Slabs repaired with latex modified concrete had an initial 
polarization resistance of $20,000 \mathrm{ohm}-\mathrm{cm}^{2}$. The polarization resistance of the slabs repaired with the other concrete mixes was between these values.

Corrosion current density was calculated based on the polarization resistance data. Generally, corrosion current density increased as the exposure time increased. Except for slabs repaired with latex modified concrete and concrete containing the organic corrosion inhibitor, the initial corrosion current density was below $0.4 \mu \mathrm{A} / \mathrm{cm}^{2}$.

After exposure to the wetting and drying cycles, the corrosion current density increased significantly for the slabs repaired with silica fume concrete and fly ash concrete.

The characteristic parameter of the constant phase element (CPE) was also calculated from the impedance spectroscopy data. All the slabs, except for those repaired with the silica fume concrete, maintained a constant value of CPE during exposure to wetting and drying cycles. The influence of concrete composition on CPE characteristic parameter was negligible.

The alpha values of the CPE decreased as the exposure time increased, except for slabs repaired with latex modified concrete. Slabs repaired with silica fume concrete and fly ash concrete had low initial alpha values (or about 0.6 ). For the other slabs, this value was between 0.65 to 0.80 . After about 180 days of exposure, alpha was below 0.60 for all but slabs repaired with latex modified concrete.

\subsection{Conclusions}

Based on the results of this research, the following conclusions were obtained: 
1. The measured corrosion current density in all slabs was about $0.5 \mu \mathrm{A} / \mathrm{cm}^{2}$ at the beginning of exposure to wetting and drying cycles. Corrosion current density increased with the increase in exposure time. Corrosion current density was about 3.0 $\mu \mathrm{A} / \mathrm{cm}^{2}$ after about 6 months of exposure before repair was initiated. This indicated that exposure to wetting and drying cycles and to salt solution initiated active corrosion on the steel. The corrosion rate of steel increased as the exposure time increased.

2. The polarization resistance of the slabs repaired with silica fume concrete decreased with the increase in exposure time. After about 6 months of exposure to wetting and drying cycles and to salt solution, the corrosion current density was higher than that of in the other repaired slabs. Based on these observation, the repair material containing silica fume has found to be the least effective system for repair of corrosion damaged structures with this repair method.

3. As expected, the development of mechanical properties in concrete containing fly ash was slower than that observed in other concretes. This concrete developed high electrical resistivity at late age (six months). The polarization resistance of the slabs repaired with fly ash concrete was low, while the corrosion current density was high. Compared with the control concrete (INDOT 9-bag mix), fly ash concrete was not found to be particularly effective material for repair of corrosion damaged structures.

4. Concrete containing shrinkage reducing admixture had high electrical resistivity. Slabs repaired with this concrete had an initial polarization resistance which was at the same level as that of INDOT 9-bag concrete (control concrete). Relatively high polarization resistance and low corrosion current density were maintained during the 
exposure time. Based on the results from this research, both INDOT 9-bag mix containing shrinkage reducing admixture appears to be an effective repair material.

5. Slabs repaired with latex modified concrete had relatively low polarization resistance and high corrosion current density. This indicates that latex modified concrete was not particularly effective material for repair of corrosion damaged structures.

6. The addition of shrinkage reducing admixture reduced the shrinkage of repair concrete and improved its mechanical properties.

7. Concrete with organic corrosion inhibitor developed fair freeze-thaw resistance. When compared to control mix, this concrete requires higher dosage of air entraining admixture to attain the same percent of entrained air.

8. Based on the results from chloride ponding test, air cured latex modified concrete significantly reduced penetration of chloride ions.

9. Immediately after the repairs were completed, slabs patched with new concrete developed more positive potentials in both the repaired areas and the adjacent areas previously exposed to chlorides. However, with the increase in exposure time, the potentials became more and more negative and eventually active corrosion took place on the steel in both repaired and non-repaired concrete.

10. Polarization resistance increased significantly when the concrete slabs were repaired with new concrete mixes. Repaired slabs had lower corrosion current density than the original slabs.

11. The characteristic parameter of the constant phase element (CPE) did not change significantly during the exposure time. Its value was similar for all slabs, except for those repaired with silica fume concrete. 
12. High value of CPE characteristic parameter for slabs repaired with silica fume concrete was attributed to the increase in the double layer capacitance of the interface between the steel and the concrete.

13. The alpha value of the CPE decreased as the corrosion rate increased, indicating that alpha value can be used as an index to represent the corrosion rate. 


\section{CHAPTER 8 RECOMMENDATIONS FOR FUTURE RESEARCH}

Polarization resistance technique and electrochemical impedance spectroscopy technique can be used to measure the polarization resistance of the corrosion cell. Using measured value of polarization resistance, the corrosion current density can be calculated if the anode area is known. Unfortunately, chloride-induced corrosion of reinforcing steel is usually non-uniform and typically takes form of pitting corrosion. The assumption of the whole steel surface acting as an anode surface will artificially decrease the corrosion rate. Future study of corrosion in reinforced concrete should particularly focus on this point and establish a reliable method for accurate assessment of the anode area.

Calcium nitrite can keep the steel in passive state as long as no corrosive species damage the oxide film. Concrete with addition of silica fume and shrinkage reducing admixture has high impermeability. Thus, the combination of those advantages may produce concrete with great protective ability. Besides, the combination of both calcium nitrite and organic corrosion inhibitor or other cathodic corrosion inhibitors may also improve the re-passivation and protective ability of concrete. Further study of the effectiveness of the combination of calcium nitrite and shrinkage reducing admixture should be conducted in the future. 


\section{BIBLIOGRAPHY}

Al Khalaf, M. N., and Page, C. L., "Steel/Mortar Interfaces: Microstructural Features and Mode of Failure", Cement and Concrete Research, Vol. 9, 1979, pp. 197-208.

Atkins, P. W., Physical Chemistry, 6th edition, Oxford University Press, 1998, pp. 215-274.

Barnes, B. D., and Dolch, W. L., Cement and Concrete Research, Vol. 8, 1978, pp. 233-244.

Bentur, A., Diamond, S., and Mindess, S., "The Microstructure of the Steel Fiber-Cement Interface”, Journal of Materials Science, Vol. 20, 1985, pp. 3610-3620.

Bentur, A., Diamond, S., and Berke, N. S., Steel Corrosion in Concrete, E \& FN SPON, 1998.

Berke, N. S., and Hicks, M. C., "Estimating the Life Cycle of Reinforced Concrete Decks and Marine Piles Using Laboratory Diffusion and Corrosion Data", Corrosion Forms and Control for Infrastructure, Edited by Chaker, V., ASTM STP 1137, American Society of Testing and Materials, 1992, pp. 207-231.

Bird, H. E. H., Pearson, B. R., and Brook, P. A., "The Breakdown of Passive Films on Iron”, Corrosion Science, Vol. 28, 1988, pp. 81-86.

Brown R. P., Tinnea J. S., "Cathodic Protection Design Problems for Reinforced Concrete", Materials Performance, August, 1991, pp. 28-31.

Brunauer, S., American Scientists, Vol. 50, No. 1, 1962, pp. 210-29.

Crentsil, K. K. S.; Glasser, F. P.; and Irvine, J. T. S., "Electrochemical Characteristics of Reinforced Concrete Corrosion as Determined by Impedance Spectroscopy”, British Corrosion Journal, Vol. 27, 1992, pp. 457-465

Diamond, S., "Effects of Microsilica (Silica Fume) on Pore Solution Chemistry of Cement Pastes", Journal of the American Ceramic Society, Vol.66, No.5, 1983, pp 82-84. 
Eisenberg, D. and Crothers, D., Physical Chemistry with Application to the Life Science, The Benjamin/Cummings Publishing Company, Inc., Menlo Park, California, 1979.

Escadeillas, G., and Maso, J. C., In Advances in Cementitious Materials, Edited by Mindess, S., 1991, pp. 169-184.

Evans, U. R., Transaction of the Faraday Society, Vol. 18, 1922, p. 1.

Evans, U. R., Journal of the Chemical Society, 1927, p. 1020.

Evans, U. R., Elektrochemie, Vol. 62, 1958, pp. 619.

Farren, J., Revue Des Materiaux De Construction, 1956, pp. 490-492.

Feldman, R. F., and Sereda, P. J., Engineering Journal (Canada), Vol. 53, N0. 8-9, 1970, pp. 53-59.

Feliu S., Gonzalez C., Andrade C., and Feliu E., Corrosion Science, Vol. 25, 1985 , p. 917.

Fidjestol, P., "Reinforcement Corrosion and the Use of CSF-Based Additives", Concrete Durability, Katharine and Bryant Mather International Conference, Editor: John M.

Csanlon, ACI SP-100 Vol.2, 1987, pp. 12-17.

Fontana, M. G., Corrosion Engineering, Third Edition, McGraw-Hill, New York, NY, 1986.

Ford, S. J., Monitoring the Corrosion of Reinforcing Steel in Cement-Based Systems Using Impedance Spectroscopy, Ph.D Thesis, Northwestern University, 1998.

Gjorv, O. E., "Effect of Condensed Silica Fume on Steel Corrosion in Concrete", ACI Materials Journal, Vol.92, 1995, pp. 591-598.

Goodisman, J., Electrochemistry: Theoretical Foundations, John Wiley \& Sons, Inc., 1987, pp. 1-58.

Grandet, J., and Ollivier, J. P., In the Seventh International Congress on the Chemistry of Cement, Part 3, Paris, 1980, pp. 85-89.

Gu P., Elliot S., Hristova R., Beaudion J. J., Brousseau R., and Baldock B., “A Study of Corrosion Inhibitor Performance in Chloride Contaminated Concrete by Electrochemical Impedance Spectroscopy”, ACI Materials Journal, Vol. 94, No. 5, 1997.

Hadley, D. W., The Nature of The Paste-Aggregate Interface, Ph.D Thesis, Purdue University, 1972. 
Hammond, E., and Robson, T. D., "Comparison of Electrical Properties of Various Cements and Concretes", The Engineer, Vol. 199, January, 1955, pp. 114-115.

Hansson, C. M., "Comments on Electrochemical Measurements of the Rate of Corrosion of Steel in Concrete", Cement and Concrete Research, Vol. 14, 1984, pp. 574-584.

Indiana Department of Transportation, Book of Standard Specifications, 1995, $868 \mathrm{p}$.

John, D. G., Searson, P. C., and Dawson, J. L., British Corrosion Journal, Vol.16, 1988, p. 102.

Jones, D. A., Principles and Prevention of Corrosion, 2nd edition, Prentice Hall Inc., Upper Saddle River, NJ, 1996.

Keddam, M., Novoa, X. R., Soler, L., Andrade, C., and Takenouti H., Corrosion Science, Vol.36, 1994, pp. 1155.

Kruger, J., Journal of Electrochemical Society, Vol. 110, 1963. pp. 654.

MacDonald J. R., Impedance Spectroscopy: Emphasizing Solid Materials and Systems, Jonh Wiley \& Sons, 1987, pp. 1-20.

MacDonald, D. D., Mckubre, M. C. H., and Urquidi-MacDonald, M., "Theoretical Assessment of AC Impedance Spectroscopy for Detecting Corrosion of Rebar in Reinforced Concrete", Corrosion, NACE Vol. 44, No. 1, January, 1988.

Maso, J. C., In the Seventh International Congress on the Chemistry of Cement, Part 3, Paris, 1980, pp. 1-9.

Mehta, P. K., and Monteiro, P. J. M., Concrete: Microstructure, properties, and Materials, Second Edition, College Custom Series, The McGraw-Hill Companies, Inc., 1993.

Menzies, T. R., "National Cost of Damage from Highway De-icing Salt", Corrosion Forms and Control for Infrastructure, ed. Chaker V., ASTM STP 1137, American Society of Testing and Materials, Philadelphia, 1992, pp. 30-45.

Monteiro, P. J. M., Prezzi, M., Wang, K. J., and Ghio, V., "Durability, Tomography, and Repair of Reinforced Concrete", Report No. UCB/SEMM-95/11, Department of Civil Engineering, University of California, Berkeley, California, September 1995, pp. 168

Neville, A. M., Properties of Concrete, Addison Wesley Longman Limited, Fouth Edition, 1997, pp. 48.

Newton C. J., and Sykes J. M., "A Galvanostatic Pulse Technique for Investigation of Steel Corrosion in Concrete", Corrosion Science, Vol. 28, No. 11,1988, pp. 1051-1074. 
Page, C. L., and Treadaway, K. W. J., "Aspects of the Electrochemistry of Steel in Concrete", Nature, Vol. 297, 1982, pp. 109-114.

Page, C. L., Short, N. R., and El-Tarra, A., "Diffusion of Chloride Ions in Hardened Cement Paste", Cement and Concrete Research, Vol. 11, 1981, pp. 395-406.

Powers, T. C., Journal of American Ceramic Society, Vol. 61, No.1, 1958, pp. 1-5.

RILEM Committee 124-SRC, "Draft recommendation for re manuscripts of repair strategies for concrete structures damaged by steel corrosion: Materials and Structures", 27 (171), 1994, pp. 415-436.

Rozenfeld, I. L., Corrosion Inhibitors, McGraw-Hill International Book Company, 1981, pp. 145-180.

Sagues, A. A., Kranc, S. C., and Moreno, E. I., "The Time-Domain Response of A Corrosion System with Constant Angle Interfacial Component: Application to Steel in Concrete", Corrosion Science, Vol. 37, No. 7, 1995, pp. 1097-1113.

Simmons, E. J., Corrosion, Vol.11, p. 255, 1955.

Skold, R. V., and Larsen, T. E., Corrosion, Vol.13, p. 139, 1957.

Stern, M. and Geary, A. L., J. Electrochem. Soc., Vol.104, p.56, 1957

Stern, M., Corrosion, Vol.14, p.440, 1958

Stern, M., and Weisert, E. D., Proc. ASTM, Vol.32, p.1280, 1959.

Taylor, H. F. W., Cement Chemistry, Academic Press, San Diego, California, 1990.

Tuuti, K., Corrosion of Steel in Concrete, Swedish Cement and Concrete Research Institute, Stockholm, 1982.

Uhlig, H. H., Chemical Engineering News, Vol. 24, p. 3154, 1946.

Uhlig, H. H., Elektrochemie, Vol. 61, p. 1291, 1957.

USA Today, “The Day of Reckoning is Here”, August 29, 1994.

Wheat, H. G., and Eliezer, Z., "Comments on the Identification of a Chloride Threshold in the Corrosion of Steel in Concrete”, Corrosion, Vol. 43, 1987, pp. 126-128. 
APPENDIX A

RESULTS FROM COMPRESSIVE STRENGTH TEST 
Table A Results from Compressive Strength Test

\begin{tabular}{|c|c|c|c|c|}
\hline \multicolumn{5}{|c|}{ 7-day Compressive Strength } \\
\hline & \multicolumn{3}{|c|}{ Compressive Strength (MPa) } & Average (MPa) \\
\hline INDOT Class C Concrete & 38.4 & 42.3 & 41.3 & 40.7 \\
\hline Silica Fume Concrete & 39.5 & 43.8 & 44.3 & 42.5 \\
\hline Concrete with Calcium Nitrite & 35.6 & 33.8 & 31.7 & 33.7 \\
\hline Concrete with Organic Corrosion Inhibitor & 67.3 & 62.5 & 64.5 & 64.8 \\
\hline Fly Ash Concrete & 32.4 & 29.8 & 29.3 & 30.5 \\
\hline INDOT 9-bag Concrete & 52.7 & 47.9 & 48.2 & 49.6 \\
\hline Concrete with Shrinkage Reducing Agent & 65.7 & 70.2 & 67.2 & 67.7 \\
\hline Latex Modified Concrete & 32.2 & 35.1 & 36.7 & 34.7 \\
\hline \multicolumn{5}{|c|}{ 28-day Compressive Strength } \\
\hline & \multicolumn{3}{|c|}{ Compressive Strength (MPa) } & Average $(\mathrm{MPa})$ \\
\hline INDOT Class C Concrete & 50.3 & 45.8 & 44.6 & 46.9 \\
\hline Silica Fume Concrete & 57.3 & 50.4 & 49.2 & 52.3 \\
\hline Concrete with Calcium Nitrite & 41.5 & 36.2 & 34.7 & 37.5 \\
\hline Concrete with Organic Corrosion Inhibitor & 71.5 & 76.4 & 75.1 & 74.3 \\
\hline Fly Ash Concrete & 39.2 & 33.5 & 36 & 36.2 \\
\hline INDOT 9-bag Concrete & 55.3 & 62.8 & 57.2 & 58.4 \\
\hline Concrete with Shrinkage Reducing Agent & 82.3 & 75.4 & 80.4 & 79.4 \\
\hline Latex Modified Concrete & 33.5 & 36.5 & 38.4 & 36.1 \\
\hline \multicolumn{5}{|c|}{ 56-day Compressive Strength } \\
\hline & \multicolumn{3}{|c|}{ Compressive Strength (MPa) } & Average (Mpa) \\
\hline INDOT Class C Concrete & 52.6 & 45.3 & 44.5 & 47.5 \\
\hline Silica Fume Concrete & 60.2 & 52.7 & 54.3 & 55.7 \\
\hline Concrete with Calcium Nitrite & 38.5 & 43.2 & 41.5 & 41.1 \\
\hline Concrete with Organic Corrosion Inhibitor & 75.6 & 63.8 & 68.3 & 69.2 \\
\hline Fly Ash Concrete & 42.6 & 34 & 37.4 & 38.0 \\
\hline INDOT 9-bag Concrete & 55.3 & 63.8 & 61.2 & 60.1 \\
\hline Concrete with Shrinkage Reducing Agent & 78 & 73.8 & 72.5 & 74.8 \\
\hline Latex Modified Concrete & 38.6 & 44.3 & 41 & 41.3 \\
\hline \multicolumn{5}{|c|}{ 180-day Compressive Strength } \\
\hline & \multicolumn{3}{|c|}{ Compressive Strength (Mpa) } & Average (Mpa) \\
\hline INDOT Class C Concrete & N/A & N/A & N/A & N/A \\
\hline Silica Fume Concrete & $\mathrm{N} / \mathrm{A}$ & $\mathrm{N} / \mathrm{A}$ & N/A & N/A \\
\hline Concrete with Calcium Nitrite & 80.5 & 72.3 & 73.6 & 75.5 \\
\hline Concrete with Organic Corrosion Inhibitor & 92.1 & 85.7 & 82.6 & 86.8 \\
\hline Fly Ash Concrete & 78.6 & 69.7 & 74 & 74.1 \\
\hline INDOT 9-bag Concrete & 55.6 & 64.2 & 62.1 & 60.6 \\
\hline Concrete with Shrinkage Reducing Agent & $\mathrm{N} / \mathrm{A}$ & $\mathrm{N} / \mathrm{A}$ & N/A & N/A \\
\hline Latex Modified Concrete & 52.3 & 45.6 & 45.5 & 47.8 \\
\hline
\end{tabular}


APPENDIX B

RAW DATA FOR DYNAMIC MODULUS OF ELASTICITY 
Table B.1 Specimens Made from Silica Fume Concrete, Cured in Moist Room.

\begin{tabular}{|c|c|c|c|c|c|c|c|c|}
\hline \multirow{3}{*}{$\begin{array}{l}\text { Curing } \\
\text { Time } \\
\text { (day) }\end{array}$} & \multicolumn{2}{|c|}{ Weight (lb) } & \multicolumn{2}{|c|}{$\begin{array}{c}\text { Transverse } \\
\text { Frequency }(\mathrm{kHz})\end{array}$} & \multicolumn{2}{|c|}{$\begin{array}{c}\text { Longitudinal } \\
\text { Frequency }(\mathrm{kHz})\end{array}$} & \multicolumn{2}{|c|}{$\begin{array}{c}\text { Torsional Frequency } \\
(\mathrm{kHz})\end{array}$} \\
\hline & Specimen & Specimen & Specimen & Specimen & Specimen & Specimen & Specimen & Specimen \\
\hline & 1 & 2 & 1 & 2 & 1 & 2 & 1 & 2 \\
\hline 1 & 7.450 & 7.475 & 2.770 & 2.850 & 3.800 & 4.040 & 1.570 & 1.600 \\
\hline 2 & 7.446 & 7.466 & 3.290 & 3.410 & 4.680 & 4.680 & 1.930 & 1.930 \\
\hline 3 & 7.450 & 7.476 & 3.570 & 3.640 & 5.010 & 5.030 & 1.990 & 2.080 \\
\hline 4 & 7.460 & 7.487 & 3.730 & 3.770 & 5.120 & 5.220 & 2.080 & 2.110 \\
\hline 5 & 7.464 & 7.491 & 3.770 & 3.880 & 5.380 & 5.370 & 2.180 & 2.200 \\
\hline 6 & 7.463 & 7.489 & 3.880 & 3.930 & 5.310 & 5.430 & 2.200 & 2.240 \\
\hline 7 & 7.463 & 7.490 & 3.860 & 3.960 & 5.380 & 5.460 & 2.200 & 2.340 \\
\hline 8 & 7.464 & 7.491 & 3.950 & 4.020 & 5.500 & 5.520 & 2.280 & 2.260 \\
\hline 9 & 7.465 & 7.489 & 3.980 & 4.050 & 5.530 & 5.640 & 2.240 & 2.310 \\
\hline 10 & 7.463 & 7.488 & 4.000 & 4.090 & 4.920 & 5.620 & 2.280 & 2.340 \\
\hline 11 & 7.464 & 7.489 & 4.030 & 4.110 & 5.590 & 5.760 & 2.290 & 2.340 \\
\hline 12 & 7.466 & 7.492 & 4.090 & 4.140 & 5.620 & 5.700 & 2.280 & 2.340 \\
\hline 13 & 7.468 & 7.494 & 4.050 & 4.160 & 5.770 & 5.830 & 2.310 & 2.340 \\
\hline 14 & 7.471 & 7.499 & 4.110 & 4.180 & 5.750 & 5.850 & 2.310 & 2.360 \\
\hline 15 & 7.471 & 7.498 & 4.150 & 4.190 & 5.780 & 5.870 & 2.310 & 2.360 \\
\hline 16 & 7.475 & 7.504 & 4.140 & 4.210 & 5.690 & 5.860 & 2.340 & 2.370 \\
\hline 17 & 7.475 & 7.499 & 4.170 & 4.220 & 5.820 & 5.910 & 2.340 & 2.380 \\
\hline 26 & 7.474 & 7.501 & 4.220 & 4.250 & 5.890 & 6.000 & 2.350 & 2.390 \\
\hline 33 & 7.494 & 7.519 & 4.287 & 4.390 & 6.011 & 6.047 & 2.442 & 2.486 \\
\hline 40 & 7.487 & 7.514 & 4.277 & 4.398 & 6.007 & 6.139 & 2.457 & 2.493 \\
\hline 60 & 7.492 & 7.518 & 4.327 & 4.439 & 6.018 & 6.018 & 2.463 & 2.463 \\
\hline
\end{tabular}


Table B.2 Specimens Made from Concrete with Calcium Nitrite, Cured in Moist Room.

\begin{tabular}{|c|c|c|c|c|c|c|c|c|}
\hline \multirow{2}{*}{$\begin{array}{c}\text { Curing } \\
\text { Time } \\
(\text { day })\end{array}$} & \multicolumn{2}{|c|}{ Weight $(\mathrm{lb})$} & \multicolumn{2}{c|}{$\begin{array}{c}\text { Transverse } \\
\text { Frequency }(\mathrm{kHz})\end{array}$} & \multicolumn{2}{c|}{$\begin{array}{c}\text { Longitudinal } \\
\text { Frequency }(\mathrm{kHz})\end{array}$} & $\begin{array}{c}\text { Torsional Frequency } \\
(\mathrm{kHz})\end{array}$ \\
\hline & $\begin{array}{c}\text { Specimen } \\
1\end{array}$ & $\begin{array}{c}\text { Specimen } \\
2\end{array}$ & $\begin{array}{c}\text { Specimen } \\
1\end{array}$ & $\begin{array}{c}\text { Specimen } \\
2\end{array}$ & $\begin{array}{c}\text { Specimen } \\
1\end{array}$ & $\begin{array}{c}\text { Specimen } \\
2\end{array}$ & $\begin{array}{c}\text { Specimen } \\
1\end{array}$ & $\begin{array}{c}\text { Specimen } \\
2\end{array}$ \\
\hline 1 & 7.673 & 7.598 & 3.150 & 3.090 & 4.540 & 3.930 & 1.730 & 1.790 \\
\hline 2 & 7.667 & 7.586 & 3.760 & 3.700 & 5.460 & 5.340 & 1.770 & 2.140 \\
\hline 3 & 7.674 & 7.599 & 4.020 & 3.950 & 5.540 & 5.460 & 2.260 & 2.230 \\
\hline 4 & 7.677 & 7.606 & 4.130 & 4.040 & 5.660 & 5.610 & 2.350 & 2.280 \\
\hline 5 & 7.680 & 7.606 & 4.210 & 4.140 & 5.820 & 5.770 & 2.370 & 2.320 \\
\hline 6 & 7.679 & 7.605 & 4.240 & 4.170 & 5.880 & 5.900 & 2.410 & 2.330 \\
\hline 7 & 7.681 & 7.608 & 4.270 & 4.190 & 5.900 & 5.830 & 2.470 & 2.440 \\
\hline 8 & 7.685 & 7.614 & 4.310 & 4.240 & 6.050 & 6.070 & 2.450 & 2.420 \\
\hline 9 & 7.684 & 7.611 & 4.340 & 4.260 & 5.990 & 5.880 & 2.450 & 2.430 \\
\hline 10 & 7.681 & 7.609 & 4.370 & 4.290 & 6.170 & 6.080 & 2.520 & 2.420 \\
\hline 11 & 7.683 & 7.613 & 4.390 & 4.300 & 6.060 & 5.910 & 2.540 & 2.410 \\
\hline 12 & 7.687 & 7.615 & 4.410 & 4.330 & 6.060 & 6.100 & 2.500 & 2.420 \\
\hline 13 & 7.688 & 7.617 & 4.420 & 4.320 & 6.150 & 6.020 & 2.510 & 2.440 \\
\hline 14 & 7.691 & 7.623 & 4.460 & 4.360 & 6.210 & 5.940 & 2.520 & 2.440 \\
\hline 15 & 7.692 & 7.620 & 4.460 & 4.350 & 6.170 & 6.010 & 2.530 & 2.440 \\
\hline 16 & 7.698 & 7.628 & 4.470 & 4.370 & 6.160 & 6.000 & 2.530 & 2.440 \\
\hline 17 & 7.694 & 7.625 & 4.480 & 4.380 & 6.210 & 6.060 & 2.540 & 2.460 \\
\hline 26 & 7.697 & 7.626 & 4.500 & 4.400 & 6.370 & 6.250 & 2.550 & 2.450 \\
\hline 33 & 7.717 & 7.649 & 4.626 & 4.514 & 6.508 & 6.456 & 2.625 & 2.537 \\
\hline 40 & 7.714 & 7.644 & 4.639 & 4.534 & 6.521 & 6.426 & 2.626 & 2.538 \\
\hline 60 & 7.722 & 7.652 & 4.764 & 4.582 & 6.555 & 6.486 & 2.669 & 2.571 \\
\hline
\end{tabular}


Table B.3 Specimens Made from Concrete with Organic Corrosion Inhibitor, Cured in Moist Room.

\begin{tabular}{|c|c|c|c|c|c|c|c|c|}
\hline \multirow{2}{*}{$\begin{array}{c}\text { Curing } \\
\text { Time } \\
\text { (day) }\end{array}$} & \multicolumn{2}{|c|}{ Weight (lb) } & \multicolumn{2}{c|}{$\begin{array}{c}\text { Transverse } \\
\text { Frequency (kHz) }\end{array}$} & \multicolumn{2}{c|}{$\begin{array}{c}\text { Longitudinal } \\
\text { Frequency (kHz) }\end{array}$} & $\begin{array}{c}\text { Torsional Frequency } \\
(\mathrm{kHz})\end{array}$ \\
\cline { 2 - 9 } & $\begin{array}{c}\text { Specimen } \\
1\end{array}$ & $\begin{array}{c}\text { Specimen } \\
2\end{array}$ & $\begin{array}{c}\text { Specimen } \\
1\end{array}$ & $\begin{array}{c}\text { Specimen } \\
2\end{array}$ & $\begin{array}{c}\text { Specimen } \\
1\end{array}$ & $\begin{array}{c}\text { Specimen } \\
2\end{array}$ & $\begin{array}{c}\text { Specimen } \\
1\end{array}$ & $\begin{array}{c}\text { Specimen } \\
2\end{array}$ \\
\hline 1 & 8.675 & 8.734 & 5.140 & 5.150 & 6.930 & 6.940 & 1.930 & 2.890 \\
\hline 2 & 8.685 & 8.742 & 5.850 & 5.890 & 8.170 & 8.240 & 3.320 & 3.320 \\
\hline 3 & 8.690 & 8.747 & 6.070 & 6.100 & 8.480 & 8.650 & 3.410 & 3.430 \\
\hline 4 & 8.691 & 8.748 & 6.170 & 6.200 & 8.970 & 8.660 & 3.490 & 3.520 \\
\hline 5 & 8.692 & 8.749 & 6.220 & 6.250 & 8.630 & 8.660 & 3.530 & 3.550 \\
\hline 6 & 8.689 & 8.744 & 6.270 & 6.300 & 8.670 & 8.740 & 3.580 & 3.630 \\
\hline 7 & 8.692 & 8.748 & 6.320 & 6.350 & 8.750 & 8.790 & 3.570 & 3.630 \\
\hline 8 & 8.690 & 8.747 & 6.340 & 6.380 & 8.690 & 8.870 & 3.580 & 3.620 \\
\hline 9 & 8.691 & 8.745 & 6.370 & 6.410 & 8.380 & 8.330 & 3.660 & 3.640 \\
\hline 10 & 8.691 & 8.746 & 6.400 & 6.430 & 8.970 & 8.890 & 3.640 & 3.630 \\
\hline 11 & 8.695 & 8.750 & 6.420 & 6.450 & 8.840 & 9.510 & 3.610 & 3.610 \\
\hline 12 & 8.696 & 8.749 & 6.420 & 6.460 & 9.200 & 9.080 & 3.610 & 3.630 \\
\hline 13 & 8.698 & 8.753 & 6.450 & 6.490 & 8.980 & 9.070 & 3.630 & 3.650 \\
\hline 14 & 8.697 & 8.750 & 6.460 & 6.490 & 9.020 & 9.070 & 3.630 & 3.650 \\
\hline 15 & 8.703 & 8.755 & 6.480 & 6.510 & 9.000 & 9.050 & 3.640 & 3.660 \\
\hline 16 & 8.701 & 8.701 & 6.490 & 6.530 & 9.090 & 9.090 & 3.640 & 3.670 \\
\hline 17 & 8.701 & 8.755 & 6.490 & 6.530 & 9.420 & 9.480 & 3.680 & 3.690 \\
\hline 26 & 8.707 & 8.762 & 6.590 & 6.640 & 9.320 & 9.450 & 3.710 & 3.720 \\
\hline 33 & 8.718 & 8.776 & 6.646 & 6.691 & 9.345 & 9.364 & 3.728 & 3.748 \\
\hline 40 & 8.715 & 8.769 & 6.666 & 6.718 & 9.358 & 9.438 & 3.738 & 3.749 \\
\hline 60 & 8.722 & 8.775 & 6.731 & 6.783 & 9.419 & 9.543 & 3.780 & 3.811 \\
\hline & & & & & & & & \\
\hline
\end{tabular}


Table B.4 Specimens Made from Fly Ash Concrete, Cured in Moist Room

\begin{tabular}{|c|c|c|c|c|c|c|c|c|}
\hline \multirow{2}{*}{$\begin{array}{c}\text { Curing } \\
\text { Time } \\
\text { (day) }\end{array}$} & \multicolumn{2}{|c|}{ Weight (lb) } & \multicolumn{2}{c|}{$\begin{array}{c}\text { Transverse } \\
\text { Frequency (kHz) }\end{array}$} & \multicolumn{2}{c|}{$\begin{array}{c}\text { Longitudinal } \\
\text { Frequency (kHz) }\end{array}$} & $\begin{array}{c}\text { Torsional Frequency } \\
(\mathrm{kHz})\end{array}$ \\
\cline { 2 - 9 } & $\begin{array}{c}\text { Specimen } \\
1\end{array}$ & $\begin{array}{c}\text { Specimen } \\
2\end{array}$ & $\begin{array}{c}\text { Specimen } \\
1\end{array}$ & $\begin{array}{c}\text { Specimen } \\
2\end{array}$ & $\begin{array}{c}\text { Specimen } \\
1\end{array}$ & $\begin{array}{c}\text { Specimen } \\
2\end{array}$ & $\begin{array}{c}\text { Specimen } \\
1\end{array}$ & $\begin{array}{c}\text { Specimen } \\
2\end{array}$ \\
\hline 1 & 7.745 & 7.695 & 3.100 & 3.090 & 4.210 & 4.410 & 1.790 & 1.760 \\
\hline 2 & 7.747 & 7.699 & 3.920 & 3.930 & 5.400 & 5.450 & 2.220 & 2.230 \\
\hline 3 & 7.756 & 7.711 & 4.140 & 4.180 & 5.750 & 5.730 & 2.410 & 2.400 \\
\hline 4 & 7.756 & 7.709 & 4.270 & 4.310 & 5.850 & 5.940 & 2.410 & 2.480 \\
\hline 5 & 7.762 & 7.710 & 4.340 & 4.390 & 6.060 & 6.100 & 2.500 & 2.480 \\
\hline 6 & 7.755 & 7.707 & 4.380 & 4.430 & 6.120 & 6.060 & 2.500 & 2.540 \\
\hline 7 & 7.757 & 7.709 & 4.430 & 4.480 & 6.160 & 6.180 & 2.580 & 2.550 \\
\hline 8 & 7.757 & 7.708 & 4.450 & 4.500 & 5.810 & 6.180 & 2.640 & 2.540 \\
\hline 9 & 7.759 & 7.709 & 4.470 & 4.530 & 6.220 & 6.230 & 2.600 & 2.570 \\
\hline 10 & 7.758 & 7.709 & 4.500 & 4.550 & 6.230 & 6.300 & 2.540 & 2.570 \\
\hline 11 & 7.762 & 7.711 & 4.510 & 4.570 & 6.290 & 6.320 & 2.570 & 2.610 \\
\hline 12 & 7.764 & 7.713 & 4.530 & 4.580 & 6.260 & 6.330 & 2.580 & 2.590 \\
\hline 13 & 7.768 & 7.718 & 4.560 & 4.600 & 6.600 & 6.390 & 2.590 & 2.600 \\
\hline 14 & 7.766 & 7.715 & 4.560 & 4.620 & 6.470 & 6.490 & 2.590 & 2.600 \\
\hline 15 & 7.774 & 7.722 & 4.580 & 4.630 & 6.440 & 6.450 & 2.610 & 2.650 \\
\hline 16 & 7.774 & 7.721 & 4.600 & 4.650 & 6.330 & 6.450 & 2.610 & 2.620 \\
\hline 17 & 7.773 & 7.721 & 4.610 & 4.660 & 6.500 & 6.600 & 2.620 & 2.630 \\
\hline 26 & 7.781 & 7.730 & 4.750 & 4.750 & 6.490 & 6.490 & 2.660 & 2.680 \\
\hline 33 & 7.799 & 7.749 & 4.743 & 4.804 & 6.606 & 6.651 & 2.684 & 2.706 \\
\hline 40 & 7.795 & 7.744 & 4.767 & 4.830 & 6.675 & 6.782 & 2.733 & 2.714 \\
\hline 60 & 7.806 & 7.756 & 4.842 & 4.891 & 6.763 & 6.685 & 2.731 & 2.751 \\
\hline & & & & & & & & \\
\hline
\end{tabular}


Table B.5 Specimens Made from INDOT 9-bag Concrete, Cured in Moist Room.

\begin{tabular}{|c|c|c|c|c|c|c|c|c|}
\hline \multirow{3}{*}{$\begin{array}{l}\text { Curing } \\
\text { Time } \\
\text { (day) }\end{array}$} & \multicolumn{2}{|c|}{ Weight (lb) } & \multicolumn{2}{|c|}{$\begin{array}{c}\text { Transverse } \\
\text { Frequency }(\mathrm{kHz})\end{array}$} & \multicolumn{2}{|c|}{$\begin{array}{c}\text { Longitudinal } \\
\text { Frequency }(\mathrm{kHz})\end{array}$} & \multicolumn{2}{|c|}{$\begin{array}{c}\text { Torsional Frequency } \\
(\mathrm{kHz})\end{array}$} \\
\hline & \begin{tabular}{|l|} 
Specimen \\
\end{tabular} & Specimen & Specimen & Specimen & Specimen & Specimen & Specimer & Specimen \\
\hline & 1 & 2 & 1 & 2 & 1 & 2 & 1 & 2 \\
\hline 1 & 7.275 & 7.434 & 2.890 & 3.080 & 4.090 & 4.450 & 1.650 & 1.770 \\
\hline 2 & 7.291 & 7.452 & 3.350 & 3.540 & 4.810 & 4.940 & 1.900 & 2.010 \\
\hline 3 & 7.298 & 7.456 & 3.510 & 3.710 & 4.840 & 5.180 & 2.010 & 2.100 \\
\hline 4 & 7.302 & 7.463 & 3.580 & 3.790 & 5.220 & 5.470 & 2.050 & 2.140 \\
\hline 5 & 7.301 & 7.461 & 3.630 & 3.830 & 5.200 & 5.260 & 2.050 & 2.160 \\
\hline 6 & 7.306 & 7.468 & 3.680 & 3.860 & 5.240 & 5.450 & 2.110 & 2.210 \\
\hline 7 & 7.306 & 7.466 & 3.710 & 3.910 & 5.340 & 5.320 & 2.130 & 2.250 \\
\hline 8 & 7.308 & 7.467 & 3.730 & 3.930 & 5.270 & 5.500 & 2.110 & 2.250 \\
\hline 9 & 7.310 & 7.469 & 3.750 & 3.950 & 5.350 & 5.390 & 2.130 & 2.230 \\
\hline 10 & 7.313 & 7.472 & 3.770 & 3.970 & 5.490 & 5.660 & 2.120 & 2.250 \\
\hline 11 & 7.315 & 7.474 & 3.780 & 3.990 & 5.420 & 5.590 & 2.140 & 2.260 \\
\hline 12 & 7.318 & 7.480 & 3.810 & 4.010 & 5.330 & 5.540 & 2.140 & 2.260 \\
\hline 13 & 7.318 & 7.478 & 3.810 & 4.020 & 5.670 & 5.550 & 2.150 & 2.270 \\
\hline 14 & 7.325 & 7.483 & 3.840 & 4.040 & 5.510 & 5.740 & 2.170 & 2.300 \\
\hline 15 & 7.324 & 7.483 & 3.840 & 4.040 & 5.530 & 5.590 & 2.180 & 2.290 \\
\hline 16 & 7.324 & 7.484 & 3.860 & 4.060 & 5.620 & 5.680 & 2.180 & 2.290 \\
\hline 25 & 7.338 & 7.495 & 3.930 & 4.130 & 5.420 & 5.690 & 2.230 & 2.330 \\
\hline 32 & 7.357 & 7.516 & 3.972 & 4.171 & 5.547 & 5.721 & 2.242 & 2.351 \\
\hline 39 & 7.352 & 7.510 & 3.998 & 4.203 & 5.545 & 5.770 & 2.252 & 2.359 \\
\hline 59 & 7.361 & 7.524 & 4.035 & 4.244 & 5.632 & 5.908 & 2.271 & 2.394 \\
\hline
\end{tabular}


Table B.6 Specimens Made from Concrete with Shrinkage Reducing Admixture, Cured in Moist Room.

\begin{tabular}{|c|c|c|c|c|c|c|c|c|}
\hline \multirow{2}{*}{$\begin{array}{c}\text { Curing } \\
\text { Time } \\
\text { (day) }\end{array}$} & \multicolumn{2}{|c|}{ Weight (lb) } & \multicolumn{2}{c|}{$\begin{array}{c}\text { Transverse } \\
\text { Frequency }(\mathrm{kHz})\end{array}$} & \multicolumn{2}{c|}{$\begin{array}{c}\text { Longitudinal } \\
\text { Frequency }(\mathrm{kHz})\end{array}$} & \multicolumn{2}{c|}{$\begin{array}{c}\text { Torsional Frequency } \\
(\mathrm{kHz})\end{array}$} \\
\cline { 2 - 9 } & $\begin{array}{c}\text { Specimen } \\
1\end{array}$ & $\begin{array}{c}\text { Specimen } \\
2\end{array}$ & $\begin{array}{c}\text { Specimen } \\
1\end{array}$ & $\begin{array}{c}\text { Specimen } \\
2\end{array}$ & $\begin{array}{c}\text { Specimen } \\
1\end{array}$ & $\begin{array}{c}\text { Specimen } \\
2\end{array}$ & $\begin{array}{c}\text { Specimen } \\
1\end{array}$ & $\begin{array}{c}\text { Specimen } \\
2\end{array}$ \\
\hline 1 & 8.282 & 8.371 & 4.290 & 4.350 & 5.690 & 6.180 & 2.410 & 2.450 \\
\hline 2 & 8.297 & 8.388 & 5.080 & 5.140 & 7.060 & 7.180 & 2.980 & 3.040 \\
\hline 3 & 8.309 & 8.402 & 5.380 & 5.470 & 7.540 & 7.660 & 3.070 & 3.070 \\
\hline 4 & 8.313 & 8.401 & 5.550 & 5.550 & 7.830 & 7.830 & 3.160 & 3.190 \\
\hline 5 & 8.311 & 8.402 & 5.580 & 5.630 & 7.690 & 7.770 & 3.130 & 3.200 \\
\hline 6 & 8.315 & 8.406 & 5.630 & 5.700 & 7.840 & 8.130 & 3.190 & 3.200 \\
\hline 7 & 8.314 & 8.405 & 5.670 & 5.740 & 7.810 & 7.910 & 3.190 & 3.230 \\
\hline 8 & 8.316 & 8.407 & 5.710 & 5.770 & 7.830 & 8.210 & 3.220 & 3.210 \\
\hline 9 & 8.316 & 8.408 & 5.730 & 5.800 & 7.890 & 8.180 & 3.220 & 3.250 \\
\hline 10 & 8.319 & 8.410 & 5.760 & 5.820 & 7.970 & 8.060 & 3.230 & 3.270 \\
\hline 11 & 8.320 & 8.412 & 5.800 & 5.850 & 8.000 & 8.290 & 3.240 & 3.300 \\
\hline 12 & 8.322 & 8.414 & 5.790 & 5.870 & 7.980 & 8.230 & 3.250 & 3.310 \\
\hline 13 & 8.323 & 8.415 & 5.810 & 5.870 & 8.010 & 8.240 & 3.270 & 3.310 \\
\hline 14 & 8.327 & 8.418 & 5.830 & 5.900 & 8.050 & 8.470 & 3.290 & 3.340 \\
\hline 15 & 8.328 & 8.419 & 5.860 & 5.930 & 8.080 & 8.300 & 3.280 & 3.330 \\
\hline 16 & 8.328 & 8.419 & 5.880 & 5.940 & 8.290 & 8.460 & 3.280 & 3.350 \\
\hline 25 & 8.341 & 8.432 & 5.960 & 6.030 & 8.580 & 8.680 & 3.340 & 3.380 \\
\hline 32 & 8.358 & 8.448 & 6.006 & 6.057 & 8.551 & 8.722 & 3.334 & 3.419 \\
\hline 39 & 8.360 & 8.447 & 6.021 & 6.087 & 8.599 & 8.766 & 3.368 & 3.459 \\
\hline 59 & 8.374 & 8.343 & 6.083 & 6.146 & 8.573 & 8.731 & 3.430 & 3.447 \\
\hline
\end{tabular}


Table B.7 Specimens Made from Latex Modified Concrete, Cured in Moist Room.

\begin{tabular}{|c|c|c|c|c|c|c|c|c|}
\hline \multirow{2}{*}{$\begin{array}{c}\text { Curing } \\
\text { Time } \\
\text { (day) }\end{array}$} & \multicolumn{2}{|c|}{ Weight (lb) } & \multicolumn{2}{c|}{$\begin{array}{c}\text { Transverse } \\
\text { Frequency (kHz) }\end{array}$} & \multicolumn{2}{c|}{$\begin{array}{c}\text { Longitudinal } \\
\text { Frequency (kHz) }\end{array}$} & $\begin{array}{c}\text { Torsional Frequency } \\
(\mathrm{kHz})\end{array}$ \\
\cline { 2 - 9 } & $\begin{array}{c}\text { Specimen } \\
1\end{array}$ & $\begin{array}{c}\text { Specimen } \\
2\end{array}$ & $\begin{array}{c}\text { Specimen } \\
1\end{array}$ & $\begin{array}{c}\text { Specimen } \\
2\end{array}$ & $\begin{array}{c}\text { Specimen } \\
1\end{array}$ & $\begin{array}{c}\text { Specimen } \\
2\end{array}$ & $\begin{array}{c}\text { Specimen } \\
1\end{array}$ & $\begin{array}{c}\text { Specimen } \\
2\end{array}$ \\
\hline 1 & 7.573 & 7.623 & 2.970 & 2.960 & 4.320 & 4.190 & 1.810 & 1.810 \\
\hline 2 & 7.500 & 7.552 & 3.510 & 3.500 & 4.910 & 4.970 & 2.070 & 2.050 \\
\hline 3 & 7.482 & 7.523 & 3.590 & 3.640 & 5.120 & 5.180 & 2.120 & 2.160 \\
\hline 4 & 7.476 & 7.526 & 3.650 & 3.640 & 5.270 & 5.200 & 2.130 & 2.130 \\
\hline 5 & 7.472 & 7.523 & 3.670 & 3.660 & 5.330 & 5.300 & 2.150 & 2.150 \\
\hline 6 & 7.468 & 7.520 & 3.680 & 3.670 & 5.350 & 5.690 & 2.160 & 2.190 \\
\hline 7 & 7.465 & 7.516 & 3.690 & 3.680 & 5.380 & 5.310 & 2.170 & 2.160 \\
\hline 8 & 7.459 & 7.511 & 3.660 & 3.660 & 5.440 & 5.440 & 2.150 & 2.150 \\
\hline 9 & 7.456 & 7.508 & 3.670 & 3.650 & 5.380 & 5.490 & 2.160 & 2.150 \\
\hline 10 & 7.455 & 7.507 & 3.670 & 3.660 & 5.410 & 5.470 & 2.160 & 2.150 \\
\hline 11 & 7.454 & 7.506 & 3.670 & 3.660 & 5.390 & 5.620 & 2.160 & 2.160 \\
\hline 20 & 7.435 & 7.488 & 3.660 & 3.660 & 5.510 & 5.310 & 2.160 & 2.180 \\
\hline 27 & 7.433 & 7.485 & 3.663 & 3.656 & 5.462 & 5.297 & 2.157 & 2.178 \\
\hline 34 & 7.437 & 7.490 & 3.691 & 3.689 & 5.352 & 5.352 & 2.162 & 2.176 \\
\hline 54 & 7.425 & 7.479 & 3.726 & 3.719 & 5.322 & 5.518 & 2.200 & 2.237 \\
\hline
\end{tabular}


Table B. 8 Specimens Made from Silica Fume Concrete, Cured in Air.

\begin{tabular}{|c|c|c|c|c|c|c|c|c|}
\hline \multirow{3}{*}{$\begin{array}{l}\text { Curing } \\
\text { Time } \\
\text { (day) }\end{array}$} & \multicolumn{2}{|c|}{ Weight (lb) } & \multicolumn{2}{|c|}{$\begin{array}{c}\text { Transverse } \\
\text { Frequency }(\mathrm{kHz})\end{array}$} & \multicolumn{2}{|c|}{$\begin{array}{c}\text { Longitudinal } \\
\text { Frequency }(\mathrm{kHz})\end{array}$} & \multicolumn{2}{|c|}{\begin{tabular}{|c}
$\begin{array}{c}\text { Torsional Frequency } \\
(\mathrm{kHz})\end{array}$ \\
\end{tabular}} \\
\hline & \begin{tabular}{|l|} 
Specimen \\
\end{tabular} & Specimen & Specimen & Specimen & Specimen & Specimen & Specimen & Specimen \\
\hline & 1 & 2 & 1 & 2 & 1 & 2 & 1 & 2 \\
\hline 1 & 7.736 & 7.842 & 3.300 & 2.970 & 4.640 & 4.320 & 1.950 & 1.810 \\
\hline 2 & 7.673 & 7.771 & 4.060 & 4.120 & 5.750 & 5.940 & 2.330 & 2.420 \\
\hline 3 & 7.659 & 7.755 & 4.160 & 4.230 & 5.930 & 6.010 & 2.380 & 2.470 \\
\hline 4 & 7.656 & 7.749 & 4.190 & 4.250 & 5.890 & 6.160 & 2.410 & 2.470 \\
\hline 5 & 7.653 & 7.747 & 4.200 & 4.270 & 5.980 & 6.250 & 2.070 & 2.480 \\
\hline 6 & 7.649 & 7.744 & 4.210 & 4.270 & 6.080 & 6.260 & 2.430 & 2.480 \\
\hline 7 & 7.646 & 7.740 & 4.210 & 4.270 & 5.960 & 6.240 & 2.430 & 2.470 \\
\hline 8 & 7.641 & 7.734 & 4.200 & 4.260 & 6.050 & 6.240 & 2.420 & 2.480 \\
\hline 9 & 7.638 & 7.732 & 4.190 & 4.250 & 6.150 & 6.280 & 2.420 & 2.490 \\
\hline 10 & 7.637 & 7.731 & 4.210 & 4.270 & 6.120 & 6.300 & 2.420 & 2.490 \\
\hline 11 & 7.637 & 7.730 & 4.210 & 4.260 & 6.170 & 6.310 & 2.430 & 2.490 \\
\hline 20 & 7.619 & 7.713 & 4.180 & 4.230 & 6.000 & 6.100 & 2.420 & 2.480 \\
\hline 27 & 7.623 & 7.716 & 4.185 & 4.228 & 5.978 & 6.043 & 2.408 & 2.474 \\
\hline 34 & 7.616 & 7.709 & 4.205 & 4.257 & 5.991 & 6.142 & 2.436 & 2.478 \\
\hline 54 & 7.608 & 7.700 & 4.227 & 4.273 & 5.992 & 6.097 & 2.455 & 2.505 \\
\hline
\end{tabular}


Table B. 9 Specimens Made from Concrete with Calcium Nitrite, Cured in Air.

\begin{tabular}{|c|c|c|c|c|c|c|c|c|}
\hline \multirow{2}{*}{$\begin{array}{c}\text { Curing } \\
\text { Time } \\
(\text { day) }\end{array}$} & \multicolumn{2}{|c|}{ Weight (lb) } & \multicolumn{2}{c|}{$\begin{array}{c}\text { Transverse } \\
\text { Frequency }(\mathrm{kHz})\end{array}$} & \multicolumn{2}{c|}{$\begin{array}{c}\text { Longitudinal } \\
\text { Frequency }(\mathrm{kHz})\end{array}$} & \multicolumn{2}{c|}{$\begin{array}{c}\text { Torsional Frequency } \\
(\mathrm{kHz})\end{array}$} \\
\cline { 2 - 9 } & $\begin{array}{c}\text { Specimen } \\
1\end{array}$ & $\begin{array}{c}\text { Specimen } \\
2\end{array}$ & $\begin{array}{c}\text { Specimen } \\
1\end{array}$ & $\begin{array}{c}\text { Specimen } \\
2\end{array}$ & $\begin{array}{c}\text { Specimen } \\
1\end{array}$ & $\begin{array}{c}\text { Specimen } \\
2\end{array}$ & $\begin{array}{c}\text { Specimen } \\
1\end{array}$ & $\begin{array}{c}\text { Specimen } \\
2\end{array}$ \\
\hline 1 & 8.802 & 8.744 & 5.290 & 5.320 & 7.300 & 7.370 & 2.960 & 2.990 \\
\hline 2 & 8.757 & 8.703 & 6.020 & 6.090 & 8.510 & 8.630 & 3.430 & 3.450 \\
\hline 3 & 8.750 & 8.697 & 6.100 & 6.180 & 8.600 & 8.680 & 3.450 & 3.520 \\
\hline 4 & 8.747 & 8.693 & 6.130 & 6.240 & 8.710 & 9.310 & 3.480 & 3.520 \\
\hline 5 & 8.743 & 8.689 & 6.160 & 6.240 & 8.810 & 8.810 & 3.500 & 3.550 \\
\hline 6 & 8.740 & 8.685 & 6.180 & 6.270 & 8.830 & 8.880 & 3.520 & 3.560 \\
\hline 7 & 8.735 & 8.681 & 6.180 & 6.270 & 8.920 & 8.930 & 3.520 & 3.580 \\
\hline 8 & 8.733 & 8.679 & 6.190 & 6.280 & 8.870 & 8.950 & 3.520 & 3.570 \\
\hline 9 & 8.731 & 8.677 & 6.210 & 6.290 & 8.900 & 8.950 & 3.530 & 3.600 \\
\hline 10 & 8.730 & 8.675 & 6.220 & 6.300 & 8.990 & 9.040 & 3.540 & 3.610 \\
\hline 19 & 8.715 & 8.660 & 6.250 & 6.340 & 8.990 & 9.080 & 3.560 & 3.640 \\
\hline 26 & 8.710 & 8.656 & 6.266 & 6.356 & 8.994 & 9.098 & 3.576 & 3.722 \\
\hline 33 & 8.712 & 8.657 & 6.285 & 6.375 & 9.022 & 9.214 & 3.586 & 3.644 \\
\hline 53 & 8.697 & 8.643 & 6.289 & 6.389 & 8.999 & 9.106 & 3.625 & 3.681 \\
\hline
\end{tabular}


Table B.10 Specimens Made from Concrete with Organic Corrosion Inhibitor, Cured in Air.

\begin{tabular}{|c|c|c|c|c|c|c|c|c|}
\hline \multirow{2}{*}{$\begin{array}{c}\text { Curing } \\
\text { Time } \\
\text { (day) }\end{array}$} & \multicolumn{2}{|c|}{ Weight (lb) } & \multicolumn{2}{c|}{$\begin{array}{c}\text { Transverse } \\
\text { Frequency }(\mathrm{kHz})\end{array}$} & \multicolumn{2}{c|}{$\begin{array}{c}\text { Longitudinal } \\
\text { Frequency }(\mathrm{kHz})\end{array}$} & \multicolumn{2}{c|}{$\begin{array}{c}\text { Torsional Frequency } \\
(\mathrm{kHz})\end{array}$} \\
\cline { 2 - 9 } & $\begin{array}{c}\text { Specimen } \\
1\end{array}$ & $\begin{array}{c}\text { Specimen } \\
2\end{array}$ & $\begin{array}{c}\text { Specimen } \\
1\end{array}$ & $\begin{array}{c}\text { Specimen } \\
2\end{array}$ & $\begin{array}{c}\text { Specimen } \\
1\end{array}$ & $\begin{array}{c}\text { Specimen } \\
2\end{array}$ & $\begin{array}{c}\text { Specimen } \\
1\end{array}$ & $\begin{array}{c}\text { Specimen } \\
2\end{array}$ \\
\hline 1 & 7.573 & 7.547 & 2.730 & 2.770 & 3.770 & 4.010 & 1.610 & 1.620 \\
\hline 2 & 7.499 & 7.471 & 3.570 & 3.620 & 4.340 & 5.140 & 2.090 & 2.090 \\
\hline 3 & 7.490 & 7.459 & 3.640 & 3.690 & 5.280 & 5.310 & 2.110 & 2.140 \\
\hline 4 & 7.483 & 7.452 & 3.670 & 3.710 & 5.310 & 5.340 & 2.120 & 2.150 \\
\hline 5 & 7.478 & 7.447 & 3.670 & 3.710 & 5.320 & 5.410 & 2.160 & 2.160 \\
\hline 6 & 7.473 & 7.442 & 3.680 & 3.710 & 5.320 & 5.410 & 2.140 & 2.160 \\
\hline 7 & 7.466 & 7.436 & 3.670 & 3.710 & 5.420 & 5.440 & 2.140 & 2.160 \\
\hline 8 & 7.463 & 7.433 & 3.660 & 3.700 & 5.360 & 5.390 & 2.130 & 2.150 \\
\hline 9 & 7.461 & 7.431 & 3.660 & 3.700 & 5.380 & 5.420 & 2.130 & 2.160 \\
\hline 10 & 7.460 & 7.430 & 3.670 & 3.700 & 5.380 & 5.390 & 2.130 & 2.160 \\
\hline 19 & 7.441 & 7.410 & 3.640 & 3.680 & 5.340 & 5.320 & 2.120 & 2.140 \\
\hline 26 & 7.437 & 7.406 & 3.638 & 3.676 & 5.283 & 5.307 & 2.116 & 2.142 \\
\hline 33 & 7.445 & 7.414 & 3.675 & 3.713 & 5.325 & 5.351 & 2.128 & 2.157 \\
\hline 53 & 7.430 & 7.400 & 3.718 & 3.761 & 5.329 & 5.378 & 2.153 & 2.180 \\
\hline
\end{tabular}


Table B.11 Specimens Made from Fly Ash Concrete, Cured in Air.

\begin{tabular}{|c|c|c|c|c|c|c|c|c|}
\hline $\begin{array}{c}\text { Curing } \\
\text { Time } \\
\text { (day) }\end{array}$ & \multicolumn{2}{|c|}{ Weight (lb) } & \multicolumn{2}{c|}{$\begin{array}{c}\text { Transverse } \\
\text { Frequency (kHz) }\end{array}$} & \multicolumn{2}{c|}{$\begin{array}{c}\text { Longitudinal } \\
\text { Frequency (kHz) }\end{array}$} & $\begin{array}{c}\text { Torsional Frequency } \\
(\mathrm{kHz})\end{array}$ \\
\cline { 2 - 9 } & $\begin{array}{c}\text { Specimen } \\
1\end{array}$ & $\begin{array}{c}\text { Specimen } \\
2\end{array}$ & $\begin{array}{c}\text { Specimen } \\
1\end{array}$ & $\begin{array}{c}\text { Specimen } \\
2\end{array}$ & $\begin{array}{c}\text { Specimen } \\
1\end{array}$ & $\begin{array}{c}\text { Specimen } \\
2\end{array}$ & $\begin{array}{c}\text { Specimen } \\
1\end{array}$ & $\begin{array}{c}\text { Specimen } \\
2\end{array}$ \\
\hline 1 & 7.447 & 7.494 & 3.080 & 3.180 & 4.320 & 3.900 & 1.760 & 1.850 \\
\hline 2 & 7.416 & 7.454 & 3.500 & 3.590 & 5.100 & 5.230 & 2.050 & 2.110 \\
\hline 3 & 7.403 & 7.443 & 3.560 & 3.660 & 5.300 & 5.300 & 2.100 & 2.110 \\
\hline 4 & 7.395 & 7.436 & 3.600 & 3.690 & 5.360 & 5.380 & 2.120 & 2.140 \\
\hline 5 & 7.390 & 7.431 & 3.620 & 3.710 & 5.360 & 5.440 & 2.130 & 2.140 \\
\hline 6 & 7.382 & 7.423 & 3.620 & 3.700 & 5.400 & 5.500 & 2.130 & 2.150 \\
\hline 7 & 7.379 & 7.419 & 3.610 & 3.700 & 5.370 & 5.350 & 2.130 & 2.140 \\
\hline 8 & 7.376 & 7.417 & 3.620 & 3.710 & 5.420 & 5.440 & 2.130 & 2.150 \\
\hline 9 & 7.375 & 7.416 & 3.620 & 3.710 & 5.420 & 5.430 & 2.140 & 2.150 \\
\hline 18 & 7.353 & 7.393 & 3.590 & 3.690 & 5.250 & 5.360 & 2.120 & 2.140 \\
\hline 25 & 7.348 & 7.389 & 3.594 & 3.680 & 5.334 & 5.349 & 2.122 & 2.137 \\
\hline 32 & 7.355 & 7.396 & 3.625 & 3.714 & 5.355 & 5.474 & 2.134 & 2.168 \\
\hline 52 & 7.338 & 7.379 & 3.642 & 3.720 & 5.351 & 5.453 & 2.133 & 2.168 \\
\hline
\end{tabular}


Table B.12 Specimens Made from Concrete with Shrinkage Reducing Admixture, Cured in Air.

\begin{tabular}{|c|c|c|c|c|c|c|c|c|}
\hline \multirow{2}{*}{$\begin{array}{c}\text { Curing } \\
\text { Time } \\
\text { (day) }\end{array}$} & \multicolumn{2}{|c|}{ Weight (lb) } & \multicolumn{2}{|c|}{$\begin{array}{c}\text { Transverse } \\
\text { Frequency }(\mathrm{kHz})\end{array}$} & \multicolumn{2}{|c|}{$\begin{array}{c}\text { Longitudinal } \\
\text { Frequency }(\mathrm{kHz})\end{array}$} & \multicolumn{2}{|c|}{$\begin{array}{c}\text { Torsional Frequency } \\
(\mathrm{kHz})\end{array}$} \\
\hline & \begin{tabular}{|c|} 
Specimen \\
1
\end{tabular} & $\begin{array}{c}\text { Specimen } \\
2\end{array}$ & $\begin{array}{c}\text { Specimen } \\
1\end{array}$ & $\begin{array}{c}\text { Specimen } \\
2\end{array}$ & $\begin{array}{c}\text { Specimen } \\
1\end{array}$ & $\begin{array}{c}\text { Specimen } \\
2\end{array}$ & \begin{tabular}{|c|} 
Specimen \\
1
\end{tabular} & $\begin{array}{c}\text { Specimen } \\
2\end{array}$ \\
\hline 1 & 8.478 & 8.477 & 3.940 & 3.940 & 5.490 & 5.650 & 2.130 & 2.140 \\
\hline 2 & 8.413 & 8.397 & 5.110 & 5.140 & 7.400 & 7.520 & 2.810 & 2.810 \\
\hline 3 & 8.396 & 8.381 & 5.420 & 5.460 & 7.610 & 7.690 & 2.990 & 3.000 \\
\hline 4 & 8.387 & 8.373 & 5.530 & 5.580 & 7.880 & 8.070 & 3.060 & 3.070 \\
\hline 5 & 8.382 & 8.367 & 5.600 & 5.630 & 7.920 & 8.000 & 3.090 & 3.100 \\
\hline 6 & 8.376 & 8.360 & 5.620 & 5.640 & 7.990 & 8.060 & 3.160 & 3.120 \\
\hline 7 & 8.372 & 8.357 & 5.620 & 5.660 & 7.900 & 5.020 & 3.120 & 3.140 \\
\hline 8 & 8.369 & 8.353 & 5.640 & 5.690 & 8.020 & 8.040 & 3.160 & 3.140 \\
\hline 9 & 8.367 & 8.352 & 5.660 & 5.690 & 8.060 & 8.210 & 3.140 & 3.150 \\
\hline 18 & 8.345 & 8.329 & 5.720 & 5.740 & 8.150 & 8.190 & 3.170 & 3.170 \\
\hline 25 & 8.339 & 8.323 & 5.728 & 5.747 & 8.186 & 8.139 & 3.195 & 3.200 \\
\hline 32 & 8.342 & 8.328 & 5.754 & 5.764 & 8.162 & 8.254 & 3.204 & 3.200 \\
\hline 52 & 8.322 & 8.308 & 5.773 & 5.780 & 8.096 & 7.875 & 3.220 & 3.209 \\
\hline
\end{tabular}


Table B.13 Specimens 1 and 2 Made from Latex Modified Concrete, Cured in Air.

\begin{tabular}{|c|c|c|c|c|c|c|c|c|}
\hline \multirow{2}{*}{$\begin{array}{c}\text { Curing } \\
\text { Time } \\
(\text { day) }\end{array}$} & \multicolumn{2}{|c|}{ Weight (lb) } & \multicolumn{2}{c|}{$\begin{array}{c}\text { Transverse } \\
\text { Frequency (kHz) }\end{array}$} & \multicolumn{2}{c|}{$\begin{array}{c}\text { Longitudinal } \\
\text { Frequency (kHz) }\end{array}$} & $\begin{array}{c}\text { Torsional Frequency } \\
(\mathrm{kHz})\end{array}$ \\
\cline { 2 - 9 } & $\begin{array}{c}\text { Specimen } \\
1\end{array}$ & $\begin{array}{c}\text { Specimen } \\
2\end{array}$ & $\begin{array}{c}\text { Specimen } \\
1\end{array}$ & $\begin{array}{c}\text { Specimen } \\
2\end{array}$ & $\begin{array}{c}\text { Specimen } \\
1\end{array}$ & $\begin{array}{c}\text { Specimen } \\
2\end{array}$ & $\begin{array}{c}\text { Specimen } \\
1\end{array}$ & $\begin{array}{c}\text { Specimen } \\
2\end{array}$ \\
\hline 1 & 8.941 & 8.948 & 5.160 & 4.950 & 7.210 & 6.770 & 2.840 & 2.800 \\
\hline 2 & 8.906 & 8.913 & 6.530 & 6.440 & 9.280 & 9.300 & 3.740 & 3.660 \\
\hline 3 & 8.900 & 8.906 & 6.730 & 6.440 & 9.640 & 9.660 & 3.820 & 3.750 \\
\hline 4 & 8.895 & 8.902 & 6.810 & 6.720 & 9.660 & 9.730 & 3.830 & 3.840 \\
\hline 5 & 8.890 & 8.897 & 6.840 & 6.760 & 9.980 & 9.860 & 3.990 & 3.840 \\
\hline 6 & 8.889 & 8.895 & 6.840 & 6.780 & 9.940 & 9.820 & 3.870 & 3.870 \\
\hline 7 & 8.886 & 8.893 & 6.870 & 6.790 & 10.070 & 9.860 & 3.950 & 3.860 \\
\hline 8 & 8.886 & 8.892 & 6.890 & 6.790 & 10.220 & 9.900 & 3.890 & 3.860 \\
\hline 17 & 8.872 & 8.879 & 6.940 & 6.880 & 9.960 & 9.920 & 3.930 & 3.890 \\
\hline 24 & 8.870 & 8.876 & 6.959 & 6.884 & 10.251 & 10.028 & 3.933 & 3.899 \\
\hline 31 & 8.875 & 8.882 & 6.986 & 6.922 & 10.055 & 9.879 & 3.956 & 3.916 \\
\hline 51 & 8.864 & 8.870 & 7.053 & 6.974 & 10.036 & 9.970 & 4.003 & 3.955 \\
\hline
\end{tabular}


Table B.14 Specimens 3 and 4 Made from Latex Modified Concrete, Cured in Air.

\begin{tabular}{|c|c|c|c|c|c|c|c|c|}
\hline \multirow{2}{*}{$\begin{array}{c}\text { Curing } \\
\text { Time } \\
\text { (day) }\end{array}$} & \multicolumn{2}{|c|}{ Weight (lb) } & \multicolumn{2}{c|}{$\begin{array}{c}\text { Transverse } \\
\text { Frequency }(\mathrm{kHz})\end{array}$} & \multicolumn{2}{c|}{$\begin{array}{c}\text { Longitudinal } \\
\text { Frequency }(\mathrm{kHz})\end{array}$} & $\begin{array}{c}\text { Torsional Frequency } \\
(\mathrm{kHz})\end{array}$ \\
\cline { 2 - 9 } & $\begin{array}{c}\text { Specimen } \\
3\end{array}$ & $\begin{array}{c}\text { Specimen } \\
4\end{array}$ & $\begin{array}{c}\text { Specimen } \\
3\end{array}$ & $\begin{array}{c}\text { Specimen } \\
4\end{array}$ & $\begin{array}{c}\text { Specimen } \\
3\end{array}$ & $\begin{array}{c}\text { Specimen } \\
4\end{array}$ & $\begin{array}{c}\text { Specimen } \\
3\end{array}$ & $\begin{array}{c}\text { Specimen } \\
4\end{array}$ \\
\hline 1 & 8.446 & 8.471 & 4.840 & 4.690 & 6.750 & 6.860 & 2.690 & 2.560 \\
\hline 2 & 8.438 & 8.461 & 5.120 & 5.000 & 7.460 & 7.360 & 3.120 & 2.990 \\
\hline 3 & 8.436 & 8.458 & 5.230 & 5.150 & 7.510 & 7.440 & 2.970 & 2.850 \\
\hline 4 & 8.434 & 8.456 & 5.310 & 5.220 & 7.600 & 7.580 & 2.960 & 2.930 \\
\hline 5 & 8.431 & 8.453 & 5.300 & 5.220 & 7.920 & 7.290 & 3.060 & 2.870 \\
\hline 6 & 8.430 & 8.452 & 5.330 & 5.210 & 7.910 & 7.710 & 3.030 & 2.920 \\
\hline 7 & 8.429 & 8.451 & 5.380 & 5.240 & 7.870 & 7.600 & 3.030 & 3.000 \\
\hline 8 & 8.428 & 8.450 & 5.380 & 5.240 & 7.910 & 7.730 & 3.340 & 3.100 \\
\hline 17 & 8.420 & 8.441 & 5.430 & 5.340 & 7.800 & 7.760 & 3.100 & 3.050 \\
\hline 24 & 8.417 & 8.438 & 5.458 & 5.351 & 7.923 & 7.725 & 3.116 & 3.121 \\
\hline 31 & 8.419 & 8.440 & 5.482 & 5.391 & 7.828 & 7.858 & 3.126 & 3.075 \\
\hline 51 & 8.410 & 8.431 & 5.503 & 5.386 & 7.870 & 7.540 & 3.108 & 3.120 \\
\hline
\end{tabular}


APPENDIX C

LENGTH CHANGE OF CONCRETE SAMPLES 
Table C Length Change of Concrete Samples

\begin{tabular}{|c|c|c|c|c|c|c|c|c|}
\hline \multicolumn{9}{|c|}{ Concrete Specimens Cured in Moist Room. } \\
\hline $\begin{array}{l}\text { Concrete } \\
\text { Sample }\end{array}$ & $\begin{array}{l}\text { Testing } \\
\text { Time } \\
\text { (M.D) }\end{array}$ & $\begin{array}{c}\text { Initial } \\
\text { Length of } \\
\text { Reference } \\
\text { Bar }\end{array}$ & $\begin{array}{c}\text { Initial } \\
\text { Length of } \\
\text { Concrete } \\
\text { Samples }\end{array}$ & $\begin{array}{l}\text { Initial } \\
\text { CRD }\end{array}$ & $\begin{array}{c}\text { Reading of } \\
\text { Reference Bar }\end{array}$ & $\begin{array}{c}\text { Reading } \\
\text { of } \\
\text { Concrete } \\
\text { Sample }\end{array}$ & $\begin{array}{c}\text { Tested } \\
\text { CRD }\end{array}$ & $\begin{array}{c}\text { Length } \\
\text { Change in } \\
\%\end{array}$ \\
\hline No.2 A & 6.18 & 0.0917 & 0.1686 & 0.0769 & 0.0866 & 0.1636 & 0.077 & 0.0009 \\
\hline No.2 B & 6.18 & 0.0917 & 0.0922 & 0.0005 & 0.0866 & 0.0869 & 0.0003 & -0.0018 \\
\hline No.3 A & 6.18 & 0.0917 & 0.0829 & -0.0088 & 0.0866 & 0.0782 & -0.0084 & 0.0036 \\
\hline No.3 B & 6.18 & 0.0917 & 0.0774 & -0.0143 & 0.0866 & 0.0727 & -0.0139 & 0.0036 \\
\hline No.2 A & 6.19 & 0.0917 & 0.1686 & 0.0769 & 0.0846 & 0.1609 & 0.0763 & -0.0055 \\
\hline No.2 B & 6.19 & 0.0917 & 0.0922 & 0.0005 & 0.0846 & 0.0842 & -0.0004 & -0.0082 \\
\hline No.3 A & 6.19 & 0.0917 & 0.0829 & -0.0088 & 0.0846 & 0.0761 & -0.0085 & 0.0027 \\
\hline No.3 B & 6.19 & 0.0917 & 0.0774 & -0.0143 & 0.0846 & 0.0704 & -0.0142 & 0.0009 \\
\hline No.2 A & 6.20 & 0.0917 & 0.1686 & 0.0769 & 0.0857 & 0.1624 & 0.0767 & -0.0018 \\
\hline No.2 B & 6.20 & 0.0917 & 0.0922 & 0.0005 & 0.0857 & 0.0857 & 0 & -0.0046 \\
\hline No.3 A & 6.20 & 0.0917 & 0.0829 & -0.0088 & 0.0857 & 0.0772 & -0.0085 & 0.0027 \\
\hline No.3 B & 6.20 & 0.0917 & 0.0774 & -0.0143 & 0.0857 & 0.0715 & -0.0142 & 0.0010 \\
\hline No.2 A & 6.21 & 0.0917 & 0.1686 & 0.0769 & 0.0863 & 0.1628 & 0.0765 & -0.0036 \\
\hline No.2 B & 6.21 & 0.0917 & 0.0922 & 0.0005 & 0.0863 & 0.0861 & -0.0002 & -0.0064 \\
\hline No.3 A & 6.21 & 0.0917 & 0.0829 & -0.0088 & 0.0863 & 0.0775 & -0.0088 & 0 \\
\hline No.3 B & 6.21 & 0.0917 & 0.0774 & -0.0143 & 0.0863 & 0.0718 & -0.0145 & -0.0018 \\
\hline No.2 A & 6.22 & 0.0917 & 0.1686 & 0.0769 & 0.0843 & 0.161 & 0.0767 & -0.0018 \\
\hline No.2 B & 6.22 & 0.0917 & 0.0922 & 0.0005 & 0.0843 & 0.0843 & 0 & -0.0046 \\
\hline No.3 A & 6.22 & 0.0917 & 0.0829 & -0.0088 & 0.0843 & 0.0756 & -0.0087 & 0.0009 \\
\hline No.3 B & 6.22 & 0.0917 & 0.0774 & -0.0143 & 0.0843 & 0.07 & -0.0143 & $\overline{0}$ \\
\hline No.2 A & 6.23 & 0.0917 & 0.1686 & 0.0769 & 0.0864 & 0.1629 & 0.0765 & -0.0036 \\
\hline No.2 B & 6.23 & 0.0917 & 0.0922 & 0.0005 & 0.0864 & 0.0863 & -0.0001 & -0.0055 \\
\hline No.3 A & 6.23 & 0.0917 & 0.0829 & -0.0088 & 0.0864 & 0.0776 & -0.0088 & U \\
\hline No.3 B & 6.23 & 0.0917 & 0.0774 & -0.0143 & 0.0864 & 0.072 & -0.0144 & -0.0009 \\
\hline No.2 A & 6.24 & 0.0917 & 0.1686 & 0.0769 & 0.0865 & 0.1626 & 0.0761 & -0.0073 \\
\hline No.2 B & 6.24 & 0.0917 & 0.0922 & 0.0005 & 0.0865 & 0.0864 & $-1 \mathrm{E}-04$ & -0.0055 \\
\hline No.3 A & 6.24 & 0.0917 & 0.0829 & -0.0088 & 0.0865 & 0.0776 & -0.0089 & -0.0009 \\
\hline No.3 B & 6.24 & 0.0917 & 0.0774 & -0.0143 & 0.0865 & 0.0721 & -0.0144 & -0.0009 \\
\hline No.2 A & 6.25 & 0.0917 & 0.1686 & 0.0769 & 0.086 & 0.1626 & 0.0766 & -0.0027 \\
\hline No.2 B & 6.25 & 0.0917 & 0.0922 & 0.0005 & 0.086 & 0.086 & 0 & -0.0045 \\
\hline
\end{tabular}

Note: A, B, C, and D are different specimens from the same concrete mix. 
Table C Length Change of Concrete Samples (Continued)

\begin{tabular}{|c|c|c|c|c|c|c|c|c|}
\hline \multicolumn{9}{|c|}{ Concrete Specimens Cured in Moist Room. } \\
\hline $\begin{array}{l}\text { Concrete } \\
\text { Sample }\end{array}$ & $\begin{array}{c}\text { Testing } \\
\text { Time } \\
\text { (M.D) }\end{array}$ & $\begin{array}{c}\text { Initial } \\
\text { Length of } \\
\text { Reference } \\
\text { Bar }\end{array}$ & $\begin{array}{c}\text { Initial } \\
\text { Length of } \\
\text { Concrete } \\
\text { Samples }\end{array}$ & $\begin{array}{l}\text { Initial } \\
\text { CRD }\end{array}$ & $\begin{array}{c}\text { Reading of } \\
\text { Reference Bar }\end{array}$ & $\begin{array}{c}\text { Reading } \\
\text { of } \\
\text { Concrete } \\
\text { Sample }\end{array}$ & $\begin{array}{l}\text { Tested } \\
\text { CRD }\end{array}$ & $\begin{array}{c}\text { Length } \\
\text { Change in } \\
\%\end{array}$ \\
\hline No.2 A & 6.26 & 0.0917 & 0.1686 & 0.0769 & 0.087 & 0.1633 & 0.0763 & -0.0055 \\
\hline No.2 B & 6.26 & 0.0917 & 0.0922 & 0.0005 & 0.087 & 0.0868 & -0.0002 & -0.0064 \\
\hline No.3 A & 6.26 & 0.0917 & 0.0829 & -0.0088 & 0.087 & 0.0783 & -0.0087 & 0.0009 \\
\hline No.3 B & 6.26 & 0.0917 & 0.0774 & -0.0143 & 0.087 & 0.0726 & -0.0144 & -0.0009 \\
\hline No.2 A & 6.27 & 0.0917 & 0.1686 & 0.0769 & 0.087 & 0.1634 & 0.0764 & -0.0045 \\
\hline No.2 B & 6.27 & 0.0917 & 0.0922 & 0.0005 & 0.087 & 0.0869 & $-1 E-04$ & -0.0055 \\
\hline No.3 A & 6.27 & 0.0917 & 0.0829 & -0.0088 & 0.087 & 0.0782 & -0.0088 & 0.0000 \\
\hline No.3 B & 6.27 & 0.0917 & 0.0774 & -0.0143 & 0.087 & 0.0727 & -0.0143 & 0.0000 \\
\hline No.2 A & 6.28 & 0.0917 & 0.1686 & 0.0769 & 0.0873 & 0.1636 & 0.0763 & -0.0055 \\
\hline No.2 B & 6.28 & 0.0917 & 0.0922 & 0.0005 & 0.0873 & 0.0871 & -0.0002 & -0.0064 \\
\hline No.3 A & 6.28 & 0.0917 & 0.0829 & -0.0088 & 0.0873 & 0.0785 & -0.0088 & 0.0000 \\
\hline No.3 B & 6.28 & 0.0917 & 0.0774 & -0.0143 & 0.0873 & 0.0729 & -0.0144 & -0.0009 \\
\hline No.2 A & 6.29 & 0.0917 & 0.1686 & 0.0769 & 0.087 & 0.1632 & 0.0762 & -0.0064 \\
\hline No.2 B & 6.29 & 0.0917 & 0.0922 & 0.0005 & 0.087 & 0.0867 & -0.0003 & -0.0073 \\
\hline No.3 A & 6.29 & 0.0917 & 0.0829 & -0.0088 & 0.087 & 0.078 & -0.009 & -0.0018 \\
\hline No.3 B & 6.29 & 0.0917 & 0.0774 & -0.0143 & 0.087 & 0.0724 & -0.0146 & -0.0027 \\
\hline No.2 A & 6.30 & 0.0917 & 0.1686 & 0.0769 & 0.0867 & 0.163 & 0.0763 & -0.0055 \\
\hline No.2 B & 6.30 & 0.0917 & 0.0922 & 0.0005 & 0.0867 & 0.0864 & -0.0003 & -0.0073 \\
\hline No.3 A & 6.30 & 0.0917 & 0.0829 & -0.0088 & 0.0867 & 0.0778 & -0.0089 & -0.0009 \\
\hline No.3 B & 6.30 & 0.0917 & 0.0774 & -0.0143 & 0.0867 & 0.0722 & -0.0145 & -0.0018 \\
\hline No.2 A & 7.01 & 0.0917 & 0.1686 & 0.0769 & 0.0873 & 0.1636 & 0.0763 & -0.0055 \\
\hline No.2 B & 7.01 & 0.0917 & 0.0922 & 0.0005 & 0.0873 & 0.0871 & -0.0002 & -0.0064 \\
\hline No.3 A & 7.01 & 0.0917 & 0.0829 & -0.0088 & 0.0873 & 0.0785 & -0.0088 & 0.0000 \\
\hline No.3 B & 7.01 & 0.0917 & 0.0774 & -0.0143 & 0.0873 & 0.0729 & -0.0144 & -0.0009 \\
\hline No.2 A & 7.02 & 0.0917 & 0.1686 & 0.0769 & 0.0868 & 0.1631 & 0.0763 & -0.0055 \\
\hline No.2 B & 7.02 & 0.0917 & 0.0922 & 0.0005 & 0.0868 & 0.0866 & -0.0002 & -0.0064 \\
\hline No.3 A & 7.02 & 0.0917 & 0.0829 & -0.0088 & 0.0868 & 0.078 & -0.0088 & 0.0000 \\
\hline No.3 B & 7.02 & 0.0917 & 0.0774 & -0.0143 & 0.0868 & 0.0723 & -0.0145 & -0.0018 \\
\hline No.2 A & 7.03 & 0.0917 & 0.1686 & 0.0769 & 0.0876 & 0.1639 & 0.0763 & -0.0055 \\
\hline No.2 B & 7.03 & 0.0917 & 0.0922 & 0.0005 & 0.0876 & 0.0873 & -0.0003 & -0.0073 \\
\hline No.3 A & 7.03 & 0.0917 & 0.0829 & -0.0088 & 0.0876 & 0.0789 & -0.0087 & 0.0009 \\
\hline No.3 B & 7.03 & 0.0917 & 0.0774 & -0.0143 & 0.0876 & 0.0732 & -0.0144 & -0.0009 \\
\hline
\end{tabular}


Table C Length Change of Concrete Samples (Continued)

\begin{tabular}{|c|c|c|c|c|c|c|c|c|}
\hline \multicolumn{9}{|c|}{ Concrete Specimens Cured in Moist Room. } \\
\hline $\begin{array}{l}\text { Concrete } \\
\text { Sample }\end{array}$ & $\begin{array}{c}\text { Testing } \\
\text { Time } \\
\text { (M.D) }\end{array}$ & $\begin{array}{c}\text { Initial } \\
\text { Length of } \\
\text { Reference } \\
\text { Bar }\end{array}$ & $\begin{array}{c}\text { Initial } \\
\text { Length of } \\
\text { Concrete } \\
\text { Samples }\end{array}$ & $\begin{array}{l}\text { Initial } \\
\text { CRD }\end{array}$ & $\begin{array}{c}\text { Reading of } \\
\text { Reference Bar }\end{array}$ & $\begin{array}{c}\text { Reading } \\
\text { of } \\
\text { Concrete } \\
\text { Sample }\end{array}$ & $\begin{array}{l}\text { Tested } \\
\text { CRD }\end{array}$ & \begin{tabular}{|c|} 
Length \\
Change in \\
$\%$
\end{tabular} \\
\hline No.2 A & 7.12 & 0.0917 & 0.1686 & 0.0769 & 0.0775 & 0.1539 & 0.0764 & -0.0045 \\
\hline No.2 B & 7.12 & 0.0917 & 0.0922 & 0.0005 & 0.0775 & 0.0773 & -0.0002 & -0.0064 \\
\hline No.3 A & 7.12 & 0.0917 & 0.0829 & -0.0088 & 0.0775 & 0.0689 & -0.0086 & 0.0018 \\
\hline No.3 B & 7.12 & 0.0917 & 0.0774 & -0.0143 & 0.0775 & 0.0633 & -0.0142 & 0.0009 \\
\hline No.4 A & 6.18 & 0.0917 & 0.0959 & 0.0042 & 0.0866 & 0.0912 & 0.0046 & 0.0036 \\
\hline No.4 B & 6.18 & 0.0917 & 0.1113 & 0.0196 & 0.0866 & 0.1065 & 0.0199 & 0.0027 \\
\hline No.5 A & 6.18 & 0.0917 & 0.1643 & 0.0726 & 0.0866 & 0.1596 & 0.073 & 0.0036 \\
\hline No.5 B & 6.18 & 0.0917 & 0.095 & 0.0033 & 0.0866 & 0.0904 & 0.0038 & 0.0045 \\
\hline No.4 A & 6.19 & 0.0917 & 0.0959 & 0.0042 & 0.0846 & 0.0885 & 0.0039 & -0.0027 \\
\hline No.4 B & 6.19 & 0.0917 & 0.1113 & 0.0196 & 0.0846 & 0.104 & 0.0194 & -0.0018 \\
\hline No.5 A & 6.19 & 0.0917 & 0.1643 & 0.0726 & 0.0846 & 0.1571 & 0.0725 & -0.0009 \\
\hline No.4 A & 6.20 & 0.0917 & 0.0959 & 0.0042 & 0.0857 & 0.0902 & 0.0045 & 0.0027 \\
\hline No.4 B & 6.20 & 0.0917 & 0.1113 & 0.0196 & 0.0857 & 0.1056 & 0.0199 & 0.0027 \\
\hline No.5 A & 6.20 & 0.0917 & 0.1643 & 0.0726 & 0.0857 & 0.1585 & 0.0728 & 0.0018 \\
\hline No.5 B & 6.20 & 0.0917 & 0.095 & 0.0033 & 0.0857 & 0.0895 & 0.0038 & 0.0045 \\
\hline No.4 A & 6.21 & 0.0917 & 0.0959 & 0.0042 & 0.0863 & 0.0905 & 0.0042 & 0.0000 \\
\hline No.4 B & 6.21 & 0.0917 & 0.1113 & 0.0196 & 0.0863 & 0.1059 & 0.0196 & 0.0000 \\
\hline No.5 A & 6.21 & 0.0917 & 0.1643 & 0.0726 & 0.0863 & 0.1591 & 0.0728 & 0.0018 \\
\hline No.5 B & 6.21 & 0.0917 & 0.095 & 0.0033 & 0.0863 & 0.0898 & 0.0035 & 0.0018 \\
\hline No.4 A & 6.22 & 0.0917 & 0.0959 & 0.0042 & 0.0843 & 0.0888 & 0.0045 & 0.0027 \\
\hline No.4 B & 6.22 & 0.0917 & 0.1113 & 0.0196 & 0.0843 & 0.1041 & 0.0198 & 0.0018 \\
\hline No.5 A & 6.22 & 0.0917 & 0.1643 & 0.0726 & 0.0843 & 0.157 & 0.0727 & 0.0009 \\
\hline No.5 B & 6.22 & 0.0917 & 0.095 & 0.0033 & 0.0843 & 0.0877 & 0.0034 & 0.0009 \\
\hline No.4 A & 6.23 & 0.0917 & 0.0959 & 0.0042 & 0.0864 & 0.0908 & 0.0044 & 0.0018 \\
\hline No.4 B & 6.23 & 0.0917 & 0.1113 & 0.0196 & 0.0864 & 0.1062 & 0.0198 & 0.0018 \\
\hline No.5 A & 6.23 & 0.0917 & 0.1643 & 0.0726 & 0.0864 & 0.1594 & 0.073 & 0.0036 \\
\hline No.5 B & 6.23 & 0.0917 & 0.095 & 0.0033 & 0.0864 & 0.0901 & 0.0037 & 0.0036 \\
\hline No.4 A & 6.24 & 0.0917 & 0.0959 & 0.0042 & 0.0865 & 0.0909 & 0.0044 & 0.0018 \\
\hline No.4 B & 6.24 & 0.0917 & 0.1113 & 0.0196 & 0.0865 & 0.1063 & 0.0198 & 0.0018 \\
\hline No.5 A & 6.24 & 0.0917 & 0.1643 & 0.0726 & 0.0865 & 0.1594 & 0.0729 & 0.0027 \\
\hline No.5 B & 6.24 & 0.0917 & 0.095 & 0.0033 & 0.0865 & 0.0901 & 0.0036 & 0.0027 \\
\hline No.4 A & 6.25 & 0.0917 & 0.0959 & 0.0042 & 0.086 & 0.0905 & 0.0045 & 0.0027 \\
\hline
\end{tabular}


Table C Length Change of Concrete Samples (Continued)

\begin{tabular}{|c|c|c|c|c|c|c|c|c|}
\hline \multicolumn{9}{|c|}{ Concrete Specimens Cured in Moist Room. } \\
\hline $\begin{array}{l}\text { Concrete } \\
\text { Sample }\end{array}$ & $\begin{array}{c}\text { Testing } \\
\text { Time } \\
\text { (M.D) }\end{array}$ & $\begin{array}{c}\text { Initial } \\
\text { Length of } \\
\text { Reference } \\
\text { Bar }\end{array}$ & $\begin{array}{c}\text { Initial } \\
\text { Length of } \\
\text { Concrete } \\
\text { Samples }\end{array}$ & $\begin{array}{l}\text { Initial } \\
\text { CRD }\end{array}$ & $\begin{array}{c}\text { Reading of } \\
\text { Reference Bar }\end{array}$ & $\begin{array}{c}\text { Reading } \\
\text { of } \\
\text { Concrete } \\
\text { Sample }\end{array}$ & $\begin{array}{l}\text { Tested } \\
\text { CRD }\end{array}$ & \begin{tabular}{|c|} 
Length \\
Change in \\
$\%$
\end{tabular} \\
\hline No.4 B & 6.25 & 0.0917 & 0.1113 & 0.0196 & 0.086 & 0.1059 & 0.0199 & 0.0027 \\
\hline No.5 A & 6.25 & 0.0917 & 0.1643 & 0.0726 & 0.086 & 0.1589 & 0.0729 & 0.0027 \\
\hline No.5 B & 6.25 & 0.0917 & 0.095 & 0.0033 & 0.086 & 0.0897 & 0.0037 & 0.0036 \\
\hline No.4 A & 6.26 & 0.0917 & 0.0959 & 0.0042 & 0.087 & 0.0914 & 0.0044 & 0.0018 \\
\hline No.4 B & 6.26 & 0.0917 & 0.1113 & 0.0196 & 0.087 & 0.1067 & 0.0197 & 0.0009 \\
\hline No.5 A & 6.26 & 0.0917 & 0.1643 & 0.0726 & 0.087 & 0.1599 & 0.0729 & 0.0027 \\
\hline No.5 B & 6.26 & 0.0917 & 0.095 & 0.0033 & 0.087 & 0.0906 & 0.0036 & 0.0027 \\
\hline No.4 A & 6.27 & 0.0917 & 0.0959 & 0.0042 & 0.087 & 0.0914 & 0.0044 & 0.0018 \\
\hline No.4 B & 6.27 & 0.0917 & 0.1113 & 0.0196 & 0.087 & 0.1065 & 0.0195 & -0.0009 \\
\hline No.5 A & 6.27 & 0.0917 & 0.1643 & 0.0726 & 0.087 & 0.1598 & 0.0728 & 0.0018 \\
\hline No.5 B & 6.27 & 0.0917 & 0.095 & 0.0033 & 0.087 & 0.0905 & 0.0035 & 0.0018 \\
\hline No.4 A & 6.28 & 0.0917 & 0.0959 & 0.0042 & 0.0873 & 0.0917 & 0.0044 & 0.0018 \\
\hline No.4 B & 6.28 & 0.0917 & 0.1113 & 0.0196 & 0.0873 & 0.107 & 0.0197 & 0.0009 \\
\hline No.5 A & 6.28 & 0.0917 & 0.1643 & 0.0726 & 0.0873 & 0.1602 & 0.0729 & 0.0027 \\
\hline No.5 B & 6.28 & 0.0917 & 0.095 & 0.0033 & 0.0873 & 0.0909 & 0.0036 & 0.0027 \\
\hline No.4 A & 6.29 & 0.0917 & 0.0959 & 0.0042 & 0.087 & 0.0913 & 0.0043 & 0.0009 \\
\hline No.4 B & 6.29 & 0.0917 & 0.1113 & 0.0196 & 0.087 & 0.1065 & 0.0195 & -0.0009 \\
\hline No.5 A & 6.29 & 0.0917 & 0.1643 & 0.0726 & 0.087 & 0.1597 & 0.0727 & 0.0009 \\
\hline No.5 B & 6.29 & 0.0917 & 0.095 & 0.0033 & 0.087 & 0.0905 & 0.0035 & 0.0018 \\
\hline No.4 A & 6.30 & 0.0917 & 0.0959 & 0.0042 & 0.0867 & 0.0912 & 0.0045 & 0.0027 \\
\hline No.4 B & 6.30 & 0.0917 & 0.1113 & 0.0196 & 0.0867 & 0.1064 & 0.0197 & 0.0009 \\
\hline No.5 A & 6.30 & 0.0917 & 0.1643 & 0.0726 & 0.0867 & 0.1595 & 0.0728 & 0.0018 \\
\hline No.5 B & 6.30 & 0.0917 & 0.095 & 0.0033 & 0.0867 & 0.0903 & 0.0036 & 0.0027 \\
\hline No.4 A & 7.01 & 0.0917 & 0.0959 & 0.0042 & 0.0873 & 0.0918 & 0.0045 & 0.0027 \\
\hline No.4 B & 7.01 & 0.0917 & 0.1113 & 0.0196 & 0.0873 & 0.1071 & 0.0198 & 0.0018 \\
\hline No.5 A & 7.01 & 0.0917 & 0.1643 & 0.0726 & 0.0873 & 0.1601 & 0.0728 & 0.0018 \\
\hline No.5 B & 7.01 & 0.0917 & 0.095 & 0.0033 & 0.0873 & 0.091 & 0.0037 & 0.0036 \\
\hline No.4 A & 7.02 & 0.0917 & 0.0959 & 0.0042 & 0.0868 & 0.0914 & 0.0046 & 0.0036 \\
\hline No.4 B & 7.02 & 0.0917 & 0.1113 & 0.0196 & 0.0868 & 0.1066 & 0.0198 & 0.0018 \\
\hline No.5 A & 7.02 & 0.0917 & 0.1643 & 0.0726 & 0.0868 & 0.1597 & 0.0729 & 0.0027 \\
\hline No.5 B & 7.02 & 0.0917 & 0.095 & 0.0033 & 0.0868 & 0.0906 & 0.0038 & 0.0045 \\
\hline No.4 A & 7.03 & 0.0917 & 0.0959 & 0.0042 & 0.0876 & 0.0922 & 0.0046 & 0.0036 \\
\hline No.4 B & 7.03 & 0.0917 & 0.1113 & 0.0196 & 0.0876 & 0.1074 & 0.0198 & 0.0018 \\
\hline
\end{tabular}


Table C Length Change of Concrete Samples (Continued)

\begin{tabular}{|c|c|c|c|c|c|c|c|c|}
\hline \multicolumn{9}{|c|}{ Concrete Specimens Cured in Moist Room. } \\
\hline $\begin{array}{l}\text { Concrete } \\
\text { Sample }\end{array}$ & $\begin{array}{c}\text { Testing } \\
\text { Time } \\
\text { (M.D) }\end{array}$ & $\begin{array}{c}\text { Initial } \\
\text { Length of } \\
\text { Reference } \\
\text { Bar }\end{array}$ & $\begin{array}{c}\text { Initial } \\
\text { Length of } \\
\text { Concrete } \\
\text { Samples }\end{array}$ & $\begin{array}{l}\text { Initial } \\
\text { CRD }\end{array}$ & $\begin{array}{c}\text { Reading of } \\
\text { Reference Bar }\end{array}$ & $\begin{array}{c}\text { Reading } \\
\text { of } \\
\text { Concrete } \\
\text { Sample }\end{array}$ & $\begin{array}{l}\text { Tested } \\
\text { CRD }\end{array}$ & \begin{tabular}{|c|} 
Length \\
Change in \\
$\%$
\end{tabular} \\
\hline No.5 A & 7.03 & 0.0917 & 0.1643 & 0.0726 & 0.0876 & 0.1605 & 0.0729 & 0.0027 \\
\hline No.5 B & 7.03 & 0.0917 & 0.095 & 0.0033 & 0.0876 & 0.0912 & 0.0036 & 0.0027 \\
\hline No.4 A & 7.04 & 0.0917 & 0.0959 & 0.0042 & 0.0775 & 0.0824 & 0.0049 & 0.0064 \\
\hline No.4 B & 7.04 & 0.0917 & 0.1113 & 0.0196 & 0.0775 & 0.0976 & 0.0201 & 0.0045 \\
\hline No.5 A & 7.04 & 0.0917 & 0.1643 & 0.0726 & 0.0775 & 0.1505 & 0.073 & 0.0036 \\
\hline No.5 B & 7.04 & 0.0917 & 0.095 & 0.0033 & 0.0775 & 0.0814 & 0.0039 & 0.0055 \\
\hline No.6 A & 6.19 & 0.0866 & 0.1017 & 0.0151 & 0.0846 & 0.0993 & 0.0147 & -0.0036 \\
\hline No.6 B & 6.19 & 0.0866 & 0.1662 & 0.0796 & 0.0846 & 0.1634 & 0.0788 & -0.0073 \\
\hline No.7 A & 6.19 & 0.0866 & 0.0758 & -0.0108 & 0.0846 & 0.0731 & -0.0115 & -0.0064 \\
\hline No.7 B & 6.19 & 0.0866 & 0.1072 & 0.0206 & 0.0846 & 0.1046 & 0.02 & -0.0055 \\
\hline No.6 A & 6.20 & 0.0866 & 0.1017 & 0.0151 & 0.0857 & 0.1009 & 0.0152 & 0.0009 \\
\hline No.6 B & 6.20 & 0.0866 & 0.1662 & 0.0796 & 0.0857 & 0.165 & 0.0793 & -0.0027 \\
\hline No.7 A & 6.20 & 0.0866 & 0.0758 & -0.0108 & 0.0857 & 0.0745 & -0.0112 & \begin{tabular}{|c|}
-0.0036 \\
\end{tabular} \\
\hline No.7 B & 6.20 & 0.0866 & 0.1072 & 0.0206 & 0.0857 & 0.1061 & 0.0204 & -0.0018 \\
\hline No.6 A & 6.21 & 0.0866 & 0.1017 & 0.0151 & 0.0863 & 0.1012 & 0.0149 & -0.0018 \\
\hline No.6 B & 6.21 & 0.0866 & 0.1662 & 0.0796 & 0.0863 & 0.1653 & 0.079 & -0.0055 \\
\hline No.7 A & 6.21 & 0.0866 & 0.0758 & -0.0108 & 0.0863 & 0.0749 & -0.0114 & -0.0055 \\
\hline No.7 B & 6.21 & 0.0866 & 0.1072 & 0.0206 & 0.0863 & 0.1065 & 0.0202 & -0.0036 \\
\hline No.6 A & 6.22 & 0.0866 & 0.1017 & 0.0151 & 0.0843 & 0.0993 & 0.015 & -0.0009 \\
\hline No.6 B & 6.22 & 0.0866 & 0.1662 & 0.0796 & 0.0843 & 0.1633 & 0.079 & -0.0055 \\
\hline No.7 A & 6.22 & 0.0866 & 0.0758 & -0.0108 & 0.0843 & 0.0729 & -0.0114 & -0.0055 \\
\hline No.7 B & 6.22 & 0.0866 & 0.1072 & 0.0206 & 0.0 & 0.1044 & 0.0201 & -0.0045 \\
\hline No.6 A & 6.23 & 0.0866 & 0.1017 & 0.0151 & 0.0864 & 0.1015 & 0.0151 & 0.0000 \\
\hline No.6 B & 6.23 & 0.0866 & 0.1662 & 0.0796 & 0.0864 & 0.1656 & 0.0792 & -0.0036 \\
\hline No.7 A & 6.23 & 0.0866 & 0.0758 & -0.0108 & 0.0864 & 0.0752 & -0.0112 & -0.0036 \\
\hline No.7 B & 6.23 & 0.0866 & 0.1072 & 0.0206 & 0.0864 & 0.1067 & 0.0203 & \begin{tabular}{|c|}
-0.0027 \\
\end{tabular} \\
\hline No.6 A & 6.24 & 0.0866 & 0.1017 & 0.0151 & 0.0865 & 0.1016 & 0.0151 & 0.0000 \\
\hline No.6 B & 6.24 & 0.0866 & 0.1662 & 0.0796 & 0.0865 & 0.1657 & 0.0792 & -0.0036 \\
\hline No.7 A & 6.24 & 0.0866 & 0.0758 & -0.0108 & 0.0865 & 0.0752 & -0.0113 & -0.0045 \\
\hline No.7 B & 6.24 & 0.0866 & 0.1072 & 0.0206 & 0.0865 & 0.1068 & 0.0203 & -0.0027 \\
\hline No.6 A & 6.25 & 0.0866 & 0.1017 & 0.0151 & 0.086 & 0.1012 & 0.0152 & 0.0009 \\
\hline No.6 B & 6.25 & 0.0866 & 0.1662 & 0.0796 & 0.086 & 0.1652 & 0.0792 & -0.0036 \\
\hline No.7 A & 6.25 & 0.0866 & 0.0758 & -0.0108 & 0.086 & 0.0748 & -0.0112 & -0.0036 \\
\hline
\end{tabular}


Table C Length Change of Concrete Samples (Continued)

\begin{tabular}{|c|c|c|c|c|c|c|c|c|}
\hline \multicolumn{9}{|c|}{ Concrete Specimens Cured in Moist Room. } \\
\hline $\begin{array}{l}\text { Concrete } \\
\text { Sample }\end{array}$ & $\begin{array}{c}\text { Testing } \\
\text { Time } \\
\text { (M.D) }\end{array}$ & $\begin{array}{c}\text { Initial } \\
\text { Length of } \\
\text { Reference } \\
\text { Bar }\end{array}$ & $\begin{array}{c}\text { Initial } \\
\text { Length of } \\
\text { Concrete } \\
\text { Samples }\end{array}$ & $\begin{array}{l}\text { Initial } \\
\text { CRD }\end{array}$ & $\begin{array}{c}\text { Reading of } \\
\text { Reference Bar }\end{array}$ & $\begin{array}{c}\text { Reading } \\
\text { of } \\
\text { Concrete } \\
\text { Sample }\end{array}$ & $\begin{array}{c}\text { Tested } \\
\text { CRD }\end{array}$ & $\begin{array}{c}\text { Length } \\
\text { Change in } \\
\%\end{array}$ \\
\hline No.7 B & 6.25 & 0.0866 & 0.1072 & 0.0206 & 0.086 & 0.1063 & 0.0203 & -0.0027 \\
\hline No.6 A & 6.26 & 0.0866 & 0.1017 & 0.0151 & 0.087 & 0.1021 & 0.0151 & 0.0000 \\
\hline No.6 B & 6.26 & 0.0866 & 0.1662 & 0.0796 & 0.087 & 0.1662 & 0.0792 & -0.0036 \\
\hline No.7 A & 6.26 & 0.0866 & 0.0758 & -0.0108 & 0.087 & 0.0757 & -0.0113 & -0.0045 \\
\hline No.7 B & 6.26 & 0.0866 & 0.1072 & 0.0206 & 0.087 & 0.1073 & 0.0203 & -0.0027 \\
\hline No.6 A & 6.27 & 0.0866 & 0.1017 & 0.0151 & 0.087 & 0.1021 & 0.0151 & 0.0000 \\
\hline No.6 B & 6.27 & 0.0866 & 0.1662 & 0.0796 & 0.087 & 0.1661 & 0.0791 & -0.0045 \\
\hline No.7 A & 6.27 & 0.0866 & 0.0758 & -0.0108 & 0.087 & 0.0758 & -0.0112 & -0.0036 \\
\hline No.7 B & 6.27 & 0.0866 & 0.1072 & 0.0206 & 0.087 & 0.1073 & 0.0203 & -0.0027 \\
\hline No.6 A & 6.28 & 0.0866 & 0.1017 & 0.0151 & 0.0873 & 0.1024 & 0.0151 & 0.0000 \\
\hline No.6 B & 6.28 & 0.0866 & 0.1662 & 0.0796 & 0.0873 & 0.1665 & 0.0792 & -0.0036 \\
\hline No.7 A & 6.28 & 0.0866 & 0.0758 & -0.0108 & 0.0873 & 0.076 & -0.0113 & -0.0045 \\
\hline No.7 B & 6.28 & 0.0866 & 0.1072 & 0.0206 & 0.0873 & 0.1076 & 0.0203 & -0.0027 \\
\hline No.6 A & 6.29 & 0.0866 & 0.1017 & 0.0151 & 0.087 & 0.1019 & 0.0149 & -0.0018 \\
\hline No.6 B & 6.29 & 0.0866 & 0.1662 & 0.0796 & 0.087 & 0.166 & 0.079 & -0.0055 \\
\hline No.7 A & 6.29 & 0.0866 & 0.0758 & -0.0108 & 0.087 & 0.0756 & -0.0114 & -0.0055 \\
\hline No.7 B & 6.29 & 0.0866 & 0.1072 & 0.0206 & 0.087 & 0.107 & 0.02 & -0.0055 \\
\hline No.6 A & 6.30 & 0.0866 & 0.1017 & 0.0151 & 0.0867 & 0.1017 & 0.015 & -0.0009 \\
\hline No.6 B & 6.30 & 0.0866 & 0.1662 & 0.0796 & 0.0867 & 0.1658 & 0.0791 & -0.0045 \\
\hline No.7 A & 6.30 & 0.0866 & 0.0758 & -0.0108 & 0.0867 & 0.0754 & -0.0113 & -0.0045 \\
\hline No.7 B & 6.30 & 0.0866 & 0.1072 & 0.0206 & 0.0867 & 0.107 & 0.0203 & -0.0027 \\
\hline No.6 A & 7.01 & 0.0866 & 0.1017 & 0.0151 & 0.0873 & 0.1022 & 0.0149 & -0.0018 \\
\hline No.6 B & 7.01 & 0.0866 & 0.1662 & 0.0796 & 0.0873 & 0.1665 & 0.0792 & -0.0036 \\
\hline No.7 A & 7.01 & 0.0866 & 0.0758 & -0.0108 & 0.0873 & 0.0761 & -0.0112 & -0.0036 \\
\hline No.7 B & 7.01 & 0.0866 & 0.1072 & 0.0206 & 0.0873 & 0.1076 & 0.0203 & -0.0027 \\
\hline No.6 A & 7.02 & 0.0866 & 0.1017 & 0.0151 & 0.0868 & 0.1019 & 0.0151 & 0.0000 \\
\hline No.6 B & 7.02 & 0.0866 & 0.1662 & 0.0796 & 0.0868 & 0.1661 & 0.0793 & -0.0027 \\
\hline No.7 A & 7.02 & 0.0866 & 0.0758 & -0.0108 & 0.0868 & 0.0756 & -0.0112 & -0.0036 \\
\hline No.7 B & 7.02 & 0.0866 & 0.1072 & 0.0206 & 0.0868 & 0.1072 & 0.0204 & -0.0018 \\
\hline No.6 A & 7.03 & 0.0866 & 0.1017 & 0.0151 & 0.0876 & 0.1027 & 0.0151 & 0.0000 \\
\hline No.6 B & 7.03 & 0.0866 & 0.1662 & 0.0796 & 0.0876 & 0.1668 & 0.0792 & -0.0036 \\
\hline No.7 A & 7.03 & 0.0866 & 0.0758 & -0.0108 & 0.0876 & 0.0764 & -0.0112 & -0.0036 \\
\hline No.7 B & 7.03 & 0.0866 & 0.1072 & 0.0206 & 0.0876 & 0.1078 & 0.0202 & -0.0036 \\
\hline
\end{tabular}


Table C Length Change of Concrete Samples (Continued)

\begin{tabular}{|c|c|c|c|c|c|c|c|c|}
\hline \multicolumn{9}{|c|}{ Concrete Specimens Cured in Moist Room. } \\
\hline $\begin{array}{l}\text { Concrete } \\
\text { Sample }\end{array}$ & $\begin{array}{l}\text { Testing } \\
\text { Time } \\
\text { (M.D) }\end{array}$ & \begin{tabular}{|c|} 
Initial \\
Length of \\
Reference \\
Bar
\end{tabular} & $\begin{array}{c}\text { Initial } \\
\text { Length of } \\
\text { Concrete } \\
\text { Samples }\end{array}$ & $\begin{array}{l}\text { Initial } \\
\text { CRD }\end{array}$ & $\begin{array}{c}\text { Reading of } \\
\text { Reference Bar }\end{array}$ & $\begin{array}{c}\text { Reading } \\
\text { of } \\
\text { Concrete } \\
\text { Sample }\end{array}$ & $\begin{array}{c}\text { Tested } \\
\text { CRD }\end{array}$ & $\begin{array}{c}\text { Length } \\
\text { Change in } \\
\%\end{array}$ \\
\hline No.6 A & 7.12 & 0.0866 & 0.1017 & 0.0151 & 0.0775 & 0.093 & 0.0155 & 0.0036 \\
\hline No.6 B & 7.12 & 0.0866 & 0.1662 & 0.0796 & 0.0775 & 0.1567 & 0.0792 & -0.0036 \\
\hline No.7 A & 7.12 & 0.0866 & 0.0758 & -0.0108 & 0.0775 & 0.0665 & -0.011 & -0.0018 \\
\hline No.7 B & 7.12 & 0.0866 & 0.1072 & 0.0206 & 0.0775 & 0.0985 & 0.021 & 0.0036 \\
\hline No.8 A & 6.20 & 0.0846 & 0.1181 & 0.0335 & 0.0857 & 0.1203 & 0.0346 & 0.0100 \\
\hline No.8 B & 6.20 & 0.0846 & 0.0727 & -0.0119 & 0.0857 & 0.0748 & -0.0109 & 0.0091 \\
\hline No.8 C & 6.20 & 0.0846 & 0.0726 & -0.012 & 0.0857 & 0.0746 & -0.0111 & 0.0082 \\
\hline No.8 D & 6.20 & 0.0846 & 0.0826 & -0.002 & 0.0857 & 0.0848 & -0.0009 & 0.0100 \\
\hline No.8 A & 6.21 & 0.0846 & 0.1181 & 0.0335 & 0.0863 & 0.1208 & 0.0345 & 0.0091 \\
\hline No.8 B & 6.21 & 0.0846 & 0.0727 & -0.0119 & 0.0863 & 0.0753 & -0.011 & 0.0082 \\
\hline No.8 C & 6.21 & 0.0846 & 0.0726 & -0.012 & 0.0863 & 0.0752 & -0.0111 & 0.0082 \\
\hline No.8 D & 6.21 & 0.0846 & 0.0826 & -0.002 & 0.0863 & 0.0853 & -0.001 & 0.0091 \\
\hline No.8 A & 6.22 & 0.0846 & 0.1181 & 0.0335 & 0.0843 & 0.1188 & 0.0345 & 0.0091 \\
\hline No.8 B & 6.22 & 0.0846 & 0.0727 & -0.0119 & 0.0843 & 0.0736 & -0.0107 & 0.0109 \\
\hline No.8 C & 6.22 & 0.0846 & 0.0726 & -0.012 & 0.0843 & 0.0736 & -0.0107 & 0.0118 \\
\hline No.8 D & 6.22 & 0.0846 & 0.0826 & -0.002 & 0.0843 & 0.0837 & -0.0006 & 0.0127 \\
\hline No.8 A & 6.23 & 0.0846 & 0.1181 & 0.0335 & 0.0864 & 0.1212 & 0.0348 & 0.0118 \\
\hline No.8 B & 6.23 & 0.0846 & 0.0727 & -0.0119 & 0.0864 & 0.0761 & -0.0103 & 0.0145 \\
\hline No.8 C & 6.23 & 0.0846 & 0.0726 & -0.012 & 0.0864 & 0.0759 & -0.0105 & 0.0136 \\
\hline No.8 D & 6.23 & 0.0846 & 0.0826 & -0.002 & 0.0864 & 0.0861 & -0.0003 & 0.0155 \\
\hline No.8 A & 6.24 & 0.0846 & 0.1181 & 0.0335 & 0.0865 & 0.1214 & 0.0349 & 0.0127 \\
\hline No.8 B & 6.24 & 0.0846 & 0.0727 & -0.0119 & 0.0865 & 0.0763 & -0.0102 & 0.0155 \\
\hline No.8 C & 6.24 & 0.0846 & 0.0726 & -0.012 & 0.0865 & 0.076 & -0.0105 & 0.0136 \\
\hline No.8 D & 6.24 & 0.0846 & 0.0826 & -0.002 & 0.0865 & 0.0863 & -0.0002 & 0.0164 \\
\hline No.8 A & 6.25 & 0.0846 & 0.1181 & 0.0335 & 0.086 & 0.1211 & 0.0351 & 0.0145 \\
\hline No.8 B & 6.25 & 0.0846 & 0.0727 & -0.0119 & 0.086 & 0.0762 & -0.0098 & 0.0191 \\
\hline No.8 C & 6.25 & 0.0846 & 0.0726 & -0.012 & 0.086 & 0.0758 & -0.0102 & 0.0164 \\
\hline No.8 D & 6.25 & 0.0846 & 0.0826 & -0.002 & 0.086 & 0.086 & 0 & 0.0182 \\
\hline No.8 A & 6.26 & 0.0846 & 0.1181 & 0.0335 & 0.087 & 0.1222 & 0.0352 & 0.0155 \\
\hline No.8 B & 6.26 & 0.0846 & 0.0727 & -0.0119 & 0.087 & 0.0772 & -0.0098 & 0.0191 \\
\hline No.8 C & 6.26 & 0.0846 & 0.0726 & -0.012 & 0.087 & 0.077 & -0.01 & 0.0182 \\
\hline No.8 D & 6.26 & 0.0846 & 0.0826 & -0.002 & 0.087 & 0.0871 & 0.0001 & 0.0191 \\
\hline No.8 A & 6.27 & 0.0846 & 0.1181 & 0.0335 & 0.087 & 0.1222 & 0.0352 & 0.0155 \\
\hline
\end{tabular}


Table C Length Change of Concrete Samples (Continued)

\begin{tabular}{|c|c|c|c|c|c|c|c|c|}
\hline \multicolumn{9}{|c|}{ Concrete Specimens Cured in Moist Room. } \\
\hline $\begin{array}{l}\text { Concrete } \\
\text { Sample }\end{array}$ & $\begin{array}{c}\text { Testing } \\
\text { Time } \\
\text { (M.D) }\end{array}$ & \begin{tabular}{|c|} 
Initial \\
Length of \\
Reference \\
Bar
\end{tabular} & $\begin{array}{c}\text { Initial } \\
\text { Length of } \\
\text { Concrete } \\
\text { Samples }\end{array}$ & $\begin{array}{l}\text { Initial } \\
\text { CRD }\end{array}$ & $\begin{array}{c}\text { Reading of } \\
\text { Reference Bar }\end{array}$ & $\begin{array}{c}\text { Reading } \\
\text { of } \\
\text { Concrete } \\
\text { Sample }\end{array}$ & $\begin{array}{l}\text { Tested } \\
\text { CRD }\end{array}$ & $\begin{array}{c}\text { Length } \\
\text { Change in } \\
\%\end{array}$ \\
\hline No.8 B & 6.27 & 0.0846 & 0.0727 & -0.0119 & 0.087 & 0.0772 & -0.0098 & 0.0191 \\
\hline No.8 C & 6.27 & 0.0846 & 0.0726 & -0.012 & 0.087 & 0.0769 & -0.0101 & 0.0173 \\
\hline No.8 D & 6.27 & 0.0846 & 0.0826 & -0.002 & 0.087 & 0.0871 & 0.0001 & 0.0191 \\
\hline No.8 A & 6.28 & 0.0846 & 0.1181 & 0.0335 & 0.0873 & 0.1227 & 0.0354 & 0.0173 \\
\hline No.8 B & 6.28 & 0.0846 & 0.0727 & -0.0119 & 0.0873 & 0.0777 & -0.0096 & 0.0209 \\
\hline No.8 C & 6.28 & 0.0846 & 0.0726 & -0.012 & 0.0873 & 0.0773 & -0.01 & 0.0182 \\
\hline No.8 D & 6.28 & 0.0846 & 0.0826 & -0.002 & 0.0873 & 0.0875 & 0.0002 & 0.0200 \\
\hline No.8 A & 6.29 & 0.0846 & 0.1181 & 0.0335 & 0.087 & 0.1222 & 0.0352 & 0.0155 \\
\hline No.8 B & 6.29 & 0.0846 & 0.0727 & -0.0119 & 0.087 & 0.0774 & -0.0096 & 0.0209 \\
\hline No.8 C & 6.29 & 0.0846 & 0.0726 & -0.012 & 0.087 & 0.0769 & -0.0101 & 0.0173 \\
\hline No.8 D & 6.29 & 0.0846 & 0.0826 & -0.002 & 0.087 & 0.087 & 0 & 0.0182 \\
\hline No.8 A & 6.30 & 0.0846 & 0.1181 & 0.0335 & 0.0867 & 0.1222 & 0.0355 & 0.0182 \\
\hline No.8 B & 6.30 & 0.0846 & 0.0727 & -0.0119 & 0.0867 & 0.0772 & -0.0095 & 0.0218 \\
\hline No.8 C & 6.30 & 0.0846 & 0.0726 & -0.012 & 0.0867 & 0.0769 & -0.0098 & 0.0200 \\
\hline No.8 D & 6.30 & 0.0846 & 0.0826 & -0.002 & 0.0867 & 0.0871 & 0.0004 & 0.0218 \\
\hline No.8 A & 7.01 & 16 & 31 & 0.0335 & 0.0873 & 0.1229 & 0.0356 & 0.0191 \\
\hline No.8 B & 7.01 & 6 & 0.0727 & -0.0119 & 873 & 0.078 & -0.0093 & 0.0236 \\
\hline No.8 C & 7.01 & 6 & 0.0726 & 12 & 73 & 0.0776 & -0.0097 & 0.0209 \\
\hline No.8 D & 7.01 & 46 & 0.0826 & -0.002 & 0.0873 & 0.0878 & 0.0005 & 0.0227 \\
\hline No.8 A & 7.02 & 846 & 0.1181 & 0.0335 & 0.0868 & 0.1226 & 0.0358 & 0.0209 \\
\hline No.8 B & 7.02 & 0.0846 & 0.0727 & -0.0119 & 0.0868 & 0.0776 & -0.0092 & 0.0245 \\
\hline No.8 C & 7.02 & 0.0846 & 0.0726 & -0.012 & 0.0868 & 0.0774 & -0.0094 & 0.0236 \\
\hline No.8 D & 7.02 & 0.0846 & 0.0826 & -0.002 & 0.0868 & 0.0875 & 0.0007 & 0.0245 \\
\hline No.8 A & 7.03 & 0.0846 & 0.1181 & 0.0335 & 0.0876 & 0.1236 & 0.036 & 0.0227 \\
\hline No.8 B & 7.03 & 0.0846 & 0.0727 & -0.0119 & 0.0876 & 0.0786 & -0.009 & 0.0264 \\
\hline No.8 C & 7.03 & 0.0846 & 0.0726 & -0.012 & 0.0876 & 0.0781 & -0.0095 & 0.0227 \\
\hline No.8 D & 7.03 & 0.0846 & 0.0826 & -0.002 & 0.0876 & 0.0883 & 0.0007 & 0.0245 \\
\hline No.8 A & 7.12 & 0.0846 & 0.1181 & 0.0335 & 0.0775 & 0.1143 & 0.0368 & 0.0300 \\
\hline No.8 B & 7.12 & 0.0846 & 0.0727 & -0.0119 & 0.0775 & 0.0692 & -0.0083 & 0.0327 \\
\hline No.8 C & 7.12 & 0.0846 & 0.0726 & -0.012 & 0.0775 & 0.0688 & -0.0087 & 0.0300 \\
\hline No.8 D & 7.12 & 0.0846 & 0.0826 & -0.002 & 0.0775 & 0.0791 & 0.0016 & 0.0327 \\
\hline
\end{tabular}


Table C Length Change of Concrete Samples (Continued)

\begin{tabular}{|c|c|c|c|c|c|c|c|c|}
\hline \multicolumn{9}{|c|}{ Concrete Specimens Cured in Air. } \\
\hline $\begin{array}{l}\text { Concrete } \\
\text { Sample }\end{array}$ & $\begin{array}{c}\text { Testing } \\
\text { Time } \\
\text { (M.D) }\end{array}$ & \begin{tabular}{|c|} 
Initial \\
Length of \\
Reference \\
Bar
\end{tabular} & $\begin{array}{c}\text { Initial } \\
\text { Length of } \\
\text { Concrete } \\
\text { Samples }\end{array}$ & $\begin{array}{l}\text { Initial } \\
\text { CRD }\end{array}$ & $\begin{array}{c}\text { Reading of } \\
\text { Reference Bar }\end{array}$ & $\begin{array}{c}\text { Reading } \\
\text { of } \\
\text { Concrete } \\
\text { Sample }\end{array}$ & $\begin{array}{l}\text { Tested } \\
\text { CRD }\end{array}$ & $\begin{array}{c}\text { Length } \\
\text { Change in } \\
\%\end{array}$ \\
\hline No.2 A & 7.19 & 0.0917 & 0.1686 & 0.0769 & 0.0778 & 0.1543 & 0.0765 & -0.003 \\
\hline No.2 B & 7.19 & 0.0917 & 0.0922 & 0.0005 & 0.0778 & 0.0778 & 0.0000 & -0.0045 \\
\hline No.3 A & 7.19 & 0.0917 & 0.0829 & -0.0088 & 0.0778 & 0.0693 & -0.0085 & 0.0027 \\
\hline No.3 B & 7.19 & 0.0917 & 0.0774 & -0.0143 & 0.0778 & 0.0637 & -0.0141 & 0.0018 \\
\hline No.4 A & 7.19 & 0.0917 & 0.0959 & 0.0042 & 0.0778 & 0.0829 & 0.0051 & 0.0082 \\
\hline No.4 B & 7.19 & 0.0917 & 0.1113 & 0.0196 & 0.0778 & 0.0918 & 0.0140 & -0.0509 \\
\hline No.5 A & 7.19 & 0.0917 & 0.1643 & 0.0726 & 0.0778 & 0.1510 & 0.0732 & 0.0055 \\
\hline No.5 B & 7.19 & 0.0917 & 0.0950 & 0.0033 & 0.0778 & 0.0818 & 0.0040 & 0.0064 \\
\hline No.6 A & 7.19 & 0.0866 & 0.1017 & 0.0151 & 0.0778 & 0.0933 & 0.0155 & 0.0036 \\
\hline No.6 B & 7.19 & 0.0866 & 0.1662 & 0.0796 & 0.0778 & 0.1573 & 0.0795 & -0.0009 \\
\hline No.7 A & 7.19 & 0.0866 & 0.0758 & -0.0108 & 0.0778 & 0.0669 & -0.0109 & -0.0009 \\
\hline No.7 B & 7.19 & 0.0866 & 0.1072 & 0.0206 & 0.0778 & 0.0988 & 0.0210 & 0.0036 \\
\hline No.8 A & 7.19 & 0.0846 & 0.1181 & 0.0335 & 0.0778 & 0.1151 & 0.0373 & 0.0345 \\
\hline No.8 B & 7.19 & 0.0846 & 0.0727 & -0.0119 & 0.0778 & 0.0702 & -0.0076 & 0.0391 \\
\hline No.8 C & 7.19 & 0.0846 & 0.0726 & -0.0120 & 0.0778 & 0.0698 & -0.0080 & 0.0364 \\
\hline No.8 D & 7.19 & 0.0846 & 0.0826 & -0.0020 & 0.0778 & 0.0799 & 0.0021 & 0.0373 \\
\hline No.2 A & 7.26 & 0.0917 & 0.1686 & 0.0769 & 0.0846 & 0.1611 & 0.0765 & -0.0036 \\
\hline No.2 B & 7.26 & 0.0917 & 0.0922 & 0.0005 & 0.0846 & 0.0845 & -0.0001 & -0.0055 \\
\hline No.3 A & 7.26 & 917 & 29 & -0.0088 & 0.0846 & 0.0761 & -0.0085 & 0.0027 \\
\hline No.3 B & 7.26 & 0.0917 & 0.0774 & -0.0143 & 346 & 0.0706 & -0.0140 & 0.0027 \\
\hline No.4 A & 7.26 & 0.0917 & 0.0959 & 0.0042 & 0.0846 & 0.0898 & 0.0052 & 0.0091 \\
\hline No.4 B & 7.26 & 0.0917 & 0.1113 & 0.0196 & 0.0846 & 0.1049 & 0.0203 & 0.0064 \\
\hline No.5 A & 7.26 & 0.0917 & 0.1643 & 0.0726 & 0.0846 & 0.1578 & 0.0732 & 0.0055 \\
\hline No.5 B & 7.26 & 0.0917 & 0.0950 & 0.0033 & 0.0846 & 0.0886 & 0.0040 & 0.0064 \\
\hline No.6 A & 7.26 & 0.0866 & 0.1017 & 0.0151 & 0.0846 & 0.1000 & 0.0154 & 0.0027 \\
\hline No.6 B & 7.26 & 0.0866 & 0.1662 & 0.0796 & 0.0846 & 0.1641 & 0.0795 & -0.0009 \\
\hline No.7 A & 7.26 & 0.0866 & 0.0758 & -0.0108 & 0.0846 & 0.0740 & -0.0106 & 0.0018 \\
\hline No.7 B & 7.26 & 0.0866 & 0.1072 & 0.0206 & 0.0846 & 0.1054 & 0.0208 & 0.0018 \\
\hline No.8 A & 7.26 & 0.0846 & 0.1181 & 0.0335 & 0.0846 & 0.1222 & 0.0376 & 0.0373 \\
\hline No.8 B & 7.26 & 0.0846 & 0.0727 & -0.0119 & 0.0846 & 0.0773 & -0.0073 & 0.0418 \\
\hline No.8 C & 7.26 & 0.0846 & 0.0726 & -0.0120 & 0.0846 & 0.0768 & -0.0078 & 0.0382 \\
\hline No.8 D & 7.26 & 0.0846 & 0.0826 & -0.0020 & 0.0846 & 0.0870 & 0.0024 & 0.0400 \\
\hline
\end{tabular}


Table C Length Change of Concrete Samples (Continued)

\begin{tabular}{|c|c|c|c|c|c|c|c|r|}
\hline \multicolumn{10}{|c|}{$\begin{array}{c}\text { Concrete Specimens Cured in Air. } \\
\text { Concrete } \\
\text { Sample }\end{array}$} & $\begin{array}{c}\text { Testing } \\
\text { Time } \\
\text { (M.D) }\end{array}$ & $\begin{array}{c}\text { Initial } \\
\text { Length of } \\
\text { Reference } \\
\text { Bar }\end{array}$ & $\begin{array}{c}\text { Initial } \\
\text { Length of } \\
\text { Concrete } \\
\text { Samples }\end{array}$ & $\begin{array}{c}\text { Initial } \\
\text { CRD }\end{array}$ & $\begin{array}{c}\text { Reading of } \\
\text { Reference Bar }\end{array}$ & $\begin{array}{c}\text { Reading } \\
\text { of } \\
\text { Concrete } \\
\text { Sample }\end{array}$ & $\begin{array}{c}\text { Tested } \\
\text { CRD }\end{array}$ & $\begin{array}{c}\text { Length } \\
\text { Change in } \\
\%\end{array}$ \\
\hline No.2 A & 8.15 & 0.0917 & 0.1686 & 0.0769 & 0.0842 & 0.1607 & 0.0765 & -0.0036 \\
\hline No.2 B & 8.15 & 0.0917 & 0.0922 & 0.0005 & 0.0842 & 0.0842 & 0.0000 & -0.0045 \\
\hline No.3 A & 8.15 & 0.0917 & 0.0829 & -0.0088 & 0.0842 & 0.0758 & -0.0084 & 0.0036 \\
\hline No.3 B & 8.15 & 0.0917 & 0.0774 & -0.0143 & 0.0842 & 0.0702 & -0.0140 & 0.0027 \\
\hline No.4 A & 8.15 & 0.0917 & 0.0959 & 0.0042 & 0.0842 & 0.0894 & 0.0052 & 0.0091 \\
\hline No.4 B & 8.15 & 0.0917 & 0.1113 & 0.0196 & 0.0842 & 0.1048 & 0.0206 & 0.0091 \\
\hline No.5 A & 8.15 & 0.0917 & 0.1643 & 0.0726 & 0.0842 & 0.1575 & 0.0733 & 0.0064 \\
\hline No.5 B & 8.15 & 0.0917 & 0.0950 & 0.0033 & 0.0842 & 0.0883 & 0.0041 & 0.0073 \\
\hline No.6 A & 8.15 & 0.0866 & 0.1017 & 0.0151 & 0.0842 & 0.0997 & 0.0155 & 0.0036 \\
\hline No.6 B & 8.15 & 0.0866 & 0.1662 & 0.0796 & 0.0842 & 0.1638 & 0.0796 & 0.0000 \\
\hline No.7 A & 8.15 & 0.0866 & 0.0758 & -0.0108 & 0.0842 & 0.0738 & -0.0104 & 0.0036 \\
\hline No.7 B & 8.15 & 0.0866 & 0.1072 & 0.0206 & 0.0842 & 0.1051 & 0.0209 & 0.0027 \\
\hline No.8 A & 8.15 & 0.0846 & 0.1181 & 0.0335 & 0.0842 & 0.1231 & 0.0389 & 0.0491 \\
\hline No.8 B & 8.15 & 0.0846 & 0.0727 & -0.0119 & 0.0842 & 0.0782 & -0.0060 & 0.0536 \\
\hline No.8 C & 8.15 & 0.0846 & 0.0726 & -0.0120 & 0.0842 & 0.0771 & -0.0071 & 0.0445 \\
\hline No.8 D & 8.15 & 0.0846 & 0.0826 & -0.0020 & 0.0842 & 0.0875 & 0.0033 & 0.0482 \\
\hline
\end{tabular}


APPENDIX D

HALF-CELL POTENTIALS OF THE REINFORCED SLABS 


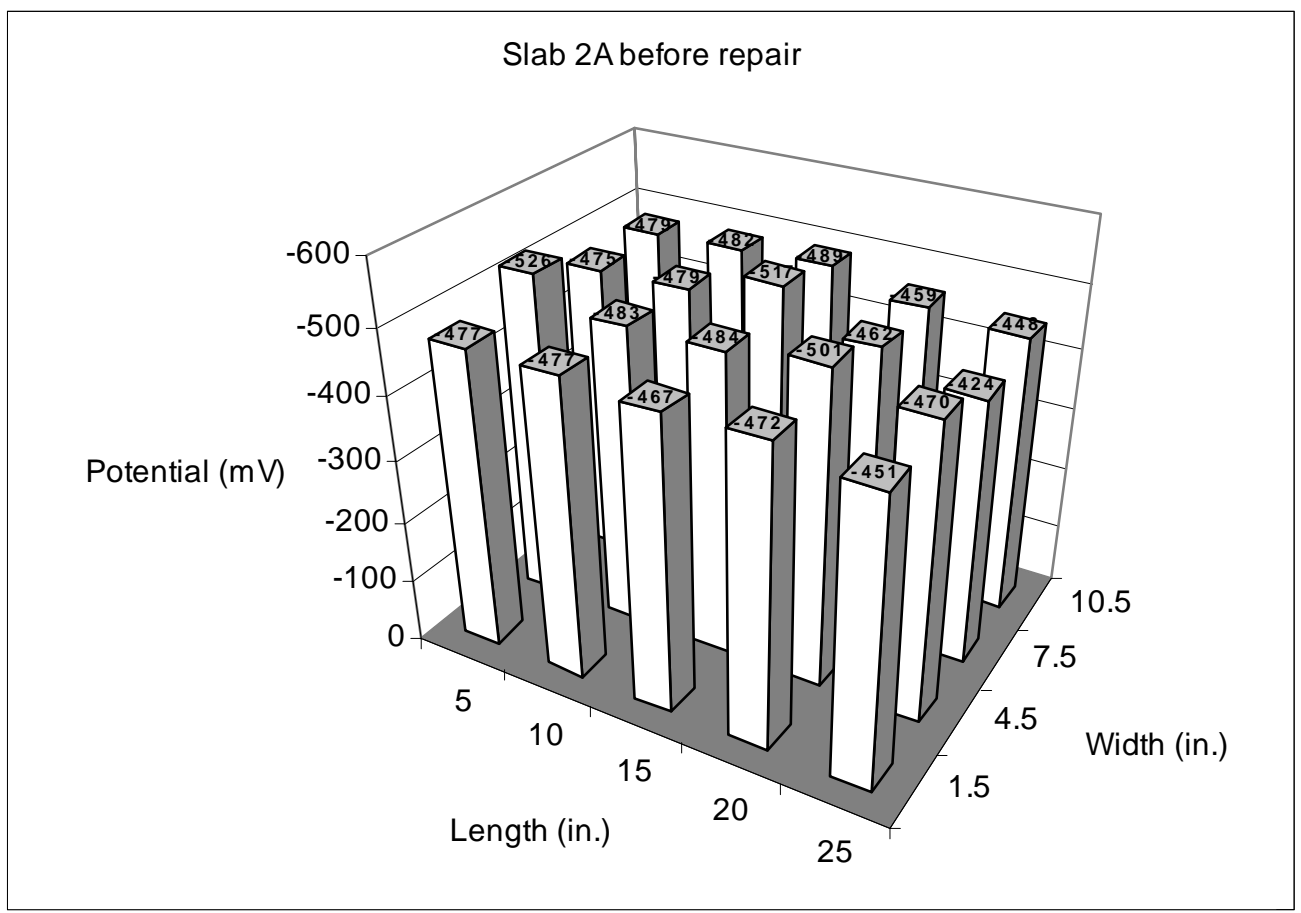

Figure C.1 Half-cell potentials of slab 2A before repair. Potential values are versus copper-copper sulfate electrode.

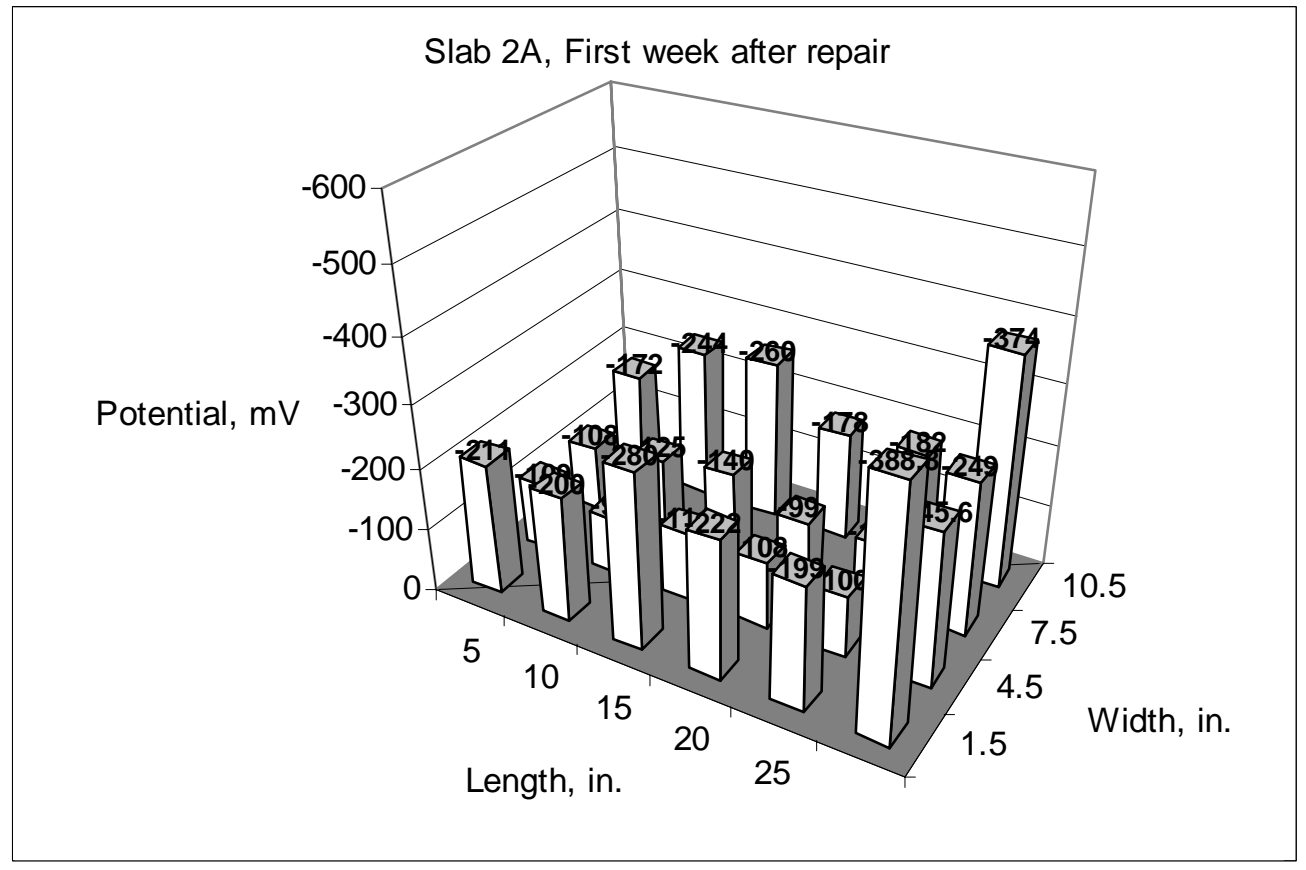

Figure C.2 Half-cell potentials of slab 2A one week after repair with silica fume concrete. Potential values are versus copper-copper sulfate electrode. 


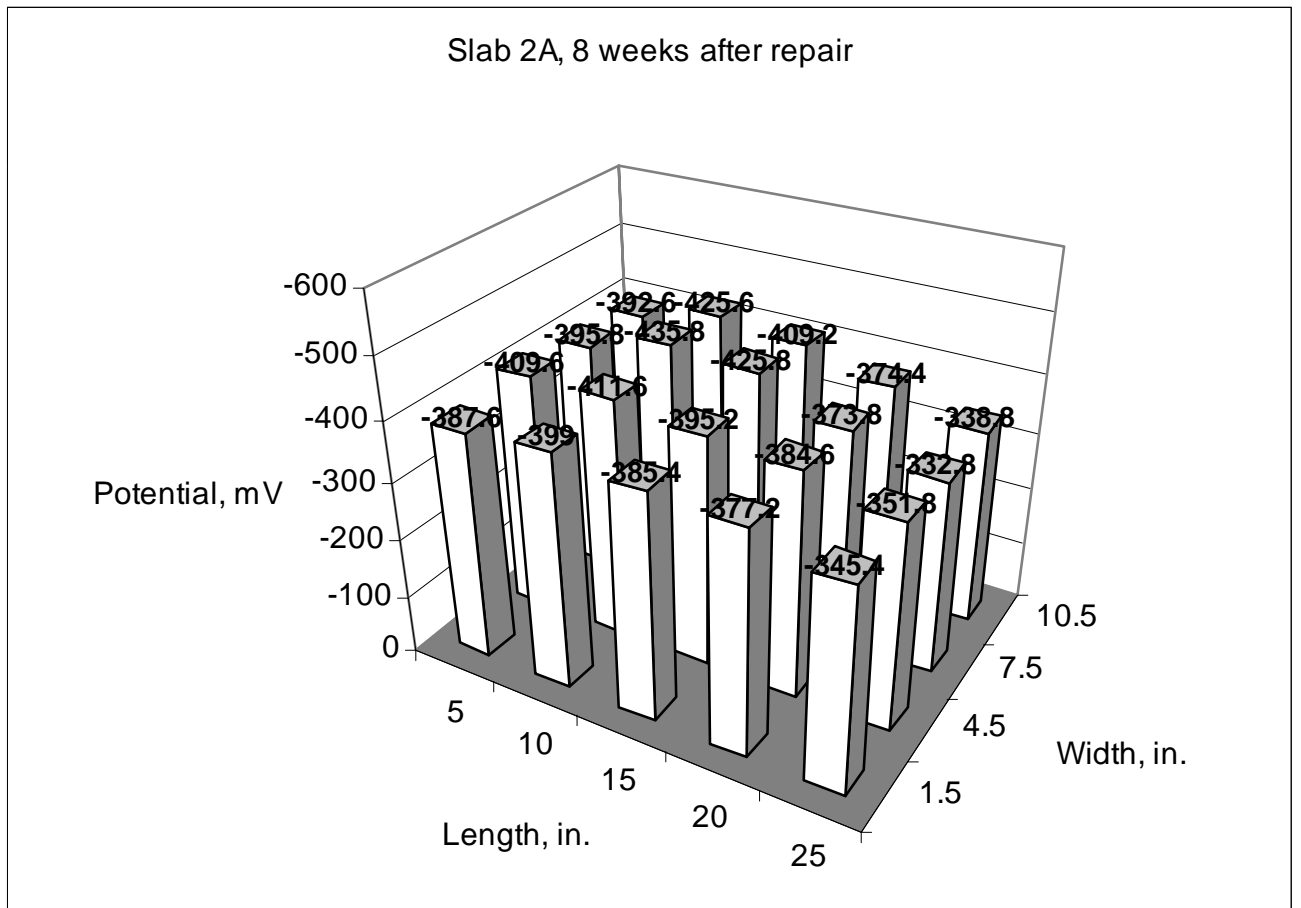

Figure C.3 Half-cell potentials of slab 2A eight weeks after repair with silica fume concrete. Potential values are versus copper-copper sulfate electrode.

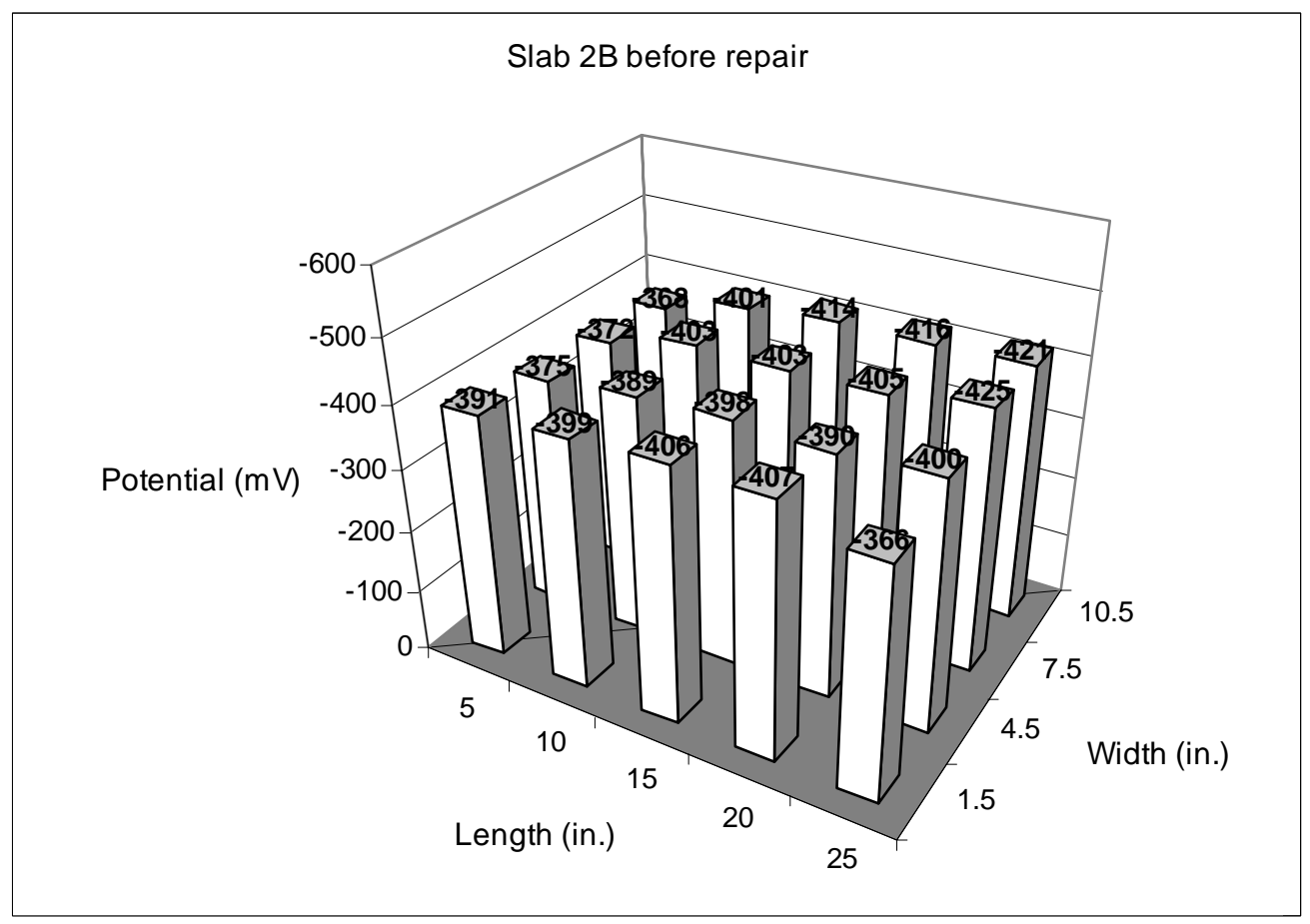

Figure C.4 Half-cell potentials of slab 2B before repair. Potential values are versus copper-copper sulfate electrode. 


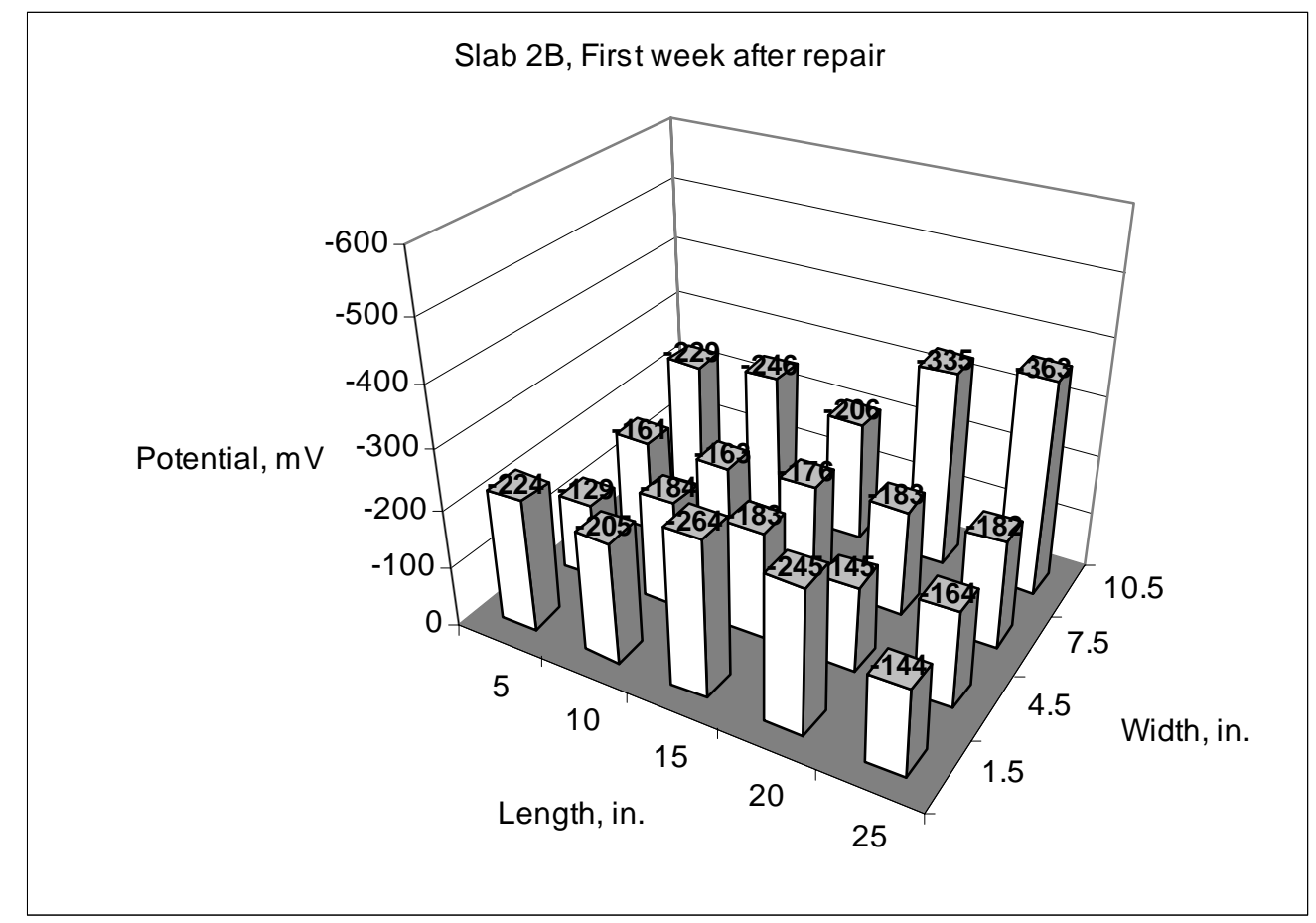

Figure C.5 Half-cell potentials of slab 2B one week after repair with silica fume concrete. Potential values are versus copper-copper sulfate electrode.

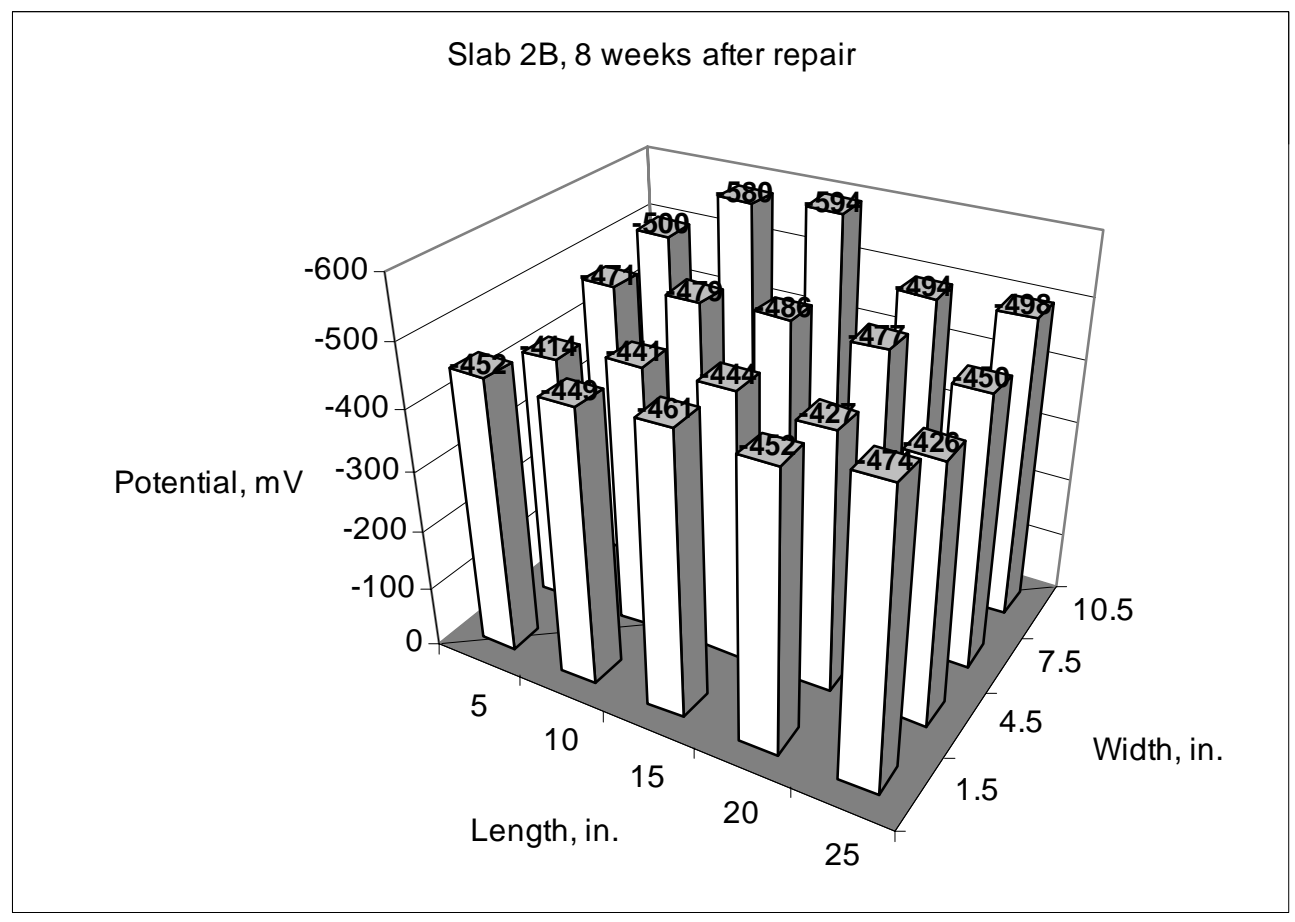

Figure C.6 Half-cell potentials of slab 2B eight weeks after repair with silica fume concrete. Potential values are versus copper-copper sulfate electrode. 


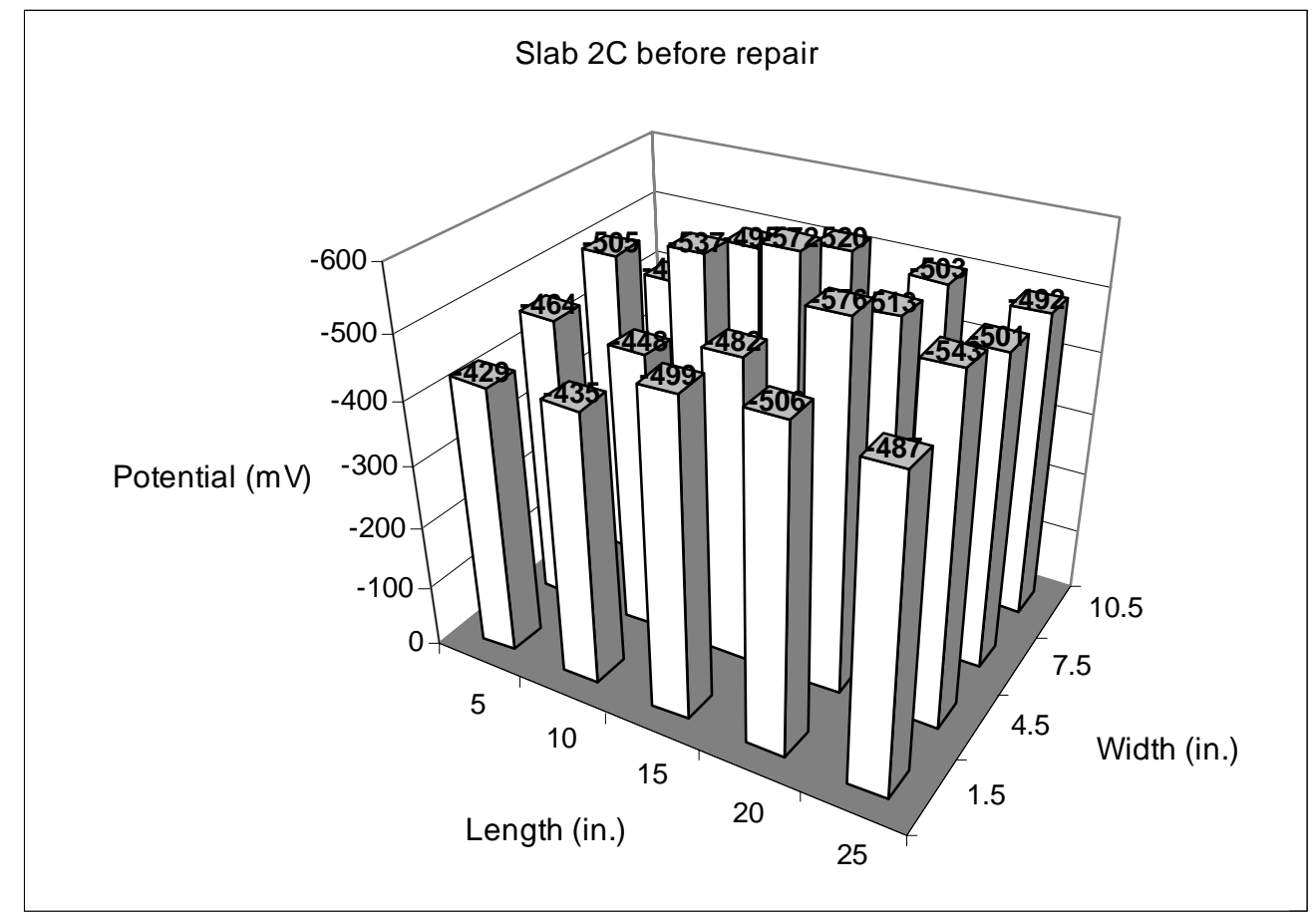

Figure C.7 Half-cell potentials of slab 2C before repair with silica fume concrete. Potential values are versus copper-copper sulfate electrode.

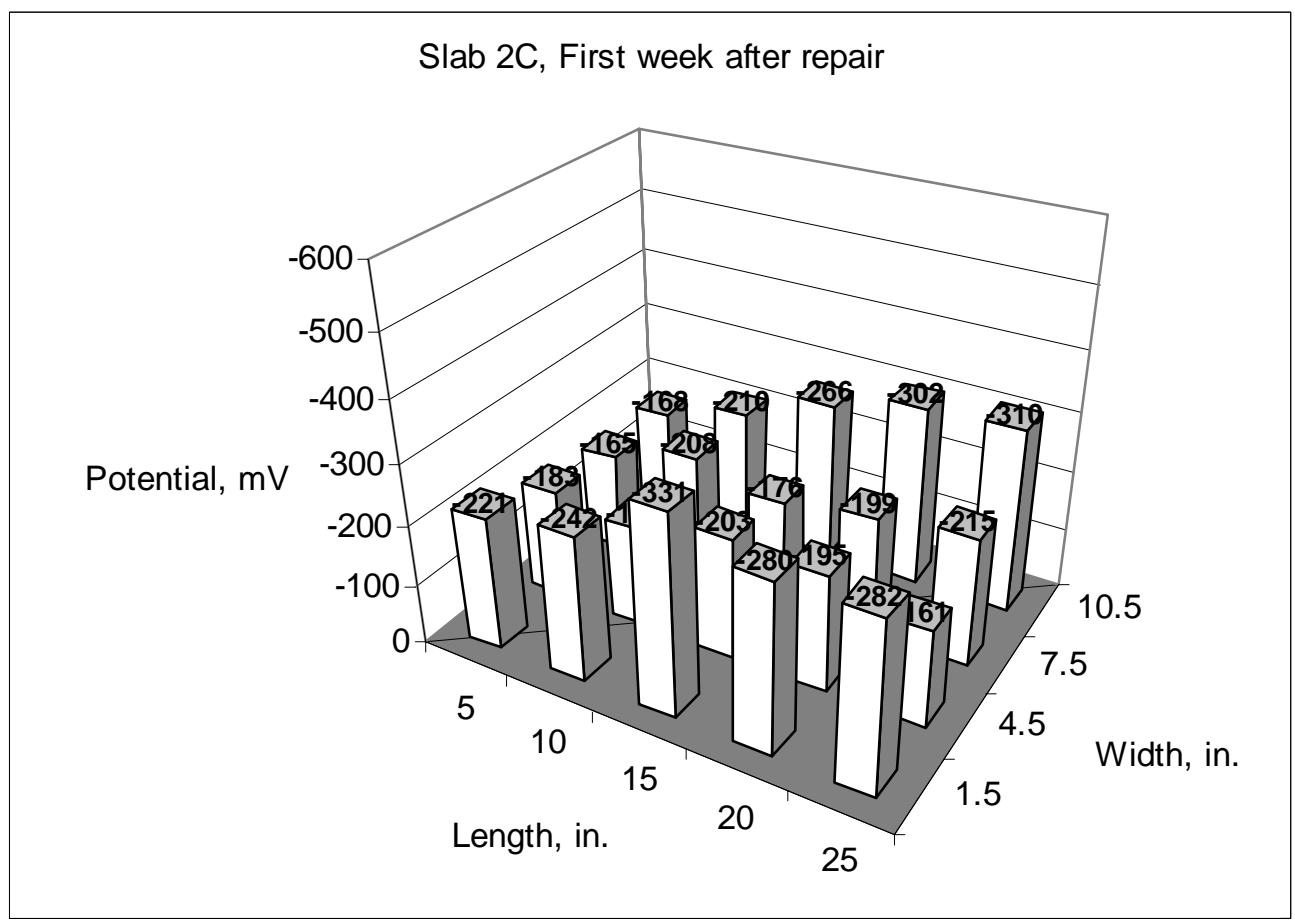

Figure C.8 Half-cell potentials of slab $2 \mathrm{C}$ one week after repair with silica fume concrete. Potential values are versus copper-copper sulfate electrode. 


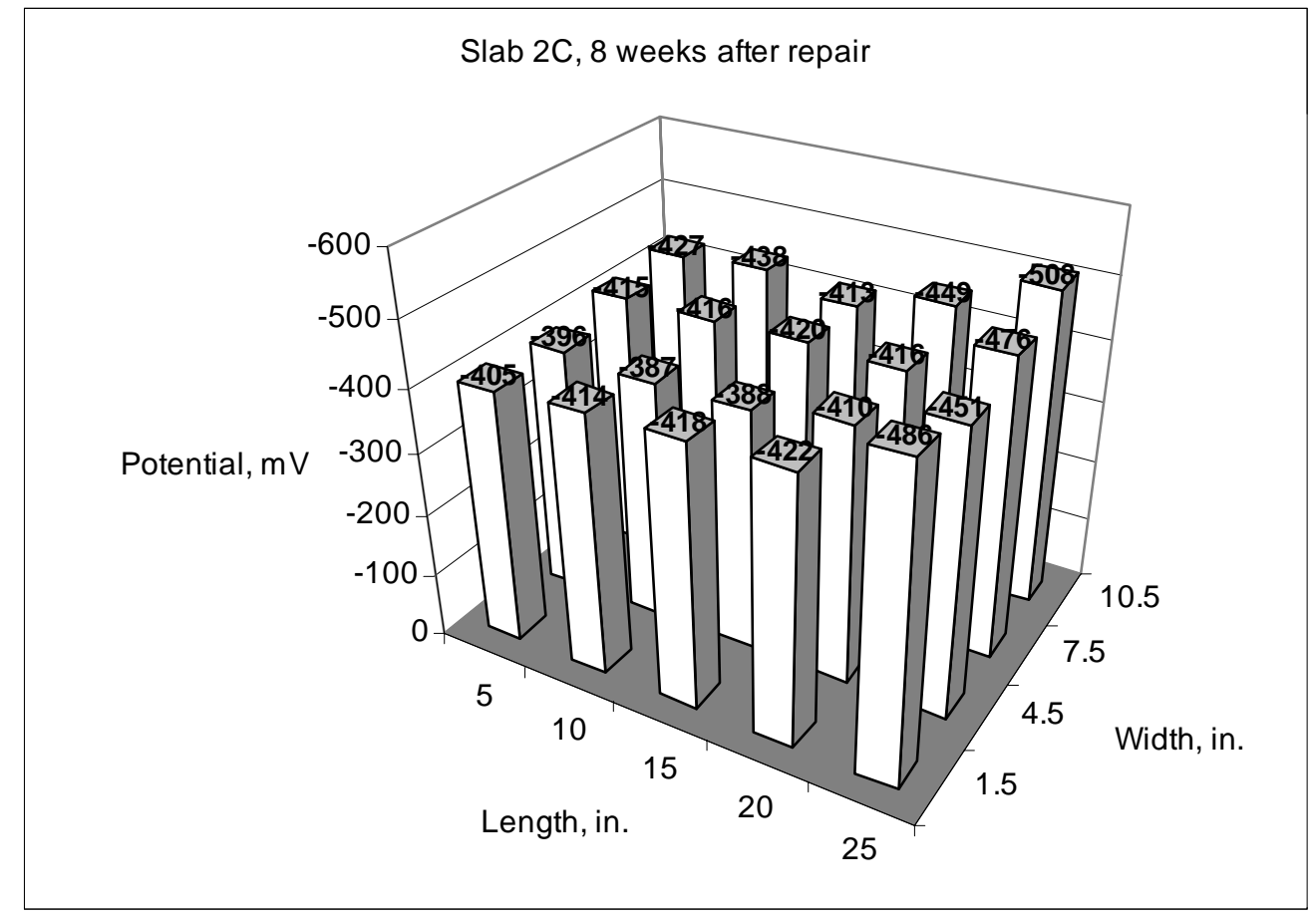

Figure C.9 Half-cell potentials of slab 2C eight weeks after repair with silica fume concrete. Potential values are versus copper-copper sulfate electrode.

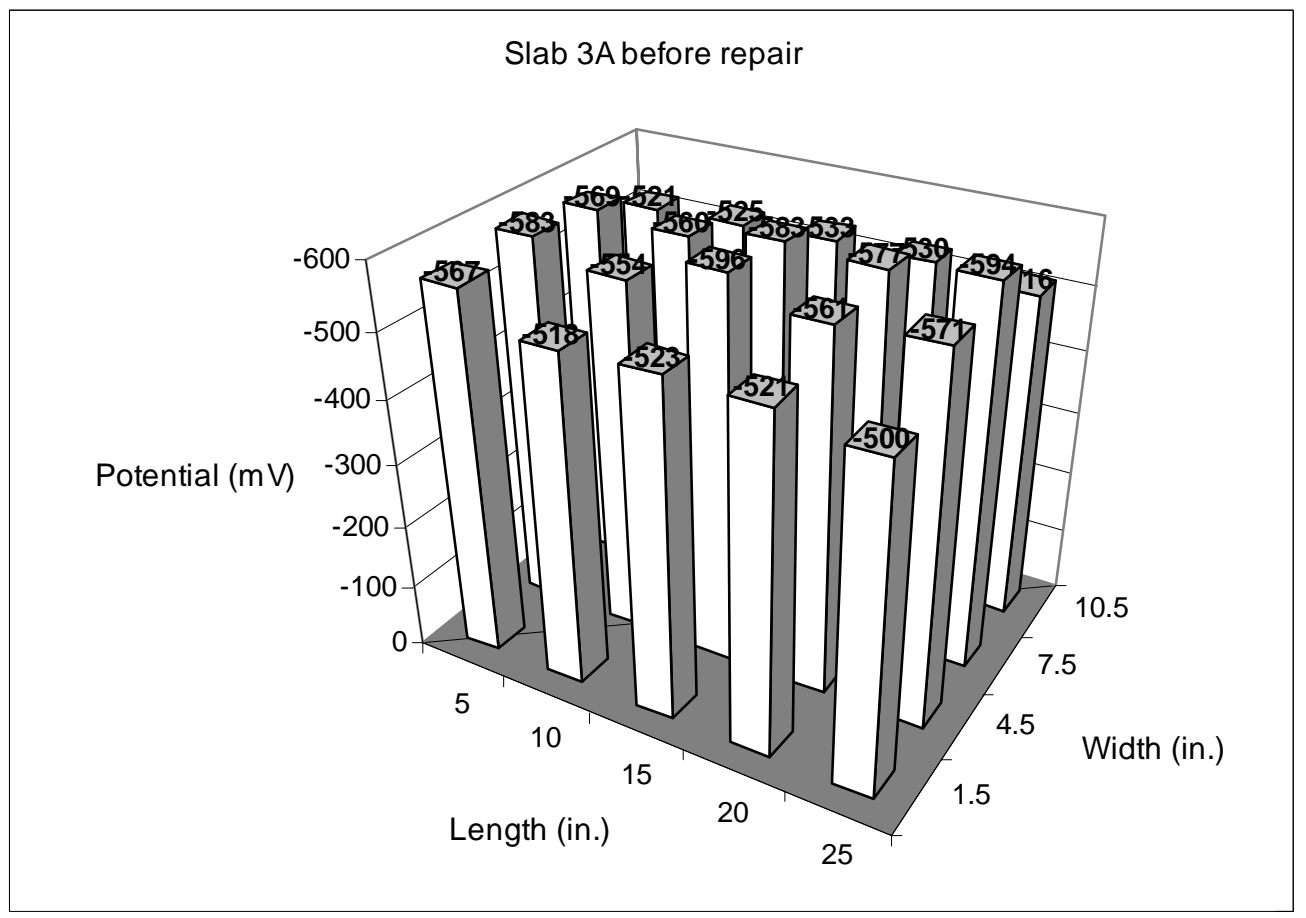

Figure C.10 Half-cell potentials of slab 3A before repair with concrete containing calcium nitrite. Potential values are versus copper-copper sulfate electrode. 


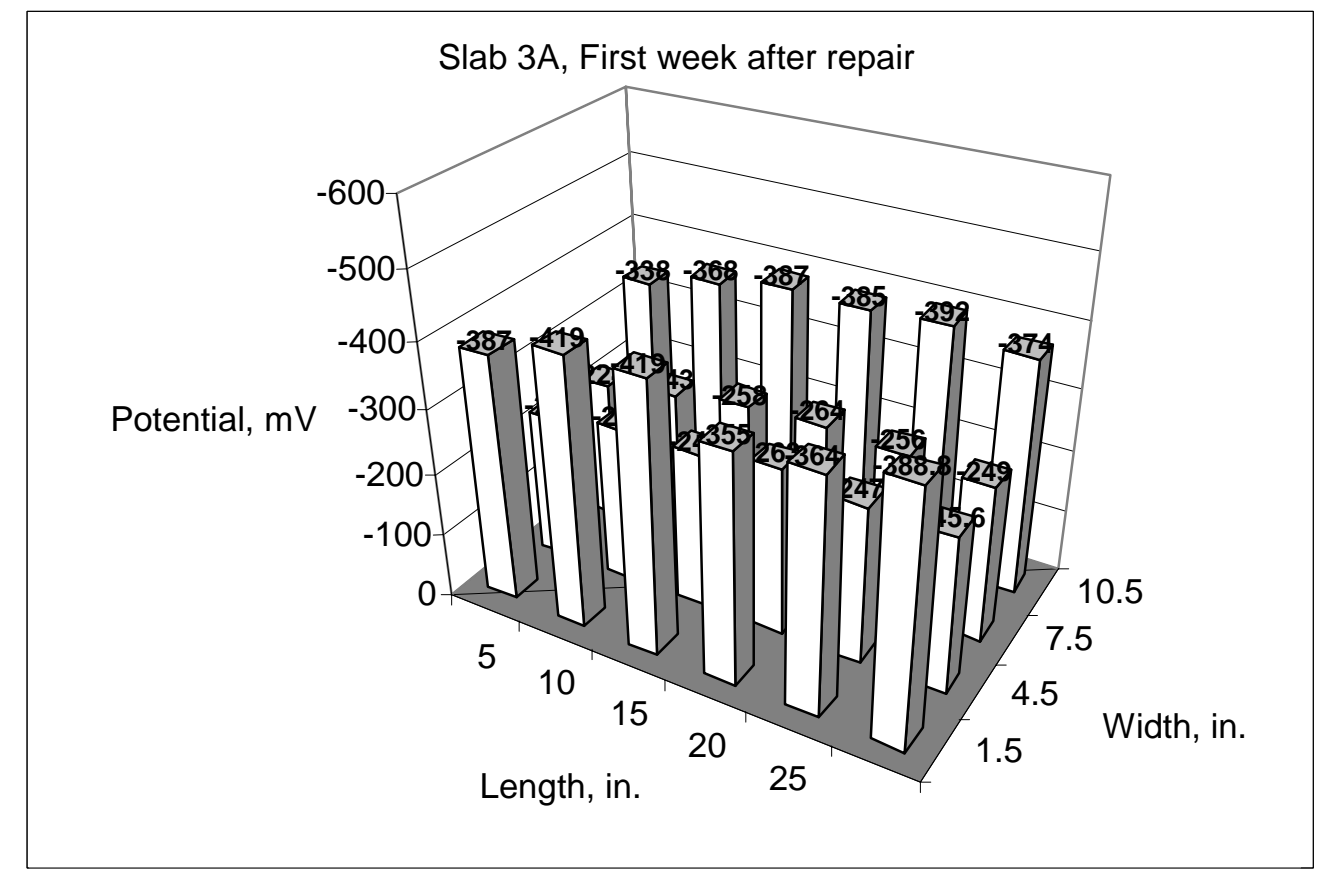

Figure C.11 Half-cell potentials of slab 3A first week after repair with concrete containing calcium nitrite. Potential values are versus copper-copper sulfate electrode.

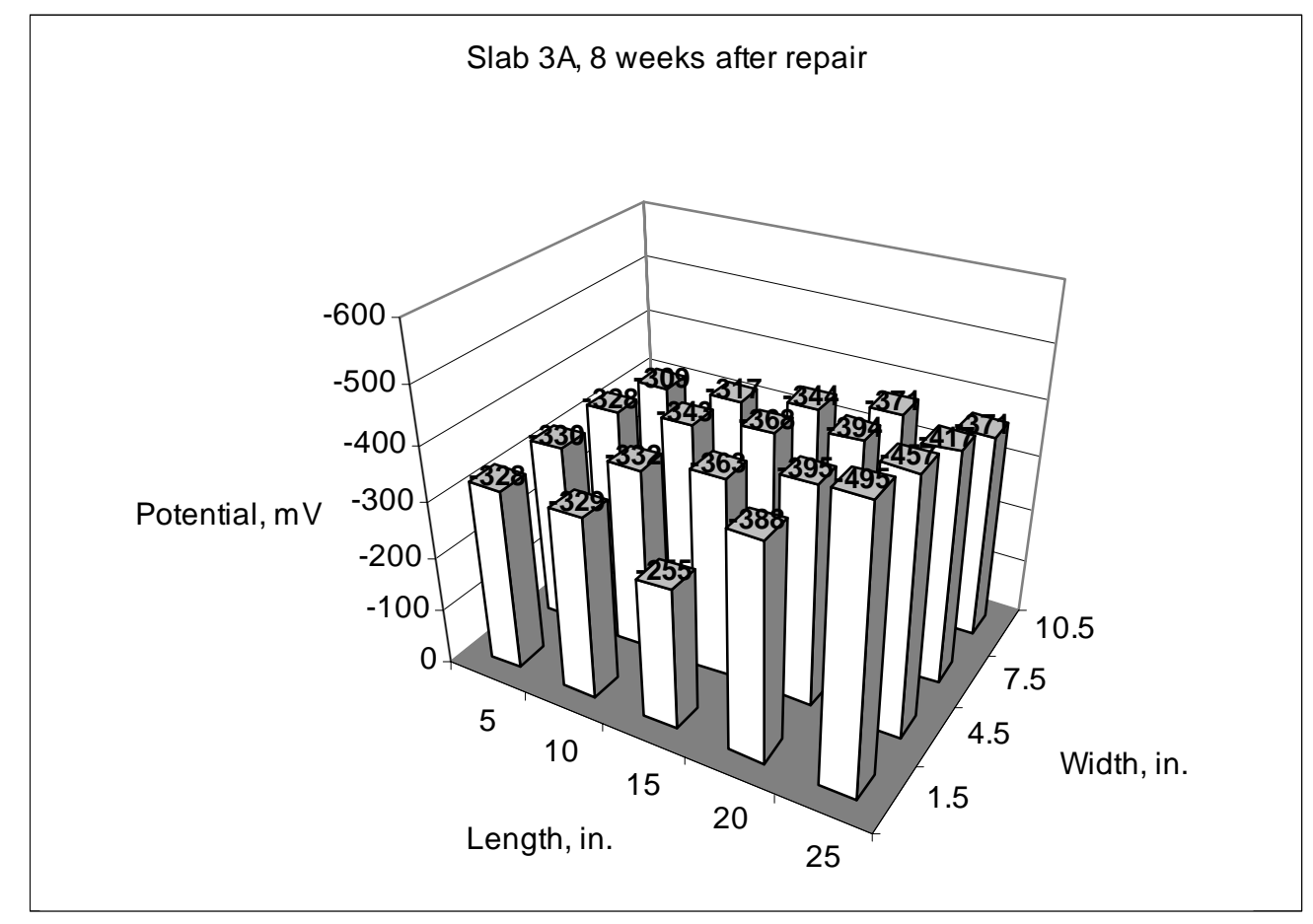

Figure C.12 Half-cell potentials of slab 3A eight weeks after repair with concrete containing calcium nitrite. Potential values are versus copper-copper sulfate electrode. 


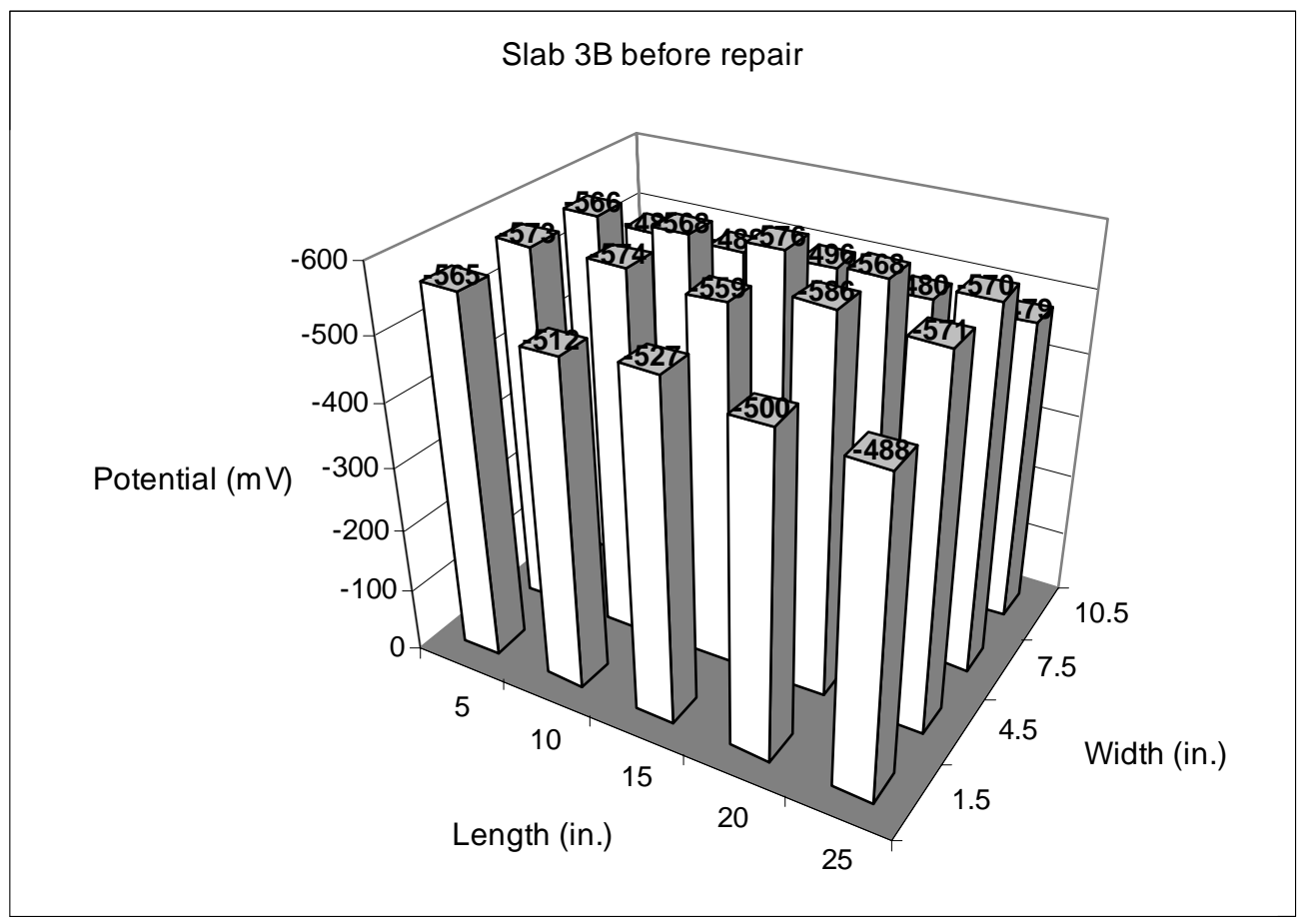

Figure C.13 Half-cell potentials of slab 3B before repair with concrete containing calcium nitrite. Potential values are versus copper-copper sulfate electrode.

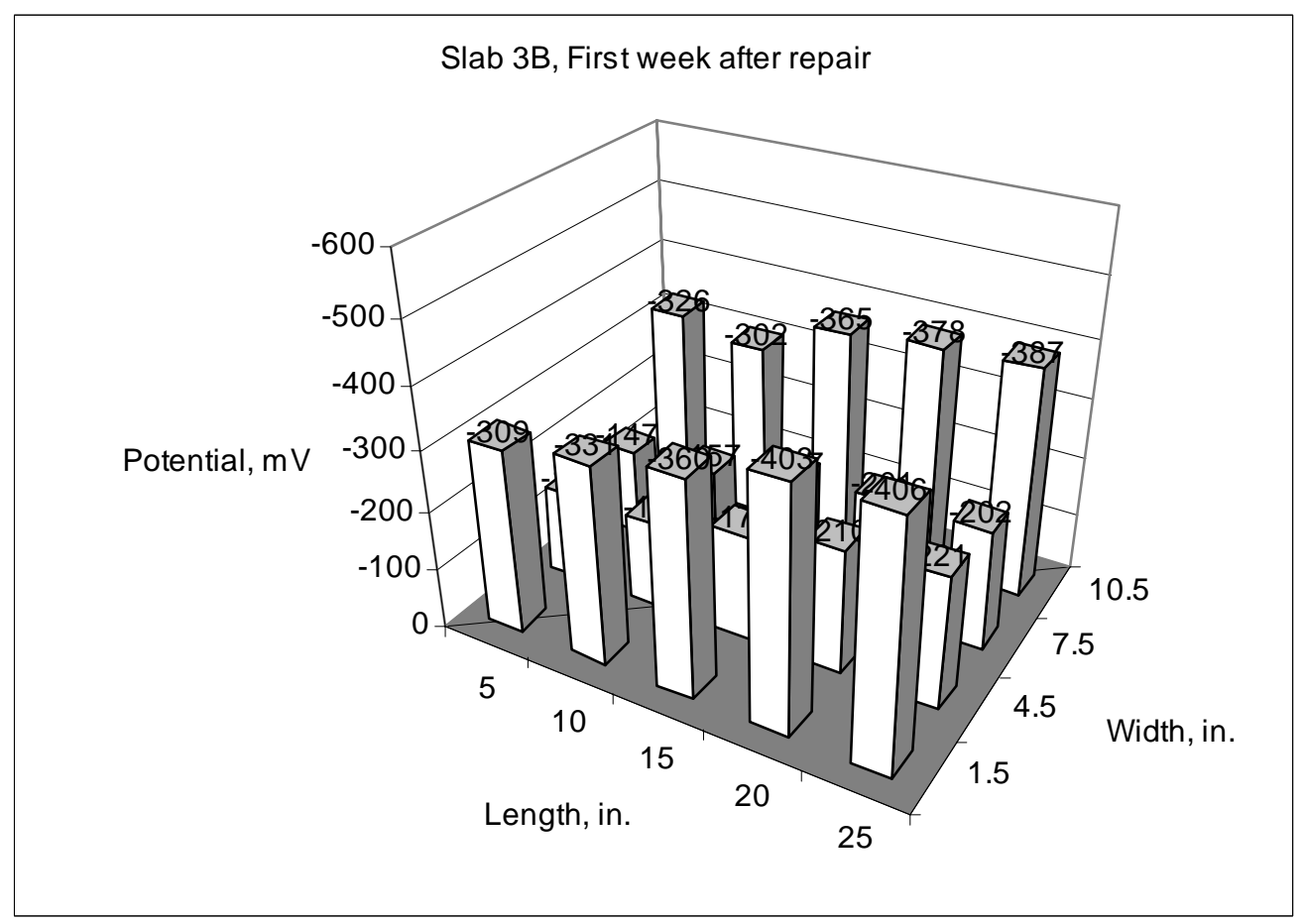

Figure C.14 Half-cell potentials of slab 3B first week after repair with concrete containing calcium nitrite. Potential values are versus copper-copper sulfate electrode. 


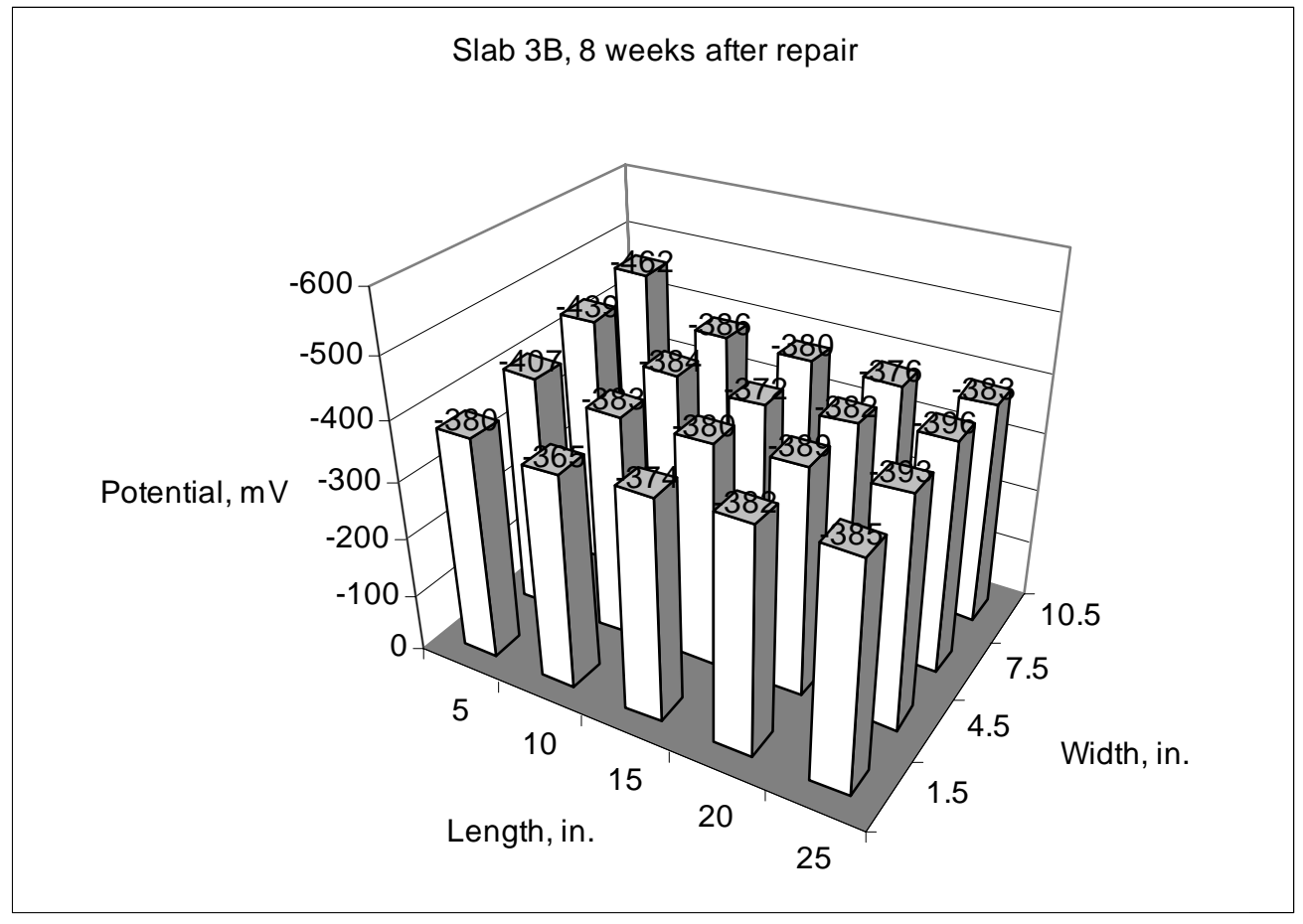

Figure C.15 Half-cell potentials of slab 3B eight weeks after repair with concrete containing calcium nitrite. Potential values are versus copper-copper sulfate electrode.

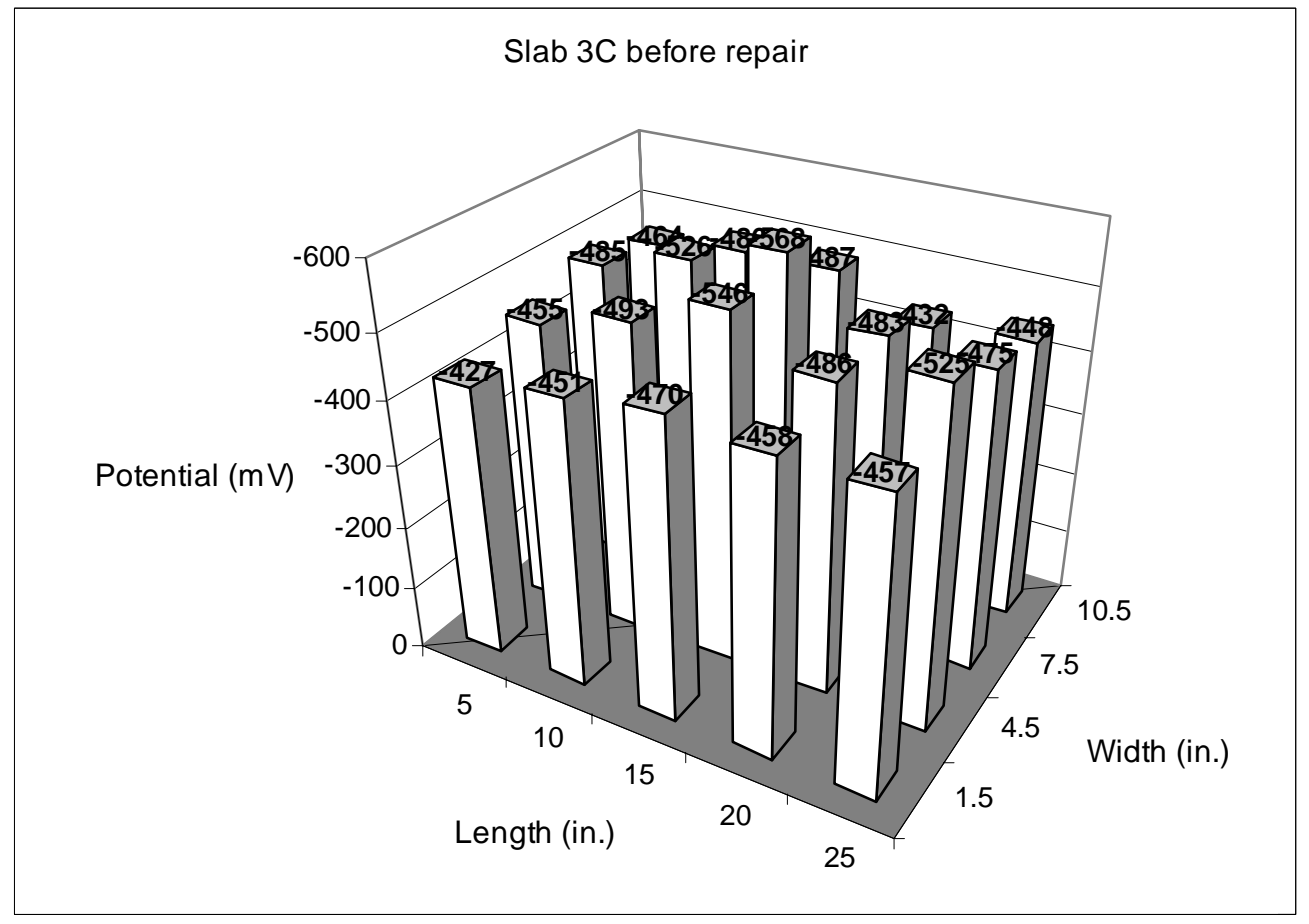

Figure C.16 Half-cell potentials of slab 3C before repair with concrete containing calcium nitrite. Potential values are versus copper-copper sulfate electrode. 


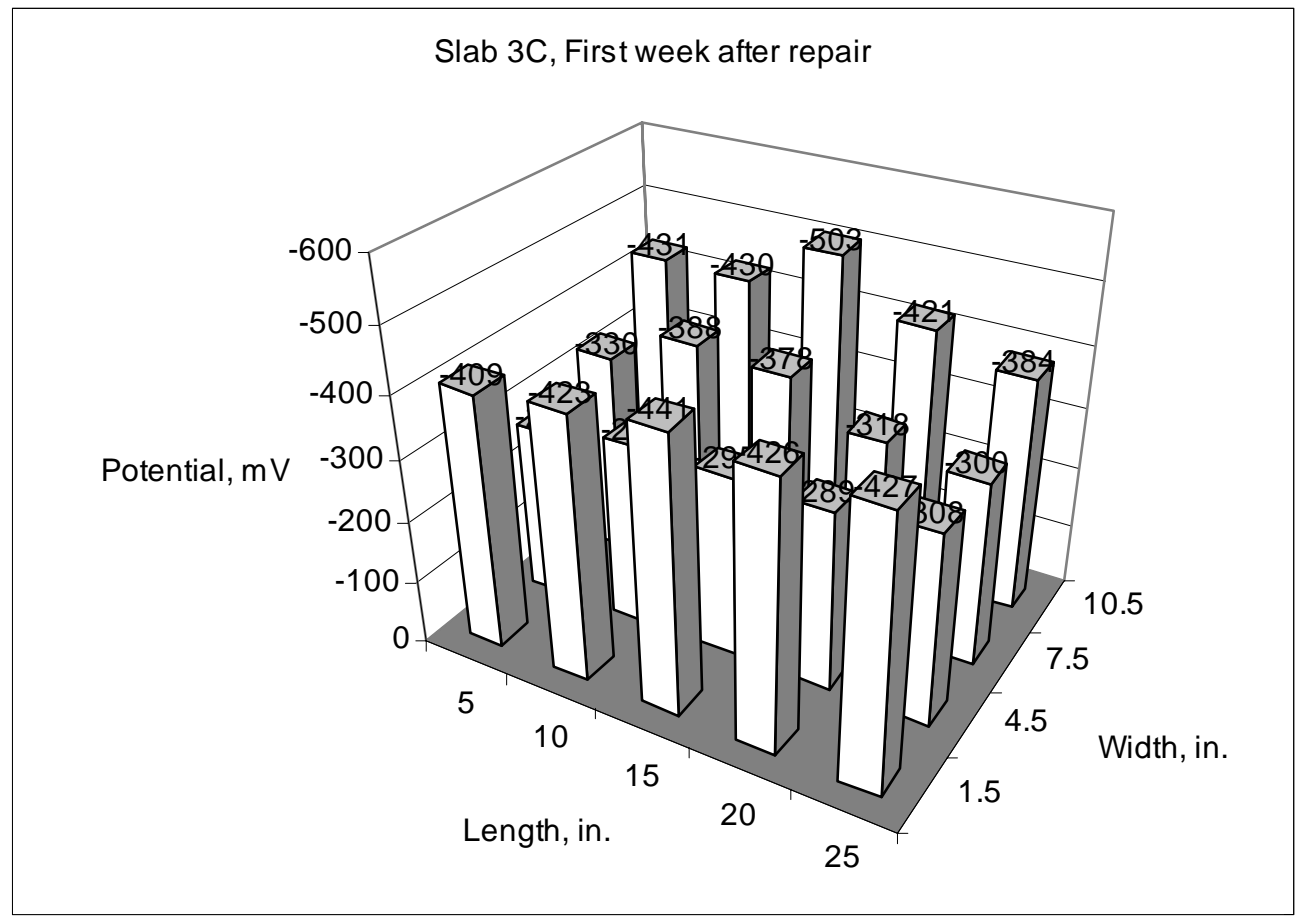

Figure C.17 Half-cell potentials of slab 3C first week after repair with concrete containing calcium nitrite. Potential values are versus copper-copper sulfate electrode.

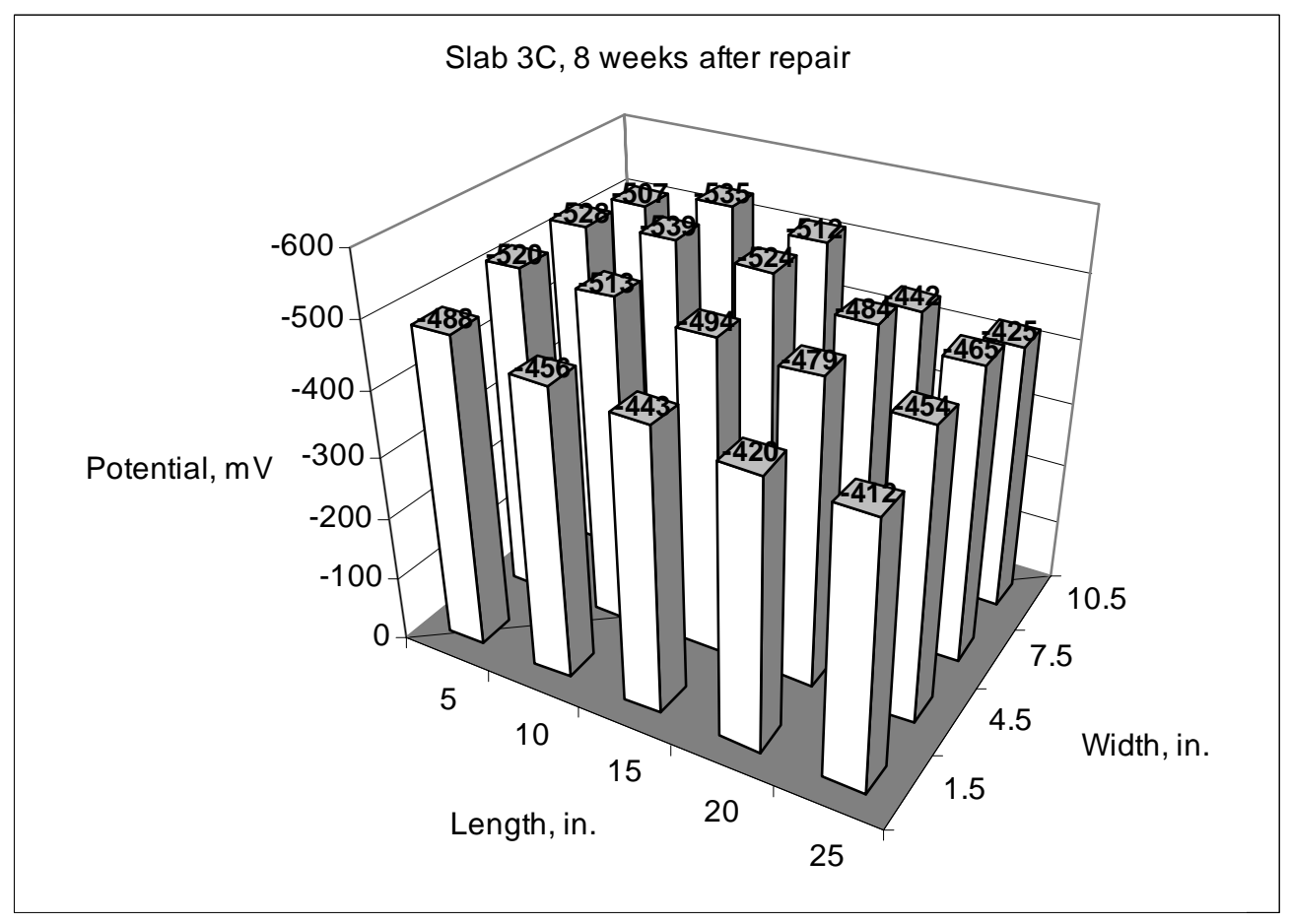

Figure C.18 Half-cell potentials of slab 3C eight weeks after repair with concrete containing calcium nitrite. Potential values are versus copper-copper sulfate electrode. 


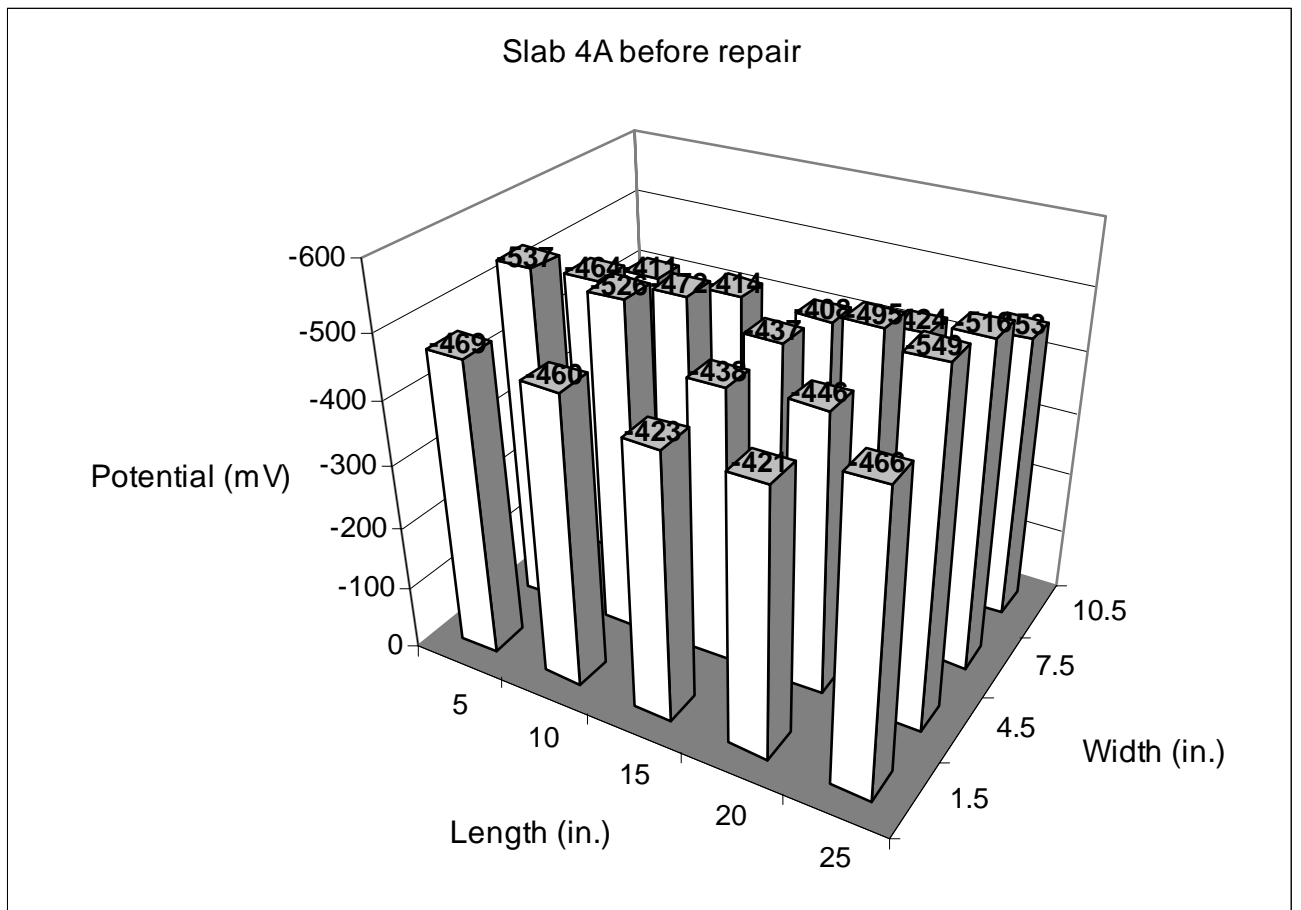

Figure C.19 Half-cell potentials of slab 4A before repair with the concrete containing organic corrosion inhibitor. Potential values are versus copper-copper sulfate electrode.

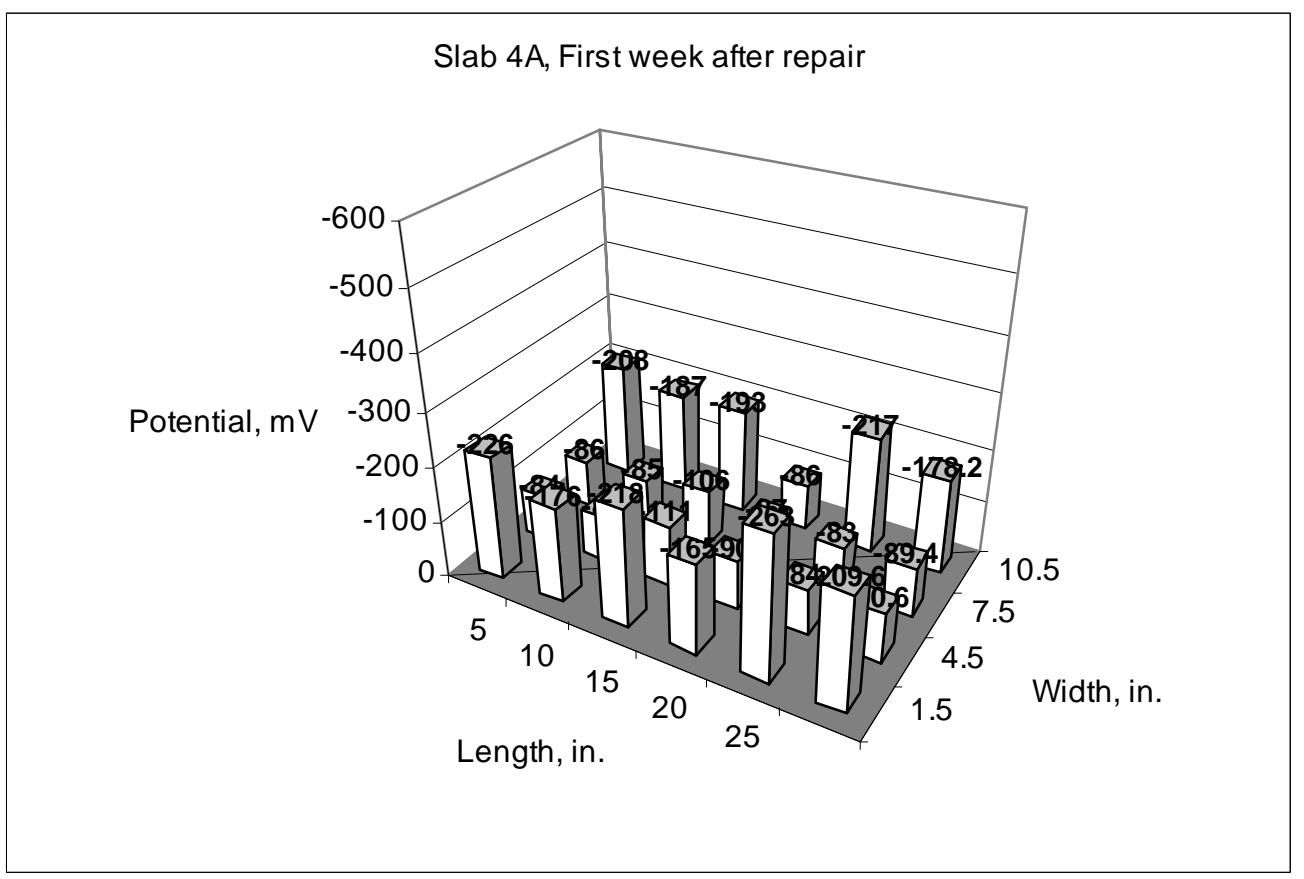

Figure C.20 Half-cell potentials of slab 4A first week after repair with the concrete containing organic corrosion inhibitor. Potential values are versus copper-copper sulfate electrode. 


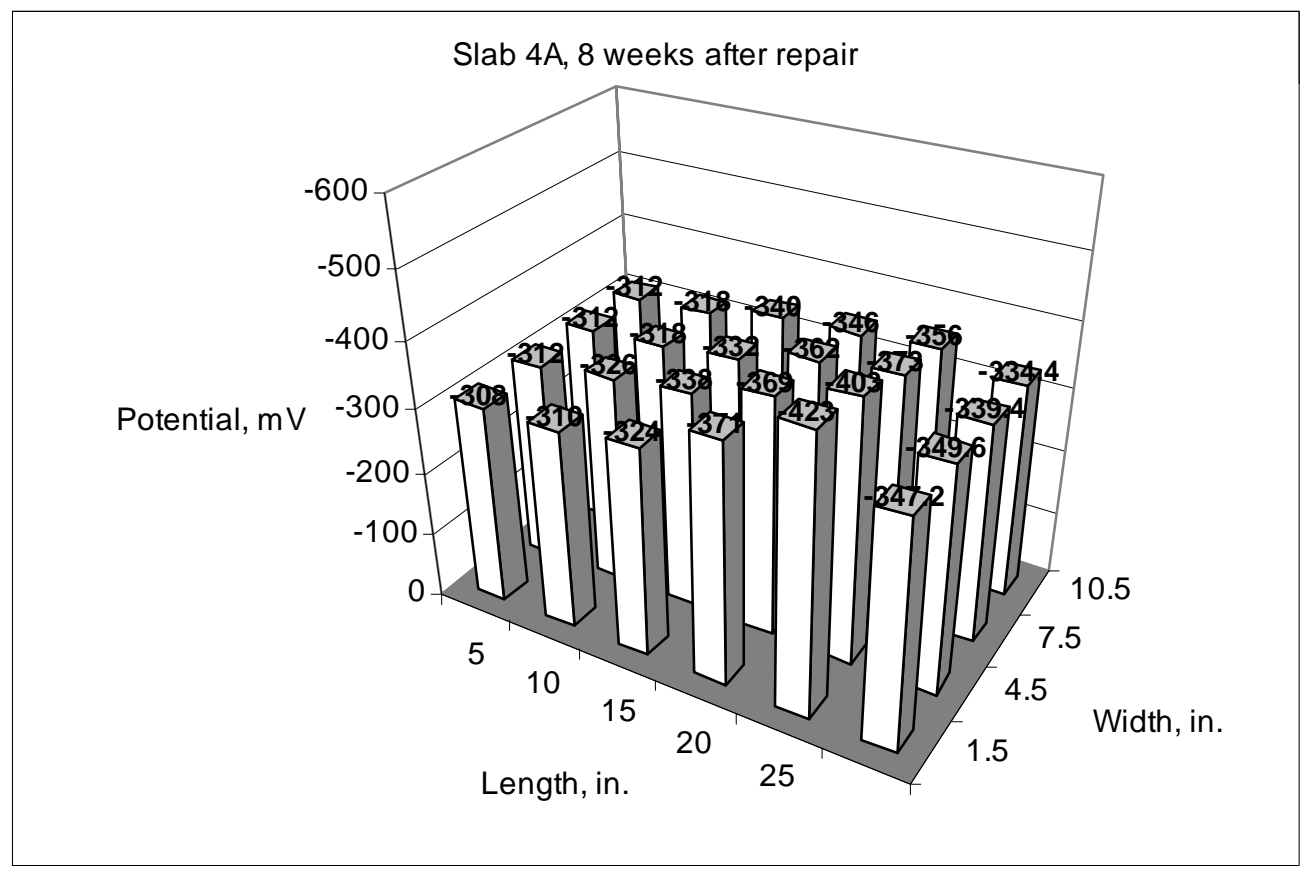

Figure C.21 Half-cell potentials of slab 4A eight weeks after repair with the concrete containing organic corrosion inhibitor. Potential values are versus copper-copper sulfate electrode.

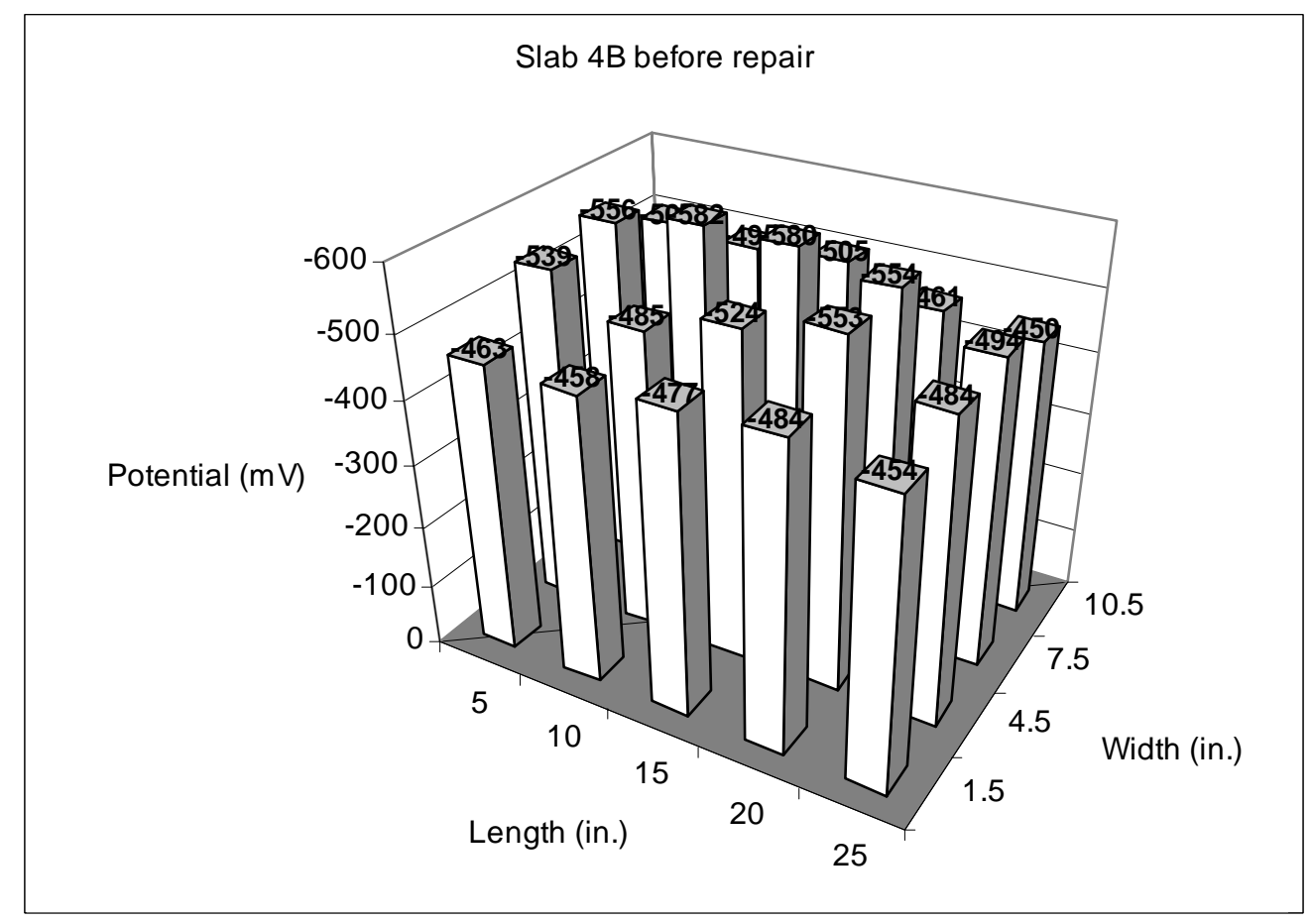

Figure C.22 Half-cell potentials of slab 4B before repair with the concrete containing organic corrosion inhibitor. Potential values are versus copper-copper sulfate electrode. 


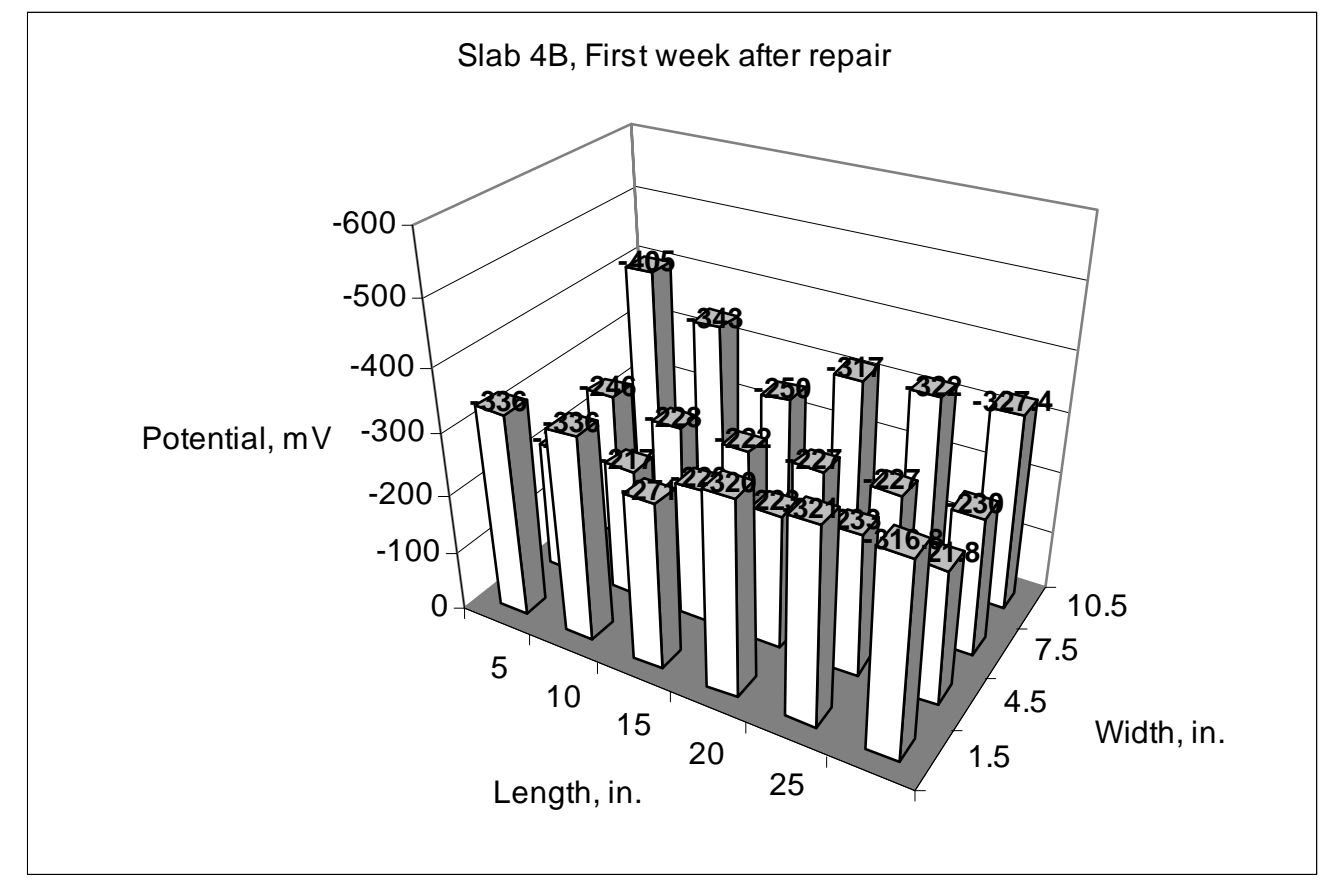

Figure C.23 Half-cell potentials of slab 4B first week after repair with the concrete containing organic corrosion inhibitor. Potential values are versus copper-copper sulfate electrode.

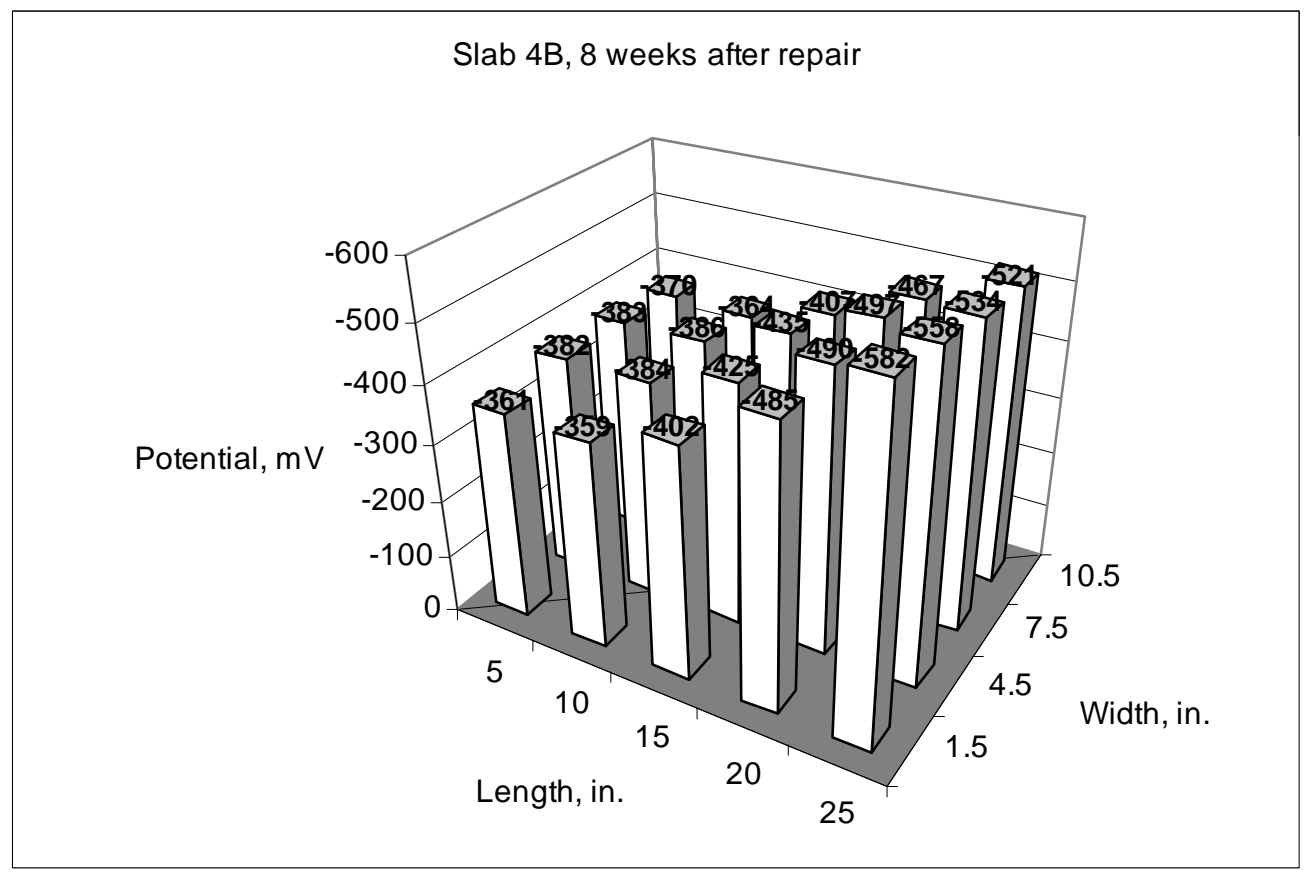

Figure C.24 Half-cell potentials of slab 4B eight weeks after repair with the concrete containing organic corrosion inhibitor. Potential values are versus copper-copper sulfate electrode. 


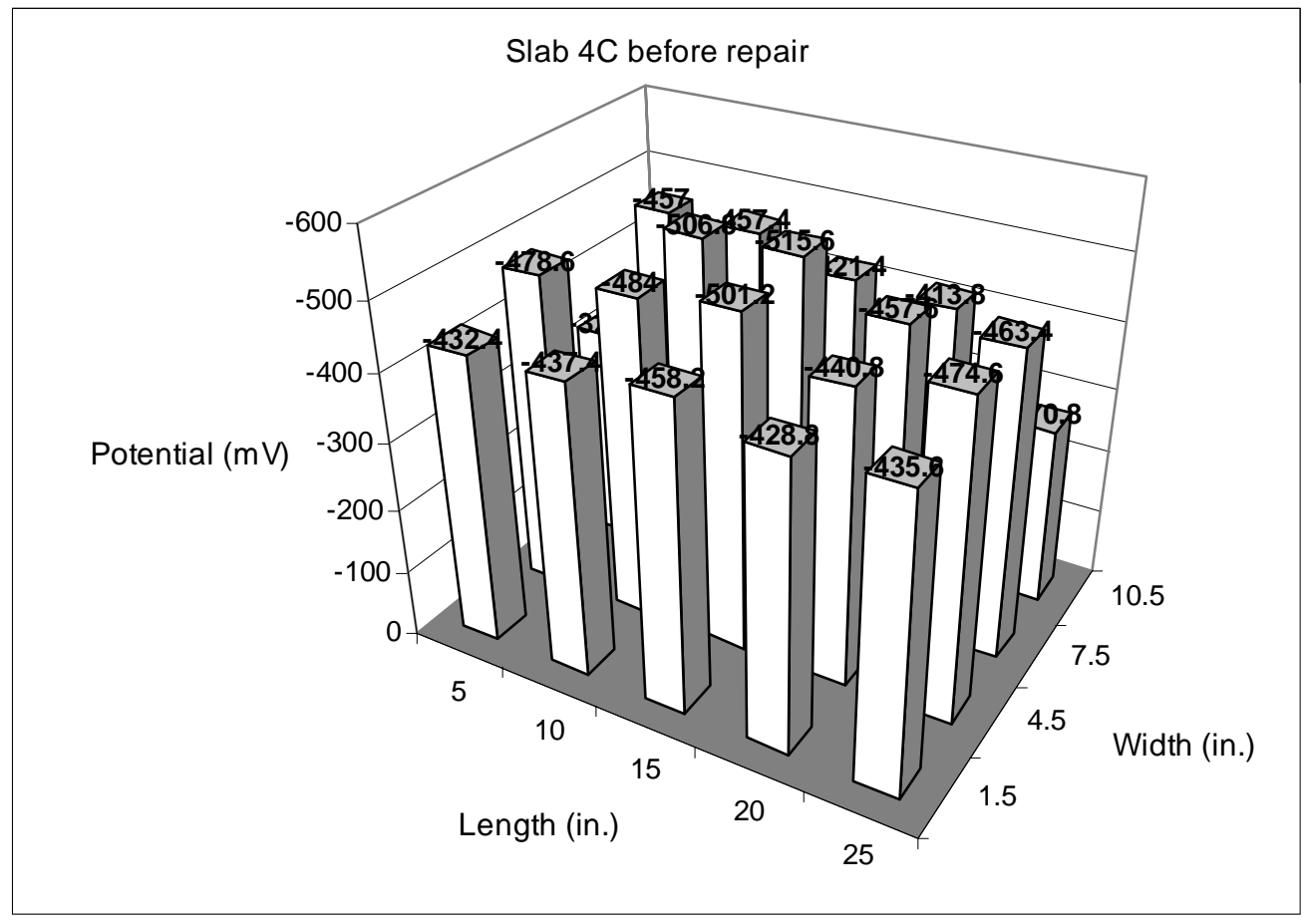

Figure C. 25 Half-cell potentials of slab $4 \mathrm{C}$ before repair with the concrete containing organic corrosion inhibitor. Potential values are versus copper-copper sulfate electrode.

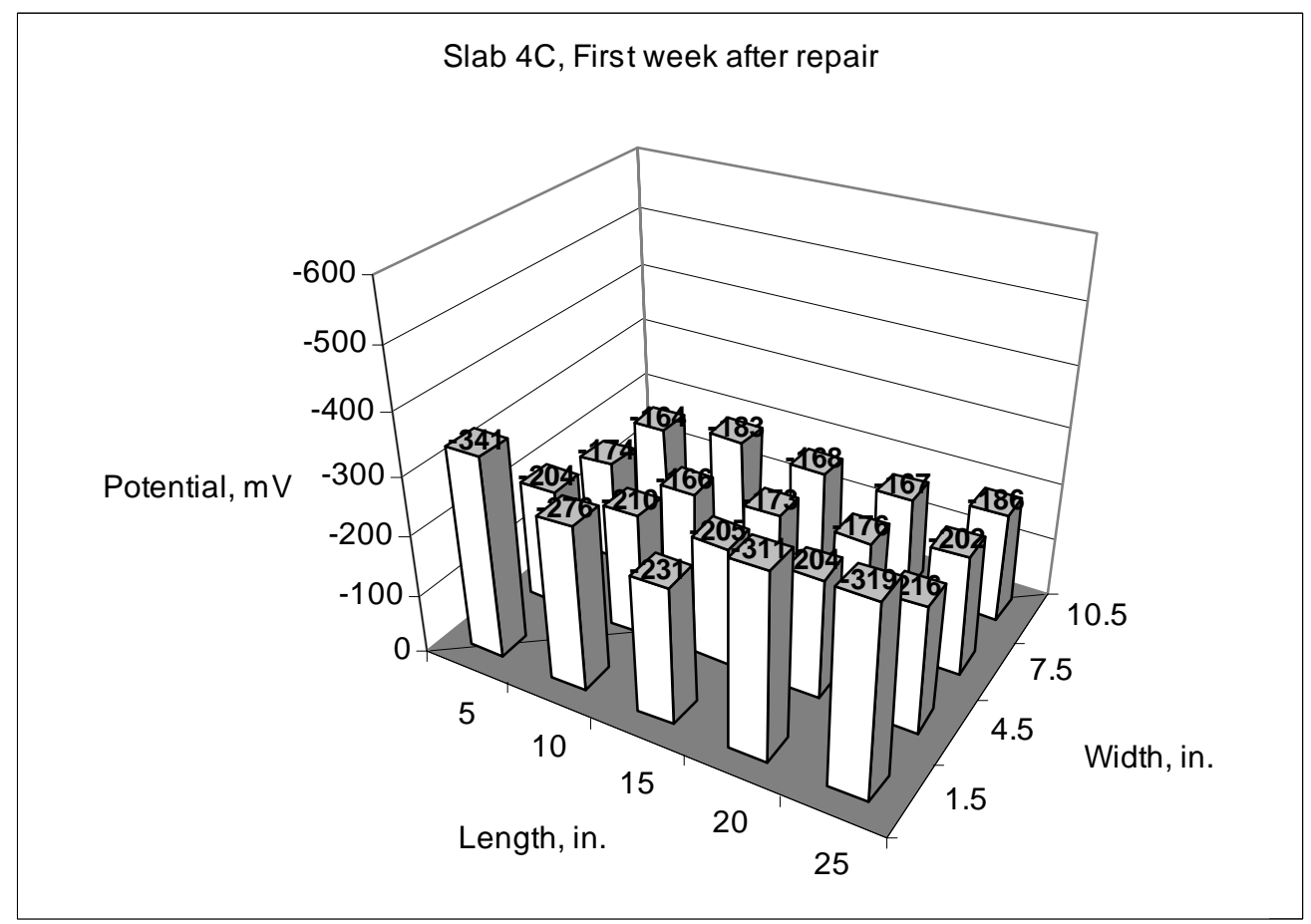

Figure C.26 Half-cell potentials of slab 4C first week after repair with the concrete containing organic corrosion inhibitor. Potential values are versus copper-copper sulfate electrode. 


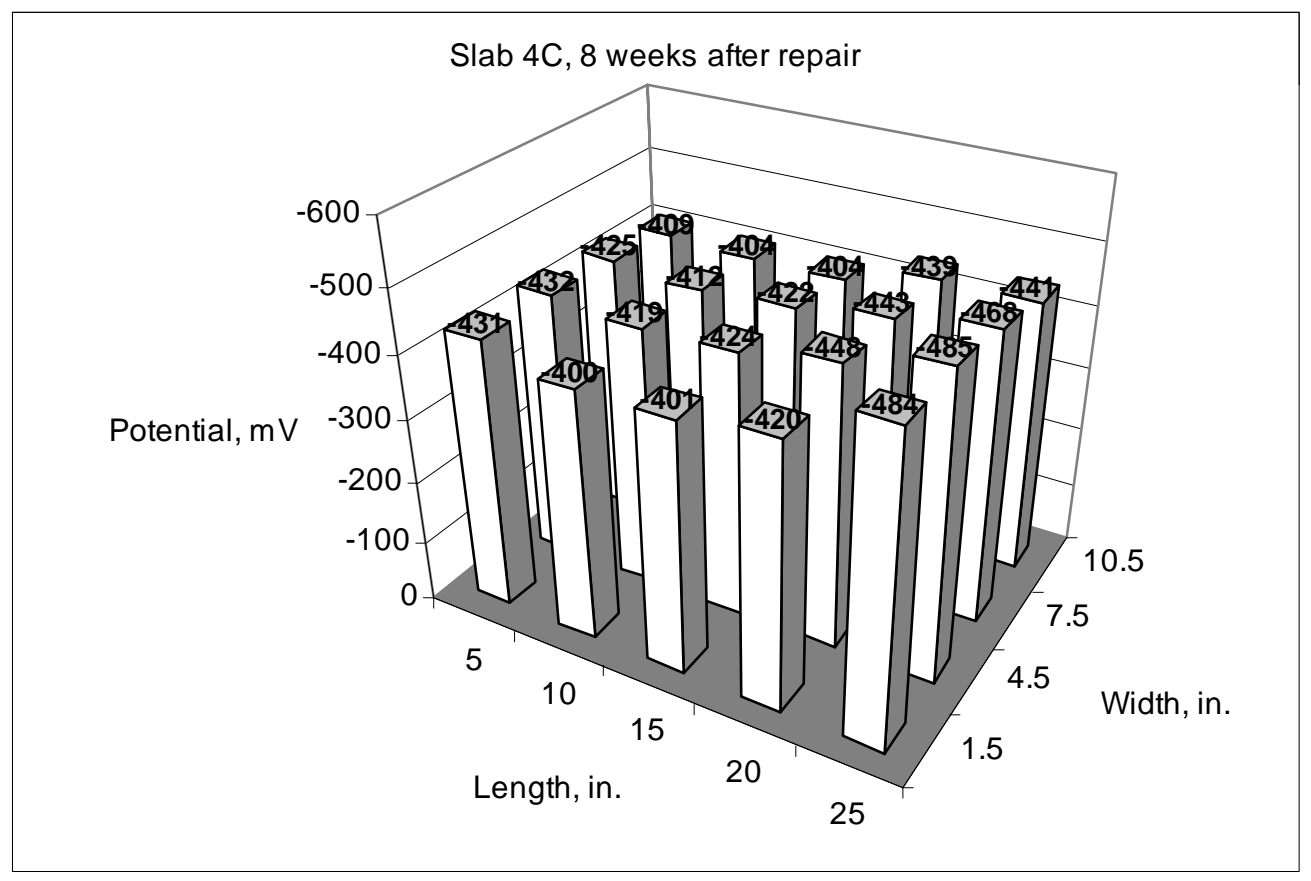

Figure C.27 Half-cell potentials of slab 4C eight weeks after repair with the concrete containing organic corrosion inhibitor. Potential values are versus copper-copper sulfate electrode.

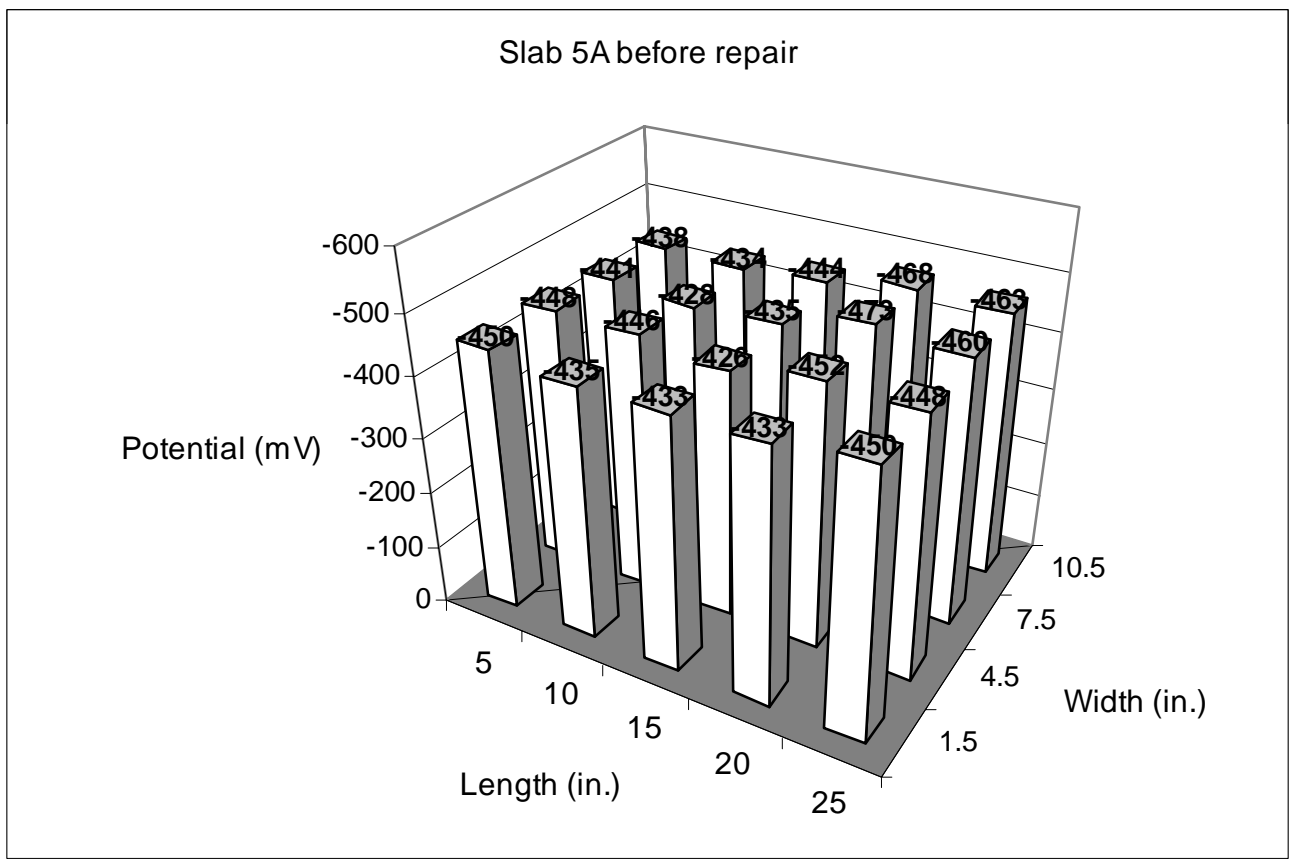

Figure C.28 Half-cell potentials of slab 5A before repair with the fly ash concrete.

Potential values are versus copper-copper sulfate electrode. 


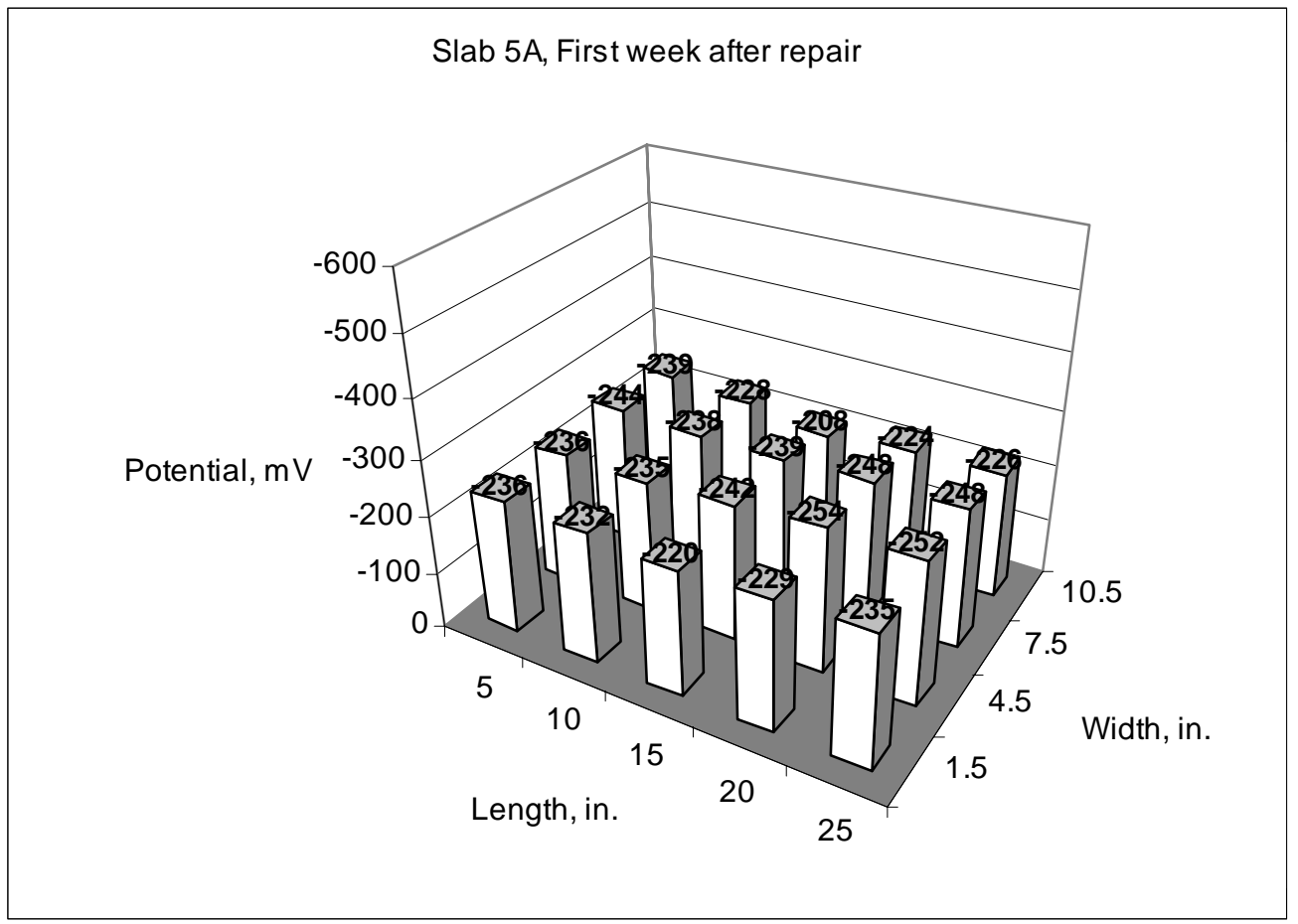

Figure C.29 Half-cell potentials of slab 5A first week after repair with the fly ash concrete. Potential values are versus copper-copper sulfate electrode.

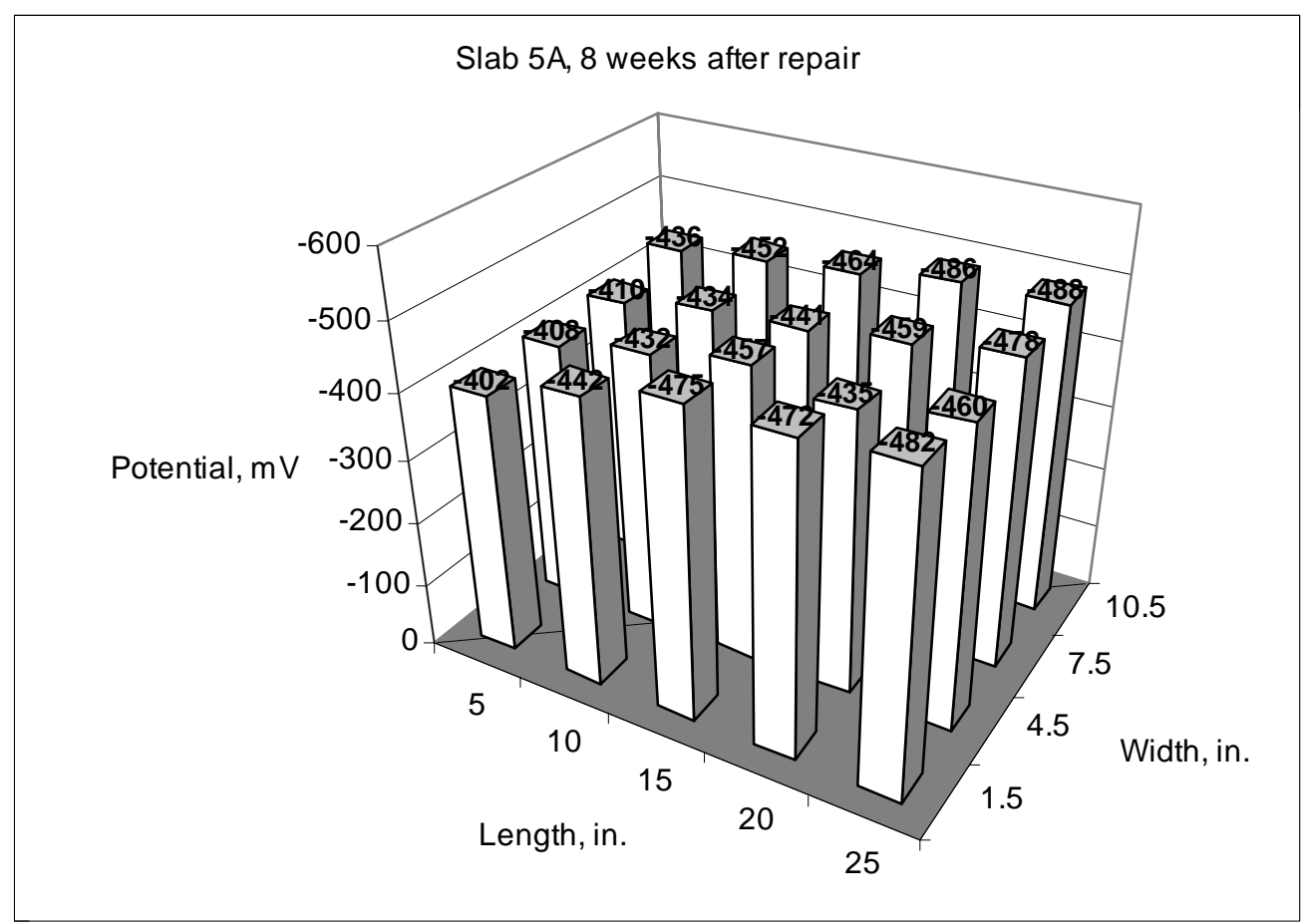

Figure C.30 Half-cell potentials of slab 5A eight weeks after repair with the fly ash concrete. Potential values are versus copper-copper sulfate electrode. 


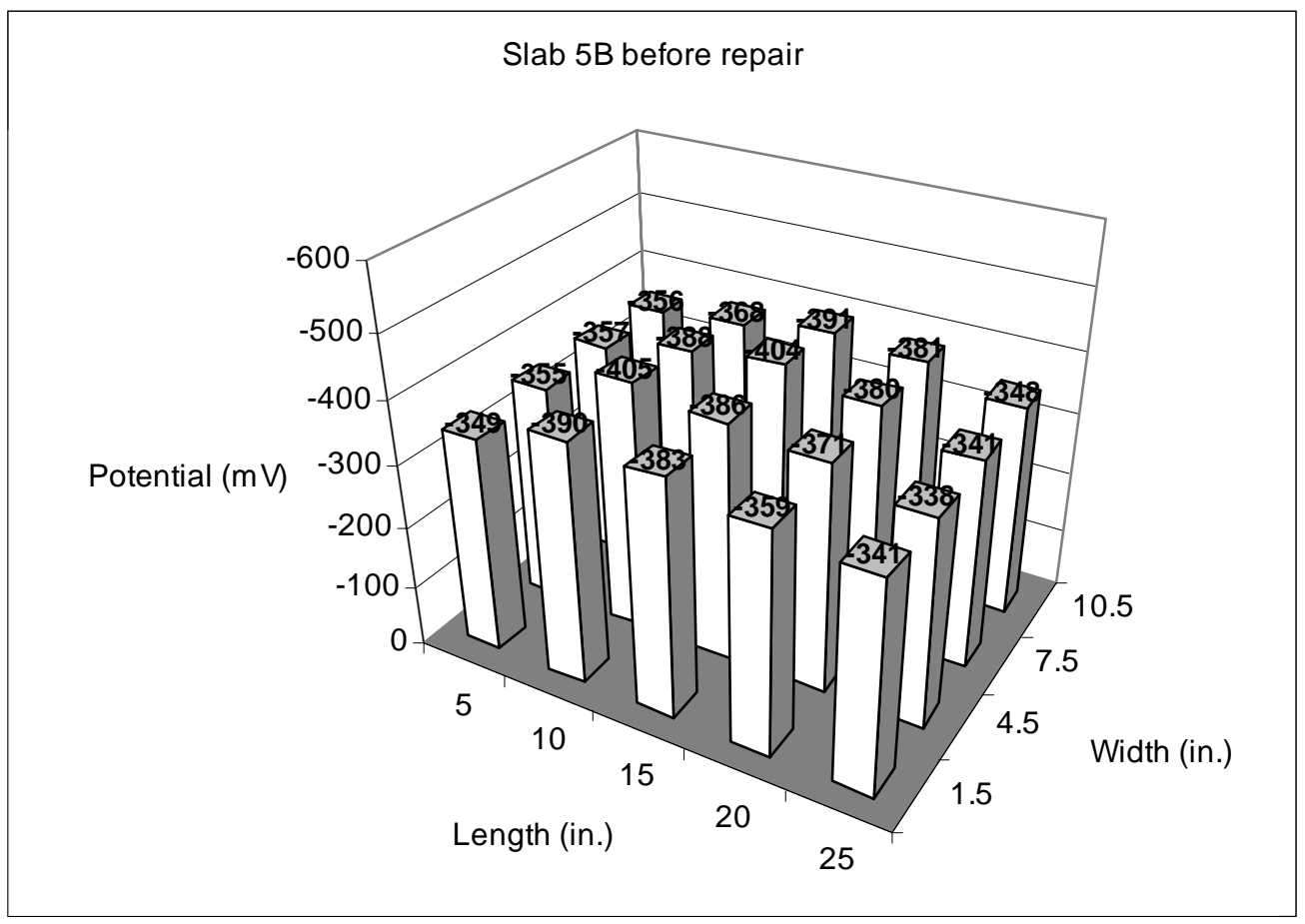

Figure C.31 Half-cell potentials of slab 5B before repair with the fly ash concrete. Potential values are versus copper-copper sulfate electrode.

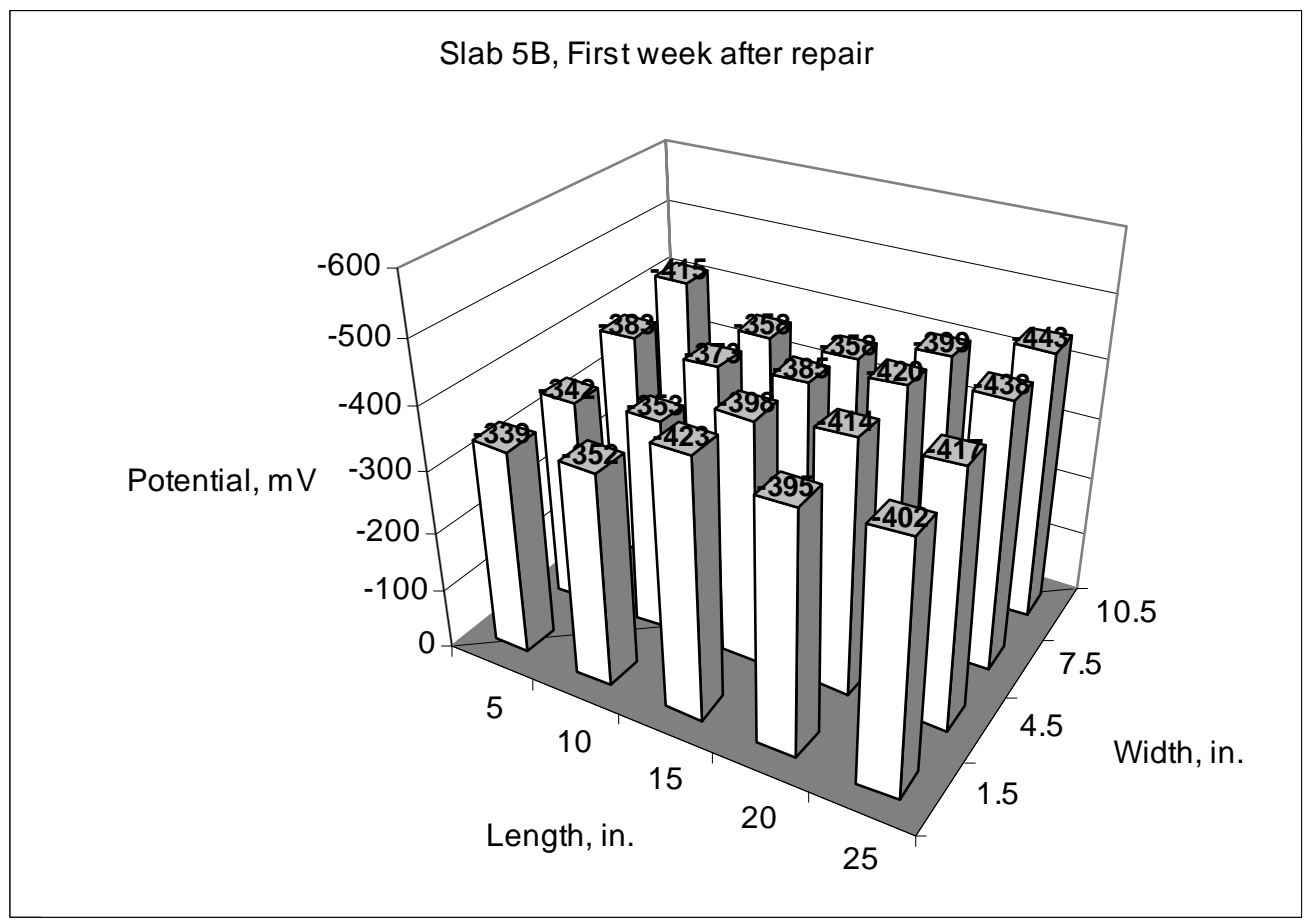

Figure C.32 Half-cell potentials of slab 5B first week after repair with the fly ash concrete. Potential values are versus copper-copper sulfate electrode. 


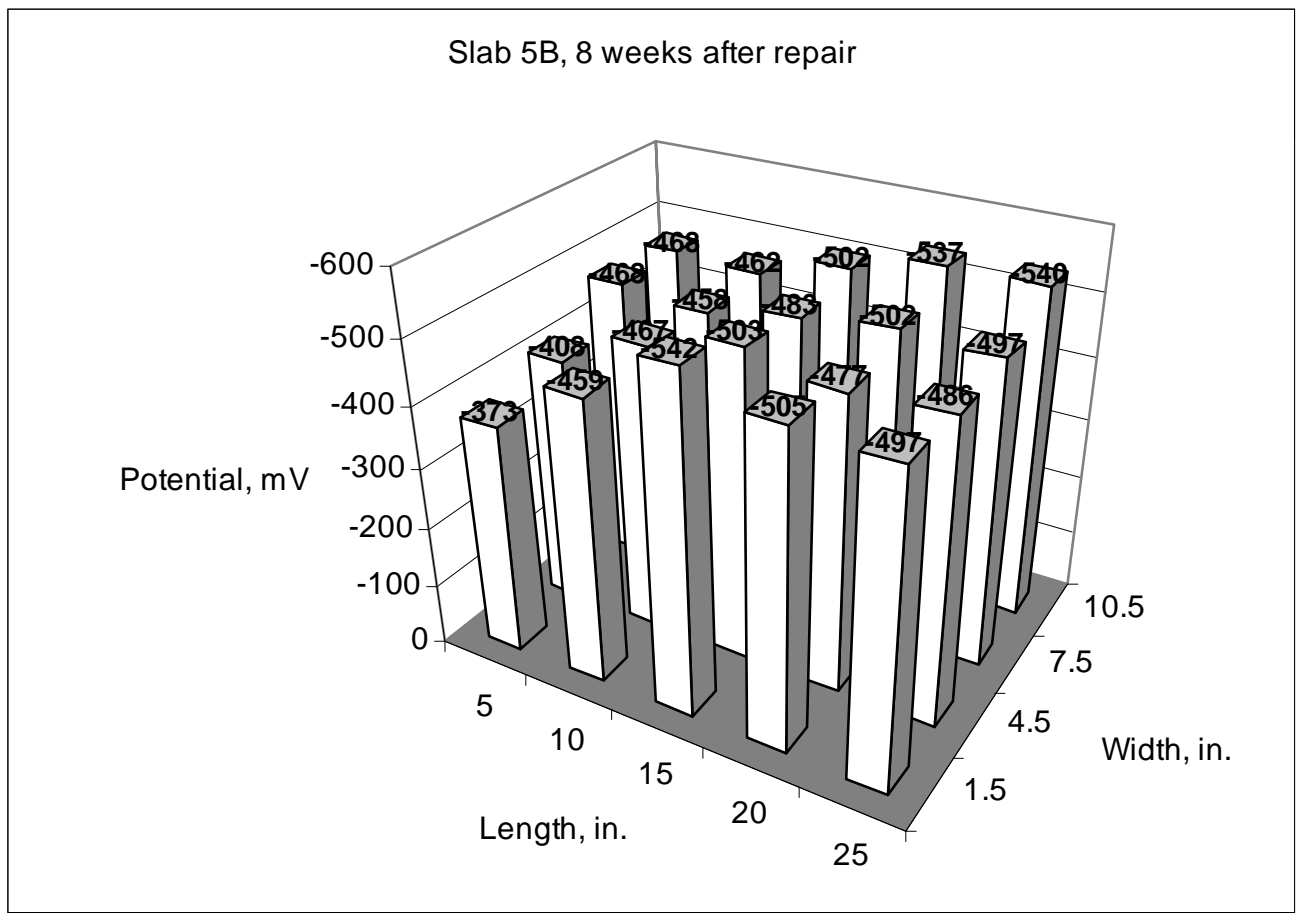

Figure C.33 Half-cell potentials of slab 5B eight weeks after repair with the fly ash concrete. Potential values are versus copper-copper sulfate electrode.

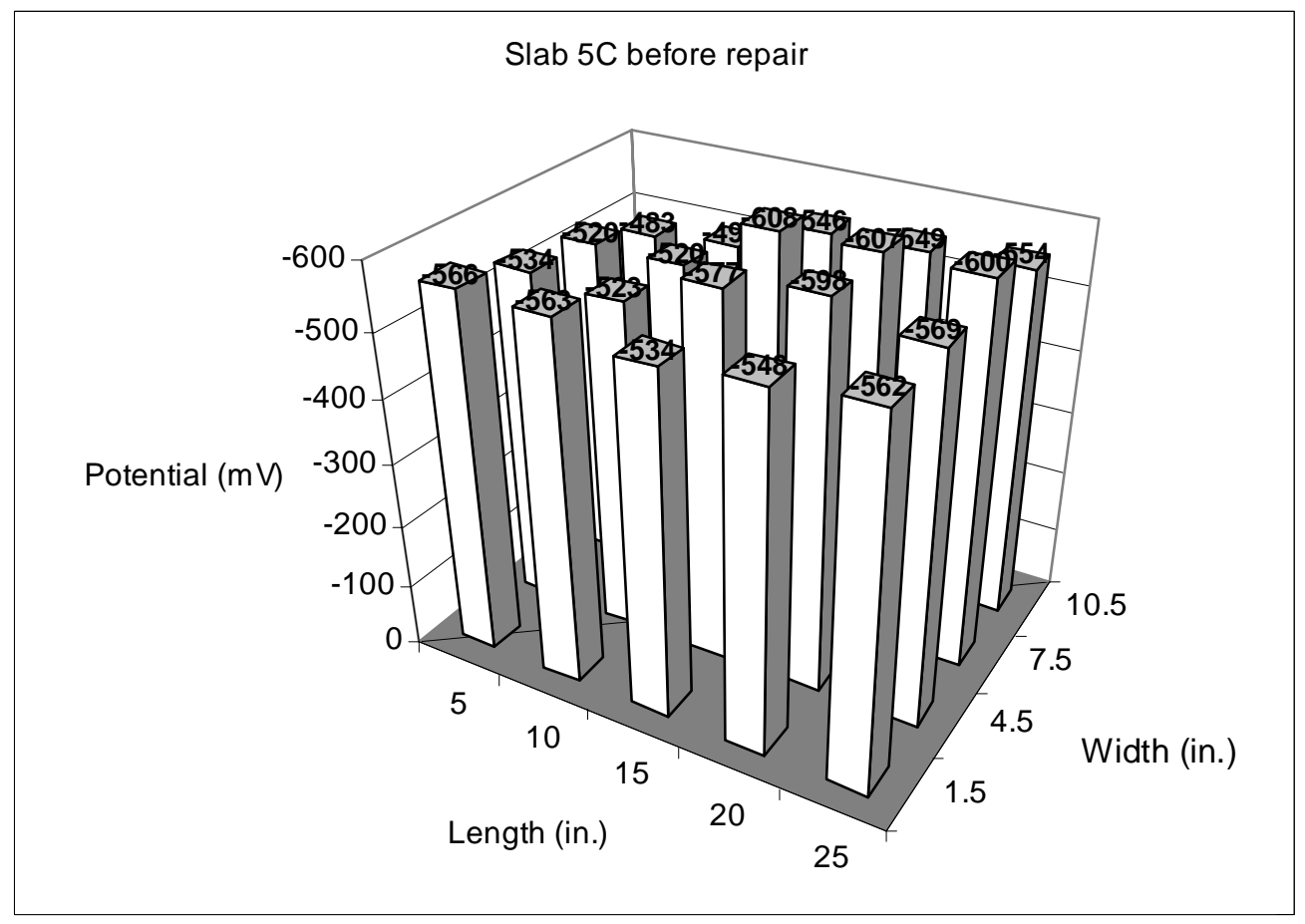

Figure C.34 Half-cell potentials of slab 5C before repair with the fly ash concrete. Potential values are versus copper-copper sulfate electrode. 


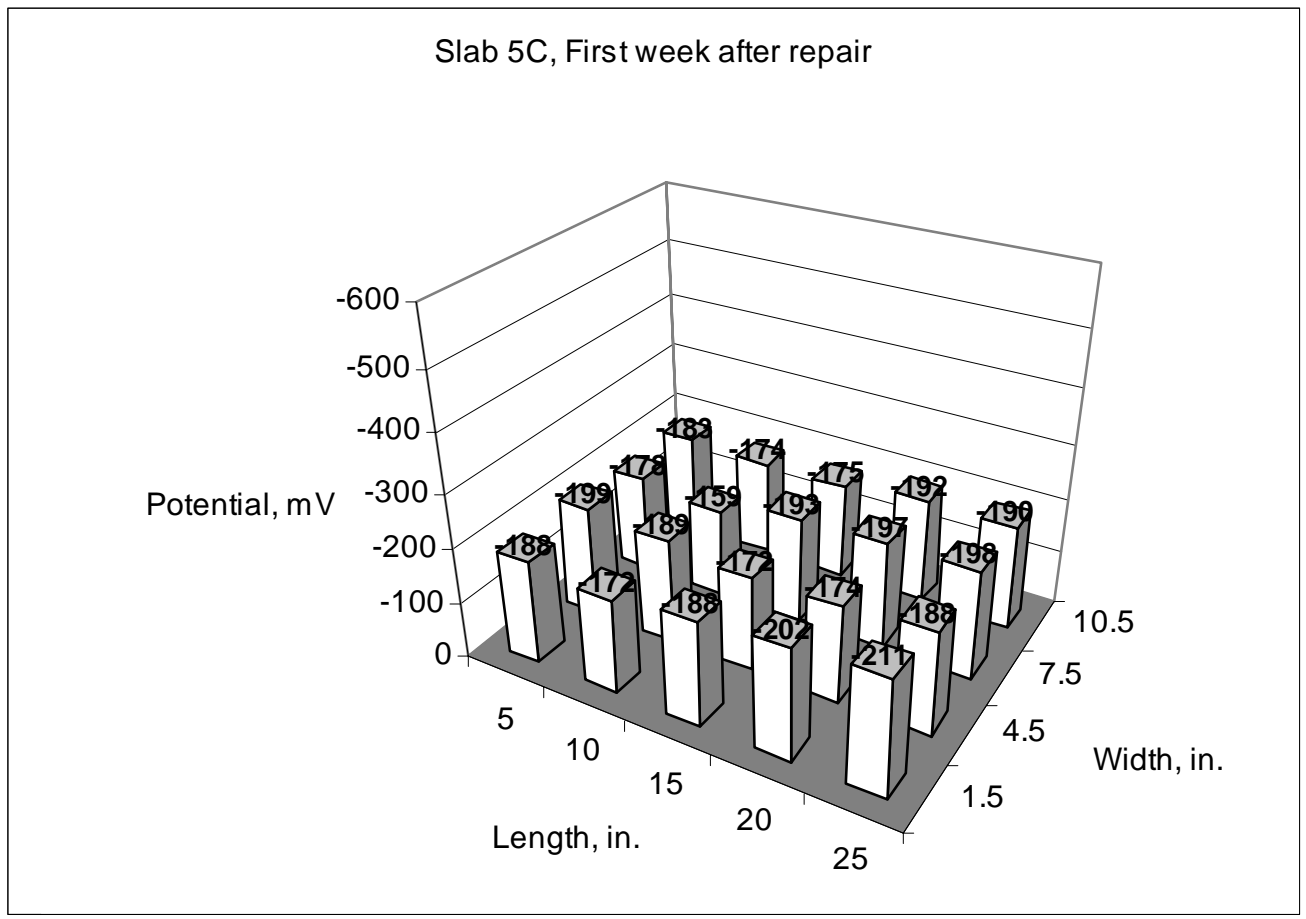

Figure C.35 Half-cell potentials of slab 5C first week after repair with the fly ash concrete. Potential values are versus copper-copper sulfate electrode.

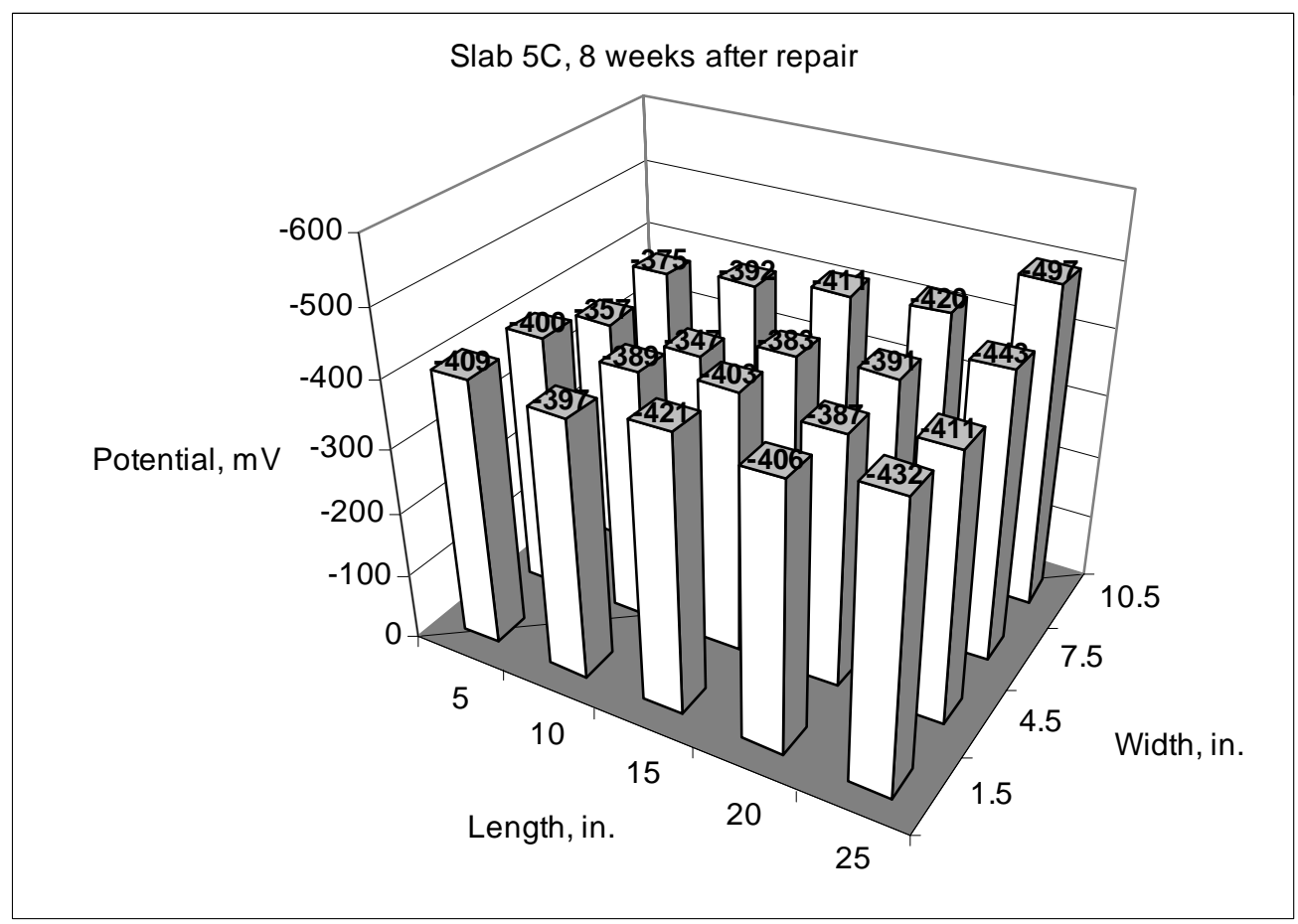

Figure C.36 Half-cell potentials of slab 5C eight weeks after repair with the fly ash concrete. Potential values are versus copper-copper sulfate electrode. 


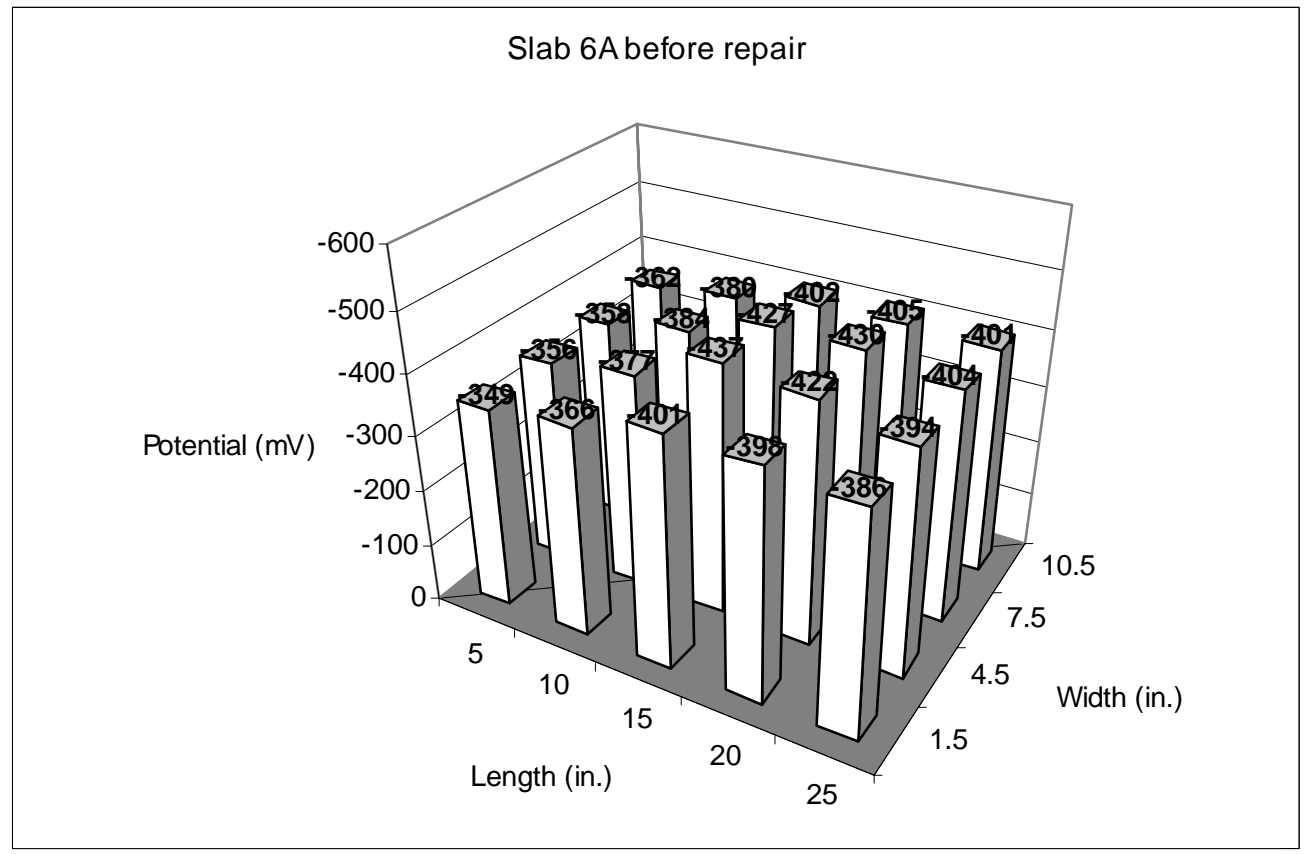

Figure C.37 Half-cell potentials of slab 6A before repair with the INDOT 9-bag concrete. Potential values are versus copper-copper sulfate electrode.

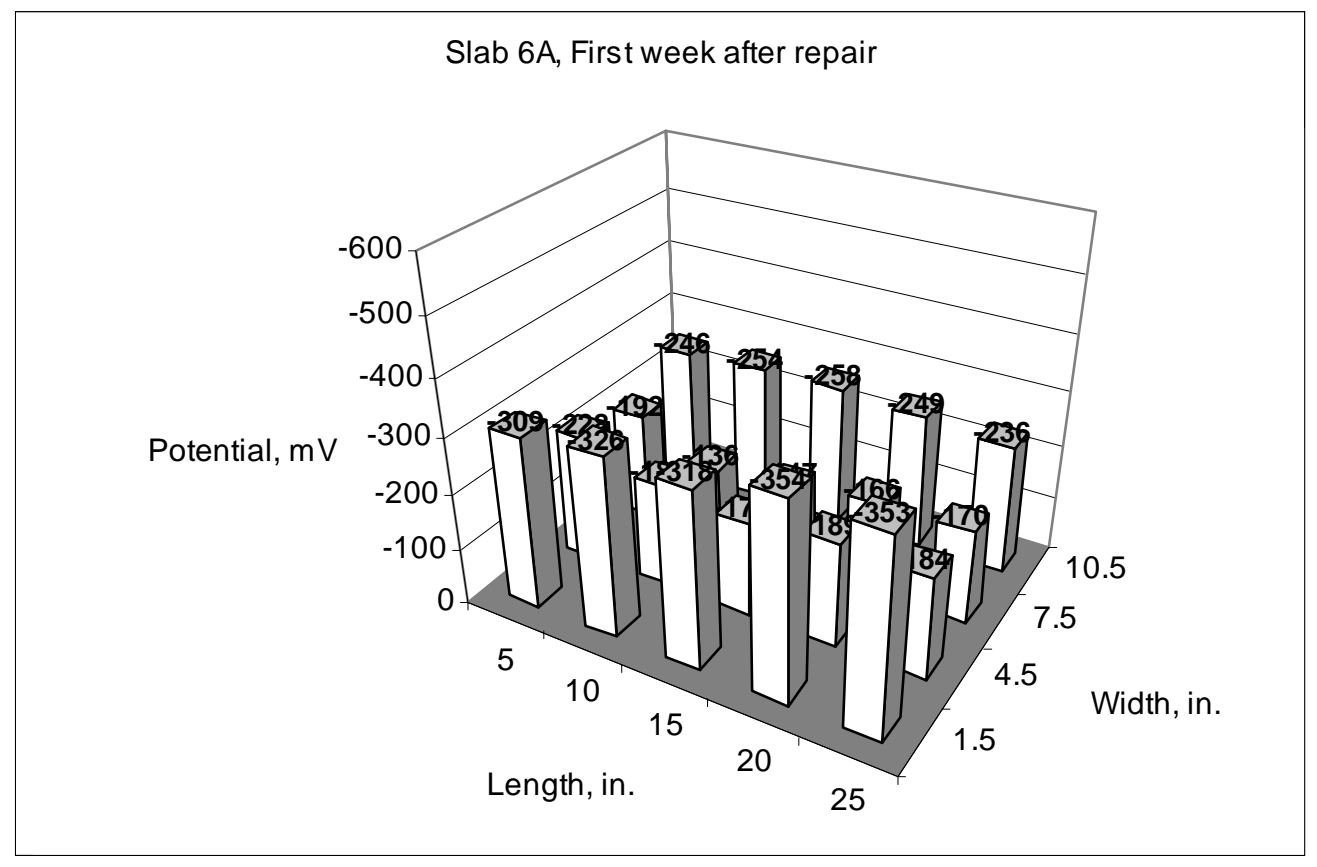

Figure C.38 Half-cell potentials of slab 6A first week after repair with the INDOT 9-bag concrete. Potential values are versus copper-copper sulfate electrode. 


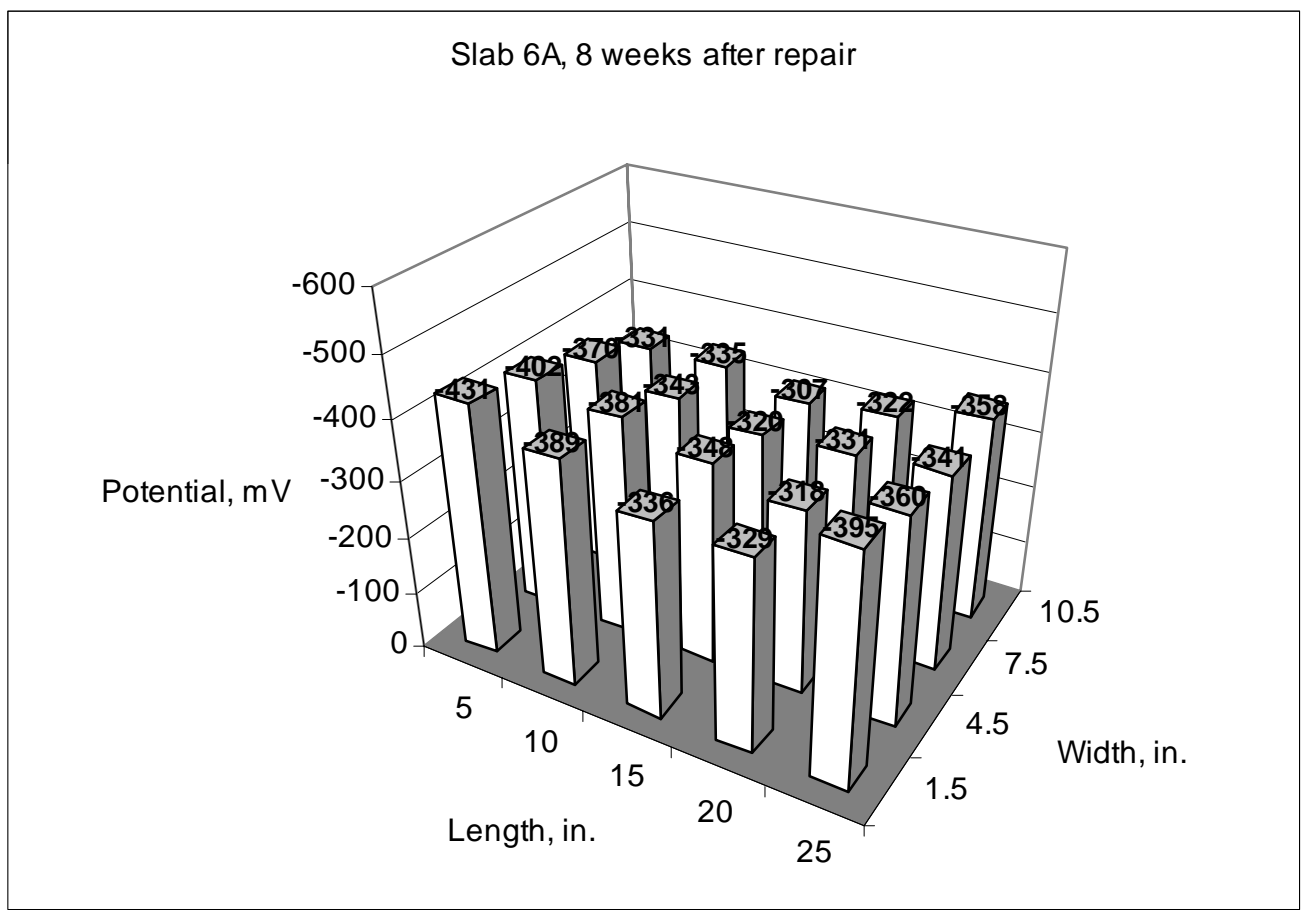

Figure C.39 Half-cell potentials of slab 6A eight weeks after repair with the INDOT 9-bag concrete. Potential values are versus copper-copper sulfate electrode.

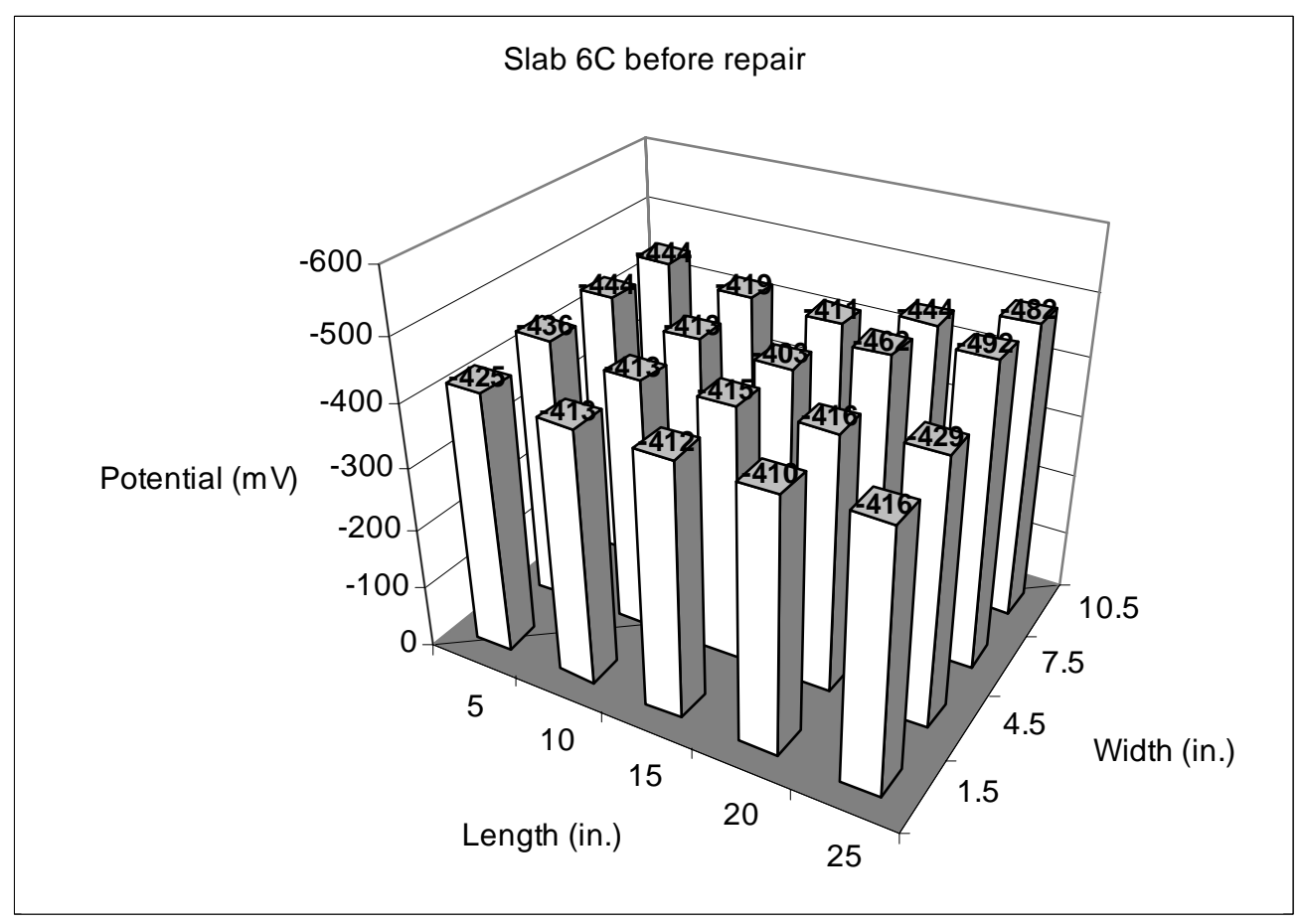

Figure C.40 Half-cell potentials of slab 6C before repair with the INDOT 9-bag concrete. Potential values are versus copper-copper sulfate electrode. 


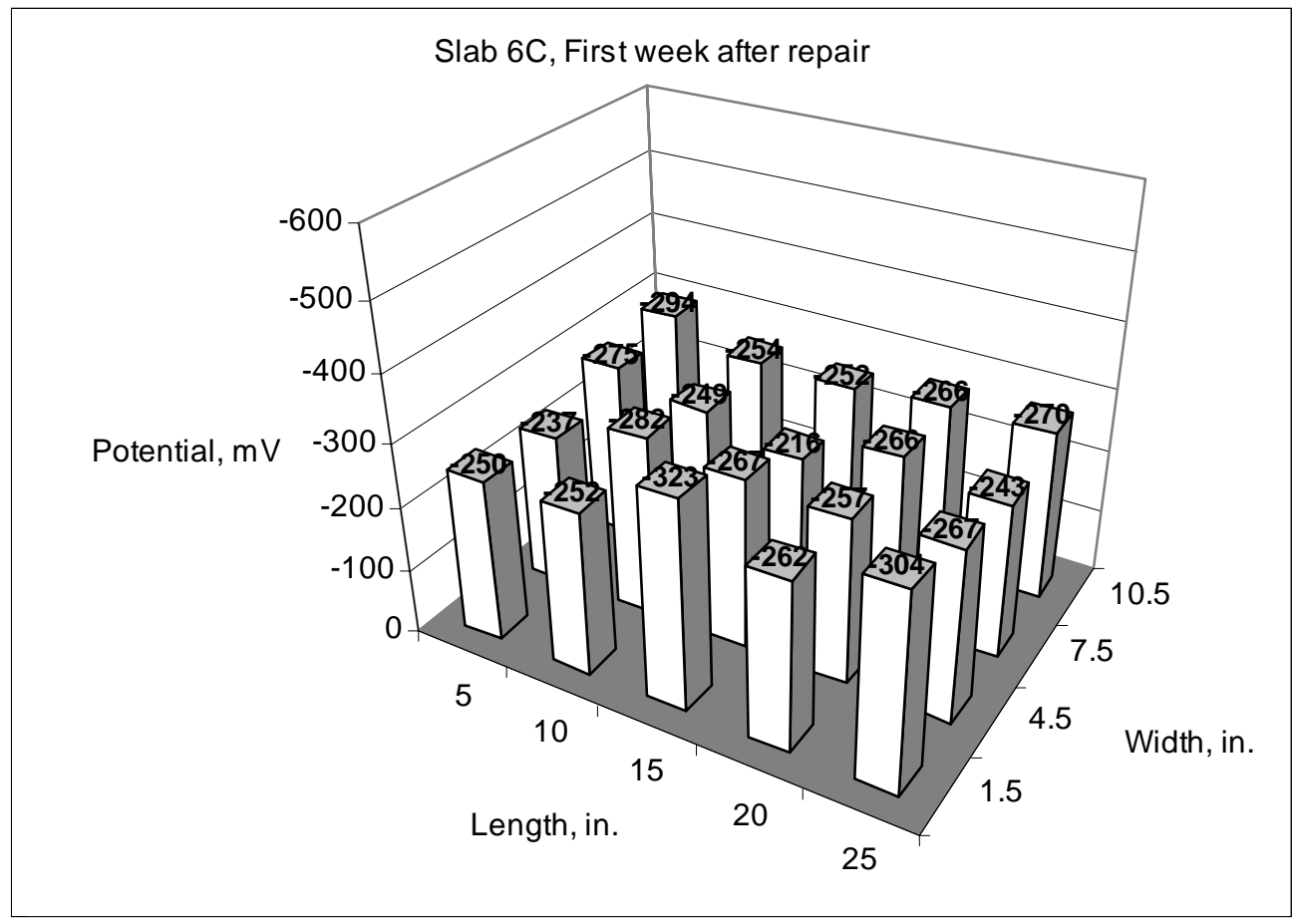

Figure C.41 Half-cell potentials of slab 6C first week after repair with the INDOT 9-bag concrete. Potential values are versus copper-copper sulfate electrode.

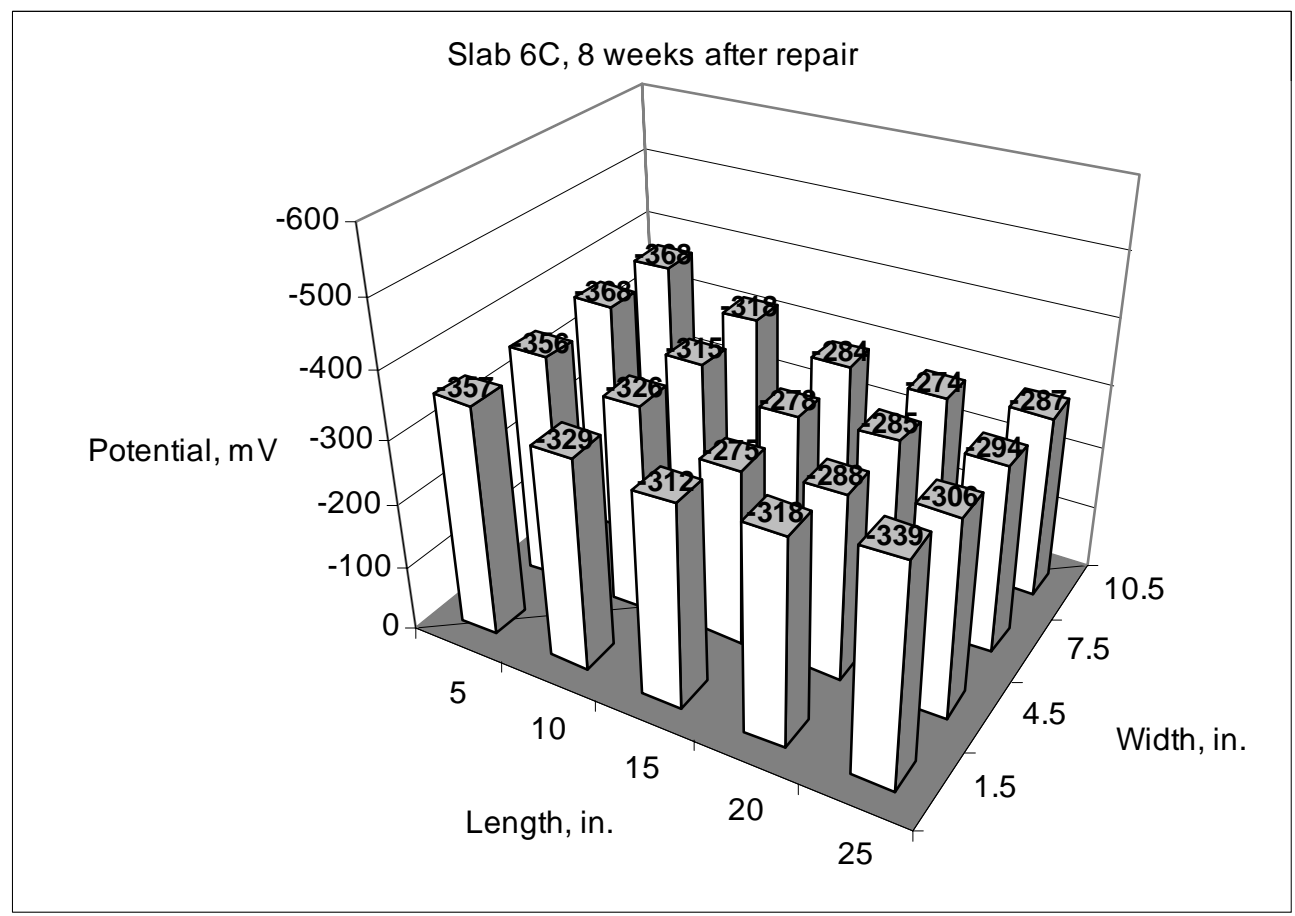

Figure C.42 Half-cell potentials of slab 6C eight weeks after repair with the INDOT 9-bag concrete. Potential values are versus copper-copper sulfate electrode. 


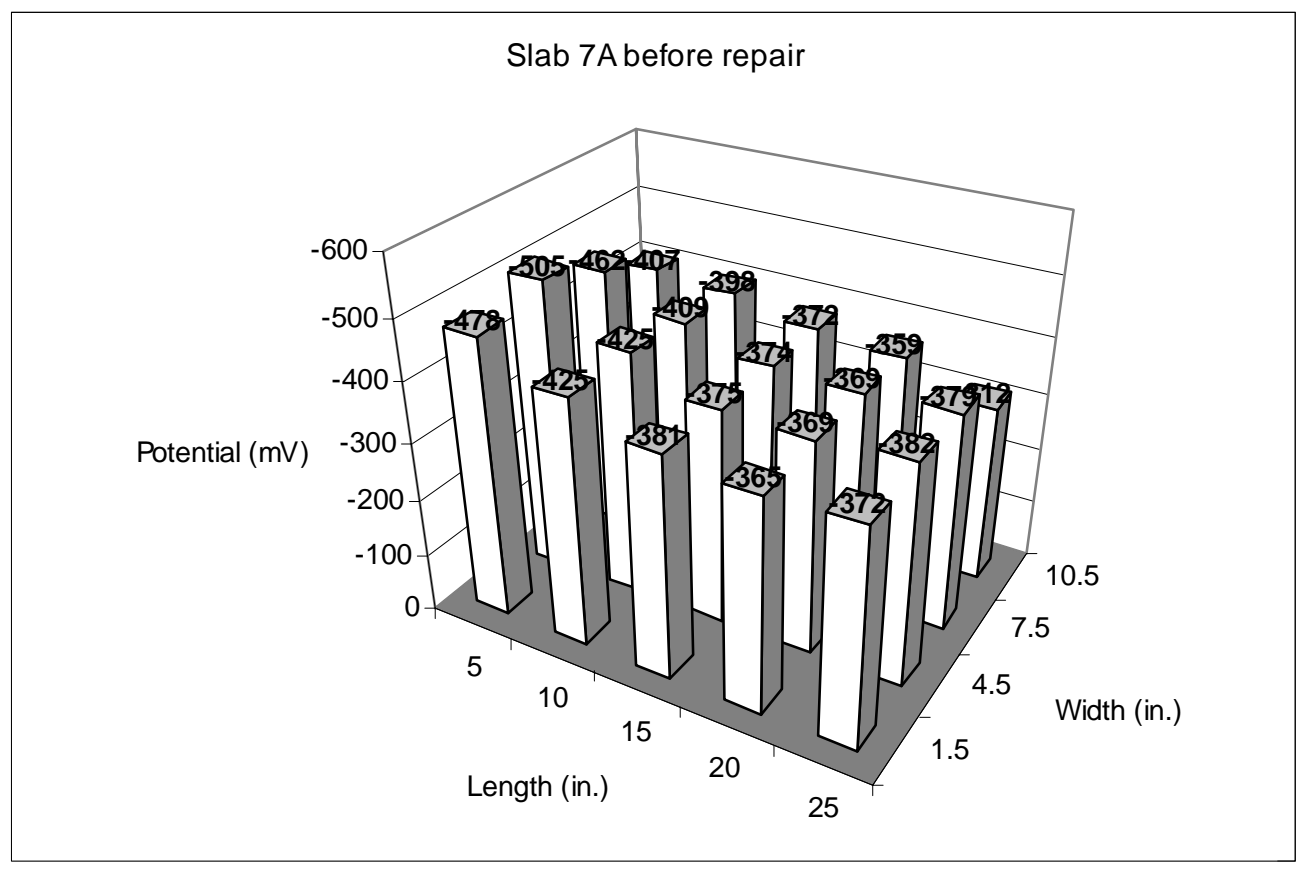

Figure C.43 Half-cell potentials of slab 7A before repair with the concrete containing the shrinkage reducing admixture. Potential values are versus copper-copper sulfate electrode.

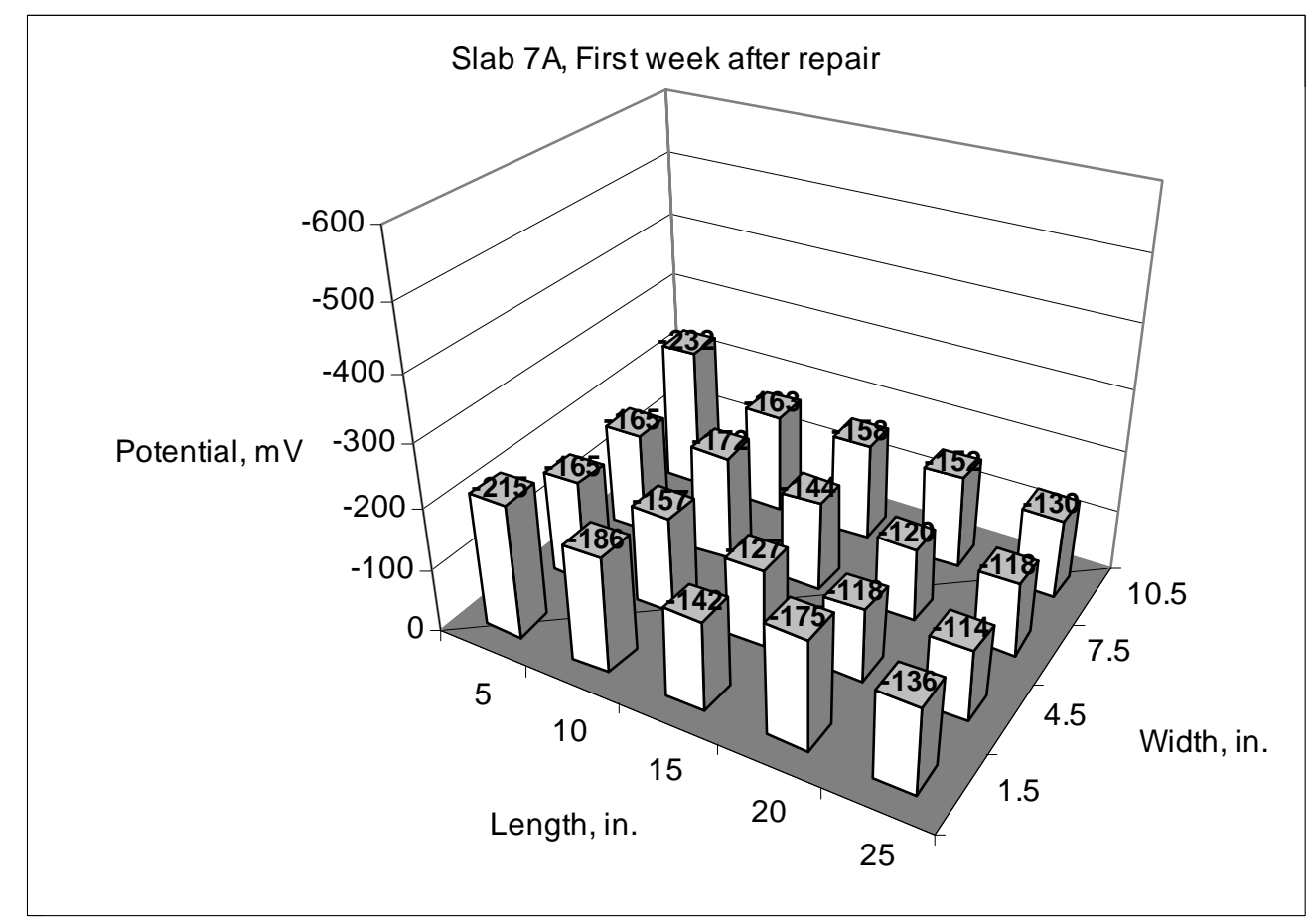

Figure C.44 Half-cell potentials of slab 7A first week after repair with the concrete containing the shrinkage reducing admixture. Potential values are versus copper-copper sulfate electrode. 


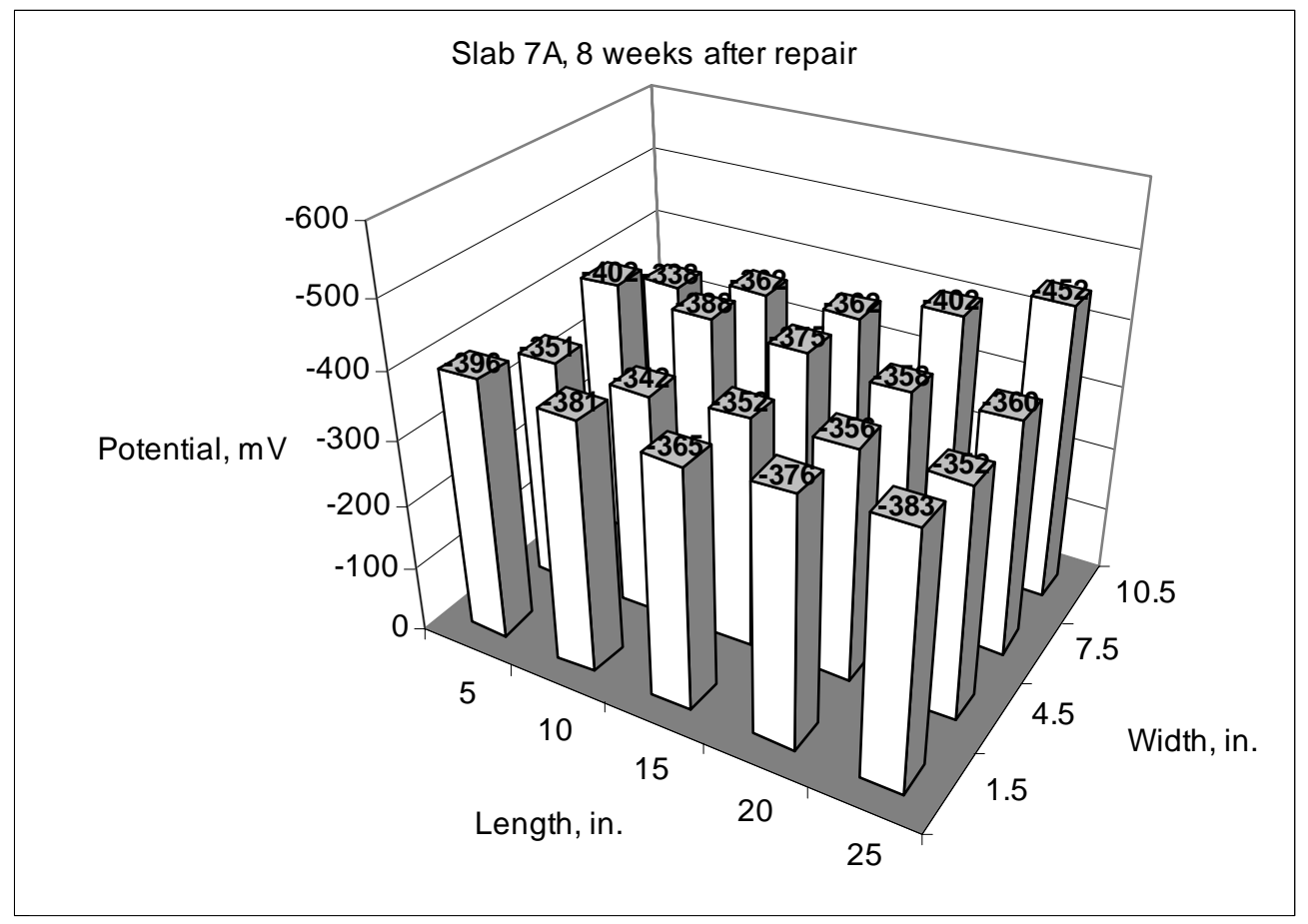

Figure C.45 Half-cell potentials of slab 7A eight weeks after repair with the concrete containing the shrinkage reducing admixture. Potential values are versus copper-copper sulfate electrode.

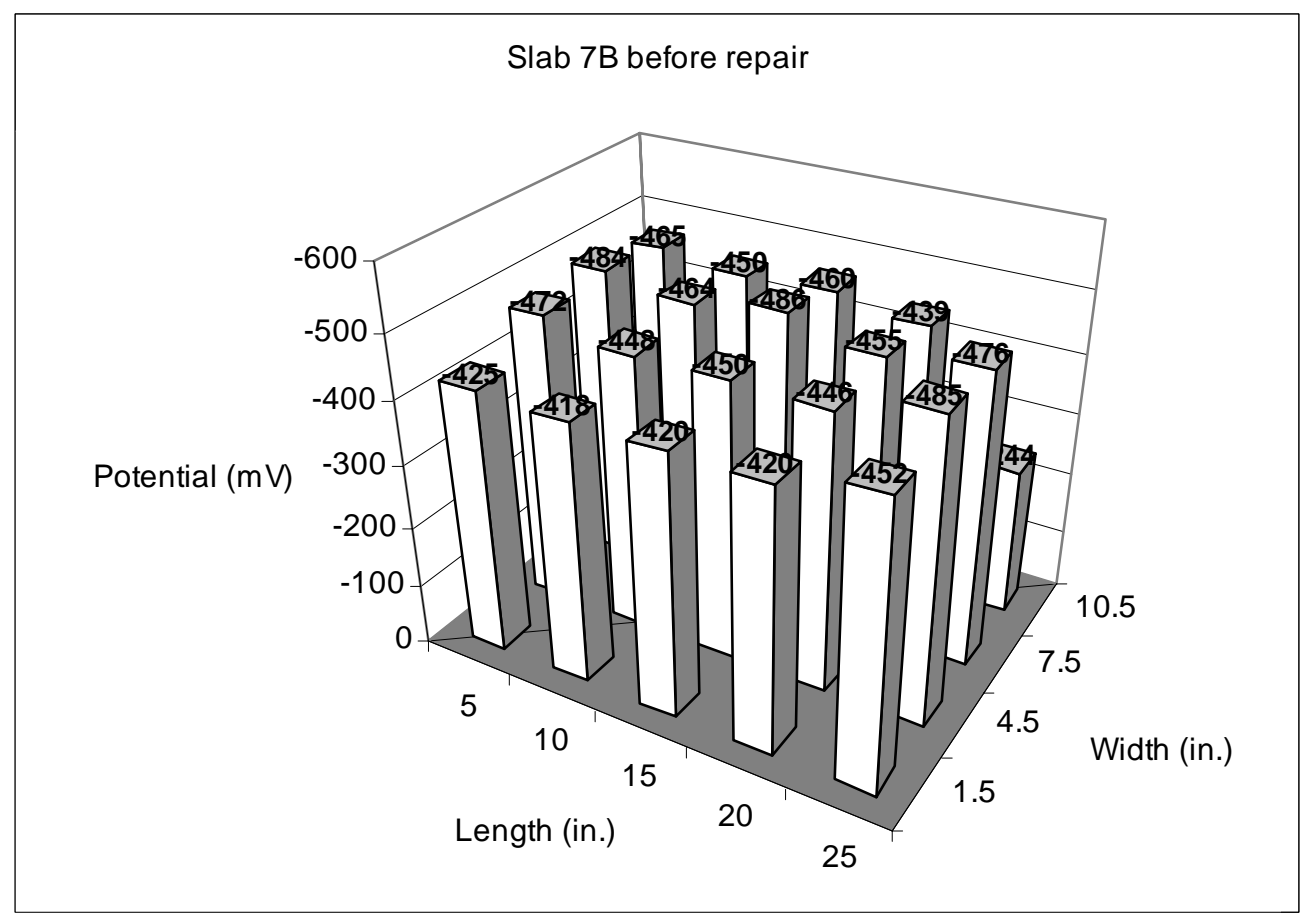

Figure C.46 Half-cell potentials of slab 7B before repair with the concrete containing the shrinkage reducing admixture. Potential values are versus copper-copper sulfate electrode. 


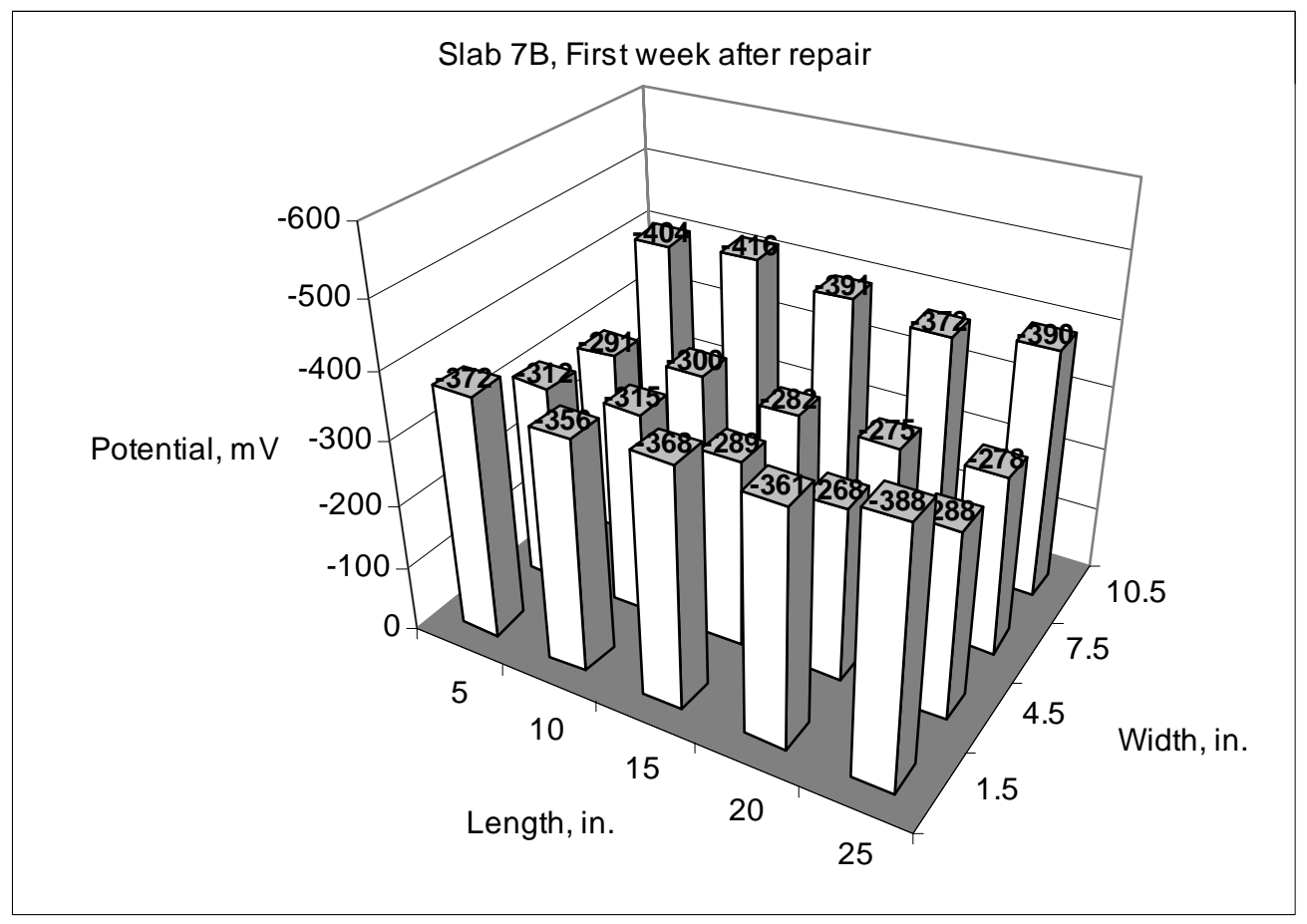

Figure C. 47 Half-cell potentials of slab 7B first week after repair with the concrete containing the shrinkage reducing admixture. Potential values are versus copper-copper sulfate electrode.

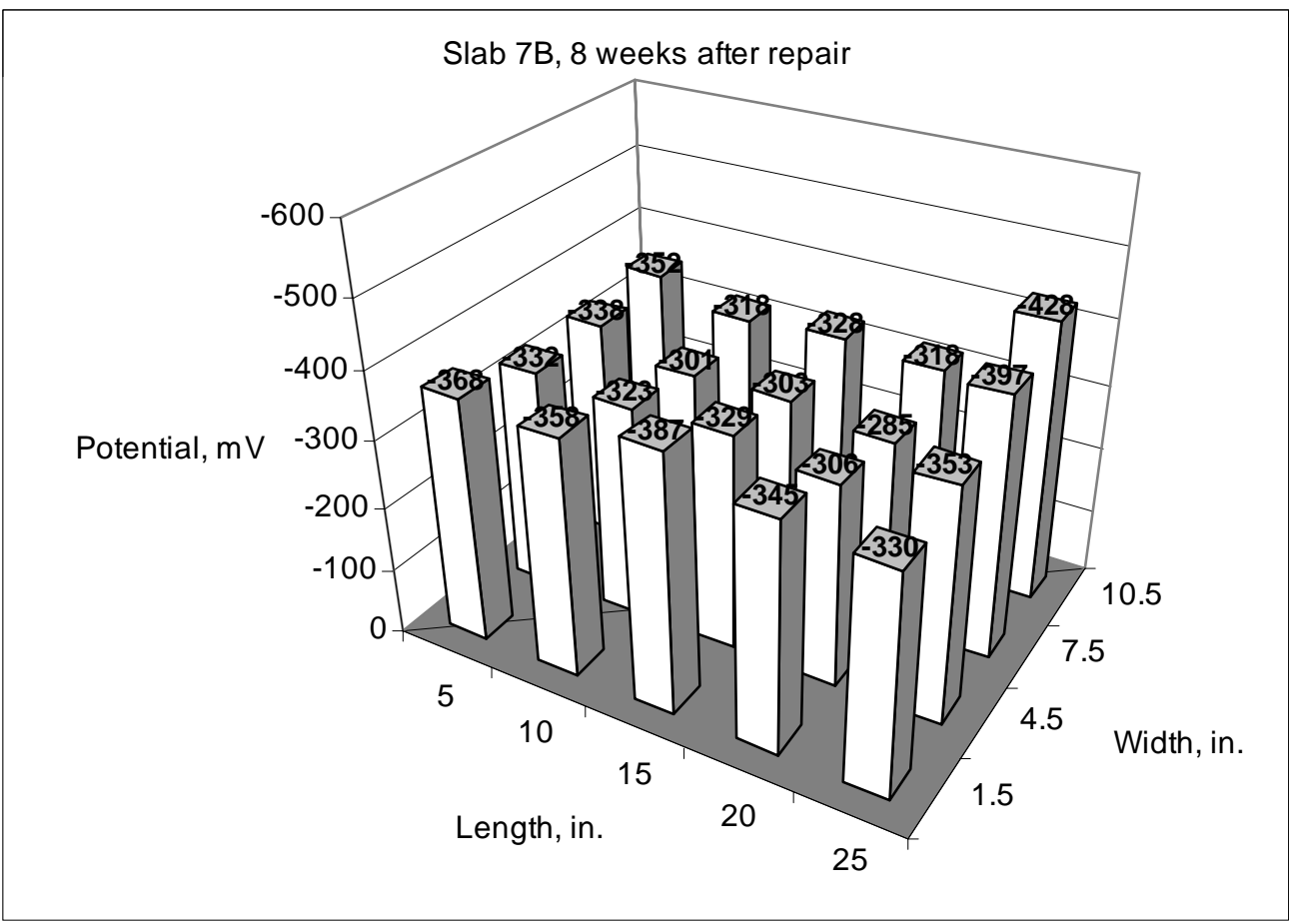

Figure C.48 Half-cell potentials of slab 7B eight weeks after repair with the concrete containing the shrinkage reducing admixture. Potential values are versus copper-copper sulfate electrode. 


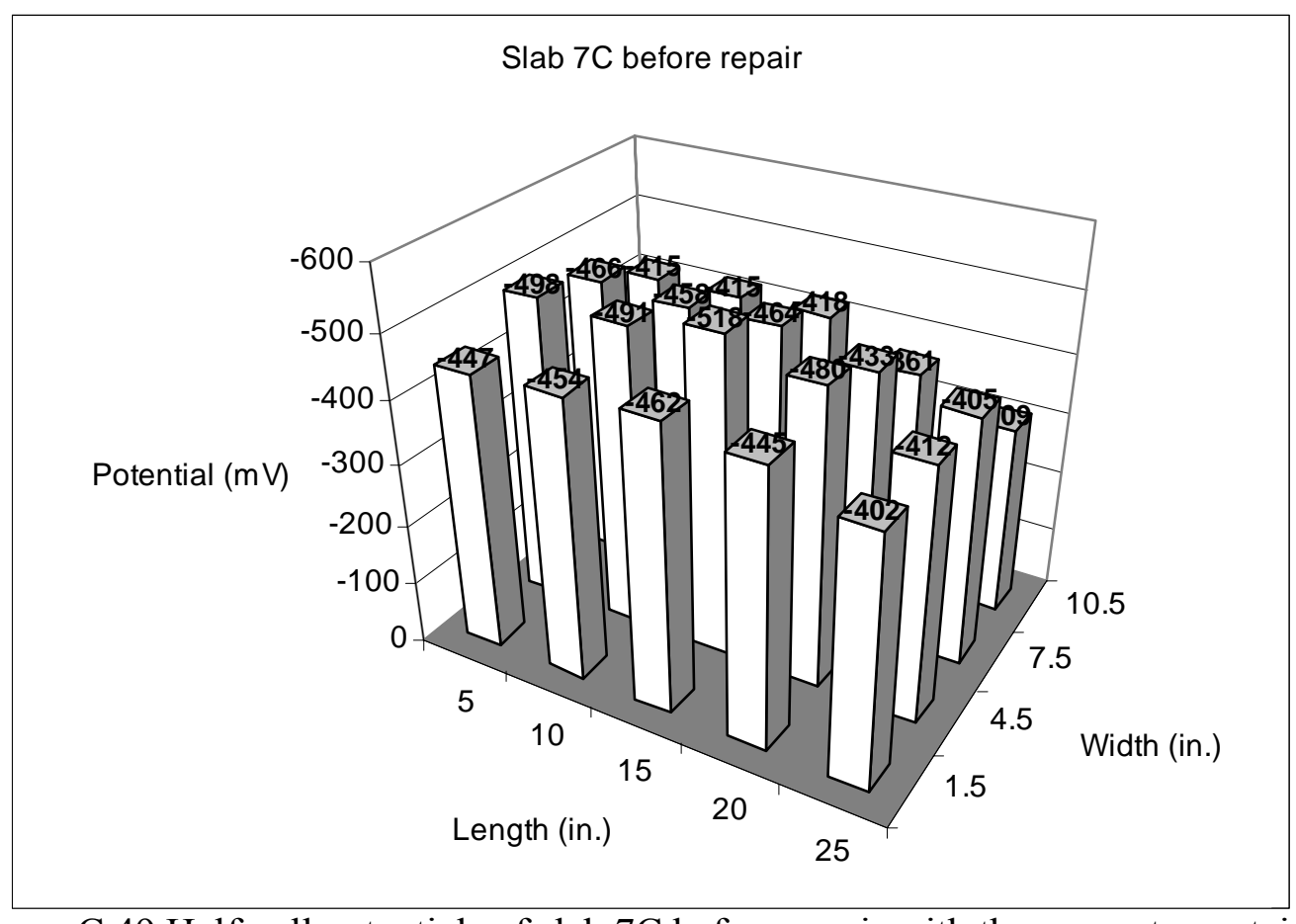

Figure C.49 Half-cell potentials of slab 7C before repair with the concrete containing the shrinkage reducing admixture. Potential values are versus copper-copper sulfate electrode.

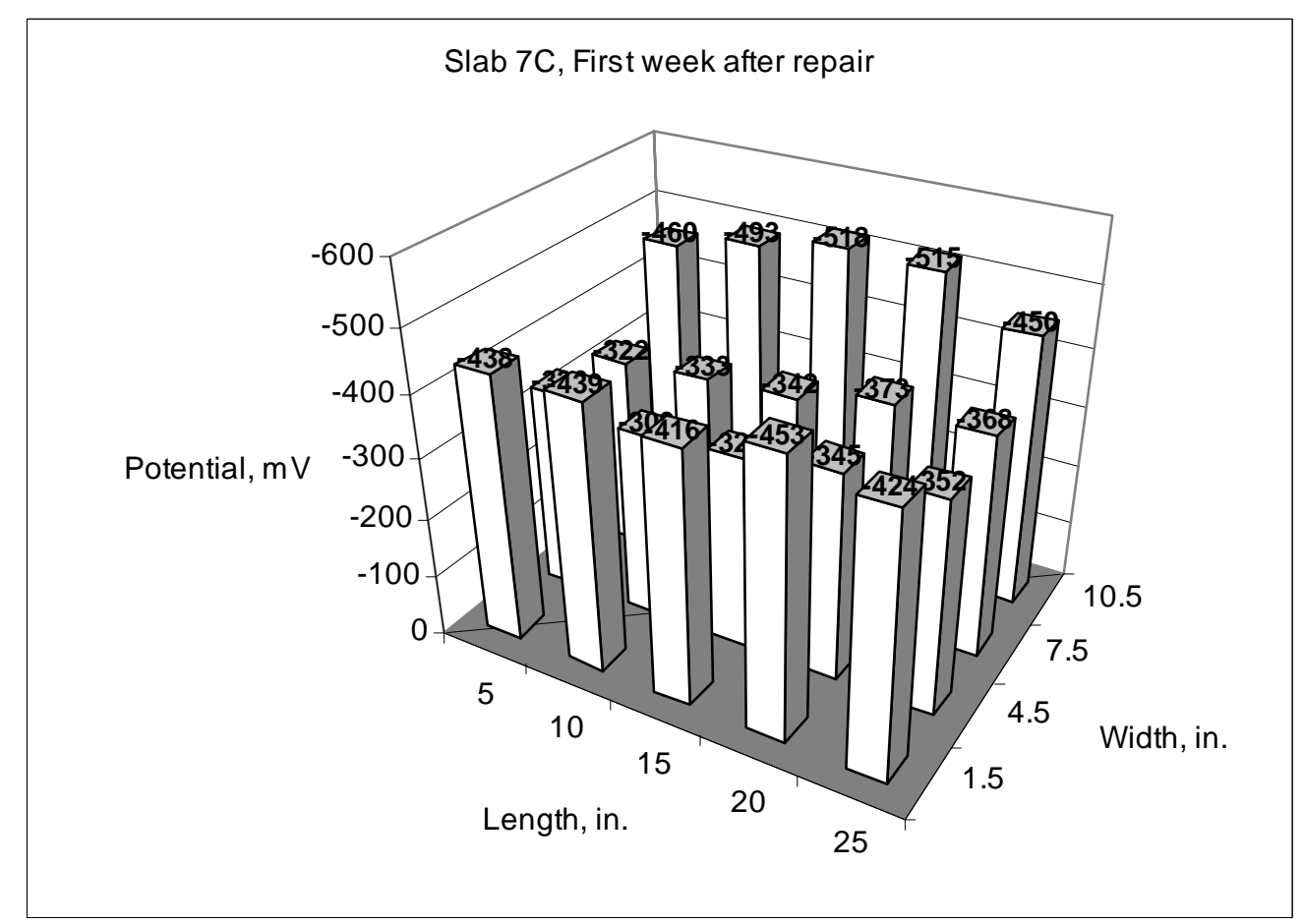

Figure C.50 Half-cell potentials of slab 7C first week after repair with the concrete containing the shrinkage reducing admixture. Potential values are versus copper-copper sulfate electrode. 


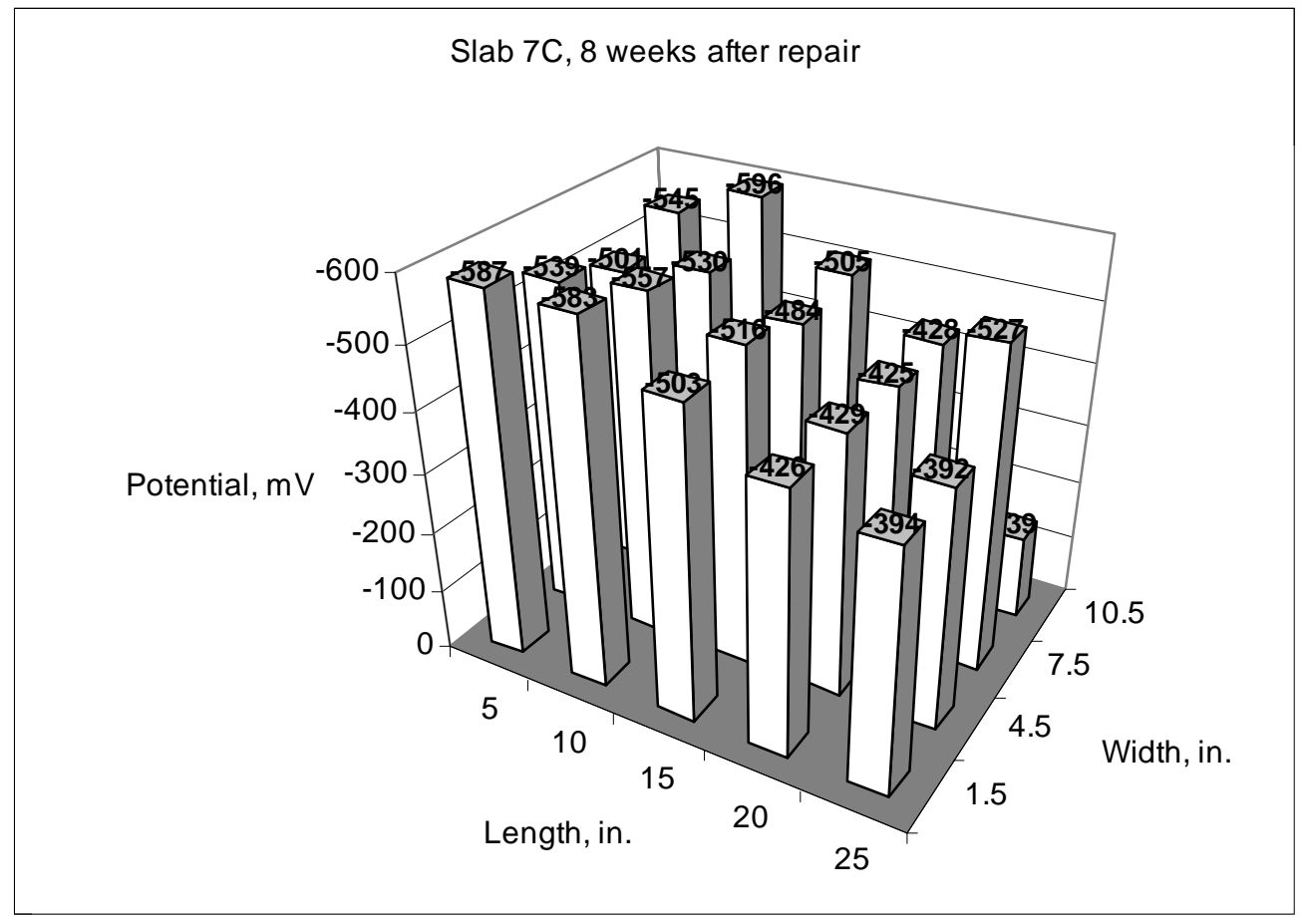

Figure C.51 Half-cell potentials of slab 7C eight weeks after repair with the concrete containing the shrinkage reducing admixture. Potential values are versus copper-copper sulfate electrode.

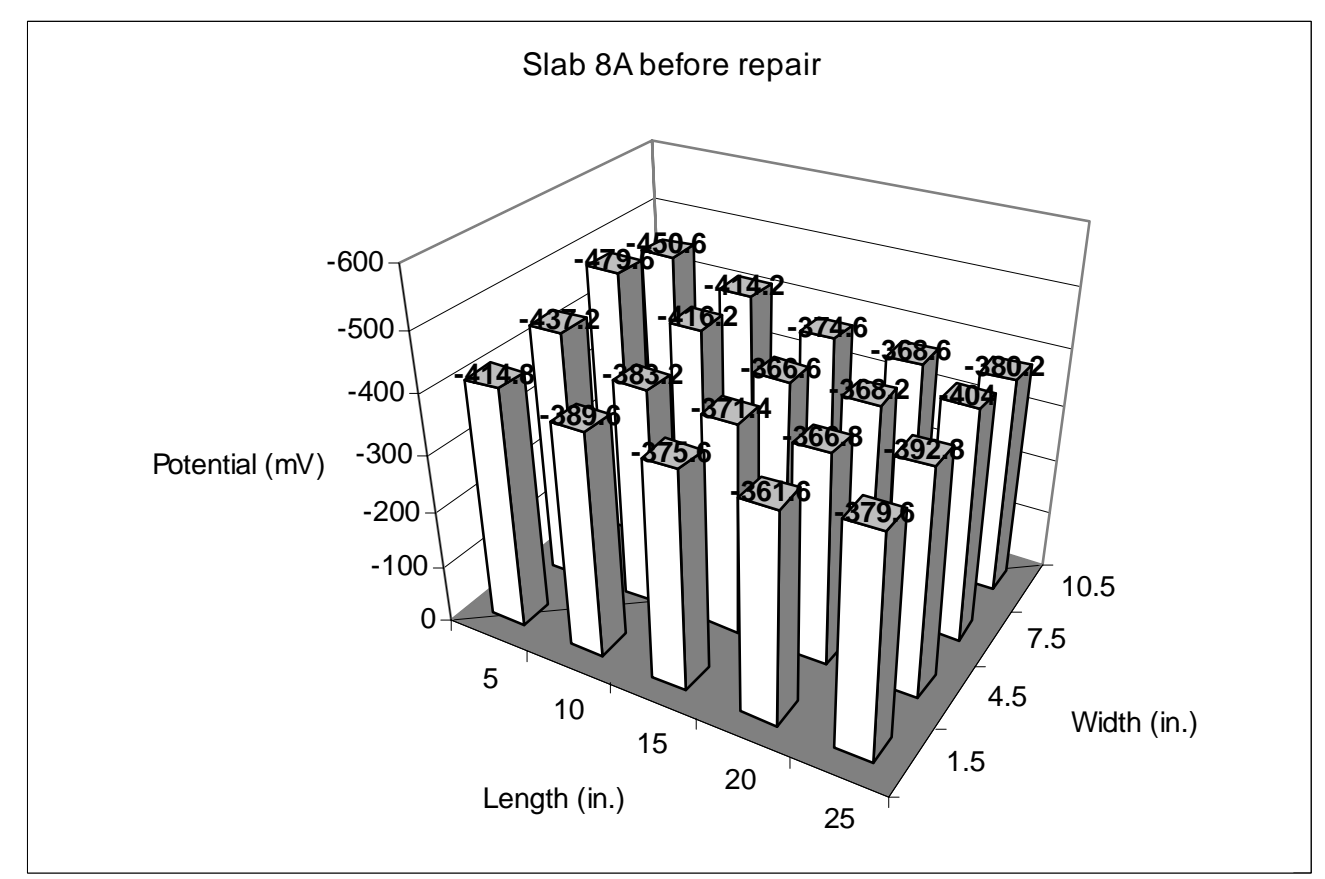

Figure C.52 Half-cell potentials of slab 8A before repair with the latex modified concrete. Potential values are versus copper-copper sulfate electrode. 


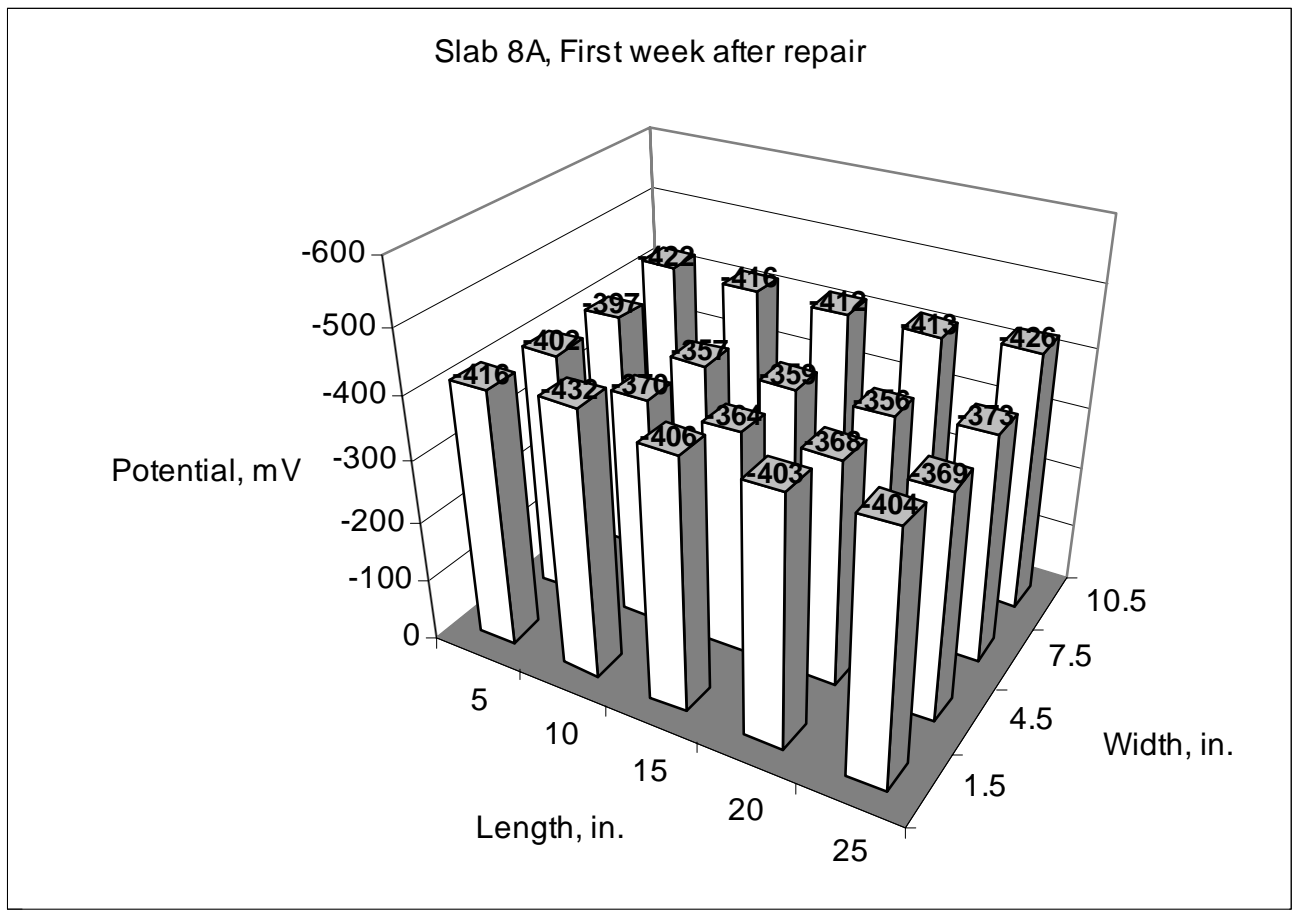

Figure C.53 Half-cell potentials of slab 8A first week after repair with the latex modified concrete. Potential values are versus copper-copper sulfate electrode.

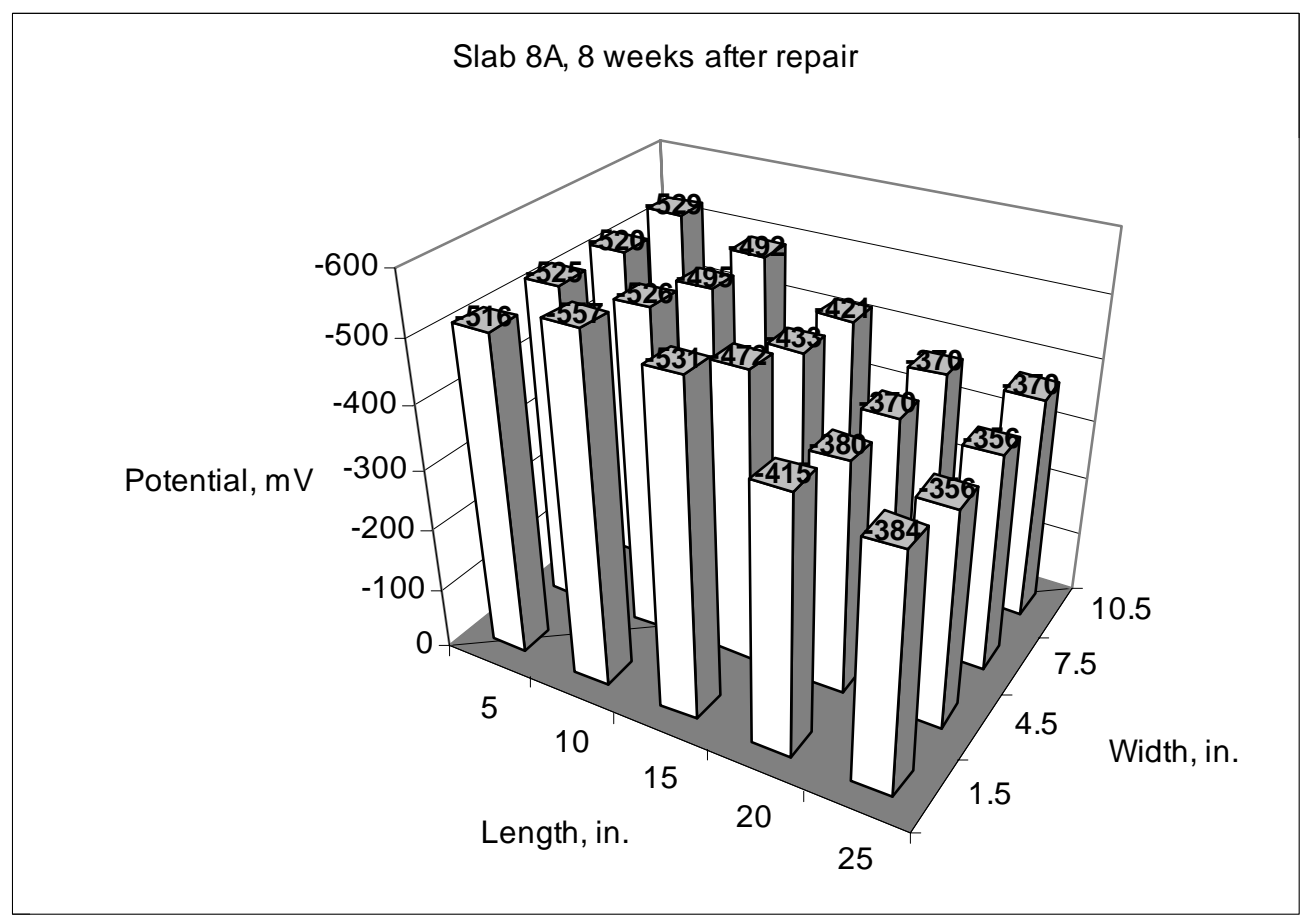

Figure C.54 Half-cell potentials of slab 8A eight weeks after repair with the latex modified concrete. Potential values are versus copper-copper sulfate electrode. 


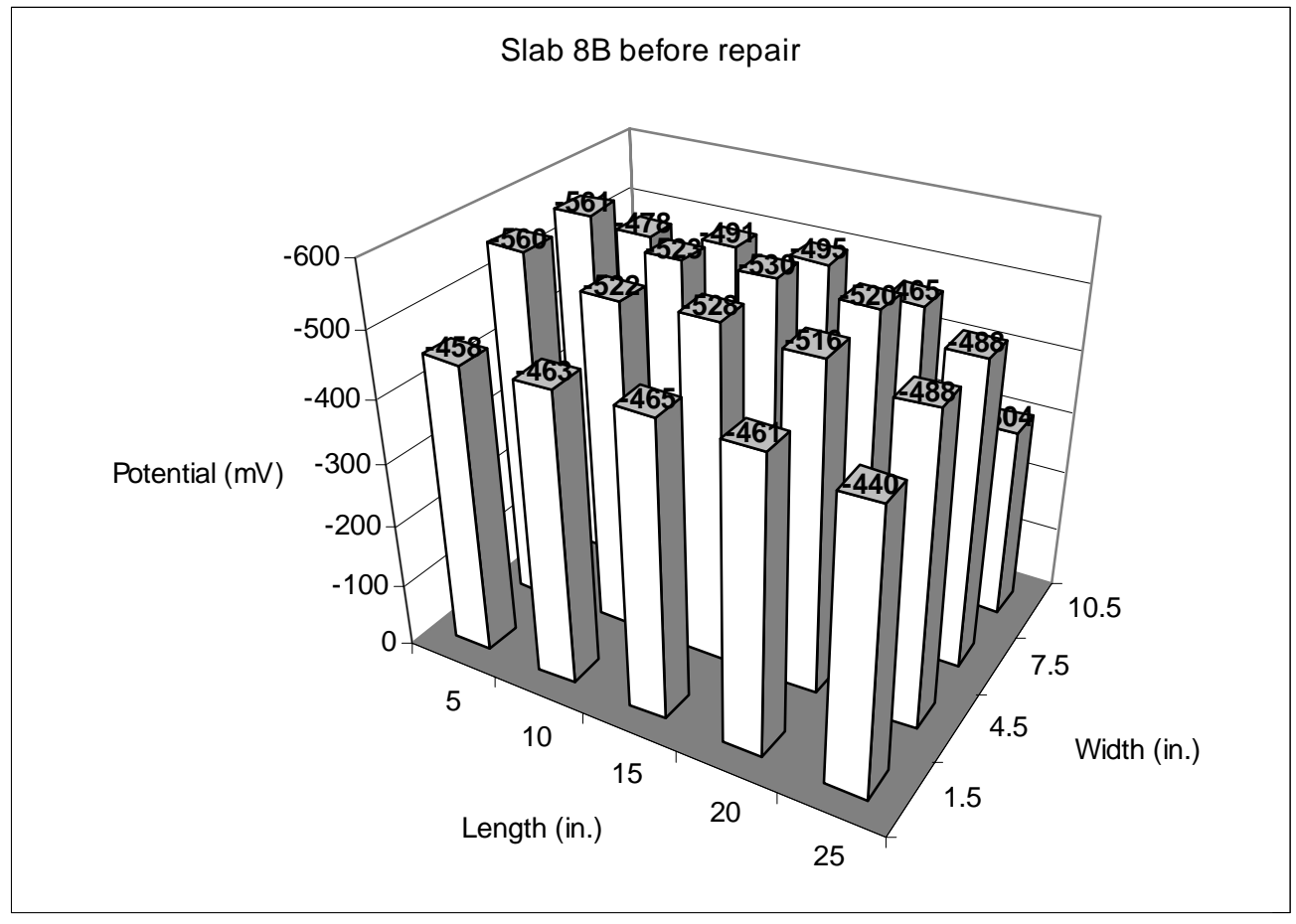

Figure C.55 Half-cell potentials of slab $8 \mathrm{~B}$ before repair with the latex modified concrete. Potential values are versus copper-copper sulfate electrode.

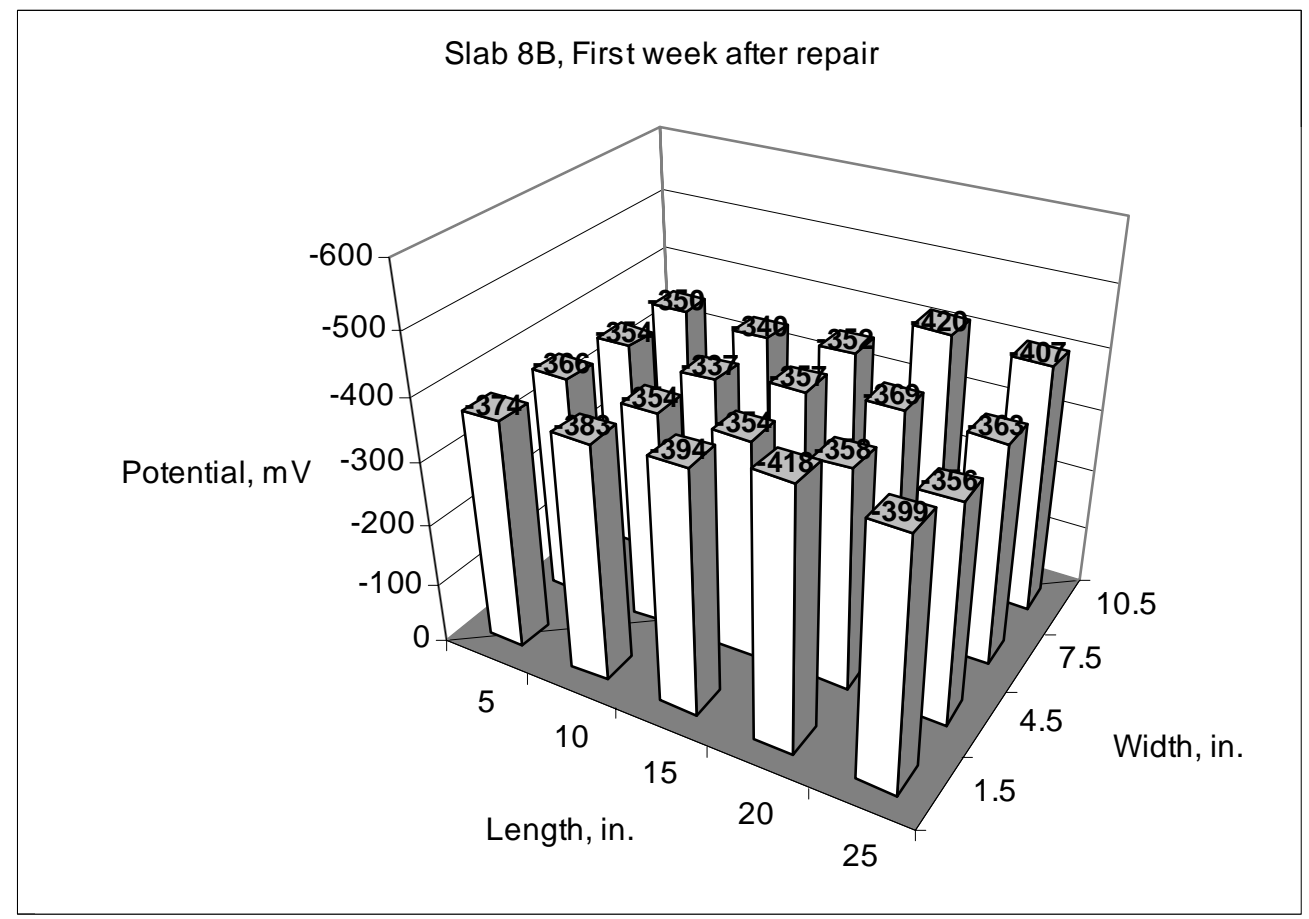

Figure C.56 Half-cell potentials of slab 8B first week after repair with the latex modified concrete. Potential values are versus copper-copper sulfate electrode. 


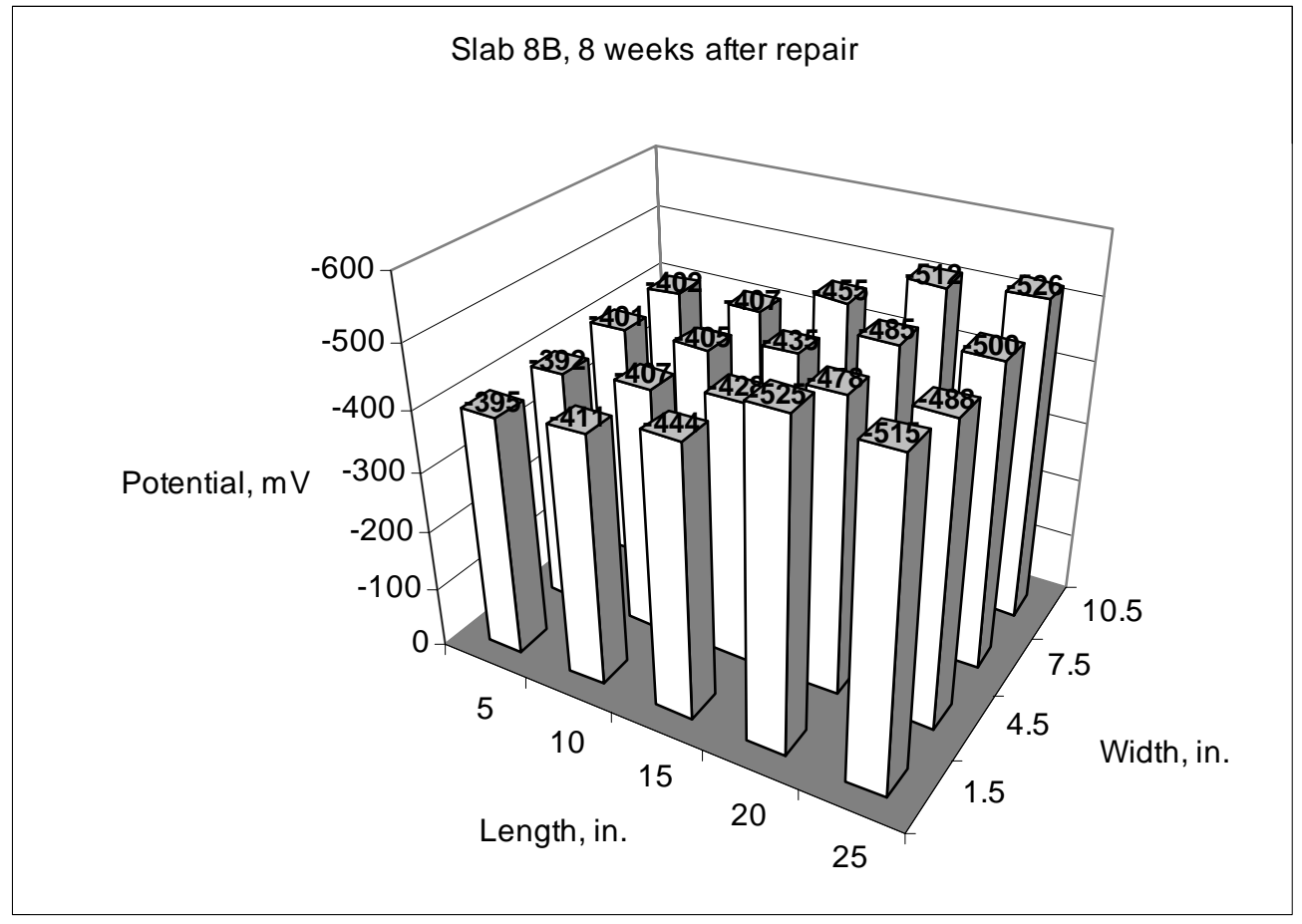

Figure C.57 Half-cell potentials of slab 8B eight weeks after repair with the latex modified concrete. Potential values are versus copper-copper sulfate electrode.

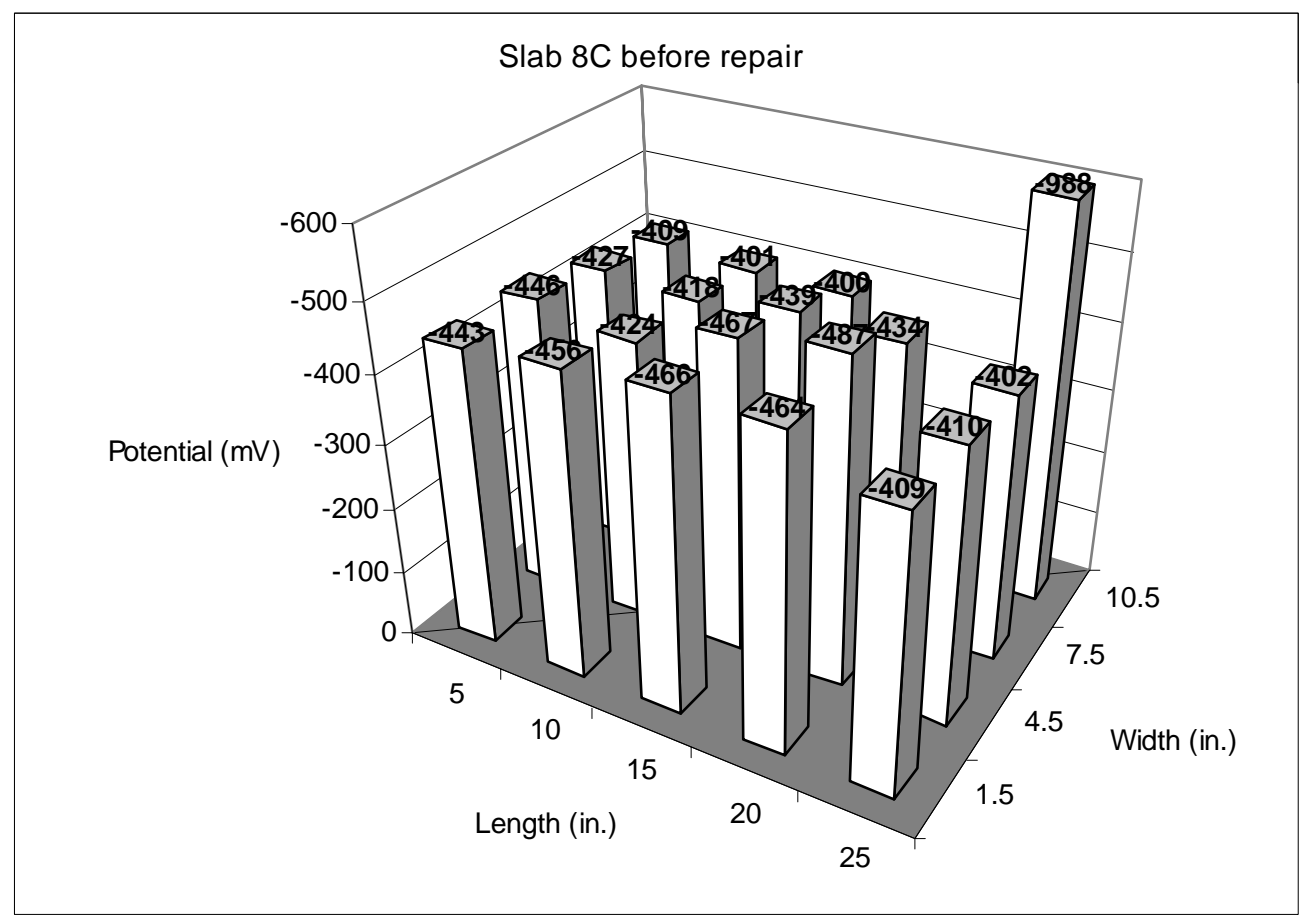

Figure C.58 Half-cell potentials of slab 8C before repair with the latex modified concrete. Potential values are versus copper-copper sulfate electrode. 


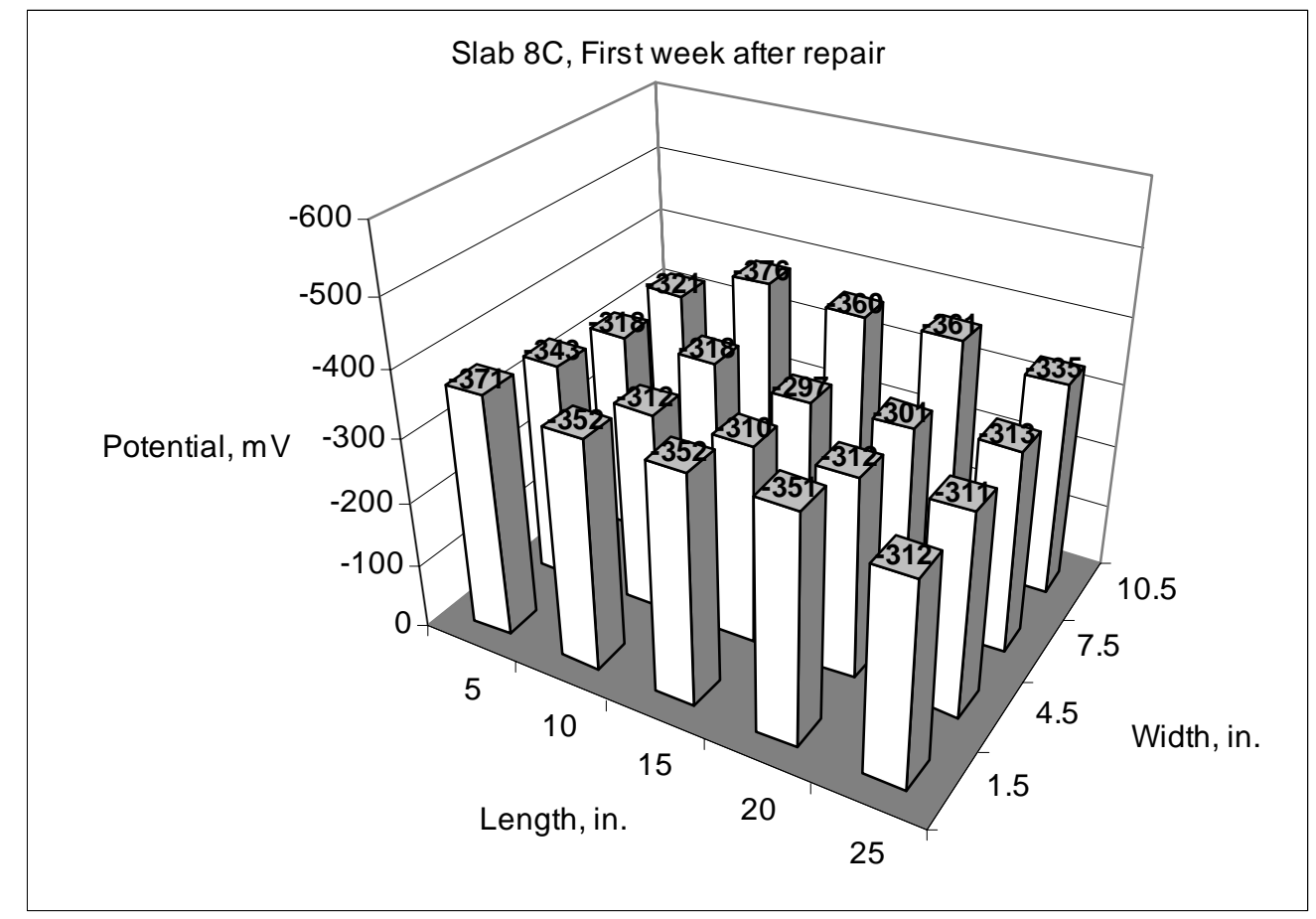

Figure C.59 Half-cell potentials of slab 8C first week after repair with the latex modified concrete. Potential values are versus copper-copper sulfate electrode.

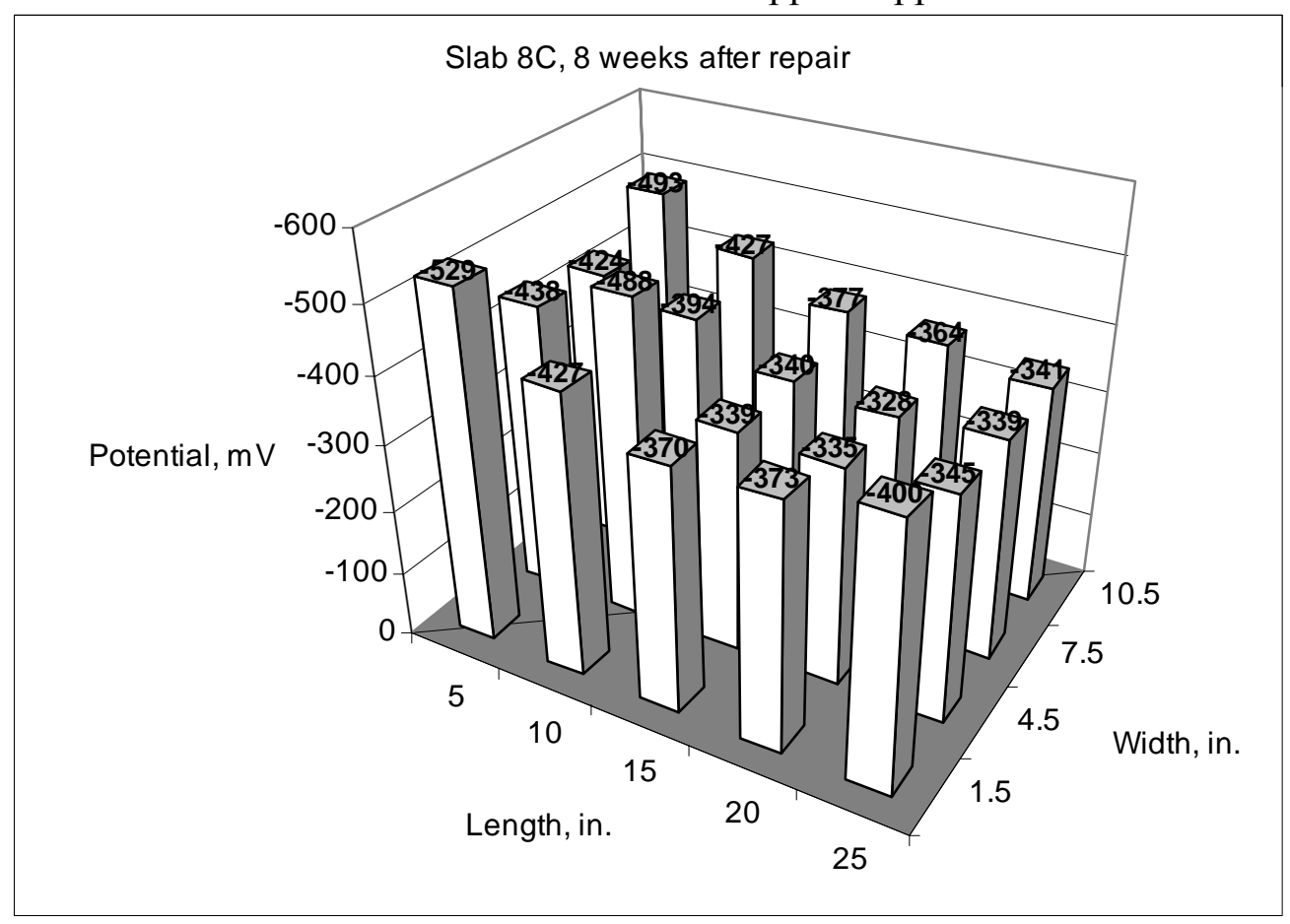

Figure C.60 Half-cell potentials of slab 8C eight weeks after repair with the latex modified concrete. Potential values are versus copper-copper sulfate electrode. 